\title{
Zyklus und Serie
}

Van Goghs Ansichten des ummauerten Feldes in Saint-Rémy

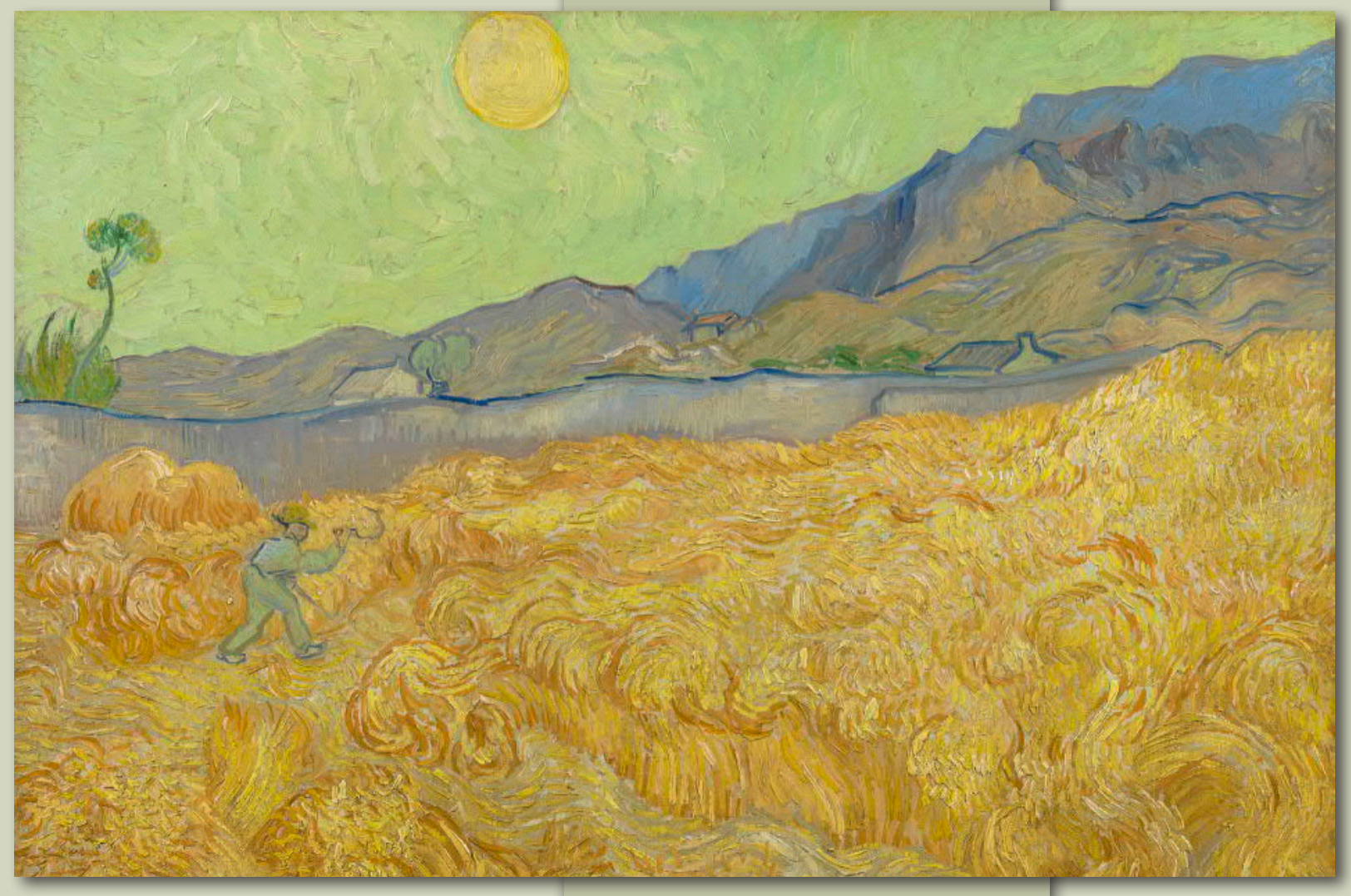

\section{Universitätsverlag Göttingen}



Lukas Baumann

Zyklus und Serie

Dieses Werk ist lizenziert unter einer Creative Commons Namensnennung-Nicht kommerziell 4.0 International Lizenz.

(a) $(1)(9)$ 
erschienen im Universitätsverlag Göttingen 2018 
Lukas Baumann

Zyklus und Serie

Van Goghs Ansichten des

ummauerten Feldes in Saint-Rémy

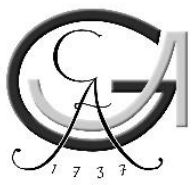

Universitätsverlag Göttingen 2018 


\section{Bibliographische Information der Deutschen Nationalbibliothek}

Die Deutsche Nationalbibliothek verzeichnet diese Publikation in der Deutschen Nationalbibliographie; detaillierte bibliographische Daten sind im Internet über $<$ http://dnb.dnb.de $>$ abrufbar.

Anschrift des Autors

Lukas Baumann

E-Mail: lukas_baumann@hotmail.com

Dieses Buch ist auch als freie Onlineversion über die Homepage des Verlags sowie über den Göttinger Universitätskatalog (GUK) bei der Niedersächsischen Staats- und Universitätsbibliothek Göttingen (http://www.sub.uni-goettingen.de) erreichbar. Es gelten die Lizenzbestimmungen der Onlineversion.

Satz und Layout: Sascha Bühler

Umschlaggestaltung: Jutta Pabst

Titelabbildung: Wheatfield with a Reaper

Vincent van Gogh (1853 - 1890), Saint-Rémy-de-Provence, September 1889

Van Gogh Museum, Amsterdam (Vincent van Gogh Foundation)

(C) 2018 Universitätsverlag Göttingen

http://univerlag.uni-goettingen.de

ISBN: 978-3-86395-395-9

DOI: https://doi.org/10.17875/gup2018-1120 
„...Ach mein lieber Freund, aus der Malerei das zu machen, was schon vor uns die Musik von Berlioz und Wagner bedeutet ... eine Kunst des Trostes für zerrissene Herzen!"1

Brief 739/in anderer Fassung 573a, Arles, 21.1.1889, an Paul Gauguin, zitiert nach Erpel 1968, Bd. 5, S. 308-309. 



\section{Inhalt}

1. Einleitung und Forschungsstand $\ldots \ldots \ldots \ldots \ldots \ldots \ldots \ldots$

1.1 Der Zugang über die Briefe....................... 9

1.2 Forschungsstand zu van Goghs seriellem Arbeiten und seiner

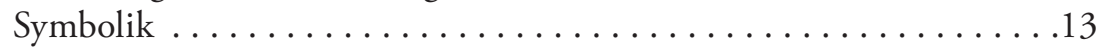

1.3 Methodische Probleme ........................... 15

1.4 Der Untersuchungsgegenstand: die Serie des ummauerten Feldes . . . . 17

2. Der Aufenthalt in Saint-Rémy. ...................... 21

2.1 Hintergründe der Einweisung in die Nervenheilanstalt ..........21

2.2 Die Ansichten der ummauerten Felder. . . . . . . . . . . . . . .23

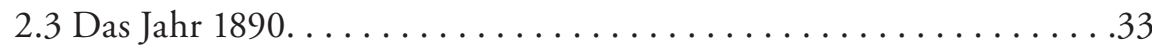

3. Wiederholung, Variation, Serie und Zyklus . . . . . . . . . . . . 39

3.1 Serialität - Ursprünge und Begriffsbedeutung ............ 39

3.2 Die Entwicklung zur Serialität im ausgehenden 19. Jahrhundert . . . 42

3.3. Van Goghs Wiederholungspraxis zur Serialität ............. 46

3.4 Von der Übungskopie zur Bilderserie . . . . . . . . . . . . . . . 48

3.4.1 Kopieren zum Erlernen des künstlerischen Handwerkes . . . . . 48

3.4.2 Erste Aufträge und Bilderserien in Den Haag. . . . . . . . . . . 51

3.4.3 Sien und weitere Serien der Porträtmalerei in Den Haag . . . . . . 56

3.4.4 Weitere Figurenstudien in Den Haag. . . . . . . . . . . . . . 59

3.4.5 Vervielfältigungen durch Lithographien und

„Blätter für das Volk“ . . . . . . . . . . . . . . . . . . . . . . . 60

3.4.6 Die Serie der Weber. . . . . . . . . . . . . . . . . . . . . . . . 64

3.4.7 Durch Wiederholungen zum Ergebnis - Die Kartoffelesser . . . . 667

3.4.8 Entwicklungssprünge in Paris . . . . . . . . . . . . . 69

4. Die Entwicklung zur zyklischen Serialität unter Berücksichtigung der Bedeutung der Natur und der Landschaftsmalerei van Goghs. . . . . 75

4.1 Die Bedeutung von Natur und Landschaft in van Goghs Jugend und vor seiner Entscheidung Künstler zu werden . . . . . . . . . . . 75

4.2 Van Goghs Naturauffassung nach $1880 \ldots \ldots \ldots \ldots \ldots \ldots \ldots . \ldots 2$

4.3 Die Entwicklung der Zyklizität im Werk van Goghs .......... 88

4.3.1 Exkurs: Zyklische Darstellungen der Jahreszeiten und Monatsbilder ........................ 88

4.3.2 Ein Jahreszeitenprojekt ................... 99

4.3.3 Die Farben im Kreislauf der Jahreszeiten . . . . . . . . . . . . 101

4.3.4 Gesichtspunkte der seriellen Ordnung: Die Jahreszeiten in Arles . 104

4.3.5 Weitere Gliederungsprinzipien: Die Décoration. . . . . . . . . 115 
5. Die Entwicklung von van Goghs Kunst als Ausdruck von Trost . . . 119

5.1 Die Sinnsuche: van Goghs soziokulturelle und religiöse Prägung . . . 119

5.2 Gebrauch des Trostbegriffs nach van Goghs Entscheidung,

Künstler zu werden............................ 125

5.2.1 Exkurs: Klassische Musik als Mittel der künstlerischen

Sensibilisierung und zur Steigerung des Ausdrucks . . . . . . . 128

5.2.2 Der Ausdruck von Trost in Arles . . . . . . . . . . . . . . . 132

6. Das Jahr in Saint-Rémy. . . . . . . . . . . . . . . . . . . 151

6.1 Der Zyklus des ummauerten Kornfeldes. . . . . . . . . . . . . 151

6.1.1 Der Zyklus: eine Bestandsaufnahme . . . . . . . . . . . . . 152

6.1.2 Der Farbkreislauf. . . . . . . . . . . . . . . . . . . . . 153

6.1.3 Landwirtschaftliche Motive im Jahreskreis..............155

6.2 Religiöse Malerei vs. Natur: die Serie der Olivenhaine

in Saint-Rémy . . . . . . . . . . . . . . . . . . . . . . . . . . 169

6.3 Trost durch Kopien: der Kreis schließt sich. . . . . . . . . . . . 180

\section{Im Vergleich: Monets Getreideschober und Cézannes}

Ansichten der Montagne Sainte-Victoire . . . . . . . . . . . . . . . . 187

7.1 Monets Serie der Getreideschober in Giverny . . . . . . . . . . . . 187

7.2 Paul Cézanne und die Ansichten der Montagne

Sainte-Victoire ..................................203

7.3 Vergleich der Serien ........................ 210

8. Fazit . . . . . . . . . . . . . . . . . . . . . . . . . 219

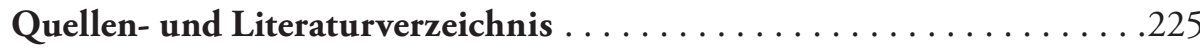

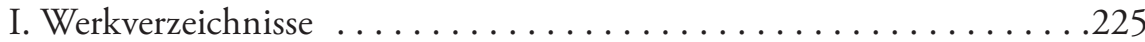

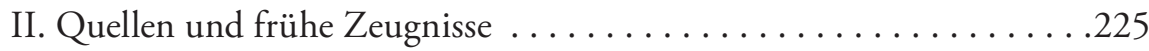

III. Sekundärliteratur . . . . . . . . . . . . . . . . . . . . . . .227

a. Sekundärliteratur über Vincent van Gogh. . . . . . . . . . . . .227

b. Sonstige Sekundärliteratur . . . . . . . . . . . . . . . . 235

c. Auktions- und Antiquariatskataloge . . . . . . . . . . . . . . 239

d. Lexika und Nachschlagewerke . . . . . . . . . . . . . . . . . 240

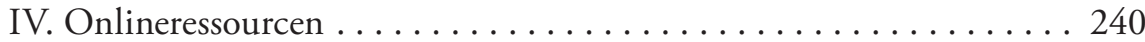

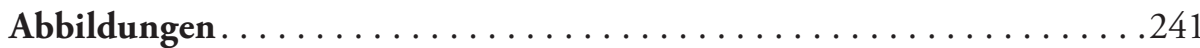

Abbildungsnachweis ............................ 309

Danksagung...................................... 319 


\section{Einleitung und Forschungsstand}

\subsection{Der Zugang über die Briefe}

Noch vor Vincent van Goghs Tod hatte der Kunstkritiker Albert Aurier im Januar 1890 in seinem Aufsatz „Les Isolés“ (dt. Die Einzelgänger) für die symbolistische Zeitschrift „Mercure de France“1 die Ambivalenz im Werk van Goghs zwischen Wirklichkeitsbezügen sowie subjektiven Bedeutungsebenen, für welche die Darstellung des Sämanns ein prominentes Beispiel darstellt, aufgezeigt. ${ }^{2}$ Gleichzeitig wies er aber auch auf die dem Werk immanente pathologische Ebene hin, die er durch eine Wahrnehmung der Wirklichkeit von „vielleicht sogar schmerzhafter Intensität “" ${ }^{\text {3 }}$ begründet sah und stellte eine Verbindung zwischen van Goghs Arbeitsweise, die „kraftvoll, gesteigert, derb zupackend, eindringlich [...] fieberhaft, wuchtig, oft ungeschickt und etwas schwerfällig " ${ }^{\text {"4 }}$ sei, und seinem Temperament her. Aurier steckte so bereits 1890 das Feld ab, in dem sich eine Vielzahl von Analysen der nachfolgenden Jahrzehnte bewegen sollte, denn sehr häufig wurde in der Folge eine direkte Verbindung zwischen der Malweise und der labilen Psyche des Künstlers aufgezeigt.

Für die frühe wissenschaftliche Auseinandersetzung mit Vincent van Gogh einhergehend mit einer sich allmählich ausbreitenden Beliebtheit seiner Werke unter Kunstsammlern - ist insbesondere Julius Meier-Graefe (1867-1935) hervorzuheben, der sich bis zu seinem Tode nicht nur wiederholt monographisch mit van

1 Aurier, Gabriel-Albert: Les Isolés. Vincent van Gogh, in: Mercure de France, Januar 1890, S. 24 29. Eine dt. Übersetzung des Aufsatzes Auriers findet sich bei Erpel 1968, Bd. 6, S. 89-94.

2 Vgl. zur Rezeption Auriers sehr ausführlich Rewald 1967, S. 232-235 sowie Noll 1994, S. 11-13.

3 Zitiert aus dt. Übersetzung des Aufsatzes Auriers in Erpel 1968, Bd. 6, S. 89-94, S. 92.

4 Zitiert aus dt. Übersetzung des Aufsatzes Auriers in Erpel 1968, Bd. 6, S. 89-94, S. 92. 
Gogh befasst, sondern auch zahlreiche weitere Werke zur Entwicklungsgeschichte moderner Kunst veröffentlicht hat. ${ }^{5}$ Meier-Graefe pries van Gogh in seiner 1907 erschienenen Abhandlung zum Impressionismus und zu van Goghs Kunst im Kontext von Malern wie Édouard Manet (1832-1883), Camille Pissarro (1830-1903) und Paul Cézanne (1839-1906) zwar in höchsten Tönen, spielte aber, wie auch Aurier, auf die tragische Komponente im Leben und Wirken van Goghs an: „Sein Werk zeigt absonderliche Tiefen, und hinter seinem Schicksal verbirgt sich mehr, als des Einzelfalls spannendes Ereignis. Er ist, wie jeder Künstler, eine wohlorganisierte Welt, in die sich unsere Gedanken und Empfindungen ausdehnen können, und die dem Reichsten unerwarteten Zuwachs verspricht."

Diese Lesart ist in der Folge vielfach aufgegriffen worden und noch mehr als 100 Jahre später klingt beispielsweise die Beschreibung der Malweise van Goghs durch die Kunsthistorikerin Debora Silverman ähnlich Auriers erster Einschätzung, wenn sie von einer „,vigorous action of hand on brush that yields a multidirectional and grimy mix of tar, crust and color "7 und einer „exuberantly kinesthetic attack" ${ }^{\text {“8 }}$ schreibt. Die Verwendung der Termini kräftig/heftig - „,vigorous“, überschäumend/ temperamentvoll - „exuberantly“ sowie Angriff - ,attack“ deuten auf den von seiner Psyche getriebenen Künstler hin, der - ohne recht zu wissen, was er tut - Leinwände traktiert.

H. R. Graetz veröffentlichte im Jahr 1963 mit „The Symbolic Language of Vincent van Gogh" ${ }^{\text {“9 }}$ den kritisch zu lesenden Versuch, sich der Symbolik des Künstlers auf psychologischer Ebene durch dessen Briefe anzunähern. ${ }^{10}$ Bei den überlieferten Briefen van Goghs handelt es sich um einen kunsthistorischen Glücksfall von großer Bedeutung. Von wenig anderen Künstlern sind derart umfangreiche selbstreflexive Schriftzeugnisse erhalten, welche die Werke und Lebensumstände van Goghs in vergleichbarem Umfang inhaltlich aus der Perspektive des Künstlers kommentieren. Heute umfasst die erhaltene Korrespondenz insgesamt 903 Briefe - 820 geschriebene und 83 empfangene -, wobei etwa vier Fünftel der Briefe van Goghs an seinen jüngeren Bruder Theo (1857-1891) gerichtet sind. Die große Zahl von Briefen an Malerkollegen, darunter allein 58 an Anthon van Rappard (1858-1892) und 22 an Émile Bernard (1868-1941), geben in vielerlei Hinsicht Aufschluss über

5 Meier-Graefe, Julius: Vincent, München 1912, sowie Vincent van Gogh. Der Zeichner, Berlin 1928 u. Vincent van Gogh. Der Roman eines Gottsuchers, Berlin u.a. 1932. Darüber hinaus zu nennen ist: Impressionisten. Guys, Manet, Van Gogh, Pissarro, Cezanne. Mit einer Einleitung über den Wert der französischen Kunst, München u.a. 1907.

6 Meier-Graefe 1907, S. 113.

7 Silverman 2000, S. 208.

8 Silverman 2000, S. 209.

9 Graetz, H. R.: The Symbolic Language of Vincent van Gogh, London 1963.

10 Noll kritisiert, dass sich Graetz bspw. für seine Aussagen bzgl. des Sämanns von 1888 (u.a. F 451) auf Textstellen aus mehreren Briefen aus unterschiedlichen Jahren, zum Teil mehr als 10 Jahre vor Entstehung des Bildes, zu den Bildelementen stützt - wie der Bedeutung von Licht, eines knorrigen Baumes als lebendiges Wesen und des Horizontes als Lebenslinie - und daraus allgemeine Interpretationsschlüsse für das Gesamtwerk gewinnt. Vgl. Noll 1994, S. $13 f$. 
künstlerische Fragen, die van Gogh beschäftigten. Fast die Hälfte aller empfangenen Briefe ist von van Goghs Bruder verfasst worden. Aufgrund von Bemerkungen in van Goghs eigenen Briefen, in denen seiner Familie oder in denen von Freunden und aufgrund von Hinweisen aus anderen Quellen, kann von mindestens 550 weiteren Briefen an van Gogh und 290 von ihm geschriebenen Briefen ausgegangen werden. Dies erhöht die Zahl aller bekannten Briefe auf ca. 1.750. Letztendlich wird die eigentliche Gesamtzahl aber noch höher gelegen haben. Obschon die Briefe in gedruckter Fassung mehrere Bände umfassen, ist die Zahl der erhaltenen Briefe im Vergleich mit denen anderer Künstler mitnichten außerordentlich, umfasst Eugène Delacroix' Korrespondenz doch 1.500 Briefe, Claude Monet schrieb mehr als 3.000, James McNeill Whistler 13.000 Briefe. Voltaire verfasste im Laufe seines Lebens gar fast 20.000 Briefe an über 1.700 Empfänger. ${ }^{11}$

Der Briefwechsel mit Theo begann im Jahr 1872, zu einer Zeit, als van Gogh im Kunsthandel beschäftigt war und diente zunächst nur dazu, mit dem entfernt lebenden Bruder in Kontakt zu bleiben. Der Charakter der Briefe wandelte sich mit seinem Reifeprozess, so dass die Briefe mehr und mehr zum Spiegel seiner persönlichen Entwicklung wurden. Die Briefe zeigen nicht nur die Intellektualität van Goghs, sondern auch mit welch großem Maß an Reflexion er konsequent sein eigenes Handeln hinterfragte. ${ }^{12}$ Bis auf wenige Ausnahmen - im Jahr vor seinem Tod hinderten ihn seine „Anfälle“13 daran, zu schreiben - ist die Frequenz der Korrespondenz sehr konstant. Der relativ geringe Anteil empfangener Briefe erklärt sich dadurch, dass van Gogh eine Vielzahl der Schreiben vernichtete. ${ }^{14}$ Die herausragende Bedeutung der Briefe wurde schon früh erkannt. Rainer Maria Rilke (18751926) schrieb im Dezember 1906 aus Italien, nachdem er die Briefe gelesen hatte, an seine Frau Clara:

Vielleicht seh ich das alles, weil ich seine Briefe gelesen habe (in der vollständigen Buchausgabe, die ich mir noch in München besorgte, und die auf der langen Reise mein liebstes war[en] und wirklich schön sind, nicht reif in manchem, aber unsäglich ernst, unsäglich rührend, und für Maler wirklich wie eine gute hilfreiche Stimme) $[\ldots] .^{15}$

11 In den 903 Briefen sind auch 25 Briefe enthalten, die entweder nicht beendet, unvollständig oder nicht gesendet wurden („RM“-Nummern in der Online-Ausgabe der Briefe). Vgl. für die Zählungen und die Vergleiche mit anderen Künstlern die Online-Ausgabe der Briefe, abgerufen unter: http://vangoghletters.org/vg/letter_writer_1.html u. http://vangoghletters.org/vg/overview.html.

12 Vgl. Boehm 2009, S. 32.

13 Van Gogh benutzt im französischen den Terminus „crise“. Vgl. Brief 820/614, Saint-Rémy, ca.19.11.1889, V. van Gogh an Theo, zitiert nach Erpel 1965, Bd. 4, S. 337-340, S. 339 und Internetseite des van Gogh Museums: http://vangoghletters.org/vg/letters/let820/letter.html. In der Folge werden für die Briefe grundsätzlich die Datierungen der Online-Ausgabe der Briefe des van Gogh Museums übernommen, da sie dem aktuellen Forschungsstand entsprechen.

14 Vgl. Bakker/Jansen/Luijten 2010, S. 16 u. Feilchenfeldt 2009, S. 51.

15 Rainer Maria Rilke an seine Frau Clara, 2.12.1906, zitiert nach Krießbach-Thomasberger 2000, S. 33-37, S. 35. 
Lange bevor Graetz 1963 die Briefe als entscheidenden Schlüssel zum Werk verstanden hatte, äußerte Meier-Graefe im Jahr 1932, dass die Briefe noch wichtiger anzusetzen seien als das gemalte Werk, das er nur als schmückendes Beiwerk auffassen könne. ${ }^{16}$ Infolgedessen kritisierte im Jahr 1970 Abraham Marie Hammacher, der Herausgeber der Neuerscheinung des Werkverzeichnisses von Jacob-Baart de la Faille, das Übergewicht des den Briefen entgegengebrachten Interesses. ${ }^{17}$

Der Zugang über die Briefe und deren Berücksichtigung bei einem kontextuellen Verständnis hat sich jedoch als die gängigen methodischen Ansätze bei der Beschäftigung mit van Goghs Werk durchgesetzt. Beispielsweise durch die seit Mitte der 1960er Jahre in der deutschen Neuübersetzung von Fritz Erpel herausgegebenen sechsbändigen Edition sämtlicher Briefe und relevanter Dokumente ist diese Quelle leicht zu erschließen. Als ein Meilenstein kann die frei zugängliche Veröffentlichung der Briefe im Internet durch das Van Gogh Museum in Amsterdam verstanden werden. Seitdem werden die Briefe nun nicht nur als digitales Faksimile, in Originalsprache und in der englischen Übersetzung gegenübergestellt, sondern auch durch jeweils relevantes Bildmaterial, weitere Kommentierungen und Querverweise ergänzt. Das Onlinearchiv ist so zu einer unvergleichlich verlässlichen Arbeitsgrundlage geworden, die auch für diese Arbeit von herausragender Bedeutung war.

Die Ausstellung „The Real van Gogh. The Artist and His Letters“ in der Londoner Royal Academy of Arts war im Jahr 2010 anlässlich der englischen Neuausgabe der Briefe ein Vorhaben, das in einer Gegenüberstellung von Briefen und Bildern dieses Thema aufbereitete. Dafür wurden 40 Originalbriefe ausgewählt, in die van Gogh Skizzen neben den Text gezeichnet hatte, mittels derer er beabsichtigte, dem Adressaten die Essenz eines neuen Gemäldes zu visualisieren. In der Ausstellung wurden daraufhin Skizzen mit den entsprechenden Referenzwerken versammelt. Dies geschah mit der Zielsetzung, van Gogh nicht als wahnsinniges Genie, sondern als ,einen reflektierten, hochgebildeten Menschen mit systematischen Arbeits-

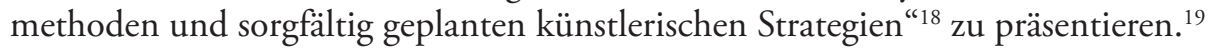

16 Meier-Graefe, Julius: Vincent van Gogh. Der Roman eines Gottsuchers, Berlin u.a. 1932. Kritisch kommentiert bei Noll 1994, S. 18.

17 Hammacher, Abraham Marie, van Gogh and the Words, in: Jacob-Baart de la Faille, The Works of Vincent van Gogh. His Paintings and Drawings, London 1970, S. 32.

18 Nicholas Grimshaw im Vorwort des Ausst. Kat. von ,Van Gogh: Der Künstler und seine Briefec, Köln 2010, S. 9.

19 Anmerkung zur Zitierweise der Briefe: Die in den Fußnoten zuerst genannte Zahl bezieht sich auf die Nummerierung der 2009 erschienenen Neuausgabe der Briefe, die zweite Zahl auf die bei Erpel verwendete Nummerierung. Für den besseren Textfluss wird aus der weithin bekannten und anerkannten deutschen Ausgabe von Erpel, erschienen 1965 und 1968, zitiert. Die Datierungen der Briefe werden hingegen weitestgehend von der Online-Ausgabe der Briefe übernommen, da sie häufig einem aktuelleren Forschungsstand entsprechen. In begründeten Einzelfällen wurde auf das niederländische, französische oder englische Original verwiesen, um van Goghs sprachliche Nuancierungen erfahrbar zu machen oder ungenaue oder falsche Übersetzungen der Briefe aus der Erpel-Ausgabe zu korrigieren. 


\subsection{Forschungsstand zu van Goghs seriellem Arbeiten und seiner Symbolik}

Für das Verständnis der christlichen sowie der Natursymbolik im Werk van Goghs sind von grundlegender Bedeutung Tsukasa Kōderas monographische Gegenüberstellung „Vincent van Gogh. Christianity versus Nature“ von 1990 und Thomas Nolls vier Jahre danach erschienene Studie „Der große Sämann: Zur Sinnbildlichkeit in der Kunst von Vincent van Gogh“.

Im Jahre 2003 wurde anlässlich der Ausstellung „Van Goghs Musée imaginaire“ des Van Gogh Museums ein Katalog mit aufschlussreichen Aufsätzen zu der Symbolik in seinen Werken publiziert. Für die vorliegende Untersuchung waren dabei besonders der Beitrag Chris Stolwijks zu van Goghs Haltung zur Natur, ferner Leo Janssens Aufsatz zur Frage, wie van Gogh Trost in seinen Bildern vermitteln wollte, und Joan Greers Untersuchung von van Goghs "Socio-Religious Canon of Art" bedeutsam.

Von Bedeutung für einen Überblick über van Goghs seriellem Arbeiten und seinen Gliederungsprinzipien in Arles ist Roland Dorns 1990 publizierte Dissertation „Décoration. Vincent van Goghs Werkreihe für das Gelbe Haus in Arles“ und für das technische Verständnis führt auch nach fast 30 Jahren an Dorns Arbeit mit ihrem umfassenden Anhang kaum ein Weg vorbei. Für den Aspekt der Kopien und Wiederholungen ist, vor allem auch durch ihre genaue Untersuchung von van Goghs autodidaktischer Ausbildung, Cornelia Homburgs 1996 publizierte Studie "The Copy turns Original. Vincent van Gogh and a new Approach to Traditional Art Practice" hilfreich. Zu diesem Thema lieferte zudem die 2013 in Cleveland durchgeführte Ausstellung zur Wiederholungspraxis van Goghs wertvolle neue Erkenntnisse hinsichtlich der technischen Ausführungen des Künstlers. Da der Schwerpunkt in Cleveland jedoch hauptsächlich auf die technische Untersuchung der Wiederholungen gelegt wurde, kam die inhaltliche Analyse des Seriellen etwas zu kurz. Dies entsprach einer Tendenz hin zu einer technischen Auswertung von van Goghs Werken, die insbesondere im sehr umfangreichen Band zu „Van Gogh's Studio Practice“, 2013 nach mehreren Jahren intensiver interdisziplinärer Forschungsarbeit erschienen, deutlich wurde.

Kurz vor dem 150. Geburtstag des Künstlers am 30. März 2003 nahm sich die Kunsthalle Bremen mit der Ausstellung „Van Gogh: Felder. Das Mohnfeld und der Künstlerstreit" den Feldbildern van Goghs an. Ausgehend von van Goghs Gemälde Das Mohnfeld, ${ }^{20}$ dessen Ankauf durch die Kunsthalle Bremen im Jahr 1911 unter dem Direktor Gustav Pauli den „Protest deutscher Künstler“ auslöste, wurden 50 Gemälde, Aquarelle und Zeichnungen van Goghs gezeigt. Ziel der Ausstellung war neben der Untersuchung der Entstehungsgeschichte des Mohnfeldes im Kontext anderer Darstellungen von Feldern van Goghs aus der Zeit in Arles, Saint-Rémy und Auvers-sur-Oise, auch die Betrachtung der Ankaufpolitik deutscher Museen in

20 Das Mohnfeld, Juni 1889, Öl auf Leinwand, 72 x 91 cm, Kunsthalle, Bremen, F 581, JH 1751. 
den Jahren vor dem Ersten Weltkrieg, um die Situation, die zu dem Protest führte, zu beleuchten. Der Ausstellungskatalog folgte dieser thematischen Zweiteilung, ließ jedoch hinsichtlich der Entstehungsgeschichte und des Werkkomplexes der Felder viele Fragen offen. In einer Rezension des Ausstellungskatalogs bemerkte Thomas Noll, dass man sich nicht einmal mit der zentralen Frage auseinandergesetzt habe, welche Bedeutung das Motiv der Felder für van Gogh besaß. Zudem seien naheliegende Kontextualisierungen zu wichtigen zeitgenössischen Künstlern - namentlich Monet und Cézanne - ausgeblieben, deren wiederholte Ansichten von Getreideschobern und der Montagne Sainte-Victore sich idealerweise für Vergleiche eigneten. ${ }^{21}$ Die 1999/2000 erschienene Dissertation Martina Sauers „Cézanne - van Gogh - Monet. Genese der Abstraktion" mit einem deutlichen Fokus auf dem Verhältnis von Bild und Betrachter, konnte aufgrund der abweichenden Thematik diesbezüglich ebenfalls keine Antworten liefern. Dies soll in der vorliegenden Arbeit nachgeholt werden.

Im Jahr 2009 richtete das Kunstmuseum Basel die umfangreiche Ausstellung „Vincent van Gogh. Zwischen Erde und Himmel“ aus. Obschon in der Ausstellung mit Kornfeld, der Schnitter ${ }^{22}$ aus dem Museum Folkwang eine Ansicht eines ummauerten Feldes gezeigt werden konnte und weitere Felder dieser Serie im insgesamt sehr fundierten Katalog abgebildet wurden, fiel der Beitrag zu der Frage nach der Bedeutung der ummauerten Felder für van Gogh und zu Vergleichen mit anderen Künstlern eher kurz aus. Dennoch sind insbesondere die Katalogbeiträge Gottfried Boehms und Nina Zimmers aufschlussreich für die Bedeutung der Landschaftsmalerei, der Serialität und des zyklischen Arbeitens in van Goghs Werk. Ausgehend von der nach den Ausstellungen in Bremen und Basel feststellbaren Lücke im Hinblick auf die zu untersuchende Werkgruppe van Goghs und Serien vergleichbarer Künstler soll im Folgenden das Augenmerk auf die Beantwortung bisher wenig beachteter Fragen und die Verknüpfung relevanter Sachverhalte gerichtet werden.

Verstärkt seit den 1980er Jahren stattfindende, häufig globale Ausstellungsprojekte, unter Einsatz eines großen materiellen, logistischen und mitunter auch wissenschaftlichen Aufwands, sind eine Folgeerscheinung der weltweit stetig gewachsenen Popularität des Künstlers. In den letzten zwei Jahrzehnten widmeten sich solche Ausstellungen jedoch häufig vor allem späten Werkkomplexen, wie der Zeit in Arles und Saint-Rémy, der Zusammenarbeit mit Paul Gauguin und den letzten Wochen des Künstlers in Auvers, also Themen, bei denen wohl davon ausgegangen wird, dass die Publikumswirksamkeit durch die tragische biographische Komponente erhöht werde. Hervorzuheben, aufgrund des äußerst umfangreichen wissenschaftlichen Aufwands und des vielseitigen Forschungsansatzes, ist der Katalog anlässlich der Ausstellung „Van Gogh and Gauguin: The Studio of the South“ (2001/2002 im

21 Vgl. Noll, Thomas: Van Gogh: Felder. Das Mohnfeld und der Künstlerstreit (Rezension Ausst. Kat.), in: Kunstchronik, 56. Jahrgang, Heft 7, Nürnberg 2003, S. 349-356.

22 Kornfeld, der Schnitter, „réduction“, Oktober 1889, Öl auf Leinwand, 59,5 x 73 cm, Museum Folkwang, Essen, F 619, JH 1792. 
Art Institute in Chicago und im Amsterdamer Van Gogh Museum). Zusammen mit der um die Jahrtausendwende erschienenen Monographie „Van Gogh and Gauguin, The Search for Sacred Art" von Debora Silverman ist vor allem die Thematik van Gogh/Gauguin extensiv, facettenreich und mit neuen Erkenntnissen bearbeitet worden. Ausstellungen zum Frühwerk und allgemein der Zeit vor 1888 finden dagegen deutlich seltener statt. Eine gelungene Ausnahme bot im Frühjahr 2015 im belgischen Mons die Ausstellung zu van Goghs Zeit im Borinage. Der dazu erschienene Katalog „Van Gogh. The Birth of an Artist“ warf ein neues und helles Licht auf die prägende Zeit, während der sich van Gogh entschloss, Künstler zu werden.

Große Ausstellungsprojekte bieten nicht zwangsläufig neue Erkenntnisse, wenn wissenschaftliche Positionen lediglich wiederholt und nur um ein paar neue Fakten ergänzt werden. Dies ist wohl eine unvermeidliche Folge der Häufigkeit von Ausstellungen zu van Gogh, die schwerlich jedes Mal mit bahnbrechenden Erkenntnissen aufwarten können. Ein Beispiel für einen solchen Katalog ist der 2014 anlässlich der Einweihung der Fondation Vincent Van Gogh in Arles erschienene Katalog „Colours of the North. Colours of the South“.

Trotz zahlreicher Neuerscheinungen sind die von Ronald Pickvance bearbeiteten Ausstellungskataloge zu der Zeit in Arles und Saint-Rémy von 1984 und 1986 weiterhin Standardwerke, um einen ersten Überblick zu erlangen, von dem aus eine entsprechende Untersuchung ausgehen kann. Das Van Gogh Museum in Amsterdam hat sich in den letzten Jahren nicht nur durch die neue Ausgabe der Briefe besonders verdient gemacht, sondern auch durch die sukzessive Veröffentlichung neuer Bestandskataloge.

Bei allen Werken van Goghs findet sich nach gängiger Praxis ein Verweis auf die Werknummern in den anerkannten Werkverzeichnissen Jacob Baart de la Failles und Jan Hulskers („F“ und „JH“). Wenn nötig, wird zudem auch auf die neueren Werkverzeichnisse Walter Feilchenfeldts (Vincent van Gogh. Die Gemälde 18861890. Händler, Sammler, Ausstellungen. Die Frühen Provenienzen, Wädenswill 2009) sowie Marie Vellekoops und Roelie Zwikkers (Vincent van Gogh. Drawings. Arles, Saint-Rémy \& Auvers-sur-Oise. 1888-1890 [Van Gogh Museum, Bd. 4], Amsterdam 2007) zurückgegriffen.

\subsection{Methodische Probleme}

Kōdera warnte in der Einleitung zu seiner Studie „Christianity versus Nature“ davor, bei einer ikonographischen Untersuchung der Motive van Goghs allzu schnell auf traditionelle - vielfach christliche oder emblematische - Bedeutungen zurückzugreifen. Vielmehr sei es zur ikonologischen Entschlüsselung von van Goghs Themen und Motiven zwingend erforderlich, abzuwägen, ob und wann traditionelle Bedeutungen zutreffend sind. Dies könne nicht nur durch den Vergleich mit brieflichen Äußerungen erfolgen, sondern auch durch eine Untersuchung, wie die Motive in den einzelnen Werken und, insbesondere durch das Ermitteln empiri- 
scher Evidenzen, über das Gesamtwerk hinweg, Verwendung finden. Dabei kann es beispielsweise eine Rolle spielen, ob und wie unterschiedliche Motive miteinander kombiniert oder im Laufe der Zeit verändert werden. ${ }^{23}$

Van Goghs Korrespondenz als Primärquelle ist in der Tat häufig ein wertvoller Schlüssel, da Werke und Entstehungskontexte in den Briefen an seinen Bruder und an andere Familienmitglieder, aber auch an Künstlerfreunde wie Paul Gauguin (1848-1903) und Émile Bernard (1868-1941), ausführlich diskutiert werden. Gleichzeitig darf nicht vergessen werden, dass es sich bei aller in den Briefen zum Vorschein kommenden Ehrlichkeit und Aufrichtigkeit van Goghs natürlich um ein durch den Künstler gefiltertes Medium handelt, das entsprechend mit Vorsicht zu verwenden ist. Auch wenn es sich bei den Äußerungen van Goghs um Zeugnisse aus erster Hand handelt, bedeutet dies im Umkehrschluss nicht die Objektivität des Geschilderten. Gleichzeitig kann den Briefen doch eine weitaus höhere Glaubwürdigkeit attestiert werden als beispielsweise den im Nachhinein angefertigten Aufzeichnungen Paul Gauguins, die mit der Absicht entstanden, von der Nachwelt gelesen zu werden. ${ }^{24}$

Durch die große Anzahl von Briefen ist eine Vielzahl von Aussagen van Goghs zu den unterschiedlichsten Themen überliefert, die sich unter Umständen auch widersprechen können. Dazu kommt, dass zwar ein Großteil der Korrespondenz erhalten ist, aber mitnichten alle jemals von van Gogh geschriebenen Briefe. Erschwerend kommt hinzu, dass während der Zeit in Paris, als sich die Brüder mündlich austauschen konnten, kaum Briefe geschrieben wurden. Es gilt folglich zu bedenken, dass inhaltliche Schlüsse aus den Briefen nur aufgrund der erhaltenen Zeugnisse getroffen werden können und dass diese nicht unbedingt ein vollständiges Bild ergeben.

Ein allzu freier, assoziativer Umgang mit Textstellen und scheinbar dazu passenden Werken sollte daher vermieden werden, um nicht der Gefahr der Über- oder Fehlinterpretation zu unterliegen. Wie Gottfried Boehm festhält, kann das Werk jedoch auch nicht ohne die Lebensgeschichte und die Briefe des Autors aufgeschlüsselt werden. Fundamental sei deswegen, „zwischen den Werken und ihren Auslösern und Kontexten eine sinnvolle Verbindung herzustellen." ${ }^{25}$

Vergleichbar mit Kōderas Studie, ist ein Ziel dieser Arbeit, durch ein systematisches Erschließen von van Goghs Werk, angefangen mit der Zeit noch vor seiner Entscheidung, Künstler zu werden, bis zum Jahr in Saint-Rémy 1889-1890, aufzuzeigen, was van Gogh dazu motivierte, in der Nervenheilanstalt den Zyklus der Natur vor seinem Fenster in einer Serie von Bildern festzuhalten. Ähnliche methodische Einschränkungen wie für die Briefe gelten auch für die künstlerischen

23 Vgl. Kōdera 1990, S. 5.

24 Vgl. bspw. die aufschlussreiche Einführung Donatien Graus für die englische Ausgabe von Gauguins Racontars de rapin: Ramblings of a Wannabe Painter. Paul Gauguin, hg. u. übersetzt v. Donatien GRAU, New York 2016.

25 Boehm 2009, S. 31. 
Zeugnisse van Goghs. Wenn auch durch seinen Bruder und dessen Nachfahren ein Großteil von van Goghs Werk gesichert wurde, bedeutet dies trotz allem nicht, dass uns van Goghs künstlerisches Schaffen in seiner Gänze bekannt ist. Van Gogh erwähnt mehrfach, dass er einzelne Werke, mit denen er unzufrieden war, wieder von der Leinwand abgekratzt habe. Durch die Briefe wissen wir zumindest - unter Umständen - von deren Existenz. Entsprechend muss davon ausgegangen werden, dass er auch andere Werke, die er für nicht gelungen erachtete, vernichtete. Darüber hinaus tauchen immer wieder Werke auf, die, nach eingehender Prüfung und Zertifizierung des Van Gogh Museums, dem Oeuvre zugerechnet werden. Mit Regelmäßigkeit werden andere Werke dagegen als Fälschungen entlarvt und folglich aus dem Kanon entfernt, was zur Folge hat, dass sich das Gesamtwerk van Goghs - wenn auch nur an den Rändern - in einem beständigen Fluss befindet.

Um den Erwartungshorizont für diese Arbeit abzustecken, scheint es mir erforderlich, auch auf das Problem der psychologischen Deutung von van Goghs künstlerischer Arbeit einzugehen. Da es sich bei dem betrachteten Zeitraum um den Aufenthalt in einer Nervenheilanstalt in Folge eines Zusammenbruchs handelt, ist die Versuchung groß, auf eine entsprechende Form der Analyse zurückzugreifen. In diesem Zusammenhang halte ich es jedoch mit Kōdera, der, unter anderem auf Graetz anspielend, richtig bemerkt, dass, obgleich psychologische Faktoren bei der Entstehung von van Goghs Motiven nicht vollkommen ausgeschlossen werden können, in einer kunsthistorischen Arbeit auf psychoanalytische Erklärungsmuster verzichtet werden sollte. Diese Prämisse hat auch für diese Untersuchung Gültigkeit. Wenn Empfindungen van Goghs beschrieben oder aus Briefen zitiert werden, dann erfolgt dies ausschließlich auf der Grundlage vorliegender Zeugnisse und dies auch nur zur Erklärung von Entstehungskontexten. Der Fokus dieser Arbeit richtet sich auf van Goghs Kunst, nicht auf seine psychologische Befindlichkeit.

\subsection{Der Untersuchungsgegenstand: die Serie des ummauerten Feldes}

Die im Laufe des Jahres zwischen Frühling 1889 und 1890 entstandenen Ansichten des ummauerten Feldes vor van Goghs Fenster werden innerhalb der Forschungsund Ausstellungsliteratur immer wieder als "Serie“ zusammengefasst. ${ }^{26}$ Dies geschieht vor allem aufgrund des immer gleichen Motivs eines Feldes im Lauf des Jahres und des vielfach beinahe identischen Bildausschnitts mit nur leichten Variationen, was die Komposition betrifft. ${ }^{27}$ Van Gogh verwendet für die Ansichten der ummauerten Felder selbst nicht explizit den Begriff "Serie“, obwohl ihm der

\footnotetext{
26 Beispielsweise in den Katalogen der thematisch auf van Goghs Landschaften ausgerichteten Ausstellungen in Bremen 2002 und Basel 2009.

27 Vgl. Hansen 2002, S. 40.
} 
Terminus durchaus, im Sinne der impressionistischen Bilderreihe, vertraut war. ${ }^{28}$ So berichtet van Gogh auch mehrfach in Briefen, dass er wieder das gleiche Feld gemalt habe: „Ich komme eben mit einem Bild nach Hause, an dem ich seit einiger Zeit arbeite - es ist dasselbe Feld wie beim ,Schnitter [sic]. " ${ }^{29}$ Van Gogh erläutert immer wieder, dass Verknüpfungen zwischen seinen Werken jenseits bloßer impressionistischer Parameter bestehen. Gleichzeitig wird erkennbar, dass van Gogh durch die Darstellung des sich im Jahreskreis wandelnden Feldes und der geschilderten landwirtschaftlichen Arbeit einen vollständigen Zyklus der Natur abbildet. ${ }^{30}$

In den Bildern der ummauerten Felder, die den Kern dieser Arbeit bilden, kulminieren diverse künstlerische Entwicklungsstränge, die im Werk van Goghs teilweise über mehrere Jahre nachgezeichnet werden können. Vergleiche mit anderen, insbesondere zeitnah entstandenen Serien in van Goghs Werk, können so entscheidend zum inhaltlichen Verständnis beitragen. Aufzuzeigen, dass es sich bei den Ansichten des ummauerten Feldes um ein komplexes Beziehungsgeflecht von Wiederholungen des gleichen Sujets, auf gestalterischer und inhaltlicher Ebene, handelt, soll infolgedessen Gegenstand dieser Arbeit sein. So sollen zunächst, eingebettet in einer chronologischen Hinführung an die Serie der ummauerten Felder, konzeptionelle Voraussetzungen für die Entstehung von Serien, der Verknüpfung von Werken sowie der Wiederholung von Sujets im Werk van Goghs diskutiert werden, bevor zum zentralen Thema, der Analyse der zyklischen Ansichten der ummauerten Felder und schlussendlich der Gegenüberstellung von zeitgenössischen Serien Claude Monets und Paul Cézannes, übergeleitet wird. Die Auswahl der Künstler erfolgt nicht willkürlich, sondern soll aufzeigen, welch divergente Formen der Landschaftsauffassung bei drei der wichtigsten Maler im ausgehenden 19. Jahrhundert in Frankreich, denen allgemein jeweils eine Vorreiterrolle für die Entwicklung der Malerei der Moderne zuerkannt wird, zum Ausdruck kommen, auf welchen Voraussetzungen sie beruhen und was sie ausdrücken können. ${ }^{31}$

Hauptgegenstand dieser Arbeit sind Landschaftsbilder van Goghs in Saint-Rémy. Um jedoch sein Streben, durch mehrere Einzelbilder übergreifende Werkzusammenhänge herzustellen oder ein Bildthema mittels mehrerer Ansichten in seiner Gänze zu illustrieren, vollständig erfassen zu können, sind Exkurse in andere Bildgegenstände und vergleichbare Werkgruppen unerlässlich. Aus diesem Grund gilt es zu verstehen, welche Formen der Wiederholung oder Variation einem Künstler des

28 Vgl. Brief 810/610, Saint-Rémy, ca. 8.10.1889, an Theo, zitiert nach Erpel 1965, Bd. 4, S. 332334. Bei dem entsprechenden Werk handelte es sich um Felsenschlucht, 1889, Öl auf Leinwand, 73 x $92 \mathrm{~cm}$, Boston, Museum of Fine Arts, F 662, JH 1804. Zu diesem Vorhaben sollte es jedoch nicht mehr kommen.

29 Brief 810/610, Saint-Rémy, ca. 8.10.1889, an Theo, zitiert nach Erpel 1965, Bd. 4, S. 332-334, S. 332 .

30 Der Terminus ist van Gogh vertraut, er verwendet ihn jedoch nicht im Zusammenhang mit den Bildern des ummauerten Feldes oder anderen seiner Darstellungen.

31 Vgl. Noll, Thomas: Van Gogh: Felder. Das Mohnfeld und der Künstlerstreit (Rezension Ausst. Kat.), in: Kunstchronik, 56. Jahrgang, Heft 7, Nürnberg 2003, S. 349-356. 
ausgehenden 19. Jahrhunderts in Frankreich zur Verfügung standen und inwiefern dies Einfluss auf van Gogh hinsichtlich seines künstlerischen Werdegangs bis zum Frühjahr 1889 ausgeübt haben könnte. Besonderes Augenmerk wird auf van Goghs Prägung in seiner Jugend als Sohn eines Pastors, dann auf seine Lehrzeit als Angestellter im Kunsthandel und schließlich auf seine mannigfaltigen Einflüsse aus Kunst, Literatur und Musik gelegt, um seine Vorstellungen von Themen wie Natur, Landschaftsmalerei und Religion nachvollziehen zu können.

Inwiefern die posthume Etikettierung der Werke als Serie zutreffend ist - oder in Ermangelung einer genaueren Definition vielmehr eher als terminologischer "Behelf" fungiert - und wie diese mit van Goghs Verständnis von serieller Bildproduktion und Interkonnektivität harmoniert, wird Gegenstand dieser Untersuchung sein. Im Gegensatz zu den Ausstellungen in Bremen und Basel mit ihren fundierten Katalogen zu diesem Thema werden für diese Arbeit mit Kornfeld, Blick auf die Kirche von Saint-Paul-de-Mausole (Abb. 11) und Ummauertes Feld mit den Alpillen im Hintergrund (Abb. 14) der Serie zwei weitere Werke hinzugefügt, die damals aus nicht nachvollziehbaren Gründen ausgelassen wurden. ${ }^{32}$

32 Kornfeld, Blick auf die Kirche von Saint-Paul-de-Mausole, Herbst 1889, 45,1 x 60,4 cm, Öl auf Leinwand, Privatsammlung, zuletzt Christie’s London, 7.2.2012, Los 12, F 803, JH 2124 u. Ummauertes Feld mit den Alpillen im Hintergrund, Januar-Februar 1890, Öl auf Leinwand, 33 x 28.5 cm, Amsterdam, Van Gogh Museum, F 723, JH 1722. Der Blickwinkel ist zwar leicht verschoben, aber es handelt sich zweifelsfrei um das gleiche ummauerte Feld wie bei den anderen Werken. 



\section{Der Aufenthalt in Saint-Rémy}

\subsection{Hintergründe der Einweisung in die Nervenheilanstalt}

Die gemeinsame Zeit Vincent van Goghs und Paul Gauguins im Herbst 1888 in Arles - für van Gogh die ersehnte Erfüllung seines Traums vom „Atelier des Südens“ - währte nur zwei Monate, bevor sie sich als „beklagenswerter, schmerzlicher Fehlschlag herausstellte. " ${ }^{1}$ Diese Phase war jedoch für beide Künstler außerordentlich prägend. Der Reichtum der entstandenen Bilder und die Bedeutung der künstlerischen Entwicklungsschritte, insbesondere unter Berücksichtigung der dem Besuch vorausgehenden Korrespondenz zwischen den Künstlern, untermauern dies. Mehrere Monate nach dem Streit mit Gauguin verließ van Gogh auf Drängen der Bevölkerung von Arles, die seines auffälligen Verhaltens überdrüssig geworden war, die Stadt. Er empfand große Zweifel, ob er selbstständig für sich sorgen könne und hielt eine Internierung in einer Nervenheilanstalt für die vorläufig beste Entscheidung:

Hoffentlich genügt es, wenn ich Dir sage, daß ich mich völlig außerstande fühle, ein neues Atelier zu nehmen und dort allein zu wohnen - hier in Arles oder anderswo, das kommt zur Zeit auf dasselbe hinaus; ich habe versucht, mich an den Gedanken zu gewöhnen, von neuem anzufangen, jedoch im Augenblick ist das nicht möglich. Ich hätte Angst, die Arbeitsfähigkeit zu verlieren, die sich jetzt wieder einstellt, wenn ich mir Zwang antäte und all die Verantwortlichkeiten auf mich nähme, die ein Atelier mit sich bringt.

Brief 761/586, Arles, 24.4.1889, an Theo, zitiert nach Erpel 1965, Bd. 4, S. 267-268, S. 268. 
Vorläufig möchte ich interniert bleiben, um meiner eigenen Ruhe willen und auch der anderen wegen. ${ }^{2}$

Daraufhin begab er sich am 8. Mai 1889 in Begleitung des Pastors der reformierten protestantischen Kirche in Arles, Reverend Frédéric Salles, unter permanente medizinische Aufsicht in die etwa 25 Kilometer nordwestlich von Arles gelegene Nervenheilanstalt Saint-Paul-de-Mausole in Saint-Rémy-de-Provence. Salles hatte van Gogh seit dessen Zusammenbruch im Dezember regelmäßig besucht und ihm diese Klinik vorgeschlagen. ${ }^{3}$ Untergebracht in einem ehemaligen Kloster, war die Anstalt seit dem beginnenden 19. Jahrhundert dazu bestimmt, Nervenkranke aufzunehmen, damit diese in der Abgeschiedenheit der nahe der Alpillen gelegenen Kleinstadt Heilung finden konnten. Auch wenn die Klinik sich in einem ehemaligen Kloster befand und Nonnen zum Personal gehörten, war der Schwerpunkt der Therapien nicht religiös, sondern lag vor allem auf der beruhigenden Wirkung des in der Einsamkeit liegenden Klosters und der Natur, die es umgab.

Van Gogh plante zunächst, drei Monate zu bleiben und dann über eine Verlängerung des Aufenthaltes zu entscheiden. ${ }^{4}$ Am 9. Mai wurde seine Ankunft durch den Anstaltsarzt Dr. Peyron im Eingangsregister der Klinik vermerkt, der bei ihm Anfälle von Epilepsie diagnostizierte. ${ }^{5}$ In der Klinik, die er zunächst nicht verlassen durfte, hatte er im Obergeschoss zwei Zimmer zur Verfügung, wovon er eines als Schlafzimmer und das andere als Atelier nutzte. Während seines etwas mehr als einjährigen Aufenthaltes entstanden ungefähr 150 Gemälde und etwa genauso viele Zeichnungen.

In den ersten Tagen in der Klinik malte er nahsichtige Darstellungen mit Blumen und Bäumen des Anstaltsgeländes und schrieb an seinen Bruder: „Wenn Du diese Bilder erhältst, die ich im Garten gemalt habe, wirst Du sehen, daß ich hier nicht allzu trübselig bin. ${ }^{\text {"6 }}$ Aus dem Fenster des nach Osten weisenden Schlafzimmers konnte er auf ein ummauertes Kornfeld blicken (vgl. Abb. 16-19), hinter dem sich ein Olivenhain und die abwechslungsreiche hügelige provenzalische Landschaft entfaltete, die sich deutlich von der Weite der Landschaft rings um Arles unterschied. Wenige Tage nach seiner Ankunft in Saint-Rémy beschrieb er die Aussicht aus dem vergitterten Fenster seiner Anstaltszelle auf das ummauerte Kornfeld als „[...] à la van Goyen; darüber sehe ich am Morgen die Sonne in ihrer Herrlichkeit aufgehen. ${ }^{\text {"7 }}$ Kurze Zeit später äußerte er sich erneut zu dem Ausblick, wieder in

Brief 760/585, Arles, 21.4.1889, an Theo, zitiert nach Erpel 1965, Bd. 4, S. 263-266, S. 264.

Vgl. Hansen 2002, S. 27.

Vgl. Brief 760/585, Arles, 21.4.1889, an Theo, zitiert nach Erpel 1965, Bd. 4, S. 263-266 S. 264.

Vgl. Hansen 2002, S. 27.

6 Brief 777/593, Saint-Rémy, zw. 31.5. u. 6.6. 1889, an Theo, zitiert nach Erpel 1965, Bd. 4, S. 284-286, S. 286.

7 Brief 776/592, Saint-Rémy, ca. 23.5.1889, an Theo, zitiert nach Erpel 1965, Bd. 4, S. 279-284, S. 281. 
kunsthistorischer Kontextualisierung, durch die bereits seine tiefere Auseinandersetzung mit dem Motiv vor seinem Fenster deutlich wird:

Von meinem Fenster aus habe ich heute morgen lange vor Sonnenaufgang die Landschaft betrachtet, am Himmel nur der Morgenstern, der ungemein groß schien. Daubigny und Rousseau haben das gemacht und die ganze Innigkeit ausgedrückt, die es hat, die ganze Stille und Größe, und sie haben ein so herzbewegendes, so persönliches Empfinden hineingemalt. Solche Gemütsstimmungen sind mir durchaus nicht zuwider. ${ }^{8}$

\subsection{Die Ansichten der ummauerten Felder}

Es handelt sich bei den Werken der vorliegenden Untersuchung um elf unterschiedliche Ansichten desselben Motivs, von denen eine in insgesamt drei Versionen und zwei in zwei weiteren Ausführungen vorliegen, so dass insgesamt 15 Werke zu der Serie gezählt werden können. Mit einer Ausnahme sind alle Ansichten im Querformat konzipiert. ${ }^{9}$ Darüber hinaus hat van Gogh das ummauerte Feld mehrfach in zeichnerischen Studien festgehalten. Grundsätzlich ist das verbindende Element aller Ansichten die das Feld begrenzende und somit das Anstaltsgelände von der Außenwelt abschirmende Mauer. Auf fast allen Gemälden sind im Hintergrund, zumeist am rechten oberen Bildrand, die südlich der Anstalt gelegenen Kalksteinformationen der Alpillen zu sehen. Der abgebildete Kamm der Alpillen erzeugt durch viele Bilder der Serie eine von links unten nach rechts oben aufsteigende Horizontlinie. Van Goghs Blickwinkel auf das Feld variierte im Grad der Aufsicht, je nachdem ob er in seinem Zimmer oder auf dem Feld selbst stand. Nicht alle Bilder sind von seinem Fenster aus entstanden. Wenn es ihm gestattet war, verließ van Gogh sein Zimmer und malte im Freien. Die Positionierung im Feld erlaubte ihm, den Betrachterstandpunkt zu verändern und den Blick beispielsweise mehr nach Süden zu den Alpillen oder der auf dem Anstaltsgelände gelegenen Kirche Saint-Paul-de Mausole zu richten.

Das wahrscheinlich erste Werk der Serie zeigt das Kornfeld, nach dem Unwetter (Abb. 1). ${ }^{10}$ Es gilt als eines der ersten beiden Landschaftsbilder überhaupt aus Saint-

8 Brief 777/593, Saint-Rémy, zw. 31.5. u. 6.6. 1889, an Theo, zitiert nach Erpel 1965, Bd. 4, S. 284-286, S. 285.

9 Kornfeld, der Schnitter liegt in drei Versionen vor - einer Studie und einer großen sowie einer verkleinerten Wiederholung (in van Goghs eigener Terminologie als „étude“ und „réduction“ klassifiziert) - und Gepflügte Äcker sowie Kornfeld, nach dem Unwetter jeweils in zwei Varianten, wobei im Werkverzeichnis von Vellekoop/Zwikker die zweite Variante von Gepflügte Äcker (F 706, JH 1794) nicht zu der Serie gezählt wird, weil es (vermutlich) das einzige Werk ist, bei dem van Gogh auf die Mauer verzichtete. Vgl. Vellekoop/Zwikker 2007, S. 392.

10 Kornfeld, nach dem Unwetter, Juni 1889, Öl auf Leinwand, 70,5 x 88,5 cm, Kopenhagen, Ny Carlsberg Glyptothek, F 611, JH 1723. 
Rémy ${ }^{11}$ und entstand um den 9. Juni 1889. Ein Brief van Goghs an seinen Bruder, der am selben Tag verfasst wurde, enthält die Bemerkung, das Weizenfeld sei

nach einem Gewitter völlig verwüstet, die Halme zu Boden gedrückt. Eine Mauer als Einfriedung, jenseits der Mauer das Graugrün einiger Ölbäume, Hütten und Berge. Hoch oben auf dem Bild eine große weiße- und graue Wolke, ertrunken in Blau. Es ist eine Landschaft von äußerster Einfachheit auch in der Farbgebung. ${ }^{12}$

Das Feld, das van Gogh mittels pastos aufgetragener gekrümmter Striche in unterschiedlich abgestuften Grün-, Ocker- und Gelbtönen sowie Weiß darstellt, nimmt nahezu die Hälfte des Bildraumes ein. Er fasst dabei immer mehrere Striche in ihrer Ausrichtung zusammen und stellt diese „Strichbündel“ anders orientierten Strichen gegenüber. So entsteht der Eindruck eines stark bewegten, von einem Sturm zerzausten Feldes. Hinter dem Feld verläuft über die gesamte Bildbreite leicht diagonal die Mauer des Anstaltsgeländes und fungiert nicht nur gegenständlich als Zäsur im Bildraum zwischen dem, was sich vor und hinter der Mauer befindet, sondern auch in perspektivischer Hinsicht als Raum erzeugendes Gliederungselement. Hinter der Mauer schließt sich eine summarisch angedeutete hügelige Landschaft an, die von einem mächtigen, aufgetürmtem Wolkengebilde überfangen wird.

Der Verlauf der Mauer ist analog zu dem der Hügel, die zur rechten oberen Bildecke hin ansteigen. Van Gogh erzeugt Bildtiefe durch linearperspektivische Mittel, wie die in den Bildraum verlaufende Mauer, aber auch durch eine abnehmende Detailgenauigkeit mit zunehmender Bildtiefe und den Einsatz der Farbperspektive. Letzteres wird erreicht durch das Zusammenspiel der Farbabfolge Gelb-Ocker im Vordergrund, überwiegend Grüntönen im Mittelgrund und Blautönen im Hintergrund. Dieses Schema führt er sogar so weit aus, dass er die Hügel ganz links sowie ganz rechts durchgehend blau färbte. Dagegen fehlt - wie schon in der Arleser Zeit - eine Luftperspektive, die den Eindruck einer dunstig-schemenhaften Weite entstehen lässt; die wenigen, aber kräftigen und klaren Farben vermitteln dennoch den Eindruck von vollkommen reiner Luft nach einem Gewitter.

Vier Wochen nach seiner Ankunft in Saint-Rémy hatte sich Van Gogh anscheinend zunächst mit seiner Situation arrangiert. So formulierte er an seinen Bruder Ende Mai, Anfang Juni:

Gesundheitlich geht es mir gut, und mit dem Kopf, das ist hoffentlich eine Frage der Zeit und Geduld. [...] Nun bin ich fast schon einen Monat hier;

11 „Ich habe zwei Landschaften in Arbeit (Bilder zu 30), Ansichten aus der hügeligen Gegend hier; die eine ist die Aussicht aus meinem Schlafzimmerfenster." Brief 779/594, Saint-Rémy, 9.6.1889, an Theo, zitiert nach Erpel 1965, Bd. 4, S. 286-289, S. 287. Bei dem zweiten Bild, von dem van Gogh schreibt, handelt es sich vermutlich um das Mohnfeld, Juni 1889, Öl auf Leinwand, 72 × $91 \mathrm{~cm}$, Kunsthalle, Bremen, F 581, JH 1751.

12 Brief 779/594, Saint-Rémy, 9.6.1889, an Theo, zitiert nach Erpel 1965, Bd. 4, S. 286-289, S. 287. 
kein einziges Mal ist mir der Wunsch gekommen, irgendwo anders zu sein, nur der Wille, wieder zu arbeiten, ist ein klein bisschen stärker geworden. ${ }^{13}$

Im Juni entstand eine weitere Ansicht des ummauerten Feldes, die möglicherweise in ihrer Darstellung des Feldes Auskunft über van Goghs wechselnden Gemütszustand geben könnte (Abb. 3). ${ }^{14}$ Der Blick ist nun so steil auf das Feld gerichtet, dass van Gogh die Alpillen, die er sonst in der rechten oberen Bildecke hintereinander aufragen lässt, abschneiden muss. Die Mauer verläuft zunächst vom Gebäude weg in den Bildraum hinein und erzeugt Tiefenwirkung, bevor sie nach rechts abknickt und in einer leichten Diagonale in die rechte obere Bildecke führt. Durch die dunklen Konturen und Schatten erhält sie eine besondere Präsenz. ${ }^{15}$ Das Feld nimmt den größten Teil des Bildes ein und ist raumgreifender als bei vielen anderen Werken der Serie. Statt des weich geschwungenen Pinselduktus dominiert im Bereich des Feldes nun ein Farbauftrag mit eher geraden, parallel geführten Pinselstrichen. Der gelb gefärbte Himmel, der nur einen schmalen Streifen in der oberen linken Bildhälfte einnimmt, ist im Vergleich zu anderen Ansichten stark zurückgedrängt. Zwischen roten Farbtupfern, die auf dem grünen Feld Klatschmohn andeuten, entstehen Komplementärkontraste. Ebenso stark ist der Farbkontrast zwischen den blauen Hügeln und dem gelben Himmel.

Ende Juni entstanden weitere Landschaftsbilder, zu denen die erste Version von Kornfeld, der Schnitter ${ }^{16}$ (Abb. 4) gehört: „[...] ein Tag ist wie der andere, durch den Kopf geht mir weiter nichts, als daß ich mir überlege, ob ein Kornfeld oder eine Zypresse es verlohnen, sie näher anzusehen, und so fort. Ich habe ein ganz gelbes, ganz

13 Brief 777/593, Saint-Rémy, zw. 31.5. u. 6.6. 1889, an Theo, zitiert nach Erpel 1965, Bd. 4, S. 284-286, S. 284 u. 285.

14 Kornfeld, Ende Mai oder Anfang Juni 1889?, Öl auf Leinwand, 72 x 92 cm, Otterlo, KröllerMüller Museum, F 720, JH 1728. Die zeitliche Einordnung dieses von van Gogh nicht datierten Werkes ist nicht unumstritten. Es könnte bereits Ende Mai 1889 entstanden sein (vgl. Vellekoop/ Zwikker 2007, S. 392 u. Datierung des Kröller-Müller Museums, bspw. im Online Katalog der Sammlung, abgerufen unter https://krollermuller.nl/en/vincent-van-gogh-enclosed-wheat-fieldwith-rising-sun). Es wird verschiedentlich auch in den Mai des Folgejahres datiert, bspw. durch Hansen aufgrund inhaltlicher und stilistischer Beweggründe. Hansen weist jedoch auch auf die Möglichkeit einer Entstehung im Jahr 1889 hin (vgl. Hansen 2002, S. 102f.). Die Datierung des Kröller-Müller Museums auf Ende Mai 1889 muss auch hinsichtlich der Feldfarbe diskutiert werden, die hier bereits mehr gelbes und damit reifes Korn als bei Kornfeld, nach dem Unwetter zeigt. Van Gogh malte bereits Ende Juni, Anfang Juli mit F 617, JH 1753 das erste Erntebild.

15 Vgl. Hansen 2002, S. 102. Bei der Beschreibung eines anderen Werkes aus Saint-Rémy hatte er bezüglich der dunklen Konturen von einem Angstgefühl gesprochen, das diese auslösen könnten. Vgl. Brief 822/B 21, Saint-Rémy, um 26.11.1889, an Émile Bernard, zitiert nach Erpel 1968, Bd. 5, S. 291-295, S. 293. Bei dem Werk handelt es sich um Der Garten von St. Paul, November 1889, Öl auf Leinwand, 71,5 x 90,5, Amsterdam, Van Gogh Museum, F 659, JH 1850. Vgl. für die extreme Diagonalität auch Tralbaut 1970, S. 100-102.

16 Kornfeld, der Schnitter, „étude“, Juni-Juli 1889, Öl auf Leinwand, 72 x 92 cm, Otterlo, KröllerMüller Museum, F 617, JH 1753. 
helles Kornfeld, vielleicht das hellste Bild, das ich je gemacht habe. ${ }^{\text {"17 }}$ In einem kurze Zeit später entstandenen Brief fährt er fort: „Das letzte [Bild], das ich angefangen habe, ist ein Kornfeld mit einem kleinen Schnitter und einer großen Sonne. Das ganze Bild ist gelb, ausgenommen die Mauer und der Hintergrund von violetten Bergen. "18 Im Unterschied zu den vorher entstandenen Ansichten hat van Gogh den Betrachterstandpunkt hinsichtlich der Blickrichtung und der Höhe geändert. Der Betrachter steht jetzt selbst auf dem Feld und sein Blick richtet sich nun mehr nach Süden als vorher, so dass der Mauerabschnitt, der linker Hand nach Osten verläuft, nicht mehr im Bild sichtbar ist. Zentral im Vordergrund befindet sich eine große Korngarbe, die van Gogh als Repoussoir einsetzte. Links hinter der Garbe steht im Ausfallschritt und mit erhobener Sichel in der rechten Hand ein Schnitter, der sich von links nach rechts durch die noch stehenden Korngarben vorarbeitet. Der Schnitter ist in Farbgestaltung und Größe sehr zurückgenommen dargestellt. Zwei Drittel des Bildraumes nimmt das in leuchtend goldenen Gelbtönen und mit pastosem Farbauftrag gemalte Feld ein.

Die diagonal durch den Bildraum verlaufende Mauer trennt das Feld von den dahinter liegenden Hügeln der Alpillen, die nach Süden immer höher aufragen und dabei in der Farbgebung von gelb zu blau wechseln. Anders als bei den vorher entstandenen Ansichten schließt die Mauer jedoch auf der linken Seite das Bild nicht $\mathrm{ab}$, so dass - auch wenn der Betrachterstandpunkt niedriger ist und sich eher auf Augenhöhe des Feldes befindet - ein insgesamt etwas offenerer Eindruck des Feldes entsteht. Ein ebenfalls in leuchtenden Gelbtönen gemalter Himmel lastet durch die horizontale Anordnung und Breite der Pinselstriche und durch den extrem pastosen Farbauftrag schwer auf der Szenerie. Die noch tief stehende, kreisrunde Sonne ist zwar gerade erst hinter den Hügeln aufgegangen, doch ist die von ihr ausgehende Hitze dieses Hochsommertages bereits deutlich fühlbar.

Van Gogh fertigt in dieser Zeit auch Zeichnungen in Bleistift und Rohrfeder nach seinen „études“ an, die seine weitere intensive Beschäftigung mit dem Thema des Feldes bezeugen: „Damit Du eine Vorstellung davon bekommst, was ich jetzt mache, schicke ich Dir heute etwa zehn Zeichnungen, alle nach Bildern, die ich in Arbeit habe. ${ }^{\text {"19 }} \mathrm{Zu}$ diesem Konvolut für Theo gehörten Zeichnungen, die er nach dem Kornfeld, nach dem Unwetter und der ersten Fassung von Kornfeld, der Schnitter angefertigt hatte. ${ }^{20}$ Durch die Monochromie der Zeichnungen verliert der Aspekt

17 Brief 783/596, Saint-Rémy, 25.6.1889, an Theo, zitiert nach Erpel 1965, Bd. 4, S. 292-294, S. 292.

18 Brief 784/597, Saint-Rémy, zw. 25.6.1889 u. 5.7.1889, an Theo, zitiert nach Erpel 1965, Bd. 4, S. 294-297, S. 296.

19 Brief 784/597, Saint-Rémy, zw. 25.6.1889 u. 5.7.1889, an Theo, zitiert nach Erpel 1965, Bd. 4, S. 294-297, S. 296.

20 Kornfeld, nach dem Unwetter, 1889, Bleistift, Rohrfeder und Feder in Braun, 47 x 61,8 cm, Amsterdam, Van Gogh Museum, F 1547, JH 1724 sowie Kornfeld, der Schnitter, 1889, Bleistift, Rohrfeder und Feder in Braun, 45 x 58,5 cm, Staatliche Museen zu Berlin, Kupferstichkabinett, F 1546, JH 1754. Für eine genaue Angabe, welche Zeichnungen van Gogh an seinen Bruder 
der intensiven Farbigkeit seine Bedeutung. Stattdessen rücken - entsprechend der Arbeitsweise mit der Rohrfeder - die Konturen und Binnenstrukturen in den Vordergrund. Dabei sind in beiden Zeichnungen besonders das dynamisch gezeichnete Getreide im Kontrast zu der gleichmäßig schraffierten Mauer hervorzuheben. Es sei aber darauf hingewiesen, dass van Gogh dennoch durch die graphische Struktur seiner Zeichnungen (teilweise) die Farbigkeit anzuzeigen sucht. ${ }^{21}$

Die Auseinandersetzung mit dem Sujet mittels der Zeichnungen wirkte sich auf die in der Folge im September und Oktober angefertigten Fassungen von Kornfeld, der Schnitter in Öl aus („tableau“ und „réduction“22, Abb. 5 und 6). Anfang September arbeitete van Gogh ausschließlich in seinem Zimmer, „das tut mir wohl und verjagt, wie ich mir einbilde, die krankhaften Gedanken. ${ }^{23}$ Motivisch unterscheiden sich die Wiederholungen nur geringfügig von der Studie, die vor der Natur entstanden war. Abweichungen werden in der Komposition und beim Farbauftrag deutlich, welche die Wiederholungen wesentlich ausgewogener und weniger spontan erscheinen lassen. ${ }^{24}$ Van Gogh ersetzt die dominierende Korngarbe im Vordergrund durch eine größere Fläche noch stehenden Getreides, das der Schnitter noch abernten muss. Der Pinselduktus ist gleichmäßiger und die Komposition durch den vergrößerten Baum am linken Bildrand stabiler, der nun stärker im Zusammenspiel mit den Hügeln auf der rechten Seite die Szenerie rahmend einklammert. Die Sonne ist in beiden Wiederholungen an den mittleren oberen Bildrand gewandert. Bei der im Oktober entstandenen „réduction“ entfernte sich van Gogh durch das Andeuten von einzelnen Steinen bei der Mauer noch deutlicher vom spontanen Eindruck der Studie aus dem Juni. ${ }^{25}$

Der Sommer verlief für van Gogh sehr ambivalent. Nach zunächst guten Nachrichten, die ihn beflügelten - so sollte Theos Sohn nach ihm benannt werden, und er wurde gefragt, ob er an der nächsten Ausstellung der Gruppe ,Les XX' in Brüssel teilnehmen wolle -, erlitt er Mitte Juli einen Anfall, der ihn für fast fünf Wochen

geschickt hat, vgl. Kommentar zu diesem Brief in der Online-Ausgabe, abgerufen unter: http:// vangoghletters.org/vg/letters/let784/letter.html.

21 Auf die Unterschiede zwischen den „études“ und den Zeichnungen weist sehr deutlich Dorothee Hansen hin. Vgl. Hansen 2002, S. 88.

22 Kornfeld, der Schnitter, „tableau“, September 1889, Öl auf Leinwand, 73 x 92 cm, Amsterdam, Van Gogh Museum, F 618, JH 1773. Van Gogh griff hier bspw. auf die in der Zeichnung (F 1546, JH 1754) bei der Darstellung der Büsche am linken Bildrand angewendeten gekrümmten Pinselstriche statt auf die geraden Striche aus der nach der Natur entstandenen Studie. Vgl. Hansen 2002, S. 88. Kornfeld, der Schnitter, „réduction“, Oktober 1889, Öl auf Leinwand, 59,5 x 73 cm, Essen, Museum Folkwang, F 619, JH 1792.

23 Brief 800/604, Saint-Rémy, 5./6.9.1889, an Theo, zitiert nach Erpel 1965, Bd. 4, S. 308-315, S. 309.

24 Farblich ist van Gogh bei den Wiederholungen von der Dominanz des golden leuchtenden Gelbs etwas abgerückt, indem er die Berge akzentuierter in Beige und Blau sowie den Himmel in grünlichem Gelb darstellt. Der Schnitter ist nun stärkerer konturiert und hebt sich so mehr von seiner gelben Umgebung ab.

25 Vgl. Hansen 2002, S. 90. 
vom Arbeiten abhielt. ${ }^{26}$ Kurz davor war mit Kornfeld, Mondaufgang ${ }^{27}$ (Abb. 7) das einzige Werk der Serie entstanden, das das Feld zur Nachtzeit wiedergibt. „[...] Eins habe ich in Arbeit von einem Mondaufgang über demselben Feld wie auf der Skizze in dem Brief an Gauguin, aber das Korn steht nicht mehr auf dem Halm, sondern stattdessen in Puppen. Es ist mattes Ockergelb und Violett. " 28

Im Gegensatz zu dem zuvor entstandenen Kornfeld, der Schnitter wird das Feld auch auf der linken Seite wieder von der Mauer eingefasst, die im rechten Winkel abknickt, um dann wie ein gerades, horizontales Band den Bildraum zu teilen. Statt diagonal nach rechts oben verläuft die Mauer nun waagerecht. Der Verlauf scheint dadurch mehr der Wirklichkeit zu entsprechen als bei anderen Versionen. Durch den niedrigen Betrachterstandpunkt und den Verlauf der nach Osten, in den Bildhintergrund, weisenden Mauer links entsteht der Eindruck eines abgeschlossenen Feldes. Dagegen ist das Bild kompositorisch vereinfacht und weist weniger Details auf als Kornfeld, der Schnitter. Mittels vieler, gleichmäßig geschwungener, kurzer Pinselstriche in warmen Beige- und Ockertönen gibt van Gogh dem Feld eine Struktur und verteilt darauf in regelmäßigen Abständen Heuhaufen. Als Folge des erwähnten Anfalls versuchte van Gogh, sich am 16. oder 17. Juli mit seinen Farben zu vergiften. ${ }^{29}$ Daraufhin wurde ihm das Malen vorerst untersagt. Dass ihm diese Regelung nicht zusagte, bezeugt der Brief, den er am 22. August an seinen Bruder schrieb:

Vielleicht wäre es gut, wenn Du Herrn Dr. Peyron ein paar Worte schreiben würdest, daß die Arbeit an meinen Bildern eigentlich zu meiner Genesung nötig ist, denn die Tage jetzt, wo ich nichts tue und nicht in das Zimmer darf, das er mir als Malraum angewiesen hatte, sind mir beinah unerträglich. ${ }^{30}$

Zwei Wochen später berichtete er, dass es ihm etwas besser gehe: „Gestern habe ich wieder angefangen, ein bißchen zu arbeiten - eine Sache, die ich von meinem Fenster aus sehe - ein gelbes Stoppelfeld, das umgepflügt wird, der Gegensatz der violetten, umgepflügten Erde zu den gelben Stoppelstreifen, Berge im Hinter-

26 Vgl. Hansen 2002, S. 28.

27 Kornfeld, Mondaufgang, Juli 1889, Öl auf Leinwand, 72 x 92 cm, Otterlo, Kröller-Müller Museum, F 735, JH 1761.

28 Brief 790/603, Saint-Rémy, 14.7. oder 15.7.1889, an Theo, zitiert nach Erpel 1965, Bd. 4, S. 306-308, S. 307. Hansen weist darauf hin, dass Untersuchungen ergeben haben, dass die Farbe, die ursprünglich in kräftigem Pink leuchtete, nun verblichen ist und Blau erscheint. Vgl. Hansen 2002, S. 92, Anm. 2.

29 Für das Datum vgl. die Kommentierung zu Brief 793/T 13, Paris, 29.7.1889, Theo v. Gogh an Vincent, auf der Internetseite des van Gogh Museums: http://vangoghletters.org/vg/letters/ let793/letter.html. Bzgl. der versuchten Vergiftung vgl. das Telegramm von Jo van Gogh-Bonger an ihre Schwester Mien im Kommentar zu Brief 794/T 14, Paris, 4.8.1889, Theo v. Gogh an Vincent, auf der Internetseite des van Gogh Museums: http://vangoghletters.org/vg/letters/let794/ letter.html.

30 Brief 797/601, Saint-Rémy, 22.8.1889, an Theo, zitiert nach Erpel 1965, Bd. 4, S. 301-302, S. 301 . 
grund. “31 Van Gogh bezog sich in seinem Brief auf Gepflügte Äcker (Abb. 8), ${ }^{32}$ das nun nach dem Erntebild Kornfeld, der Schnitter den nächsten Schritt im Jahreskreis zeigt: das Pflügen des Feldes für die erneute Aussaat. Von rechts nach links zieht ein Pferd einen Pflug, der von einem Bauern gehalten wird. Die dadurch entstehenden Ackerfurchen des Feldes formt van Gogh mit pastosen Strichen in unterschiedlich stark gemischten Blau-Grüntönen, hin und wieder mit gelben Einsprengseln durchsetzt, die in ihrer dynamischen Orientierung entschieden von links unten nach rechts oben weisen. Der Blickwinkel ist weniger erhöht und das Feld nimmt eine größere Fläche ein als bei den Bildern zuvor. Mauer und Hügel sind flacher, der Himmel stellt nur noch eine kleine Fläche am oberen Bildrand dar, und die gelbe Sonnenscheibe wird vom oberen Bildrand abgeschnitten. Komplementärkontraste zwischen Blau- und Gelbtönen bestimmen hauptsächlich den farblichen Eindruck dieses Spätsommertages. Dem Schnitter ähnlich ist hier auch der pflügende Bauer in seiner Größe und Platzierung sehr zurückgenommen.

Das danach entstandene Werk Gepflügte Äcker, Morgenlicht ${ }^{33}$ (Abb. 9) unterscheidet sich trotz des gleichen Themas in mehreren Aspekten von seinem Vorläufer: Van Gogh verzichtet jetzt auf die Mauer und platziert in der zentralen Bildflucht eine große und daneben eine kleine Windmühle. Den ansonsten gleichmäßigen Duktus bricht er im Vordergrund auf und stellt die bereits umgepflügte Erde als eine bewegte Struktur aus violetten, blauen und weißen Strichen, Kreisen und Punkten dar. ${ }^{34}$ Dennoch ist auch hier wieder, wenngleich insgesamt gedämpfter, eine Gegenüberstellung von Gelb- und Blautönen auffällig.

Im Spätsommer, als es ihm nicht gut ging, wollte van Gogh Kopien nach Werken des von ihm verehrten Jean-François Millet anfertigen. Zu den Drucken, die van Gogh dafür von seinem Bruder anforderte, gehörte Paul-Edmé le Rats Radierung nach Millets Der Sämann. ${ }^{35}$ Auch vom thematisch komplementären Schnitter fertigte van Gogh Kopien an. ${ }^{36}$ Die Serie von 23 Kopien in Öl, die van Gogh schließlich ab September von Drucken nach Millets Feldarbeiten (im Original Les travaux des champs) malte, entstanden aus einer Vielzahl von Gründen. Es ist im Zusammenhang der parallel entstehenden Serie des ummauerten Feldes kein Zufall, dass er sich gerade mit dem Thema der Jahreszeiten, dargestellt durch die einzelnen

31 Brief 798/602, Saint-Rémy, 2.9.1889, an Theo, zitiert nach Erpel 1965, Bd. 4, S. 302-306, S. 302.

32 Gepflügte Äcker, Ende August 1889, Öl auf Leinwand, 49 x 62 cm, Privatbesitz (Christie’s NY, Auktion 15004, Los 28A, 13.11.2017), F 625, JH 1768.

33 Gepflügte Äcker, Morgenlicht, Oktober 1889, Öl auf Leinwand, 54 x 67 cm, Museum of Fine Arts, Boston, F 706, JH 1794.

34 Vgl. Hansen 2002, S. 94.

35 Paul-Edmé le Rat (1849-1892), Der Sämann (nach Jean-François Millet, 1814-1875), 1873, Radierung, 12 x 9,5 cm, Van Gogh Museum, Amsterdam.

36 Der Schnitter mit Sichel (nach Millet), September 1889, Öl auf Leinwand, 44 x 33 cm, Amsterdam, Van Gogh Museum, F 687, JH 1782 u. Der Schnitter (nach Millet), September 1889, Öl auf Leinwand, 43,5 x 25 cm, Privatbesitz, F 688, JH 1783. 
Tätigkeiten auf dem Feld, beschäftigen wollte. Aber an seinen Bruder schrieb er auch: „[...] besonders jetzt, wo ich krank bin, suche ich etwas mir zum Trost und zur Freude zu machen. [...] Sehr viele Maler kopieren nicht, viele andere wieder kopieren - ich selber bin durch Zufall darauf gekommen, und ich finde, es lehrt einen manches, und vor allem tröstet es einen manchmal.“37

Anfang Oktober verließ van Gogh zum ersten Mal seit seinem Anfall Mitte Juli wieder das Anstaltsgelände. Er beschloss, noch bis zum kommenden Frühling in der Klinik zu bleiben und dann wieder in den Norden, nach Auvers-sur-Oise, zu ziehen. Camille Pissarro hatte ihm empfohlen, sich dort von dem bekannten und der modernen Kunst sehr zugeneigten Doktor Paul Gachet (1828-1909) behandeln zu lassen. Zu dieser Zeit, während die zweite Wiederholung - „réduction“ - von Kornfeld, der Schnitter entstand, wandte sich van Gogh einem neuen Motiv zu und malte Ummauertes Feld mit Bauern (Abb. 10), das er als Pendant dazu verstand. ${ }^{38}$

Ich komme eben mit einem Bild nach Hause, an dem ich seit einiger Zeit arbeite - es ist dasselbe Feld wie beim ,Schnitter'. Aber jetzt sind es Erdschollen und im Hintergrund ausgedörrtes Land und die Felsenberge der Alpinen. Ein Stück blaugrüner Himmel mit einer kleinen weiß-und-violetten Wolke. Im Vordergrund eine Distel und dürres Kraut. In der Mitte ein Bauer, der ein Bündel Stroh hinter sich herschleppt. ${ }^{39}$

In diesem Bild richtet van Gogh den Blick mehr als zuvor nach Süden und zeigte das ummauerte Feld vor den im Hintergrund steil aufsteigenden Alpillen. Stabilität gewinnt das Bild durch die als Repoussoir in den Vordergrund platzierte große Distel, die horizontale Ebene des Feldes, die waagerecht positionierte Mauer und die massive Formation der Alpillen dahinter. Für die Berge hatte van Gogh ein Interesse entwickelt. Wehmütig schrieb er an Theo: „Von diesen Alpinen könnte ich bestimmt eine ganze Serie machen, denn jetzt habe ich sie lange Zeit vor Augen gehabt und mich allmählich daran gewöhnt. Erinnerst Du Dich an die schöne Landschaft von Monticelli, die wir bei Delarebeyrette gesehen haben, ein Baum auf Felsen gegen einen Sonnuntergang. Solche Stimmungen gibt es jetzt viele, aber bei Sonnenuntergang darf ich nicht mehr ins Freie, sonst hätte ich es schon zu machen versucht. " 40

Im Gegensatz zu den vorherigen Bildern des ummauerten Feldes sind nun Grau, helles Blau und Beige die dominierenden Farben. ${ }^{41}$ Obgleich der niedrige Betrach-

37 Brief 805/607, Saint-Rémy, ca. 20.9.1889, an Theo, zitiert nach Erpel 1965, Bd. 4, S. 322-327, S. $324 f$. Pickvance 1986, S. 37 verweist auf diesen Brief.

38 Ummauertes Feld mit Bauern, Oktober 1889, Öl auf Leinwand, 73 x 92 cm, Indianapolis Museum of Art, F 641, JH 1795.

39 Brief 810/610, Saint-Rémy, ca. 8.10.1889, an Theo, zitiert nach Erpel 1965, Bd. 4, S. 332-334, S. 332 .

40 Brief 810/610, Saint-Rémy, ca. 8.10.1889, an Theo, zitiert nach Erpel 1965, Bd. 4, S. 332-334, S. 333 .

41 Van Gogh wird wahrscheinlich nicht Grau, sondern Lila verwendet haben. 
terstandpunkt suggeriert, dass van Gogh beim Malen auf dem Feld selbst gestanden haben könnte, erwecken der gleichmäßige Duktus und die vielen detailliert ausgearbeiteten Einzelheiten - wie die Bäume auf den Hängen - kaum den Eindruck einer spontan vor der Natur entstandenen Studie. Auch die Komposition mit der sorgfältig ausgearbeiteten Bildstruktur und Tiefenstaffelung lässt eine Ausführung im Atelier vermuten. Ausgehend vom Repoussoir weisen die noch stehenden gold-gelben Stoppeln in einer direkten Linie auf den etwas rechts vom Bildzentrum platzierten Bauern hin, dessen blaue Kleidung mit dem gelben Strohballen einen starken Kontrast erzeugt. Mühsam schleppt er das Stroh vom Feld und veranschaulicht damit einen weiteren Arbeitsschritt im landwirtschaftlichen Jahreskreis.

Ein Zeugnis seiner wiedererlangten Erlaubnis im Freien zu malen, ist auch Kornfeld, Blick auf die Kirche von Saint-Paul-de-Mausole, das in der Serie aufgrund des dargestellten Motivs der Kirche eine Sonderstellung einnimmt (Abb. 11). ${ }^{42}$ In einem Brief von Anfang Dezember bezieht sich van Gogh auf eine Reihe von Herbststudien, die er Theo für seine Mutter und Schwester geschickt hatte. Erwähnt wird unter anderem das bereits beschriebene Bild Gepflügte Äcker (Abb. 8), ${ }^{43}$ und es wird angenommen, dass auch Kornfeld, Blick auf die Kirche von Saint-Paul-de-Mausole in der gleichen Sendung enthalten gewesen sein könnte. ${ }^{44}$ Van Gogh muss dabei an einer ähnlichen Stelle im Kornfeld vor dem Anstaltsgebäude gestanden haben, wie bei dem ebenfalls im Herbst entstandenen Ummauerten Feld mit Bauern, ${ }^{45}$ richtete gleichwohl jetzt seinen Fokus mehr nach Südwesten aus, auf die romanische Kirche des ehemaligen Augustinerklosters, als auf die Alpillen, die nur als ganz schmaler Streifen im linken Bildrand zu erahnen sind. ${ }^{46}$ Im Vordergrund ist das bereits abgeerntete Feld zu sehen, mit diagonal von rechts unten nach links oben verlaufenden Ackerfurchen, das etwas mehr als die Hälfte der Bildfläche einnimmt. Etwas nach rechts vom Bildmittelpunkt versetzt, zeigt van Gogh die nach Osten ausgerichtete Kirche mit ihrer Apsis und dem Turm mit pyramidalem Dach. Vor der Kirche trennt die horizontal durch den Bildraum verlaufende südliche Begrenzungsmauer das Kornfeld von der Klosteranlage.

42 Kornfeld, Blick auf die Kirche von Saint-Paul-de-Mausole, Herbst 1889, 45,1 x 60,4 cm, Öl auf Leinwand, Privatsammlung, zuletzt Christie's London, 7.2.2012, Los 12, F 803, JH 2124. Dieses Werk wurde weder im Bremer noch im Baseler Katalog der Serie zugerechnet, obwohl Pickvance es 1986 erwähnte.

43 Gepflügte Äcker, Ende August 1889, Öl auf Leinwand, 49 x 62 cm, Privatbesitz (Christie’s NY, Auktion 15004, Los 28A, 13.11.2017), F 625, JH 1768.

44 Vgl. Brief 824/618, Saint-Rémy, ca. 8.12.1889, an Theo, zitiert nach Erpel 1965, Bd. 4, S. 344 345 und Anmerkung 9 zu diesem Brief in der Online-Ausgabe der Briefe, abgerufen unter http:// vangoghletters.org/vg/letters/let824/letter.html\#.

45 Ummauertes Feld mit Bauern, Oktober 1889, Öl auf Leinwand, 73 x $92 \mathrm{~cm}$, Indianapolis Museum of Art, F 641, JH 1795.

46 Vgl. Pickvance 1886, S. 152 f. 
Van Gogh hatte im September beschrieben, dass er sich von den grellen Tönen lösen und mehr den Halbtönen zuwenden wolle. ${ }^{47}$ So fing er in Kornfeld, Blick auf die Kirche von Saint-Paul-de-Mausole die Stimmung, der „wunderbare[n] Herbsttage “48 mit leuchtenden, gleichwohl im Vergleich zu Werken aus Arles oder vorher entstandenen Werken des ummauerten Feldes, beispielsweise Kornfeld, nach dem Unwetter (Abb. 1) ${ }^{49}$ deutlich gedämpfteren Farben ein. Im Feld kontrastieren Hellblau und Türkis mit Ocker, womit es in der Farbempfindung Gepflügte Äcker nicht unähnlich ist. ${ }^{50}$ Dieser Komplementärkontrast setzt sich im Bereich der Kirche zwischen den blauen Konturen der Architektur und den warmen Gelbtönen des Heus und Herbstlaubs sowie im von goldenen Lichtstrahlen durchfluteten Himmel fort. Im Jahreskreis zeigt dieses Werk das nach der Ernte ruhende Feld.

Im November und Dezember entstanden zwei in ihrer Komposition ähnliche Ansichten des ummauerten Feldes aus van Goghs Zimmer heraus: Ummauertes Feld, Regen und Kornfeld, Sonnenaufgang (Abb. 12 u. 13). ${ }^{51}$ Beide Werke bilden das Feld mit der gerade aufgegangenen Wintersaat ab. Tiefe Ackerfurchen laufen vom Anstaltsgebäude in steiler Flucht nach Osten auf die Mauer zu. Ummauertes Feld, Regen ist einzigartig für die Zeit van Goghs in Saint-Rémy. Es erinnert in der Darstellung des dichten Niederschlags an van Goghs Versuch zwei Jahre zuvor, bei einem entsprechenden Motiv die stilistische Form eines japanischen Farbholzschnitts in Ölgemälde zu übertragen. ${ }^{52}$ Zwar stehen das Grün des Feldes und das Gelb der Mauer in Kontrast, aber sonst bewirkt der starke Niederschlag eine gedämpfte Atmosphäre mit reduziertem Farbspektrum. Einem trüb-grauen, verregneten Novembertag entsprechend, wirken die Farben wie vom Regen ausgewaschen. Vom ebenfalls im November entstandenen Kornfeld, Sonnenaufgang war van Gogh sehr überzeugt. An Émile Bernard schrieb er Anfang Dezember über dieses Werk:

47 Vgl. Brief 800/604, Saint-Rémy, 5./6.9.1889, an Theo, zitiert nach Erpel 1965, Bd. 4, S. 308315, S. 315.

48 Brief 808/609, Saint-Rémy, 5.10.1889, an Theo, zitiert nach Erpel 1965, Bd. 4, S. 329-331, S. 330. Auf diese Briefstelle sowie Brief 800/604 weist die Katalogisierung von Christie’s für Kornfeld, Blick auf die Kirche von Saint-Paul-de-Mausole, Los 12, Auktion 8049, hin. Abgerufen unter http://www.christies.com/lotfinder/paintings/vincent-van-gogh-vue-de-lasile-et-5532359details.aspx.

49 Kornfeld, nach dem Unwetter, Juni 1889, Öl auf Leinwand, 70,5 x 88,5 cm, Ny Carlsberg Glyptothek, Kopenhagen, F 611, JH 1723.

50 Gepflügte Äcker, Ende August 1889, Öl auf Leinwand, 49 x 62 cm, Privatbesitz (Christie’s NY, Auktion 15004, Los 28A, 13.11.2017), F 625, JH 1768.

51 Ummauertes Feld, Regen, November 1889, 73,5 x 92,5 cm, Öl auf Leinwand, Philadelphia Museum of Art, F 650, JH 1839. Kornfeld, Sonnenaufgang, November 1889, Öl auf Leinwand, 71 x 90,5 cm, Privatsammlung, F 737, JH 1862.

52 Vgl. Utagawa Hiroshige (1797-1858), Regen über der Ohashi-Brücke, aus Hundert berühmte Ansichten von Edo, 1857. Dieser Farbholzschnitt gehörte zu van Goghs Sammlung. In Die Brücke im Regen (nach Hiroshige), September/Oktober 1887, Öl auf Leinwand, 73 x 54 cm, Amsterdam, Van Gogh Museum, F372, JH1297 übertrug er den Farbholzschnitt in ein Ölgemälde, S. das Kapitel Entwicklungssprünge in Paris dieser Arbeit. 
Ein anderes Bild stellt einen Sonnenaufgang über einem Feld mit jungem Korn dar; fliehende Linien, Furchen, die gegen eine Mauer und eine lila Hügelkette hoch ins Bild hinaufsteigen. Das Feld ist violett und grüngelb. Die weiße Sonne ist von einem großen gelben Strahlenkranz umgeben. Darin habe ich [...] Ruhe ausdrücken wollen, einen tiefen Frieden. ${ }^{53}$

Am Horizont steigt eine große Sonnenscheibe auf, deren leuchtend gelbe Strahlen auf dem grünen Feld zu tanzen scheinen und es in ein goldenes Licht tauchen. Van Gogh erzielt diesen Lichteffekt durch viele kurze und schmale gelbe Striche, die er in das Grün des Feldes mischt. Die dadurch entstehende Farbwirkung unterscheidet sich deutlich von Ummauertes Feld, Regen. Überzeugt von seiner Qualität wählte van Gogh es neben fünf anderen Werken für die im Folgejahr in Brüssel stattfindende 7. Ausstellung der Vingtisten aus. ${ }^{54}$

Ebenfalls im November-Dezember entstand als Geschenk für seine Schwester eine weitere Wiederholung, eine kleinere und stark vereinfachte Version von Kornfeld, nach dem Unwetter, das nach seiner Terminologie als „réduction“ gelten kann (Abb. 2). ${ }^{55}$ Van Gogh wandte deutlich weniger Zeit und Mühe für diese Wiederholung des ersten Werkes der Serie des ummauerten Feldes mit der charakteristischen großen Wolke über der sturmumtosten Wiese auf. Er vollendete sie in einem großzügigen Duktus, wobei an mehreren Stellen die Leinwand kaum mit Farbe bedeckt ist. Dennoch ist auch hier, wie in der ursprünglichen Fassung durch die hellen Farbtöne im Bereich des Feldes, der Eindruck der klaren Luft nach dem Unwetter deutlich vermittelt.

\subsection{Das Jahr 1890}

Im Dezember und Januar erlitt van Gogh Anfälle, die jeweils gut eine Woche andauerten. Mehrere wichtige Ereignisse trugen sich im Januar $1890 \mathrm{zu}$, die sich auf van Goghs Zustand ausgewirkt haben werden. Es erschien nicht nur Albert Auriers Artikel „Les Isolés“ in der Zeitschrift Mercure de France, sondern in Brüssel wurde auch die Ausstellung der Vingtisten eröffnet, während der die Malerin Anna Boch für 400 Francs sein Werk Der rote Weinberg ${ }^{56}$ erwarb, das erste und einzige zu seinen Lebzeiten verkaufte Gemälde. ${ }^{57}$ Von großer Bedeutung war dann die Geburt des

53 Brief 822/B 21, Saint-Rémy, um 26.11.1889, an Émile Bernard, zitiert nach Erpel 1968, Bd. 5, S. 291-295, S. 293 f.

54 Vgl. Brief 820/614, Saint-Rémy, November 1889, an Theo, zitiert nach Erpel 1965, Bd. 4, S. 337-340.

55 Kornfeld, nach dem Unwetter, „réduction“, November-Dezember 1889, Öl auf Leinwand, 24,1 x 33,7 cm, Richmond, Virginia Museum of Fine Arts, F 722, JH 1872.

56 Der rote Weinberg, November 1888, Öl auf Leinwand, 75 x 93 cm, Moskau, Puschkin-Museum, F 495, JH 1626.

57 Wie später erläutert werden soll, hatte van Gogh 1882 Kommissionen seines Onkels erhalten, für die dieser ihn entlohnte. 
nach ihm benannten Neffen Vincent, anlässlich derer er als Geschenk für Theos Sohn Blühende Mandelzweige malte. ${ }^{58}$

Neben den ausschnitthaften Blühenden Mandelzweigen als Geburtsgeschenk entstand zum Thema der Blüte außerdem als Vorarbeit für eine weitere Ansicht des ummauerten Feldes ein fein ausgearbeitetes Studienblatt in schwarzer Kreide, das das Feld erstmals im Hochformat vor den im Hintergrund aufragenden Alpillen zeigt. ${ }^{59}$ Van Goghs Blickrichtung nach Südosten, auf die gegenüber dem Anstaltsgelände gelegenen Hütten, ähnelt dem von Ummauertes Feld mit Bauern ${ }^{60}$ aus dem vergangenen Herbst. Die quer im Bild dargestellte Mauer verläuft vom Anstaltsgebäude aus nach Osten und trifft dort auf die parallel zum Gebäude verlaufende Begrenzungsmauer des Feldes. Farbangaben van Goghs, in einzelnen Bereichen der Zeichnung eingetragen, geben Aufschluss darüber, wie er sich das Kolorit des Gemäldes vorstellte. ${ }^{61}$

In einem nächsten Vorbereitungsschritt malte van Gogh zunächst noch eine kleine Farbstudie in Öl, in der der Betrachter im Vergleich zur Skizze etwas näher an die Mauer und die weiß und zart violett blühenden Bäume heranrückt (vgl. Abb. 10). ${ }^{62}$ Überfangen wird die Szene von einem kräftigen hellblauen Himmel. Wie bei den ersten Ansichten des ummauerten Feldes aus dem Frühjahr 1889 dominiert auch hier wieder der Kontrast zwischen Grün-, Blau- und Weißtönen. Zu einer großformatigen Ausführung sollte es jedoch nicht mehr kommen, und es scheint, dass van Gogh in diesem Jahr der Blüte wenig Trost, geschweige denn Hoffnung auf einen Neuanfang abgewinnen konnte. Diese Zeugnisse veranschaulichen dennoch, dass van Gogh sich, wie im Vorjahr in Arles, auch in Saint-Rémy wieder mit der in der Provence bereits Ende Januar oder Anfang Februar einsetzenden Obst- und Mandelblüte und damit dem Erwachen der Natur auseinandersetzte.

Ende Februar erlitt van Gogh bei einem Ausflug nach Arles einen weiteren Anfall, dessen Folgen ihn für Wochen an der Malerei und somit wohl auch an der Ausführung des großen Tableaus hinderten. Albert Aurier hatte er Anfang Februar, noch vor diesem erneuten Anfall, gestanden, dass es ihm Probleme bereite, in der Natur zu malen, „denn die Erregung, die mich angesichts der Natur ergreift, steigert sich bei mir bis zur Ohnmacht, und dann folgen vierzehn Tage, an denen ich un-

58 Blühender Mandelbaum, Februar 1890, Öl auf Leinwand, 73 x 92 cm, Amsterdam, Van Gogh Museum, F 671, JH 1891.

59 Ummauertes Feld, „Studienblatt“, Januar-Februar 1890, Schwarze Kreide auf Papier, 31 x 23,5 cm, Amsterdam, Van Gogh Museum, F 1549v, JH 1721.

60 Ummauertes Feld mit Bauern, Oktober 1889, Öl auf Leinwand, 73 x $92 \mathrm{~cm}$, Indianapolis Museum of Art, F 641, JH 1795.

${ }_{61}$ Wie Hansen treffend festhält, unterscheidet sich die Zeichnung dadurch in ihrem vorbereitenden Charakter von anderen Zeichnungen, die van Gogh häufig zur Illustration eines Motivs für Freunde nachträglich anfertigte. Vgl. Hansen 2002, S. 98.

62 Ummauertes Feld mit den Alpillen im Hintergrund, Januar-Februar 1890, Öl auf Leinwand, 33 x 28.5 cm, Amsterdam, Van Gogh Museum, F 723, JH 1722. Dieses Werk wird weder im Bremer noch im Baseler Katalog der Serie zugerechnet. 
fähig zur Arbeit bin.“63 Noch im März eröffnete der Salon des „Indépendants in Paris“, in dessen Verlauf van Goghs Werke bei anderen Künstlern, wie Gauguin, Monet und Pissarro, einen starken Eindruck hinterließen. ${ }^{64}$

Erst Ende April antwortete er wieder auf die Briefe seines Bruders. „Ich bin krank geworden, als ich die blühenden Mandelzweige malte. Hätte ich weiterarbeiten können, so hätte ich noch mehr blühende Bäume gemacht, das kannst Du Dir denken. Jetzt ist es mit der Baumblüte schon fast vorbei, ich habe wirklich Pech. "65 So blieb, neben der japanisch inspirierten Ansicht der als Geschenk für den neugeborenen Neffen gedachten Blühenden Mandelzweige die kleine Ölstudie vom ummauerten Feld die einzige Darstellung blühender Bäume aus Saint-Rémy im Frühling 1890. Sie reiht sich in den Zyklus der Natur als Darstellung des Frühlingsauftaktes ein.

In der Zeit, in der van Gogh die Klinik nicht verlassen konnte, malte er keine weiteren Ansichten des ummauerten Feldes in Öl. Stattdessen ging er erneut auf das ummauerte Feld und zeichnete dort mit Bleistift auf Papier ein Konvolut von mindestens sieben querformatigen Skizzen, allesamt im Format von ca. 25 x 32,5 cm. Anders als bei Ansichten von seinem Fenster aus, ist der Blick bei diesen Skizzen durch die Mauer - hervorgehoben durch dichte, vertikale Schraffuren und kräftige Konturen - blockiert. Van Gogh schuf mehrere Skizzen entlang der Mauer, wobei vielfach eine starke perspektivische Wirkung des Feldes kennzeichnend ist. Mehrfach ist die Ecke dargestellt, von der an die Mauer parallel zum Anstaltsgebäude verläuft (vgl. Abb. 23). ${ }^{66}$

Diese Studien könnten im Hinblick auf eine letzte gemalte Ansicht des ummauerten Feldes entstanden sein, das van Gogh während der letzten Tage seines

63 Brief 853/626a, Saint-Rémy, 9./10.2.1889, an Albert Aurier, zitiert nach Erpel 1968, Bd. 5, S. 326-328, S. 328.

64 Vgl. Hansen 2002, S. 29.

65 Brief 863/629, Saint-Rémy, 29.4.1890, an Theo, zitiert nach Erpel 1965, Bd. 4, S. 361-363, S. 363. Auf diesen Brief weist Hansen 2002, S. 98 hin.

Möglicherweise sind die Nervenzusammenbrüche auf die Geburt seines Neffen und die sich dadurch wandelnde Familienkonstellation zurückzuführen, in der sich van Gogh mehr und mehr als Last seinem Bruder gegenüber empfand. In mehreren Briefen aus den Wochen vor und nach der Geburt diskutiert van Gogh Möglichkeiten, seine Lebenshaltungskosten deutlich zu reduzieren, bspw. in Brief 839/623, Saint-Rémy, um 13.1.1890, an Theo, nach Erpel 1965, Bd. 4, S. 351354. Diese Sorge wird sich im Laufe des Frühlings wohl weiter zugespitzt haben, nachdem Theo seinem Bruder mitgeteilt hatte, dass er erwog, sich von Boussod, Valadon \& Cie zurückzuziehen und selbstständig zu machen. Vgl. Brief 894/T39, Paris, 30.6./1.7.1890, Theo an Vincent, zitiert nach Erpel 1968, Bd. 6, S. 45-47.

66 Die das Kornfeld eingrenzende Mauer, April-Mai 1890, Kreide auf Papier, 23,8 x 31,9 cm, Amsterdam, Van Gogh Museum, F 1602r, JH 1720; Ummauertes Feld, April-Mai 1890, Bleistift auf Papier, 24,9 x 32,3 cm, Amsterdam, Van Gogh Museum, F 1558, JH 1716; Ummauertes Feld, April-Mai 1890, Bleistift auf Papier, 24,9 x 32,9 cm, Amsterdam, Van Gogh Museum, F 1557, JH 1715; Ummauertes Feld, April-Mai 1890, Bleistift auf Papier, 25 x 33 cm, Amsterdam, Van Gogh Museum, F 1559, JH 1717; Ummauertes Feld, April-Mai 1890, Bleistift, 25,3 x 32,5 cm, Amsterdam, Van Gogh Museum, F 1556, JH 1714; Ummauertes Kornfeld, April-Mai 1890, Blei- 
Aufenthaltes in der Klinik im Mai - wie bereits ein Jahr zuvor - nun wieder in frischem Frühlingsgrün abbildete (vgl. Abb. 15). Er könnte sich dafür zunächst erneut zeichnerisch dem Motiv angenähert haben, das er von diesem Blickwinkel seit fast einem halben Jahr nicht mehr gemalt hatte. ${ }^{67}$ Wie die Skizzen ist dieses Grüne Kornfeld von einem Betrachterstandpunkt auf dem Feld aus gemalt. Dadurch wirkt die Komposition, anders als beispielsweise noch bei Kornfeld aus dem Kröller-Müller Museum mit seiner haltlosen, beinahe stürzenden Aufsicht auf das Feld, sehr ausgewogen. ${ }^{68}$ Die Mauer umschließt das Feld in einer fast horizontalen Linie. Rechts erheben sich sanft die Alpillen, hinter denen die Sonne aufzugehen scheint und das Bild in klares Licht taucht, das die unterschiedlich abgestuften Grüntöne im Feld und die Blau-Weißtöne im Himmel zum Leuchten bringt. Rote Mohnblumen im Bildvordergrund erzeugen dabei Komplementärkontraste zum Grün des Korns. Die kurzen, diagonalen Striche, die das junge Korn bezeichnen, erinnern an die schraffierten Andeutungen in den Skizzen. Pickvance beschreibt diese Ansicht im Vergleich zu allen anderen der Serie als ,the gentlest in color [...] Spatially, it is the least acerbic.“ Der Verlauf der Mauer sei im Vergleich zu anderen Werken „calming horizontal. "“9 Mit diesem letzten Werk der Serie in Öl gelang es van Gogh, den Kreislauf der Natur vor seinem Fenster, begonnen im Frühling ein Jahr zuvor und nun beendet zur gleichen Jahreszeit, zu einem Abschluss zu bringen.

Außerdem entwickelte er im Frühling Motive aus Studien, die während seiner Zeit in Holland entstanden waren oder seiner Phantasie entstammten. Thematisch beschäftigte er sich jedoch weiterhin mit Feldern und Menschen, die landwirtschaftlicher Arbeit nachgehen. ${ }^{70}$ Dabei wurde auch der Sämann wieder relevant, den er

stift, 25,2 x 32,8 cm, Amsterdam, Van Gogh Museum, F 1561, JH 1719 u. Ummauertes Kornfeld, April-Mai 1890, Bleistift, 25 x 33 cm, Amsterdam, Van Gogh Museum, F 1560, JH 1718.

Das Van Gogh Museum, dem hier gefolgt wird, datiert diese Zeichnungen allesamt in den Frühling 1890 (vgl. insbesondere Vellekoop/Zwikker 2007, S. 392f. Einer der Gründe für die Datierung auf Frühling 1890 ist der Umstand, dass es sich um das gleiche Papier handelte, das van Gogh für die sicher in das Jahr 1890 datierten „Souvenirs du Nord" verwendete.). Hulsker datierte die Zeichnungen auf das Frühjahr 1889. Für die Diskussion um die Datierung S. auch Hansen 2002, S. 100.

67 Grünes Kornfeld, Mai 1890, Öl auf Leinwand, 73 x 92 cm, Privatsammlung, F 718, JH 1727. Diese Ansicht wurde in der Vergangenheit verschiedentlich in den Mai-Juni 1889 datiert, vgl. Blotkamp 2008, S. 68. Hier wird der Datierung und schlüssigen Erklärung im Werkverzeichnis von Vellekoop/Zwikker gefolgt, in der auf Brief 891/644, Auvers-sur-Oise, 24.6.1890, an Theo, nach Erpel 1965, S. 382-383, verwiesen wird, in dem van Gogh die Werke aufzählte, die er in Saint-Rémy zurückgelassen hatte, da sie noch nicht getrocknet waren. In der Aufzählung erwähnte er auch ein Kornfeld. Vgl. Vellekoop/Zwikker 2007, S. 401f. Pickvance 1986, S.94 hatte 1986 bereits auf eine mögliche Entstehung 1890 hingewiesen. Wildenstein folgt in seinem 2009 erschienenen Werkverzeichnis der Datierung in das Jahr 1890. Vgl. Feilchenfeldt 2009, S. 238.

68 Vgl. Kornfeld, Ende Mai oder Juni 1889?, Öl auf Leinwand, 72 x 92 cm, Otterlo, Kröller-Müller Museum, F 720, JH 1728. Auch das gewählte Farbschema könnte nicht unterschiedlicher sein.

69 Pickvance 1986, S. $94 \mathrm{f}$.

70 Beispielhaft dafür ist: Grabende, aus der Serie „Souvenirs du Nord“, März-April 1890, Öl auf Papier auf Leinwand, 49,3 x 64 cm, Stiftung Sammlung Emil Bührle, Zürich, F 695, JH 1923. 
nun in mehreren Skizzen bei der Aussaat auf dem Feld festhielt. In zweien davon ist die begrenzende Mauer im Hintergrund des Feldes deutlich zu erkennen. ${ }^{71}$ Die Art der Darstellung des Regens in beiden Fassungen erinnert an Ummauertes Feld, Regen aus dem November und die Übertragungen aus japanischen Farbholzschnitten. Ob van Gogh eine Übertragung des Sämanns auf die Leinwand beabsichtigte, ist nicht überliefert, aber es zeigt seine Beschäftigung mit diesem für ihn so wichtigen und bedeutungsvollen Motiv (Abb. 24 u. 25).

Anfang Mai teilte van Gogh der Anstaltsleitung mit, dass er Saint-Rémy verlassen wolle, um sich nach Auvers in die Behandlung Dr. Gachets zu begeben. Resümierend schrieb er an seinen Bruder:

Ich betrachte die Reise hierher als einen Schiffbruch; man kann nicht, wie man will, und auch nicht, wie man sollte. [...] Ich habe mehr Ideen im Kopf als ich je werde ausführen können, aber ohne daß sie mich verwirren. Die Pinselstriche gehen wie mit der Maschine. Darauf beruht meine Hoffnung, daß ich im Norden mein Gleichgewicht wiederfinden würde, wenn ich nur erst einmal aus einer Umgebung und aus Verhältnissen befreit bin, die ich nicht verstehe und auch nicht zu verstehen wünsche. ${ }^{72}$

Am 16. Mai verließ er Saint-Rémy und begab sich auf die Reise zurück in den Norden. ${ }^{73}$

Hulsker erkannte in dieser Serie „the signs of his mental collapse in this period.“ Hulsker 1984, S. 442. Sogar eine Neuauflage der Kartoffelesser war geplant. Diese Bilder stehen formal in starkem Kontrast zu den vorherigen Werken aus der Provence, insbesondere zu dem von ihm geprägten Begriff des „Ateliers des Südens“ und dessen künstlerischen Implikationen. Vgl. Blotkamp 2009, S. 77.

71 Ummauertes Feld mit Sämann im Regen, März-April 1890, Bleistift und schwarze Kreide auf Papier, 23,5 x 31,5 cm, Essen, Museum Folkwang, F1550, JH1897 u. Sämann im Regen, März-April 1890, Bleistift auf Papier, 23,9 x 27,3cm, Amsterdam, Van Gogh Museum, F 1551r, JH1898. Die Parallelen zu Ummauertes Feld, Regen, November 1889, 73,5 x 92,5 cm, Öl auf Leinwand, Philadelphia Museum of Art, F 650, JH 1839 sind auch bei den tiefen Ackerfurchen zu erkennen.

72 Brief 865/630, Saint-Rémy, ca. 1.5.1890, an Theo, zitiert nach Erpel 1965, Bd. 4, S. 363-365, S. 365.

$73 \mathrm{Zu}$ den letzten Werken, die in Saint-Rémy entstanden, gehörten weitere Kopien nach Werken bedeutender Künstler, unter anderem: Die Auferweckung des Lazarus (nach Rembrandt), SaintRémy, Mai 1890, Öl auf Papier, 50 x 65 cm, Amsterdam, Van Gogh Museum, F 677, JH 1972, mit einem Lazarus, der ihm ähnelnde Gesichtszüge aufweist sowie Der barmherzige Samariter (nach Delacroix), Saint-Rémy, Mai 1890, Öl auf Leinwand, 73 x 60 cm, Otterlo, Kröller-Müller Museum, F 633, JH 1974. 



\section{Wiederholung, Variation, Serie und Zyklus}

\subsection{Serialität - Ursprünge und Begriffsbedeutung}

Anhand der Einleitung zu van Goghs Zeit in Saint-Rémy ist deutlich geworden, dass er nicht nur auf serielle, sondern insbesondere auf zyklische Darstellungsprinzipien zurückgriff, um den Kreislauf der Natur vor seinem Fenster abzubilden. Dieses Kapitel beschäftigt sich zunächst mit den theoretischen Aspekten der Wiederholung und der Serie. Danach soll auch auf den Aspekt des Zyklus eingegangen werden.

Wie bereits Katharina Sykora in ihrer vielfach zitierten Dissertation zum Phänomen des Seriellen in der Kunst (1983) konstatiert, bleibt in der Literatur „das

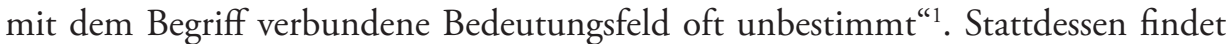
häufig eine dem Alltagsgebrauch entlehnte, verallgemeinernde und auf den größten gemeinsamen Nenner gebrachte Vorstellung von Serie Anwendung, die abgeleitet von der lateinischen Bedeutung des Verbs „serere“ (fügen, reihen) das Phänomen als „Reihe oder Gruppe gleichartiger Gegenstände“ ${ }^{2}$ beschreibt. So sieht denn auch eine hier exemplarisch ausgewählte Definition in einem Konversationslexikon „serielle Kunst [als] Methode der zeitgenöss. Kunst, Strukturprogramme zu entwickeln, die in Form serienmäßiger Reihungen, Verdopplungen oder Wiederholungen und Variationen eine ästhet. Wirkung erzielen [...]."3 Dies geht wiederum einher mit

$1 \quad$ Sykora 1983, S. 4. Manche Lexika, wie beispielsweise Jane Turners Dictionary of Art, eines der weltweit meist verbreiteten kunsthistorischen Nachschlagewerke, erwähnen das Thema nicht einmal.

2 Meyers großes Taschenlexikon, 7. Aufl., Bd. 20, Schl-Siy, red. Leitung Annette Zwahr, Mannheim 1999, s.v. „Serie“, S. 235. Vgl. auch Görgen 2001, S. 46.

3 Meyers großes Taschenlexikon, 7. Aufl., Bd. 20, Schl-Siy, red. Leitung Annette Zwahr, Mannheim 1999, s.v. „serielle Kunst“, S. 235. 
der Bedeutung des lateinischen „re-petere“ als ein Bestreben, etwas „von neuem zu erreichen “4.

Mit dem Ziel, die Entwicklung serieller Bildproduktion zu ergründen, angefangen mit Claude Monet (1884-1926) über Piet Mondrian (1872-1944) bis hin zu damals zeitgenössischen Künstlern, wie Frank Stella (geb. 1936) und Andy Warhol (1928-1987), wanderte in den Jahren 1968-69 die wegweisende Ausstellung „Serial Imagery" des Pasadena Art Museums durch verschiedene amerikanische Museen. Das Hauptaugenmerk richtete sich dabei auf die gegenstandslose Malerei. Im dazugehörigen Ausstellungskatalog, der bis heute immer wieder als Referenzwerk für serielle Kunst genannt wird, bemerkt der Kunstkritiker John Coplans grundsätzlich, dass „Serial Imagery [...] a type of repeated form or structure shared equally by each work in a group of related works made by one artist" sei. Coplans betonte hinsichtlich der inhaltlichen Verbindungen der Werke:

Seriality is identified by a particular inter-relationship, rigorously consistent, of structure and syntax: Serial structures are produced by a single indivisible process that links the internal structure of a work to that of other works within a differentiated whole. ${ }^{5}$

John Klein fasst 1998 in seinem Aufsatz „The Dispersal of the Modernist Series“ die Definition etwas weiter und verweist zudem auf den für diese Arbeit wichtigen Aspekt der allegorischen und zyklischen Darstellungen: „The traditional agent of unity in a series of paintings is the subject matter, the traditional form of this agency is liturgical, narrative, allegorical, or cyclical, among other iconographic frameworks. Each of these frameworks has an internal logic, so that the meaning of the individual works in a series is mutually reinforcing." ${ }^{\circ}$

Auch Gottfried Boehm hatte zehn Jahre vor Klein in seinem vielbeachteten Aufsatz „Werk und Serie. Probleme des modernen Bildbegriffs seit Monet“ zunächst grundlegend festgehalten, „dass sich eine Serie von Bildern durch ein gemeinsames Thema ausbildet"7. Gleichzeitig sei es wichtig, den Unterschied zwischen Variationen eines Themas und Wiederholungen zu verstehen. „Variationen haben untereinander keinen direkten Bezug, sondern sie beziehen sich untereinander nur dadurch, dass sie am gleichen Thema partizipieren. Spricht man dagegen von Iteration [„Wiederholung"], so ist damit ausdrücklich die Verbindung gemeint, welche die Glieder einer Serie vereint. ${ }^{\text {"8 }}$ Bei der Art der Verbindung sollte es sich nicht nur um

\footnotetext{
Vgl. Görgen 2001, S. 45.

Coplans 1968, S. 10f. Neben anderen diskutieren Sykora und Klein Coplans. Vgl. Skykora 1983, S. 1 u. Klein 1998, S. 130 f.

Klein 1998, S. 123.

7 Boehm 2017, S. 143. Es handelt sich hier um einen Sammelband von Aufsätzen Boehms. Der Aufsatz erschien zuerst 1988 und wird immer wieder zitiert, bspw. bei Heinrich 2001, S. 7-12.

8 Boehm 2017, S. 143.
} 
das gleiche Thema, sondern auch um eine Struktur handeln, die sich in den nachfolgenden Bildern einer Serie wiederholen lässt. ${ }^{\text {' }}$

Boehm beschäftigt sich in seinem Aufsatz auch mit dem Wesen der Serie und dem des Einzelwerkes und veranschaulichte anhand von Monets Serien der Getreideschober, der Pappeln und der Kathedralen, wie der Charakter und das Spezifische des Einzelwerkes modifiziert werden, wenn es zu einem Teil einer Serie werde, das in seiner Gemeinsamkeit mit anderen Teilen eine Aussage vermittele. Laut Boehm stehe „[h]inter der Serie [...] kein - erreichtes oder nicht erreichtes - ,Zielbild' (kein leitendes Ideal), höchstens könnte man sagen, alle Glieder einer Serie bilden [zusammen] einen solchen Inbegriff aus, zu dem sich alle Bilder zusammenfügen. " ${ }^{10}$ Auf diesen Komplex soll in den Kapiteln 7 und 8 bei der Diskussion bezüglich Monets Getreideschobern ausführlich eingegangen werden.

Annabelle Görgen konstatiert in einem Aufsatz, der 2001 anlässlich einer Ausstellung in der Hamburger Kunsthalle („Monets Vermächtnis. Serie - Ordnung und Obsession“) erschien, die die Anfänge seriellen Arbeitens hin zur zeitgenössischen Malerei zu ergründen suchte, dass die „Serie [...] in den Dienst ganz unterschiedlicher künstlerischer Ansätze treten [kann, aber] als Folge gleichartiger Dinge [...] immer auf dem ersten anschaulichen Bezug auf[baut], dem der Gleichheit." ${ }^{11}$ Ähnlich wie Coplans und Boehm argumentiert sie, dass den Bildern (oder Bildelementen) „eine durchschaubare Struktur innewohnen [müsse], die sich im nächsten Angang wiederholen [... lasse].“ Wichtig sei dabei, dass „die Wiederholung [...] nicht nur additiv [geschieht], Bildelemente können [vielmehr] regelmäßig abgewandelt wiederkehren, bis hin zu ihrem Gegensatz." 12

Diese Erklärung von Görgen entspricht im Wesentlichen der Definition von Kopien im Dictionnaire de l'Académie des Beaux-Arts, ${ }^{13}$ erschienen 1858-1896. Primär sind hier unter Kopien diejenigen Versionen eines Werkes zu verstehen, die durch den gleichen Künstler als Variationen seines eigenen Werkes gemalt und im französischen als „répétitions“ bezeichnet werden. Entscheidend ist, dass sich jede weitere Version von der Ursprungsfassung unterscheidet. ${ }^{14}$

In ihrem Aufsatz verweist Görgen zudem, wie bereits zuvor von Klein aufgezeigt, auf den Aspekt der Temporalität seriellen Arbeitens, denn der „periodische Wechsel in der Zeit setzt Rückblick und Vorschau voraus. Er führt zum Rhythmus, einer

\footnotetext{
Vgl. Boehm 2017, S. 143.

Boehm 2017, S. 138.

Görgen 2001, S. 45.

Beide Zitate Görgen 2001, S. 45.

„Les copies $[\ldots]$ sont là de simples répétitions, reconaissables souvent à quelque variante qu'y a introduite à dessein le maître lui-même.“ "copie“, in: Dictionnaire de l'Académie des Beaux-Arts, Bd. 4, Paris 1884, S. 262-265. Vgl. auch Mainardi 2000, S. 63.

14 Diese variierenden Fassungen eines Sujets wurden vom Künstler selbst erstellt, für Repliken mit der Zielsetzung möglichst getreuer Duplizierung der Vorlage waren dagegen vorrangig Schüler oder Werkstattassistenten verantwortlich.
} 
gleichmäßig gegliederten Bewegung, deren Gestalt eine Ordnung bilde [...]. "15 So ist über das Kriterium der Interkonnektivität in Inhalt und Struktur hinaus festzuhalten, dass Serien als geschlossene zyklische Gruppen oder als unendlich fortsetzbare Reihen konzipiert sein können. Entscheidend für die Untersuchung dieser Arbeit ist, inwiefern durch eine wiederholte - sprich serielle - Darstellung des gleichen Bildgegenstandes eine ästhetische, aber auch inhaltliche Aussage erzeugt werden soll. Wie Sykora erklärt, sollte das Hauptaugenmerk „,der Betrachtung des Seriellen in der Kunst [...] dem in diesem Phänomen verkörperten Gehalt [gelten], der zwar durch die jeweilige ideengeschichtliche Realität geprägt wird, der aber darüber hinaus in der Auseinandersetzung mit dieser Wirklichkeit ihr den eigenen, spezifisch künstlerischen Stempel aufdrückt. " ${ }^{16}$

Christoph Heinrich weist in seinem Aufsatz „Serie - Ordnung und Obsession“, ebenfalls 2001 anlässlich der Ausstellung in Hamburg erschienen, auf den Aspekt der „Ewigkeit und Beständigkeit ${ }^{“ 17}$ und psychologische Aspekte der jeweiligen Künstler hin, die vielen Serien immanent seien. Ferner: „Etwas zu wiederholen, kann Freude bereiten, Vertrautheit und Sicherheit schaffen - die Ordnung eines Systems offenbaren, in dem das Individuum seinen Platz hat und seine Wünsche kennt, sich seines Glückes versichert. ${ }^{\text {"18 }}$ Dass der Akt der Wiederholung ein- und desselben Sachverhaltes positiv für das handelnde Individuum konnotiert sein kann, veranschaulichte bereits der Philosoph Sören Kierkegaard in seiner Schrift Die Wiederholung (1842): „Wer jedoch nicht begreift, daß das Leben eine Wiederholung ist, und daß das die Schönheit des Lebens bedeutet, der hat sich selbst gerichtet und verdient es nicht besser, als daß er - was denn auch mit ihm geschehen wird zugrunde geht; denn die Hoffnung ist eine lockende Frucht, die nicht sättigt, die Erinnerung ist ein kümmerlicher Zehrpfennig, der nicht sättigt; die Wiederholung jedoch ist das tägliche Brot, das mit Segen sättigt. ${ }^{\text {"19 }}$

\subsection{Die Entwicklung zur Serialität im ausgehenden 19. Jahrhundert}

Bilderserien sind im ausgehenden 19. und beginnenden 20. Jahrhundert, an der Schwelle zur technischen Reproduzierbarkeit von Kunstwerken, ${ }^{20}$ „[e] in weit gefächertes Phänomen der Bildenden Kunst mit engen konzeptionellen Verflechtungen zu ähnlichen Methoden in Literatur, Musik, aber auch in der Mathematik." ${ }^{21}$ In

15 Görgen 2001, S. 45.

16 Sykora 1983, S. 3.

17 Heinrich 2001, S. 12.

18 Heinrich 2001, S. 12.

19 Kierkegaard, Sören: Die Wiederholung, übersetzt, mit Einleitung und Kommentar, hg. v. Hans Rochol, Hamburg 2000, S. 4. Vgl. für den Hinweis auf die Verbindung zwischen Kierkegaard und der Serialität Heinrich 2001, S. 12.

20 Vgl. Benjamin 2008, S. 5.

21 Schulz, Martin: Serielle Kunst, in: Prestel Lexikon. Kunst und Künstler im 20. Jahrhundert, München 1999, S. 298-299. Etwas spätere Beispiele aus anderen Gattungen, entstanden wenige 
der kunsthistorischen Literatur wird allgemein der Beginn der seriellen Kunstproduktion im Impressionismus gesehen, „in Bilderfolgen, deren serielles Prinzip einen erkenntnistheoretischen Anspruch hat. "22 Konsens herrscht allgemein über die herausragende Bedeutung von Claude Monets Anfang der 1890er Jahre entstandenen Serien der Getreideschober sowie der Pappeln und der Ansichten der Kathedrale von Rouen, wenige Jahre später, als Beginn des modernen seriellen Arbeitens. ${ }^{23}$ Wie dargestellt werden soll, spielten jedoch bei deren Entstehung nicht nur impressionistische Bildparadigmen, also das Einfangen des flüchtigen Augenblicks zu unterschiedlichen Tages- und Jahreszeiten unter sich verändernden Witterungs- und Lichtverhältnissen und den damit einhergehenden Wandel ein und desselben Bildmotivs, sondern auch handfeste kommerzielle Faktoren eine Rolle.

Um beispielsweise Coplans Definitionsversuch von Serialität aufzugreifen, der wie die anderen auf den Aspekt der Wiederholung hinweist, und sie als „repeated form or structure shared equally by each work in a group of related works made by one artist" 24 beschreibt, muss ganz grundlegend die Ausgangsituation für Künstler im ausgehenden 19. Jahrhundert und ihre Haltung zur Wiederholungspraxis analysiert werden. Wie sind der Ursprung und die Bedeutung von Wiederholungen und Kopien von Kunstwerken für die Entstehung von Serialität zu verstehen?

Auch wenn der Beginn des modernen seriellen Arbeitens im Impressionismus gesehen wird, handelte es sich bei der Wiederholung von Motiven unter Verwendung von gliedernden Prinzipien, wie dem der seriellen Reihung, mitnichten um eine Erfindung des ausgehenden 19. Jahrhunderts. Görgen geht sehr weit in die Vergangenheit zurück und verweist in ihrem Aufsatz als Ursprung der Praxis der Wiederholung gar auf prähistorische Felsritzungen, bei denen „sich neben unregelmäßigen Streuungen von Einzelgestalten auch Symmetrien in Einzelmotiven "25 finden lassen. „Die Symmetrie“ sei „eine dem Prinzip der Reihe historisch wie ästhetisch vorgeordnete Form der Bildkonstitution [...]. " ${ }^{26}$ Darüber hinaus könnten

Jahre nach Monets Serien, sind Gertrude Steins Gedicht „Rose is a rose is a rose is a rose“ oder Arnold Schönbergs serielle Formen in seinen Zwölftonkompositionen. Vgl. Coplans 1968, S. 7. Als ein Beispiel seriellen Arbeitens kann auch die Arbeit Wilson Bentleys gesehen werden, der über 50 Winter lang, zwischen 1885-1931, Schneeflocken photographisch festhielt und über 5.000 Kristallformen fand. Vgl. Görgen 2001, S. 45 u. eine diesem Vorhaben gewidmete Internetseite, abgerufen unter: http://www.snowflakebentley.com/bio.htm.

22 Schulz, Martin: Serielle Kunst, in: Prestel Lexikon. Kunst und Künstler im 20. Jahrhundert, München 1999, S. 298-299.

23 Vgl. Coplans 1968, S. 7 oder auch Boehm 2017, S. 140. Je nach Auslegung werden bereits Gustav Caillebottes (1848-1894) in den Jahren 1870-1880 entstandene Städteszenen als lose Serie aufgefasst (vgl. Rubin 2008, S. 115). Coplans verstand Monets 1876 entstandene Ansichten des Bahnhofs von St. Lazare trotz ihrer evidenten thematischen Verwandtschaft aufgrund ihrer disparaten Konzeption und Ausführung eher als Thema und Variation statt als Serie (vgl. dazu Coplans 1968, S. 21).

24 Coplans 1968, S. $10 f$.

25 Görgen 2001, S. 46.

26 Görgen 2001, S. 46. 
laut Görgen aufgrund der reihenden Darstellungsformen Verbindungslinien zu altägyptischen oder später griechischen Reliefplastiken gezogen werden. ${ }^{27}$

Boehm dagegen stellt die Frage, „ob nicht auch in der Gattung des Capriccios, etwa in Guardis Phantasieveduten, Vorspiele für das Serienphänomen entdeckt werden können "28. Unabhängig von der Frage, ob es sich dabei möglicherweise eher um Variationen eines Themas anstatt um eine Serie handeln könne, zielt Boehms Hinweis auf die Veduten doch auch auf den Einfluss des Kunstmarktes, der nicht nur für die Entstehung von Wiederholungen in den Niederlanden im 17. Jahrhundert ein nicht ganz unbedeutender Faktor war, als erfolgreiche Motive - dabei insbesondere Stilleben - mit mehr oder weniger großer Variation wiederholt wurden. Ähnlich verhielt es sich ein Jahrhundert später mit den Stadtansichten der Canaletto-Familie, deren Vorgehen es ermöglichte, bei einem ökonomischen Einsatz der Mittel, den Markt mit unverwechselbaren Produkten zu bedienen. ${ }^{29}$ Wie später anhand von Claude Monets Serie diskutiert werden soll, spielten ähnliche Marktmechanismen auch im ausgehenden 19. Jahrhundert in Frankreich eine entscheidende Rolle. ${ }^{30}$

Der Fokus richtet sich hinsichtlich der Entstehung von Serialität hauptsächlich auf Frankreich, das nicht nur aufgrund der drei Protagonisten dieser Arbeit und ihrer jeweiligen Verbindungen zur Kunst in Frankreich, sondern auch aufgrund seiner Rolle als der wohl bedeutendste Ort der Kunstproduktion in Europa im 19. Jahrhundert als Referenz gelten muss. Der Blick geht dabei zunächst zurück auf die Rolle der Akademien und ihren Einfluss auf die künstlerische Praxis. Ausgangspunkt der akademischen Ausbildung in den bildenden Künsten im 19. Jahrhundert - an der Akademie oder in privat geführten Ateliers - war neben dem theoretischen Kunstunterricht das exakte Kopieren von Vorlagen, beginnend mit grundlegendem Zeichenunterricht. Bevorzugtes Medium für die Vorlagen waren dabei Stiche, seltener auch Lithographien, die aufgrund ihrer exakten Linienführung die Schüler zu einer langsamen und sehr aufwendigen Arbeitsweise zwangen. Gleichzeitig erzog diese Akribie die Schüler zu der von dem damaligen akademischen Zeitgeist erwünschten Präzision. ${ }^{31}$

Im Prinzip verfolgte die Akademie in ihrer Position zum Kopieren eine strenge Haltung - lange wurde nur identischen Reproduktionen des Originals Bedeutung

27 Görgen verweist auf den Unterschied zwischen den offenen ägyptischen Reliefs, bei denen die Figuren in einem unbegrenzten, ewig fortsetzbaren Raum abgebildet sind und griechischen Reliefs, bei denen der „Ereignisraum“" geschlossen sei. Vgl. Görgen 2001, S. 46.

28 Boehm 2017, S. 139.

29 Vgl. Heinrich 2001, S. 13. Boehm diskutiert die Frage, ob es sich bei Guardis Phantasieveduten um „Vorspiele für das Serienphänomen“ oder um „Variationen eines Themas" handele. Boehm 2017, S. 139.

30 Auch Walter Benjamin weist in Das Kunstwerk im Zeitalter seiner technischen Reproduzierbarkeit dezidiert auf den finanziellen Anreiz hin, Kopien von Werken zu erstellen. Vgl. Benjamin 2008, S. 3.

31 Eine Haltung, die bis in die mittelalterlichen Vorstellungen der Zünfte von pflichtbewusster Erfüllung der künstlerischen Aufgaben als Handwerk zurückreichte. Vgl. Boime 1971, S. 24. 
für die praktische Ausbildung eines Künstlers beigemessen -, die vielfach auf vehemente Kritik von Künstlern traf, die einen individuelleren, weniger reglementierten Ansatz vertraten. ${ }^{32}$ In der Praxis konnte die Position jedoch mitunter wesentlich weniger streng sein. Jean-Auguste-Dominique Ingres (1780-1867) beispielsweise wies seine Schüler an, schnelle und einfache Skizzen nach Gemälden Alter Meister anzufertigen, da die exakte Reproduktion Zeitverschwendung sei und den Fokus von der Essenz eines Werkes zu sehr auf dessen technische Umsetzung verschiebe. ${ }^{33}$ Im Zuge des sich im Laufe des 19. Jahrhunderts verändernden Kunstgeschmacks verschob sich auch die Perspektive dahingehend, welche Alten Meister normativ waren. Eugène Delacroix (1798-1863) betonte infolgedessen die Bedeutung des Kopierens von Werken Jacopo Tintorettos (1518-1594) oder Peter Paul Rubens' (1577-1640). Damit einhergehend ist denn auch ein Übergang vom lange Zeit propagierten Ideal der exakten Kopie zu einer freieren, skizzenhafteren Form, erkennbar. $^{34}$

Bis zum Ende des Jahrhunderts war die freie, skizzenhafte Kopie in das Curriculum der Akademie aufgenommen worden. Viele unabhängige Künstler, die an der École des Beaux-Arts ihre Ausbildung genossen hatten, wechselten im Laufe der Zeit von exakten zu freieren Kopien. ${ }^{35}$ Neben den Übungskopien von Studenten in der Ausbildung und den Kopien von Werken Alter Meister im Zusammenhang von Kommissionen, war für Maler auch nach dem Abschluss ihrer Ausbildung - beispielsweise Gustave Courbet (1819-1877), Édouard Manet (1832-1883), Edgar Degas (1834-1917) und Paul Cézanne (1839-1906) - eine verbreitete Praxis, Alte Meister zu Übungszwecken zu kopieren. Das Inventar des Nachlasses von Delacroix führt beispielsweise allein dreizehn Kopien nach Rubens auf. ${ }^{36}$

Viele impressionistische Künstler zeigten ein begrenztes Interesse am akribischen Erlernen der Kunst der Vergangenheit durch Kopien. Dadurch, dass die akademische Ausbildung maßgeblich auf das Erlernen der menschlichen Figur ausgerichtet war, konnte diese ihnen auf ihrer Suche nach neuen Darstellungsformen der Landschaftsmalerei wenig Hilfestellung geben. Das Kopieren alter Vorlagen war für sie unweigerlich mit den überkommenen Prinzipien der Akademie verbunden, von denen sie sich zu distanzieren suchten. Da der Salon nach und nach nicht mehr nur die einzige Möglichkeit der öffentlichen Präsentation für Kunstwerke darstellte,

\footnotetext{
32 Vgl. Homburg 1996, „Opposition to academic teaching“, S. 17-30.

33 Vgl. Boime 1971, S. 42f.

34 Eugène Delacroix äußerte sich über die Ausbildung durch das Kopieren in seinem Dictionnaire des Beaux-Arts, das er im Januar 1857, nach seiner Berufung an die Académie des beaux-arts, begonnen hatte und an dem er bis zu seinem Tod 1863 arbeitete. Der Entwurf ist Teil seines Journal. Vgl. Eugène Delacroix, Dictionnaire des Beaux-Arts, beispielsweise in der Ausgabe hg. v. Anne Larue, Paris 1996, S. 40, Eintrag 13.1. 1857. Vgl. auch Mainardi 2000, S. 64f. zu Delacroix' Journal.

35 Vgl. Boime 1971, S. 127 u. 130.

36 Vgl. Mainardi 2000, S. 65.
} 
war für immer weniger Künstler das Einhalten akademischer Prinzipien, wie dem Kopieren Alter Meister, verpflichtend. ${ }^{37}$

Beachtung fand bei den Impressionisten stattdessen die Empfehlung des Malers und Akademielehrers Pierre Henri de Valenciennes (1750-1819), die in dessen weit verbreitetem Lehrbuch Élemens de perspective practique (1799/1800) dargelegt ist, ein Motiv wiederholt unter sich verändernden Lichtverhältnissen zu malen, nicht nur zur Schulung des Auges, sondern auch zur Sensibilisierung für die Effekte des Lichtes. Die Ideen von de Valenciennes auch auf vollendete Kompositionen zu übertragen und damit die vor dem Motiv gemalte Landschaft als vollwertig zu erachten, setzte mit den Freilichtmalern der Schule von Barbizon seit dem zweiten Drittel des 19. Jahrhunderts ein - an die die Impressionisten nahtlos anschlossen - als beispielsweise Théodore Rousseau (1812-1867), Charles-François Daubigny (1817-1878) und Jean-Baptiste-Camille Corot (1796-1875) Werke ausstellten, die unter anderem das gleiche Motiv zu unterschiedlichen Tageszeiten zeigten (vgl. Kapitel 7.1.). ${ }^{38}$

\subsection{Van Goghs Wiederholungspraxis zur Serialität}

Verknüpfungen zwischen einzelnen Werken van Goghs lassen sich auf unterschiedlichste Art und Weise herstellen. Sie können von motivisch-inhaltlicher Natur sein, so dass sich mehrere Bilder aufgrund des gleichen Sujets oder durch eine gemeinsame Thematik zu Gruppen zusammenfügen lassen. Dazu zählt in einem inhaltlich sehr engen Verhältnis einzelner Bilder untereinander die Praxis des wiederholten Malens des gleichen Motivs. Für diese mehrfach ausgeführten Varianten ein und desselben Motivs in mehr oder weniger veränderter Darstellungsweise verwendete van Gogh in späteren Jahren, im Einklang mit akademischen Konventionen seiner Zeit, den Terminus „répétition“.39

Der Begriff „répétition“ fällt zum ersten Mal in zwei Briefen an seinen Bruder im April 1888, kurz nach seiner Ankunft im Süden Frankreichs, als er Theo wissen lässt, dass er gern weitere Versionen zweier neuer Werke anfertigen wolle. Zu dieser Zeit war van Gogh damit beschäftigt, den Jahreskreis der Natur anhand mehrerer Bilderserien abzubilden. ${ }^{40}$ Wichtig dabei ist, dass sich van Gogh mit den „répétitions“ nur

37 Vgl. Homburg 1996, S. 30.

38 Vgl. Heinrich 2001, S. 14. Corots Lehrer waren Jean-Victor Bertin (1767-1842) und Achille Etna Michallon (1796-1822), die ihrerseits bei de Valenciennes studiert hatten. Letzterer war der erste Gewinner des Rompreises für Landschaftsmalerei im Jahre 1817.

39 Der bereits erwähnte Lexikoneintrag zu „copie“ im Dictionnaire de l'Académie des Beaux-Arts weist auf diese Differenzierung in der Kategorisierung von Kopien hin, die im Hinblick auf die Bilderserien der Impressionisten, aber auch van Goghs Praxis außerordentlich relevant ist. „Les copies $[\ldots]$ sont là de simples répétitions, reconaissables souvent à quelque variante qu’y a introduite à dessein le maître lui-même." Zitiert nach dem Artikel zu „copie“, in: Dictionnaire de l'Académie des Beaux-Arts, Bd. 4, Paris 1884, S. 262-265. Vgl. auch Mainardi 2000, S. 63.

40 Vgl. Brief 595/476, Arles, 11.4.1888, an Theo, zitiert nach Erpel 1965, Bd. 4, S. 27-28, S. 27 sowie Brief 597/477, Arles, 13.4.1888, an Theo, zitiert nach Erpel 1965, Bd. 4, S. 28- 29, S. 28. Bei 
auf diejenigen Wiederholungen bezog, die er von seinen eigenen Werken schuf. Handelte es sich dagegen um Werke anderer Künstler, die er abmalte und interpretierte, so bezeichnete er diese im Sinne akademischer Traditionen mit dem Begriff „copie“. ${ }^{41}$

Die von ihm als „répétitions“ seiner eigenen Werke bezeichneten Bilder waren Ergebnis eines künstlerisches Konzepts, das ihm die Möglichkeit der Revision seiner eigenen Werke erlaubte. Zudem hatte sich spätestens in Saint-Rémy folgende Begriffstrias für seine Wiederholungen entwickelt: „étude“ - „tableau“ - „reduction“. Die erste, daher für gewöhnlich an Ort und Stelle entstandene Ansicht eines Motivs, die später im Atelier - wenn überhaupt - nur noch geringfügige Änderungen erfuhr, nannte van Gogh üblicherweise „étude d'après nature“. Diese oft nur kurz als „études“ bezeichneten Fassungen verwendete er als Vorlage und malte sie erneut im Atelier, wobei diese überdachten und verfeinerten Fassungen daraufhin als „tableaux“ bezeichnet wurden. Unter Umständen malte er im Atelier eine dritte Fassung des gleichen Motivs, eine sogenannte „réduction“ in kleinerem Format, die als Geschenk für Verwandte oder Freunde bestimmt sein konnte. ${ }^{42}$ Auch hierbei hielt er sich an die Terminologie der Akademie. Das Dictionnaire de l'Académie des Beaux-Arts erwähnt „réductions“ als diejenigen Kopien, die in kleinerem Format als das Original gemalt seien. ${ }^{43}$

Die ausgeprägte Praxis der Wiederholung ist jedoch bereits lange vor der Zeit in Arles in van Goghs Werk erkennbar, ja sogar von Anfang an ein integraler Bestandteil seiner Arbeit, so dass über die Jahre ein vielschichtiger Entwicklungsprozess hin zur Schaffung von Bilderserien feststellbar ist, der im Folgenden anhand wichtiger Stationen im Oeuvre des Künstlers vorgestellt werden soll.

den Werken handelte es sich um Die Brücke von Langlois, 1888, Öl auf Leinwand, 53,4 x $64 \mathrm{~cm}$, Otterlo, Kröller-Müller Museum, F 397, JH 1368 u. Blühender Pfirsichbäum (Souvenir de Mauve), März 1888, Öl auf Leinwand, 73 x 59,5 cm, Otterlo, Kröller-Müller Museum, F 394, JH 1379.

41 „Ich habe jetzt sieben Kopien von Millets zehn ,Feldarbeiten'. Ich versichere Dir, Kopieren interessiert mich ungemein, und da ich zur Zeit keine Modelle habe, bedeutet es, daß ich die Figur nicht aus den Augen verliere." Brief 805/607, Saint-Rémy, 6.9.1889, an Theo, zitiert nach Erpel, Bd.4, S. 322-327, S. 324. Auf die Briefe 595, 597 sowie 805 mit den daraus abzuleitenden Termini weist Robinson 2013, S. 16 hin.

42 Vgl. Zimmer 2009, S 110 sowie Bürgi/Zimmer/Feilchenfeldt 2009, S. 28. Beispiele für diese Praxis sind Schlafzimmer in Arles, Oktober 1889, Öl auf Leinwand, 57,5 x $74 \mathrm{~cm}$, Musée d'Orsay, Paris, F 483, JH 1793 sowie Kornfeld, der Schnitter, „réduction“, Oktober 1889, Öl auf Leinwand, 59,5 x $73 \mathrm{~cm}$, Museum Folkwang, Essen, F 619, JH 1792.

Viele „études“ malte van Gogh in Arles und Saint-Rémy auf „Toiles de 30“ (Leinwänden zu 30), dem französischen Standardkeilrahmenmaß von 73 x $92 \mathrm{~cm}$. Erst in Auvers sollte er auf Leinwänden mit einem ausgeprägten Querformat von 50 x $100 \mathrm{~cm}$ malen.

43 Vgl. „copie“, in: Dictionnaire de l'Académie des Beaux-Arts, Bd. 4, Paris 1884, S. 262-265. 


\subsection{Von der Übungskopie zur Bilderserie}

\subsubsection{Kopieren zum Erlernen des künstlerischen Handwerkes}

Im Sommer 1880, im Alter von 27 Jahren und nach dem Scheitern unterschiedlichster beruflicher Vorhaben, zuletzt einer Anstellung als Laienprediger im belgischen Borinage, bei der er sich um die dort lebenden Bergarbeiter kümmern wollte, entschied sich van Gogh endlich dafür, Künstler zu werden und damit zu einer Sphäre zurückzukehren, mit der er bereits seit seiner Zeit als Lehrling in der Kunsthandlung Goupil \& Cie bestens vertraut war:

Ich bin ein leidenschaftlicher Mensch, dazu imstande und geneigt, mehr oder weniger unsinnige Dinge zu tun, die ich zuweilen mehr oder weniger bereue. Es passiert mir oft, daß ich ein wenig schnell spreche und handle, wenn es besser wäre, mit mehr Geduld zu warten. [...] Soll man sich für einen gefährlichen Menschen halten, der nichts taugt? Ich glaube nicht. Vielmehr geht es darum, mit allen Mitteln zu versuchen, gerade aus diesen Leidenschaften Nutzen zu ziehen [...]. Als ich in einer anderen Umgebung war, in einer Umgebung von Bildern und Kunstwerken, hat mich [...] für diese Umgebung eine heftige Leidenschaft erfaßt, die bis zum Überschwang ging. Und ich bereue das nicht, und jetzt fern der Heimat, habe ich oft Heimweh nach der Heimat der Bilder. ${ }^{44}$

Eindringlich beschreibt van Gogh seine Stimmungslage, die in den zehn Jahren seines künstlerischen Schaffens nicht an Bedeutung verlieren und eine entscheidende Triebfeder für die Hinwendung zur Malerei bleiben sollte. „Statt mich in Verzweifelung gehen zu lassen, habe ich mich für die tätige Melancholie entschieden, [...] oder, mit anderen Worten, ich habe die Melancholie, die hofft und strebt und sucht, einer Melancholie vorgezogen, die trübsinnig und tatenlos verzweifelt. " ${ }^{45}$

Während seiner Gymnasialzeit hatte van Gogh im Rahmen des Schulunterrichts rudimentäre Grundlagen des perspektivischen Zeichnens erlernt, die in ehrlichen, aber etwas unbeholfen wirkenden Naturskizzen aus den frühen 1870er Jahren überliefert sind. ${ }^{46}$ Mit dieser limitierten praktischen Erfahrung, jedoch einer mehr als profunden Kenntnis der Kunstgeschichte durch seine Arbeit im Kunsthandel in Den Haag, London und Paris stürzte sich van Gogh mit großem Eifer und Glauben an die eigenen Stärken in die Arbeit und begann, sich autodidaktisch zu schulen.

Das anfängliche Kopieren von Drucken war in der akademischen Ausbildung so tief verwurzelt, dass auch van Gogh dieser Tradition wie selbstverständlich folgte

44 Brief 155/133, Cuesmes, 22-24.6.1880, an Theo, zitiert nach Erpel 1965, Bd. 1, S. 201-209, S. 202f. Auf diesen Brief verweist Schneede 2003, S. 10.

45 Brief 155/133, Cuesmes, 22-24.6.1880, an Theo, zitiert nach Erpel 1965, Bd. 1, S. 201-209, S. 203. Auf die Bedeutung dieses Briefes verweist Schneede 2003, S. 13.

46 Vgl. Verschlossene Einfahrt, 1872-73, Graphit und braune Tinte, 18,3 x 22,4 cm, Amsterdam, Van Gogh Museum, F 836r, JH -. Auf diese Zeichnung macht Ives 2005, S. 4 aufmerksam. 
und sich durch das Abzeichnen von Figuren in Magazinen, Kunstbüchern oder in Drucken aus seiner eigenen Sammlung mit Kohle und Bleistift die Grundlagen des Zeichnens aneignete. Auch wenn er sich weitestgehend von Kunstakademien fernhielt, war sein Vorgehen einer klassischen Ausbildung an einem solchen Institut nicht unähnlich. Ebenso die Auswahl seiner Lehrbücher, beispielsweise Charles Bargues Cours de dessin und auch Exercices au fusain, letzteres eine lose Blattsammlung von Schwarzweiß-Lithographien antiker Statuen und Akten in unterschiedlichen Posen, von Alten Meistern sowie von Bargue selbst, entsprach der Praxis, wie sie damals von Kunststudenten geübt wurde. ${ }^{47}$

Als weitere Vorlagen, die für van Gogh von noch größerer Bedeutung waren, sind darüber hinaus Werke von Jean-François Millet (1814-1875) und Jules Breton (1827-1906) zu nennen. ${ }^{48}$ Van Gogh betrachtete deren Darstellung des ländlichen Lebens als wichtige Innovation in der zeitgenössischen Kunst. Seine Vorliebe für sie ging einher mit seiner Identifikation und seinem Mitgefühl für die benachteiligten Gruppen der Gesellschaft, denen er sich zuvor als Prediger zugewandt hatte und deren Sprachrohr er nun als Künstler werden wollte. ${ }^{49}$ Für Millets Darstellungen der hart arbeitenden Bevölkerung auf dem Land hatte er bereits seit seiner Zeit bei Goupil in Paris eine große Bewunderung entwickelt und schon 1876 drei Drucke des Barbizonmalers erworben. ${ }^{50}$ Am 20. August 1880 bat er Theo, ihm Millets Serie Die Feldarbeiten zu schicken. ${ }^{51}$ Dabei handelte es sich um zehn von Adrien Lavieille (1848-1920) angefertigte Gravuren, basierend auf Millets Darstellungen von Bauern bei unterschiedlichen landwirtschaftlichen Tätigkeiten, beispielsweise zwei Darstellungen von Schnittern, eine Bäuerin, die Ähren zu Bündeln zusammen bindet, oder auch eine Schafschererin (vgl. Abb. 26). ${ }^{52}$ Bis Anfang September hatte er nach

47 Vgl. Vellekoop 2015, S. 54. Bald darauf entdeckte er auch das Aktzeichnen für sich - im Januar 1881 zeichnete er fast jeden Tag ein anderes Modell. Vgl. Vellekoop 2015, S. 59.

Van Gogh arbeitete sich drei Mal durch Bargues Exercices au fusain und noch in Auvers, zehn Jahre später, bat er seinen Bruder, ihm das Werk erneut zuzuschicken, damit er sich daran orientieren könne. Vgl. Ives 2005, S. 7.

48 Vgl. für den Einfluss von Millet auf van Gogh insbesondere bspw. Tilborgh 1989, S. 9-24 und auch die anderen Aufsätze in dem Katalog von 1989 zur Ausstellung Van Gogh \& Millet im Van Gogh Museum.

49 Vgl. Schneede 2003, S. 14.

50 Millets Ruf erreichte einen Höhepunkt nach seinem Tod Anfang des Jahres 1875. Van Gogh sah eine Auswahl von Millets Werken wohl in der Ausstellung der Sammlung Émile Gavets, bevor diese in Paris veräußert wurde. Van Gogh pries die Ausstellung in einem Brief an seinen Bruder: „Es ist hier eine Versteigerung Milletscher Zeichnungen gewesen, ich weiß nicht, ob ich Dir davon schon schrieb. Als ich in den Saal des Hôtel Drouot kam, wo sie ausgestellt waren, hatte ich so ein Gefühl wie: Ziehe die Schuhe aus von deinen Füßen, denn die Stätte, da du stehest, ist heiliges Land." Brief 29/36, 29.6.1875, an Theo, Erpel 1965, Bd. 1, S. 32-33. Auf diesen Brief verweist Ives 2005, S. 6.

51 Vgl. Brief 156/134, Cuesmes, 7.9.1880, an Theo, Erpel 1965, Bd. 1, S. 210-211. Auf diesen Brief verweist Robinson 2013, S. 19.

52 Van Goghs Nachlass umfasst zwei gestochene Exemplare, eins mit allen zehn Drucken auf einem Blatt und des Weiteren alle zehn Drucke einzeln ausgeschnitten. Zuerst erschien die Serie jedoch 
eigener Aussage schon insgesamt „zwanzig Blätter nach Millet“53 angefertigt und allein die Darstellung von Millets Sämann bereits mindestens fünfmal kopiert. ${ }^{54}$

Bedeutsam für das weitere Werk van Goghs ist dabei nicht nur die wiederholte Auseinandersetzung mit dem Sujet der ländlichen Bevölkerung, mit der er sich mit Breton und Millet messen wollte, sondern auch seine frühe Beschäftigung mit der Darstellungsform einer inhaltlich zusammenhängenden Bilderserie. Auch nach van Goghs Umzug nach Brüssel im Oktober 1880, wo er Rat bei dem Maler Anton van Rappard (1858-1892) suchte und dessen Atelier nutzte, arbeitete er im Laufe des Herbstes zumeist allein und setzte das Kopieren von Lehrbüchern zur Perspektivund Anatomieschulung nach einem selbst erarbeiteten Lehrplan fort.

Im April des folgenden Jahres zog van Gogh zurück zu seinen Eltern in das holländische Etten, wo weitere Kopien nach Werken Millets folgten. Dabei ist insbesondere eine Übertragung von Millets Sämann hervorzuheben, bei der er die gedruckte Vorlage nicht nur mittels einer Rastervergrößerung in eine fast viermal so große Zeichnung übertrug, sondern auch die charakteristisch-akzentuierten Linien der Radierung nun mit Bleistift, Tinte sowie grauen und grünen Aquarellfarben in einer wesentlich weicheren und flächigeren Formensprache neu interpretierte (vgl. Abb. 24 u. 25). ${ }^{55}$ Deutlich wird, dass van Gogh zwar in seiner Frühzeit als Künstler auf perspektivische Hilfsmittel angewiesen war, dass er aber dennoch Vorlagen nicht lediglich kopierte, sondern den Prozess der Auseinandersetzung mit dem Original vielmehr als Reflektion über die Technik und das Sujet nutzte.

als Holzschnitte, in der Zeitschrift L'Illustration, 5. Februar 1853, no. 519, S. 92-93, von dem sich auch einzelne Drucke im Nachlass van Goghs befinden und später dann gestochen, in Dessins de J.-F. Millet, gravés par Adrien Lavieille. Paris 1855. Vgl. Anmerkung 1 zu Brief 134/156, abgerufen unter http://vangoghletters.org/vg/letters/let156/letter.html u. Tilborgh/Consibee 1989, S. $122 f$.

53 Vgl. Brief 157/135, Cuesmes, 7.9.1880, an Theo, Erpel 1965, Bd. 1, S. 211-213, S. 212.

54 Diese fünf Darstellungen sind nicht erhalten und es ist auch nicht klar, welche Vorlage van Gogh verwendete. Vgl. Vellekoop 2015, S. 59.

55 Der Sämann, April 1881, Zeichnung, 48,1 x 36,7 cm, Amsterdam, Van Gogh Museum, F 830 JH 1. Vgl. Robinson 2013, S. 19. Bei der Vorlage handelte es sich um Paul-Edmé le Rat (1849-1892), Der Sämann (nach Millet), 1873, Radierung, 12 x 9,5 cm, Amsterdam, Van Gogh Museum, die ihrerseits auf einer Lithographie des Motivs von 1853 beruht. Vgl. auch Anmerkung 3 zu Brief 156/134, abgerufen unter: http://vangoghletters.org/vg/letters/let156/letter.html. Ein maßgeblicher Vorteil des Rasters besteht darin, dass sich aufgrund der Parzellierung des Ursprungswerkes viele Referenzpunkte herstellen und sich dadurch Bilder leicht vergrößern oder verkleinern lassen; ein Umstand, den van Gogh wenig später in einem Brief an Theo kommentierte: „Eben habe ich noch zwei Grabende gezeichnet. Falls dieses Format zu groß ist $[\ldots]$, so würde ich $[\ldots]$ die Zeichnungen auf die Hälfte oder ein Drittel verkleinern, ohne daß sie an Genauigkeit einbüßen, nämlich mit Hilfe von Quadraten." Vgl. Steele, M./Steele E. 2013, S. 173. Die Autoren weisen auch auf van Goghs Brief 281/243, Den Haag, 7.11.1882, an Theo, zitiert nach Erpel 1965, Bd. 2, S. 128-130, S. 130, hin. 


\subsubsection{Erste Aufträge und Bilderserien in Den Haag}

Während seines Aufenthaltes in Den Haag, wohin van Gogh in der letzten Dezemberwoche 1881 gezogen war, nachdem ihm sein Vater infolge eines Streits den Auszug aus dem elterlichen Haus unmissverständlich nahegelegt hatte, suchte er zunächst künstlerischen Rat und Unterstützung bei Anton Mauve (1838-1888), dem Ehemann seiner Kusine Ariëtte (Jet) Carbentus. Mauve war ein erfolgreicher, geschätzter Maler und führendes Mitglied der Haager Schule, deren Kunst die Stadt zum Zentrum der zeitgenössischen niederländischen Malerei hatte werden lassen. Nach relativ kurzer Zeit kam es jedoch bereits zum Zerwürfnis mit Mauve, da van Gogh dem Ratschlag des älteren Malers, seine Technik weiter mit dem Abmalen von Gipsabgüssen zu verfeinern, nicht Folge leisten wollte. ${ }^{56}$

Am 11. März besuchte ihn sein Onkel, der Kunsthändler Cornelis (Cor) Marinus und nachdem er ihm mehrere seiner gezeichneten Milieustudien Den Haags gezeigt hatte, beauftragte dieser ihn mit einer Serie von zwölf Ansichten der Stadt. Van Gogh war überwältigt von dieser positiven Entwicklung und von der Aussicht, im Anschluss daran möglicherweise Aufträge für weitere Serien zu erhalten. ${ }^{57}$

Den Haag war im ausgehenden 19. Jahrhundert eine kleine und durchaus ansehnliche Residenzstadt, doch zeigt van Gogh in den Zeichnungen für seinen Onkel wenig von ihrer repräsentativen und historischen Bausubstanz, stattdessen legt er den Fokus auf die von öden Industrieanlagen geprägten städtischen Randgebiete. ${ }^{58}$ Darüber hinaus illustriert er im Zuge der fortschreitenden Industrialisierung und ihrer Folgen die Situation der unteren Bevölkerungsschichten, wie etwa in der Darstellung des Eingangs zum städtischen Pfandleihhaus in Den Haag (vgl. Abb. 29). ${ }^{59}$

56 Vgl. Brief 219/189, Den Haag, 21.4.1882, an Theo, Erpel 1965, Bd. I., S. 345-348.

57 Er berichtete seinem Bruder: „Theo, es ist beinah wie ein Wunder. [...] Da kommt [...] C.M. und bestellt zwölf kleine Federzeichnungen bei mir, Ansichten vom Haag, weil er einige, die fertig waren, gesehen hat [...] für einen Reichstaler das Stück. Preis von mir bestimmt, mit dem Versprechen, zwölf weitere zu bestellen, wenn ich sie nach seinem Wunsche mache, doch für die will er den Preis höher ansetzen als ich." Brief 210/180, Den Haag, 11.3.1882, an Theo, zitiert nach Erpel 1965, Bd. 1, S. 322-325, S. 325.

58 Eine Ausnahme war Brücke und Häuser an der Ecke Herengracht-Prinsessegracht, März 1882, Bleistift, Feder, braune Tinte (urspr. schwarz), Aquarell, weiß gehöht und Spuren eines Rasters auf Papier, 24 x 35,5 cm, Amsterdam, Van Gogh Museum, F 1679, JH 121.

59 Sechs Zeichnungen können mit Sicherheit der ersten Serie von zwölf Zeichnungen für van Goghs Onkel Cornelis zugerechnet werden: 1. Straßenszene, ,Paddemoes', März 1882, Bleistift und Feder auf Papier, 25 x 31 cm, Otterlo, Kröller-Müller Museum, F 918, JH 111; 2. Bäckerei in der Noordstraat, ,Geest', März 1882, Bleistift und Feder auf Papier, 20,5 x 33,5 cm, Den Haag, Gemeentemuseum, F 914, JH 112, 3. ,Vleersteeg' (Werk und Verbleib unbekannt); 4. ,Vischmarkt (Werk und Verbleib unbekannt), erwähnt in Brief 211/181; 5. Scheveningseweg, März 1882, Bleistift und Feder auf Papier, 20 x 33,5 cm, Privatsammlung, F 920, JH 113; 6. Bauarbeiter in den Dünen, März 1882, Bleistift auf Papier, 27 x 20 cm, Aufenthaltsort unbekannt, F 922, JH 114, die letzten beiden Zeichnungen werden in Brief 212/182 erwähnt.

Der Rest der Serie besteht aus sechs der folgenden acht Zeichnungen, wie anhand der jeweiligen Provenienzen oder weiterer Hinweise, beispielsweise handschriftlichen Angaben auf den Rücksei- 
In mehreren Zeichnungen lassen sich mit Bleistift eingezeichnete Raster finden, die auf die Verwendung seines Perspektivrahmens hindeuten. Für Das Pfandleihhaus in Den Haag nutzte er dieses Hilfsmittel, um den Vorplatz vor dem Eingangsportal und die Architektur korrekt wiederzugeben. Die Figuren fügte van Gogh erst später, wohl in seinem Atelier, hinzu. ${ }^{60}$ Van Gogh muss diese ersten Zeichnungen zügig, in weniger als zwei Wochen, vollendet und abgeschickt haben, äußerte er doch bereits in einem Brief vom 24. März seinen Unmut darüber, dass er von seinem Onkel noch keine Bezahlung erhalten habe. ${ }^{61}$

Von April bis Juni, nach Erhalt seines Lohns für die erste Serie, arbeitete van Gogh an einer weiteren Serie für seinen Onkel, „die aber ziemlich schwierig ist: sechs bis ins Einzelne gehende, bestimmte Stadtansichten. Aber ich will sehen, daß ich sie mache, weil ich für die sechs, wenn ich recht verstanden habe, so viel bekomme wie für die ersten zwölf." 62 Der Brief, in dem van Gogh mitteilt, dass er die Werke an seinen Onkel gesendet habe, erwähnt insgesamt sieben Zeichnungen. ${ }^{63}$

ten der Zeichnungen, ermittelt werden konnte: 1. Brücke in der Nähe des Schenkwegs, März 1882, Bleistift auf Papier, 21,5 x 33,5 cm, Den Haag, Privatsammlung, F 917, JH 115; 2. Graben neben dem Schenkweg, März 1882, Feder, Bleistift, schwarze Kreide, weiß gehöht, auf Papier, 18,5 x 34 cm, Otterlo, Kröller-Müller Museum, F 921, JH 116; 3. Van Stolk Park, März 1882, schwarze Kreide, Kohle und Feder, weiß gehöht, auf Papier, 18 x 33,5 cm, Privatsammlung, F 922a, JH 119; 4. Gasometer, März 1882, Kreide, Bleistift, 24 x 33,5 cm, Privatsammlung, F 924, JH 118; 5. Fabrikgebäude in Den Haag, März 1882, Bleistift und Feder auf Papier, Karlsruhe, Staatliche Kunsthalle, F 925, JH 117; 6. Brücke und Häuser an der Ecke Herengracht-Prinsessegracht, März 1882, Bleistift, Feder, braune Tinte (urspr. schwarz), Aquarell, weiß gehöht und Spuren eines Rasters auf Papier, 24 x 35,5 cm, Amsterdam, Van Gogh Museum, F 1679, JH 121; 7. Das Pfandleihhaus in Den Haag, März 1882, Bleistift, Feder, braune Tinte (urspr. schwarz), Aquarell, weiß gehöht und Spuren eines Rasters auf Papier, 24 x 34 cm, Amsterdam, Van Gogh Museum, F -, JH 126 u. Der Bahnhof von Den Haag, März 1882, Bleistift und Feder auf Papier, 24 x 33,5 cm, Den Haag, Gemeentemuseum, F 919, JH 123 war möglicherweise ebenfalls Bestandteil dieser Gruppe. Vgl. den Kommentar zu Brief 210/180 in der Online-Ausgabe der Briefe, abgerufen unter: http:// vangoghletters.org/vg/letters/let210/letter.html\#.

60 Vgl. Heugten 2005, S. 70. Ein weiteres Beispiel für die Nutzung des Perspektivrahmens in dieser Serie ist Brücke und Häuser an der Ecke Herengracht-Prinsessegracht (F 1679, JH 121). Für van Goghs Gedanken zum Perspektivrahmen S. Brief 235/205, 3.6.1882, an Theo, Erpel 1965, Bd. 2, S. 15-19, S. 17.

61 Brief 213/183, Den Haag, 24.3.1882, an Theo, Erpel 1965, Bd. 1, S. 334-335.

62 Brief 214/184, Den Haag, 2.4.1882, an Theo, Erpel 1965, Bd. 1, S. 335-338, S. 338.

63 Vgl. Brief 235/205, Den Haag, 3.6.1882, an Theo, Erpel 1965, Bd. 2, S. 15-19. Bei den Werken handelt es sich um 1. Das Haus von Siens Mutter, Frühling 1882, Bleistift und Feder, weiß gehöht auf Papier, 29 x $45 \mathrm{~cm}$, Privatsammlung (zuletzt Auktion Christie's London, 6.2.2006), F 941, JH 146; 2. Das Haus von Siens Mutter, Nahansicht, Frühling 1882, Bleistift, Feder, weiß gehöht auf Papier, 46 x 59,5 cm, Pasadena, Norton Simon Museum, F 942, JH 147; 3. Gärtnerei am Schenkweg, große Ansicht, Frühling 1882, Bleistift, Feder, schwarze Kreide und Pinsel, weiß gehöht auf Papier, 29,5 x 58,5 cm, New York, The Metropolitan Museum of Art, F 930, JH 138; 4. Zimmermannsschuppen und Wäscherei, Frühling 1882, Bleistift, schwarze Kreide, Feder, Pinsel, schwarze Tinte, Aquarell, weiß gehöht und Spuren eines Rasters auf Papier, 28,5 x $47 \mathrm{~cm}$, Otterlo, Kröller-Müller Museum, F 939, JH 150; 5. Fischtrocknerei in den Dünen, Frühling 
Dem übergeordneten Thema der ersten Gruppe folgend, legte van Gogh wieder den Fokus auf die Lebensverhältnisse und die harte Arbeit der armen und benachteiligten Bevölkerungsschichten. Inhaltlich noch konsistenter als zuvor richtete sich sein Blick wieder auf die Randbezirke der Residenzstadt, um das dortige Geschehen in den Hinterhöfen und Seitenstraßen in einer Zusammenstellung von unterschiedlichen Ansichten zu beleuchten. Von seinem Atelier aus überblickte van Gogh eine Wäscherei und den Hof einer Zimmermannswerkstatt, deren Angestellte er bei ihren jeweiligen Tätigkeiten in der aufwendigen Zeichnung Zimmermannsschuppen und Wäscherei festhielt (Abb. 30). ${ }^{64}$

Der Ausblick aus seinem Fenster faszinierte ihn so sehr, dass er ihn im Laufe der nächsten Monate mit etwas verschobenem Blickwinkel und bei unterschiedlichen Witterungsverhältnissen wiederholt zeichnete, um sich in der Perspektive und verschiedenen zeichnerischen Techniken zu schulen, begann er doch viele Zeichnungen zunächst mit Bleistift, wechselte dann zur Tinte und füllte schließlich die Flächen mit Aquarellfarben. Theo berichtete er im Juli von seiner Arbeitsweise.

Du mußt Dir also vorstellen, wie ich früh gegen vier schon vor meinem Bodenfenster sitze und mit meinem Perspektiv-Rahmen die Wiesen und den Hof absuche, wenn man in den kleinen Häusern ringsum die Feuer zum Kaffeekochen anzündet und der erste Arbeiter auf den Zimmerplatz geschlendert kommt. Über die roten Ziegeldächer segelt ein Flug weißer Tauben daher, zwischen den schwarzen, rauchenden Schornsteinen hindurch. Und dahinter eine Unendlichkeit von feinem, weichem Grün, Meilen und Meilen flaches Wiesenland und ein grauer Himmel - so still, so friedlich wie Corot und van Goyen [vgl. Abb. 31]. ${ }^{65}$

Auch wenn die Stadtansichten für seinen Onkel nicht alle die gleiche Größe aufweisen, sind sich diese doch, aufgrund des aufwendigen Einsatzes unterschiedlicher zeichnerischer Techniken, von Bleistift und schwarzer Kreide zu Tinte und Aquarellfarben, stilistisch ähnlich. Zudem legte van Gogh durchweg besonderen Wert auf eine korrekte perspektivische Tiefenstaffelung, deren Bewältigung gerade bei

1882, Bleistift, Feder und Pinsel und schwarze Tinte (in Teilen zu Braun verfärbt), Aquarell und Spuren eines Rasters auf Papier, 28 x 44 cm, Otterlo, Kröller-Müller Museum, F 938, JH 152; 6. Fischtrocknerei in den Dünen, Frühling 1882, Bleistift, Tusche, weiß gehöht, 27,5 x 46,5 cm, Groninger Museum, F 946a, JH 151; 7. Gärtnerei am Schenkweg, kleine Ansicht, Frühling 1882, schwarze Kreide, Feder, weiß gehöht auf Papier, 23,5 x 33 cm, Amsterdam, Rijksmuseum, F 923, JH 125. Vgl. Anmerkungen zu Brief 214/184, abgerufen unter: http://vangoghletters.org/ vg/letters/let214/letter.html.

64 Zimmermannsschuppen und Wäscherei, Frühling 1882, Bleistift, schwarze Kreide, Feder, Pinsel, schwarze Tinte, Aquarell, weiß gehöht und Spuren eines Rasters auf Papier, 28,5 x $47 \mathrm{~cm}$, Otterlo, Kröller-Müller Museum, F 939, JH 150.

65 Brief 250/219, Den Haag, 23.7.1882, an Theo, zitiert nach Erpel 1965, Bd. 2, S. 59-63, S. 61f. Bei dem besprochenen Werk handelte es sich um Dächer, Juli 1882, Aquarellfarben, weißgehöht auf Papier, 39 x 55 cm, Privatbesitz, zuletzt Sotheby's New York, Auktion 3.5.2006, F 943, JH 156. 
Zimmermannsschuppen und Wäscherei durch sichtbare Spuren des von van Gogh eingezeichneten Rasters nachvollziehbar ist. Eine große Ansicht der Gärtnerei am Schenkweg stellt eine gelungene Kombination räumlicher Gliederung des quer im Vordergrund verlaufenden Grabens und der dahinter anschließenden Blumenwiesen und Häusern dar. ${ }^{66}$ Hatte van Gogh die Zeichnungen zunächst noch als Übung in der Perspektivdarstellung beschrieben, war er doch durch die abweisende Haltung seines Onkels, womit sich die Hoffnung auf weitere Aufträge zerschlug, verstimmt. ${ }^{67}$ Nach Erteilung des zweiten Auftrags hatte van Gogh noch spekuliert, ob er danach möglicherweise eine Serie von Ansichten von Amsterdam für Cornelis würde anfertigen dürfen. ${ }^{68}$ Der Frustration über die Ablehnung gab van Gogh in einem Brief an seinen Bruder freien Lauf. ${ }^{69}$

Van Gogh war sich der sperrigen Sujets und insbesondere der nüchternen Formensprache der Serie bewusst, die er auch aufgrund vermeintlich vorherrschender gestalterischer Ideale und in Anbetracht nun ausbleibender Aufträge seines Onkels nicht aufzugeben gewillt war - eine bemerkenswerte Entscheidung, die von großer Charakterstärke und Überzeugung hinsichtlich des eigenen Werkes zeugt:

Ich will gern zugeben, daß Zeichnungen in die mit der Feder hineingekritzelt ist, auf denen Lichter wieder herausgekratzt worden sind, etwas Kahles, Ungefälliges haben mögen für ein Auge, das ausschließlich an Aquarelle gewöhnt ist. Doch es gibt auch Menschen, die - ebenso wie es manchmal angenehm und erfrischend für einen gesunden Körper ist, mal bei starkem Wind einen Spaziergang machen - es gibt auch Liebhaber, sage ich, die vor diesem Ungefälligen, Kahlen keine Angst haben. ${ }^{70}$

Seine künstlerischen Vorstellungen verteidigend, zitierte er auch die Meinung seines Freundes Rappard, der „von einer solchen Zeichnung, wie sie C.M. hat, sehr eingenommen [war], übrigens auch von allen anderen, die C.M. hat, besonders von

66 Gärtnerei am Schenkweg, große Ansicht, Frühling 1882, Bleistift, Feder, schwarze Kreide und Pinsel, weiß gehöht auf Papier, 29,5 x 58,5 cm, New York, The Metropolitan Museum of Art, F 930, JH 138.

67 „Ich arbeite wieder an den Zeichnungen für C.M. - aber ob sie ihm gefallen werden? Vielleicht nicht. Ich kann solche Zeichnungen nur als Studien in Perspektive auffassen, und deshalb vor allem mache ich sie, um mich dadurch zu üben." Brief 230/200, Den Haag, 23.5.1882, an Theo, Erpel 1965, Bd. 1, S. 382-384, S. 382.

68 Vgl. Brief 214/184, Den Haag, 2.4.1882, an Theo, Erpel 1965, Bd. 1, S. 335-338, S. 338.

69 „Ich habe Nachricht von C.M. bekommen in Form einer Postanweisung über zwanzig Gulden, doch ohne ein Wort dabei. Ob er wieder etwas bei mir bestellt, ob die Zeichnungen ihm gefallen, weiß ich vorläufig also noch gar nicht. Jedoch im Vergleich mit dem Preis, den er für die vorigen bezahlt hat, dreißig Gulden, und in Anbetracht dessen, daß diese letzte Sendung (die erste waren zwölf kleine, die jetzige: eine kleine, vier so wie die beiliegende, zwei große, also sieben Stück) doch belangvoller war als die erste, kommt es mir so vor, als wäre Seine Hochwohlgeboren nicht gerade guter Laune gewesen, als er sie erhielt, oder vielleicht haben sie ihn aus irgendeinem Grund enttäuscht." Brief 235/205, Den Haag, 3.6.1882, an Theo, Erpel 1965, Bd. 2, S. 15-19, S. 16. 
der größten, dem Hof. Und er ist jemand, der versteht, was ich will, und weiß die Schwierigkeit der Sache zu schätzen. " ${ }^{71}$ Nachdem von seinem Onkel keine weiteren Aufträge für Bilderserien zu erwarten waren, musste sich van Gogh auch von der Idee verabschieden, durch diese kleineren Auftragsarbeiten zumindest für seine eigene Miete aufkommen zu können. ${ }^{72}$ Doch der anhaltenden Hilfe seines Bruders konnte er gewiss sein.

Van Goghs Beschäftigung mit sozialkritischen Darstellungen aus den wöchentlich erscheinenden und miteinander konkurrierenden englischen Zeitschriften The Illustrated London News und The Graphic war ein wichtiger Impetus für seine realistischen Sujets in Den Haag. Die Bildersprache und die Motive der Illustrationen, für die führende Künstler und Illustratoren der Zeit, wie Samuel Luke Fildes (18441927) oder Hubert von Herkomer (1849-1914), arbeiteten, hatte van Gogh zuerst während seiner Lehre in der Londoner Niederlassung der Galerie Goupil, in den Jahren 1873 bis 1875, kennengelernt. Besonders The Graphic, das 1869 in Konkurrenz zu der über die Jahre konservativ gewordenen The Illustrated London News gegründet worden war, beschäftigte eine junge Generation von Künstlern, die sich des Themas der sozialen Ungerechtigkeit annahmen. ${ }^{73}$ Van Goghs Ausbildungszeit bei Goupil, damals der größte Herausgeber von gedruckten Kunstreproduktionen in Europa, ${ }^{74}$ kann dabei gar nicht hoch genug für seine künstlerische Sozialisation bewertet werden, wie sein Bericht Jahre später an van Rappard verdeutlicht:

Vor mehr als zehn Jahren bin ich in London jede Woche zu den Schaukästen der Druckerei des Graphic und der London News gelaufen und habe mir die allwöchentlichen Ausgaben angesehen. Die Eindrücke, die ich da an Ort und Stelle empfing, waren so stark, daß mir die Zeichnungen noch klar und deutlich in Erinnerung sind, trotz allem, was ich seitdem erlebt habe. Und jetzt ist mir manchmal zumute, als läge nichts zwischen jenen alten Tagen und jetzt - höchstens ist meine damalige Begeisterung noch gewachsen. ${ }^{75}$

Infolgedessen war van Gogh außerordentlich erfreut, kurz nach dem Umzug nach Den Haag seinem Bruder mitteilen zu können, „einen erstaunlichen Gelegenheitskauf gemacht [zu haben]: wunderbare Holzschnitte aus dem Graphic, zum Teil nicht Abzüge von den Klischees, sondern von den eigentlichen Holzstöcken. Genau das, was ich mir seit Jahren gewünscht habe, Zeichnungen von Herkomer, Frank Holl, Walker und anderen. Ich habe sie von Blok, dem Bücherjuden, gekauft und habe aus einem riesigen Stoß Graphics und London News ausgesucht, was das beste war,

Brief 235/205, Den Haag, 3.6.1882, an Theo, Erpel 1965, Bd. 2, S. 15-19, S. $15 f$.

Vgl. Brief 235/205, Den Haag, 3.6.1882, an Theo, Erpel 1965, Bd. 2, S. 15-19, S. $16 f$.

Vgl. Bailey 1990, S. 119.

Vgl. Ives 2005, S. 4.

75 Brief 307/R20, Den Haag, 4.2.1883, an van Rappard, zitiert nach Erpel 1968, Bd. 5, S. 152-157,

S. 152. 
für fünf Gulden. Es sind Sachen dabei, die wunderbar sind, unter anderem Houseless and Homeless von Fildes (arme Leute, die vor einem Nachtasyl warten)."

\subsubsection{Sien und weitere Serien der Porträtmalerei in Den Haag}

Parallel zu der Entstehung der Stadtansichten hatte sich van Gogh auch dem Zeichnen von Figuren zugewandt. Bereits unmittelbar nach dem Bruch mit Mauve hatte er seinem Bruder im März mitgeteilt, dass er sich auf Genredarstellungen konzentrieren wolle, da diese ihm als ein lukrativer Broterwerb erschienen. Er beabsichtigte, sich durch weitere Studien nach dem Modell zu schulen, um endlich „eine Komposition von mehreren Figuren, z.B. einen Wartesaal dritter Klasse oder ein Leihhaus oder ein Interieur" ${ }^{\text {" }} 77$ in Angriff nehmen zu können. In den beiden danach entstandenen Serien für seinen Onkel sind Anklänge an diese sozialkritischen Themen bereits sehr gut zu erkennen.

Nachdem van Gogh im April mit den Stadtansichten aufgrund des anhaltend schlechten Wetters kaum Fortschritte erzielen konnte, widmete er sich stattdessen Studien von Figuren, von denen zwei mit dem Titel Sorrow versehene Aktzeichnungen einer auf dem Boden sitzenden, unbekleideten Frau besonders herausragen (vgl. Abb. 32).$^{78}$ Dargestellt hatte er seine damalige Lebensgefährtin, die Prostituierte Sien Hoornik, die er nur wenige Wochen vorher in einem Brief an seinen Bruder erstmals als Modell für seine Figurenstudien erwähnt hatte: „Es ist ein neues Modell, das ich jetzt habe, obwohl ich sie schon früher einmal oberflächig gezeichnet habe. Oder richtiger, es ist mehr als ein Modell, denn aus demselben Haus habe ich schon drei Personen gehabt, eine Frau von etwa fünfundvierzig Jahren, [...], dann ihre

76 Brief 199/169, Den Haag, 8. oder 9.1.1882, an Theo, zitiert nach Erpel 1965, Bd. 1, S. 298-304, S. 303. Houseless and hungry von Samuel Luke Fildes erschien in The Graphic 1 (4.12.1869), S. 9 und wurde 1877 in The Graphic Portfolio neu aufgelegt. Der Druck aus van Goghs Besitz befindet sich heute im van Gogh Museum, Amsterdam. Vgl. Anmerkungen zu Brief 199/169 in der Online-Ausgabe der Briefe, abgerufen unter: http://vangoghletters.org/vg/letters/let199/letter. html.

77 Brief 207/178, Den Haag, 3.3.1882, an Theo, zitiert nach Erpel 1965, Bd. 1, S. 319-321, S. 320.

78 Vgl. Hulsker 1984, S. 40-42.

Sorrow, April 1882, Bleistift auf Papier, 45,5 x 29,5 cm, Privatsammlung, F 929, JH. 129 u. Sorrow, April 1882, schwarze Kreide auf Papier, 44,5 x 27 cm, Walsall Museum and Art Gallery, F 929a, JH 130. Van Gogh erklärt den Grund, warum es zwei Versionen gibt: „Die beiliegende ist meiner Ansicht nach die beste Figur, die ich bisher gezeichnet habe, darum dachte ich daß Du sie haben solltest. Dies ist nicht die Studie nach dem Modell, und doch ist es direkt nach dem Modell. Ich hatte nämlich zwei Bogen als Unterlage unter meinem Papier. Nun hatte ich tüchtig darauf herumgewerkt, um die Kontur richtig rauszukriegen, und als ich die Zeichnung vom Brett nahm, hatte sie sich sehr sauber auf die zwei Bogen Unterlage durchgedrückt, und da habe ich es unmittelbar nach der ersten Studie darauf gezeichnet. So daß diese sogar noch frischer ist als die erste. Die beiden anderen habe ich selbst behalten, ich würde sie nicht gern weggeben." Brief 216/186, Den Haag, 10.4.1882, an Theo, zitiert nach Erpel 1965, Bd. 1, S. 341-342, S. 341. Die dritte Fassung von Sorrow ist nicht erhalten. 
Tochter, ungefähr dreißig Jahre, und ein jüngeres Mädchen von zehn oder zwölf. Es sind arme Leute, die, das muß ich sagen, unbezahlbar willig sind." ${ }^{\circ 9}$

Die Haltung der auf dem Boden sitzenden Sien, deren Kopf gesenkt ist und auf den verschränkten Armen ruht, ähnelt dabei sehr einer Lithographie von Charles Bargue aus van Goghs Lehrbuch Cours de dessin. ${ }^{80}$ Siens Körper ist in Sorrow nur durch wenige Linien mit reduzierter Schraffur kantig und klar gefasst, so dass er trotz des durch die fortgeschrittene Schwangerschaft bereits sichtbar gewölbten Bauches auf drastische Weise sehnig und ausgemergelt wirkt. ${ }^{81}$ Van Gogh brachte am unteren Rand die Beschriftung „Comment se fait-il qu'il y ait sur la terre une femme seule - délaissée? [„Wie kann es auf Erden eine einsame - eine verlassene Frau geben?"] Michelet" an, die von einem Zitat aus Jules Michelets 1860 erschienener Sozialstudie La Femme abgeleitet war. ${ }^{82}$ Van Gogh wollte Michelet zitierend „damit so etwas sagen wie: Mais reste le vide du cœur, Que rien ne remplira [Doch bleibt die Leere des Herzens, die nichts zu füllen vermag]" 83 und „in dieser weißen, schlanken Frauengestalt etwas [...] vom Kampf des Lebens ausdrücken. " ${ }^{84}$ Damit erhob er das Porträt seiner Lebensgefährtin Sien zu einer exemplarischen Milieustudie einer von Armut und harten Lebensbedingungen geprägten Prostituierten und rückte ihr Schicksal, ihr Leid und ihren Kummer („,sorrow“) in einen größeren gesellschaftlichen Kontext.

Im Bewusstsein der Qualität dieses Blattes bezeichnete van Gogh Sorrow als die „beste Figur, die ich bisher gezeichnet habe“ ${ }^{\text {85 }}$. Im gleichen Brief stellte er die Verbindung zu der gedruckten Darstellung einer Schäferin Millets her, die sich ebenfalls

79 Brief 207/178, Den Haag, 3.3.1882, an Theo, zitiert nach Erpel 1965, Bd. 1, S. 319-321, S. 321. Siens eigentlicher Name lautete Clasina Maria.

80 Dessen Druck zeigt einen in ähnlicher Pose auf dem Boden sitzenden Jungen. Van Gogh beschrieb selbst, dass er bei der Motivfindung von Bargue beeinflusst worden war. Charles Bargue, Auf dem Boden sitzender Junge, sein Kopf auf seinen Knien, Lithographie, Maße unbekannt, aus Cours de dessin (Paris, ca. 1873), Farbtafel 24. Vgl. Ives 2005, S. 7 u. Hulsker 1984, S. 42. Van Gogh beschrieb selbst, dass er von Bargue beeinflusst war. „Viele Aktstudien habe ich noch nicht, doch es sind welche dabei, die besonders viel von den Bargues haben; sind sie deshalb weniger ursprünglich? Es kommt vielleicht vielmehr daher, daß ich durch die Bargues der Natur ins Auge zu sehen gelernt habe." Brief 215/185, Den Haag, 6.4.1882, an Theo, zitiert nach Erpel 1965, Bd. 1, S. 338-341, S. 339. Darüber hinaus wird vermutet, dass van Gogh von Albrecht Dürers Darstellung der Melancholia beeinflusst gewesen sein könnte. Vgl. Schneede 2003, S. 18.

81 Vgl. Schneede 2003, S. 18.

82 Vgl. Michelet 1860, S. XXXIII. Das Originalzitat lautet: „Et comment se fait-il sur la terre qu'il y ait une femme seule?" Van Gogh hatte die Originalbuchstelle möglicherweise nicht zur Hand als er die Beschriftung anbrachte. Das Wort „délaissée“ fügte er selbst hinzu. Vgl. auch die Anmerkungen zu Brief 186/216 in der Online-Ausgabe der Briefe, unter: http://vangoghletters.org/vg/ letters/let216/letter.html.

83 „Doch bleibt die Leere des Herzens, die nichts zu füllen vermag.“ Brief 186/216, Den Haag, 10.4.1882, an Theo, zitiert nach Erpel 1965, Bd. 1, S. 341-342, S. 342.

84 Brief 222/195, Den Haag, 1.5.1882, an Theo, zitiert nach Erpel 1965, Bd. 1, S. 368-371, S. $368 f$.

85 Brief 216/186, Den Haag, 10.4.1882, an Theo, zitiert nach Erpel 1965, Bd. 1, S. 341-342, S. 341 . 
in seiner Sammlung von Druckgrafik befand. Wichtig ist der Wille, die Zeichnung mit Emotionen aufzuladen. „Als Du mir vorigen Sommer den großen Holzschnitt von Millet La Bergère [Die Schäferin] bei Dir zeigtest, da dachte ich: was kann man mit einer einzigen Linie alles machen! Ich erhebe natürlich nicht den Anspruch, mit einer einzigen Linie so viel zu sagen wie Millet. Jedoch habe ich versucht, etwas Gefühl in diese Figur zu legen. " ${ }^{86}$

Neben Millet war auch der Einfluss der englischen Illustrationen von Bedeutung, zu dem er sich erläuternd äußerte: „Natürlich zeichne ich nicht immer so wie diesmal. Doch die englischen Zeichnungen, die in diesem Stil gemacht sind, gefallen mir besonders gut, und da ist es kein Wunder, daß ich es einmal so versucht habe, und weil es für Dich war, der solche Dinge versteht, habe ich mich nicht gescheut, ein wenig melancholisch zu sein. " ${ }^{87}$ Van Rappard beschrieb er später, wie er von Siens Leid berührt war und sie daher zu sich aufnahm: „Was sollte ich nun tun? In dem Augenblick galt es viel zu bedenken. Sie hatte eine sehr schwere Entbindung gehabt, das arme Wesen von einer Mutter. Gibt es nicht Augenblicke im Leben, wo es ein Verbrechen ist, untätig dabeizustehen oder zu sagen: ,Was geht mich das an?"“88

Sien Hornik und ihre Familie sollten für die nächsten gut anderthalb Jahre eine große Rolle in van Goghs Leben spielen. Sien befeuerte seine künstlerische Arbeit. Nachdem er Sorrow fertig gestellt hatte, berichtete er seinem Bruder erfreut: „Und da siehst Du auch gleich, daß ich tüchtig an der Arbeit bin. Nun ich einmal damit angefangen habe, würde ich gern etwa dreißig Aktstudien machen. "89 Sien inspirierte ihn in dieser Zeit darüber hinaus zu einer Reihe von Porträts, die sie in unterschiedlichen, dabei jedoch vorwiegend häuslichen Kontexten zeigen und durch ihre thematischen Analogien den Charakter einer Serie erhalten. Die Darstellungen variieren dabei zwischen Ganzkörperporträts, Bruststücken, Porträts im Profil und Doppelporträts mit anderen Familienmitgliedern. Van Goghs Hauptaugenmerk war auf die Wiedergabe von Sien in ihrer Rolle als Frau und Mutter und dabei auf die Dokumentation des häuslichen und familiären Zusammenlebens gerichtet, das er zum ersten Mal mit ihr erfuhr und das ihn mit Glück erfüllte. ${ }^{90}$ Mehrere Porträts zeigen Sien bei häuslicher Arbeit, beispielsweise nähend oder Kartoffeln schälend, doch überwiegen deutlich Darstellungen mit ihrem am 2. Juli geborenen

86 Brief 216/186, Den Haag, 10.4.1882, an Theo, zitiert nach Erpel 1965, Bd. 1, S. 341-342, S. 341. Bei dem von van Gogh angesprochenen Werk handelt es sich um Jean-François Millet, La grande bergère assise (Die große Schäferin sitzend), Stich durch Jean Baptiste Millet, Jahr der Ausführung unbekannt, 27,3 x 21,9 cm, Amsterdam, Van Gogh Museum,.

87 Brief 216/186, Den Haag, 10.4.1882, an Theo, zitiert nach Erpel 1965, Bd. 1, S. 341-342, S. $341 \mathrm{f}$.

88 Brief 307/R20, Den Haag, 4.2.1883, an van Rappard, zitiert nach Erpel 1968, Bd. 5, S. 152-157, S. 154.

89 Brief 216/186, Den Haag, 10.4.1882, an Theo, zitiert nach Erpel 1965, Bd. 1, S. 341-342, S. 341 .

90 Vgl. Brief 245/213, Den Haag, 6. u. 7.7.1882, an Theo, zitiert nach Erpel 1965, Bd. 2, S. 38-40. 
Sohn Willem, dessen Vater van Gogh zwar nicht war, den er aber wie einen Sohn behandelte. ${ }^{91}$

Um die Zeit ihrer Niederkunft hatte van Gogh eine neue, größere Wohnung bezogen, in der er arbeiten und entgegen bürgerlicher Konventionen und zum Verdruss seiner Familie mit Sien und dem neugeborenem Sohn zusammen leben wollte. In diesem häuslichen Rahmen umkreiste van Gogh das Sujet der sich liebevoll dem Baby zuwendenden, stillenden Mutter mit dem Ergebnis einer Serie von mindestens sieben Doppelporträts auf Papier. ${ }^{92}$ Er versuchte sich an Bruststücken im Profil und frontalen Ganzfigurenporträts, wechselte die Technik, beginnend mit dem Bleistift, verwendete später auch Kreide, Aquarell und Tusche, um den Bildgegenstand zu erfassen. Van Gogh konzentrierte sich dabei einzig auf die Figuren und reduzierte die Bildhintergründe zu bloßen Andeutungen von Räumlichkeit oder gleich zu einer unbestimmten monochromen Fläche.

\subsubsection{Weitere Figurenstudien in Den Haag}

Mit der technischen Umsetzung einer mehrfigurigen Komposition ringend, beschäftigte sich van Gogh im Laufe des Jahres weiter intensiv mit Figurenstudien. „Ich glaube bestimmt, was ich jetzt in Arbeit habe, wird Dir gefallen. Du wirst gleich einsehen, wie auch ich, daß ich eine Menge Figurenstudien brauche. Deshalb setze ich alle Kraft daran und arbeite fast täglich mit Modell [...] glaube mir, Komponieren mit Figuren ist nicht so einfach, ich stecke tief in der Arbeit. Es ist wie mit dem Weben, man hat seine ganze Aufmerksamkeit nötig, um die Fäden auseinanderzuhalten, man muß verschiedene Dinge gleichzeitig überwachen und im Auge haben."

91 Sien, nähend, März-April 1883, Bleistift und Kreide, 53 x $37,5 \mathrm{~cm}$, Rotterdam, Museum Boijmans-Van Beuningen, F1025, JH346 u. Sien, Kartoffeln schälend, 1883, Kreide, 60 x 37 cm, Den Haag, Gemeentemuseum, F1053a, JH358. Diese Darstellungen lassen unweigerlich an Vergleiche mit Millets Serie der Feldarbeiter bei den unterschiedlichen Tätigkeiten auf dem Land denken.

92 Sien, das Baby stillend, Bruststück, Sommer 1882, Bleistift auf Papier, 43,5 x $27 \mathrm{~cm}$, Otterlo, Kröller-Müller Museum, F 1062, JH 216; Sien, das Baby stillend, Bruststück, Sommer 1882, Bleistift, Sepia u. Tusche auf Papier, 36,5 x 24 cm, Aufenthaltsort unbekannt, F 1065, JH 217; Sien, das Baby stillend, Ganzkörperporträt, Sommer 1882, Bleistift auf Papier, 49,5 x $27 \mathrm{~cm}$, Otterlo, Kröller-Müller Museum, F 1063, JH 218; Sien, das Baby stillend, Ganzkörperporträt, Sommer 1882, Aquarell u. schwarze Kreide auf Papier, 47,5 x 30 cm, Aufenthaltsort unbekannt, F 1068, JH 219; Frau mit Baby auf ihrem Schoß (Sien?), Bruststück, Sommer 1882, Bleistift u. Aquarell, weiß gehöht mit Ölfarben auf Papier, 40,5 x 24 cm, Otterlo, Kröller-Müller Museum, u. Sien, das Baby stillend, Sommer 1882, Bleistift u. schwarze Kreide auf Papier, 48 x 26 cm, Aufenthaltsort unbekannt, F 1064, JH 221.

93 Brief 271/236, Den Haag, 8.10.1882, an Theo, zitiert nach Erpel 1965, Bd. 2, S. 107-108, S. 107. Bakker 2010, S. 64 verweist auf diesen Brief. 
Noch viel häufiger als Sien zeichnete van Gogh in der Haager Zeit Adrianus Zuyderland, den Bewohner eines örtlichen Altenheimes. ${ }^{94}$ Dutzende Zeichnungen des alten Mannes entstanden ab Mitte September. Van Gogh versuchte sich zunächst an Ganzfigurenstudien in Bleistift, später auch in Kreide, die den alten Mann aus unterschiedlichem Blickwinkel, in wechselnden Posen und mit unterschiedlichen Attributen darstellen. ${ }^{95}$ „Und ich habe bis zum Dunkelwerden mit ihm gearbeitet; er hatte einen großen alten Überrock an, wodurch die Gestalt sonderbar breit erschien [...] Dann habe ich ihn auch noch mal sitzend gezeichnet, mit einem Pfeifchen. Er hat einen netten kahlen Kopf, große - übrigens taube - Ohren und einen weißen Backenbart. ${ }^{" 96}$ Auch bei diesen Studien ist der Einfluss der englischen Illustrationen greifbar.

\subsubsection{Vervielfältigungen durch Lithographien und „Blätter für das Volk“997}

Im November 1882 machte Theo seinen Bruder auf französisches Zwischenträgerpapier zum Anfertigen von Lithographien aufmerksam, das sogleich sein reges Interesse weckte. Begeistert stellte van Gogh fest, „daß eine Zeichnung, die man darauf macht [...], so wie sie ist, ohne Vermittlung eines Zeichners oder Graveurs oder Lithographen auf einen Stein übertragen werden kann oder daß ein Klischee davon gemacht werden kann, von dem sich eine unbeschränkte Anzahl Abdrucke machen lässt. "98 Van Gogh war von der Technik eingenommen, die seine Idee beflügelte, sich wie die von ihm geschätzten englischen Illustratoren mit der Herstellung günstiger Drucke für die breiten Massen verdingen zu können.

Voller Ungeduld wartete er auf weitere Informationen von seinem Bruder und auf eine Lieferung des Papiers. Nachdem er einige Tage nichts von Theo gehört hatte, beschaffte er sich schließlich selbst das entsprechende Material und begann, damit Lithographien mit unterschiedlichen Motiven anzufertigen (vgl. Abb. 33). ${ }^{99}$

94 Zuyderland lebte im Heim für alte Menschen in Om en Bij (Straße in Den Haag), das von der Niederländisch Reformierten Kirche finanziell unterstützt wurde. Vgl. Anmerkungen zu Brief 267/R13, in der Online-Ausgabe der Briefe, abgerufen unter: http://vangoghletters.org/vg/letters/ let267/letter.html\#.

$95 \mathrm{Zu}$ den ersten Zeichnungen dieser Reihe gehört Waisenmann mit Zylinder und gekreuzten Händen, September 1882, Bleistift auf Papier, 49 x 25 cm, Otterlo, Kröller Müller Museum, F 975, JH 235. Des weiteren F 953, JH 234; F 973, JH 236; F 972, JH 237; F 978, JH 238; F 972a, JH 239; F 978a, JH 240 etc.

96 Brief 270/235, Den Haag, 1.10.1882, an Theo, zitiert nach Erpel 1965, Bd. 2, S. 105-107, S. 106.

97 Brief 289/249, Den Haag, 1.12.1882, an Theo, zitiert nach Erpel 1965, Bd. 2, S. 143-147, S. 145.

98 Brief 280/241, Den Haag, 5.11.1882, an Theo, zitiert nach Erpel 1965, Bd. 2, S. 120-125, S.121. Auf diesen Brief verweist Robinson 2013, S. 19.

99 In chronologischer Reihenfolge nach Hulsker 1984, S. 64: Alter Mann (Waisenmann) mit Stock, November 1882, Lithographie, 45,3 x 34,2 cm, Amsterdam, Van Gogh Museum, F 1658, JH 256, basierend auf Zeichnung F 962, JH 212; Sorrow, November 1882, Lithographie, 38,5 x $29 \mathrm{~cm}$, u.a. Amsterdam, Van Gogh Museum, F 1655, JH 259, vgl. Zeichnung F 929, JH. 129; Grabender 
Ideengeber waren stilistisch die angesprochenen Druckgraphiken der englischen Illustratoren, die van Gogh während seiner Zeit in London kennen und schätzen gelernt hatte. ${ }^{100}$

Die Umsetzung der zuerst entstandenen Zeichnungen in Lithographien ist für van Goghs Entwicklung insofern bedeutsam, als dass sie weitere entscheidende Einblicke in seinen Arbeitsprozess und Umgang mit Kopien eröffnet. Für Alter Mann mit Stock wird angenommen, dass van Gogh zunächst eine Zeichnung anfertigte, die er dann als Vorlage für den Druck verwendete. ${ }^{101}$ Unterstützt wird diese Annahme durch das noch schemenhaft erkennbare Gitternetz in der Zeichnung, das vermuten lässt, dass er für die korrekte Darstellung der Proportionen wieder den auf Albrecht Dürer zurückgehenden Perspektivrahmen nutzte, den er seinem Bruder ausführlich in Briefen aus dem Juni und August erläutert hatte. ${ }^{102}$

Obwohl Zeichnung und Lithographie von Alter Mann mit Stock auf den ersten Blick nahezu identisch erscheinen, ist doch ersichtlich, dass van Gogh Details wie den Orden am Revers, die Länge des Stocks sowie die Augen des Mannes, die im Druck nun deutlich geöffnet sind, in der Lithographie verändert hat. ${ }^{103}$ Zudem trägt die druckgraphische Version seine Signatur. Ähnliche Akzentuierungen und Korrekturen sind bei der Lithographie von Sorrow zu erkennen. Van Gogh arbeitete mit den Effekten, die das Medium der Lithographie ihm ermöglichte, um den inhaltlichen Ausdruck zu schärfen. Siens in der vorausgehenden Kohlezeichnung ohnehin schon dürrer Körper erscheint in der überarbeiteten druckgraphischen Version noch wesentlich sehniger und ausgemergelter. ${ }^{104}$

Mann, November 1882, Lithographie, 52 x 37 cm, u.a. Amsterdam, Van Gogh Museum, F 1656, JH 262, Originalzeichnung unbekannt; Alter Mann mit Zylinder, Kaffee trinkend, November 1882, Lithographie, 57 x 37,5 cm, diverse Sammlungen, F 1657, JH 266, vgl. Zeichnungen, F1682, JH 263 u. F 996a, JH 264; Trauernder Alter Mann („At Eternity's Gate“), November 1882, Lithographie, 55,5 x 36,5 cm, diverse Sammlungen, u.a. Amsterdam, Van Gogh Museum, F 1662, JH 268, vgl. dazu Zeichnung F 997, JH 267 u. Arbeiter, auf einem Korb sitzend, Brot schneidend, November 1882, Lithographie, 45 x 29 cm, diverse Sammlungen, u.a. Amsterdam, Van Gogh Museum, F1663, JH 272, korrespondierende Zeichnung unbekannt. Letztendlich umfasst van Goghs Oeuvre jedoch insgesamt nur neun Lithographien und eine Radierung.

100 Die Darstellung des auf einem Stuhl kauernden alten Mannes, der die Hände vor das Gesicht geschlagen hat (Trauernder Alter Mann „At Eternity's Gate“), war beispielsweise direkt von einer Illustration Arthur Hougtons für den Roman Hard Times von Charles Dickens beeinflusst. Vgl. Bailey 1990, S. 124.

101 Alter Mann mit Stock, November 1882, Lithographie, 45,3 x 34,2 cm, Van Gogh Museum, Amsterdam, F 1658, JH 256, basierend auf Zeichnung F 962, JH 212.

102 Brief 235/205, Den Haag, 3.6.1882, an Theo, vgl. Erpel 1965, Bd. 2, S. 15-19 sowie Brief 254/223, Den Haag, 5. oder 6.8.1882, an Theo, vgl. Erpel 1965, Bd. 2, S. 74-75.

103 Alter Mann mit Stock, November 1882, Lithographie, 45,3 x 34,2 cm, Van Gogh Museum, Amsterdam, F 1658, JH 256, basierend auf Zeichnung F 962, JH 212.

104 Die Lithographie ähnelt damit mehr der zweiten und überarbeiteten Zeichnung von Sorrow, F 929a, JH 130, April 1882, schwarze Kreide, 44,5 x 27 cm, London, Sammlung Garman-Ryan. 
Voller Tatendrang sprach er in einem Brief an seinem Bruder davon, 30 Lithographien herstellen zu wollen, „die zusammen eine Art Ganzes bilden“105 sollten, und war überzeugt von der Idee, seriell zu arbeiten: „Ich muß sagen, ich fände es ungeheuer erfreulich, wenn ich dazu kommen könnte, mal eine richtige Serie zu machen. " ${ }^{106}$ Wie van Gogh übergreifende Zusammenhänge, und damit eine inhaltliche Gesamtaussage konzipiert hatte, erläuterte er selbst in einem Brief an seinen Bruder. Das übergreifende Thema dieser Serie sollte die Darstellung von „Arbeitertypen [...], Säer, Grabende, Holzhauer, Pflüger, [eine] Waschfrau, dazwischen auch mal eine Kinderwiege oder ein[...] Waisenmann" ${ }^{107}$ sein. Die Ausführung der Drucke sah van Gogh im Licht einer regelrechten Verpflichtung. „Es geht sogar noch tiefer: ist es Pflicht und Recht, oder ist es verkehrt? Das ist die Frage. Wäre ich wohlhabend, so würde ich ohne Zögern entscheiden, ich würde sagen: los, und zwar schleunigst. " ${ }^{108}$

Van Gogh entwickelte konkrete Pläne für die serielle Herstellung von günstigen Drucken zum Verkauf an einkommensschwache Bevölkerungsgruppen, aber auch als Lehrmittel zur Verwendung in Schulen. ${ }^{109}$ In einem sehr idealistischen Plädoyer unterbreitete er seinem Bruder seine Pläne zur Bildung eines gemeinnützigen Unternehmens zur Herstellung von erschwinglichen Drucken für das Volk:

Ich finde, man müßte folgendes festsetzen: da es nützlich und nötig ist, daß holländische Zeichnungen gemacht, gedruckt und verbreitet werden, die für Arbeiterwohnungen und Bauernhäuser, mit einem Wort, für jeden Werktätigen bestimmt sind, so verpflichten sich einige Leute, für dieses Ziel alles einzusetzen und ihre besten Kräfte einzuspannen. [...] Der Preis der Blätter darf zehn, höchstens fünfzehn Cents nicht übersteigen.

Mit der Herausgabe soll begonnen werden, sobald eine Reihe von dreißig Blättern gezeichnet und gedruckt ist und die damit verbundenen Kosten für Steine, Druckerlohn, Papier abgerechnet sind. Diese dreißig Blätter sollen gleichzeitig erscheinen, aber auch einzeln käuflich sein; sie sollen zusammen ein Ganzes bilden, in Leinen-

Der Übergang von Oberschenkel zu Bauch sowie weitere Körpermerkmale wie Haare und Falten wurden prononciert und verfeinert.

105 Brief 292/242, Den Haag, 10.12.1882, an Theo, zitiert nach Erpel 1965, Bd. 2, S. 125-128, S. 127. Hulsker bezeichnet die danach entstandenen Lithographien als „Serie“. Vgl. Hulsker 1980, S. 66. Van Gogh spricht im Brief auf Niederländisch von "geheel“ = Ganzes.

106 Brief 283/245, Den Haag, 16. oder 17.11.1882, an Theo, zitiert nach Erpel 1965, Bd. 2, S. 132 133, S. 133. Hinweis durch Zimmer 2009, S. 96.

107 Brief 289/249, Den Haag, 1.12.1882, an Theo, zitiert nach Erpel 1965, Bd. 2, S. 143-147, S. 144.

108 Brief 289/249, Den Haag, 1.12.1882, an Theo, zitiert nach Erpel 1965, Bd. 2, S. 143-147, S. 144. Van Gogh war für den letzten zur Unterstreichung der Aussage sogar ins Französische gewechselt: „en avant et plus vite que ça.“

109 Vgl. Brief 292/242, Den Haag, 10.12.1882, an Theo, nach Erpel 1965, Bd. 2, S. 125-128, S. 127 und Anmerkungen zu Brief 292/242, abgerufen unter: http://vangoghletters.org/vg/letters/ let292/letter.html\#. 
umschlag, mit kurzem Text - nicht zu den Bildern, die sprechen für sich selbst -, um kurz und bündig zu erklären, wie und warum sie gemacht worden sind usw. ${ }^{110}$

Letztendlich wurden nur sechs der angestrebten 30 Drucke realisiert. ${ }^{111}$ Mit der Entscheidung, unter anderem Sorrow, Alter Mann mit Stock, und Trauernder Alter Mann („At Eternity’s Gate“) zu lithographieren, hatte van Gogh eine Gruppe inhaltlich sehr kohärenter Sujets ausgewählt. Er erhob damit eine Prostituierte, einen verarmten Pensionär und einfache Arbeiter zu den bildwürdigen Protagonisten seiner zum Verkauf und als Lehrmittel gedachten Serie von Drucken.

Van Goghs Begeisterung für Illustrationen aus The Graphic hielt auch im darauf folgenden Jahr an, und Anfang Januar 1883 gelang es ihm, 21 Ausgaben der Jahrgänge 1870-1880 günstig zu erwerben. ${ }^{12}$ Van Rappard schilderte er, was ihn anhaltend an den Drucken bewegte: „Glaub mir, wenn ich mal nicht recht in Stimmung bin, finde ich in meiner Holzschnittsammlung immer wieder neue Lust zur eigenen Arbeit. Bei diesen Leuten sehe ich eine Energie, eine Willenskraft und einen freien, gesunden, lebhaften Geist, die mich anregen. In ihren Arbeiten ist eine Hoheit, eine Vornehmheit - und wenn sie einen Misthaufen zeichnen. "113 In der Folge entstand eine als „Heads of the People“ betitelte Serie von Porträts, bei der van Gogh erneut Illustrationen aus The Graphic nacheiferte. ${ }^{114}$

England wurde in der ersten Jahreshälfte 1883 zum zentralen Gegenstand von van Goghs Zukunftsträumen. Je mehr Übung er mit den Zeichnungen im Stil der englischen Illustrationen hatte, desto selbstbewusster äußerte er sich auch seinem Bruder gegenüber hinsichtlich seines Vorhabens, als Illustrator zu arbeiten. "Weißt $\mathrm{Du}$, was ich oft überlege? Ob ich nicht in England Beziehungen zum "Graphic“ oder zu den „London News“ kriegen könnte. Ich würde jetzt, wo es mir gut von der Hand geht, so furchtbar gern an einigen größeren Kompositionen weiterarbeiten, die für illustrierte Zeitschriften geeignet wären. [...] Ich würde darauf hinarbeiten, gegen ein monatliches Entgelt fest angestellt zu werden [...]." ${ }^{115}$ Wohl auch aus diesem Grund gab er einigen seiner Zeichnungen englische Titel, in der Hoffnung, dass sie dadurch englischen Herausgebern attraktiver erscheinen würden.

110 Brief 289/249, Den Haag, 1.12.1882, an Theo, zitiert nach Erpel 1965, Bd. 2, S. 143-147, S. 146.

111 Es wird vermutet, dass van Gogh das Arbeiten mit den Lithographien abbrach, weil ihm bei Arbeiter, auf einem Korb sitzend, Brot schneidend, F1663, JH 272, die Tinte verlaufen war. Hulsker 1980, S. 66 führt dafür Brief 290/250, 3.12.1882, an.

112 Vgl. Bailey 1990, S. 126.

113 Brief 276/R16, Den Haag, ca. 29.10.1882, an van Rappard, zitiert nach Erpel 1968, Bd. 5, S. $142-145$, S. 144.

114 „Heads of the People“ ist ein Zitat aus Brief 302/R22, Den Haag, 18.1.1883, an van Rappard, zitiert nach Erpel 1968, Bd. 5, S. 161-162, S. 161. Teil der Serie waren diverse Ausführungen des Fischer mit Sou'Wester: F 1016, JH 304; F 1017, JH 302; F 1015, JH 307; F 1012, JH 308; F 1011, JH 309 u. F 1014, JH 310.

115 Brief 348/288, Den Haag, 3.6.1883, an Theo, zitiert nach Erpel 1965, Bd. 2, S. 257-264, S. 261. 
Doch van Goghs Traum, in England eine Karriere als Illustrator beginnen zu können, erfüllte sich nicht. Nach dem Ende der Beziehung zu Sien verließ er Den Haag voller Bitterkeit und Enttäuschung mit dem Gefühl, gescheitert zu sein. Statt nach London zu ziehen, verschlug es ihn nach Drenthe, eine sehr ländlich-karge und dünn besiedelte Provinz im Norden der Niederlande, wo er malen und zeichnen wollte. Drei Monate hielt er es dort in schwierigen Verhältnissen aus, bevor er widerwillig bei seinen Eltern in Nuenen, im Osten Brabants, Unterschlupf suchte. ${ }^{116}$

\subsubsection{Die Serie der Weber}

Wie auch beim nächsten Beispiel, den zahlreichen Darstellungen der Brabanter Weber, zu erkennen ist, war van Gogh beim wiederholten Anfertigen ein und desselben Motivs entschieden darum bemüht, dieses technisch und zur Verdeutlichung des zu übermittelnden Inhalts gestalterisch zu verbessern. Mindestens zwölf Zeichnungen, sechs Aquarelle und zehn Ölgemälde, entstanden während des Aufenthalts bei seinen Eltern in Nuenen, zwischen Dezember 1883 und August 1884. ${ }^{117}$

Bereits 1876 hatte van Gogh George Eliots Roman Silas Marner. The Weaver of Raveloe gelesen, der sein Interesse am Schicksal der Weber entschieden befördert haben dürfte. Eine weitere wichtige Anregung war Jules Michelets Werk Le Peuple, in dem das handwerkliche Weben gegenüber der industriellen Arbeitsweise gelobt wird. ${ }^{118}$ Während einer Reise durch den Pas-de-Calais im März 1880, bei der van Gogh mehrere Weberdörfer durchquert hatte, zeigte er sich tief betroffen vom Schicksal der dort lebenden und bis zur Erschöpfung arbeitenden Weber. ${ }^{119}$ Im September 1881 hatte er seinem Bruder angekündigt, dass er die Weber gerne zeichnen und auf ihr Schicksal aufmerksam machen wolle. ${ }^{120}$ Dazu sollte es gute dreieinhalb Jahre später mit der Darstellung der unweit des elterlichen Hauses in Nuenen lebenden Weber kommen. Die akribische Auseinandersetzung mit dem Sujet und die Entstehung der zahlreichen Studien wurde wohl neben seinem großen Interesse an den Webern und seiner emotionalen Hingabe zusätzlich durch den Umstand befördert, dass sich van Gogh nach einem Sturz seiner Mutter gezwungen

\footnotetext{
116 Vgl. Bailey 1990, S. 137.

117 F 1110, JH 437; F 1109, JH 439; JH 441 nicht in F; JH 442 nicht in F; F 1120, JH 443; F 1114, JH 444; F 1107, JH 445; F 1125, JH 448; F 1119, JH 449; F 26, JH 450; F 1108, JH 451; F 1118, JH 452; F 1121, JH 453; F 1122, JH 454; F 1123, JH 455; F 1124, JH 456; F 162, JH 457; F 1116, JH 462; F 29, JH 471; F 35, JH 478; F 30, JH 479; F 32, JH 480; F 1134, JH 481; F 1688, JH 482; F 1111, JH 483; F 33, JH 489; F 1116a v, JH 499; F 24, JH 500; F 37, JH 501; F 1115, JH 502; F 27, JH 503.

118 George Eliot, Silas Marner. The Weaver of Raveloe, Edinburgh u. London 1861 und Jules Michelet, Le Peuple, Paris 1846. Auf beide Werke macht Heugten 2015, S. 31 u. 33 aufmerksam.

119 Vgl. Heugten 2015, S. $30 f$.

120 Vgl. Brief 158/136, Cuesmes, 24.9.1880, an Theo, nach Erpel 1965, Bd. 1, 213-218, S. 216. Auf diesen Brief verweist Robinson 2013, S. 43.
} 
sah, mehr Zeit zuhause bei ihr zu verbringen - und folglich in geringerem Maße neue Motive verarbeitete. ${ }^{121}$

Die meisten Ansichten zeigen in Nahsicht einen einzelnen männlichen Weber an einem Webstuhl, der bald nach rechts, bald nach links ausgerichtet ist und sich in einem zumeist nicht näher definierten Raum befindet. Inspiration für diese Form der Komposition könnte van Gogh aus seiner Sammlung von Zeitschriftenillustrationen gewonnen haben, in der mehrere Darstellungen von Webern an ihren Webstühlen zu finden sind. ${ }^{122}$ In einigen Varianten van Goghs ist die rückwärtige Wand durchfenstert und gibt den Blick auf eine Windmühle oder den alten Kirchturm von Nuenen frei, den van Gogh zu dieser Zeit mehrfach in eigenständigen Werken in Öl auf Leinwand und in Zeichnungen festgehalten hat (vgl. Abb. 34). ${ }^{123}$

Van Gogh setzte sich intensiv mit der Haltung des Webers auseinander, der sitzend, stehend oder vornüber gebeugt erscheinen kann. Eine ausschnitthafte und detailreiche Zeichnung eines am Webstuhl sitzenden Webers veranschaulicht, wie van Gogh die Haltung der Figur, insbesondere ihrer Hände, studierte (Abb. 35). ${ }^{124}$ Wie sehr ihn die Mechanik des Webstuhls und dessen malerische Umsetzung umtrieb, geht aus der Korrespondenz mit Anthon van Rappard hervor, an den er im März 1884 schrieb: „Die Studie vom Webstuhl habe ich wirklich von Anfang bis Ende an Ort und Stelle selbst gemacht, und es war nicht leicht - denn man muß so dicht dran sitzen, daß es sehr schwierig war, Maße abzunehmen; die Figur habe ich doch noch hineingezeichnet [...] Als ich meine Zeichnung von der Maschine recht sorgfältig fertig hatte, fand ich es so unausstehlich [...]." ${ }^{125}$

Darüber hinaus zeigt die Durchfensterung der Rückwand in einigen Bildern, dass er mit einer Gegenlichtsituation und der Tiefenstaffelung des Raums expe-

121 Vgl. Brief 423/352, Nuenen, 17.1.1884, an Theo, vgl. Erpel 1965, Bd. 3, S. 134-135.

122 Vgl. Heugten 2015, S. 33. Besonders hervorzuheben ist meiner Ansicht nach Ryckebuschs, Les Industries qui disparaissent, un tisserand, aus L'Illustration, No. 10, September 1881, Holzschnitt, $21,7 \mathrm{~cm} \times 31,1 \mathrm{~cm}$, Van Gogh Museum, Amsterdam.

123 Mit Blick auf eine Windmühle: Weber, 1884, Öl auf Leinwand auf Paneel, 47,5 x $61 \mathrm{~cm}$, Rotterdam, Museum Boijmans-van Beuningen, F 27 JH 503, des Weiteren mit Blick auf einen Kirchturm: Weber, 1884, Öl auf Leinwand auf Karton, 68,5 x 93 cm, München, Neue Pinakothek, F 24 JH 500. Für andere Ansichten des alten Kirchturms siehe beispielsweise Der alte Kirchturm von Nuenen mit Pflüger, Öl auf Leinwand, 34,5 x 42 cm, Otterlo, Kröller-Müller Museum, F34 JH 459.

124 Vgl. Weber, Februar-März 1884, Federzeichnung, Bister und Weißhöhung, 26 x 21 cm, Amsterdam, Van Gogh Museum, F 1122 JH 454. Diese Zeichnung entstand nach der Ölstudie Weber, 1884, Öl auf Leinwand, 48 x 46 cm, Privatbesitz, F 26 JH 450. Die Chronologie der Weberserie ist nicht abschließend ermittelt, aber die These, dass eine zeitliche Einordnung anhand der Entwicklung der Ausarbeitung der Figur und des Webstuhls sowie der abnehmenden Nähe des Betrachters zum Webstuhl abzuleiten sei, erscheint jedoch schlüssig. Diese Faktoren waren bei der Entstehung zweifelsohne besonders relevant und sicherlich auch für die Vielzahl der unterschiedlichen Ausarbeitungen mit verantwortlich. Vgl. Robinson 2013, S. 43f. und die kurze Zusammenfassung der Meinungen Sjaar van Heugtens, Gabriel van den Brinks und Elizabeth Heenks.

125 Brief 437/R 44, Nuenen, ca. 13.3.1884, an van Rappard, zitiert nach Erpel 1968, Bd. 5, S. 215217, S. 215. 
rimentierte. Insbesondere die Darstellung der auf dem Feld arbeitenden Frau vor dem alten Kirchturm in der Blickachse des geöffneten Fensters in der Münchner Variante (Abb. 34) bietet eine mögliche geographische Verortung, aber vor allem auch inhaltliche Interpretationsspielräume, auf die an dieser Stelle nicht vertiefend eingegangen werden kann. Es sei jedoch auf die von Noll vorgeschlagene Interpretation hingewiesen, dass der Kirchturm positiv konnotiert und als Sinnbild von "quelque chose là-haut" zu verstehen sein könnte, ,als ein religiöses Denkmal und Hinweis auf Gott, in dessen Angesicht und unter dessen Schirm und Schutz die alltägliche Arbeit geschieht. " ${ }^{26}$

In anderen Briefen aus dem Frühjahr 1884 an van Rappard wird deutlich, wie sehr van Gogh das Sujet des Webers in Anspruch nahm: „Ich arbeite immer noch an den Webern [...] Wie ich Dir schrieb, habe ich mehrere Studien in Wasserfarben direkt nach der Natur gemacht. Nach denen will ich [...] Aquarelle versuchen, denn ich muß jetzt meistens zu Hause bleiben." ${ }^{227}$ Gut einen Monat später war er noch immer mit den Webern beschäftigt: „In den letzten Wochen habe ich meistens gemalt - an den Webern - und mich ziemlich damit abgeschunden [...]. ${ }^{128}$ Seinen Bruder ließ er wissen, dass er fünf Federzeichnungen von Webern nach Ölstudien fertiggestellt habe. ${ }^{129}$

Nicht unwichtig ist daher hinsichtlich der verwendeten Terminologie van Goghs Brief an seinen Bruder wenige Wochen später: „Wenn ich ein Motiv einmal empfinde - kenne, dann mache ich es meistens in drei oder mehr Fassungen [,variaties“ im niederländisch geschriebenen Brief], ob es sich nun um eine Figur oder um eine Landschaft handelt [...]." 130 Interessant ist dabei der gewählte Begriff „variaties“, der nicht die Anfertigung eines Duplikats, sondern Veränderungen im Vergleich zum Original impliziert. ${ }^{131}$ Dies entspricht durchaus der Arbeitsweise van Goghs bei den Webern: Er fertigte demnach zunächst erste Studien vor der Natur an, um danach weitere Fassungen - im gleichen oder in einem anderen Medium - nach seinen eigenen Studien auszuführen und sich dabei mit inhaltlichen Herausforderungen

126 Inhaltlich bieten sich für die Münchner Variante noch mehr Interpretationsansätze, stellt van Gogh doch in einer Blickachse den Weber, eine auf dem Feld arbeitende Frau und die Kirche dar. Zur Interpretation des Kirchturms vgl. Noll 1994, S. 67

127 Brief 426/R 39, Nuenen, ca. 20.1.1884, an van Rappard, zitiert nach Erpel 1968, Bd. 5, S. $206-$ 207, S. 206. Auf die Briefe 424 und 426 verweist Robinson 2013, S. 43.

128 Brief 431/R 40, Nuenen, 26.2.1884, an van Rappard, zitiert nach Erpel 1968, Bd. 5, S. 207.

129 Brief 430/357, Nuenen, 18.-23.2.1884, an Theo, vgl. Erpel 1965, Bd. 3, S. 141-145.

130 Brief 437/vormals zugehörig zu R37, nun als Bestandteil von R44 erachtet, Nuenen, ca. 13.3.1884, an van Rappard, zitiert nach Erpel 1968, Bd. 5, S. 197-202, S. 200. Auf diesen Brief verweist Robinson 2013, S. 21.

131 Vgl. Robinson 2013, S. 21. Der später von ihm genutzte französische Terminus „répétition“ lässt viel eher an originalgetreue Wiedergaben denken, obgleich er diesen bei Werken verwendet, die sich - wie im Laufe dieses Textes deutlich wird - mehr voneinander unterscheiden als die Bilder der Weber. 
wie der Komplexität des Webstuhls oder gestalterischen Variationen und maltechnischen Fragen auseinanderzusetzen. ${ }^{132}$

Im August 1883 hatte sich van Gogh mit einer Darstellung von Bauern bei der Kartoffelernte zum ersten $\mathrm{Mal}$ an einer großformatigen Komposition in Öl versucht, musste jedoch einsehen, dass dieses Vorhaben seine Fähigkeiten zum damaligen Zeitpunkt überstieg. So blieb es bei einer Studie und einer Skizze in einem Brief an Theo. ${ }^{133}$ Über das Jahr 1884 machte er, auch durch die vielen Darstellungen der Weber, Fortschritte in seiner Maltechnik. Dennoch war ihm weiterhin kein kommerzieller Erfolg beschieden, was ihn zunehmend verzweifeln ließ. ${ }^{134}$

\subsubsection{Durch Wiederholungen zum Ergebnis - Die Kartoffelesser}

Im März 1885 erhielt er von seinem Bruder, der ihn motivieren wollte, nicht aufzugeben, die Anfrage, ob er ein Werk beim Pariser Salon einreichen wolle. Van Gogh hatte in den Wintermonaten davor mehrfach erwähnt, dass er sehr beschäftigt mit dem Malen sowie Zeichnen von Kopfstudien sei, von denen er nach eigener Aussage bis Februar wohl schon jeweils 30 in beiden Techniken angefertigt hatte. ${ }^{135}$ Er war der Meinung, dass keines seiner Werke es wert sei, beim Salon eingereicht zu werden, aber schickte doch einige der Porträtstudien an seinen Bruder mit dem Hinweis, dass diese bald vereinigt in einem größeren Werk kulminieren könnten. ${ }^{136}$ Van Goghs Darstellung von Körpern hatte sich verbessert, nachdem er im April das Buch Causeries sur les artistes de mon temps von Jean Gigoux studiert hatte. Gigoux hatte Eugène Delacroixs Credo zitiert, dass man bei Figuren nicht mit der Kontur, sondern mit „dem Kreis oder ellipseförmigen Grundformen der Massen anfangen"137 solle. Van Gogh folgte diesem Ratschlag und konstatierte, dass er nach zahlreichen Studien zunehmend imstande sei, seinen Figuren Plastizität zu verleihen und sie mit Leben zu erfüllen. ${ }^{138}$

132 Wie Robinson ausführt, zeichnen sich insbesondere zwei spätere Zeichnungen (F 1123, JH 455; F1114 JH 444) inhaltlich dadurch aus, dass van Gogh nun weniger mit der Mechanik des Webstuhls als der Individualisierung des Webers beschäftigt war. Auf der maltechnischen Seite sei eine Verfeinerung der Zeichnungen durch die kombinierte Verwendung von Graphit, Tinte und Wasserfarben augenfällig. Dass van Gogh diese Zeichnungen signierte, könnte dem Umstand geschuldet gewesen sein, dass er sie als würdig für den Verkauf auf dem Kunstmarkt vorgesehen hatte. Vgl. Robinson 2013, S. 44.

133 Bspw. Kartoffelgraber, 1883, Aufenthaltsort unbekannt, F 1034, JH 372 sowie Brief 359/296, Den Haag, 27.6.1883, an Theo. Faksimile aus der Online-Ausgabe der Briefe des Van Gogh Museums, abgerufen unter: http://vangoghletters.org/vg/letters/let357/letter.html.

134 Vgl. Tilborgh 1993, S. 10.

135 Vgl. Brief 483/394, 26.2.1884, an Theo, vgl. Erpel 1965, Bd. 3, S. 235-236, S. 235. Auf diesen Brief verweist Hulsker 1984, S. 136.

136 Vgl. Tilborgh 1993, S. 10, der auch auf Brief 396/485, zw. 9.-23.3.1885, Erpel 1965, Bd. 3, S. 238-239, verweist.

137 Brief 494/401, Nuenen, 18.April 1885, an Theo, zitiert nach Erpel 1965, Bd. 3, S. 248-249, S. 248.

138 Vgl. Bakker 2010, S. 65. 
Bei dem angekündigten großen Werk handelte es sich um die auf zahlreichen vorbereitenden Skizzen und Studien basierenden Kartoffelesser, ein großes Figurenbild mit fünf in ihrer Wohnstube um einen Esstisch gruppierten Bauern (Abb. 36). ${ }^{139}$ Van Gogh hatte gleich nach seiner Ankündigung begonnen, in ersten Skizzen die Anordnung der Bauern um einen Tisch zu erproben und sie Theo in einer kleinen spontanen Ölskizze veranschaulicht. ${ }^{140}$ Drei Tage lang arbeitete er dann an einer großen Studie in Öl, bei der er die Komposition weiterentwickelte und das Thema inhaltlich leicht modifizierte. ${ }^{141}$ Van Gogh war stolz darauf, dass er diese Studie nach dem Leben gemalt und dabei eine strukturierte Komposition ohne gleichzeitigen Verlust von Spontaneität geschaffen hatte. Diesen Fortschritt machte er seinem Bruder in einer weiteren Skizze deutlich und schrieb in dem begleitenden Brief: „Auf dem Punkt, wo ich jetzt bin, glaube ich aber, einen empfundenen Eindruck von dem, was ich sehe, wiedergeben zu können. " ${ }^{42}$ Darüber hinaus fertigte er in seiner Hochstimmung noch eine Lithographie der Studie an, von der er Abzüge an van Rappard und Theo schickte (Abb. 37); letzteren bat er, die Grapik an den Pariser Kunsthändler Portier weiterzuleiten, um das fertige Werk anzukündigen, das zu diesem Zeitpunkt gleichwohl noch gemalt werden musste. ${ }^{143}$

Van Gogh vollendete zwischen dem 13. April und Anfang Mai 1885 die finale Fassung auf einer größeren Leinwand als der der Studie. Den Arbeitsprozess bezeichnete er als „tüchtiges Gefecht [...], aber eines, zu dem [er] große Lust hatte.“"144 Er arbeitete in seinem Atelier und malte "größtenteils aus dem Kopf ${ }^{\star 145}$, nahm gleichzeitig aber auch Korrekturen im Haus der Bauern vor, um die Spontaneität der Studie in der endgültigen Studie zu bewahren. Zu zeigen, dass er nicht nur in der Lage war zu reproduzieren, was er direkt vor sich sah, sondern auch die Früchte seiner Vorstellungskraft, war ihm ein großes Anliegen. ${ }^{146}$ Seinem Bruder erläuterte er: „[B] eim Malen lasse ich meinen eigenen Kopf im Sinn von Gedanken und Ein-

139 Die Kartoffelesser, April-Mai 1885, Öl auf Leinwand, 82 x 114 cm, Amsterdam, Van Gogh Museum, F 82 JH, 764.

140 Bauern bei ihrem Mahl, Kompositionsskizze, März-April 1885, Öl auf Leinwand, 33 x 41 cm, Amsterdam, Van Gogh Museum, F 77r, JH 686.

141 Studie für Kartoffelesser, April 1885, Öl auf Leinwand, 72 x 93 cm, Otterlo, Kröller-Müller Museum, F 78, JH 734. Da seine Arbeiten durch den Tod seines Vaters unterbrochen worden waren, setzte er sein Vorhaben Anfang April fort. Zwischen dem 6. und 13. April entstand die große Studie. Van Gogh fügte eine weitere Person hinzu. Außerdem ließ er die Bauern nicht nur Kartoffeln essen, sondern auch ein Heißgetränk trinken. Da Kaffee zu teuer war, wird es sich wahrscheinlich um einen Chicorée-Aufguss gehandelt haben. Vgl. Tilborgh 1993, S. 12 und dort Fußnote 13.

142 Brief 492/399, Nuenen, 9.4.1885, an Theo, zitiert nach Erpel 1965, Bd. 3, S. 244-245, S. 244. Vgl. für die Skizze (F-, JH 735) das Faksimile aus der Online-Ausgabe der Briefe, abgerufen unter: http://vangoghletters.org/vg/letters/let492/letter.html.

143 Die Kartoffelesser, nach der Studie, April 1885, Lithographie auf Velinpapier, 26,9 x 31,8 cm, Amsterdam, Van Gogh Museum, F 1661, JH 737. Vgl. Tilborgh 1993, S. 11 u. 14.

144 Brief 497/404, Nuenen, 30.4.1885, an Theo, zitiert nach Erpel 1965, Bd. 3, S. 255-259, S. 255.

145 Brief 497/404, Nuenen, 30.4.1885, an Theo, zitiert nach Erpel 1965, Bd. 3, S. 255-259, S. 255.

146 Vgl. Tilborgh 1993, S. 13. 
bildungskraft mitarbeiten, was bei den Studien nicht so sehr der Fall ist, wo kein Schöpfungsvorgang stattfinden darf, wo man vielmehr aus der Wirklichkeit sich Nahrung für seine Einbildungskraft holt, damit die richtig werde." 147 Zufrieden mit dem Ergebnis, bewertete er Die Kartoffelesser als sein erstes durchgestaltetes Gemälde. ${ }^{148}$

Der Entstehungsprozess der Kartoffelesser ist nicht nur bedeutsam für van Goghs künstlerischen Reifeprozess, an dessen vorläufigem Höhepunkt nach diversen Studien - bei denen selbst von ganzen Serien von Studien (er zeichnete bestimmte Köpfe immer wieder!) gesprochen werden könnte - und vorbereitenden Versionen ein vollwertiges „tableau“ stehen sollte, sondern auch anschaulich im Hinblick auf seine Terminologie.

Während er an den einzelnen Varianten arbeitete, schrieb er Theo einen Brief, der bis auf einen Satz in Holländisch, der Sprache, in der die Brüder zu der Zeit korrespondierten, gehalten ist. Für die Erklärung seines Arbeitens mit dem entsprechenden akademischen Vokabular war es ihm jedoch offenbar wichtig, ins Französische zu wechseln: „Jusqu'à présent je n'ai fait que des études - mais - les tableaux vont venir" [Bis jetzt habe ich nur Studien gemacht, aber die Bilder werden kommen]. ${ }^{149}$ Es ist vorauszusetzen, dass van Gogh durch seine kunsthistorische Vorbildung mit den unterschiedlichen Nuancen der Terminologie vertraut war und sich über die Bedeutung des Begriffs „tableau“ für die finale Version eines Gemäldes, oft bedeutungsgleich mit besonders hoher Qualität, bewusst war - dies im Gegensatz zu einer vorbereitenden Version, einer „étude“.

\subsubsection{Entwicklungssprünge in Paris}

Ende November 1885 verließ van Gogh die Niederlande. Von seinem darauf folgenden, nur drei Monate dauernden Aufenthalt in Antwerpen, ist zwar bekannt, dass er zahlreiche Museen besuchte und auch an der Kunstakademie studierte, aber nur wenig ist zur Wiederholungspraxis seiner eigenen Werke oder von denen anderer Künstler überliefert. ${ }^{150}$ Der nächste bedeutsame Schritt sollte für van Gogh der Aufenthalt in Paris bei seinem Bruder werden, wohin er im Februar 1886 reiste.

Van Gogh suchte auch hier seine Studien unter Anleitung voranzubringen und schrieb sich kurz nach seiner Ankunft im Atelier Cormon, an der privaten Kunstakademie des Malers Fernand Cormon (1845-1924), ein. Letztlich schulte van Gogh sich dennoch mehr durch den Besuch von Museen und Kunstausstellungen - er sah

\footnotetext{
147 Brief 496/403, Nuenen, 28.4.1885, an Theo, zitiert nach Erpel 1965, Bd. 3, S. 253-255, S. 254.

148 Van Gogh sprach von „schilderij“ anstelle von „studies“ und kennzeichnete außerdem die Transportkiste, in der er seinem Bruder die Kartoffelesser schickte, mit „V1“ (Vincent 1). Vgl. Brief 501/407, Nuenen, 6.5.1885, an Theo, Erpel 1965, Bd. 3, S. 265-266, S. 265.

149 Brief 496/403, Nuenen, 28.4.1885, an Theo, frz. Fassung zitiert nach Erpel 1965, Bd. 3, S. $253-$ 255, S. 254. Auf diesen Brief sowie die Bedeutung der einzelnen Begriffe und den Zusammenhang mit der Serie der Kartoffelesser weist Robinson 2013, S. 24 u. 28, hin.

150 Vgl. Robinson 2013, S. 23
} 
im Frühling die letzte Ausstellung der Impressionisten und im Sommer möglicherweise die zweite Gruppenausstellung der Indépendents um Georges Seurat (1859_ 1891) und Paul Signac (1863-1935) - sowie im Austausch mit Künstlerkollegen, wie Émile Bernard, John Peter Russell (1858-1930) und Henri de Toulouse-Lautrec (1864-1901). Durch Theos Rolle als Kunsthändler für aufstrebende Künstler bei Goupil hatte er zudem relativ leichten Zugang zur zeitgenössischen Kunst. ${ }^{151}$ Vor seiner Ankunft im Frühjahr 1886 war van Gogh hinsichtlich der neuesten Kunstströmungen ahnungslos und konnte auch dem Impressionismus zunächst nur wenig Positives abgewinnen. Doch innerhalb des ersten Jahres hellte van Gogh, inspiriert von seinem neuen künstlerischen Umfeld, den Malern des „petit boulevard“, seine Farbpalette auf und versuchte sich an unterschiedlichen neuen Maltechniken. Van Gogh erkannte, dass er seine Technik durch den Gedankenaustausch mit anderen Künstlern entwickeln und so seinem Ziel, sich endlich als modern arbeitender Maler zu etablieren, näher kommen konnte. ${ }^{152}$

151 Vgl. Robinson, Steele u.Olmsted 2013, S. 51.

152 Vgl. Homburg 2001, S. 23. Van Gogh verwendet den Terminus „petit boulevard“ in mehreren Briefen aus der ersten Jahreshälfte 1888 (z.B. Brief 584/468, Arles, 10.3.1888, an Theo). Im Zuge seiner neuen Künstlerbekanntschaften schlug er beispielsweise Charles Angrand (1854-1926), John Russell und Frank Boggs (1855-1926) vor Bilder auszutauschen. Angrand schrieb er im Oktober 1886, dass er eine Ansicht der Moulin de la Galette abzugeben habe (Vgl. Robinson 2013, S. 23. Vgl. Brief 570/nicht in Erpel, Paris, 25.10.1886, an Charles Angrand, abgerufen aus dem Online-Archiv der Briefe, unter http://vangoghletters.org/vg/letters/let570/letter.html. Hier jedoch mit dem Hinweis, dass nicht überliefert sei, ob der Austausch jemals stattgefunden habe.). Es existieren mindestens zwei Varianten dieses Sujets, heute in Museumssammlungen in Berlin und Otterlo, bei denen van Gogh eine der großen Windmühlen auf dem Montmartre, dem damals am nördlichen Rand der Stadt gelegenen Hügel, darstellte (Le Moulin de la Galette, Oktober 1886, Öl auf Leinwand, 38,4 x 46 cm, Otterlo, Kröller-Müller Museum, F 227, JH 1170 u. Le Moulin de la Galette, Oktober 1886, Öl auf Leinwand, 38,4 x 46,5 cm, Berlin, Nationalgalerie, F 228, JH 1171. Die Authentizität einer dritten Variante, im Museum Langmatt im schweizerischen Baden, ist umstritten.). Da sich die einzelnen Varianten sehr in Leinwandgröße und kompositorischen Details ähneln, wird spekuliert, ob van Gogh die Komposition abgepaust oder mithilfe einer anderen Reproduktionsmethode übertragen hatte (Vgl. Robinson, Steele u. Olmsted 2013, S. 51 und Fußnote 5. Es sind bisher keine Abpausspuren entdeckt worden. Wie im Text hinsichtlich der Kopie des Titels der Zeitschrift Paris Illustré ausgeführt, praktizierte van Gogh jedoch Abpausmethoden in Paris, was diese Kopiervariante nicht unwahrscheinlich erscheinen lässt.).

Basierend auf der spontaneren und flüchtigeren Malweise des Otterloer Werkes wird angenommen, dass van Gogh diese Version zuerst und in einer einzigen Sitzung an Ort und Stelle gemalt hatte. Der Pinselduktus der Berliner Variante ist hingegen deutlich kontrollierter und reflektierter, was darauf schließen lassen könnte, dass es sich um eine spätere und wohl nicht in situ, sondern um eine im Atelier entstandene Version handelt. Wie bereits in früheren Situationen seiner künstlerischen Laufbahn nutzte van Gogh das wiederholte Malen der Moulin de la Galette zur Verfeinerung seiner Komposition, möglicherweise mit dem Ziel, diese kopierte Fassung zum Austausch mit einem anderen Künstler einzusetzen (Vgl. Robinson, Steele u. Olmsted 2013, S. 51. Es entstanden darüber hinaus noch ca. 20 weitere Ansichten von Windmühlen auf dem Montmartre, die auch als Serie aufgefasst werden könnten.). 
Von nicht zu unterschätzender Bedeutung für van Goghs weitere künstlerische Entwicklung war seine Beschäftigung mit Japan, mit dem er, ohne genauere Kenntnisse des Landes zu besitzen, im Hinblick auf die Kunst und das Verhältnis der Natur bestimmte Vorstellungen verknüpfte. Das Interesse an japanischen Drucken hatte bei van Gogh bereits 1885 in Antwerpen eingesetzt, woraufhin er mit dem Sammeln entsprechender japanischer Druckgrafik, die - wie Utagawa Hiroshiges (1797-1858) Hundert berühmte Ansichten von Edo aus dem Jahre 1857 - häufig in thematisch zusammenhängenden Serien publiziert wurden, begann. ${ }^{153} \mathrm{Wie}$ viele andere Künstler seiner Zeit war auch van Gogh von den leuchtenden Farben und einnehmenden Motiven in ungewohnten Kompositionen fasziniert und hatte zusammen mit seinem Bruder innerhalb kurzer Zeit eine Sammlung von mehreren hundert Einzelblättern aufgebaut, die sogar im Frühjahr 1887 im Café du Tambourin am Boulevard de Clichy, einem beliebten Treffpunkt avantgardistischer Künstler, ausgestellt wurde. Die japanischen Holzschnitte wurden schnell zu einer wichtigen Inspirationsquelle für van Gogh, vergleichbar mit den englischen Drucken zuvor. ${ }^{154}$

Seine praktische Auseinandersetzung mit japanischer Druckgrafik in Paris war vom Übertragen und Kopieren von Motiven, vom Blatt auf die Leinwand, mit entsprechenden Zwischenschritten, geprägt. Zunächst näherte sich van Gogh den Farbholzschnitten tastend, mit einer mehr oder weniger unmittelbaren Kopie, an. Anhand einer entsprechenden Skizze ist zu sehen, dass er den Holzschnitt einer Kurtisane des japanischen Künstlers Keisai Eisen von der Titelseite der Zeitschrift Paris Illustré (Abb. 38), einer Publikation, die bei Theos Firma Goupil erschien, abpauste und mithilfe eines Rasters, das er über die abgepauste Zeichnung legte (Abb. 39), ganz ähnlich wie bereits in seinen Anfängen als Künstler, in ein großes Ölgemälde übertrug (Abb. 40). Die dekorativen Ergänzungen für die Gestaltung des Rahmens (Frosch, Störche, Seerosen etc.) entnahm van Gogh anderen japanischen Farbholzschnitten aus seiner Sammlung. ${ }^{155}$

Bei seiner Japonaiserie Blühender Pflaumenbaum (nach Hiroshige) (Abb. 42) ging van Gogh weiter und übertrug nicht nur den Pflaumenbaum aus Utagawa Hiroshiges Druck Garten der Pflaumenbäume in Kameido (Abb. 41), aus der erwähnten Serie der Hundert Ansichten von Edo, sondern „intensivierte [...] auch die Farben des Drucks und verwandelte dessen glatte Oberfläche in die ausgesprochen unebene Textur dieses Gemäldes. Er umgab die Darstellung mit einem schmalen braunen Rand und legte das Ganze derart über ein Feld aus leuchtendem Orange,

153 Vgl. Childs 2001, S. $121 \mathrm{f}$

154 Vgl. Arnold 1997, S. 155. Der Umfang von van Goghs (Rest-)Sammlung beträgt über 350 Blätter. Vgl. Arnold 1997, S. 159.

155 Abpausskizze der Titelseite von Paris Illustré. Le Japon, Bd. 4, Nr. 45 u. 46, Mai 1886, Bleistift und Tinte auf Papier, 39,4 cm x 26,3 cm, Amsterdam, Van Gogh Museum, nicht im Werkverzeichnis. u. Die Kurtisane (nach Eisen), 1887, Öl auf Leinwand, 105,5 x 60,5 cm, Amsterdam, Van Gogh Museum, F 373, JH 1298. Das korrespondierende Raster ist mithilfe eines Mikroskops weiterhin im Gemälde erkennbar. Vgl. Robinson S. 24 und Fußnote 20. Vgl. Arnold 1997, S. 160 u. Steele, M./Steele E. 2013, S. 173. 
dass der Eindruck eines vertikalen, hängenden Rollbildes entsteht. " ${ }^{156}$ Die vertikal auf den Rändern angebrachten japanischen Schriftzeichen, die van Gogh aus einer anderen Bildquelle entlehnt hatte und über deren Bedeutung er sich wohl nicht im Klaren war, dienten wahrscheinlich zur Verdeutlichung der Szene als eines japanischen Motivs. ${ }^{157}$

Die Übertragung von Hiroshiges Druck Regen über der Ohashi-Brücke, der ebenfalls zu van Goghs Sammlung gehörte, in ein Ölgemälde, zeigt wie genau und doch abweichend van Gogh seine Vorlagen kopierte (Abb. 43 u. 44). ${ }^{158}$ Wie Arnold festhält, ist es beachtlich, „wie van Gogh die Farbflächen des Holzschnittes in strukturierte Malerei umsetzte, wie er das feine Liniengerüst der Regen-Darstellung mit dem Pinsel nachzugestalten imstande war. "159 Ähnlich dem Blühenden Pflaumenbaum fügte van Gogh eine gemalte Umrandung hinzu, doch statt die Signaturen und Bezeichnungen zu verwenden, die Hiroshige in das Bild integriert hatte, erfand er kurzerhand eigene Zeichen. ${ }^{160}$ Den sehr charakteristischen bindfadenartigen Regen Hiroshiges übertrug van Gogh in Saint-Rémy in die Darstellung des ummauerten Feldes im November (Abb. 8) und in Zeichnungen des Sämanns aus dem Frühling 1890 (Abb. 24 u. 25).

Nach diesen drei Übungskopien fertigte van Gogh im anschließenden Winter 1887-88 drei eng miteinander in Beziehung stehende Porträts des Farbenhändlers Julien („Père“) Tanguy (1825-1894) an, die er durch verschiedene formale Mittel japonisierte (Abb. 45 u. 46). ${ }^{161}$ Ab dem Herbst 1886 hatte van Gogh häufiger dessen Farbenladen in der Rue Clauzel, auf dem Weg von Theos Wohnung zu dessen Galerie gelegen, frequentiert, wo er nicht nur Bilder Seurats, Cézannes und Gauguins zu sehen bekam, sondern sehr wahrscheinlich auch auf die meisten Künstler selbst traf. ${ }^{162}$ Tanguy war progressiv gesinnt und mit diversen Malern freundschaftlich verbunden. Er stellte ihre Bilder in seinem Laden aus und versorgte sie mit Mal-

156 Vgl. Childs 2001, S. 122.

157 Blühender Pflaumenbaum (nach Hiroshige), September-Oktober 1887, Öl auf Leinwand, 55 x 46 cm, Amsterdam, Van Gogh Museum, F 371, JH 1296 u. Utagawa Hiroshige (1797-1858), Garten der Pflaumenbäume in Kameido, 11. Monat, aus Hundert berühmte Ansichten von Edo, 1857, Holzschnitt, 36 x 24,1 cm, diverse Quellen, bspw. Amsterdam, Van Gogh Museum. Bei dem japanischen Text handelte es sich um Werbung für ein Bordell. Vgl. Childs 2001, S. 122.

158 Vgl. Utagawa Hiroshige (1797-1858), Regen über der Ohashi-Brücke, 9. Monat, aus Hundert berühmte Ansichten von Edo, 1857, Holzschnitt auf Papier, $22.6 \mathrm{~cm}$ x $33.8 \mathrm{~cm}$, Amsterdam, Van Gogh Museum. In Die Brücke im Regen (nach Hiroshige), September/Oktober 1887, Öl auf Leinwand, 73 x 54 cm, Amsterdam, Van Gogh Museum, F372, JH1297, übertrug er den Farbholzschnitt in ein Ölgemälde.

159 Arnold 1997, S. 160.

160 Vgl. Arnold 1997, S. 160.

161 Père Tanguy, Winter 1887, Bleistiftzeichnung, 21,5 x 13,5 cm, Amsterdam, Van Gogh Museum, F 1412, JH 1350; Père Tanguy, Winter 1887-88, Öl auf Leinwand, 65 x $51 \mathrm{~cm}$, Privatsammlung, F 364, JH 1352 u. Père Tanguy, Winter 1887-88, Öl auf Leinwand, 92 x 75 cm, Paris, Musée Rodin, F 363, JH 1351.

162 Vgl. Childs 2001, S. 124. 
utensilien und so wurde sein Laden ein Treffpunkt vieler Impressionisten und PostImpressionisten. Ende Juli 1887 zeigte Tanguy auch ein Werk von van Gogh im Schaufenster seines Ladens. ${ }^{163}$

Zuerst entstand eine kleine Bleistiftzeichnung in Form eines Bruststücks Tanguys, der von einem stilisierten Holzschnitt des Fuji hinterfangen wird (Abb. 42). ${ }^{164}$ Dann porträtierte van Gogh Tanguy in zwei Ölgemälden sitzend. Die frontale Ansicht der mächtigen Gestalt mit den vor dem Leib verschränkten Händen erinnert an Darstellungen des meditierenden Buddhas. ${ }^{165}$ Jegliche Bezüge zu einem bestimmbaren räumlichen Umfeld sind in der Skizze und den beiden Porträts in Öl durch eine mit japanischen Farbholzschnitten lückenlos bedeckte Wand hinter Tanguy aufgehoben. ${ }^{166}$ Die von van Gogh im Hintergrund der Porträts imaginierten Holzschnitte, die sowohl blühende Natur, den schneebedeckten Fuji als auch Frauen in traditioneller Tracht zeigen (beispielsweise die erwähnte Kurtisane nach Keisai Eisen), verweisen inhaltlich nicht auf Tanguy, sondern vielmehr auf van Goghs ideale Vorstellungen von Japan (vgl. dazu ausführlich Kapitel 5.2. Van Goghs Naturauffassung nach 1880). ${ }^{167}$

Aufgrund des Zusammenlebens mit seinem Bruder und der nicht gegebenen Notwendigkeit sich schriftlich auszutauschen, sind aus der Pariser Zeit wesentlich weniger Briefe als aus den Jahren zuvor und danach erhalten, so dass van Goghs Vorstellungen, beispielsweise zu den Porträts Tanguys, nicht überliefert sind. Dieser Mangel ist besonders bedauerlich, da van Gogh in Paris einer Vielzahl neuer Einflüsse ausgesetzt war, die ihn nicht nur seine Farbpalette aufhellen und neue Techniken erproben, sondern gewiss auch seine künstlerische Haltung hinsichtlich der Fragen nach Eigenständigkeit und Kopien eines Werkes hinterfragen lassen mussten. ${ }^{168}$

Dass sich van Goghs Verständnis dahingehend definitiv weiterentwickelte, wird jedoch anhand der Auseinandersetzung mit japanischen Drucken, die ihm neue künstlerische Gestaltungsmöglichkeiten eröffneten und zu künstlerischen Experimenten anregten, klar ersichtlich. Wie bei den zuvor genannten Beispielen diente van Gogh die Wiederholung des Porträts zur Akzentuierung der für ihn zentralen Bildinhalte. Es würde zu weit gehen, die in Paris im Kontext mit der Auseinandersetzung von japanischen Drucken entstandenen Bilder van Goghs als Serie zusammenzufassen. Grundsätzlich lässt sich aber bei der wiederholten Beschäftigung mit den Farbholzschnitten und dem danach angefertigten Kopien ein progressives und komplexer werdendes Arbeiten konstatieren, dass van Gogh mit einer getreuen Kopie des Zeitschriftentitels beginnen, dann mit Blühender Pflaumenbaum (nach

\footnotetext{
163 Vgl. Thomson 2001, S. 79.

164 Vgl. Arnold 1997, S. 160.

165 Vgl. Robinson 2013, S. 24.

166 Tanguy saß van Gogh in Émile Bernards Atelier Modell. Vgl. Thomson 2001, S. 79. Das zuerst entstandene Porträt ist im Format kleiner und mit gröberen und schnelleren Pinselstrichen gemalt.

167 Vgl. Childs. 2001, S. 126.

168 Vgl. Robinson 2013, S. 24.
} 
Hiroshige) (Abb. 42) seine eigene Interpretation eines bekannten Farbholzschnitts malen ließ, bis er schließlich in den Porträts Père Tanguys dazu kam, ein eigenes Bildsujet zu japonisieren und mit einer von ihm konfigurierten Farbholzschnittcollage zu hinterfangen.

Van Goghs Übertragungen japanischer Farbholzschnitte weisen ein hohes Maß an gestalterischer Reflexion auf und sind laut Childs „weit mehr als bloße Reproduktionen, sie beweisen eindeutig van Goghs Distanz zu seiner exotischen Quelle und offenbaren sich als ästhetische Mischform französischer und japanischer Kunst. "169 Arnold charakterisierte sie „als Vorübungen für Arles“, mit denen er „sich kurz vor seinem Aufbruch in den Süden auf eine neue „Seh- und Schaffensweise [ein]stimmte, über die er dann [...] vom ersten Tag an in Arles verfügte. “170

169 Childs 2001, S. 122.

170 Diese beiden Zitate von Arnold 1997, S. 161. 


\section{Die Entwicklung zur zyklischen Serialität unter Berücksichtigung der Bedeutung der Natur und der Landschaftsmalerei van Goghs}

\subsection{Die Bedeutung von Natur und Landschaft in van Goghs Jugend und vor seiner Entscheidung Künstler zu werden}

Im Februar 1888 hatte van Gogh das Leben in Paris, das er später enttäuscht als „unmenschlich und wider die Natur"1 beschreiben sollte, nach zwei Jahren derart erschöpft, dass er sich nach einer ruhigeren und vor allem ländlichen Umgebung sehnte, um „sich [zu] erholen und [seine] Ruhe und Gleichgewicht wieder[zu]finden“2. Dass er sich wieder für das Leben auf dem Land entschied, hatte biographische Gründe, die schließlich auch maßgeblich seine künstlerische Arbeit im Süden beeinflussen sollten.

Wie er Bernard aus Arles schrieb, fühlte er sich der Natur und dem Leben auf dem Land inmitten von landwirtschaftlicher Arbeit schon seit Kindheitstagen verbunden: „Ich verhehle Dir nicht, daß ich das Landleben durchaus nicht verabscheue, denn ich bin auf dem Lande groß geworden - noch wie früher entzücken mich unvermutet auftauchende Kindheitserinnerungen, Sehnsüchte nach jenem Unendlichen, wofür Sämann und Garbe Sinnbilder sind.“3

Brief 602/480, Arles, 1.5.1888, an Theo, zitiert nach Erpel 1965, Bd. 4, S. 33-36, S. 35. Vgl. für diesen Brief Dorn 1990, S. 26.

2 Brief 577/463, Arles, 21.2.1888, an Theo, zitiert nach Erpel 1965, Bd. 4, S. 5.

3 Brief 628/B 7, Arles, 19.6.1888, an Émile Bernard, zitiert nach Erpel 1968, Bd. 5, S. 257-261, S. 258. 
So persönlich van Goghs Erfahrungen und die Wiedergabe der Landschaft sind, können sie doch gleichzeitig in einen größeren Kontext religiöser, wissenschaftlicher, kulturhistorischer und künstlerischer Ideen hinsichtlich der Rolle der Natur für die Kunst und der sie darstellenden Künstler gesehen werden. Aus diesem Grund gilt es zunächst, seine eigene Wahrnehmung von Natur und Landschaft in den besonders prägenden Jahren der Jugend und zu Anfang seines Erwachsenenalters zu verstehen, um diese dann in den Kontext der ihn bestimmenden künstlerischen und literarischen Einflüsse zu stellen. Dabei nimmt in van Goghs Biographie besonders der Aspekt der Religion einen besonderen Stellenwert ein. ${ }^{4}$

Dass van Gogh auf dem Land, in der Provinz Brabant, nahe der niederländischbelgischen Grenze aufwuchs, übte großen Einfluss auf die Art und Weise aus, wie er die Natur wahrnahm und später die Landschaftsmalerei, besonders von Künstlern, die sich der Darstellung des einfachen ländlichen Lebens annahmen, bewertete. Van Goghs zahlreiche Naturbeschreibungen in seinen Briefen zeugen schon früh von einer erstaunlichen Beobachtungsgabe, dabei großer Präzision und Kenntnis der entsprechenden Fachterminologie. Namen von Bäumen, Sträuchern, Blumen, aber auch Vögeln und Insekten waren ihm in hohem Maße bekannt und tauchen in vielen Briefen an seinen Bruder, an andere Familienmitglieder oder Freunde auf. Wie sehr dieser Themenkomplex van Gogh beschäftigte, zeigt der Umstand, dass in fast einem Drittel aller erhaltenen Briefe das Wort „Natur“ enthalten ist.

Zundert, der Ort, in dem sein Vater Theodorus zunächst eine Pastorenstelle bekleidete, lag in einem eher unterentwickelten und dünn besiedelten Landstrich Brabants. In den 1850er Jahren war aufgrund des sandigen Bodens mit dessen begrenzter Fruchtbarkeit nur die Hälfte des umliegenden Landes landwirtschaftlich bestellt, wobei primär von den örtlich ansässigen Bauern in Subsistenzwirtschaft Kartoffeln und Winterweizen angebaut wurden. Weite Teile der Region bestanden dagegen lediglich aus unkultiviertem Heide- und Marschland, auf dem Schafe weideten und Torf gestochen wurde.

Van Gogh ergründete bereits in jungen Jahren auf langen Spaziergängen die raue Landschaft mit ihrer Vielfalt an Flora und Fauna in dem unberührten Heide- und Marschland und den angrenzenden Nadelwäldern. ${ }^{6}$ Dies ermöglichte ihm einen unmittelbaren Zugang zur Natur, der ihn nicht nur die „Lerchen [... singen hören ließ,] über den schwarzen Äckern mit der jungen grünen Saat, darüber der leuchtend blaue Himmel mit den weißen Wolken“7, sondern ihn derart prägte, dass er

Vgl. Stolwijk 2015, S. 29.

Zahl ermittelt über die Suchfunktion der Online-Ausgabe der Briefe. Vgl. für diesen Hinweis auf die Zählung auch Kendall/van Heugten/Stolwijk 2015, S. 16.

6 Vgl. Chris Stolwijks sehr aufschlussreichen Aufsatz zu van Goghs Naturempfinden im 2003 erschienenen Katalog zur Ausstellung „Van Gogh’s Musée Imaginaire“, vgl. hier Stolwijk 2003, S. 25 sowie eine aktualisierte Fassung im Katalog zur Ausstellung „Van Gogh and Nature“, vgl. hier Stolwijk 2015, S. 36.

7 Brief 102/85, Dordrecht, 7.u. 8.2.1877, an Theo, zitiert nach Erpel 1965, Bd. 1, S. 99-102, S. 101. Auf diesen Brief verweist auch Stolwijk 2003, S. 25. 
trotz der Verlockungen der großen Städte letztendlich immer wieder auf das Land zurückkehren sollte.

Konnte van Gogh als junger Mann London noch eine „eigenartige Schönheit“8 zugestehen und gar erklären, dass er „London [liebe], obwohl [... er] ein Kind der Kiefernwälder"9 sei, wies er seinen Bruder doch mit kritischem Blick gleichzeitig auch auf die „armseligen Gegenden mit ihren lauten, belebten Straßen “10 hin. Van Gogh ging in seiner Londoner Zeit regelmäßig in den bis heute außerordentlich grünen und belaubten süd-westlichen Vororten spazieren, um sich, so oft es ging, in der Natur aufzuhalten: „Ich gehe hier so viel wie möglich spazieren [...] Es ist hier wunderbar schön (obwohl es in der Stadt ist). In allen Gärten blühen Flieder und Rotdorn und Goldregen, und die Kastanien sind herrlich." ${ }^{11}$

Ein ähnliches Gefühl der Freude, auch im Zentrum der Stadt das Gefühl von Natur zu erleben, wurde zwei Jahre später durch die träumerischen Beschreibungen eines frühmorgendlichen Besuches von Hyde Park deutlich: „An jenem Morgen bin ich zeitig hier fortgegangen, um vier, die Nacht war schön hier im Park mit den dunklen Ulmenalleen und der nassen Straße und dem grauen Regenhimmel darüber, und in der Ferne gewitterte es. Als es hell wurde, war ich im Hyde Park, dort fielen schon die Blätter von den Bäumen, und der wilde Wein war so wunderbar rot an den Häusern, und es nebelte." ${ }^{2}$

Seinen Eltern schrieb er im Oktober 1883 folgerichtig, dass „man auf dem Lande mehr Aussicht [hat], einem vernünftigen Menschen zu begegnen, als in der Stadt“, in der man sich in einem "Dunkel von Unbildung und Dummheit und Schlechtigkeit“ bewege. Für van Gogh war „ein einfacher Bauer, der arbeite und bei seiner Arbeit denke, [...] der gebildete Mann. "13 Der Gegensatz zwischen krank machendem Stadt- und gesundem Landleben war in der zweiten Hälfte des 19. Jahrhunderts im Zuge der rasant voranschreitenden Industrialisierung und Urbanisierung ein aktueller Topos, über den van Gogh durch Werke von Autoren wie Émile Zola (1840-1902) und Charles Dickens (1812-1870) mehr erfuhr. Alfred Sensiers (1815-1877) Künstlermonographie La vie et l'oeuvre de J.-F. Millet, die van Gogh bald nach ihrem Erscheinen 1881 gelesen hatte, vermittelte ihm ein idealisiertes Bild vom Leben des Künstlers inmitten der Landbevölkerung. ${ }^{14}$

Van Goghs Wissen stützte sich jedoch mitnichten nur auf literarische Quellen. Nachdem er selbst immer wieder für längere Zeiträume in Metropolen, wie London, Paris und Amsterdam gelebt hatte, kannte er aus eigenen Beobachtungen

8 Brief 93/76, Isleworth, 7. u. 8.10.1876, an Theo, zitiert nach Erpel 1965, Bd. 1, S. 78-81, S. 80. Auf diesen Brief verweist Stolwijk 2003, S. 26.

9 Brief 90/82a, Isleworth, zw. 2./8.9.1876, an Theo, zitiert nach Erpel 1965, Bd. 1, S. 88-96, S. 91.

10 Brief 93/76, Isleworth, 7. u. 8.10.1876, an Theo, zitiert nach Erpel 1965, Bd. 1, S. 78-81, S. 80.

11 Brief 22/16, London, 30.4.1874, an Theo, ztiert nach Erpel 1965, Bd. 1, S. 22.

12 Brief 92/75, Isleworth, 3.10.1876, an Theo, zitiert nach Erpel 1965, Bd. 1, S. 76-78, S. 77.

13 Beide Zitate aus Brief 399/334, Nieuw-Amsterdam, ca. 26.10.1883, an seine Eltern, zitiert nach Erpel 1968, Bd. 5, S. 14-15. Auf diesen Brief verweist Stolwijk 2003, S. 26.

14 Vgl. Stolwijk 2003, S. 26 u. Greer 2003, S. 72. 
den allmählichen gesellschaftlichen Wandel vom einstmals agrarisch dominierten traditionellen Landleben hin zum Aufschwung der Städte im Zuge des beginnenden Industriezeitalters mit seinen expandierenden Großstädten, den wachsenden Fabrikanlagen und dem sich ausbreitenden öffentlichen Nah- und Fernverkehr, in dem die Natur und der Kreislauf der Jahreszeiten eine zunehmend untergeordnete Rolle spielen sollten. ${ }^{15}$

Nachdem van Gogh für sich die Erfahrung gemacht hatte, dass sich das umtriebige Paris nicht gut auf sein Gemüt und seinen Gesundheitszustand auswirkte, was ihn daher zur Reise in den ländlichen Süden bewog, resümierte er im Januar 1890 in einem Brief an seine Schwester auch allgemein die Konsequenzen des urbanen Lebens für das künstlerische Schaffen:

Unterhältst Du Dich gut in Paris? Ich könnte mir sehr gut denken, daß Du den Eindruck hättest, die Stadt sei zu groß, zu verworren. Leuten wie uns, die mehr an einfachere Umgebungen gewöhnt sind, geht das gegen den Strich. [...] Ich fürchte mich ein bißchen vor der Wirkung, die Paris auf mich haben wird [...] weil ein längerer Aufenthalt dort Unruhe und Aufregung mit sich bringt. Es ist richtig, wenn man den Malern sagt: Es arbeitet sich besser auf dem Lande, alles spricht dort klarer und deutlicher, alles bleibt dort beim alten, alles wird klar. Und wenn man in einer großen Stadt müde und erschöpft ist, versteht man nichts mehr und fühlt sich wie verloren. ${ }^{16}$

Lange vor seiner Entscheidung, als Künstler zu arbeiten, hatte van Gogh Anfang der 1870er Jahre Bleistiftskizzen der Landschaft um Den Haag angefertigt, die bei aller Einfachheit der kompositorischen Anlage und der zeichnerischen Ausführung bereits seine Fähigkeit erkennen lassen, eine bestimmte Stelle in der Landschaft akkurat zu erfassen und wiederzugeben. ${ }^{17}$ Wenige Jahre später, durch seine Arbeit im Kunsthandel in künstlerischen Fragen weiter geschult, hatte van Gogh verstanden, dass das Erfahren und Beobachten von Natur „der richtige Weg [ist], die Kunst immer besser zu begreifen. Die Maler begreifen die Natur und lieben sie und lehren uns sehen. "18

Infolgedessen wird schon sehr früh in van Goghs künstlerischerer Entwicklung die Bedeutung der Natur für seine Bilder fassbar, beispielsweise bei seinen ersten Übungen als Künstler, als er sich im Spätsommer 1880 an der Übertragung der Feldarbeiten nach Jean-François Millet versuchte. ${ }^{19}$ Van Gogh hatte eine Auswahl

15 Vgl. Kendall/van Heugten/Stolwijk 2015, S. 17.

16 Brief 841/W 19, Saint-Rémy, 20.1.1890, an Willemien, zitiert nach Erpel 1968, Bd. 5, S. 75-77, S. 75. Vgl. für den Brief in diesem Kontext auch Stolwijk 2015, S. 27.

17 Bspw. Graben, 1872-1873, Bleistift u. Tinte auf Papier, 24,8 x 18,3 cm, Amsterdam, Van Gogh Museum, F XV, JH juv.

18 Brief 17/13, London, Anfang Januar 1875, an Theo, zitiert nach Erpel 1965, Bd. 1, S. 19-21, S. 20. Auf diesen Brief verweist Stolwijk 2003, S. 26.

19 Vgl. Brief 157/135, Cuesmes, 7.9.1880, an Theo, nach Erpel 1965, Bd. 1, S. 211-213, S. 211. Er machte Skizzen nach Millet. 
von Millets Werken wohl im Sommer 1875 in der Ausstellung der Sammlung Émile Gavets gesehen, bevor diese in Paris bei einer Auktion veräußert wurde. Van Gogh pries die Ausstellung in einem Brief an seinen Bruder: „Es ist hier eine Versteigerung Milletscher Zeichnungen gewesen [...]. Als ich in den Saal des Hôtel Drouot kam, wo sie ausgestellt waren, hatte ich so ein Gefühl wie: Ziehe die Schuhe aus von deinen Füßen, denn die Stätte, da du stehest, ist heiliges Land. “20

Dieser ehrfürchtige Verweis van Goghs auf seine Empfindung, die er beim Anblick von Millets Werken spürte, leitet zu der Frage nach der religiösen Symbolik im Hinblick auf seine Wahrnehmung der Natur über. Bei einer Betrachtung von van Goghs Familie, die von Geistlichen und Kunsthändlern bestimmt war, wird schnell ersichtlich, dass er in einem gehobenen gesellschaftlichen Umfeld von Kunst und Kirche aufwuchs, das intellektuell entsprechend stimulierend war. Bei der Entscheidung für die Arbeit im Kunsthandel war van Gogh zunächst dreien seiner Onkel gefolgt. Sein Vater hingegen war, wie auch bereits sein Großvater, Pastor der niederländisch-reformierten Kirche. Für eine gewisse Zeit verfolgte er schließlich mit großer Leidenschaft das Ziel, seinerseits Theologie zu studieren und seinem Vater nachzufolgen.

Die Sozialisierung van Goghs geschah in einem Spannungsfeld theologischer Einflüsse, unter denen die modernen protestantischen Strömungen, die er innerhalb seiner Familie kennenlernte, großen Anteil hatten. Im Hinblick auf die prägenden Faktoren seiner Kindheit ist es wichtig, zu verstehen, dass in den Niederlanden im 19. Jahrhundert Theologen eine dominierende Rolle in der Gesellschaft spielten, und zwar nicht nur als Geistliche, sondern auch als Politiker, Erzieher, Dichter, Schriftsteller und Literatur- und Kunstkritiker. Dies führte noch in van Goghs Kindheit und Jugend zu einer Kultur, die maßgeblich von der konservativen Sichtweise der Reformierten Kirche geprägt war. Für diese Form der Dominanz durch den Klerus hat sich in der Literatur der Terminus „dominocratie“ eingebürgert. ${ }^{21}$

Van Goghs Vater war Mitglied der Groninger Schule, einer Gruppe von Theologen, die sich um Petrus Hofstede de Groot (1802-1886), seit 1829 Theologieprofessor an der Universität von Groningen, gebildet hatte. ${ }^{22}$ Ihre Mitglieder konzentrierten sich auf den Dienst an ihren Mitmenschen und lebten entsprechend der Lehre, dass Gott in allen Menschen und in der Natur zu finden sei. Gemäßigt und undogmatisch in ihrer Haltung, glaubten sie, dass religiöse Erkenntnis durch eine Vielzahl unterschiedlicher Wege - das Studium der Bibel, aber auch nicht-religiöser Texte und Bilder - erreicht werden könne. Es war ebenso eine weit verbreitete Auffassung innerhalb der Anhänger der Groninger Schule, dass Kunst im visuellen wie auch im übertragenen Sinne religiöse Inhalte vermitteln könne. Dieser Aspekt hatte,

20 Brief 36/29, Paris, 29.6.1875, an Theo, Erpel 1965, Bd. 1, S. 32-33. Auf diesen Brief verweist Ives 2005, S. 6.

21 Greer 2003, S. 67 u. Kōdera 1990, S. 15f. u. Fußnote 26. Der Begriff „dominocratie“ wurde von Gerard Brom in seiner Monographie De dominee in onze Literatur, Nijmegen-Utrecht 1924, geprägt.

22 Inhaltlich zeigten sich dabei Parallelen zu Friedrich Schleiermachers Vermittlungstheologie. 
neben der Forderung und dem Verlangen, es Christus in seiner Demut und seiner Hingabe für andere gleichzutun, einen sehr großen Einfluss auf van Gogh. ${ }^{23}$

Die Groninger Schule, und hier insbesondere die undogmatischen Schriften des niederländischen Pastors und Dichters Eliza Laurillard (1830-1908), den van Gogh in Amsterdam selbst predigen hörte, sind folglich hinsichtlich der Naturwahrnehmung besonders bedeutsam. Theo berichtete er von Laurillards Predigt über „Das Ährenraufen am Sabbat" (Matthäus 12, 1, Markus 2, 23 und Lukas 6, 1), die mit der Auslegung des Gleichnisses vom Sämann auf ihn einen „großen Eindruck“ ${ }^{24}$ gemacht hatte. Weiter lobte er Laurillard dafür, dass er in seinen Predigten „malt [...] und seine Arbeit ist gleichzeitig hohe und edle Kunst. Er hat das Gefühl eines Künstlers im wahren Sinne des Worts “25. Dieser Vergleich ist insofern interessant, als dass van Gogh eine Verbindung zwischen der Vermittlung von Gottes Wort und der Kunst herstellt und Laurillard damit zu einer Art Künstler-Prediger erhebt. Kōdera nennt van Gogh in der Folge „Prediger-Künstler“ ${ }^{26}$

Laurillards Geen dag zonder God (dt. „Kein Tag ohne Gott"), zuerst erschienen 1869, war im ausgehenden 19. Jahrhundert ein ausgesprochen populäres Buch, und es ist nicht unwahrscheinlich, dass auch van Gogh es gelesen hat. Laurillard erklärt dabei in einfacher und verständlicher Sprache verschiedene Bibelstellen. Der Titel des Buchs zeigt dazu passend Illustrationen einiger Themen aus Laurillards Predigten und dabei an prominentester Stelle den von van Gogh vielfach dargestellten Sämann (Abb. 47) ${ }^{27}$ Ein weiteres wichtiges Werk Laurillards, Met Jezus in de natuur (dt. „Mit Jesus in der Natur"), gibt weitere Aufschlüsse über die Wahrnehmung von Natur und, im Zusammenhang damit, wie zu van Goghs Zeit Bibeltexte von einem der führenden Theologen ausgelegt wurden. ${ }^{28}$

Genauso hatten die Publikationen des englischen Predigers Charles Haddon Spurgeon (1834-1892) Einfluss auf van Goghs Naturwahrnehmung. Spurgeon, der insbesondere in England sehr populär war, soll van Gogh vor allem während seiner Zeit in Dordrecht intensiv studiert haben. ${ }^{29}$ Die erst nach Spurgeons Tod veröffentlichte Sammlung seiner Predigten, Teachings of nature in the Kingdom of Grace, wies mit Kapiteln, wie "Spring follows Winter“", „The Ploughman overtaking the reaper“, „A Place called Gethsemane“, „Christ in the Garden“, „Supposing Him to be the Gar-

23 Vgl. Greer 2003, S. 64 u. 67.

24 Brief 120/101, Amsterdam, 12.6.1877, an Theo, zitiert nach Erpel 1965, Bd. 1, S. 123-126, S. 125 für Laurillard. Vgl. dort auch Anmerkung 15 aus der Online-Ausgabe zu der Bibelstelle „Jesus ging durch die Saat", abgerufen unter http://vangoghletters.org/vg/letters/let120/letter.html.

25 Brief 121/101a, Amsterdam, 9.7.1877, an Theo, zitiert nach Erpel 1965, Bd. 1, S. 126-128, S. 127. Vgl. Kōdera 1990, S. 23 für diesen Brief.

26 Vgl. Kōdera 1990, S. 24, hier im Original: „preacher-artist“.

27 Vgl. Kōdera 1990, S. 22 u. Abb. 47, die den Umschlag der 1876 erschienenen dritten Ausgabe zeigt.

28 Vgl. Kōdera 1990, S. 22.

29 Vgl. Anmerkung 2 zu Brief 104/87, Dordrecht, 28.2.1877, an Theo, abgerufen aus der OnlineAusgabe der Briefe, unter http://vangoghletters.org/vg/letters/let104/letter.html für den Hinweis auf Spurgeon. 
dener“ und „Harvest Time“ deutliche Parallelen zu den Themen auf, die van Gogh später in seinen Bildern immer wieder beschäftigen sollten. Hinsichtlich der Frage nach der Natursymbolik fällt vornehmlich die Predigt „Harvest time, is it not wheatharvest to-day“ auf. Darin schrieb Spurgeon bezugnehmend auf 1 Samuel 12, 17:

Let us not be forgetful of times and seasons. There is much to be learned from them, and I would refresh your memories by a harvest field. What a wondrous temple this world is; for in truth it is a temple of God's building wherein men ought to worship Him. What a wondrous temple it is to a mind spiritually enlightened, which can bring to bear upon it the resources of intellect, and the illuminations of God's Holy Spirit! There is not a single flower in it that does not teach us a lesson, there is not a single wave, or blast of thunder, that has not some lesson to teach to us, the sons of men. This world is a great temple, and as, if you walk in an Egyptian temple, you know that every mark and every figure in the temple has a meaning, so when you walk this world you must believe that everything about you has a meaning. ${ }^{30}$

Diese Art des Aufladens der Natur mit symbolischen Inhalten zeigte sich bei van Gogh danach immer wieder in seinen Briefen. Ein frühes Beispiel ist noch vor seiner Zeit als Künstler fassbar. Wie Spurgeon in seiner Predigt mit seinem Verweis auf den göttlichen „blast of thunder“ berichtete er Theo aus dem Borinage, als er dort als Prediger arbeitete, von einem Gewitter, das er sogleich mit der Erzählung der Sintflut im Buch Genesis verglich:

Bei diesem Gewitter in der stockfinsteren Nacht, wenn beim Licht der Blitze ab und zu alles einen Augenblick sichtbar wurde, ergab sich eine merkwürdig starke Wirkung: ganz nahe die großen, düsteren Gebäude der Grube Marcasse, für sich und abgesondert auf freiem Felde, die einen in dieser Nacht wahrlich an den Koloß der Arche Noah denken ließen, wie die bei dem gewaltigen Platzregen und in der Finsternis der Sintflut sich beim Licht des Blitzstrahls ausgenommen haben mag. Dieses Gewitter habe ich zum Anlaß genommen, heute abend in der Bibelstunde einen Schiffbruch zu beschreiben. ${ }^{31}$

30 Spurgeon 1896, S. 222 (digitalisierte Ausgabe). Bei 1 Samuel 12, 17 heißt es: „Ist jetzt nicht gerade Weizenernte? Ich werde zum HERRN rufen und er wird Gewitter und Regen schicken. So werdet ihr erkennen und einsehen, wie groß euer Unrecht in den Augen des HERRN ist, das ihr dadurch begangen habt, dass ihr für euch einen König verlangt habt." Vgl. auch Kōdera 1990, S. 22f. für den Verweis und den zitierten Auszug aus der Predigt.

31 Brief 152/130, Wasmes, ca. 19.6.1879, an Theo, zitiert nach Erpel 1965, Bd. 1, S. 194-197, S. 195. Parallelen werden auch zu Lukas 17, 24-27 über das Kommen des Menschensohnes deutlich: „Denn wie der Blitz von einem Ende des Himmels bis zum andern leuchtet, so wird der Menschensohn an seinem Tag erscheinen. Vorher aber muss er vieles erleiden und von dieser Generation verworfen werden. Und wie es in den Tagen des Noach war, so wird es auch in den Tagen des Menschensohnes sein. Die Menschen aßen und tranken und heirateten bis zu dem Tag, an dem Noach in die Arche ging; dann kam die Flut und vernichtete alle."Vgl. auch Anmerkung 
Wie Kōdera eingehend erläutert, war in der Mitte des 19. Jahrhunderts die religiöse Wahrnehmung der Natur in den Niederlanden weiterhin sehr präsent. ${ }^{32}$ Dies ist nicht unwesentlich durch den Einfluss von Predigern wie Laurillard zu erklären. Trotz eines grundsätzlichen Rückgangs bei der Zahl der Veröffentlichungen und der Popularität von emblematischen Büchern während des 18. und 19. Jahrhunderts wurde die emblematische Tradition durch die Schriften der Prediger aufrechterhalten (vgl. auch Kapitel 6.1.). ${ }^{33}$

Als van Gogh sich 1880 entschloss, Künstler zu werden, war die Gesellschaft bereits in einem großen Umbruch zur Moderne begriffen, der den Rückzug der alten „dominocratie“ zur Folge hatte, den auch Prediger wie Laurillard oder Modernisierer, wie van Goghs Onkel Stricker, nicht aufhalten konnten. In dieser Zeit der Umwälzung begannen die Geistlichen ihre vorherrschende soziale und intellektuelle Position nach und nach zu verlieren. In der Folge verschob sich in den Niederlanden der Fokus weg von der deutschen Kultur, die wenige Jahrzehnte zuvor noch maßgebliche Bedeutung für die Theologen hatte, hin zu Frankreich. Dieser Kontrast zwischen den zwei kulturellen Polen sollte auch für die weitere künstlerische Entwicklung van Goghs von großer Relevanz bleiben. ${ }^{34}$

\subsection{Van Goghs Naturauffassung nach 1880}

Bereits zu einer Zeit, als van Gogh noch das Ziel verfolgte, Geistlicher zu werden, lässt sich bei ihm die Tendenz erkennen, religiöse Themen mit der Natur zu verknüpfen. Diese Praxis nahm nach seiner Entscheidung, Künstler zu werden, deutlich zu, und führte dazu, dass er religiöse Aspekte und Naturphänomene miteinander verknüpfte. Aus diesem Grunde schrieb er beispielsweise aus Den Haag im November 1882 an Theo als Antwort auf dessen Beschreibung vom Montmartre:

Deinen Montmartre finde ich prachtvoll, und die Gemütsbewegung, die ihn bei Dir zuwege gebracht hat, würde ich sicher geteilt haben; mir scheint übrigens, auch Jules Dupré und Daubigny haben solche Gedanken in ihrem Werk oft anregen wollen. Solche Stimmungen haben manchmal etwas Unbe-

8 zu Brief 152/130 der Online-Ausgabe, abgerufen unter http://vangoghletters.org/vg/letters/ let152/letter.html. Vgl. für den Hinweis auf den Brief auch Kōdera 1990, S. 23.

32 Bei dieser Wahrnehmung handelt es sich um die der Physikotheologie, die im 18. Jahrhundert ihre weiteste Verbreitung erlebte, aber noch bis in das biblische Naturverständnis (s. z.B. Psalm 19, 2-4 zu „Gottes Herrlichkeit in seiner Schöpfung und in seinem Gesetz“ sowie Römer 1, 20 „Denn sein unsichtbares Wesen - das ist seine ewige Kraft und Gottheit - wird seit der Schöpfung der Welt, wenn man es wahrnimmt, ersehen an seinen Werken, sodass sie keine Entschuldigung haben.") zurückreicht. Ich danke Professor Thomas Noll für diesen Hinweis. Vgl. zur Physikotheologie u.a. besonders Wolfgang Philipp: Das Werden der Aufklärung in theologiegeschichtlicher Sicht (Forschungen zur systematischen Theologie und Religionsphilosophie, Bd. 3), Göttingen 1957.

33 Vgl. Kōdera 1990, S. 17.

34 Vgl. Kōdera 1990, S. 26. 
schreibliches, es ist als spräche die ganze Natur, und wenn man nach Hause geht, hat man ein Gefühl, als hätte man ein Buch von Victor Hugo zu Ende gelesen. Ich für mein Teil kann nicht begreifen, daß nicht jeder Mensch es sieht und fühlt; die Natur oder Gott tut es doch für jeden, der Augen und Ohren hat und ein Herz zum Verstehen. Mir scheint, ein Maler ist darum glücklich, weil er in Harmonie mit der Natur ist, sobald er einigermaßen wiedergeben kann, was er sieht. ${ }^{35}$

Laut van Gogh empfindet der sensible Maler die Natur, die von Gott kündet und ist glücklich, wenn er vermitteln kann, was er wahrnimmt. Der Betrachter bekommt dadurch die Augen für die Herrlichkeit von Gottes Schöpfung geöffnet. Gleichzeitig fällt bei diesem Brief auf, dass Gott von van Gogh noch erwähnt wird. Auch sein Vokabular ist noch weiter dem eines Predigers sehr ähnlich, klingt doch seine Aussage über die Menschen, die nicht in der Lage seien, die Natur wahrzunehmen, so als sei sie aus Deuteronomium 29, 3 abgeleitet, wo es heißt: „Aber einen Verstand, der wirklich erkennt, Augen, die wirklich sehen, und Ohren, die wirklich hören, hat der HERR euch bis zum heutigen Tag nicht gegeben. “36

Daneben findet sich bei van Gogh eine enge Verknüpfung von Natur und Gefühl; sie zeigt sich bei einer 1882 entstandenen Zeichnung von mächtigen Baumwurzeln im Sandboden (Abb. 48), in die er „den Kampf des Lebens einschreiben [... wollte], der nichts anderes als sein eigener Lebenskampf war." ${ }^{37}$ Die Erklärung zu dieser Zeichnung kann wie eine Anleitung zur Deutung seiner weiteren Landschaftsmalerei gelesen werden:

Die andere [Zeichnung], ,Les racines', sind ein paar Baumwurzeln im Sandboden. Ich habe versucht, in die Landschaft dasselbe Gefühl zu legen wie in die Figur. Das gleichsam krampfhafte und leidenschaftliche Sich-fest-Wurzeln in der Erde und das Halb-losgerissen-Sein durch die Stürme. Ich wollte sowohl in dieser weißen, schlanken Frauengestalt wie in diesen schwarzen, knorrigen Wurzeln mit ihren Knorzen etwas vom Kampf des Lebens ausdrücken. Oder richtiger: weil ich bestrebt war, der Natur, die ich vor mir hatte, treu zu sein, ohne dabei zu philosophieren, ist fast unwillkürlich in beiden Fällen etwas von diesem großen Kampf hineingekommen. Wenigstens schien es mir, als wäre ein einziges Gefühl darin, aber ich kann irren, na, Du mußt eben selber sehen. ${ }^{38}$

35 Brief 288/248, Den Haag, 26. u. 27.11.1882, an Theo, zitiert nach Erpel 1965, Bd. 2, S. 138 143, S. 141. Auf diesen Brief weist Kōdera 1990, Fußnote 64, hin.

36 Vgl. auch für den Verweis auf die Bibelstelle in Deuteronomium Anmerkung 20 in der OnlineAusgabe dieses Briefs, abgerufen unter http://vangoghletters.org/vg/letters/let288/letter.html\#. Wobei hier fälschlicherweise auf Deut. 29, 4 verwiesen wird.

37 Bürgi/Zimmer/Feilchenfeldt 2009, S. 28.

38 Brief 222/195, Den Haag, 1.5.1882, an Theo, zitiert nach Erpel 1965, Bd. 1, S. 368-371, S. 368f. Bei dem angesprochenen Werk handelte es sich um Les Racines, April-Mai 1882, Blei- 
Deutlich wird, dass der Bildgegenstand sinnbildlich verstanden wird und entsprechend dargestellt werden soll und insbesondere, dass van Gogh eine Beziehung zwischen der Natur und dem Menschen herstellte. Wie bei Les Racines anthropomorphisiert van Gogh die Natur immer wieder, spricht beispielsweise von „einem

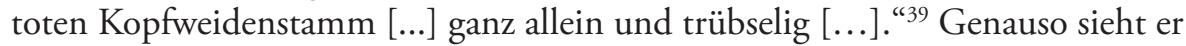

in Bäumen [...] Ausdruck und gewissermaßen eine Seele. So hat eine Reihe Kopfweiden manchmal etwas von einer Prozession von Weisenmännern. Das junge Korn kann etwas unsagbar Reines, Zartes haben, das uns z.B. ebenso rührt wie der Ausdruck eines schlafenden Kindes. Das zertretene Gras am Rande einer Straße hat etwas Müdes und Bestaubtes wie die Bewohner eines Armenviertels. Als es neulich geschneit hatte, sah ich ein Grüppchen Wirsingkohl, das so verfroren in der Kälte stand und mich an ein paar Frauen erinnerte, die ich am frühen Morgen in ihren dünnen Röcken und alten Umschlagtüchern in einem Wasser- und Feuerkeller hatte stehen sehen. ${ }^{40}$

Wenn es dem Künstler gelang, die Schönheit der Natur abzubilden, dann würde dieser etwas schaffen, das sich letztlich über die sichtbare Natur erhob. Dies konnte erreicht werden, wenn ,als Endergebnis vieler Studien [nach der Natur] etwas ganz anderes entstehe [...]. Das ist das höchste der Kunst und da ist die Kunst manchmal der Natur überlegen ... wie zum Beispiel in Millets Sämann mehr Seele ist als in einem gewöhnlichen Sämann auf dem Feld. “41 Es sei „eine Pflicht des Malers, zu versuchen, einen Gedanken in sein Werk zu legen" und, wie auch die von ihm geschätzten niederländischen Maler des 17. Jahrhunderts oder die Maler der Haager Schule, unter denen van Gogh Anton Mauve (1838-1888), Jacob Maris (18371899) und Jozef Israëls (1827-1911) erwähnte, Kunst zu schaffen, die „deutlicher spricht als die Natur selbst. “42

Genauso war er auch den Malern der Schule von Barbizon verpflichtet, die er in den 1870er Jahren während seiner Zeit bei Goupil zu schätzen gelernt hatte. Er pries Théodore Rousseau (1812-1867) und Jules Dupré (1811-1889) angesichts einer Malerei von anderen „Landschaftern [... denen] tiefdringende Naturkenntnis [fehle], wie Menschen sie haben, die von Kindheit an Felder gesehen haben und etwas dabei empfunden haben. [...] Wie gut tut es, mal einen schönen Rousseau

stift, schwarze Kreide, Tinte, braune und graue Lavierung sowie deckende Aquarellfarben auf Papier, 51,5 x 70,7 cm, Otterlo, Kröller-Müller Museum, F 933r, JH 142.

39 Brief 251/220, Den Haag, 26.7.1882, an Theo, zitiert nach Erpel 1965, Bd. 2, S. 63-68, S. 64. Stolwijk 2003, S. 27 verwendet den treffenden Begriff , anthropomorphised“.

40 Brief 292/242, Den Haag, 10.12.1882, an Theo, zitiert nach Erpel 1965, Bd. 2, S. 125-128, S. 127. Auf diesen Brief verweist Stolwijk 2003, S. 27.

41 Brief 298/257, Den Haag, 3.1.1883, an Theo, zitiert nach Erpel 1965, Bd. 2, S. 171-173, S. 172.

42 Brief 152/130, Wasmes, ca. 19.6.1879, an Theo, zitiert nach Erpel 1965, Bd. 1, S. 194-197, S. 196. Neben Rembrandt kann als Beispiel auch Jacob van Ruisdael (1628/29-1682) aufgeführt werden, dessen Werk Der Busch (1647-50, Öl auf Leinwand, 68 x 82 cm, Paris, Louvre. Vgl. Brief 361/299, Den Haag, 11.7.1883, Erpel 1965, Bd. 2, S. 295-301, S. 295. 
zu sehen, an dem hart gearbeitet worden ist, um treu und ehrlich zu sein [...] wieviel Saft und Kraft und wieviel Liebe steckt [... in Duprés Werken] und doch, wie frei und fröhlich sind sie gemacht!" 43 Über ein Werk von Jean-Baptiste Camille Corot (1796-1875), das einen Waldrand an einem Sommermorgen zeigt, schrieb van Gogh schwärmerisch, dass „[e]in einziges kleines rosa Wölkchen [andeutet ...], daß die Sonne bald aufgehen wird. Eine Stille, eine Ruhe, ein Friede, die einen verzaubern. " ${ }^{4}$ Wie genau van Gogh dieses Gefühl in seinen eigenen Werken umzusetzen gedachte und wie er die Menschen erreichen wollte, erklärte er anhand seiner Darstellung von Trauernder Alter Mann („At Eternity’s Gate“) (Abb. 33), ${ }^{45}$ denn

einer der stärksten Beweise für die Existenz von ,quelque chose là-haut', woran Millet glaubte, an das Dasein eines Gottes und einer Ewigkeit nämlich, ist das unsagbar Rührende, das im Ausdruck eines alten Mannes liegen kann, vielleicht ohne daß er selbst sich dessen bewußt ist, wenn er so still in seinem Ofenwinkel sitzt. Zugleich ist da etwas vornehmes, das nicht für die Würmer bestimmt werden kann. ${ }^{46}$

Van Gogh war sich bewusst, dass dies kein intellektuell anspruchsvolles Konzept darstellte, sondern „fern von aller Theologie einfach die Tatsache beschreibt, daß der ärmste kleine Holzfäller, Heidebauer oder Bergarbeiter Augenblicke einer Gemütsbewegung und Stimmung haben kann, die ihm das Gefühl einer ewigen Heimat geben, der er ganz nahe ist. " ${ }^{77}$

Im Frühling 1885 hatte sich van Gogh im Anschluss an sein Vorbild Millet als „Bauernmaler“ 48 bezeichnet und malte zu dieser Zeit in erster Linie einfache Menschen, die im Einklang mit der Natur das Feld bestellen. Im Kontext der Entstehung der Kartoffelesser (vgl. Abb. 36) war es ihm wichtig, „die Bauern [so zu] malen, [... dass] man selber einer von ihnen ist und fühlt und denkt wie sie, indem man nichts anderes sein kann, als man ist. “49 Demnach war für van Gogh „die Natur kein Anlass ästhetischen Schauvergnügens [...], sondern der Ort mensch-

43 Brief 291/251, Den Haag, zw. 4.-9.12.1882, zitiert nach Erpel 1965, Bd. 1, S. 152-157, S. 155. Vgl. in diesem Zusammenhang auch Stolwijk 2015, S. $44 \mathrm{f}$.

44 Brief 246/215, Den Haag, 15.u.16.7.1882, an Theo, zitiert nach Erpel 1965, Bd. 1, S. 42-48, S. 47 Van Gogh bezieht sich hier möglicherweise auf Corots Vijver bij Ville d'Avray (Pond at Ville-d'Avray), Aufenthaltsort unbekannt. Vgl. Anmerkung $17 \mathrm{zu}$ diesem Brief aus der OnlineAusgabe der Briefe, abgerufen unter: http://vangoghletters.org/vg/letters/let246/letter.html. Vgl. auch Stolwijk 2015, S. 45.

45 Trauernder Alter Mann („At Eternity’s Gate“), November 1882, Lithographie, 55,5 x 36,5 cm, diverse Sammlungen, u.a. Amsterdam, Van Gogh Museum, F 1662, JH 268

46 Beide Zitate aus Brief 288/248, Den Haag, 26.u.27.11.1882, an Theo, zitiert nach Erpel 1965, Bd. 2, S. 138-143, S. 140. Auf diesen Brief verweisen Uiters 2003, S. 79 u. Noll 1994, S. 148, Fußnote 733.

47 Brief 288/248, Den Haag, 26.u.27.11.1882, an Theo, zitiert nach Erpel 1965, Bd. 2, S. 138-143, S. 141.

48 Brief 493/400, Nuenen, 13.4.1885, an Theo, zitiert nach Erpel 1965, Bd. 3, S. 246-248, S. 247.

49 Brief 497/404, Nuenen, 30.4.1885, an Theo, zitiert nach Erpel 1965, Bd. 3, S. 255-259, S. 255. 
licher Arbeit, an dem sich das Leben in seiner Mühsal vollzieht. Natur ist [...] jener Schauplatz, auf dem die Menschen mit ihrer Hände Arbeit ihr Dasein fristen. "50

Van Gogh empfand „Landschaft [nicht nur] als Resonanzraum [seiner] Innenwelt" ${ }^{\text {" }}$, überliefert ist auch seine Hoffnung auf eine therapeutische Wirkung, die er sich von der Arbeit in der Natur versprach. „Allein auf den Feldern, mit seiner Staffelei der brennenden Sonne des Südens ausgesetzt, hoffte er, Widerstandskräfte zu entwickeln. Er wollte sich selbst und der Welt beweisen, dass seine Arbeit nicht nutzloser Luxus sei, sondern notwendiger Ausdruck elementarer Bedürfnisse. " 52 So setzte er seine Arbeit in einem Brief an seine Mutter mit der der Bauern gleich, die er abbildete, verstand sich jedoch, was den Stellenwert betraf, ihnen nachgeordnet: „Nach meiner eigenen Einschätzung stehe ich denn auch entschieden niedriger als die Bauern. Nun, ich pflüge auf meinen Bildern wie sie auf ihren Äckern. " ${ }_{33}$

Die Notwendigkeit einer Verbundenheit mit der Natur sah van Gogh aber auch durch seine Beschäftigung mit japanischer Kunst bestätigt. Er erklärte über die japanischen Künstler, dass sie „in der Natur leben, als wären sie selber Blumen“; und dass ihr Studium eines einzigen Grashalms sie befähige, Einsicht in das große Ganze zu erlangen, erschien van Gogh „beinah eine wahre Religion“" ${ }^{4}$. Noll weist in diesem Zusammenhang auf eine möglicherweise damit korrespondierende Vorstellung van Goghs von „der Natur in ihrer ,ewigen“ Ordnung und harmonischen Gefügtheit" als Verweis auf „quelque chose là-haut“ hin.

Der Abschied von Paris Anfang 1888 hatte daher nicht nur persönlich-gesundheitliche Gründe, sondern war auch dezidiert künstlerisch motiviert. Paul Gauguin in die Bretagne, nach Pont-Aven, zu begleiten, hatte van Gogh abgelehnt, da er sich vorgenommen hatte, stattdessen in die Provence, eine - nach seiner Vorstellung - mit Japan vergleichbare Region zu reisen, wo ebenfalls „Kunst und Geist gediehen und der Mensch sich in harmonischem Gleichgewicht mit der Natur entfalten konnte." 56

Literarische Bestätigung für sein exotisches Bezugssystem fand er beispielsweise in den Schriften von Edmond de Goncourt (1822-1896), aber wohl auch in den Promenades japonaises von Émile Guimet (1836-1918) und Félix Régamey (18441907), die ein idealisiertes Bild von Japan zeichneten. ${ }^{57}$ Durch Zeitschriften wie

50 Boehm 2009, S. 35.

51 Bürgi/Zimmer/Feilchenfeldt 2009, S. 27.

52 Bürgi/Zimmer/Feilchenfeldt 2009, S. 28.

53 Brief 811/612, Saint-Rémy, ca. 21.10.1889, an seine Mutter, zitiert nach Erpel 1968, Bd. 5, S. 20-22, S. 21.

54 Brief 686/542, Arles, 23. o. 24. September 1888, an Theo, zitiert nach Erpel 1965, Bd. 4, S. 169174, S. $172 \mathrm{f}$.

55 Noll 1996, S. 67.

56 Childs 2001, S. 121. Reisen auf das Land waren in Künstlerkreisen zu dieser Zeit üblich, um Inspiration für neue Motive zu finden, aber auch, um abseits der Metropolen zu günstigeren Lebenshaltungskosten zu leben. In den 1880er Jahren waren bei Malern neben der Bretagne auch die französische Mittelmeerküste sehr beliebt. Vgl. Dorn 1990, S. 214 (Fußnote 28).

57 Vgl. Childs 2001, S. 121 u. 126f sowie van der Veen 2003, S. $57 f$. 
Paris Illustré, das infolge der wachsenden Popularität Japans im Westen 1886 eine enzyklopädische Japan-Ausgabe mit Farbholzschnitten japanischer Künstler und Artikeln zu Land, Leuten, Brauchtum und Kultur, herausbrachte, informierte sich van Gogh umfassend. ${ }^{58}$ Wie Elizabeth Childs in ihrer umfangreichen Untersuchung zu van Goghs Motivation für die Reise in den Süden schreibt, verstanden „[d]ie meisten französischen Autoren [...] Japan als in einer zeitlosen, vormodernen Reinheit erstarrt: das perfekte Heilmittel gegen die Krankheiten der urbanen Modernität Europas." "59 Dabei ließen viele Autoren die sozialen Realitäten des sich nach der Öffnung für den Westen Mitte des 19. Jahrhunderts inmitten eines umfassenden Modernisierungs- und Industrialisierungsprozesses befindlichen Landes außer Acht. Stattdessen „erscheint der japanische Künstler stets als sensibler, harmonisch in einer gleich-gestimmten Natur lebender Künstler-Philosoph. " ${ }^{60}$ Aus den verschiedenen Quellen leitete van Gogh ganz konkrete künstlerische Handlungsanweisungen für sich ab. „Und mir scheint, man kann sich nicht mit japanischer Kunst befassen, ohne viel heiterer und viel glücklicher zu werden, und wir müssen zurück zur Natur trotz unserer Bildung und trotz unserer Arbeit in einer Welt der Konventionen." ${ }^{1}$

Die Provence schien van Gogh seinem Ideal von Japan nicht nur am nächsten zu kommen, sondern „bot ihm [gleichzeitig] das strahlende Sonnenlicht und die Farben des Südens, die schon seine großen Vorbilder Delacroix und Monticelli gesucht hatten und die er mit eigenen Augen sehen wollte." ${ }^{22}$ Er hoffte, dass sich auch ihm im Süden neue koloristische Möglichkeiten eröffnen würden. Warum genau er jedoch nach Arles ging, eine Stadt, die vor allem aufgrund ihrer römischen und frühchristlichen Ruinen - für die sich van Gogh nicht interessierte - bekannt und im Unterschied zu anderen Orten der Provence bei Künstlern nicht sonderlich beliebt war, lässt sich trotz verschiedener Erklärungsansätze nicht gänzlich ermitteln. ${ }^{63}$

Ein Brief vom September 1888 an seine Schwester Willemien wird als Kommentar zu der Entwicklung dafür gesehen, dass seit der Arleser Zeit die Landschaft noch stärker „zum Ausdruck seiner Gefühlswelt [wurde,] sowohl im Sinne einer positiven Verstärkung des von ihm Empfundenen und Erlebten, als auch im Sinne eines ausgleichenden Gegengewichts zu seiner Einsamkeit und psychischen Bedrängnis." ${ }^{64}$

58 Vgl. Paris Illustré. Le Japon, Bd. 4, Nr. 45 u. 46, Mai 1886.

59 Childs 2001, S. 126.

60 Childs 2001, S. 127.

61 Brief 686/542, Arles, 23. o. 24. September 1888, an Theo, zitiert nach Erpel 1965, Bd. 4, S. 169 174, S. 172f. Vgl. für diesen Brief auch Noll 1996, S. 66.

62 Homburg 2001, S. 32.

63 Vgl. Vellekoop/Zwikker 2007, S. 1f. Zunächst hatte er geplant, weiter nach Marseille, das aufgrund seiner Lage am Mittelmeer besonders attraktiv schien, zu reisen, blieb dann aber doch in Arles für über ein Jahr. Es wird vermutet, dass van Gogh Konzerte von Georges Bizets Bühnenmusik L'Arlésienne besuchte, die Anfang 1888 mehrere Male aufgeführt worden war, handelte es sich doch um Musik für ein Drama des von ihm sehr geschätzten Alphonse Daudet. Morton spekuliert, dass L'Arlésienne van Gogh bei der Entscheidung nach Arles zu gehen, beeinflusst haben könnte. Vgl. dafür Morton 2000, S. $191 f$.

64 Bürgi/Zimmer/Feilchenfeldt 2009, S. 28. 
An Willemien schrieb er: „Je hässlicher, älter, boshafter, kränker ich werde, umso mehr suche ich die Scharte dadurch auszuwetzen, dass ich meine Farbe leuchtend, wohl ausgewogen, strahlend mache." 65

\subsection{Die Entwicklung der Zyklizität im Werk van Goghs}

\subsubsection{Exkurs: Zyklische Darstellungen der Jahreszeiten und Monatsbilder}

Dass van Gogh bereits lange vor seiner Entscheidung, Künstler zu werden, dem Aspekt eines Werden und Vergehen in der Natur als Ausdruck grundsätzlich des Lebens einen großen Stellenwert beigemessen hatte, veranschaulicht die erste Predigt, die er im Oktober 1876 in der Wesleyan Methodist Church in Richmond hielt. Van Gogh verglich das Leben mit einer Serie von Jahreszeiten und wies auf Parallelen des menschlichen Lebens mit dem Rhythmus der Natur hin: „Alles auf Erden wandelt sich - wir haben hier keine bleibende Stätte - das ist die Erfahrung eines jeden. [...] Wenn wir wieder geboren werden in ein ewiges Leben, in ein Leben des Glaubens, der Hoffnung und Liebe - in ein immergrünes Leben [...] so ist das zwar eine Gabe Gottes, ein Werk Gottes [...], aber dennoch laßt uns die Hand an den Pflug legen auf dem Feld unseres Herzens [...]. Segne er die Saat seines Wortes, das in unsere Herzen gesät ist. " ${ }^{66}$ Nicht die zyklische Natur ist an dieser Stelle entscheidend, sondern das Werden und Vergehen und Wieder-Werden des Menschen, womöglich auf einer anderen, höheren Ebene.

Bei der Frage nach möglichen Anregungen und Vorbildern für van Goghs zyklische Darstellungen in Saint-Rémy und zuvor wird deutlich, dass er mit der Darstellung der Arbeit auf dem sich im Jahreskreis wandelnden Feldes einen Topos aufgriff, der in der westlichen Kunst und Kultur eine lange Tradition hat. An Bernard hatte er im Juni 1888 geschrieben, dass er „kindlich-schlichte Bilder machen will wie in alten Kalendern, Bauernkalendern, wo Hagel, Schnee, Regen, Schönwetter auf eine ganz primitive Art dargestellt sind“67. Im auf Französisch verfassten Brief hatte van Gogh von einem „vieil almanach de campagne“ gesprochen, was ähnlich klingt wie bei Sensier, der hinsichtlich der Anregungen für Millet bei dessen Jahreszeitenbildern ebenfalls den „calendrier de la vie agricole“ 68 anführt.

65 Brief 678/W 7, Arles, 9. u. 14.9. 1888, an Willemien, zitiert nach Erpel 1968, Bd. 5, S. 51-54, S. 53.

66 Abschrift der Predigt in Brief 79/79a, Isleworth, 3.11.1876, an Theo, zitiert nach Erpel 1968, Bd. 6, S. 335-340, S. 335 u. 339. Vgl. zu diesem Brief auch Greer 2018, S. 64.

67 Brief 628/B 7, Arles, 19.6.1888, an Émile Bernard, zitiert nach Erpel 1968, Bd. 5, S. 257-261, S. 258. , in Van Gogh äußerte sich in Bezug auf Louis Anquetins, Die Ernte (Mäher zur Mittagszeit), 1887, Privatsammlung, vgl. Online-Ausgabe der Briefe, abgerufen unter: http://vangoghletters.org/ $\mathrm{vg} /$ letters/let628/letter.html\#.

68 Zitiert aus Sensier 1881, S. 362. 
Van Gogh muss mit entsprechenden Kalendern und den darin enthaltenen Sujets wohl mindestens seit seiner Zeit im Kunsthandel vertraut gewesen sein. Unweigerlich werden bei dem Hinweis auf alte Kalender Parallelen zu Almanachen oder auch mittelalterlichen Stundenbüchern, in denen die Darstellung der Monatsarbeiten ein fester Bestandteil war, augenfällig. Wie sich zeigen wird, finden sich Ähnlichkeiten zu solchen Kalenderbildern auf mehreren Ebenen. ${ }^{69}$ Für das Verständnis der Darstellungen des ummauerten Feldes ist es daher hilfreich, den Blick zunächst auf die Tradition zu richten, bevor sie dann hinsichtlich ihrer Ikonographie und Ikonologie untersucht werden.

Die Darstellung des Kreislaufs der Natur findet sich seit der Antike „einerseits im Zusammenhang der Jahreszeitenthematik, andererseits in einem an den Monaten orientierten kalendarischen Kontext ${ }^{\text {" }}{ }^{\circ}$. Entsprechende Illustrationen zu den Monaten in Kalenderbildern konnten dabei sowohl durch den agrarischen Jahreslauf als auch durch mythologische und kultische Kontexte inspiriert sein. ${ }^{71}$ Aufgrund ihrer Ausstrahlung auf die nachfolgende Landschafts- und Genremalerei wird Kalenderbildern aus Stundenbüchern eine große Bedeutung beigemessen. Die ersten Stundenbücher für Laien zur privaten Andacht entstanden im 13. Jahrhundert. Sie wurden im ausgehenden 14. und beginnenden 15. Jahrhundert immer populärer und gehörten bald zum beliebtesten Buchtypus. ${ }^{72}$ Waren Stundenbücher zunächst aufgrund ihrer luxuriösen Ausstattung hauptsächlich dem Hochadel vorbehalten, „erreichte die Buchmalerei der Stundenbücher [spätestens ab dem 16. Jahrhundert] in den Abstufungen ihres künstlerischen Niveaus eine soziale Breitenwirkung, die nicht ohne Zufall zeitlich mit der Erfindung der Buchdruckerkunst zusammenging. " ${ }^{~} 73$ Die günstiger zu produzierenden Druckwerke mit ihren Holzschnitten verdrängten schließlich die kostspieligen Stundenbücher auf Pergament, machten ihre Inhalte jedoch breiteren Bevölkerungsschichten zugänglich.

Stundenbücher hatten neben religiösen Texten, zu denen Auszüge aus den Evangelien, das Marienoffizium, Psalmen, die Horen der Passion, des Kreuzes und des Heiligen Geistes sowie das Totenoffizium gehörten, als festen Bestandteil zu Beginn

69 Darstellungen des Kreislaufs der Monate lassen sich nördlich der Alpen nicht nur in romanischen und gotischen Kirchen finden, sondern im 16. und 17. Jahrhundert waren sie zudem ein populäres Sujet in flämischen und französischen Tapisserien. Gerade die Portalskulpturen französischer Kathedralen nehmen jedoch einen separaten Themenkomplex ein, auf den an dieser Stelle nur hingewiesen sein soll. "Twelve Months“, in: Hall's Dictionary of Subjects \& Symbols in Art, mit einer Einführung von Kenneth Clark, überarbeitete Neuauflage, London 1996, S. $314 f$. u. Hansen 1984, S. $35 f$.

${ }_{70}$ Divjak/Wischmeyer, Bd. 1, 2014, S. 157.

${ }_{71}$ Vgl. Divjak/Wischmeyer, Bd. 1, 2014, S. 157.

72 Das Stundenbuch des William de Brailes, entstanden um 1240, ist ein frühes Beispiel (London, British Library, Add. Ms. 49999) dieser Gattung. Jean Duc de Berry konnte 15 Stundenbücher sein eigen nennen und allein die Bibliothèque National in Paris besitzt beispielsweise über 300 Stundenbücher. Im Kunsthandel tauchen immer wieder neue Stundenbücher auf. Vgl. Hansen 1984, S. 9.

73 Hansen 1984, S. 9. 
des Buches einen Kalender, der die Leser nicht nur an kirchliche Hochfeste und Gedenktage der Heiligen erinnerte, sondern den Verlauf des Jahres auch Monat für Monat anhand von realistischen Szenen aus der Landwirtschaft neben denen aus dem höfischen Leben illustrierte. ${ }^{74}$ Auf der linken Seite befand sich in der Regel die Kalenderminiatur und auf der rechten Seite der Text, verziert mit architektonischen Motiven oder kleinen Szenen. Trotz großer Variation gab es jedoch häufig wiederkehrende Monatsmotive, die - zum Teil aus spätantiken oder frühmittelalterlichen Quellen stammend - über die Jahrhunderte sich entwickelt hatten. ${ }^{75}$ Größte Verbreitung fanden die illuminierten Stundenbücher im späten Mittelalter und in der frühen Neuzeit im niederländisch-französischen Raum, wo bedeutende Buchmaler Aufträge für ihre wohlhabende Kundschaft ausführten.

Das um 1413 von den Brüdern Paul, Hermann und Jean von Limburg illuminierte Stundenbuch der Très Riches Heures des Duc de Berry beeinflusste in vielerlei Hinsicht nachfolgende Buchmalergenerationen im 15. und 16. Jahrhun-

74 Vgl. Herold 2002, S. 20f.

75 Als einer der ältesten Bildkalender gilt ein athenischer Kultkalender aus dem 1.-2. Jahrhundert v. Chr., ein in die Athener Panagia Gorgoepikoos-Kirche eingemauerter Marmorfries, bei dem die wichtigen Feste des Jahres anhand von Symbolgestalten und Tierkreiszeichen repräsentiert sind. Während manche Feste, wie das Erntefest der Pyanepsia im Oktober-November, durch Symbolgestalten, hier ein Jüngling, der einen mit Herbstfrüchten geschmückten Ölzweig trägt, dargestellt sind, zeigt beispielsweise das Fest des Ackergottes Zeus Georgos, gefeiert im November-Dezember, ein Ochsengespann mit Pflug, hinter dem ein Sämann die Saat ausbringt und damit ein landwirtschaftliches Motiv, das sich über die folgenden zwei Jahrtausende nicht wesentlich veränderte. Vgl. für den Hinweis und die Erläuterung des Kultkalenders in der Panagia Gorgopika Hansen 1984, S. 33 u. „Calendar“, in: The Grove Encyclopedia of Medieval Art and Architecture, hg. v. Colum P. Hourihane, Bd. 1, Aachen-Cecco di Pietro, New York 2012, S. 488-490.

Ein weiteres wichtiges Beispiel mit großer Strahlkraft für die Nachwelt stellt der sogenannte Chronograph vom Jahre 354 dar. Der Kalender des Chronographen zeigt jeweils ein Monatsbild neben einer Kalenderseite mit den Hauptfesten des jeweiligen Zeitraums. Die Monate werden durch je eine Gestalt und entsprechende Attribute und Tierkreiszeichen charakterisiert. Die Tierkreiszeichen sind entweder in den Text integriert oder durch Platzhalterzeichen dargestellt. In manchen Kopien des Chronographen lassen sich auch Monatsverse in Form von Distichen und Tetrastichen finden, die ebenfalls auf eine Motivgemeinschaft von Wort und Bild schließen lassen. Vgl. Divjak/Wischmeyer, Bd. I, 2014, S. 157 f.

Ebenfalls von großer Bedeutung für die Entwicklung der Kalenderillustrationen waren karolingische Kalendergedichte, wie das des Mönches Wandalbert aus der Benediktinerabtei Prüm, verfasst im zweiten Viertel des 9. Jahrhunderts, als Teil des Martyrologiums, eines Verzeichnisses von Märtyrern und Heiligen, für Kaiser Lothar I. Diese Gedichte hatten wesentlichen Anteil an der inhaltlichen Verschiebung bei den Kalendermotiven, weg von überhöhten kultischen Sujets, hin zu Darstellungen der von den Menschen erfahrbaren Natur im Wandel der Jahreszeiten. Wandalberts in Hexametern verfasstes Kalendergedicht „de mensium duodecim nominibus, signis, culturis aerisque qualitatibus" zeigt mit den dazugehörigen Bildmotiven, beispielsweise mit dem Holzfällen im Januar, der Heuernte im Juni, der Kornernte im August oder der Weinlese im September bereits den ganzen Motivkanon bäuerlicher Arbeit, der sich über die Jahrhunderte in Kalenderdarstellungen - seien es Bodenmosaike oder Skulpturen in den Archivolten gotischer Kirchenportale - finden lässt. Vgl. Hansen 1984, S. 34. 
dert. Im Frühjahr 1884 erschien eine von Léopold Delisle verfasste Einführung der Stundenbücher des Herzogs in der Gazette des Beaux-Arts, einer Publikation, die van Gogh häufig las, und durch die er die aufwendig ausgearbeiteten Kalendermotive und ihre ikonologischen Zusammenhänge in den Très Riches Heures (abgebildet daraus war bei Delisle unter anderem das Junibild, das Bauern bei der Heuernte zeigt) und in den anderen Stundenbüchern dieser einzigartigen Sammlung kennengelernt haben könnte. ${ }^{76}$

Der flämische Maler Gerard Horenbout (um 1465-um 1540) übernahm beispielsweise für den Kalender des um 1510/20 entstandenen Breviarium Grimani viele der Motive der Très Riches Heures, interpretierte sie jedoch mit größerem Realismus und erzählerischer Freiheit. ${ }^{77}$ Exemplarisch für diese Entwicklung sei auch das Kalendarium des sogenannten München-Montserrat Stundenbuchs genannt, für das Simon Benning (1483 od. 1484-1561) in Brügge die Monatsbilder schuf. Mehrere klassische Kalendermotive, die sich auch später bei van Gogh noch in ähnlicher Weise finden, wie die Kornernte mit Schnittern im August (fol. 9v) oder das Pflügen und Aussäen im September (fol. 10v), sind darin enthalten (Abb. 51 u. 52). ${ }^{78}$ Bening „nobilitierte die Kalenderdekoration, indem er sie nicht nur auf die gleiche Stufe wie die detaillierten Programme der Andachtsbilder stellte, die im

76 Paul, Hermann u. Jean von Limburg (zw. 1385 u. 1390-1416), Très Riches Heures, 1413-1416 (1485 vollendet durch Jean Colombe (1430/35-1493)), Chantilly, Musèe Condè, MS 65. Vgl. Herold 2002, S. 22 f.

Vgl. Delisle, Léopold: Les Livres d'heures du Duc de Berry, Extrait de la Gazette des Beaux-Arts, février, avril et mai 1884, Paris 1884. Vgl. für diesen Hinweis Greer 2018, S. 71. Es ist nicht gesichert, dass van Gogh Zugang zu genau diesen Ausgaben der Gazette hatte, aber durch Nennungen in anderen Briefen ist bekannt, dass er sie häufig las.

77 Gerard Horenbout (um 1465-um 1540) 1510/20, Flandern, Breviarium Grimani, Venedig, Biblioteca Marciana, ms lat. 2138.

78 Simon Bening (1483 od. 1484-1561), München-Montserrat Stundenbuch (oder Flämischer Kalender), Brügge, um 1540, München, Bayerische Staatsbibliothek, cod. lat. 23638 (nur Teile des Manuskripts sind in München, weitere Blätter befinden sich in der Abtei von Montserrat sowie im Getty Museum Los Angeles). Bening fertigte jeweils zwei Bilder pro Monat an: Januar mit einem Bauernhof im Winter (inklusive sich am Kaminfeuer wärmender Personen und dem Holzhacken, fol. 2v) und eine Schneeballschlacht (fol. 3r), Februar mit der Frühjahrsarbeit auf dem Weinberg (fol. 3v) und Fischern am Strand (fol. 4r), März mit Arbeit im Schlossgarten (Gemüsegarten, fol. 4v) und Holzeinschlag im Wald (fol. 5r), April mit einem Spaziergang im Schlossgarten (fol. 5v) und dem Austrieb der Schafe auf die Weide (fol. 6r), Mai mit einer Fahrt im geschmückten Maikahn (fol. 6v) und dem Kühemelken auf der Weide (fol. 7r), Juni mit dem Scheren der Schafe (fol. 7v und fol. 8r), Juli mit der Heuernte (fol. 8v) und einem Heuwagen (fol. 9r), August mit der Kornernte (fol. 9v) und der Apfelernte (fol 10r), September mit dem Pflügen, Säen und Eggen (fol. 10v) und dem Füttern der Schweine im Eichenwald (fol. 11r), Oktober mit dem Weinhandel (fol. 11v) und dem Schlachten von Rindern (fol. 12r), November mit einer Darstellung der Heimkehr von der Hirschjagd vor einem Bauernhof (fol. 12v) und einer Heimkehr von der Fasanenjagd (fol. 13r), schließlich Dezember mit einer abendlichen Hochzeitsgesellschaft (fol. 13v) und der Heimführung der Braut (fol. 14r). Vgl. bspw. Kren 2003, S. 474-476. 
Buch folgen, sondern sie sogar zum originellsten Teil des ganzen Bilderschmucks erhob. “79 Dies wirkte sich in großem Maße auf die flämische Landschaftsmalerei aus.

Die landwirtschaftlichen Motive illustrierten durch diesen Realismus - und dies verweist letztendlich auch auf den der Realität verpflichteten Charakter der Darstellung bei van Gogh - auch die Rolle der Bauern, deren Leben im Einklang mit den Jahreszeiten verlief und bestimmt war von der jeweils auszuführenden landwirtschaftlichen Arbeit. Der Rhythmus der Natur spiegelt und zeigt die göttliche Ordnung, die alles eingerichtet hat. Bridget Ann Henisch bemerkt in ihrer Untersuchung zur Bedeutung des mittelalterlichen Kalenderzyklus, dass „[n]o matter where it appeared, whether in solemn majesty or as a light-hearted frivolity, the calendar cycle was the embodiment of a deeply-felt, long-held belief that human life on earth was an unending round of work, shaped and driven by the year's unending round of seasons. " ${ }^{80}$ Neben den Monatsbildern waren in Stundenbüchern, wie bereits bei antiken Vorläufern, die jeweiligen Tierkreiszeichen angebracht, die das irdische Geschehen mit dem himmlischen verknüpften. Ein sehr prominentes Beispiel für die Praxis der Verknüpfung der beiden Sphären sind die Très Riches Heures, bei denen der kosmologische Zusammenhang durch die Darstellung der mit den Monaten korrespondierenden Tierkreiszeichnen und von Apoll mit seinem Sonnenwagen, in einem Halbkreis über den Kalenderminiaturen, illustriert wurde (vgl. Abb. 50). Die Form der Verknüpfung der Monatsarbeiten mit den Tierkreiszeichen ist bereits von gotischer Portalskulptur bekannt. Als ein wichtiges Beispiel dafür ist das Königsportal der Kathedrale von Chartres aus dem 12. Jahrhundert zu nennen, bei dem die zwei Archivolten über dem linken Eingang abwechselnd Darstellungen ländlicher Arbeit und die Tierkreiszeichen der dazu entsprechenden Monate zeigen. In Verbindung mit der im Tympanon dargestellten Himmelfahrt Christi - der die Menschwerdung Christi im Tympanon des rechten Eingangs und die Parusie des Erlösers im mittleren zur Seite stehen - zeigt das Bildprogramm wie der immer wiederkehrende - zyklische - Rhythmus der Natur eingeschrieben und aufgehoben erscheint in das - teleologische - Heilsgeschehen. ${ }^{81}$

Die Kalenderbilder überdauerten nicht nur den allmählichen Bedeutungsrückgang der Bilderhandschriften im Zuge des aufkommenden Buchdrucks, sondern wurden vielmehr, begünstigt durch das neue Medium, einem weiteren Kreis von Lesern zugänglich gemacht - wenn auch in zunehmend profaneren Kontexten. Parallel zu Zeiten der größten Popularität der Stundenbücher erschien 1481 zuerst bei Johannes Blaubirer in Augsburg ein gedruckter deutschsprachiger Kalender, der

79 Herold 2002, S. 23.

80 Henisch 1999, S. 8. Ein separat zu beleuchtender Sachverhalt ist die Astrologie. Die Darstellung der Gestirne und ihr Einfluss auf das irdische Leben kann mit den Monatsbildern verbunden sein (vgl. salone dei mesi im Palazzo Schifanoia, Ferrara).

81 Vgl. dazu beispielsweise Willibald Sauerländer: Das Königsportal in Chartres: Heilsgeschichte und Lebenswirklichkeit, Frankfurt 1996. 
als vielseitiger Ratgeber für Laien konzipiert war. ${ }^{82}$ In der ersten Ausgabe noch ohne Titel publiziert, war er in der Folge in den zahlreichen Neuauflagen, die seine große Popularität im ausgehenden 15. und beginnenden 16. Jahrhundert widerspiegeln, als teütscher kalender bekannt. Wie beliebt die Kalender waren, zeigt der Umstand, dass nur gut zehn Jahre später, 1492 bei Johann Schönsperger, bereits die 15. Ausgabe des Kalenders erschien. ${ }^{83}$

Blaubirers Kalender umfasst im Kalenderteil Informationen zur Tages- und Nachtdauer sowie Listen mit den Heiligentagen und unbeweglichen Kirchenfesten. Der zweite Teil dient als astrologisch-medizinischer Ratgeber und gibt durch seine iatromathematischen Daten (Zusammenspiel von Astrologie und Medizin) entsprechende Auskünfte - vornehmlich zum Aderlass. ${ }^{84} \mathrm{Wie}$ auch in den Stundenbüchern sind im Kalenderteil, am Anfang des Buches, die einzelnen Monate durch allegorische Sujets und korrespondierende Sternzeichen dargestellt. Bei den als quadratische Holzschnitte neben den Text gesetzten Motiven handelt es sich weitestgehend um die aus den Stundenbüchern bekannten Themen: Wärmebild im Februar, Bauer mit Sense bei der Heuernte im Juli, Kornernte mit Schnitter im August, Weinernte im September oder die Neuaussaat im Oktober. ${ }^{85}$

Im 16. und 17. Jahrhundert wandelte sich das Monatsbild nicht nur dadurch, dass es sich im Buchdruck zunehmend aus dem religiösen Kontext löste, sondern auch, indem es in eigenständigen bildlichen Darstellungen begegnet, und weiter auf die Malerei, Graphik und das Kunstgewerbe ausweitet. ${ }^{86} \mathrm{Zu}$ unterscheiden sind dabei im ausgehenden 16. Jahrhundert in der Tafelmalerei Zyklen, die meist in Serien von zwölf Bildern die Monatsdarstellungen und ihre üblichen Motive ländlicher Arbeit thematisieren, von vier- oder sechsteiligen Darstellungen der Jahreszeiten. Die Aufteilung des Jahres in sechs Abschnitte vollzog die in Mittel- und Nord-

82 [Deutscher Kalender], Augsburg: Johann Blaubirer, 1481, 4to, 80 Bl., (GW M16008, BSB-Ink K-4).

83 Vgl. Manfred von Arnim 2002, S. 281. Dies war gleichzeitig die sechste Schönsperger-Ausgabe. Im Durchschnitt kann davon ausgegangen werden, dass 300-500 Inkunabeln pro Ausgabe gedruckt worden sein könnten. Ich danke Charlotte Miller, Expertin für Inkunabeln beim Auktionshaus Sotheby's für diesen Hinweis.

Ein noch früherer gedruckter Almanach war Jakob Pflaums Kalender (wohl Ulm, ca. 1478, GW M32813, BSB-Ink P-407), jedoch ohne allegorische Kalendermotive, dafür jedoch beispielsweise mit Mondphasen.

84 Diese Form des deutschsprachigen Kalenders kann auf handschriftliche Vorläufer zu Anfang des 15. Jahrhunderts zurückgeführt werden. Vgl. Manfred von Arnim: Position 64, Calendar. In disem teütschen calendar vindet man gar hübsch nach einander die zwelff zeychen [...] Augsburg: Johann Schönsberger, 12. November 1492, in: A Choice of Early Printed Books (1454-1577), Dr. Jörn Günther Antiquariat, Hamburg 2002, S. 278-283, S. 281.

85 Mehr noch als in den Stundenbüchern fanden sich jedoch jetzt auch profane Darstellungen, wie die der unbekleideten Badenden mit dem Lautenspieler als Allegorie für den Mai, in den Monatszyklen.

86 Weitere Profanisierungen der Monatsbilder zeigen die graphischen Monatszyklen des 17. Jahrhunderts, beispielsweise jene von Aegidius Sadler (1570-1628), erschienen 1607, oder von Matthäus Merian d. Ä. (1593-1650) aus dem Jahre 1622.Vgl. Hansen 1984, S. $38 f$. 
europa vorherrschende natürliche Abfolge der Jahreszeiten, von Vorfrühling, Frühling, Frühsommer, Hochsommer, Herbst und Winter, nach. Motivisch bestehen zwischen beiden Arten Parallelen hinsichtlich der Verwendung von Darstellungen saisonbedingter Tätigkeiten. ${ }^{87}$

Von übergeordneter Bedeutung ist Pieter Bruegels d. Ä. (um 1530-1569) um das Jahr 1565 entstandener sechsteiliger Zyklus der Jahreszeiten (Abb. 53-57). Bruegels Jahreszeitenfolge wurde bereits zu seinen Lebzeiten sehr geschätzt, fand in den Kopien seiner Söhne zusätzliche Verbreitung und wurde dadurch für nachfolgende Malergenerationen vorbildhaft. Van Gogh war mit Bruegels Bildern und insbesondere mit dessen durch nachfolgende Künstlergenerationen in Malerei und Druckgraphik verarbeiteten Sujets durch seine Arbeit im Kunsthandel vertraut. ${ }^{88}$ Über Bruegel äußerte sich van Gogh in mindestens fünf Briefen, beispielsweise 1884 in Zusammenhang mit einem Zyklus von Darstellungen der Feldarbeiten für den Juwelier Antoon Hermans, an dem er zu dieser Zeit arbeitete (s. Kapitel 5.3.2.). ${ }^{89}$

Bei Bruegel sind, im Gegensatz zu Visualisierungen zwölfteiliger Monatsarbeiten, jeweils zwei Monate und die in diesem Zeitabschnitt typischen Tätigkeiten des Menschen sowie die Charakteristika und Veränderungen der Natur und der Witterung im Kreislauf des Jahres, in einem Bild zusammengefasst. Nur fünf der ursprünglich sechs Tafeln, die Bruegel wohl als Fries für einen Saal im Haus des Antwerpener Auftraggebers Niclaes Jongelinck konzipiert hatte, haben sich erhalten. ${ }^{90}$

Das Jahr beginnt in Bruegels Zyklus mit der Illustration des Vorfrühlings (Februar/März), Der düstere Tag. Künden die von Schnee bedeckten Bergspitzen im Hintergrund noch vom gerade endenden Winter, zeigen die „das Dunkle und

87 Vgl. Demus 1997, S. 84.

88 Pieter Breughel der Jüngere (1564-1637/38) u. Jan Brueghel der Ältere (1568-1625), vgl. Herold 2002, S. 7 u. 14. Unmittelbar von Bruegel d. Ä. beeinflusst waren beispielsweise die Jahreszeitenzyklen des Antwerpener Malers Abel Grimmer (1570-1618/19).

89 Vgl. Brief 465/381, Nuenen, 9.10.1884, an Theo, zitiert nach Erpel 1965, Bd. 3, S. 201-205, S. 203. Auf den Zyklus wird an späterer Stelle ausführlich eingegangen. Bei den anderen vier Briefen handelte es sich um 148/126, 149/127, 252/221 u. 306/263.

90 Pieter Bruegel d. Ä. (um 1530-1569), Der düstere Tag, 1565, Öl auf Eichenholz, 118 x 163 cm, Wien, Kunsthistorisches Museum, Inv. Nr. GG 1837; Die Heuernte, 1565, Öl auf Eichenholz, 114 x 158 cm, Prag, Palais Lobkowitz; Die Kornernte, 1565, Öl auf Holz, 119 x 162 cm, New York, Metropolitan Museum of Art, Inv. Nr. 19.164; Die Heimkehr der Herde, 1565, Öl auf Holz, 117 x 159 cm, Wien, Kunsthistorisches Museum, Inv. Nr. GG 1018; Die Jäger im Schnee, 1565, Öl auf Eichenholz, 117 x 162 cm, Wien, Kunsthistorisches Museum, Inv. Nr. GG 1838. Der Zyklus war vom Antwerpener Kaufmann Niclaes Jongelinck für die Ausstattung eines Raumes oder Saales seines Hauses in Auftrag gegeben worden. Es wurde spekuliert, ob der Zyklus ursprünglich zwölf Werke umfasst haben könnte, da im Inventar von Jongelincks Sammlung aus dem Jahr 1566 „Twelff maenden“ eingetragen sind. Als die Stadt Antwerpen den Zyklus 1595 ankaufte, um sie dem Erzherzog Ernst zum Geschenk darzureichen, wurde er als sechs Gemälde, die die zwölf Monate darstellen, beschrieben. Heute wird überwiegend davon ausgegangen, dass es sich um sechs Tafeln gehandelt haben wird. Dafür spricht auch, dass in Bruegels Ansichten mehrere Themen in einem Bild dargestellt sind, die in Kalenderminiaturen eines Monats in separaten Bildern auf unterschiedlichen Seiten zu finden sind. 
Leblose abschüttelnden Kräfte “91, visualisiert durch den tosenden Sturm und das schäumende Wasser in der Flussmündung, das Schiffe zum Kentern gebracht hat, das Wiedererwachen der Natur in dieser Jahreszeit, an. Für den Vorfrühling übliche Tätigkeiten, wie das Schlagen von Reisig oder das Ausbessern der Hauswand, werden im Vordergrund dargestellt. Die Thematisierung der Fastnacht durch die Dreipersonengruppe auf der rechten Bildseite ist nicht neu in der niederländischen Kunst, wohl aber ohne Vorbilder in Kalender- oder Zyklusdarstellungen. ${ }^{92}$

Das Frühlingsbild für April/Mai ist nicht erhalten. Die Ansicht des Frühsommers (Juni/Juli) zeigt in einer Landschaft, die wesentlich flacher und sanfter ausformuliert ist als die des Vorfrühlings und von warmen Farbtönen dominiert wird (Ocker und bräunliches Gelb im Vordergrund, helle und dunkle Grüntöne im Mittelgrund sowie Blau und Weiß im Hintergrund), bei heiterem Wetter die Heuernte und das Heimbringen der Obsternte. Fast die gesamte untere Bildhälfte wird von den in dieser Jahreszeit üblichen Tätigkeiten dominiert.

Daran schließt sich der Sommer (August/September) mit der Darstellung der Kornernte an, auf die der Betrachter, wie bereits bei den anderen Ansichten zuvor, von einem erhöhten Standpunkt aus blickt. Während einige Bauern bei großer Hitze unter wolkenlosem Himmel mit Sensen das Korn niedermähen, binden andere es zu Bündeln zusammen, bevor es weggetragen wird. Wieder andere haben sich im Schatten um einen Baum zu einer Rast versammelt. Kräftige Gelbtöne der Felder, kontrastiert mit Grüntönen angrenzender Wiesen und Bäume bestimmen den Farbeindruck.

Der Weideabtrieb einer Kuhherde zurück in den schützenden Dorfbereich, dargestellt in einer gerbirgig-schroffen Landschaft, in der die Herbststürme die Bäume bereits vollkommen entlaubt haben, veranschaulicht, dass die Weidezeit beendet ist und sich das Jahr dem Ende zuneigt (Oktober/November). Die winterliche Darstellung der heimkehrenden Jäger im Schnee (Dezember/Januar) in frostklarer Atmosphäre beschließt den Zyklus. ${ }^{93}$

Bruegel erweitert die aus dem Motivkanon der Stundenbücher entlehnte Themenwahl landwirtschaftlicher Arbeiten um entscheidende Neuerungen (bspw. die Fastnachtsgruppe in Der düstere Tag) und macht durch die Darstellungen des vor Erschöpfung eingeschlafenen Bauern in der Kornernte (Abb. 53) oder der mit magerer Beute und gesenkten Häuptern heimkehrenden Jäger im Winter, eine neue

\footnotetext{
91 Demus 1997, S. 86.

92 Vor Bruegel stellte Hieronymus Bosch Personifikationen des Karnevals und der Fastenzeit dar. Vgl. für die Tätigkeiten Simon Benings Februarbild aus dem Flämischen Kalender von 1540 (Simon Bening (1483 od. 1484-1561), München-Montserrat Stundenbuch (oder Flämischer Kalender), Brügge, um 1540, München, Bayerische Staatsbibliothek, cod. lat. 23 638, fol. 3v.), in dem in einem Weinberg auf einer Anhöhe über einem Fluss Bauern bei der Arbeit im Weinberg dargestellt sind. Vgl. für diese beiden Hinweise auch Herold 2002, S. 27-29.

93 Vgl. für diese Reihenfolge Demus 1981, S. 86-103. Stechow 1969, S. 96-98.
} 
Form des Realismus sichtbar. ${ }^{94}$ Diese Verpflichtung gegenüber der Realität wird durch die anschauliche Schilderung der atmosphärischen Stimmungen, insbesondere der metereologischen Erscheinungen (Gewitter, Sturm, Sonnenschein), der klimatischen Veränderungen und spezifischen Lichtverhältnisse in den einzelnen Ansichten erfahrbar. ${ }^{95}$ Gleichzeitig handelt es sich um Landschaften, die Bruegel aus Versatzstücken zusammengefügt hat.

Wie bereits im Februarbild der Très Riches Heures (vgl. Abb. 49), das keine winterliche Idylle zeigt, sondern frierende Bauern, die sich an ihrem Feuer wärmen und sich in der Kälte beim Schlagen des Feuerholzes und beim Treiben eines Esels mühen, zeigen Bruegels Landschaften „die prekäre [...] Verschränkung des vergänglichen Lebens und Wohnens auf der Erde mit dem Unermeßlichen, [...] der AllNatur. ${ }^{\text {“96 }}$ Klaus Demus interpretiert das Wintermotiv der heimkehrenden Jäger mit ihrer schmalen Beute und die dahinter anschließende schneebedeckte Landschaft, in der die Menschen ihren vielfältigen Tätigkeiten nachgehen, als „,matte Einkehr in die zuständliche Starre am Ende des Jahrs“ und sieht „eine Form der ,Einordnung“ in das Naturganze, die ebenso wie sie suggestiv für das optisch-atmosphärisch-räumliche Erleben des Winters ist, auch als Chiffre des ganzen Verhältnisses von Mensch

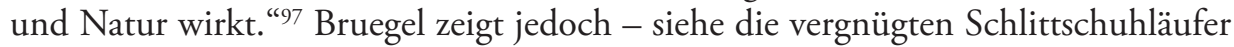
- alles: Die Mühsal und die Freuden der Menschen, eben das Leben.

In seinem viel beachteten Aufsatz zu Bruegels Zyklus argumentiert Justus Müller Hofstede, dass „eine neue, ,kontemplative 'Auffassung [...] für Bruegel geltend zu machen [ist]; ihr Impuls war es, in der Kunstform der, Überschaulandschaft' das Bild einer von vernünftigem Leben erfüllten, gleichsam nach Stoischen Prinzipien eingerichteten, auf den Menschen bezogenen und vom Menschen reflektierten Welt anklingen zu lassen oder ausdrücklicher zu formulieren. [...] Was als genremäßiges, bedeutungsloses Auftreten der Bauern erscheint, was wie eine Auflösung der spezifischen ikonographischen Motive der Tradition wirkt, ist die neue Veranschaulichung der Welt in Tätigkeit und Muße."98

Demus vertritt den Standpunkt, dass das, was Bruegel mit dem Zyklus veranschaulichen wollte, weder in der Tradition der Kalender noch in derjenigen von

94 Der schlafende Bauer ist ähnlich einer Figur aus Bruegels Gemälde Das Schlaraffenland (um 1567, Öl auf Holz, 52 x 78 cm, Alte Pinakothek, München), die dadurch die Vermutung nahe legen könnte, dass die Schläfrigkeit des Bauern nicht durch harte Arbeit, sondern Trunksucht oder Völlerei hervorgerufen sein könnte. Vgl. Herold 2002, S. 45.

Wenn auch die Kalenderillustrationen aus Stundenbüchern hinsichtlich der Themenwahl zu Bruegels wichtigsten Quellen gezählt werden können, beschränkt sich der Einfluss nicht allein auf dieses Medium. In Italien, zu nennen ist beispielsweise der salone dei mesi im Palazzo Schifanoia in Ferrara, ist die Tradition der Monatsdarstellungen als Teil der Villenausstattung bereits seit dem 14. Jahrhundert bekannt. Vgl. Herold 2002, S. 104.

95 Vgl. Herold 2002, S. 107.

96 Demus 1997, S. 87.

${ }_{97}$ Beide Zitate Demus 1981, S. 102.

98 Müller Hofstede 1979, S. 138 u. 140. Vgl. für diesen Hinweis auch Herold 2002, S. 108. 
Darstellungen liege, die - ausgehend von Vergils „Georgica“ - den Kreislauf des Jahres aus der Perspektive der bäuerlichen Arbeiten behandelten:

Bruegels Begriff vom Jahreszeitenthema ist weiter und moderner: Er zeigt [...] das Ganze nicht als abzählbare Summe, sondern als Zusammenfassung in einer Einheit. Das heißt, er bietet einen anschaulichen Begriff von dem, was jede Jahreszeit in ihrem Wesen ist, und wie sie die Welt als Wirklichkeit formt. [...] Er zeigt [...] das wenig erkannte, als Erfahrung jeden Begriff übersteigende Wesen der Natur, im Jahreslauf auf verschiedene Weisen zu „Welt“ zu werden. [...] Bruegel geht stehts auf Vollständigkeit aus. Die Thematik dieses Zyklus bot ihm die größte: die Natur und das Leben in ihr als ,Welt', im vollständig erfaßten Jahreslauf. ${ }^{99}$

Als weiteres wichtiges Beispiel bei diesem Überblick sei Nicolas Poussins (15941665) komplexer vierteiliger Jahreszeitenzyklus genannt, den van Gogh mit allergrößter Wahrscheinlichkeit bei seinem ersten Parisaufenthalt im Musée du Louvre gesehen und mit dem er sich inhaltlich auseinandergesetzt hatte. ${ }^{100}$ Durch die im Folgenden beschriebenen besonderen Charakteristika des Zyklus wird jedoch deutlich, dass die direkte Vorbildrolle für van Gogh eher eingeschränkt gewesen sein musste. Poussin, so ließ van Gogh seinen Bruder im Oktober 1885 aus Nuenen wissen, ,ist ein Maler, der bei allem denkt und zu denken gibt: in seinen Bildern ist alle Wirklichkeit gleichzeitig Symbol." ${ }^{101}$

In einem zur gleichen Zeit verfassten Brief reflektierte van Gogh die Bedeutung Poussins für nachfolgende Maler und auch sich selbst: „Die Franzosen nennen Poussin ihren allergrößten Maler unter den Alten. Eines ist gewiß: was von Poussin gesagt wird, von dem ich so wenig kenne, finde ich auch bei [Léon-Augustin] Lhermitte und Millet. Aber mit diesem Unterschied: mir scheint, Poussin ist das ursprüngliche Saatkorn, die anderen sind die volle Ähre. Ich also stelle die heutigen höher." ${ }^{102}$

Poussin hatte in seinem zwischen 1660-1664 entstandenen Zyklus in Form einer allegorie réelle versucht, auf unterschiedlichen Ebenen allegorische Erzählung und Landschaftsdarstellungen zu vereinen. Dabei stehen die vier Bilder nicht nur für die einzelnen Tages- und Jahreszeiten, sondern werden durch Poussin auch mit alttestamentlichen Themen verknüpft, durch die die eigentliche Bedeutung des Zyklus

$99 \quad$ Demus 1997, S. 85.

100 Nicolas Poussin (1594-1665), Der Frühling oder das irdische Paradies, Öl auf Leinwand, 117 x $160 \mathrm{~cm}$; Der Sommer oder Ruth und Boas auf dem Felde, Öl auf Leinwand, 119 x $160 \mathrm{~cm}$; Der Herbst oder die Heimkehr der Kundschafter aus dem Gelobten Lande, 117 x 160 cm; Der Winter oder die Sintflut, Öl auf Leinwand, 118 x $160 \mathrm{~cm}$. Der Zyklus wurde 1660-1664 für den Herzog de Richelieu angefertigt, 1665 wurde er mit dem Rest der Sammlung von Ludwig XIV erworben und befindet sich nach Stationen in den Schlössern zu Meudon und Versailles seit 1785 im Pariser Louvre, vgl. Sauerländer 1956, S. 169.

101 Brief 533/425, Nuenen, 4.10.1885, an Theo, nach Erpel, Bd. 3, S. 306-307, S. 307. Auf diesen Brief verweist Zimmer 2009, S. 99.

102 Brief 531/423, Nuenen, ca. 2.9.1885, zitiert nach Erpel 1965, Bd. 3, S. 303-305, S. 304. 
zu entschlüsseln ist. Wie Willibald Sauerländer bereits 1956 aufzeigte und danach vielfach diskutiert wurde, kann Poussins Zyklus typologisch verstanden werden und verweist auf „den teleologischen Zeitverlauf der christlichen Heilsgeschichte "103. Adam und Eva im Paradies (ante legem) stehen für den Frühling. Die von Ruth im Sommer geernteten Ähren stehen laut Sauerländer nicht nur für die Früchte des Ackers, sondern vielmehr für die „Opfergabe der Kirche: Leib Christi unter der Gestalt des Brotes “104 und damit unter typologischer Betrachtung für die Zeit „sub gratia“. Das dritte Bild, die Heimkehr der Kundschafter aus dem Gelobten Land, illustriert nicht nur den Herbst, sondern knüpft an die Darstellung von Ruth an, mit der von den Kundschaftern getragenen Weintrauben, die typologisch auf Christus am Kreuz verweist und hier im Besonderen für das Blut Christi steht. Das letzte Bild zeigt nicht nur den Winter oder die „Nacht der Natur und die Sintflut" ${ }^{\text {"105 }}$, sondern bedeutet auch das Jüngste Gericht, wobei die Arche im Bildhintergrund für die Kirche steht. Zwischen dem Sündenfall und dem Typus des Jüngsten Gerichts stehen folglich zwei Typen, die auf Leib und Blut Christi und damit auf die eucharistischen Gaben, das Erlösungsopfer Christi, verweisen. Damit gelang es Poussin in seinem Zyklus, „Formen und Sinnbilder, die einer geschichtlich zurückliegenden transzendenten Weltvorstellung entstammen, in das neuzeitliche Bild von der Landschaft, oder richtiger von der ,Natur" einzuschmelzen."106

Die Darstellung der Travaux des Champs blieb durch Künstler wie Millet und Lhermitte auch im 19. Jahrhundert relevant und wurde schließlich auch von den Impressionisten aufgegriffen. ${ }^{107}$ Camille Pissarro, mit dessen Bildern Theo seit 1887 handelte und der mit den Brüdern freundschaftlich verbunden war, ${ }^{108}$ malte in den

103 Zimmer 2009, S. 99. Zimmer zeichnet die Resonanz nach, die Sauerländers Aufsatz nach sich zog.

104 Sauerländer 1956, S. 177.

105 Sauerländer 1956, S. 181.

106 Sauerländer 1956, S. 183. Wie Nina Zimmer treffend zusammenfasste, führt die Verbindung der „auf ein Ende der Geschichte gerichtete[n] christliche[n] Zeitvorstellung [... mit der] anti$\mathrm{ke}[\mathrm{n}]$ Vorstellung von einem ewigen zyklischen Zeitverlauf [... der Natur] zu interpretatorischen Schwierigkeiten“. Zimmer 2009, S. 99. Vgl. auch in Hinblick auf van Gogh u. vgl. Wright 2007, S. 258-260.

107 Der Vollständigkeit halber sei erwähnt, dass auch im 18. Jahrhundert Künstler sich dem Thema der Jahreszeiten annahmen, dies jedoch mit vollkommen anderen Ergebnissen, die im Kontext dieser Arbeit nicht weiter von Relevanz sind. François Boucher (1703-1770) malte beispielsweise 1755 einen aus vier Bildern bestehenden Zyklus, der sich heute in der Frick Collection befindet (vormals aus der Sammlung der Marquise de Pompadour). Vgl. Katalogisierung auf der Internetseite der Frick Collection, abgerufen unter: https://collections.frick.org/objects/56/the-fourseasons-spring

108 Vgl. Hinweis zu Theos Tätigkeit als Händler Pissarros in Anmerkung 8 von Brief 626/W 4, Arles, zw. 16.-20.6.1888, abgerufen unter http://vangoghletters.org/vg/letters/let626/letter.html. Van Gogh schlug bspw. in Brief 594/474, Arles, 9.4.1888, an Theo einen Bildertausch mit Pissarro vor. Vgl. auch Anmerkung 9 zu diesem Brief in der Online-Ausgabe der Briefe, abgerufen unter: http:// vangoghletters.org/vg/letters/let594/letter.html. Im Herbst 1889 fragte Theo bei Pissarro an, ob dieser seinen Bruder im kommenden Frühjahr aufnehmen würde. Dies kam zwar nicht zustande, aber er empfahl Theo, sich an Dr. Gachet zu wenden. Vgl. Brief 807/T 18, Paris, 4.10.1889, Theo 
Jahren 1872-1873 einen vierteiligen Zyklus im breiten Querformat, für den er auf klassische Themen der Landwirtschaft zurückgriff, aber mit den Prämissen der impressionistischen Freilichtmalerei, mit besonderem Fokus auf den Eindruck jeweils von Licht und Schatten, umsetzte.

Der Zyklus besteht aus einem Frühlingsspaziergang im noch brachliegenden Feld, an dessen Rand aber die Bäume blühen, gefolgt von der Ansicht eines reifen Kornfelds, das sich sommerlich gelb-golden vor dem leuchtend blauen Himmel absetzt, einer Herbstlandschaft mit Getreideschobern und Bäumen, deren Blätter sich bereits gelblich-rot gefärbt haben. Der Zyklus wird abgeschlossen von der verschneiten Winterlandschaft eines Dorfes. ${ }^{109}$

\subsubsection{Ein Jahreszeitenprojekt}

Wenngleich van Gogh seinem Bruder andeutete, dass ihm die Kunst Poussins gefiel, hatten doch Millet und Lhermitte einen ungleich größeren Anteil an der Entwicklung seiner landwirtschaftlichen Darstellungen im Jahreskreis. ${ }^{10}$ Dies wird insbesondere anhand eines Auftrags deutlich, den er im Spätsommer 1884 von dem Eindhovener Juwelier Antoon Hermans erhalten hatte. Dabei entfernte sich van Gogh von der eigentlichen Anweisung, Szenen vom letzten Abendmahl und aus dem Leben von Heiligen für die Ausschmückung von dessen Esszimmer zu konzipieren und schlug stattdessen sechs Tafeln mit typischen Motiven aus dem ländlichen Leben vor, die die Jahreszeiten symbolisieren sollten und ihm passender erschienen als religiöse Darstellungen. ${ }^{111}$ Dabei spielte wohl für van Gogh die Absicht der Aufwertung von Bauerndarstellungen, im Gegensatz zur Verwendung von religiösen Sujets, eine große Rolle. Bei den ausgewählten Motiven handelte es sich um „Kartoffellegen, Ochsenpflug, Kornernte, Sämann, Hirte (Sturmstimmung), Reisigsammler (Schneestimmung)“, die van Gogh in größeren Ölskizzen in breitem

an Vincent, Erpel 1968, Bd. 6, S. 25-26 und auch Anmerkung 6 zu diesem Brief in der OnlineAusgabe der Briefe, abgerufen unter http://vangoghletters.org/vg/letters/let807/letter.html.

109 Camille Pissarro (1830-1903), Les Quatre Saisons (L'hiver, Le printemps, L'eté, L'automne), 1872-1873, Öl auf Leinwand, jeweils 55 x $131 \mathrm{~cm}$, wohl Privatbesitz, zuletzt Sotheby's London, Auktion L17002, 1.3.2017, Los 19. Ob van Gogh den Zyklus selbst gesehen haben wird, ist fraglich, da er bereits 1872 direkt vom Künstler an den Auftraggeber ging und erst nach van Goghs Tod bei einer Versteigerung wieder an die Öffentlichkeit gelang (Hôtel Drouot, Paris, 6.5.1891, Los 26). Auftraggeber war der wohlhabende und sehr gut vernetzte Pariser Kunstsammler Achille Arosa' dessen Bruder Gustave ab 1867 Paul Gauguins Vormund war. Arosa besaß eine sehr große Sammlung von Werken Pissarros und anderer Impressionisten, die einen großen Einfluss auf Gauguin hatten. Vgl. für die Provenienz die Internetseite des Auktionshauses Sotheby's, abgerufen für die Katalogisierung von Camille Pissarros Les Quatre Saisons (L'hiver, Le printemps, L'eté, L'automne), hier Los 19, L17002, 1.3.2017, London, abgerufen unter http://www.sothebys.com/ en/auctions/ecatalogue/lot.pdf.L17002.html/f/19/L17002-19.pdf. Vgl. auch Feist/Walther, Bd. 1, 1993, S. 107.

110 Vgl. Brief 531/423, Nuenen, ca. 2.9.1885, zitiert nach Erpel 1965, Bd. 3, S. 303-305, S. $303 f$.

11 Vgl. Zimmer 2009, S. 97 u. Brief 454/R 47, Nuenen, zw. Mitte August u. Anfang September 1884, an van Rappard, nach Erpel 1968, Bd. 5, S. 219-220. 
Querformat entwarf, damit sie von Hermans in endgültige Fassungen übertragen werden konnten (Abb. 58-61). ${ }^{112}$

Wie Tilborgh in seinem Aufsatz zu diesem Jahreszeitenprojekt erklärt, war van Gogh bei der Idee, Szenen aus dem Bauernleben mit dem Aspekt der vier Jahreszeiten zu verbinden, sehr wahrscheinlich durch Millet inspiriert, der zum Ende seines Lebens an einem ähnlichen Vorhaben arbeitete. Millet hatte wenige Jahre vor seinem Tod von dem wichtigen Mäzen Jacques Félix Frédéric Hartmann (18221880) den Auftrag zu einem Zyklus der Jahreszeiten erhalten, an dem er bis zuletzt arbeitete und den er bei seinem Tod 1875 auch bis auf die Darstellung des Winters vollendet hatte (vgl. Abb. 62 u. 67). ${ }^{113}$

Van Gogh hatte zwar den Jahreszeitenzyklus zum Zeitpunkt der Entstehung der Skizzen und Entwürfe für Hermans nicht gesehen, dürfte aber in Sensiers Biographie von Millet darüber gelesen haben. ${ }^{114}$ Hier konnte van Gogh erfahren, dass Millet den Sommer durch „Batteurs de Sarrasin“ (Weizendrescher) und den Herbst durch „Les Meules“ (Getreideschober) dargestellt hatte und dass diese Motive aus dem "calendrier de la vie agricole“ "115 abgeleitet waren. Anders als Millet, dessen Zyklus aus Landschaften bestand, entschied sich van Gogh jedoch für landwirtschaftliche Szenen mit prominent platziertem Figurenpersonal, in denen die Landschaft eine eher untergeordnete Rolle einnahm. Möglicherweise dachte er bei der Konzeption für Hermans eher an Millets Serie der Feldarbeiten.

Wie van Gogh bei dem Vorhaben für Hermans die einzelnen Motive den Jahreszeiten zuordnete, ist nicht abschließend geklärt. Die Kornernte, der Sämann und das Sammeln des Feuerholzes sind traditionelle Darstellungen des Sommers, Herbstes

112 Vgl. für die endgültige Aufzählung der Motive Brief 459/R 48, Nuenen, September 1884, zitiert nach Erpel 1968, Bd. 5, S. 220-221, S. 221. In Brief 453/374, Nuenen, August 1884, an Theo, Erpel 1965, Bd. 3, S. 184-185 schrieb van Gogh auf Niederländisch „aardappeloogst“ (Kartoffelernte), dies ist bei Erpel fälschlicherweise als Apfelernte übersetzt. Van Gogh spricht auch in einem anderen Brief vom Legen der Kartoffeln, vgl. bspw. Brief 454/R 47, Nuenen, zw. Mitte August u. Anfang September 1884, an van Rappard, nach Erpel 1968, Bd. 5, S. 219-220. Vgl. darüber hinaus für weitere Informationen Tilborgh 1998, S. 69f. u. Bakker 2010, S. 196.

Keines der Wandpanele von Hermans sind erhalten und nur vier von Goghs Szenen: Ochsenpflug, 1884, Öl auf Leinwand, 70,5 cm x $170 \mathrm{~cm}$, Wuppertal, Von der Heydt-Museum, F 172, JH 514; Kartoffellegen, 1884, Öl auf Leinwand, 66 x 149 cm, Otterlo, Kröller-Müller Museum, F 41, JH 513; Hirte, 1884, Öl auf Karton, 67 x 126 cm, Privatsammlung, F 42, JH 517; Reisigsammler (Schneestimmung), 1884, Öl auf Holz, 67 x 126, Privatsammlung, F 43, JH 516.

113 Jean-François Millet (1814-1875), Frühling, 1868-1873, Öl auf Leinwand, 86 x $111 \mathrm{~cm}$, Paris, Musée d'Orsay; Sommer, Weizendrescher, 1868-1874, Öl auf Leinwand, 85,5 x 111,1 cm, Boston, Museum of Fine Arts; Herbst, Getreideschober, 1868-1874, Öl auf Leinwand, 85,1 x 110,2 cm, New York, The Metropolitan Museum of Art u. nach Tilborgh 1998, S. 73 das unvollendete Werk Das Kuhgatter im Schnee [„La Porte aux vaches sous la neige“], 1868-1875, Material und Maße unbekannt, Philadelphia Museum of Art.

114 Zudem könnte van Gogh 1875 in der von ihm gepriesenen Ausstellung der Sammlung Émile Gavets Pastellskizzen Millets zu Jahreszeiten gesehen haben. Vgl. Brief 36/29, Paris, 29.6.1875, an Theo, Erpel 1965, Bd. 1, S. 32-33 für den Hinweis auf Gavet. Vgl. Tilborgh 1998, S. 74. 
und Winters. Das Pflanzen der Kartoffeln scheint am ehesten geeignet, den Frühling darzustellen. Der Ochsenpflüger könnte hingegen ebenfalls mit dem Frühling und der Hirte neben kahlen Bäumen unter einem gewittrig-dunklen Himmel mit dem Herbst assoziiert werden. ${ }^{116}$ Van Goghs Jahreszeitenzyklus für den Juwelier Hermans steht dadurch in der langen ikonographischen Tradition, den Menschen und die Natur im Wechsel der Jahreszeiten abzubilden. Wie Nina Zimmer zusammenfassend erklärt, wird „[d]ie Landschaft, und das gilt auch für van Goghs spätere Jahreszeitenbilder, $[\ldots]$ in dieser zutiefst niederländischen Bildtradition wichtiger Bedeutungsträger: Die Auswirkungen des Jahreszeitenwechsels auf die Natur haben einen großen Anteil an der Bildaussage [...]." ${ }^{117}$

\subsubsection{Die Farben im Kreislauf der Jahreszeiten}

Van Gogh hatte die Darstellung der Jahreszeiten seit Jahren beschäftigt, auch wenn er das Thema bis zu diesem Zeitpunkt nur vereinzelt mit eigenen Motiven in Form von Skizzen bearbeitet hatte - im Gegensatz zu den vielen Kopien von Bildern mit jahreszeitlichen Darstellungen aus dem Bauernleben, die er von Werken anderer Künstler angefertigt hatte. ${ }^{118}$ Aber seinem Bruder hatte er bereits im September 1883 vielsagend geschrieben, dass der Charakter einer Landschaft nur ergründet werden könne, wenn man sie in allen Jahreszeiten erlebt habe. ${ }^{119}$

Dann, kurz vor der Arbeit an Hermans bäuerlichen Motiven aus dem Jahreskreis, assoziierte er, beeinflusst durch das Studium von Charles Blancs Les Artistes de mon Temps, die ihn mit dem Gesetz des Simultankontrastes und der Gegenüberstellung von Komplementärfarben vertraut gemacht hatten, die Jahreszeiten mit entsprechenden Farben. ${ }^{120}$ Dies lässt eine klare Auseinandersetzung mit dem Zyklus der Natur erkennen:

Aber ich meine, es ist nicht leicht, eine Sommer-Sonnenstimmung zu finden, die ebenso reich und einfach und ebenso schön anzusehen ist, wie die charakteristischen Stimmungen der anderen Jahreszeiten. Der Frühling ist zartes, grünes junges Korn und rosa Apfelblüten. Der Herbst ist der Kontrast des gelben Laubes gegen violette Töne. Der Winter ist der Schnee mit den schwarzen Silhouetten. Wenn nun der Sommer den Gegensatz von blauen Tönen gegen ein Element von Orange im Goldbronzeton des Korns ist, könnte man so in jedem der Kontraste der Komplementärfarben (Rot und

\footnotetext{
116 Vgl. Tilborgh 1998, S. 74.

117 Zimmer 2009, S. 99.

118 Vgl. Brief 271/236, Den Haag, 8.10.1882, nach Erpel 1965, Bd. 2, S. 107. Hinweis durch Zimmer 2009, S. 100. Die Online-Ausgabe der Briefe verweist auf die entsprechenden Skizzen, abgerufen unter: http://vangoghletters.org/vg/letters/let271/letter.html.

119 Vgl. Bakker 2010, S. 196. Bakker verweist zur Erklärung auf Brief 384/322, Den Haag, 10.9.1883, an Theo, zitiert nach Erpel 1965, Bd. 2, S. 370-372, S. 371.

120 Vgl. Zimmer 2009, S. 101.
} 
Grün, Blau und Orange, Gelb und Violett, Weiß und Schwarz) ein Bild malen, das die Stimmung der Jahreszeit gut ausdrücken würde. ${ }^{121}$

Bereits in Bildern aus dieser Periode hatte van Gogh versucht, in der Art von Delacroix mit Komplementärfarben zu malen. Seine Palette blieb jedoch - wohl, weil er zu diesem Zeitpunkt keinen Zugang zu Gemälden hatte, die er unter diesem Gesichtspunkt hätte studieren können - noch gedämpft. ${ }^{122}$ In Paris lernte er 1886 die zeitgenössische französische Landschaftsmalerei von stilistisch höchst unterschiedlich arbeitenden Künstlern kennen. Van Gogh beschäftigte sich durch die Bekanntschaft mit jungen Künstlern, wie Georges Seurat oder Paul Signac, die sich mit neuen Farbkonzepten, wie dem Divisionismus, von der vorherigen Generation der Impressionisten - die meisten Elemente der impressionistischen Malerei waren zu diesem Zeitpunkt weitestgehend etabliert - abzugrenzen suchten, intensiv mit Aspekten der Farbenlehre (vgl. auch Kapitel 6.2.1). ${ }^{123}$

Mit großer Sicherheit sah van Gogh im Frühling die achte und letzte Ausstellung der Impressionisten, die zeitgleich mit dem Salon stattfand und vor deren Eröffnung es eine Kontroverse um die Einbeziehung neoimpressionistischer Arbeiten gab. Camille Pissarro verteidigte die mit divisionistischen Techniken arbeitenden Künstler, die durch die systematische Anordnung von kleinen Punkten oder Flächen aus Primär- oder Sekundärfarben den „schmutzigen“ Eindruck zu vermeiden suchten, der beim Mischen kontrastierender Pigmente entstand. ${ }^{124} \mathrm{Im}$ Sommer besuchte van Gogh möglicherweise auch die zweite Gruppenausstellung der Indépendents um Seurat und Signac.

Von den unterschiedlichen Theorien und neuen Erkenntnissen beeinflusst und motiviert von dem Ehrgeiz, sich als moderner Maler zu behaupten, experimentierte van Gogh in Paris nicht nur mit dem impressionistischen Pinselstrich und dem Pointilismus, sondern brachte auch seine theoretischen Kenntnisse hinsichtlich der Farbtheorien auf den neuesten Stand. Dafür studierte van Gogh einschlägige Publikationen, wie beispielsweise „Les impressionnistes en 1886“ des Kunstkritikers Félix Fénéon (1861-1944), in der die impressionistischen und neoimpressionistischen Theorien gegenübergestellt wurden. Fénéon äußerte sich über die von Camille Pissarro und seinem Sohn Lucien, aber auch von Seurat und Signac verwendeten Farben und deren neuartige Wirkungen im Wechselspiel miteinander und stellte sie auch in den Kontext japanischer Kunst: „Ces réactions de couleurs, ces soudaines perceptions de complémentaires, cette vision japonaise ne pouvaient s'exprimer au

121 Brief 451/372, Nuenen, ca. 2.7.1884, an Theo, zitiert nach Erpel 1965, Bd. 3, S. 181-183, S. $182 \mathrm{f}$.

122 Vgl. Homburg 2001, S. 36.

123 Vgl. Coyle 2009, S. 81 u. 83. Wichtig für van Goghs Erkundungen der für ihn neuen Landschaftsmalerei in Paris war die Kunstgalerie Boussod, Valadon \& Cie, für die sein Bruder arbeitete, die nicht nur mit Landschaften der einst umstrittenen Barbizonmaler, darunter Daubigny und Corot handelte, sondern auch mit Werken Courbets bis hin zu Monet, Sisley und Pissarro.

124 Vgl. Coyle 2009, S. $85 f$. 
moyen des ténébreuses sauces qui s'élaborent sur la palette: ces peintres firent donc notations séparées, laissant les couleurs s'émouvoir, vibrer à de brusques contacts, et se recomposer à distance; ils enveloppèrent leurs sujets de lumière et d'air, les modelant dans les tons lumineux, osant même parfois sacrifier tout modelé; du soleil enfin fut fixé sur leurs toiles." 125 Van Gogh verwendete in Paris zunehmend kräftige, leuchtende Farben und erprobte, wie sich diese auf die Visualisierung der Natur auswirkten. ${ }^{126}$

Die intensive Auseinandersetzung mit den neuen Strömungen wirkte sich ganz dezidiert auf seine Arbeitsweise, die Verwendung leuchtender Farben, seine Maltechnik aber auch die Wahl von Motiven in der Provence, aus. Nina Zimmer bemerkt richtig, dass van Gogh in der Provence beabsichtigte, den Kreislauf der Jahreszeiten und den der Farben zu vereinigen. ${ }^{127}$ Die wiederholte Auseinandersetzung mit dem gleichen Motiv, seien es die blühenden Obstbäume, die Erntebilder, die Seestücke oder die Ansichten fallenden Laubes im Herbst, unter einem übergeordneten Farbthema zeigen den Willen, Zusammenhänge herzustellen.

Wie im folgenden Kapitel näher beleuchtet werden soll, ging es van Gogh mit der Verwendung leuchtender Farben nicht nur um formale Aspekte, sondern auch inhaltlich um bestimmte Ausdrucksqualitäten, etwa „Heiterkeit [...] Glück, Hoffnung und Liebe, " 128 die er zu vermitteln suchte. „Ich glaube daran, daß im Süden eine neue Koloristen-Schule Wurzel fassen wird, denn ich sehe mehr und mehr, daß die im Norden mehr Wert auf geschickte Pinselführung und den sogenannten malerischen Effekt legen als auf das Bestreben etwas durch die Farbe selbst auszudrücken. "129 Wie Homburg zusammenfasst, wollte van Gogh „der Farbe selbst im Bild eine nahezu autonome Kraft [...] geben. Mit Hilfe der Farben konnte man den Gegenstand interpretieren und Emotionen ausdrücken. Sie sollten nicht so eingesetzt werden, wie sie in der Natur erscheinen, sondern übersteigert und zur Widerspiegelung einer emotionalen Intensität. ${ }^{\text {"130 }}$

125 Fénéon 1886, S. 19f. Es liegt nahe, dass van Gogh den Artikel aufgrund seiner Bedeutung kannte, aber es ist nicht abschließend erwiesen, dass er ihn gelesen hat. Félix Fénéon schrieb in der Septemberausgabe über die Werke van Goghs in der Ausstellung der Indépendants in Paris. Vgl. Fußnote 13 zu Brief 799/T 16, Paris, 5.9.1889, Theo an Vincent, abgerufen aus der Online-Ausgabe der Briefe, unter: http://vangoghletters.org/vg/letters/let799/letter.html\#n-13.

126 Vgl. Homburg 2001, S. 36.

127 Vgl. Zimmer 2009, S. 101.

128 Brief 678/W7, Arles, 9. u. 14.9. 1888, an Willemien, zitiert nach Erpel 1968, Bd. 5, S. 51-54, S. 53. Vgl. für diesen Brief auch Noll 1996, S. 70.

129 Brief 707/555, Arles, 17.10.1888, an Theo, zitiert nach Erpel 1965, Bd. 4, S. 199-202, S. 200. Vgl. für diesen Brief auch Homburg 2001, S. 39.

130 Homburg 2001, S. 36. 


\subsubsection{Gesichtspunkte der seriellen Ordnung: Die Jahreszeiten in Arles}

In der Provence, die er bald nach seiner Ankunft als „campagne [...] dans le midi“"131 bezeichnete, plante van Gogh, ein „Atelier des Südens“ zu gründen, in dem seine Malerfreunde mitwirken sollten, um gemeinsam an „einer neuen Kunst der Farbe, der Zeichnung - und des künstlerischen Leben s ${ }^{\text {“132 }}$ zu arbeiten. So stand er mit Bernard und Gauguin - die in der Bretagne arbeiteten - in Briefkontakt und versuchte sie zur Anreise und Teilnahme an einer von ihm erdachten sozialutopischen Künstlergenossenschaft zu bewegen, deren Zielsetzung beispielsweise die Verbesserung der gesellschaftlichen und wirtschaftlichen Situation von Künstlern sein sollte. ${ }^{133}$

Bei der gemeinschaftlichen Arbeit war die materielle Absicherung nicht das einzige Ziel, sondern, wie Dorn erklärt, „hoffte van Gogh, [dass dabei auch] die Unvollkommenheit des einzelnen Künstlers, des einzelnen Werks aufgehoben"134 werde, denn, wie er seinem Bruder erklärte, „um das Ganze zu erfassen, müßte eine ganze Akademie von Malern in derselben Gegend zusammenarbeiten, einander ergänzend wie die alten Holländer, Porträtisten, Genremaler, Landschafter, Tiermaler,

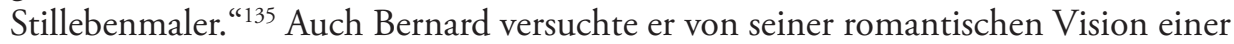
Künstlergemeinschaft zu überzeugen und argumentierte, dass durch die gemeinsame Arbeit und dem Austauschen Bilder entstehen könnten, „die [...] zusammengehören und einander ergänzen. [...] Unwillkürlich bilden die Werke ,Gruppen', ,Serien'." ${ }^{\prime 36}$

Als Quartier für diese Künstlervereinigung sollte das von ihm bezogene Gelbe Haus an der Place Lamartin in Arles dienen, das seinen Namen aufgrund seiner gelb gestrichenen Fassade erhalten hatte. ${ }^{137}$ Nach langem Zögern gab Gauguin schließlich den Bitten van Goghs nach und reiste Ende Oktober aus der Bretagne nach Arles. Die finanziellen Anreize, die Gauguin von Theo in Aussicht gestellt worden waren, hatten letztlich den Ausschlag für seine Entscheidung gegeben. Bis zu seiner Ankunft war van Goghs malerische Produktivität extrem hoch, und es entstanden allein über 80 Landschaftsbilder, darüber hinaus viele weitere Bilder zur Ausschmü-

131 Brief 602/480, Arles, 1.5.1888, an Theo, zitiert nach französischem Original, abgerufen aus der Online-Ausgabe der Briefe, unter: http://vangoghletters.org/vg/letters/let602/letter.html. Erpel übersetzt „campagne" ungenau als Aufenthalt. Vgl. Erpel 1965, Bd. 4, S. 33-36, S. 33.

132 Brief 585/469, Arles, 16.3.1888, an Theo, zitiert nach Erpel 1965, Bd. 4, S. 13-15, S. 15. Vgl. Dorn 1990, S. $28 f$.

133 Vgl. für die Erläuterung zu der Künstlergenossenschaft bspw. Brief 584/468, Arles, 10.3.1888, an Theo, nach Erpel 1965, Bd. 4, S. 11-13. Hinweis durch Dorn 1990, S. 30.

134 Dorn 1990, S. 32.

135 Brief 657/519, Arles, 8.8.1888, an Theo, zitiert nach Erpel 1965, Bd. 4, S. 113-116, S. 114. Hinweis durch Dorn 1990, S. 32.

136 Brief 643/B 11, Arles, zw. 17. u. 20.7.1888, an Émile Bernard, zitiert nach Erpel 1968, Bd. 5, S. 269-270, S. 269. Hinweis durch Dorn 1990, S. 32.

137 Vgl. Brief 602/480, Arles, 1.5.1888, an Theo, nach Erpel 1965, Bd. 4, S. 33-36, S. 33. 
ckung des Gelben Hauses. Insgesamt malte van Gogh in der Zeit in Arles ungefähr 200 Werke in Öl und fertigte zusätzlich gut 100 Zeichnungen an. ${ }^{138}$

Mit dem Verweis auf die Entstehung von Serien sprach van Gogh in dem Brief an Bernard über die Vorteile einer Künstlergemeinschaft auch einen äußerst wichtigen Aspekt seines Aufenthalts im Süden an. Denn nach der Ankunft auf dem Land war van Gogh erneut so sehr vom Wechsel der Jahreszeiten und der Arbeit auf dem Feld inspiriert, dass er sich umgehend wieder dieser Thematik annahm, ${ }^{139}$ ja er beschloss, „den eigenen Lebensrhythmus mit dem Rhythmus der Natur und seiner künstlerischen Produktion über viele Monate hinweg in Übereinstimmung zu bringen. " ${ }^{140}$ Obgleich sich auch in Arles Ende des 19. Jahrhunderts vermehrt Industrie ansiedelte und Neubauten das Stadtbild veränderten, war es doch auch weiterhin das Zentrum einer landwirtschaftlich geprägten Region, in der Mandeln, Oliven, Getreide und Wein produziert wurden. ${ }^{141}$ Dies stellte einen reichen Motivfundus für van Gogh dar.

Wie Nina Zimmer in ihrem Aufsatz zu van Goghs Serien für die Ausstellung in Basel treffend schreibt, „gewannen serielle und zyklische Prinzipien eine zunehmend größere Bedeutung für van Goghs Werkverständnis. Er dachte in immer umfassenderen Werkzusammenhängen und kombinierte verschiedene serielle Prinzipien miteinander. ${ }^{\text {142 }}$

\subsubsection{Der Frühling}

Ungefähr 15 Monate blieb van Gogh in Arles und sowohl am Anfang als auch am Ende seines Aufenthalts entstanden Ansichten blühender Obstgärten. Nach dem kalten Winter in Paris und den ersten Tagen im Schnee in Arles bedeuteten die ersten Blüten des Frühlings im Süden den Auftakt für eine zweiwöchige intensive Arbeit, die große Energien freisetzte: „Ich bin in einer richtigen Arbeitswut, weil die Bäume blühen und weil ich einen provençalischen Obstgarten von ungeheuerlicher Farbenfreudigkeit machen wollte. " 143 Bereits in seinem ersten Brief, kurz nach seiner Ankunft am 20. Februar, als der Schnee noch mehrere Zentimeter hoch die Felder bedeckte, beschrieb er seinem Bruder, wie sehr seine Erwartungen an den Süden als Substitut für Japan bereits erfüllt worden seien:

Kurz vor Tarascon habe ich eine wundervolle Landschaft mit riesenhaften gelben Felsen gesehen, gewaltige, seltsam verworrene Formen. In den kleinen Tälern dieser Felsen standen reihenweise angepflanzt kleine runde Bäume mit olivgrünem oder grüngrauem Laub, die sehr wohl Zitronenbäume ge-

\footnotetext{
138 Vgl. Vellekoop/Zwikker 2007, S. 2.

139 Vgl. Bakker 2010, S. 196.

140 Zimmer 2009, S. 105. Es sei hinzugefügt, dass die Fokussierung am Anfang des Aufenthaltes auf die Themen der Natur auch in Ermangelung anderer Modelle erfolgte.

141 Vgl. Childs S. 121.

142 Zimmer 2009, S. 105

143 Brief 592/473, Arles, 3.4.1888, an Theo, zitiert nach Erpel 1965, Bd. 4, S. 21-22, S. 21.
} 
wesen sein könnten. [...] Ich habe wundervolles rotes Gelände bemerkt, mit Weinstöcken bepflanzt, als Hintergrund Berge von zartestem Lila. Und die Landschaften im Schnee mit den weißen Berggipfeln gegen einen Himmel, ebenso leuchtend wie der Schnee - das war wie die Winterlandschaften der Japaner. ${ }^{144}$

Van Gogh malte in den ersten Wochen 15 unterschiedliche Ansichten weiß und rosa blühender Obstbäume vor dem strahlenden klar-blauen Himmel des Südens, die Ronald Pickvance treffend als „response to the pellucid atmosphere and limpid colors of a Provençal spring, joyous celebrations of pure visual enchantment "145, beschreibt. Sehr wahrscheinlich sind fast alle Ansichten in ein- und demselben Obstgarten entstanden, in dem van Gogh „en plein air“ mehrere Tage hindurch arbeitete, um die unterschiedlichen Fruchtbäume (Aprikose, Pfirsich, Pflaume, Kirsche, Birne und Apfel) einzufangen (vgl. Abb. 65 u. 66). Immer wieder tauchen ein den Garten einfassender Zaun und die vor dem Mistral schützende Reihe von Zypressen im Bildhintergrund auf, die allen Bildern einen sehr geschlossenen Charakter verleihen. Der Blick in die Ferne in Blühender Obstgarten (Pflaumenbäume), der schemenhaft die Stadt Arles erkennen lässt, stellt dagegen eine kompositorische und inhaltliche Ausnahme dar. ${ }^{146}$

Pickvance erkannte das wiederholte Malen am gleichen Ort als ein typisches Merkmal von van Goghs Arbeitsweise. Denn statt Zeit aufzuwenden, um neue Motive zu finden, bündelte van Gogh eher alle Energie auf das eingehende Studium ein- und desselben Bildgegenstandes; hier bedeutete dies, konzentriert die Essenz eines provenzalischen Obstgartens in voller Frühlingspracht aus verschiedenen Blickwinkeln, aber immer mit den Bäumen als unangefochtenen Protagonisten, einzufangen. ${ }^{147}$ Ein anderes verbindendes Merkmal ist die Abwesenheit von Menschen, Tieren und Arbeitsgeräten, was die Aufmerksamkeit ganz auf die blühenden Bäume lenkt - obwohl es sich natürlich bei dem Obstgarten um einen vom Menschen hochgradig überformten Naturraum handelt und die Anwesenheit des Menschen in der Natur dadurch indirekt sichtbar bleibt. ${ }^{148}$

Van Goghs Werke sind jedoch trotz aller farblichen und motivischen Gemeinsamkeiten weder in Format, Größe, Stil, noch in ihrer technischen Ausführung uni-

144 Brief 577/463, Arles, 21.2.1888, an Theo, zitiert nach Erpel 1965, Bd. 4, S. 5. Vgl. auch Noll 1996, S. 64.

145 Pickvance 1984, S. 45.

146 Blühender Obstgarten (Pflaumenbäume), März 1888, Öl auf Leinwand, 55 x 65 cm, Edinburgh, National Gallery of Scotland, F 553 JH 1387. Eine weitere Ausnahme ist Blühender Obstgarten, März 1888, Öl auf Leinwand, 72 x 58 cm, Privatsammlung Schweiz, F 406 JH 1399, bei dem mehrere Häuser im Hintergrund zu sehen sind.

147 Vgl. Pickvance 1984, S. 45.

148 Ausnahmen sind der Rechen und die Sense in Blühender Obstgarten, März 1888, Öl auf Leinwand, 72,4 x 53,5 cm, New York, The Metropolitan Museum of Art, F 552, JH 1381 sowie die auf dem Boden liegende Leiter in Obstgarten, von Zypressen gesäumt, April 1888, Öl auf Leinwand, 65 x 81 cm, Otterlo, Kröller-Müller Museum, F 513, JH 1389. 
form. Es handelt sich vor allem um Werke in Öl auf Leinwand, wobei einige einen pastosen, andere einen zum Teil extrem dünnen Farbauftrag aufweisen. Flächiger Farbauftrag steht experimentell-pointilistischem Tupfen gegenüber. ${ }^{149} \mathrm{Zu}$ der Serie gehören aber auch Bleistiftzeichnungen, bei denen van Gogh unter Hinzunahme von violetter Tinte und Weißhöhungen farbige Akzentuierungen vornahm, die sich damit auch in das übergeordnete Farbschema der Serie einfügen. ${ }^{150}$ Manche Fassungen entstanden in einer Sitzung vor Ort, andere wurden im Atelier nachträglich überarbeitet. ${ }^{151}$

Da der Bildraum grundsätzlich sehr sorgfältig angelegt ist, scheint es denkbar, dass van Gogh in mehreren Fällen seinen Perspektivrahmen benutzt hat; motivisch und beispielsweise auch bei der Wiedergabe in leichter Aufsicht bzw. bei den vom unteren Bildrand überschnittenen Bäumen der häufig im Vordergrund positionierten Bäume ist er zudem stark von japanischen Drucken mit vergleichbaren Szenen beeinflusst. Die motivischen und kompositorischen Verbindungen zu den in Paris wenige Monate zuvor entstandenen Japonaiserien nach den japanischen Holzschnitten, beispielsweise mit sehr ähnlichen Themen, wie Blühender Pflaumenbaum (nach Hiroshige) (Abb. 42), fallen sofort auf. ${ }^{152}$

Weiter könnten Darstellungen von Obstgärten Daubignys, aber hinsichtlich des Sujets auch der Obstgarten in Millets Frühling (Abb. 69) eine Inspiration gewesen sein. Letzteres war 1887 dem Louvre vermacht worden und wird dadurch sehr wahrscheinlich von van Gogh, da dies mit seinem Aufenthalt in der Stadt zusammenfiel, zur Kenntnis genommen worden sein. ${ }^{153}$ Wie bei van Goghs Ansichten liegt auch

149 Ein Beispiel für eher flächigen Farbauftrag ist Obstgarten, von Zypressen gesäumt, April 1888, Öl auf Leinwand, 65 x $81 \mathrm{~cm}$, Otterlo, Kröller-Müller Museum, F 513, JH 1389, wohingegen der Farbauftrag in Obstgarten mit Pfirsichblüte, April 1888, Öl auf Leinwand, 65 x $81 \mathrm{~cm}$, Privatsammlung, F 551, JH 1396, sehr pointilistisch ist.

150 Obstgarten mit Arles im Hintergrund, März 1888, Bleistift, Feder, schwarze und violette Tinte, 53,5 x 39,5 cm, New York, Hyde Collection, F 1516, JH 1376 u. Obstgarten mit blühenden Pflaumenbäumen, März 1888, Rohrfeder, Weißhöhungen, 39,5 x 54 cm, Amsterdam, Van Gogh Museum, F 1414, JH 1385. Weitere Werke dieser Serie: F 403, JH 1378; F 394, JH 1379; F 555, JH 1380; F 552, JH 1381; F 556, JH 1383; F 1469, JH 1384; F 511, JH 1386; F 553, JH 1387; F 554, JH 1388; F 513, JH 1389; F 404, JH 1391; F 405, JH 1394; F 551, JH 1396; F 557, JH 1397; F 399, JH 1398 u. F 406, JH 1399.

151 An Ort und Stelle entstand Blühender Obstgarten, März 1888, Öl auf Leinwand, 72 x 58 cm, Privatsammlung Schweiz, F 406 JH 1399, wohingegen Blühender Obstgarten, März 1888, Öl auf Leinwand, 72,4 x 53,5 cm, New York, The Metropolitan Museum of Art, F 552, JH 1381, im Studio korrigiert wurde. Vgl. Pickvance 1984, S. 46.

152 Blühender Pflaumenbaum (nach Hiroshige), September-Oktober 1887, Öl auf Leinwand, 55 x $46 \mathrm{~cm}$, Amsterdam, Van Gogh Museum, F 371, JH 1296. Besonders deutlich ist die Parallele beispielsweise bei Blühenden Pfirsichbaum, April 1888, Öl auf Leinwand, 81 x 62 cm, Amsterdam, Van Gogh Museum, F 404, JH 1391 und Kleiner Birnbaum in Blüte, April 1888, Öl auf Leinwand, 73,6 x 46,3 cm, Amsterdam, Van Gogh Museum, F 405, JH 1394.

153 Jean-François Millet (1814-1875), Frühling, 1868-1873, Öl auf Leinwand, 86 x $111 \mathrm{~cm}$, Paris, Musée d'Orsay. Vgl. Pickvance 1984, S. 46. Ob er in Paris entsprechende Beispiele von Monet, Pissarro, Sisley und Renoir zu sehen bekam, ist unklar. 
Millets in Blüte stehender Obstgarten fast gänzlich in menschenleerer Stille, wenn auch hier natürlich wieder die Natur vom Menschen kultiviert ist, einschließlich des zum Schutz vor den im Hintergrund zu erahnenden Naturgewalten errichteten Zaunes. ${ }^{154}$

Wie eingangs erwähnt, fiel im April im Zusammenhang mit den blühenden Obstgärten auch zum ersten Mal in zwei Briefen an Theo der bedeutsame Terminus „répétition ", 155 als er diesen wissen ließ, dass er gerne weitere Versionen neuer Werke anfertigen wolle, unter anderem von Blühender Pfirsichbaum (Souvenir de Mauve), einem hochformatigen Werk, das von einem großen, in voller weißer Blütenpracht stehenden Pfirsichbaum dominiert wird, den ein strahlend-hellblauer Frühlingshimmel hinterfängt. ${ }^{156}$

Zudem sprach van Gogh in Briefen an Theo bei den Bildern blühender Obstgärten mehrfach von zusammenhängenden „Serien “157. Besonders die Farben spielten bei dieser Klassifikation für van Gogh eine hervorgehobene Rolle. Wann immer er seinem Bruder oder Bernard von neu entstandenen Werken berichtete, legte er besondere Betonung auf die Wahl der Farbtöne. Bernard berichtete er Anfang April von „rosa Pfirsichbäume[n und] gelblich-weiße[n] Birnbäume[n] “158, an denen er Gefallen gefunden hatte. Diesem Brief war zudem eine Skizze „vom Eingang zu einem provenzalischen Obstgarten mit seinen gelben Zäunen, mit seinem Baumschutz von schwarzen Zypressen (gegen den Mistral), mit seinen charakteristischen Gemüsearten von unterschiedlichem Grün: gelber Salat, [...] smaragdgrüner Lauch" ${ }^{\text {"159, }}$ beigefügt (Abb. 68). Eben diese Skizze ist voller Farbangaben für die einzelnen Bildbereiche: der Himmel „ciel gros bleu“, der Pfirsichbaum links „peche rose“, das noch unbewachsene Erdreich links unten „lilas“, der Weg „chemin jaune“ und der große Birnbaum rechts sollte ein „poirier blanc“ sein. ${ }^{160}$ Die Skizze bezieht sich ferner auf

154 Internetseite des Musée d'Orsay, abgerufen unter: http://www.musee-orsay.fr/index.php?id=$851 \& \mathrm{~L}=1 \&$ tx_commentaire_pi 1 [showUid] $=7093 \&$ no_cache $=1$.

155 Vgl. Brief 595/476, Arles, 11.4.1888, an Theo, zitiert nach Erpel 1965, Bd. 4, S. 27-28, S. 27 sowie Brief 597/477, Arles, 13.4.1888, an Theo, zitiert nach Erpel 1965, Bd. 4, S. 28- 29, S. 28.

156 Bei den beiden Werken handelte es sich um Die Brücke von Langlois, 1888, Öl auf Leinwand, 53,4 x 64 cm, Otterlo, Kröller-Müller Museum, F 397, JH 1368 u. Blühender Pfirsichbaum (Souvenir de Mauve), März 1888, Öl auf Leinwand, 73 x 59,5 cm, Otterlo, Kröller-Müller Museum, F 394, JH 1379.

157 Vgl. Brief 601/479, Arles 25.4.1888, an Theo, zitiert nach Erpel 1965, Bd. 4, S. 31-33, S. 32 sowie Brief 608/486, Arles, 10.5.1888, an Theo, zitiert nach Erpel 1965, Bd. 4, S. 45- 46, S. 46. Auf beide Briefe weist Zimmer 2009, S. 107 hin.

158 Brief 596/B 3, Arles, 12.4.1888, an Émile Bernard, zitiert nach Erpel 1968, Bd. 5, S. 250-251, S. 251. Bei den beiden Werken handelt es sich um Obstgarten, von Zypressen gesäumt, April 1888, Öl auf Leinwand, 65 x 81 cm, Otterlo, Kröller-Müller Museum, F 513, JH 1389 u. Obstgarten mit Pfirsichblüte, April 1888, Öl auf Leinwand, 65 x 81 cm, Privatsammlung, New York, F 551, JH 1396.

159 Brief 596/B 3, Arles, 12.4.1888, an Émile Bernard, zitiert nach Erpel 1968, Bd. 5, S. 250-251, S. 251.

160 Bei der Skizze handelt es sich um den Brief 596/B 3 beigefügten Obstgarten, von Zypressen gesäumt, Bleistift und Tinte, 13,3 x 20,7 cm, New York, The Morgan Library, F- , JH 1390. 
das Sujet Obstgarten, von Zypressen gesäumt, das in zwei unterschiedlichen Formaten vorliegt. Zunächst entstand eine kleinere „étude“ mit flüchtigem und eher summarischem Duktus und danach eine „répétition“ als fast doppelt so großes, wesentlich feiner und detaillierter ausgearbeitetes „tableau" (Abb. 69). ${ }^{161}$

Wenige Tage später schrieb er Bernard erneut, um ihn von seinem Fortschritt in Kenntnis zu setzen. Wieder ist das maßgebliche Beschreibungskriterium die Wahl der Farben: „Ich habe neun Obstgärten in Arbeit: einen weißen, einen rosa, beinah roten, einen bläulichweißen, einen graurosa, einen grün und rosa. Einen davon (Leinwand) habe ich gestern verpfuscht, einen Kirschbaum gegen blauen Himmel; die jungen Blatttriebe waren orange und golden, die Blütenbüschel weiß - das gegen das Grünblau des Himmels war unerhört schön. "162 Auch das letzte Werk der Serie der blühenden Obstbäume illustrierte van Gogh in einem Brief an Theo wieder mit einer beigefügten Skizze und beschrieb es als "ganz hell und in einem Zuge gemacht. Eine wahre Wut dicker Pinselstriche, kaum mit Gelb und Lila abgetönt, in der weißen Blütenwolke im Vordergrund." ${ }^{163}$

Van Gogh war überzeugt von seinem Vorhaben, die Jahreszeiten abzubilden, und plante bereits mitten im Frühling, dieses Konzept im Folgejahr fortzusetzen, um den Charakter der provenzalischen Landschaft noch genauer zu erfassen: „Die neun Bilder dieses Jahres können wir als Anfang einer späteren, viel größeren Bilderreihe betrachten [...], die nach ganz den gleichen Motiven nächstes Jahr um dieselbe Zeit auszuführen wäre. "164 In einem wenig später geschriebenen Brief fragte er seinen Bruder rhetorisch: „Werden meine Arbeiten schlechter sein, weil ich am gleichen Ort bleibe und Jahreszeiten über dieselben Motive kommen und gehen sehe? Wenn ich im Frühling dieselben Obstgärten vor Augen habe und im Sommer dieselben Kornfelder, so sehe ich unwillkürlich meine Arbeit stets im Voraus von mir, und ich kann leichter Pläne machen [...,] um ein Ganzes zu schaffen, das von

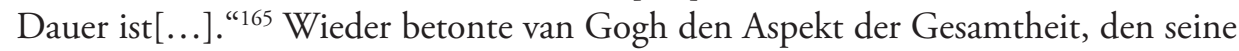
Werke ergeben sollten.

161 Obstgarten, von Zypressen gesäumt, April 1888, Öl auf Leinwand, 32,5 x $40 \mathrm{~cm}$, Privatsammlung, F 554, JH 1388 u. Obstgarten, von Zypressen gesäumt, April 1888, Öl auf Leinwand, 65 x $81 \mathrm{~cm}$, Otterlo, Kröller-Müller Museum, F 513, JH 1389.

162 Vgl. Brief 599/B 4, Arles, um 20.4.1888, an Émile Bernard, zitiert nach Erpel 1968, Bd. 5, S. 251-253, S. 253.

163 Brief 600/478, Arles, um 20.4.1888, an Theo, zitiert nach Erpel 1965, Bd. 4, S. 29-31, S. 30. Bei dem besprochenen Werk handelt es sich um Blühender Obstgarten, April 1888, Öl auf Leinwand, $72 \times 58 \mathrm{~cm}$, Privatsammlung, F406, JH 1399.

164 Brief 597/477, Arles, 13.4.1888, an Theo, zitiert nach Erpel 1965, Bd. 4, S. 28-29, S. 29. Auf diesen Brief verweist Zimmer 2009, S. 107.

165 Brief 680/535, Arles, 11.9.1888, an Theo, zitiert nach Erpel 1965, Bd. 4, S. 147-150, S. 148. Auf diesen Brief verweist Zimmer 2009, S. 107. 


\subsubsection{Saintes-Maries-de-la-Mer und La Crau-zwei Sommerserien}

Mehrere Wochen nach den Obstgärten widmete sich van Gogh dem Thema des Sommers und malte im Verlauf des Juni 1888 zwei Serien, bei denen nun mit den Farben Blau für das Wasser und Gelb für die Ernte jeweils unterschiedliche Farbaspekte dominieren sollten. Am 30. Mai brach van Gogh zunächst in das eine halbe Tagesreise entfernte Fischerdorf Les-Saintes-Maries-de-la-Mer auf, wo er insgesamt fünf Tage verbrachte und sich auf das blaue Farbspektrum konzentrierte. ${ }^{166}$ In seinem ersten Brief vom Mittelmeer beschrieb er seinem Bruder sofort die changierenden Farbeffekte des Wassers, das „eine Farbe [hat] wie die Makrelen, also wechselnd, man weiß nicht recht, ist es grün oder violett, man weiß nicht recht, ist es blau, denn eine Sekunde später schimmert es rosa oder grau. “167

Alles in allem malte er vor Ort „en plein air" drei Leinwände, zwei Seestücke und eine Ansicht des Ortes und fertigte neun Zeichnungen an, insbesondere von Fischerbooten und Hütten am Strand, von denen er einige nach seiner Rückkehr nach Arles an seinen Bruder schickte, andere wiederum im Atelier in Gemälde übertrug. ${ }^{168}$ Die zwei in situ entstanden querformatigen Seestücke weisen in Komposition und Duktus ein hohes Maß an Spontaneität auf (Abb. 70 u. 71). Besonders mit der kleineren Fassung war er sehr zufrieden, so dass er bald nach seiner Rückkehr eine Skizze mit Farbangaben anfertigte, die er an Bernard schickte. Wie in dem Brief an Theo angedeutet, enthält die Skizze Angaben zu den Farben im Bereich des Wassers, die von Blau, zu Violett-Grün, Grün und Weiß bis hin zu Rosa-Weiß reichen. ${ }^{169}$ Mehr noch als in dem großformatigen Seestück, das hauptsächlich vom Hellblau- und Flaschengrün des Dreiviertel des Bildraumes einnehmenden Wassers dominiert wird, hatte van Gogh für die kleinere Ansicht die mächtigen Wellen, die ihrerseits über die Hälfte des Bildes einnehmen, durch pastosen Auftrag von Weißund Gelbtönen akzentuiert.

166 Van Goghs Aufmerksamkeit auf das Fischerdorf könnte durch die alljährlich am 24.-25. Mai stattfindenden Feierlichkeiten zur Verehrung der Reliquien der heiligen Sarah gerichtet worden sein, die der Legende nach als Dienerin von Maria Cléophas (Schwester der Jungfrau Maria), Maria Salomé und Maria Magdalena im Jahr 45 mit in die Provence kam, als jene die dortige Bevölkerung zum Christentum bekehren wollten. Vgl. Pickvance 1984, S. 83 und für die Chronologie S. $69 f$.

167 Brief 619/499, Les Saintes-Maries-de-la-Mer, 3. oder 4.6.1888, an Theo, zitiert nach Erpel 1965, Bd. 4, S. 71-72, S. 71.

168 Vor Ort entstanden Seestück in Saintes-Maries-de-la-Mer, zw. 30.5.-3.6.1888, Öl auf Leinwand, 51 x 64 cm, Amsterdam, Van Gogh Museum, F 415, JH 1452; Kleines Seestück in Saintes-Maries-de-la-Mer, zw. 30.5.-3.6.1888, Öl auf Leinwand, 44 x 53 cm, Moskau, Puschkin-Museum, F 417, JH 1453 sowie Blick auf Saintes-Maries-de-la-Mer, zw. 30.5.-3.6.1888, Öl auf Leinwand, 64 x 53 cm, Otterlo, Kröller-Müller Museum, F 416, JH 1447. Im Atelier malte van Gogh nach Skizzen unter anderem Fischerboote am Strand, Juni 1888, Öl auf Leinwand, 64,5 x $81 \mathrm{~cm}$, Amsterdam, Van Gogh Museum, F 413, JH 1460.

169 Vgl. Skizze in Brief 622/B 6, Arles, ca. 7.6.1888, an Bernard, abgerufen in der Online-Ausgabe der Briefe, unter: http://vangoghletters.org/vg/letters/let622/letter.html. 
Ebenfalls im Brief vom 2. Juni beschreibt van Gogh seinem Bruder, wie er den Strand und das Meer bei einem nächtlichen Spaziergang empfand: „Am tiefblauen Himmel standen Wolken von noch tieferem Blau als das Grundblau, ein intensives Kobalt und noch andere von hellerem Blau, wie das blaue Weiß der Milchstraße. In der blauen Tiefe funkelten hell die Sterne [...]. Das Meer ein ganz tiefes Ultramarin - der Strand ein veilchenblauer und blaßroter Ton, wie mir schien - mit Buschwerk auf der Düne [...], preußischblaues Buschwerk." 170

Den tiefblauen Himmel hielt van Gogh in zwei nach seiner Rückkehr nach Arles entstandenen Werken fest. ${ }^{171}$ Zum einen in einem Aquarell der Fischerboote am Strand von Saintes-Maries-de-la-Mer, bei dem er in starkem Komplementärkontrast leuchtendes Blau im Bereich des Himmels und des Wassers sowie das golden-warme Gelb des Strandes gegenüberstellt. Ebenfalls nach seiner Rückkehr entstanden die Drei Hütten in Saintes-Maries-de-la-Mer (Abb. 72), wieder ein Werk voller leuchtender Farben mit einem „vollständig weiß getünchte[n] Häuschen (auch das Dach weiß) in orangefarbenem Gelände [...] jawohl, orange, denn der südliche Himmel und das blaue Mittelmeer bringen ein um so intensiveres Orange hervor, je leuchtender das Blau ist [...]." 172

Der Aufenthalt an der Küste und die Eindrücke in Les Saintes-Maries-de-laMer hatten entscheidende Auswirkungen auf van Goghs künstlerische Entwicklung und seine Beurteilung des Südens. An Theo schrieb er: "Jetzt da ich das Meer hier gesehen habe, fühle ich ganz, wie wichtig es ist, im Süden zu bleiben und zu spüren, daß man die Farbe noch mehr übersteigern muß - es ist nicht mehr weit bis Afrika. [...] Ich wünschte, Du könntest mal eine Zeit hier sein, Du würdest es nach einer Weile spüren, das Sehen wird anders, man sieht mit mehr japanischen Augen, man fühlt die Farbe anders. " ${ }^{173}$ Wie man die Farben miteinander kombinieren sollte, riet er Bernard eindringlich: „Kein Blau ohne Gelb und ohne Orange, und wenn Du das Blau malst, dann male gefälligst auch das Gelb und das Orange." 174

Daran hielt sich van Gogh bereits wenige Tage nach den Ansichten des Meeres. Statt, wie geplant, noch einmal nach Saintes-Marie-de-la-Mer zurückzukehren, um weitere Ansichten von der Küste anzufertigen, änderte sich van Goghs Fokus, und um den 12. Juni wandte er sich stattdessen der bevorstehenden Kornernte zu: „Ich habe ein neues Motiv in Arbeit, grüne und gelbe Felder, soweit man sehen kann [...]. " ${ }^{175}$ Infolgedessen entstand über mehrere Tage hinweg die Ernteserie in der

170 Brief 619/499, Les Saintes-Maries-de-la-Mer, 3. oder 4.6.1888, an Theo, zitiert nach Erpel 1965, Bd. 4, S. 71-72, S. 72.

171 Fischerboote am Strand von Les Saintes-Maries-de-la-Mer, Juni 1888, Aquarell auf Papier, 40,4 x 55,5 cm, St. Petersburg, Eremitage-Museum, F 1429, JH 1459 u. Drei Hütten in SaintesMaries-de-la-Mer, ca. 5. Juni 1888, Öl auf Leinwand, 33,5 x 41,5 cm, Kunsthaus Zürich, F 419, JH 1465.

172 Brief 622/B 6, Arles, ca. 7.6.1888, an Bernard, zitiert nach Erpel 1968, Bd. 5, S. 255-257, S. 256.

173 Brief 620/500, Arles, ca. 5.6.1888, an Theo, zitiert nach Erpel 1965, Bd. 4, S. 72-74, S. 72 u. 73.

174 Brief 622/B 6, Arles, ca. 7.6.1888, an Bernard, zitiert nach Erpel 1968, Bd. 5, S. 255-257, S. 257.

175 Brief 623/496, Arles, 12.6.1888, an Theo, zitiert nach Erpel 1965, Bd. 4, S. 63-65, S. 65. 
Ebene La Crau. Innerhalb von nur einer Woche schuf van Gogh insgesamt zehn Ansichten mit unterschiedlichen Aspekten der Kornernte auf dem Feld; man sieht, wie das Korn zunächst noch steht, bevor es geerntet und zu Garben zusammengebunden wird, und wie dann wieder neu ausgesät wird (vgl. Abb. 73). ${ }^{176}$

Bernard berichtete er voller Enthusiasmus, dass er „sogar mitten am Tage [arbeitet], mitten im Sonnenschein ohne jeden Schatten, in den Kornfeldern, kreuzvergnügt wie eine Grille.“"177 Auch Theo schrieb er von der „Woche gedrängter, harter Arbeit auf den Feldern bei glühender Sonne [...] Das Ergebnis sind Studien von Kornfeldern, Landschaften und - eine Skizze von einem Sämann. Auf einem umgepflügten Feld, einem großen Feld violetter Erdschollen, das gegen den Horizont ansteigt - ein Sämann in Blau und Weiß. Am Horizont ein niedriges reifes Kornfeld. Über dem ganzen ein gelber Himmel mit einer gelben Sonne. Du merkst an der einfachen Bezeichnung der Tonwerte, daß die Farbe in dieser Komposition eine sehr wichtige Rolle spielt. “178

Unter dem Eindruck des provenzalischen Sommers schilderte er Mitte Juni, in der Zeit, in der die Erntebilder entstanden, Willemien seine Gedanken zu der Bedeutung des vorherrschenden Farbspektrums dieser Jahreszeit:

Die Farbe ist eigentlich sehr fein hier. Wenn das Grün frisch ist, ist es ein sattes Grün, so wie wir es im Norden selten sehen, ruhig. Wenn es verbrennt und staubig wird, wird es nicht häßlich, sondern dann bekommt eine Landschaft die verschiedensten Goldtöne - Grüngold, Gelbgold, Rosagold, ebenso Bronze, Kupfer, kurz, von Zitronengelb bis zu der mattgelben Farbe wie etwa ein Haufen abgedroschenes Korn. Das zusammen mit dem Blau - vom

176 Die Ernte, Juni 1888, Öl auf Leinwand, 72,5 x 92 cm, Amsterdam, Van Gogh Museum, F 412, JH 1440; Die Strohhaufen, Juni 1888, Öl auf Leinwand, 73 x 92,5 cm, Otterlo, Kröller Müller Museum, F 425, JH 1442; Sommerabend, Juni 1888, Öl auf Leinwand, 74 x 92 cm, Kunstmuseum Winterthur, F 465, JH 1473; Ein Gehöft in der Provence, Mai-Juni 1888, Öl auf Leinwand, 46 × $61 \mathrm{~cm}$, Washington, National Gallery of Art, F 565, JH 1443; Kornfeld mit Gehöft, Juni 1888, Öl auf Leinwand, 50 x $61 \mathrm{~cm}$, Amsterdam, Stiftung Sammlung P. und N. de Boer, F 564, JH 1475; Kornfeld in der Crau, Juni 1888, Öl auf Leinwand auf Karton, 54 x 65 cm, Amsterdam, Van Gogh Museum, F 411, JH 1476; Die Garben, Juni 1888, Öl auf Leinwand, 53 x 64 cm, Honolulu Academy of Arts, F 561, JH 1480; Der Schnitter, Juni 1888, 73 x 54 cm, Öl auf Leinwand, Paris, Musée Rodin, F 545, JH 1477; Kornernte in der Provence, Juni 1888, Öl auf Leinwand, 50 x 60 cm, Jerusalem, The Israel Museum, F 558, JH 1481; sowie Sämann bei Sonnenuntergang, Juni 1888, Öl auf Leinwand, 64 x 80,5 cm, Otterlo, Kröller-Müller Museum, F 422, JH 1470. Van Gogh beschreibt den Sämann hier in einem frühen Stadium, denn wenig später überarbeitete er ihn erneut. Vgl. Fußnote 4 zu Brief 629/501, abgerufen in der Online-Ausgabe der Briefe, unter: http://vangoghletters.org/vg/letters/let629/letter.html.

177 Brief 628/B 7, Arles, 19.6.1888, an Émile Bernard, zitiert nach Erpel 1968, Bd. 5, S. 257-261, S. 258.

178 Brief 629/501, Arles, 21.6.1888, an Theo, zitiert nach Erpel 1965, Bd. 4, S. 74-76, S. 75. 
tiefsten bleu de roi im Wasser bis zu Vergißmeinnichtblau, Kobalt, vor allem helles, lichtes Blau - Grünblau und Violettblau. ${ }^{179}$

Van Gogh war von der Farbigkeit des Südens vollkommen eingenommen und sah eine klare Verbindung zu seinem Vorbild Monticelli. An Theo schrieb er im August: „Unter dem blauen Himmel bekommen die orange, gelben, roten Flecken der Blumen eine erstaunliche Leuchtkraft, und in der funkelklaren Luft schwingt es wie von etwas Glücklicherem als im Norden, wie von Verliebtsein. Das vibriert alles, wie der Blumenstrauß von Monticelli, den Du hast." ${ }^{180}$

\subsubsection{Der Herbst}

Waren die Bilder blühender Obstbäume maßgeblich weiß-rosa akzentuiert, die Erntebilder vor allem gelb-golden und die ebenfalls im Sommer in Les Saintes-Mariesde-la-Mer entstandenen Seestücke blau, so sollte der nächste Farbakzent das Grün der Weingärten im Herbst sein. ${ }^{181}$ Anknüpfend an den Brief an seine Schwester und mit Blick auf das große Ganze seines Jahreszeitenprojektes, schrieb er Theo Ende Juni: „Vielleicht mache ich mich nun auf die Suche nach dem Grün. Und der Herbst, der schenkt die ganze Tonleiter des Saitenspiels. "182 Im September teilte er Willemien mit, „daß man jetzt die reichen prächtigen Seiten der Natur malen muß.“ Im Oktober berichtete er dann voller Begeisterung: „Von Tag zu Tag wird es immer noch reicher. Und wenn beim Laubfall - ich weiß nicht, ob der hier wie bei uns in den ersten Novembertagen vor sich geht - wenn das ganze Laub gelb ist, so ergibt das gegen das Blau etwas ganz Großartiges. [...] Dann ein kurzer Winter, und dann sind wir wieder bei den blühenden Obstgärten angelangt." 183

Van Gogh malte im Herbst, als Gauguin bei ihm wohnte, nur noch vereinzelt Landschaftsbilder, aber Der grüne Weinberg und Der rote Weinberg fügen sich aufgrund ihrer Thematik und Farben in sein Jahresprojekt ein (Abb. 74 u. 75). ${ }^{184}$ Der grüne Weinberg war im Oktober entstandenen und nach van Goghs Beschreibung

grün, purpurn, gelb, mit violetten Trauben und schwarzen und orangefarbenen Reben. Am Horizont ein paar graublaue Weiden und weit, weit weg das Kelterhaus mit rotem Dach und die Silhouette der fernen lila Stadt. Im Weingarten kleine Damenfiguren mit roten Sonnenschirmen und andere

179 Brief 626/W 4, Arles, 16-20.6.1888, an Willemien, zitiert nach Erpel 1968, Bd. 5, S. 39-47, S. 45.

180 Brief 657/519, Arles, 8.8.1888, an Theo, zitiert nach Erpel 1965, Bd. 4, S. 113-116, S. 113.

181 Vgl. Bakker 2010, S. 197. Vgl. hier Brief 631/504, Arles, 25.6.1888, an Theo, nach Erpel 1965, Bd. 4, S. 79-81, S. 81.

182 Brief 631/504, Arles, 25.6.1888, an Theo, zitiert nach Erpel 1965, Bd. 4, S. 79-81, S. 81.

183 Brief 694/544, Arles, 3.10.1888, an Theo, zitiert nach Erpel 1965, Bd. 4, S. 178-182, S. 182.

184 Der grüne Weinberg, Oktober 1888, Öl aufLeinwand, 73,5 cm x 92,5 cm, Kröller-Müller Museum, Otterlo, F 475, JH 1595 u. Der rote Weinberg, November 1888, Öl auf Leinwand, 75 x 93 cm, Moskau, Puschkin-Museum, F 495, JH 1626. 
Figuren von Weinbergsarbeitern mit ihren Karren. Ein blauer Himmel darüber, und ein Vordergrund von grauem Sand. ${ }^{185}$

Der rote Weinberg hingegen zeigte ein anderes Farbspektrum des Herbstes: „[... ] wir [haben] einen roten Weingarten gesehen, ganz wie roter Wein. In der Ferne wurde er gelb, dazu ein grüner Himmel mit einer Sonne drin, das Gelände nach dem Regen violett, und hier und da, wo die untergehende Sonne sich spiegelte, funkelnd gelb." ${ }^{186}$ Aber seinem Bruder schrieb er Ende Oktober rastlos, dass er zur Komplettierung des Jahreskreises noch weitere Gemälde der anderen Jahreszeiten malen müsse. ${ }^{187}$

Die Phase großer Produktivität, in der zahlreiche Landschaftsbilder entstanden, endete direkt nach Gauguins Ankunft mit den vier Ansichten der römischen Nekropole Les Alyscamps, die in ihrem Entstehungskontext durch Gauguins Anwesenheit in vielerlei Hinsicht für van Gogh bedeutsame künstlerische Entwicklungsschritte verhießen. Gleichzeitig führten die sich an diese Alyscamps-Kampagne anschließenden Diskussionen wahrscheinlich auch zum ersten Zerwürfnis der beiden Künstler. Bis zur Abreise Gauguins malte van Gogh infolgedessen nur sehr wenige Landschaftsbilder, die jedoch, wie beispielsweise Der Sämann bei untergehender Sonne (Abb. 76) deutlich zeigt, unter dem Einfluss Gauguins aus dem Gedächtnis gemalt wurden. ${ }^{188}$ Van Gogh konzentrierte sich stattdessen auf andere Sujets, wie die noch zu besprechende Porträt-Serie der Familie Roulin (Kapitel 6.2.2.2.).

Van Gogh malte in den Alyscamps in kurzer zeitlicher Abfolge aus unterschiedlichen Blickrichtungen jeweils zwei hoch- und zwei querformatige Herbstlandschaften der durch die Nekropole führenden Pappelallee. ${ }^{189}$ In der zweiten hochformatigen Ansicht ergeben sich zwischen den Blautönen des Himmels, besonders den intensiven, dunklen Blauabstufungen des oberen Bildbereichs sowie den blau gemalten Baumstämmen auf der rechten Seite mit den leuchtend roten, gelben und orangefarbenen Blättern und der in ähnlichen Farben gehaltenen Allee einmal mehr sehr intensive Komplementärkontraste. ${ }^{190}$ Zwar erzeugte van Gogh bei der ersten hochformatigen Ansicht ebenfalls starke Farbkontraste, am deutlichsten durch das gelbe Laub der Bäume und das Graublau der Stämme sowie den hellblauen Him-

185 Brief 694/544, Arles, 3.10.1888, an Theo, zitiert nach Erpel 1965, Bd. 4, S. 178-182, S. 181.

186 Brief 717/559, Arles, 3.11.1888, an Theo, zitiert nach Erpel 1965, Bd. 4, S. 210-211, S. 211.

187 Vgl. Brief 715/558, Arles, ca. 29.10.1888, an Theo, nach Erpel 1965, Bd. 4, S. 205-207, S. 206.

188 Der rote Weinberg, 1888, Öl auf Leinwand, 75 x 93 cm, Moskau, Puschkin-Museum, F 495, JH 1626 u. Der Sämann bei untergehender Sonne, 1888, Öl auf Leinwand, 73,5 x 93 cm, Zürich, Stiftung Sammlung E. G. Bührle, F 450, JH1627. Vgl. Feilchenfeldt 2009, S. 53

189 Allée des Tombeaux (Les Alyscamps), ca. 29. Oktober 1888, 89 x $72 \mathrm{~cm}$, Öl auf Leinwand, Privatsammlung, F 568, JH 1622; Les Alyscamps, ca. 1. November 1888, 92 x 73,5 cm, Öl auf Sackleinen, Privatsammlung, zuletzt Sotheby's, New York, Auktion N09340, 5.5.2015, Los 18, F 569, JH 1623; Fallende Blätter (Les Alyscamps), ca. 1. November 1888, 73 x 92 cm, Öl auf Sackleinen, Otterlo, Kröller-Müller Museum, F 486, JH 1620 und Fallende Blätter (Les Alyscamps), ca. 1. November 1888, 72 x 91 cm, Öl auf Sackleinen, Privatbesitz, F 487, JH 1621.

190 Laut Druick/Zegers weitet er hier seine Theorie der Komplementärfarben aus. Vgl. Druick/Zegers 2001, S. 36. 
mel, doch ist die Intensivität und Leuchtkraft der Farben hier wesentlich zurückgenommener, da sie eher einem gedämpften Herbsttag entsprechen. ${ }^{191}$

Die zwei querformatigen Werke dagegen, die van Gogh in einem Brief an Bernard als „Zwei Studien vom Laubfall in einer Pappelallee“ 192 beschreibt, entstanden als Pendants und zeigen kompositorisch und farblich deutlich, wie van Gogh die künstlerischen Prinzipien Gauguins sich anzueignen suchte (Abb. 77 u. 78). Durch die Reduzierung der räumlichen Tiefe bei den querformatigen Ansichten, zugunsten von mehr Flächigkeit durch die Gliederung des Bildes in flächige Farbsegmente, näherte sich van Gogh Gauguins Auffassung von Räumlichkeit an. Die Ansichten der Alyscamps fielen gleichzeitig mit van Goghs eigenen Überlegungen und Experimenten mit den für ihn sehr wichtigen japanischen Farbholzschnitten zusammen, deren Einfluss bei der schrägen Aufsicht und der damit verbundenen Diagonalität der Kompositionen erkennbar ist.

Van Gogh schrieb an seinen Bruder über die Farbigkeit der querformatigen Ansicht, die sich heute in Privatbesitz befindet: „Es sind lila Pappelstämme - an der Stelle, wo die Belaubung anfängt, durch den Rahmen abgeschnitten. Diese Baumstämme säumen gleich Pfeilern eine Allee, an der rechts und links alte römische Grabmale von bläulichem Lila aufgereiht sind. Der Boden ist wie mit einem Teppich von einer dicken Schicht orange und gelber Blätter bedeckt; und noch immer mehr fallen herunter, wie Schneeflocken. "193

\subsubsection{Weitere Gliederungsprinzipien: Die Décoration}

Eine nähere Betrachtung, wie van Gogh unterhalb seines großen zyklischen Jahreszeitenprojektes die Werke in anderen Zusammenhängen ordnete, gibt weiteren Aufschluss über seine Arbeitsweise. ${ }^{194} \mathrm{Da}$ es sich bei den blühenden Obstgärten in Arles um gefällige Sujets, die mit intensiv leuchtenden Farben gemalt sind, handelt, die sich deutlich von den gedämpften Tönen der Maler der Haager Schule unterscheiden, hoffte van Gogh auf einen Erfolg namentlich auf dem holländischen Kunstmarkt ${ }^{195}$ und entwickelte in der Folge die „Idee, diese Gemälde für die Ausschmückung architektonischer Räume zu Triptychen und Pendants zu kombinieren." 196 Ein ähnliches Vorhaben hatte er bereits in Paris mit der Anfertigung dekorativer

191 Vorherrschende Farben im unteren Bildabschnitt sind beispielsweise unterschiedlich nuanciertes Beige, Ocker und mit Grau gemischte Grüntöne.

192 Brief 716/B 19a, Arles, Ende Oktober 1888, an Émile Bernard, zitiert nach Erpel 1968, Bd. 5, S. 288-289, S. 288.

193 Brief 717/559, Arles, 3.11.1888, an Theo, zitiert nach Erpel 1965, Bd. 4, S. 210-211, S. 211.

194 Da das Thema der Décoration in Dorns Dissertation außerordentlich ausführlich behandelt wurde, soll hier nur auf die wesentlichen Aspekte hingewiesen werden.

195 Vgl. Druick/Zegers 2001, S. 105. Damit ist van Gogh Claude Monets kommerziellen Aspirationen, die diesen nur wenig später zumindest teilweise zur Entstehung der angesprochenen Bilderserien motivierten, nicht unähnlich.

196 Bakker 2010, S. 196f. Eine weitere wichtige Rolle werden die erhaltenen Skizzen von der Dekoration von Bernards Atelier gespielt haben. 
Werkgruppen als Wandschmuck für Restaurants und Landhäuser konzipiert. Dabei hatte es sich um drei Triptychen mit querformatigen Landschaftsbildern, beispielsweise der Seine und Ansichten eines Parks in Asnières, gehandelt. ${ }^{197}$

Geplant waren in Arles zunächst drei Triptychen, von denen er schließlich jedoch nur eines realisieren konnte, und zwar dasjenige, das sich aus dem hochformatigen Blühenden Pfirsichbaum ${ }^{198}$ und den flankierenden querformatigen Werken Obstgarten mit blühenden Aprikosenbäumen sowie Obstgarten mit blühenden Pflaumenbäumen ${ }^{199}$ zusammensetzt. Neben den ähnlichen Motiven ist dabei auch das Format der Leinwände von Bedeutung, um Werke miteinander in Beziehung setzen zu können. Die im zitierten Brief von 1884 angesprochenen Komplementärfarbenpaare werden im Bemühen van Goghs, über ein Einzelwerk hinausgehende Zusammenhänge herzustellen, auch bei seinem zweiten großen Vorhaben relevant, als er sich, „[i]n der Hoffnung, [...] mit Gauguin im eigenen Atelier zu leben, [entschloss...] eine [Décoration] für das Atelier zu machen." 200

Im Zuge der Décoration für das von ihm in Arles bezogene Gelbe Haus, an der er von Mitte August bis Dezember 1888 arbeitete, ist neben dem Prinzip der Serie auch die Entstehung der Pendants bedeutsam. Bereits in seinen holländischen Jahren hatte van Gogh Bilder einander gegenübergestellt, die sich inhaltlich und thematisch ergänzten. Die Pendants sind zwar eher parallel zu seinem Vorhaben der Visualisierung der Jahreszeiten zu verstehen, doch veranschaulichen auch sie van Goghs Streben nach der Verknüpfung einzelner Werke. Vor dem Hintergrund der Ausschmückung des Gelben Hauses verfolgte van Gogh in Arles als künstlerisches Programm zunächst eine Aufteilung nach thematischen Gruppen, namentlich Sonnenblumen, kleinformatigen Portraits und dem sogenannten Garten des Dichters. ${ }^{201}$

197 Vgl. Bakker 2010, S. 197 u. Zimmer 2009, S. 102f. Bei den Bildern, die das Triptychon konstituierten, das „La Grande Jatte“ bezeichnet wurde, handelte es sich um Die Seine mit Ruderboot, Frühling 1887, Öl auf Leinwand, 55 x 65 cm, Privatsammlung, F 298, JH 1257; Allee im Park Voyer d'Argenson in Asnières, Frühling 1887, Öl auf Leinwand, 55 x 67 cm, Privatsammlung, F 277, JH 1316 u. Eingang zum Park Voyer d'Argenson in Asnières, Frühling 1887, Öl auf Leinwand, 54,6 x 66,8 cm, Jerusalem, The Israel Museum, F 305, JH 1265. Verbindende Elemente dieser Pariser Triptychen waren nicht nur ähnliche Sujets, sondern auch ein roter Rand, der noch bei einigen Gemälden sichtbar ist.

198 Blühenden Pfirsichbaum, April 1888, Öl auf Leinwand, 81 x 62 cm, Amsterdam, Van Gogh Museum, F 404, JH 1391.

199 Obstgarten mit blühenden Aprikosenbäumen, März 1888, Öl auf Leinwand, 65,5 x 80 cm, Amsterdam, Van Gogh Museum, F 555, JH 1380 sowie Obstgarten mit blühenden Pflaumenbäumen, April 1888, Öl auf Leinwand, 60 x 80 cm, Amsterdam, Van Gogh Museum, F 403, JH 1378.

200 Brief 666/526, 21 o. 22.6.1888, an Theo, vgl. Erpel 1965, Bd. 4, S. 131-132, S. 131. Vgl. Dorn 1990, S. 23. Van Gogh spricht im französischen Original von „décoration“, wohingegen die Übersetzung dafür bei Erpel ungenau „Reihe“ ist. Vgl. Online-Ausgabe der Briefe, abgerufen unter: http://vangoghletters.org/vg/letters/let666/letter.html.

201 Letzteres bezog sich auf eine Gruppe von Gemälden zu dem gleichen Thema, unter anderem Lichtung in einem Park - Der Garten des Dichters, September 1888, Öl auf Leinwand, 73 x 92 cm, Art Institute of Chicago, F 468, JH 1578. Vgl. Zimmer 2009, S. 109 u. Dorn 1990, S. 69 f. 
Dieses strenge System gab er relativ bald wieder auf, und anstatt nur Werke mit ähnlichen Motiven zusammenzustellen, kombinierte er in der Folge auch Werke, die sich aufgrund ihrer Farben oder lediglich durch ihre perspektivische Anlage ähnelten. Dies führte zu einer Vielfalt unterschiedlichster Motive. Verbindendes Element dieser Stufe der Décoration, zu der van Gogh insgesamt 17 Werke zählte, war das Format „Leinwand zu 30“. ${ }^{202}$ Roland Dorn fasst dies in seiner Dissertation zur Décoration zusammen: „Van Goghs Vorgehensweise bei der Konzeption der Werke, die der Décoration zugedacht waren, läßt insofern Regelmäßigkeit erkennen, als jedes neu entstehende Werk in der Regel recht eindeutig auf ein bestimmtes, bereits vorhandenes Bezug nimmt. [...] Stets wird in einem die Bildwirkung prägenden Moment Ähnlichkeit hergestellt, während in anderen Momenten der Gestaltung das entstehende Werk zum Gegenpol des vorhandenen ausgebildet wird. Van Gogh bedient sich hierzu eines begrenzten Repertoires ,komplementärer' Kontraste: Indem Nähe gegen Ferne, Innen gegen Außen, Offen gegen Verstellt gesetzt wird, entstehen Gegensätze in der räumlichen Wirkung [...]." ${ }^{203}$

Van Goghs bald durch formale, bald durch inhaltliche Gesichtspunkte bestimmte Motivation, Werke als Pendants auszuwählen, ist folglich vielschichtig und erscheint nicht immer kohärent. Hansen fasst dennoch treffend zusammen, dass van Goghs Pendants Werke seien, die sich „gegenseitig erläutern und im Ausdruck verstärken sollten. " ${ }^{204}$ Ein anschauliches Beispiel für Pendants dieser Schaffensphase sind die im Herbst 1888 in Arles entstandenen querformatigen Ansichten der Allee durch die Alyscamps. Als spiegelbildlich aufeinander bezogene Kompositionen von ein und derselben Allee werden sie - nebeneinander gehängt - zu Pendants, die sich wechselseitig in ihrer Wirkung verstärken. Gemeinsam ergeben sie eine panoramatische Ansicht der Allee, analog etwa einer Weitwinkelaufnahme.

202 Vgl. Dorn 1990, S. 69 u. Vgl. Zimmer 2009, S. 109. Beispiele sind Der grüne Weinberg, Oktober 1888, Öl auf Leinwand, 73,5 cm x 92,5 cm, Otterlo, Kröller-Müller Museum, F 475, JH 1595) u. Der rote Weinberg, November 1888, Öl auf Leinwand, 75 x 93 cm, Moskau, Puschkin-Museum, F 495, JH 1626. 



\section{Die Entwicklung von van Goghs Kunst als Ausdruck von Trost}

\subsection{Die Sinnsuche: van Goghs soziokulturelle und religiöse Prägung}

In diesem Kapitel soll der Frage nachgegangen werden, wie sich van Goghs Absicht, Trost durch seine Werke zu vermitteln - als einem zentralen Anliegen seines künstlerischen Schaffens - über die Jahre hinweg entwickelte, um schließlich in Saint-Rémy zu kulminieren. Der Fokus richtet sich zunächst wieder auf den Einfluss seines Elternhauses und sein soziokulturelles Umfeld, die, wie bereits erläutert wurde, ganz entscheidend seine Wahrnehmung von Kunst, Literatur und Musik geprägt haben. Darüber hinaus gilt es zu verstehen, wie diese Aspekte miteinander verwoben sind und über die Jahre zu einer künstlerischen Sensibilisierung van Goghs geführt haben. Ein Schwerpunkt ist, im Hinblick auf den Untersuchungsgegenstand dieser Arbeit, die besondere Bedeutung der Landschaftsmalerei für van Gogh.

Van Goghs Lebensweg kennzeichnen vielfach Misserfolge und Enttäuschungen. Seine zahlreichen Versuche, seinem Leben einen Sinn zu geben, scheiterten einer nach dem anderen, und es gelang ihm nicht, beruflich den Ansprüchen seiner Eltern und seines sozialen Milieus gerecht zu werden. Hinzu kamen mehrere gescheiterte Beziehungen. ${ }^{1}$ Wie Leo Jansen einleitend in seinem Aufsatz zu „Vincent van Gogh's Belief in Art as Consolation“ festhielt, litt dieser immer wieder an „severe and insistent existential malaise, and it was only natural that he should have felt an urgent need for solace. The outcome for his reasoning was a forgone conclusion: He needed

Vgl. Jansen 2003, S. 16. 
and therefore sought, with his own particular 'logic', to prove himself and to Theo that such consolation was possible. “2

Während seiner Jugend in der Provinz Brabant wird van Gogh viele Predigten seines Vaters gehört haben, in denen dieser, für die überwiegend aus verarmten Landarbeitern bestehende Gemeinde, eine Verbindung zwischen der Schrift und bestimmten Bildern herstellte, um religiöse Inhalte zu vermitteln. Die Kombination der zwei unterschiedlichen Medien wurde „bijschriften poëzie“ genannt und war bis in die 1870er Jahre in den Niederlanden eine sehr beliebte didaktische Form der Vermittlung. Viele einflussreiche Theologen, wie Jan Jakob Lodewijk ten Kate (1819-1889), griffen darauf zurück. Dies führte nicht nur zu einer weiten Verbreitung von Reproduktionen moderner Gemälde innerhalb der Bevölkerung, sondern auch zu einer Wahrnehmung eben jener Werke durch die moralisierenden Begleittexte der Theologen. ${ }^{3}$ Diese Herangehensweise sollte van Gogh später, zunächst noch bei seiner Entscheidung, selbst Geistlicher zu werden, und dann schließlich als Künstler, dazu veranlassen, Ausdrucksformen zu entwickeln, mit denen er die einfachen Menschen erreichen konnte. Ihre Sorgen und Nöte anzusprechen, war, wie bereits erwähnt, von Beginn an eines seiner Hauptziele. ${ }^{4}$

Die religiösen Konnotationen durchziehen in hohem Maße van Goghs frühe Korrespondenz mit seinem Bruder, insbesondere nach seiner ungewollten Versetzung nach Paris Mitte 1875 - damals war er noch im Kunsthandel tätig -, die zur Folge hatte, dass er sich außerordentlich intensiv mit Fragen der Religion und Sinnfindung auseinandersetzte. Er befasste sich mit Werken unterschiedlichster Art, um daraus ein spirituelles Bezugssystem aufzubauen: dazu gehörten zunächst die Bibel, aber auch andere religiöse Schriften, wie die Oraisons funèbres (1669) des gemäßigten französischen Geistlichen Jacques-Bénigne Boussuet (1627-1704) über die religiösen Vorstellungen des Autors und die Liebe Gottes. Dazu kontrastierend las van Gogh François Fénelons (1651-1715) didaktische Les aventures de Télémaque von 1699. Geschrieben als religiöses Handbuch für den Enkel Ludwig XIV., erzeugten sie im konservativen Frankreich des ausgehenden 17. Jahrhunderts aufgrund ihrer Betonung der subjektiven spirituellen Erfahrung, im Gegensatz zu den Traditionen der Kirche, nach ihrer Veröffentlichung großes Aufsehen. Van Gogh half es auf seiner intellektuellen und spirituellen Suche. ${ }^{5}$

Ein weiteres Charakteristikum der Groninger Schule waren ihre nationalistischen Tendenzen, die zu einem Wiedererwachen des Interesses an niederländischen

2 Jansen 2003, S. 13.

3 Ten Kate war besonders einflussreich. Er publizierte nicht nur regelmäßig in Kunstkronijk, dem führenden Kunstmagazin der Zeit, das auch van Gogh las, sondern auch eine Monographie über Ary Scheffers Gemälde Christus Remunerator. Vgl. Kōdera 1990, S. 16.

4 Vgl. für diesen einleitenden Absatz Greer 2003, S. 64 u. 67, wo Greer genauer erklärt, inwiefern Protestantische Geistliche im 19. Jahrhundert beispielsweise sogenannte „bijschriften poëzie“ verwendeten, eine Kombination aus Bild und Gedicht, um religiöse Botschaften zu übermitteln. Vgl. auch Kōdera 1990, S. $15 f$.

5 Vgl. Van der Veen 2003, S. 53. 
Quellen, literarischer und intellektueller Natur, aus der Zeit vor Calvin führten. Einer der Autoren, mit denen sich in der Folge auch van Gogh beschäftigte, war Thomas à Kempis (um 1380-1471), dessen De imitatione Christi von 1441 er wiederholt las und aus dem er immer wieder in Briefen zitierte. Das Werk zeigt eine für van Gogh zugängliche Beschreibung Christi und schildert das Leben als eine Pilgerfahrt, in der die Beschränkung eigener Bedürfnisse und die Aufopferung für andere als Weg zu einer Erlösung durch Christus erscheint. ${ }^{6}$ In einem Brief an Theo beschrieb er De imitatione Christi im September 1877 ehrfurchtsvoll: „Worte stehen darin, so tief und ernst, daß man sie nicht ohne Bewegung, ja fast Angst, lesen kann, wenigstens wenn man sie mit aufrichtigem Verlangen nach Licht und nach Wahrheit liest; diese Sprache ist die Beredsamkeit, die Herzen gewinnt, weil sie aus dem Herzen kommt."

Daneben wandte sich van Gogh aber auch der Poesie zu, beispielsweise mehrfach der Lyrik Friedrich Rückerts (1788-1866), der, nach dem Verlust seiner beiden Kinder um die Jahreswende 1833/34, ein halbes Jahr lang als Trauerarbeit 428 Gedichte geschrieben hatte, die später als Kindertodtenlieder erschienen. „Besten Dank für ,Aus der Jugendzeit und ,Um Mitternacht' von Rückert. Es ist ergreifend

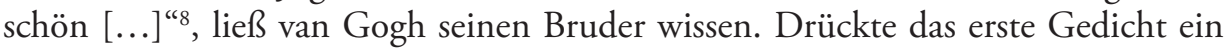
Sehnen nach verlorener Jugend aus, war „Um Mitternacht" als ein Ausdruck von Weltschmerz zu verstehen, für den Linderung bei Gott gefunden werden kann.? Rückert war in den Kindertodtenliedern überzeugt davon, dass seine toten Kinder Aufnahme im Himmel gefunden hatten und dass er sie dort wiedersehen würde. Er verstand den Tod ,as a kernel inherent in each being that eventually becomes the fruit of that life. The afterlife that follows is the realm of eternal light." ${ }^{10}$

Rückert stand damit Gustav Theodor Fechners (1801-1887) transzendentaler Naturphilosophie nahe, nach der der Tod lediglich ein Übergangsstadium auf dem Weg zu einer dritten Daseinsstufe sei. Van Gogh, in dieser Zeit noch vollkommen kirchenreligiös, interpretierte Rückerts Gedichte hingegen aus seinem eigenen christlichen Blickwinkel. Wenig später zitierte er in einem Brief an seinen Bruder aus einem anderen Gedicht Rückerts und verband dies mit dem Auftrag, Gutes in der Welt zu tun:

Flügel, Flügel übers Leben!

Flügel über Grab und Tod!

6 Vgl. für diese Interpretation von De imitatione Christi Greer 2003, S. 64 u. Van der Veen 2003, S. 52.

7 Brief 129/108, Amsterdam, 4.9.1877, an Theo, zitiert nach Erpel 1965, Bd. 1, S. 140-142, S. 140.

8 Brief 39/32, Paris, 24.7.1875, an Theo, zitiert nach Erpel 1965, Bd. 1, S. 35.

9 Vgl. Fußnote 2 zu Brief 39/32 in der Online-Ausgabe der Briefe, abgerufen unter http:// vangoghletters.org/vg/letters/let039/letter.html.

10 Hefling 2015, S. 21. 
Die haben wir nötig, und allmählich sehe ich, daß wir sie kriegen können. Sollte etwa Pa keine haben? Und wie er die bekommen hat, weißt Du, durch das Gebet und dessen Frucht - Geduld und Glauben, und durch die Bibel, die ein Licht auf seinem Wege und seines Fußes Leuchte gewesen ist.

Heute nachmittag habe ich eine schöne Predigt gehört [...], Ayez plus d'espérance que de souvenirs; ce qu'il y a eu de sérieux et de béni dans votre vie passée n'est pas perdu; ne vous en occupez donc plus, vous le retrouverez ailleurs, mais avancez. - Tout choses sont devenues nouvelles en Jésus Christ. [...] sollte es da nicht unser Streben und unsere Hoffnung sein, Männer zu werden wie unser Vater und andere? Laß uns beide das hoffen und erbitten. ${ }^{11}$

Van Goghs zunehmende Hinwendung zur Religion führte zu Konflikten und schließlich zum Bruch mit seinem Arbeitgeber; im April 1876 endete seine Beschäftigung bei Goupil. Etwas später, nachdem er zunächst eine Anstellung als Hilfslehrer im englischen Ramsgate angenommen hatte, dann auf sein Drängen als Hilfsprediger in Isleworth bei London angestellt worden war, erwähnte er in einem langen Brief an seinen Bruder verschiedene Bibelstellen unter dem Aspekt des Trostes: „Wer nicht geliebt hat, hat Gott nicht gekannt, denn Gott ist Liebe. Das aber ist das ewige Leben: Gott zu kennen und Christum, den er gesandt hat. $\mathrm{Da}$ ist in der Liebe keine Furcht. [...] Denn ich bin nicht allein, sondern der Vater ist bei mir. [...] Laß Christum den Mittelpunkt Deines Verlangens sein, den Tröster des beunruhigten Gemütes." ${ }^{12}$ Wieder und wieder kam van Gogh auch auf den Propheten Jesaja zurück. Wohl in kaum einem anderen Buch der Bibel ist das Wort "Trost" häufiger erwähnt als hier. ${ }^{13}$ Durchdrungen von seinem Glauben an Gott bekannte er seinem Bruder:

Ich für mein Teil will trachten nach der Liebe zu Christus und nach der Arbeit für ihn in meinem Leben; und wenn es auch mißlingt und wenn ich auch falle, so wird immer noch übrigbleiben, daß ich von weitem dabeistehe und aus dem Elend unten einen Seufzer nach oben emporschicke. Aber ich will unter allen Umständen den Glauben und die Liebe suchen und um

$11 \quad$ Brief 47/37, Paris, 12.9.1875, an Theo, zitiert nach Erpel 1965, Bd. 1, S. 39-40. Das Zitat aus der Predigt ist im Brief van Goghs auf Französisch während der Rest auf niederländisch ist. Das Zitat Rückerts ist dem Ende der zweiten Strophe dessen Gedichts „Flügel! Flügel um zu fliegen“ aus dem Band Liebesfrühling (1844) entlehnt. Das Wort „Flügel“ in der zweiten Zeile taucht im Originaltext nicht auf. Vgl. Fußnote 1 zu Brief 47/37 in der Online-Ausgabe der Briefe, abgerufen unter http://vangoghletters.org/vg/letters/let039/letter.html.

12 Brief 90/82a, Isleworth, zw. 2./8.9.1876, an Theo, zitiert nach Erpel 1965, Bd. 1, S. 88-96, S. 91. Van Gogh zitiert u.a. 1 Johannes 4:8 („Wer nicht liebt, hat Gott nicht erkannt, denn Gott ist Liebe“), Johannes 17, 3 („Dies aber ist das ewige Leben, dass sie dich, den allein wahren Gott, und den du gesandt hast, Jesus Christus, erkennen.") und 1 Johannes 4, 18 („Furcht ist nicht in der Liebe $\left.[\ldots]^{\prime \prime}\right)$.

13 Vgl. Brief 90/82a, Isleworth, zw. 2./8.9.1876, an Theo, zitiert nach Erpel 1965, Bd. 1, S. 88-96, S. 93 und Jansen 2003, S. 17. 
Gottes Geist weiterbitten. Dies ist nun mein Gelöbnis an den Herrn, meinen [...] Felsen. ${ }^{14}$

Van Gogh steigerte sich im Herbst 1876 mehr und mehr in seinen Glauben hinein und sah die Möglichkeit, als Geistlicher zu arbeiten als einzigen Ausweg aus seinem Leiden; er wollte die Botschaft Christi verkünden, um Trost zu spenden und um selbst Trost und Zuversicht daraus zu beziehen.

Aber wie schrecklich muß das Leben sein, besonders später, wenn in den Dingen dieser Welt das Böse jedes Tages zunimmt, falls unser Leben nicht durch den Glauben geschützt und getröstet wird. [...] Theo, wehe mir, wenn ich das Evangelium nicht predigte, wenn ich das nicht im Auge hätte und nicht auf Christus hoffte und vertraute, dann würde ich nur Weh haben, nun aber habe ich etwas Mut. ${ }^{15}$

Nach van Goghs Rückkehr nach Holland und noch bevor er nach Amsterdam gezogen war, um sich auf sein Theologiestudium vorzubereiten, lebte er für gut vier Monate in Dordrecht, im Südwesten der Niederlande, und arbeitete dort in einem Buchladen. Immer wieder kam van Gogh in dieser Zeit auf Ary Scheffers (17951858) Gemälde Christus Consolator zu sprechen, von dem er wie seine Eltern eine druckgraphische Reproduktion besaß und die nicht nur seine Kammer in Isleworth geschmückt hatte, sondern nun auch über dem Schreibtisch in seinem Zimmer in Dordrecht hing (vgl. Abb. 79). ${ }^{16}$

Scheffers im Jahre 1837 entstandenes Motiv des thronenden Christus, der der ihn umgebenden Schar notleidender Menschen von unterschiedlichster Herkunft und unterschiedlichen Alters Trost spendet, war durch einen Vers aus dem LukasEvangelium inspiriert: „Der Geist des Herrn ruht auf mir; denn der Herr hat mich gesalbt. Er hat mich gesandt, damit ich den Armen eine gute Nachricht bringe; damit ich den Gefangenen die Entlassung verkünde und den Blinden das Augenlicht; damit ich die Zerschlagenen in Freiheit setze. " 17 Mitte des 19. Jahrhunderts war Scheffers Christus Consolator zu einer der bekanntesten und beliebtesten Christus-

14 Brief 90/82a, Isleworth, zw. 2./8.9.1876, an Theo, zitiert nach Erpel 1965, Bd. 1, S. 88-96, S. 92.

15 Brief 97/80, Isleworth, 10.11.1876, zitiert nach Erpel 1965, Bd. 1, S. 85-86, S. 85. Vgl. Jansen 2003, S. 17 für den Verweis auf diese Briefstelle.

16 „Die zwei Drucke, Christus Consolator', die ich von Dir bekommen habe, hängen in meiner Stube - ich sah die Bilder im Museum, und auch von Scheffer: ,Christus in Gethsemane', das kann man nie vergessen." Brief 101/84, Dordrecht, 21.1.1877, an Theo, zitiert nach Erpel 1965, Bd. 1, S. 98-99, S. 98. Vgl. für diesen Brief auch Veldhorst 2015, S. 98. Bei den Werken handelte es sich um Reproduktionen von Gemälden Ary Scheffers (1795-1858), Christus in Gethsemane, 1839, Dordrechts Museum u. Christus Consolator, 1837, Amsterdam, Van Gogh Museum (Leihgabe des Amsterdams Historisch Museum). Vgl. Online-Ausgabe der Briefe, Fußnote 7, abgerufen unter http://vangoghletters.org/vg/letters/let101/letter.html. Van Gogh hatte seinen Bruder erinnert, ihm doch die Drucke zu schicken, die dieser ihm versprochen hatte, vgl. Brief 85/70, Isleworth, 5.7.1876, an Theo, nach Erpel 1965, Bd. 1, S. 68-70, S. 69.

17 Lukas 4, 18, zitiert Jesaja 61, 1. 
Darstellungen avanciert; zahlreiche günstige Reproduktionen machten es breiten Bevölkerungsgruppen zugänglich. ${ }^{18}$

Van Gogh hatte durch seinen Vater den Gedanken verinnerlicht, dass Gott sich nicht nur im Wort, sondern auch in der Schöpfung, also in der Natur, und in der Menschheit, dabei insbesondere in Jesus Christus, offenbare. Christus wurde, wie Jansen festhielt, erachtet ,as the personification of consolation in the biblical sense: the Consoler of the poor and weak. By extension he was thought to fulfill this function for all mankind, since according to Christian doctrine every mortal bears the mark of original sin and is thus in need of succour. "19 Jesu Demut war, wie van Gogh ebenfalls durch seinen Vater gelernt hatte, Leitgedanke für ein gotterfülltes Leben, in dem die Nächstenliebe als wichtigstes Prinzip von Tugendhaftigkeit galt. ${ }^{20}$ Die Wertschätzung von Scheffers Christus Consolator zeigt, dass van Gogh Trost nicht nur aus dem gesprochenen oder geschriebenen Wort zu beziehen vermochte, sondern auch und insbesondere aus bildlichen Darstellungen und dass diese als Träger einer tieferen Botschaft für ihn fungieren konnten. ${ }^{21}$ Dies war ein entscheidender Fingerzeig für van Goghs Arbeit als Künstler.

Als van Gogh nach Amsterdam gezogen war, um sich auf sein Theologiestudium vorzubereiten, lernte er durch seinen Onkel, den Theologen Johannes Paulus Stricker (1816-1886), die Lehren der Modernen Schule kennen, deren Anhänger seit der Mitte des 19. Jahrhunderts Erneuerung und Reformen im niederländischen Protestantismus zu implementieren suchten. Ihre Wurzeln hatte die Moderne Schule in kontroversen Schriften wie Das Leben Jesu, kritisch bearbeitet, das 1835/36 von David Friedrich Strauß (1808-1874) publiziert worden war, und in der Folge zu einer der wichtigsten theologischen Schriften des 19. Jahrhunderts avancierte. Durch die Moderne Schule wurden in vielerlei Hinsicht radikalere Ansichten als durch die Mitglieder der Groninger Schule vertreten. Dazu gehörte, durch kritische Hinterfragung des geschriebenen Wortes in der Bibel und die Zurückweisung des übernatürlichen Wirkens in Christi Leben, konkret das Postulat, dass dieser rein menschlicher Natur gewesen sei. Von den Anhängern der Modernen Schule wurde der Standpunkt vertreten, dass sich Religion, damit sie in einer sich modernisierenden Gesellschaft weiterhin Bedeutung haben könne, den Begebenheiten der sich wandelnden Zeit anpassen und wissenschaftlich greifbarer werden müsse. ${ }^{22}$

Durch seinen intensiven Austausch mit Stricker in Amsterdam verinnerlichte van Gogh nicht nur dessen Ansatz hinsichtlich der Vermittlung religiöser Inhalte, der darauf zugeschnitten war, von den einfachen Menschen verstanden zu werden, sondern auch die Art, wie Stricker religiöse und künstlerische Inhalte miteinander

18 Vgl. Greer 2003, S. 70f. u. Katalogisierung des Gemäldes auf der Internetseite des Minneapolis Institute of Art, abgerufen unter https://collections.artsmia.org/art/104894/christus-consolatorary-scheffer.

19 Jansen 2003, S. 16

20 Vgl. Stolwijk 2003, S. 26.

21 Vgl. Jansen 2003, S. 17.

22 Vgl. Greer 2003, S. 65 u. Kōdera 1990, S. 19. 
verknüpfte. Die wichtigste Erkenntnis könnte jedoch Strickers ablehnende Haltung bezüglich der Wunder und der übernatürlichen Ereignisse in Christi Leben gewesen sein, die dieser nicht wörtlich, sondern allegorisch auffasste. Stricker veröffentlichte seine Thesen 1868 in Jesus van Nazareth, volgens de historie geschetst, seiner wichtigsten Publikation. Er griff damit viele Themen auf, die Ernest Renan (1823-1892) bereits 1863 in seinem Werk La vie de Jésus diskutiert hatte. Da van Gogh letzteres sehr schätzte, werden Strickers Ansichten zur Frage nach Christi Menschlichkeit bei ihm auf fruchtbaren Boden gefallen sein. ${ }^{23}$

Die Vorbereitungen für das Theologiestudium brach van Gogh kurze Zeit später wieder ab, da sie zu viel theoretische Studienarbeit beinhalteten, um daraufhin mit wenig Erfolg eine Missionarsschule in Brüssel zu besuchen und letztlich im Borinage als Prediger bei verarmten Bergarbeitern zu arbeiten. Getrieben von seinem religiösen Eifer gab er nahezu allen seinen Besitz fort, um in gleicher Armut wie die Bergleute zu leben und ihr Schicksal zu teilen. Sein extremes Verhalten führte jedoch zu einem raschen Ende seines Anstellungsverhältnisses, als im Sommer 1879 sein Arbeitsvertrag nicht verlängert wurde. Nachdem van Gogh in all seinen Versuchen, das Wort Gottes im Auftrag der Kirche zu verbreiten und dabei den Menschen Trost zu spenden, gescheitert war, wandte er sich nach Monaten der Desillusionierung, Depression und Perspektivlosigkeit der Kunst zu.

\subsection{Gebrauch des Trostbegriffs nach van Goghs Entscheidung, Künstler zu werden}

Gebrauchte van Gogh den Terminus „Trost“ zunächst fast ausschließlich in religiösem Zusammenhang, veränderte sich diese Praxis fast schlagartig im Jahre 1880, nach seiner Entscheidung, Künstler zu werden. ${ }^{24}$ Dies geht einher mit van Goghs sich ändernder Haltung gegenüber der kirchlichen Lehre, von der er sich über die Jahre immer weiter entfernte. Im September 1888 konstatierte er gar: „Victor Hugo sagt: Gott ist ein Leuchtturm mit Blinkfeuer; da erleben wir sicher jetzt gerade den dunklen Augenblick. " ${ }^{25}$ Etwas anders verhielt es sich mit der Bibel, die für van Gogh seit seiner Jugend eine wichtige Quelle des Studiums und des Nachdenkens über Christi Leben und Wirken und damit auch über das eigene Leben dargestellt hatte. Die Verwendung von Bibelzitaten erfolgt bei van Gogh relativ konstant während seines ganzen Lebens, wobei er diese zunehmend durch Zitate aus anderen literarischen Quellen ergänzte und in demselben Zusammenhang auch Bilder erwähnte. Wie Joan Greer in ihrem Aufsatz zu „Van Gogh's Socio-religious Canon of Art“ bemerkt, handelt es sich insbesondere um Werke, die „could transit the truths he

23 Vgl. Greer 2003, S. 65f.

24 Vgl. Veldhorst 2015, S. 98 u. Jansen 2003, S. 16-18.

25 Vgl. Brief 691/543, Arles, ca. 29.9.1888, an Theo, zitiert nach Erpel 1965, Bd. 4, S. 174-178, S. 175. Vgl. für den Hinweis auf diesen Brief Noll 1996, S. 175. 
found in the Bible in a form more relevant to contemporary humanity. ${ }^{\text {26 }}$ Diese Funktion, glaubte er, könnten, Kunst, moderne Literatur und Musik gleichermaßen erfüllen.

Das letzte Mal, dass van Gogh „Trost“ in religiösem Zusammenhang verwendete, war in einem Brief an Theo aus dem Borinage vom 26.12.1878. ${ }^{27}$ Das nächste Mal tauchte das Wort in van Goghs Brief vom 24.9.1880 bereits in einem künstlerischem Zusammenhang auf, nur wenige Wochen nachdem er sich dazu entschlossen hatte, seinem Leben eine Wende zu geben und Künstler zu werden. Anlass für die Erwähnung war die Reise in die nordfranzösischen Stadt Courrièrres, wo es ihm nicht gelang, den von ihm geschätzten Maler Jules Breton zu treffen. Bereits zu diesem Zeitpunkt wird deutlich, dass für van Gogh die Fähigkeit, Trost zu spenden, ein Qualitätskriterium guter Kunst war. Ablehnend äußerte er sich über das, was er in Courrièrres gesehen hatte:

Doch von lebenden Künstlern keine Spur, nur ein Café gab es, das, Café zu den Schönen Künsten' hieß es, ebenfalls aus neuen, ungastlichen, frostigen scheußlichen Ziegeln; dieses Café war mit einer Art Fresken oder Wandmalereien geschmückt, Szenen aus dem Leben des berühmten Ritters Don Quichotte. Diese Fresken, im Vertrauen gesagt, schienen mir damals erbärmliche Tröster und recht mittelmäßig. ${ }^{28}$

In seinen Anfangsjahren als Künstler schrieb van Gogh ansonsten relativ selten über den Aspekt des Trostes. Dies änderte sich erst mit Vollendung seines ersten ausgereiften Gemäldes, der Kartoffelesser (Abb. 36). Jansen erklärt, dass die langen Jahre des autodidaktischen Studiums van Gogh bis dahin wenig Zeit und Anlass gegeben hätten, über die Wirkung seiner Bilder aus dieser Perspektive zu reflektieren. ${ }^{29}$ Dennoch hatte er bereits in seinen künstlerischen Anfängen eine klare Vision, wie er als Künstler gesehen werden und wie er die Menschen emotional erreichen wollte.

$\mathrm{Ob}$ nun in Figur oder Landschaft - ich möchte nicht etwas SentimentalWehmütiges ausdrücken, sondern ernsten Schmerz. Kurz, ich will es soweit bringen, daß man von meiner Arbeit sagt: dieser Mann fühlt tief, und dieser Mann fühlt fein. [...] Was bin ich in den Augen der meisten? - Eine Null oder ein Sonderling oder ein unangenehmer Mensch - jemand, der keine Stellung in der Gesellschaft hat oder haben wird, kurz, etwas Geringeres als die Geringsten. Gut - angenommen, das allest stimmte, dann möchte ich durch meine Arbeit einmal zeigen, was im Herzen eines solchen Sonderlings,

26 Greer 2003, S. 63.

27 Vgl. Brief 149/127, Wasmes, 26.12.1878, an Theo, zitiert nach Erpel 1965, Bd. 1, S. 188-190, S. 189.

28 Brief 158/136, Cuesmes, 24.9.1880, an Theo, zitiert nach Erpel 1965, Bd. 1, S. 213-218, S. 214-215. Auf diesen Brief verweist Jansen 2003, S. 18.

29 Vgl. Jansen 2003, S. 18. 
eines solchen Niemands steckt. Das ist mein Streben - das beruht, malgré tout, weniger auf Groll als auf Liebe [...]. ${ }^{30}$

Der bereits sehr früh bei van Gogh erkennbare Wille, Gutes für die Menschen zu tun, ging einher mit einem 1882 entwickelten, aber letztlich nicht verwirklichten Konzept, Kunst mittels billiger Reproduktionen möglichst breiten Bevölkerungsschichten zugänglich zu machen. ${ }^{31}$ Weil er sich selbst als Außenseiter wahrnahm, war es ihm ein großes Anliegen, Menschen am Rande der Gesellschaft zu helfen, indem er ihnen eine Stimme gab. Voller Leidenschaft und Tatendrang hatte er seinen Bruder rhetorisch gefragt: „Worauf also kommt es an? Auf Wagemut und Selbstaufopferung, und zwar muß etwas gewagt werden, das nicht nur des Gewinnens willen getan werden darf, sondern weil es nützlich und gut ist; man muß zu Mitmenschen und Landsleuten im allgemeinen Vertrauen haben." 32

Von Émile Zola hatte er im Sommer 1883 die Beschreibung eines guten Kunstwerkes übernommen, dass „un coin de la nature vu à travers d'un tempérament“ ${ }^{33}$ sein müsse und sprach auch in seinen Briefen in den Jahren 1884-85 wiederholt von „Empfindung“, die ein Bild transportieren müsse. Hinsichtlich der Frage, wie diese in Bildern ausgedrückt werden könne, vertrat er die Haltung, dass die technische Ausführung und Charakteristika eines Bildes Mittel und Weg zu einem höheren Ziel seien, etwas „jenseits der Technik“ 34 auszudrücken. „Mögen sie von Technik salbadern, was sie wollen, mit pharisäischen, hohlen, scheinheiligen Worten - die wahren Maler lassen sich durch jenes Gewissen leiten, das man Empfindung nennt, von ihrer Seele [...]. “35 Für van Gogh war Rembrandt besonders in der Lage gewesen, dieses Gefühl in seinen Landschaftsbildern auszudrücken: „Es ist mehr als die Natur, es hat etwas von einer Offenbarung. Und mir scheint, man tut gut daran, allen Respekt davor zu haben und sich still zu verhalten, wenn oft behauptet wird, es sei übertrieben oder manieriert. “36

30 Brief 249/218, Den Haag, ca. 21.7.1882, an Theo, zitiert nach Erpel 1965, Bd. 2, S. 57-59, S. $57 \mathrm{f}$.

31 Vgl. Jansen 2003, S. 18.

32 Brief 289/249, Den Haag, 1.12.1882, an Theo, zitiert nach Erpel 1965, Bd. 2, S. 143-147, S. 145.

33 Brief 361/299, Den Haag, 11.7.1883, zitiert und übersetzt nach Erpel 1965, Bd. 2, S. 295-301, S. 295. Für den Verweis auf Zola vgl. Fußnote 9 im Kommentar zu diesem Brief in der OnlineAusgabe der Briefe, abgerufen unter: http://vangoghletters.org/vg/letters/let361/letter.html\#n-9.

34 Brief 439/R 43, Nuenen, ca. 18.3.1884, an van Rappard, zitiert nach Erpel 1968, Bd. 5, S. 209215, S. 210. Vgl. Jansen 2003, S. 15.

35 Brief 534/426, Nuenen, ca. 10.10.1885, an Theo, zitiert nach Erpel 1965, Bd. 3, S. 307-311, S. 309.

36 Brief 361/299, Den Haag, 11.7.1883, zitiert und übersetzt nach Erpel 1965, Bd. 2, S. 295-301, S. 295. 


\subsubsection{Exkurs: Klassische Musik als Mittel der künstlerischen Sensibilisierung und zur Steigerung des Ausdrucks}

Für die weitere künstlerische Entwicklung van Goghs, dabei vor allem hinsichtlich der Frage nach Empfindung in der Malerei, und für seine Auffassung, dass das Spenden von Trost eine Aufgabe des Künstlers sei, hatte auch seine Auseinandersetzung mit der Wirkung von klassischer Musik, insbesondere im Vergleich und Wechselspiel mit der Kunst, Bedeutung. Die Auseinandersetzung mit Musik erfolgte bei van Gogh schrittweise und mit unterschiedlichen Schwerpunkten, angefangen mit eher theoretischen Überlegungen, so zum Beispiel zum Charakter der Musik im Vergleich zur Malerei. In das Jahr 1884 fiel seine erste Beschäftigung mit den Les Artistes de mon Temps betitelten Aufsätzen Charles Blancs (1813-1882), die er von seinem Freund Anton von Rappard geliehen bekommen hatte. ${ }^{37}$ Besonders der Aufsatz über Eugène Delacroix hinterließ bei ihm einen bleibenden Eindruck, machte er van Gogh doch mit dem Gesetz des Simultankontrastes und der Gegenüberstellung von Komplementärfarben vertraut. In der Einführung seiner Farbtheorie stellte Blanc jedoch auch die Theorie auf, dass die Verwendung von Farben genauso erlernt werden könne wie das Spielen von Musik und vergleicht konkret das Erlernen des Kontrapunktes mit dem der Malerei. Im Aufsatz über Delacroix verwendet Blanc außerdem musikalische Metaphern zur Beschreibung von dessen Malerei und nennt als dessen größte künstlerische Stärke „l'orchestration des couleurs“"38, die dieser einem Sänger ähnlich, der seine Stimme erklingen lässt, anwende oder wie ein Musiker, der sein Instrument spielt, um Gedanken und Gefühlen Ausdruck zu verleihen. ${ }^{39}$

Im August 1884 berichtete van Gogh Rappard, dass er ein weiteres Werk Blancs, den Grammaire des Arts du Dessin, erworben habe. ${ }^{40}$ In der Einführung des Grammaire vergleicht Blanc die Malerei mit der Musik und sieht letztere als die expressivere der beiden Ausdrucksformen, die gar in himmlischere Sphären entführen könne. ${ }^{41}$ Über die Frage der Wirkung der Farben und wie diese den Menschen erreiche, erklärt Blanc, dass diese die Augen genauso erreichten wie Geräusche und Töne die Ohren und dass wie in der Musik durch die Modulation von Tönen, so in

37 Van Gogh bedankt sich Ende Mai bei van Rappard für das Senden der Leihgaben. Vgl. Brief 448/R 50, Nuenen, ca. 29.5.1884, an van Rappard, nach Erpel 1968, Bd. 5, S. 222-223, S. 223 und Fußnote 4 aus der Online-Ausgabe der Briefe, abgerufen unter: http://vangoghletters.org/vg/ letters/let448/letter.html.

38 Blanc, Les Artistes de mon Temps 1876, S. 28.

39 Vgl. Morton 2000, S. $179 f$.

40 Vgl. Brief 454/R 47, Nuenen, zw. Mitte August u. Anfang September 1884, an van Rappard, nach Erpel 1968, Bd. 5, S. 219-220, S. 220.

41 „Plus précise que la musique, la peinture définit les sentiments et les pensées par les visible des forms et des couleurs; mais elle ne saurait, comme la musique, nous transporter dans les regions éthérées, dans le mondes impénétrables." Zitiert aus Blanc Grammaire, 1876, S. 486. Vgl. Morton 2000, S. 181 u. Fußnote 18, wo jedoch lediglich die englische Übersetzung zitiert wird. 
der Malerei durch Modulation und Modifikation der Farben unterschiedlich starke oder schwache Effekte erzielt werden könnten. ${ }^{42}$

Van Gogh studierte die Texte Blancs immer wieder zwischen Sommer 1884 und Herbst 1885, einer Zeit, in der er intensiv an seinen künstlerischen Ausdrucksmitteln arbeitete. ${ }^{43}$ Die erste von Blanc inspirierte Verwendung musikalischer Metaphern bei der Beschreibung von Bildern ließ nicht lange auf sich warten und könnte im Zusammenhang mit dem Barbizon-Maler Jules Dupré (1811-1889) erfolgt sein, dessen Farbe für van Gogh „etwas von einer prachtvollen Symphonie [hat], durchgeführt, gewollt, männlich; so etwa muß wohl auch Beethoven sein. “44 Wie ernst van Gogh in Nuenen die Verbindung zwischen Malerei und Musik nahm, zeigt seine Entscheidung, im November 1884 gar Klavierstunden zu nehmen, weil er wie er später rückblickend bemerkte - bereits zu diesem Zeitpunkt die Beziehung zwischen der Musik von Richard Wagner (1813-1883) und der Malerei gespürt habe und sich vom Erlernen des Klavierspiels versprochen hatte, ein besseres Verständnis für die Abstufung der Farben zu erlangen. ${ }^{45}$

Van Gogh wollte durch das Spielen von Tonleitern und Arpeggios nicht zunächst seine musikalischen Fähigkeiten verbessern, sondern war vielmehr an einem theoretischen Verständnis der Musik interessiert, insbesondere an Akkorden und harmonischen Beziehungen von Tönen, um daraus Schlüsse für das Arrangieren von Farben auf der Leinwand ziehen zu können. Nach wenigen Wochen soll dieses Unterfangen jedoch bereits zu einem Ende gekommen sein, da van Goghs Klavierlehrer durch dessen ständiges Vergleichen von Farben mit Tönen entnervt das Handtuch geworfen habe. ${ }^{46}$ Seine Beschäftigung mit Musiktheorie war letztlich zu kurz und oberflächlich, als dass van Gogh sich wirklich ein tiefergehendes musikalisches Wissen hätte aneignen können, aber sie wird ihn mit einigen grundlegenden

42 „Ces couleurs, comment frappent-elles nos yeux? Comme les sons frappent nos oreilles. De même que chaque son retentit en se modulant sur lui-même et passe, par des vibrations d'égale durée, de la plénitude au murmure et du murmure au silence, de même chaque couleur, vue dans le spectre solaire, a son maximum d'intensité et son minimum: elle commence par son plus clair et finit par son plus foncé." Zitiert aus Blanc Grammaire, 1876, S. 560. Vgl. Morton 2000, S. 182 u. Fußnote 20, wo jedoch lediglich die englische Übersetzung zitiert wird.

43 Vgl. Morton 2000, S. 183. Van Gogh erwähnte in keinem seiner Briefe aus der Zeit in Nuenen, dass die Beschäftigung mit Musik ihn direkt in seiner Malerei beeinflusst habe.

44 Brief 450/371, Mitte Juni 1884, an Theo, vgl. Erpel 1965, Bd. 3, S. 178-181, S. 181. Auch wenn Beethoven zu diesem Zeitpunkt fest etablierter Bestandteil des europäischen Konzertrepertoires geworden war, ist nicht klar, ob van Gogh die Gelegenheit hatte, seine Musik in Konzerten zu hören.

45 Vgl. Morton 2000, S. 185f. und Brief 683/539, 18.9.1888, an Theo, vgl. Erpel 1965, Bd. 1, S. 159-163, S. 162 und insbesondere Fußnote 29 der Online-Ausgabe der Briefe, abgerufen unter: http://vangoghletters.org/vg/letters/let683/letter.html. Dorn weist darauf hin, dass es in van Goghs Briefen aus der holländischen Zeit keine Beweise dafür gebe, dass diese Aussage korrekt sei. Vgl. Dorn 1991, Fußnote 26. Auf den Aspekt der Klavierstunden verweisen auch Veldhorst 2015, S. 10 f. u. Kōdera 1990, S. 21.

46 Vgl. Morton 2000, S. $185 f$. 
Sachverhalten vertraut gemacht und für den von der Musik abgeleiteten Aspekt der Empfindung im Hinblick auf Kunstwerke sensibilisiert haben. ${ }^{47}$

Erst der Aufenthalt in Paris, ab März 1886, bei dem er, konfrontiert mit den aktuellen Strömungen der Zeit, in raschen Schritten als Künstler sich weiter entwickelte, intensivierte sich seine Beziehung zur Musik. Wichtig war dabei der Austausch mit Künstlern der Avantgarde unter denen zeitgenössische Literatur ebenso wie Musik und bildende Kunst erörtert wurden. Zu diesem Kreis gehörte, wie bereits erwähnt, Paul Signac, der seinerseits ein großes Netzwerk von Künstlern, Autoren und Komponisten unterhielt und der sehr wahrscheinlich van Gogh in seiner Überzeugung bestärkte, dass Musik für die bildende Kunst von Bedeutung sei. So wird Signac van Gogh wohl mit Georges Seurats Gedanken einer musikalischen Ästhetik vertraut gemacht haben. ${ }^{48}$ In diesen progressiven Zirkeln verkörperte für viele die Musik Richard Wagners das Neue schlechthin, und van Goghs Aufenthalt in der französischen Hauptstadt fiel genau in die Zeit, in der Wagners Rolle für die Musik, aber auch für die Kunst allgemein besonders intensiv diskutiert wurde. ${ }^{49}$

Im Jahr 1887 fand Wagners Versuch, in Paris zehn Aufführungen seines Lohengrin auf die Bühne zu bringen, ein vorzeitiges Ende, was in der Folge zu Tumulten außerhalb des Theaters und zu ideologischen Debatten in der Presse führte. ${ }^{50}$ Diese Vorkommnisse wurden von van Gogh zwar mit keinem Wort in seinen Briefen erwähnt, könnten aber sehr wohl seine Neugierde auf Wagner geweckt haben. Es ist dokumentiert, dass er in Paris mit seinem Bruder viele Konzerte besuchte, bei denen er endlich Musik auch direkt hören konnte, insbesondere auch Aufführungen von Wagners Werken, die ihn sehr beeindruckten. ${ }^{51}$ Eine Serie von sechs spontanlebendigen, kleinen Kreidezeichnungen spielender Musiker gibt bildhaftes Zeugnis von van Goghs Konzertbesuchen in Paris. ${ }^{52}$

Zu den Stücken Wagners, die bei Aufführungen gespielt wurden, die van Gogh besuchte, gehörten die sehr bekannte Ouvertüre aus Tannhäuser, das gleichfalls berühmte „Waldweben“ aus Siegfried, der Trauermarsch aus der Götterdämmerung, einige Fragmente aus Tristan und Isolde und der „Walkürenritt“ aus der gleichna-

47 Vgl. Morton 2000, S. 187. Zum Ende des Aufenthalts in Nuenen und während der kurzen Zeit in Antwerpen, von November 1885 bis zum Februar des Folgejahres, scheint van Gogh denn auch seinem Interesse an Musik nicht weiter nachgegangen zu sein.

48 Vgl. Morton 2000, S. 194.

49 Delacroix lehnte Wagner ab. Charles Baudelaire gehörte jedoch zum Beispiel zu Wagners Verteidigern und auch Henri Fantin-Latour (1836-1904) beschäftige sich in Bild und Wort mit dem deutschen Komponisten, vgl. Henri Fantin-Latour, Tannhäuser: Venusberg, 1864, Öl auf Leinwand, 116,8 x 149,8 cm, Los Angeles County Museum of Art), vgl. dazu Patrick Noons Katalogisierung des Werkes im Ausst. Kat. Delacroix and the Rise of Modern Art, London 2015, S. 206-209.

50 Vgl. Morton 2000, S. 188.

51 Vgl. Veldhorst 2015, S. 16 u. $80 f$.

52 Bspw. Klavierspieler, Januar-April 1887, Kreide auf Papier, 25,8 cm x 34,8 cm, Amsterdam, Van Gogh Museum, F 1244c, JH 1157. Weitere Zeichnungen der Serie sind F1244cv JH 1153; F 1244a, JH 1154; F 1244b, JH 1155; F 1244c, JH 1156 sowie F 1714, JH 1160. 
migen Oper Walküre. Es ist nicht überliefert, inwieweit van Gogh zu diesem Zeitpunkt mit den Libretti und weiterführenden inhaltlichen Konzepten der einzelnen Opern vertraut war. Sämtliche Kompositionen werden aber sicherlich durch ihre gesteigerte Expressivität, Leidenschaft und Dramatik einen großen Eindruck auf ihn gemacht ${ }^{53}$ und ihren Anteil daran gehabt haben, dass van Gogh zu der Schlussfolgerung kam, dass, „wenn man alle Farben steigert, [...] man von neuem zu Ruhe und Harmonie [kommt]. Da geht etwas Ähnliches vor sich wie bei Wagnerscher Musik - sie wird mit großem Orchester gespielt und ist deshalb nicht weniger intim. " ${ }^{4}$ Auf dem Programm sämtlicher Wagnerkonzerte standen zudem Kompositionen von Ludwig van Beethoven, sodass van Gogh, nachdem er ihn bereits 1884 mit Dupré verglichen hatte, nun wohl auch zum ersten Mal dessen Werke gehört haben wird.

Ernsthaft setzte sich van Gogh mit Richard Wagner erst nach seiner Abreise aus Paris in Arles auseinander, als er von dort seinem Bruder mitteilte, dass er ein Buch über Wagner lese und begeistert sei: „Was für ein Künstler! Einer wie der unter den Malern, das wäre großartig - das wird kommen. "55 Es wird allgemein angenommen, dass sich van Gogh auf das 1887 erschienene Buch Richard Wagner, musiciens, poètes et philosophes. Aperçus et jugements précédés de lettres inédites en France et traduits de l'Allemand pour la première fois von Camille Benoît (1851-1923) bezog. Benoît erörtert zunächst anhand von Briefen Wagners dessen Verständnis einer Verschmelzung der Künste zum Gesamtkunstwerk und geht im Hauptteil des Buches auf Wagners Ansichten zur Musiktheorie, Philosophie und zu seinen eigenen Werken ein; dabei erwähnt er insbesondere das Credo des Komponisten, dass die „Musik [...] die erlösendste Kultur“ 56 sei. Benoîts Wagner fiel bei van Gogh auf fruchtbaren Boden, denn nach dem Studium von dessen Lektüre tauchten in van Goghs Briefen immer wieder Bemerkungen und Kommentare zur Musik und zu Komponisten auf. ${ }^{57}$ Mehrere in Arles entstandene Werke, unter anderem die Serie der Berceuse, wurden in der Folge von van Gogh mit Musik in Verbindung gebracht (vgl. Kapitel 6.2.2.2.).

53 Vgl. Morton 2000, S. $191 f$.

54 Brief 590/W 3, Arles, 30.3.1888, an Willemin, zitiert nach Erpel 1968, Bd. 5, S. 37 - 39, S. 38 f. Dorn 1991, S. 67 weist auf diesen Brief hin.

55 Brief 621/494, Arles, 6.6.1888, an Theo, zitiert nach Erpel 1965, Bd. 4, S. 61-62, S. 61.

56 Im Französischen Original bei Benoit 1887, S. 70: „La musique [...] ne peut cesser d'etre l'art par excellence, l’art rédempteur." Übersetzung Benoits bei Dorn 1991, S. 69. Vgl. für weitere Informationen auch Fußnote 7 der Online-Ausgabe der Briefe, abgerufen unter: http://vangoghletters. org/vg/letters/let621/letter.html\# u. Druick/Zegers 2001, S. $110 f$.

57 Dorn argumentierte in Hinblick auf Wagner, dass van Gogh die Kunst in seiner ungestillten Sehnsucht nach Religion - wie Wagner die Musik - zu einem Religionsersatz geworden sei. Gleichwohl sei auch van Gogh klar gewesen, dass die Kunst zwar keine Erlösung bringen, aber zumindest Trost spenden könne. Vgl. Dorn 1991, S. 69. 


\subsubsection{Der Ausdruck von Trost in Arles}

\subsubsection{Das Ringen mit religiöser Malerei und Abstraktionen}

„Trost" ist auch in den Briefen aus Arles ein wiederkehrender Begriff und wird von van Gogh im Zusammenhang mit den entsprechenden künstlerischen Herausforderungen und Entwicklungen diskutiert. Nach seiner Ankunft in Arles hatte van Gogh sich, wie bereits dargestellt, wesentlich darauf konzentriert, abzubilden, was er vor sich sah, beispielsweise den Beginn des Frühlings durch die blühenden Bäume. Er hatte „en plein air" und weitestgehend losgelöst von theoretischen Konzepten gemalt: „Meine Pinselführung hält sich an keine bestimmte Technik. Ich haue unregelmäßige Pinselstriche auf die Leinwand und lasse sie, wie sie sind. Dicke Farbkleckse, unbedeckte Leinwandstellen, hier und da eine völlig unfertige Ecke, Übermalungen, Roheiten; kurz das Ergebnis [...] wird Leute mit vorgefaßten Meinungen über Technik keineswegs beglücken. [...] Kurz, lieber Freund, jedenfalls keine Augentäuscher-Malerei!" 58

Roland Dorn stellt in seinem Aufsatz zur Bedeutung Richard Wagners für van Gogh die These auf, dass dieser sich in Folge der Auseinandersetzung mit Benoîts Analyse der Wagnerschen Symbolik nun bereit gefühlt habe, sich auch anspruchsvolleren Bildgegenständen, das heißt aus der Vorstellung entwickelten, symbolbeladenen Motiven, sogenannten Abstraktionen, zuzuwenden. ${ }^{59}$ Hinsichtlich der Motivfindung lässt sich feststellen, dass Van Gogh tatsächlich wieder das Thema Religion in der Kunst sehr intensiv beschäftigte. Ende Juni 1888 verknüpfte er in einem Brief an Bernard die Aufgabe des Künstlers mit der Christi und erklärte, dass dieser „als Künstler größer als alle Künstler" ${ }^{“ 60}$ gewirkt und dabei „als einziger [...] das ewige Leben, die Unendlichkeit der Zeit, die Nichtigkeit des Todes, die Notwendigkeit und Daseinsberechtigung ruhiger Gelassenheit und aufopfernder Liebe

58 Brief 596/B 3, Arles, 12.4.1888, an Émile Bernard, zitiert nach Erpel 1968, Bd. 5, S. 250-251, S. 251. Hinweis durch Dorn 1991, S. 70.

59 Vgl. Dorn 1991, S. 69. Van Gogh hatte, bevor er Arles am 30.5. in Richtung Saintes-Maries verließ, in der Tat mit keinem Wort erwähnt, dass er eine Ernteserie plante. Erst am 12.6. erfuhr Theo von seinem Bruder, dass er „ein neues Motiv in Arbeit [habe], grüne und gelbe Felder, soweit man sehen kann; ich habe sie schon zweimal gezeichnet, und jetzt fange ich ein Bild davon an [...]." Brief 623/496, Arles, 12.6.1888, an Theo, zitiert nach Erpel 1965, Bd. 4, S. 63-65, S. 65.

Der Terminus „Abstraktion“ hatte in der Auffassung Gauguins und van Goghs eine besondere Bedeutung. Abstraktion war ihrem Verständnis zufolge eine konstruierte „Kombination von Motiven unterschiedlicher, wenn nicht disparater Herkunft [... aus] Beobachtung, Photographie, Erinnerung." Dabei wirkte die eigene künstlerische Handschrift als vereinheitlichendes Verfahren, um die einzelnen Quellen miteinander zu verschmelzen, so dass es sich um ein „Motiv-Konstrukt und [der sie] deutende[n] Handschrift" handelte. Dies galt besonders auch seit der Zeit seiner Erkrankung. Robinson argumentiert dahingehend, „that while recovering from his mental breakdown he worried about venturing too far into escapist fantasy [...]." Robinson 2013, S. 12. Beide Zitate im Text: Schneede 1989, S. 13.

60 Brief 632/B 8, Arles, 26.6.1888, zitiert nach Erpel 1968, Bd. 5, S. 261-265, S. 262. 
als Grundgewißheit bekräftigt hat. "61 Über die Form der Vermittlung von Christi Botschaft stellte van Gogh fest, dass ,jener es zwar verschmäht [habe], Bücher über Ideen (Empfindungen) zu schreiben, nicht aber verschmäht [... habe] er das gesprochene Wort - das Gleichnis vor allem - (denke an den Sämann, die Ernte, den Feigenbaum! usw.).“62

Daran anknüpfend diskutiert van Gogh in dem gleichen Brief an Bernard jene Künstler, die seiner Meinung nach Christus überzeugend dargestellt hatten. „Die Gestalt Christi, wie ich sie empfinde, ist nur von Delacroix und von Rembrandt gemalt worden ... und dann hat Millet die Lehre Christi gemalt."63 Wie Greer treffend in ihrem Aufsatz zu van Goghs sozioreligiösem Kunstkanon konstatiert, handelt es sich hierbei mit unmittelbaren religiösen Motiven bei Rembrandt und Delacroix auf der einen Seite, sowie dem eher indirekten und allegorischen Ansatz Millets auf der anderen um zwei grundlegend unterschiedliche Darstellungsformen. ${ }^{64}$ Van Gogh bewunderte beide Formen der religiösen Darstellung und entwickelte in diesem Spannungsfeld in den Sommermonaten 1888 mehrere religiöse oder religiös konnotierte Studien. Als Beispiele für diese neue Form des Malens können der im Juni entstandene Sämann bei Sonnenuntergang (Abb. 80) mit seiner Verbindung zu biblischen Sämann-Gleichnissen und zwei nur in Briefen erwähnte Studien eines Christus im Garten Gethsemane gelten. ${ }^{65}$

Während van Gogh den Sämann auch nach intensiver Überarbeitung weiterhin als misslungen erachtete, aber dennoch seinem Bruder widmete, ${ }^{66}$ kratzte er beide Gethsemane-Studien, die nach van Goghs Beschreibung ein hohes Maß an Imagination, insbesondere hinsichtlich der Loslösung von Gegenstandsfarben zeigten, sofort wieder von der Leinwand. „Ich habe eine große Ölstudie wieder abgekratzt, einen Ölberg mit Christusgestalt, blau und orange, und einem gelben Engel. Erdboden rot, Berge grün und blau. Ölbäume mit violetten und karminroten Stämmen und grünem, grauem und blauem Laub. Himmel zitronengelb. Ich habe sie abge-

${ }_{61}$ Brief 632/B 8, Arles, 26.6.1888, zitiert nach Erpel 1968, Bd. 5, S. 261-265, S. 262.

${ }_{62}$ Brief 632/B 8, Arles, 26.6.1888, zitiert nach Erpel 1968, Bd. 5, S. 261-265, S. 262. Vgl. hierfür auch Greer 2003, S. 61.

63 Brief 632/B 8, Arles, 26.6.1888, zitiert nach Erpel 1968, Bd. 5, S. 261-265, S. 261.

${ }^{64}$ Vgl. Eugène Delacroix (1798-1863), Christus auf dem See Genezareth, ca. 1853, New York, Metropolitan Museum, für eine direkte Darstellung, die van Gogh bewunderte (s. Brief 632/B8, nach Erpel 1968, Bd. 5, S. 261-265, S. 263) und Jean-Fracois Millet, Der Sämann, 1850, Bosten. Museum of Fine Arts, Vgl. Greer 2003, S. 61f.

65 Sämann bei Sonnenuntergang, Juni 1888, Öl auf Leinwand, 64 x 80,5 cm, Otterlo, KröllerMüller Museum, F 422, JH 1470.

Bspw. das Gleichnis vom vierfachen Ackerfeld (bei Mk 4, 1-20, Mt 13, 1-20 u. Lk 8, 4-15), das Gleichnis vom Unkraut unter dem Weizen (Mt 13, 24-30) oder das Gleichnis von der selbstwachsenden Saat (Mk 4, 26-29).

$66, \ldots[\ldots]$ aber der Sämann ist missglückt [...] sobald er trocken ist setze ich eine Widmung an Dich drauf." Brief 659/522, Arles, ca. 12.8.1888, an Theo, zitiert nach Erpel 1965, Bd. 4, S. 121-124, S. 124 u. vgl. Pickvance 1984, S. 49. 
kratzt, weil ich mir sage, daß man Figuren von solcher Tragweite nicht ohne Modell machen kann." ${ }^{\text {"67 }}$

Wie ambivalent in dieser Zeit van Goghs Haltung zur Bibel geworden war und wie sehr er mit der Schrift als Quelle künstlerischer Arbeit haderte, veranschaulicht seine widersprüchliche Empfehlung an Bernard, dass dieser „sehr gut daran [tut], die Bibel zu lesen [... denn die] Bibel, das ist Christus [... und jener ist] der Trost dieser so trübe stimmenden Bibel, die unsere Verzweifelung und unsere Entrüstung erregt - uns durch ihre empörende Engherzigkeit und ihren verderblichen Wahn ein für allemal das Herz schwer macht ${ }^{\text {“68 }}$. Zusätzlich, so fügte er warnend hinzu, führe das Studium der Bibel gleichzeitig zum „Nervenklaps des Künstlers“69. In diesen Monaten rang van Gogh immer wieder mit der Darstellung von aus dem Gedächtnis oder aus der Phantasie entwickelten religiösen Themen. Wie sehr er zweifelte, wird durch seinen Kommentar hinsichtlich der zweiten missglückten Gethsemane-Studie deutlich, die er unzufrieden abkratzte: „Zum zweiten Mal habe ich eine Studie, Christus mit dem Engel auf dem Ölberg, abgekratzt. Weil ich hier richtige Ölbäume vor Augen habe; aber ich kann oder vielmehr will nicht mehr ohne Modelle malen [...].“70

Die ebenfalls im Sommer 1888 entstandenen Varianten der Serie von Sonnenblumen waren als Décoration für das Gelbe Haus und damit insbesondere auch als Versinnbildlichung der Hoffnung auf Gauguins Ankunft und die Künstlerpartnerschaft mit ihm konzipiert. ${ }^{71}$ Sie zeigen, dass van Gogh sich stattdessen einem auf den ersten Blick greifbareren und weniger übernatürlichen Thema zuwandte (vgl. Abb. 81). ${ }^{72}$ Nichtsdestoweniger handelte es sich nicht bloß um ein Blumenstillleben, sondern er wollte dabei „die naturnahe Farbigkeit soweit [...] forcieren, “73

67 So lässt sich auch van Goghs im Zusammenhang mit den misslungenen Abstraktionen formulierter Wunsch deuten: „Gewiss wäre es mir lieber, wenn Gauguin herkäme [...]."Beide Zitate aus Brief 637/505, Arles, 8. oder 9.7. 1888, an Theo, zitiert nach Erpel 1965, Bd. 4, S. 82-84, S. 83. Wie bereits beschrieben, sollte Gauguins Anwesenheit in Arles, wenige Monate später, eine wichtige Triebfeder für van Goghs erneuten Versuch werden, sich Abstraktionen zuzuwenden.

68 Brief 632/B 8, Arles, 26.6.1888, zitiert nach Erpel 1968, Bd. 5, S. 261-265, S. 261.

69 Brief 632/B 8, Arles, 26.6.1888, zitiert nach Erpel 1968, Bd. 5, S. 261-265, S. 261.

70 Brief 685/540, Arles, 21.9.1888, an Theo, zitiert nach Erpel 1965, Bd. 4, S. 163-164, S. 164. Hinweis auf diesen Brief durch Dorn 1991, S. 69. Die Haltung van Goghs gibt einen Hinweis darauf, dass für van Gogh nun die Landschaftsmalerei mit allegorischen Darstellungen die Funktion religiöser Malerei übernehmen würde. Dies ist insofern wichtig, als dass es einen Hinweis dafür gibt, warum sich van Gogh in Saint-Rémy statt religiösen Sujets dem Thema des Naturzyklus zuwandte.

71 Sonnenblumen, 21/26.8.1888, Öl auf Leinwand, 72 x 58 cm, Privatsammlung, F 453, JH 1559; Sonnenblumen, 21/26.8.1888, Öl auf Leinwand, 98 x 69 cm, Werk zerstört, F 459, JH 1560; Sonnenblumen, Ende August 1888, Öl auf Leinwand, 91 x 71 cm, München, Neue Pinakothek, F 456, JH 1561 u. Sonnenblumen, Ende August 1888, Öl auf Leinwand, 93 x 73 cm, London, National Gallery, F454, JH 1562.

72 Vgl. die unterschiedlichen Interpretationsansätze für die Sonnenblumen bspw. bei Noll 1994, S. $134 f$.

73 Dorn 1991, S. 70 u. vgl. Auch Druick/Zegers 2001, S. 133. 
dass auch durch sie Emotionen geweckt würden. Ende August schrieb er Émile Bernard, dass er beim Anschauen der Sonnenblumen, die kurze Zeit zuvor von van Gogh gar als „Symphonie in Blau und Gelb“74 betitelt worden waren, sich darüber tröste, dass er nicht in der Lage war, ihn und Gauguin in die Bretagne zu begleiten. ${ }^{75}$ Dies zeigt, dass van Gogh weiterhin eine Verbindung zwischen der Wirkung von Musik und Trost sah.

In diesem Zusammenhang sei darauf hingewiesen, dass van Gogh Mitte September von einem Aufsatz des Musik- und Theaterkritikers Camille Bellaigue (1858-1930) aus der neuesten Ausgabe der Revue des Deux Mondes berichtete, aus dem er abgeleitet hatte, dass Musik wohl eher im Stande sei, Gefühle und dabei insbesondere Liebe, auszudrücken als die anderen Darstellungsformen - namentlich die Malerei und Bildhauerei. ${ }^{76}$ In der Folge schrieb er, während er an einer weiteren Fassung der Sonnenblumen arbeitete, an seinen Bruder: „Die Malerei, wie sie jetzt ist, verspricht feinnerviger zu werden - mehr Musik, und weniger Skulptur - kurz, sie verspricht Farbe. "77

Wenige Tage später konstatierte er präzisierend: „Ich kann im Leben und auch in der Malerei sehr gut ohne den lieben Gott auskommen, aber ich, ein leidender Mensch, kann nicht auskommen ohne etwas, das größer ist als ich, das mein Leben ist - die Kraft zu schaffen. [...] Und in einem Bild möchte ich etwas Tröstliches sagen, wie Musik. Ich möchte Männer und Frauen mit diesem gewissen Ewigen malen, wofür früher der Heiligenschein das Symbol war und das wir durch das Leuchten, durch das Zittern und Schwingen unserer Farben zu geben versuchen. " 78 Thomas Noll hielt in diesem Zusammenhang interpretierend fest, dass in diesem Brief „die beiden Seiten seines Künstlertums [...] zum Ausdruck kommen: die Seelenangst und die Verzweiflung, vom ,wahren Leben' ausgeschlossen und vor allem ohne (religiösen) Trost ruhelos in der Welt zu sein einerseits, die Dankbarkeit andererseits, in der Kunst zumindest in gewissem Maße einen Lebenssinn gefunden zu haben und einen Anteil an der umfassenden, höheren Schöpferkraft zu besitzen. "

Gleichsam gezwungen durch den Einfluss Gauguins, nach der Erinnerung zu malen, entstanden im Herbst weitere der von van Gogh verschmähten Abstraktionen. Gauguins Anwesenheit hatte ebenfalls Einfluss auf van Goghs Entscheidung

${ }_{74}$ Vgl. Morton 2000, S. 178. Brief 666/526, 21 o. 22.6.1888, an Theo, vgl. Erpel 1965, Bd. 4, S. 131-132, S. 131.

75 Vgl. Brief 665/B 15, Arles, ca. 21.8.1888, an Bernard, nach Erpel 1968, Bd. 5, S. 279-280, S. 280.

76 Camille Bellaigue: L’Amour dans la musique, in: Revue des Deux Mondes, LVIIIe Année, Troisième Période, tome 89, 15.9.1888, S. 305-347, S. 306.

77 Brief 669/528, Arles, ca. 26.8.1888, an Theo, zitiert nach Erpel 1965, Bd. 4, S. 133-135, S. 133. Vgl. auch Morton 2000, S. 178.

78 Brief 673/531, Arles, 3.9.1888, an Theo, zitiert nach Erpel 1965, Bd. 4, S. 137-140, S. $138 f$. Vgl. auch Morton 2000, S. 178. Einen großen zeitlichen Bogen spannend, kam van Gogh im Folgenden des Briefs auch wieder auf den von ihm so geschätzten Ary Scheffer zu sprechen.

79 Noll 1994, S. 134. 
Symbole in Bildern unterzubringen. ${ }^{80}$ Ein weiteres aus dem Gedächtnis entstandenes Werk, bei dem van Gogh Tröstliches, ähnlich dem Effekt, den für ihn Musik erzeugte, zum Ausdruck bringen wollte, war Erinnerung an den Garten in Etten (Abb. 82) ${ }^{81}$ Willemien erklärte er:

Ich weiß nicht, ob Du verstehen kannst, daß man Poesie durch nichts weiter als durch gute Anordnung von Farben auszudrücken vermag, wie man Tröstendes durch Musik sagen kann. Auch sollen die bizarren, gesuchten und sich wiederholenden Linien, die sich durch das ganze Bild schlängeln, nicht den Garten in seiner gewöhnlichen Ähnlichkeit wiedergeben, sondern für uns nachzeichnen, wie im Traum gesehen, zugleich in seinem wahren Charakter und doch seltsamer als in der Wirklichkeit. ${ }^{82}$

\subsubsection{Die Serie der Familie Roulin und La Berceuse: die Vermittlung von Trost seriell vervielfältigt}

Obwohl der Fokus in den Jahren 1888-1890 insgesamt mehr auf den Landschaften lag, hegte van Gogh doch auch in dieser Zeit, insbesondere in Arles, ein großes Interesse an der Porträtmalerei. Im Sommer 1888 lernte er den Postangestellten Joseph Roulin kennen, der ihm ein loyaler Freund wurde und sich auch nach van Goghs Zusammenbruch Ende Dezember weiterhin um ihn kümmerte und im Krankenhaus besuchte. Ein zusätzlicher Gewinn aus der Verbindung mit Roulin erwuchs van Gogh dadurch, dass er dessen Familie umsonst porträtieren konnte - ein besonders glücklicher Umstand, da er seine Modelle ansonsten hätte entlohnen müssen. Stattdessen fertigte er aus Dankbarkeit und als Entlohnung von jedem der Porträts der Familienmitglieder eine Wiederholung für die Familie an. ${ }^{83}$ Die ersten Fassungen und die zusätzlich dazu im Entstehungsprozess angefertigten Ausführungen werfen ein Schlaglicht auf van Goghs serielles Arbeiten.

Mit den Porträts der Familie Roulin konnte er sich nach seiner Lebensgefährtin Sien und ihrer Familie in Den Haag sowie den vielen Studien der Bauern aus Nuenen, die ihn zu den Kartoffelessern inspirierten, nun in der Provence einer weiteren Familie der Arbeiterklasse widmen. In der Folge entstanden insgesamt über 20 Porträts der Familie, die neben Joseph Roulin und seiner Frau Augustine auch die beiden Söhne Armand und Camille sowie die neugeborene Tochter Marcelle einschlossen, in einem Zeitraum von neun Monaten, zwischen Ende Juli 1888 bis April 1889, bis kurz vor seiner Abreise nach Saint-Rémy.

80 Bspw. Fallende Blätter (Les Alyscamps), ca. 1. November 1888, 72 x 91 cm, Öl auf Sackleinen, Privatbesitz, F 487, JH 1621.

81 Erinnerung an den Garten in Etten, November 1888, 73,5 x 92,5 cm, Öl auf Leinwand, St. Petersburg, Eremitage Museum, F 496, JH 1630.

82 Brief 720/W 9, Arles, ca. 12.11.1888, an Willemien, zitiert nach Erpel 1968, Bd. 5, S. 56-57, S. 57.

83 Vgl. Rathbone 2913, S. 113. 
Es handelte sich bei der Serie der Familie Roulin um ein sehr ehrgeiziges und im Gesamtwerk einzigartiges Vorhaben, das van Gogh insbesondere auch deshalb vorantrieb, um sein Ansehen als Künstler zu verbessern und um endlich Aufträge von zahlenden Kunden zu erhalten. Gleichzeitig war es ihm jedoch auch wichtig, Werke zu schaffen, in denen er seine Ziele verfolgen und in die er persönliche Empfindungen legen konnte. Im Dezember schrieb er diesbezüglich an seinen Bruder:

Doch ich habe eine ganze Familie porträtiert - die Familie des Postmeisters, von dem ich schon mal den Kopf gemalt habe - den Mann, die Frau, das Neugeborene, den kleineren Jungen, den sechzehnjährigen Sohn, lauter Typen und sehr französisch, obwohl sie wie Russen aussehen. Bilder zu 15. Du verstehst, wie sehr ich mich da in meinem Element fühle und wie mich das bis zu einem gewissen Grade darüber tröstet, daß ich nicht Arzt bin. Ich hoffe, daß sich das weiter machen läßt und daß sie mir ernsthaftere Sitzungen gewähren, zahlbar in Porträts. Und wenn es mir gelingt, diese ganze Familie noch besser zu malen, so hätte ich wenigstens eine Sache nach meinem Geschmack gemacht, etwas Persönliches. ${ }^{84}$

Die zweifache Hervorhebung von „ganze Familie“ im Brief zeigt deutlich, wie außerordentlich wichtig es für van Gogh war, zu betonen, dass er alle Familienmitglieder porträtiert hatte, um die Familie in ihrer Gesamtheit bildlich zu erfassen. Van Goghs Beschäftigung mit moderner Literatur wird ihn bei der Idee, eine ganze Familie in Form einer Serie zu porträtieren, entschieden beeinflusst haben. Dies betraf nicht nur die inhaltliche Konzeption, sondern auch die Form und Struktur, die sich aus einer Vielzahl von Einzelelementen zu einem Gesamtbild zusammenfügt. Dass man einen Sachverhalt nur beurteilen könne, wenn man ihn in seiner Gänze kenne, betonte van Gogh immer wieder. So wie er die Jahreszeiten seit seiner Ankunft in Arles nacheinander abbilden wollte, so verhielt es sich auch jetzt mit der Familie Roulin als Verkörperung typischer Franzosen, die er als ganze Familie porträtieren wollte. ${ }^{85}$

84 Brief 723/560, Arles, 1.12.1888, an Theo, zitiert nach Erpel 1965, Bd. 4, S. 211-213, S. 212.

85 Bereits im Mai 1883 hatte er in einem Brief an van Rappard das Vorwort zu Charles Dickens Roman Little Dorrit zitiert, um ihm zu veranschaulichen, worauf es als Figurenmaler beim Entwickeln von Bildern ankomme. Im Vorwort schrieb Dickens: „I was occupied with this story during my working hours of two years. I must have been very ill employed, if I could not leave its merits and demerits as a whole to express themselves on its being read as a whole. But, as it is not unreasonable to suppose that I may have held its various threads with a more continuous attention than any one else can have given to them during its desultory publication, it is not unreasonable to ask that the weaving may be looked at in its complete state and with the pattern finished." Brief 345/R 35, Den Haag, ca. 21.5.1883, an van Rappard, zitiert nach Erpel 1968, Bd. 5, S. 193-195, S. 194. Die Hervorhebung von „continous attention“ findet sich nicht im Original, auch das Wort „complete“ lautet im Original „completed“. Vgl. hierzu den Kommentar zu diesem Brief in der Online- 
Besonders durch Émile Zolas komplexen Romanzyklus Les Rougon-Macquart, den dieser als „Histoire naturelle et sociale d'une famille sous le second empire“86 konzipiert hatte, scheint van Gogh angeregt worden zu sein, die Porträtreihe einer Familie anzufertigen.$^{87}$ Van Gogh schätzte Zolas weitverzweigte Erzählung über das Schicksal der Familie Rougon-Macquart im zweiten Kaiserreich seit seiner Zeit in Den Haag und erwähnte sie in Briefen immer wieder. ${ }^{88}$ Zola war seinerseits durch Honoré de Balzacs (1799-1850) berühmten Zyklus La Comédie humaine beeinflusst, der ab den 1830er Jahren veröffentlicht worden war und insgesamt 91 Romane umfasste. Balzac wollte in seinen Études de moeurs die „histoire generale de la Société, la collection de tous ses faits et gestes" ${ }^{\text {"89 }}$ beleuchten.

Van Gogh hatte auch Balzac Anfang der 1880er Jahre mit Begeisterung gelesen, um ihm dann jedoch weniger Beachtung zu schenken, als er in der Folgezeit die neuere französische Literatur kennenlernte. In Arles entdeckte er jedoch Balzac wieder, und im Sommer 1888 diskutierte van Gogh in einem Brief an Bernard die Rolle von „Zola und Balzac als Maler einer Gesellschaft, einer Gesamtnatur, [sie] vermitteln denen, die sie lieben, seltene künstlerische Erregungen, eben weil sie das ganze Zeitalter umfassen, das sie malen. “90

Zola hatte im Vorwort von La Curée (1871), dem zweiten Roman der Reihe, gattungsübergreifend erklärt, dass es sich dabei um ein „peinture vraie de la débâcle

Ausgabe der Briefe, abgerufen unter: http://vangoghletters.org/vg/letters/let345/letter.html sowie Dorn 1990, S. 316, Fußnote 65.

Van Gogh bezog dies auch auf sich selbst und betonte, dass bei Dickens schön ausgedrückt sei, „wie ein Figurenmaler betrachtet zu werden verdient - als ein Ganzes“ und bat van Rappard daraufhin, auch ihn „weiterhin als ein Ganzes an[zusehen], was viele andere nicht tun.“ Außerdem lobte er van Rappards Literaturauswahl: „Hugo, Zola, Dickens -, Bücher einens Figurenmalers.“ (Hier alle Zitate aus Brief 345/R 35, Den Haag, ca. 21.5.1883, an van Rappard, zitiert nach Erpel 1968, Bd. 5, S. 193-195, S. 194.) Er schloss seinen Brief mit dem Hinweis, „daß man Schriftsteller wie Dickens, Balzac, Hugo und Zola erst dann richtig kennt, wenn man ihr Gesamtwerk einigermaßen überblickt" Brief 345/R 35, Den Haag, ca. 21.5.1883, an van Rappard, zitiert nach Erpel 1968, Bd. 5, S. 193-195, S. 195.

86 Untertitel von Émile Zolas Romanserie Les Rougon-Macquart, hier zitiert aus La Curée, Bd. 2, Paris 1871.

87 Der erste der insgesamt zwanzig Romane von Zolas Romanzyklus war 1871 erschienen, der letzte nach van Goghs Tod im Jahre 1893. Vierzehn von siebzehn der zu van Goghs Lebzeiten verfügbaren Romane waren ihm vertraut. Vgl. Dorn 1990, S. 316, Fußnote 66.

88 Vgl. Dumas 2010, S. 127. Van Gogh erwähnte die Romane zum ersten Mal in Brief 259/226, Den Haag, 26.8.1882, Erpel 1965, Bd. 2, S. 79-82, S. 82. Vgl. für weitere Informationen auch den Kommentar zu diesem Brief in der Online-Ausgabe der Briefe, abgerufen unter: http://vangoghletters.org/vg/letters/let259/letter.html.

$89 \mathrm{Ab} 1842$ waren sie vereint in einer Serie erschienen und dabei in drei Unterabteilungen eingeteilt worden. Zitiert aus dem Vorwort von Honoré de Balzac, La Comédie humaine. Études de moeurs. Scènes de la vie privée, Bd. 1, Paris 1842, S. 28.

90 Brief 651/B 13, Arles, 30.7.1888, an Bernard, zitiert nach Erpel 1968, Bd. 5, S. 272-275, S. 273 Vgl. auch Dorn 1990, S. 174. 
d'une sociéte" ${ }^{\text {"91 }}$ handele. Kurz darauf bekannte van Gogh, etwa in der Entstehungszeit der ersten Porträts Joseph Roulins, dass, nachdem er Zolas Romane gelesen habe, diese „schließlich ein Stück von [... ihm] selbst geworden" ${ }^{\text {"92 }}$ seien und ihn dementsprechend beim Porträtieren von Menschen beeinflussten. Durch die Porträts der Familie Roulin bot sich van Gogh die Möglichkeit, eine eigene Serie zu beginnen, die hart arbeitende Glieder der Gesellschaft zum Thema hatte; konkret ging es darum, die einzelnen Familienmitglieder in ihren jeweiligen Rollen zu typisieren und zudem ortstypische - ländliche - Gesichter der Provence einzufangen. ${ }^{93}$

Von besonderer Signifikanz für diese Arbeit ist van Goghs Auseinandersetzung mit Madame Augustine Roulin, die er mehrfach ab Herbst mit und ohne ihr neugeborenes Kind malte. Eine Gruppe von fünf Porträts, die er ab Dezember 1888 anfertigte, die sie in ihrer Mutterrolle bei einer sehr charakteristischen Beschäftigung zeigen - dem Schaukeln der Wiege - wurden daraufhin von van Gogh als „La Berceuse" [frz. das Wiegenlied] bezeichnet. Sie bilden den thematischen Höhepunkt der Serie. ${ }^{94}$

Van Gogh hatte Ende Juli 1888 mit den Porträts des Familienvaters Joseph Roulin begonnen, von dem er insgesamt sechs Gemälde sowie drei Zeichnungen an-

91 Zitiert aus dem Vorwort von Émile Zolas La Curée, Paris 1871, S. 6.

92 Brief 663/520, Arles, 18.8.1888, an Theo, zitiert nach Erpel 1965, Bd. 4, S. 116-188, S. 117. Vgl. auch Dorn 1990, S. 174. Konkret bezog sich van Gogh hier auf das Porträt von Patience Escalier (Der Bauer), Sommer 1888, Öl auf Leinwand, 64 x 54 cm, Pasadena, Norton Simon Art Foundation, F 443, JH 1548.

93 Vgl. Steele, M./Newton 2013, S. 63. Van Gogh hatte sich Ende Juli über den amerikanischen Künstler Dodge MacKnight, der ebenfalls in der Provence arbeitete und den er aus Paris kannte, geäußert. „Das Dorf, wo sie wohnen, ist richtiger Millet, kleine Bauern, weiter nichts, ganz ländlich [im Original „agreste“] und stimmungsvoll.“ Brief 650/514, Arles, 29.7.1888, an Theo, zitiert nach Erpel 1965, Bd. 4, S. 103-106, S. 105.

Während van Gogh das zweite Porträt Joseph Roulins malte, betonte er zudem die Bedeutung des Porträtmalens für seinen künstlerischen und persönlichen Fortschritt: „Jetzt habe ich also zwei Figuren in Arbeit, den Kopf und ein Brustbild (mit Händen) von einem alten Postmeister in dunkelblauer Uniform. [...] Es gibt keinen besseren und keinen kürzeren Weg, die Arbeit zu verbessern, als Figuren zu malen. Auch gehe ich immer mit Zuversicht ans Werk, wenn ich Porträts mache, denn [...] sie erlaubt mir, das Beste und Ernsthafteste in mir zu entfalten." Brief 654/517, Arles, ca. 3.8.1888, an Theo, zitiert nach Erpel 1965, Bd. 4, S. 109-110, S. 110.

94 Brief 740/ 571a, Arles, 22.01.1889, an Arnold Koning, zitiert nach Erpel 1968, Bd. 5, S. 316-317, S. 317. Bei den fünf Ausführungen handelt es sich um La Berceuse (Porträt Madame Roulins), Dezember 1888-Januar 1889, Öl auf Leinwand, 91 x 72 cm, Otterlo, Kröller-Müller Museum, F 504, JH 1655; La Berceuse (Porträt Madame Roulins), Januar 1889, Öl auf Leinwand, 92,7 x 73,7 cm, New York, The Metropolitan Museum of Art, F 505, JH 669; La Berceuse (Porträt Madame Roulins), Januar 1889, Öl auf Leinwand, 92,7 x 73,8 cm, The Art Institute of Chicago, F 506, JH 1670; La Berceuse (Porträt Madame Roulins), März 1889, Öl auf Leinwand, 91 x 71,5 cm, Amsterdam, Stedelijk Museum, F 507, JH 1672 u. La Berceuse (Porträt Madame Roulins), Februar-März 1889, Öl auf Leinwand, 92,7 x 72,7 cm, Boston, Museum of Fine Arts, F 508, JH 1671. 
fertigte. ${ }^{95}$ Nach Gauguins Ankunft porträtierten er und van Gogh Ende November Madame Roulin ohne ihren Säugling im Gelben Haus. ${ }^{96}$ Kurz darauf porträtierte van Gogh in zwei unterschiedlich großen Werken Madame Roulin, diesmal mit ihrer neugeborenen Tochter Marcelle, vor einem leuchtend gelb-golden monochromen Hintergrund (vgl. Abb. 83). ${ }^{97}$ Van Gogh hatte mehrfach in Briefen sein großes Bedürfnis ausgedrückt, den Säugling der Familie zu malen. ${ }^{98}$ Statt das Kind schlafend in einer Wiege darzustellen, entschied sich van Gogh für eine wesentlich lebendigere Pose und stellte Madame Roulin sitzend dar, wie sie ihre Tochter, bekleidet mit einem weißen Kleid, mit beiden Händen umfängt.

Das Motiv ist voller tieferer Bedeutungsebenen und Assoziationen, die van Gogh hinsichtlich seiner Typisierung von Madame Roulin in ihrer Mutterrolle wichtig erschienen. ${ }^{99}$ Zunächst ist van Goghs Fokussierung auf die Hände seiner

95 Der Postbote Joseph Roulin, 31. Juli- 3. August 1888, Öl auf Leinwand, 81,3 x 65,4 cm, Boston, Museum of Fine Arts, F 432, JH 1522; Porträt des Postboten Joseph Roulin, Anfang August 1888, Öl auf Leinwand, 64,1 x 47,9 cm, The Detroit Institute of Arts, F 433, JH 1524; Porträt Joseph Roulins, Anfang August 1888, Rohrfeder, Pinsel, Tinte und Graphit auf Papier, 32 × $24 \mathrm{~cm}$, Privatsammlung, F 1723, JH 1523; Porträt Joseph Roulins, Anfang August 1888, Braune Tinte über Graphit auf Papier, 51,4 x 42,2 cm, Los Angeles County Museum of Art, F 1459, JH 1547; Porträt Joseph Roulins, Anfang August 1888, Rohrfeder und Federkiel, braune Tinte und schwarze Kohle auf Papier, 32,1 x 24,4 cm. Los Angeles, The J. Paul Getty Museum, F 1458, JH 1536; Der Postbote Joseph Roulin, November-Dezember 1888, Öl auf Leinwand, 65 x 54 cm, Kunstmuseum Winterthur, F 434, JH 1647; Der Postbote Joseph Roulin, Januar-Februar 1889, Öl auf Leinwand, $65,7 \mathrm{~cm} \times 55,2 \mathrm{~cm}$, Philadelphia, The Barnes Foundation, F 435, JH 1674; Der Postbote Joseph Roulin, Februar-März 1889, Öl auf Leinwand, 65 cm x 54 cm, Otterlo, KröllerMüller Museum, F 439, JH 1673 und Der Postbote Joseph Roulin, März 1889, Öl auf Leinwand, 64,4 cm x 55,2 cm, New York, Museum of Modern Art, F 436, JH 1675.

96 Madame Roulin, Ende November 1888, Öl auf Leinwand, 55 x 65 cm, Winterthur, Sammlung Oskar Reinhart, F 503, JH 1646 u. Paul Gauguin (1848-1903), Madame Roulin, Ende November 1888, Öl auf Leinwand, 50 x 63 cm, The Saint Louis Art Museum, W 298. Beide Maler malten Bruststücke der vor einem Fenster im Atelier sitzenden Mutter. Beide Maler kamen jeweils zu sehr unterschiedlichen Ergebnissen in Ausdruck und Ausführung. Ein wesentlicher Unterschied bestand darin, dass Gauguin im Gegensatz zu van Gogh den Ansatz von Madame Roulins Händen zeigte wie diese auf ihrem Schoß ruhen und dabei suggerieren, dass sie eine Schnur halten könnte mit der sie eine vor ihr, außerhalb des Bildraumes, positionierte Kinderkrippe zum Wiegen bringen könnte. Dies ist als ein wichtiges Attribut für sie als Mutter zu verstehen, das van Gogh später selbst aufgriff. Vgl. Druick/Zegers 2001, S. 229.

97 Porträt von Madame Augustine Roulin und Baby Marcelle, November-Dezember 1888, Öl auf Leinwand, 92,4 x 73,5 cm, Philadelphia Museum of Art, F 490, JH 1637 u. Porträt von Madame Augustine Roulin und Baby Marcelle, November-Dezember 1888, Öl auf Leinwand, 92,4 x 73,5 cm, New York, The Metropolitan Museum of Art, F 491, JH 1638.

98 Vgl. Brief 653/W 5, Arles, 31.7.1888, an Willemien, Erpel 1968, Bd. 5, S. 47-50, S. 48

99 Zuerst stellt sich die Frage nach einer Binnenverbindung des Porträts innerhalb der Familienserie. An eine Verbindung im Sinne eines Pendants zu einem vorher entstandenen Kniestück ihres Ehemanns (Der Postbote Joseph Roulin, 31. Juli-3. August 1888, Öl auf Leinwand, 81,3 x 65,4 cm, Boston, Museum of Fine Arts, F 432, JH 1522) lässt, wenn beide Bilder nebeneinander betrachtet werden, die ihrem Ehemann zugewandte sitzende Pose denken. Motivische Parallelen können 
Modelle zu beachten, die sowohl in Josephs wie auch Augustines Porträt besonders manieriert gespreizt sind und die ihrerseits in Zusammenhang mit den Werken Alter Meister stehen. Dass van Gogh besonderes Interesse an der Ausführung von Köpfen und insbesondere Händen hegte, verdeutlicht ein Brief an Theo aus dem Dezember 1885, in dem er sich enthusiastisch über die Ausführung von Händen in Werken von Malern wie Peter Paul Rubens und Jacob Jordaens (1593-1678) geäußert hatte. Darüber hinaus wurde eine Verbindung zwischen Madame Roulins gespreizter Hand und einem Typus Mariens in Bildern des 16. Jahrhunderts, bei dem die Gottesmutter das Kind liebevoll mit ihrer linken Hand hält, deren Mittelund Zeigefinger deutlich gespreizt sind und eine Speckfalte am Bauch des Kindes umfassen, vorgeschlagen (vgl. Abb. 84). ${ }^{100}$

Die Haltung, bei der die Mutter das Kind dem Betrachter zeigt, wurde überdies mit Madonnendarstellungen verglichen, bei denen die Gottesmutter das auf ihren Oberschenkeln stehende Kind entsprechend umfängt, um es zu stützen (vgl. Abb. 85). Auch hinsichtlich der von van Gogh gewählten leuchtend-gelben Hintergrundfarbe sind Parallelen zu italienischen Mariendarstellungen des 14. Jahrhunderts und früher möglich, bei denen der Goldgrund eine sakrale Sphäre symbolisiert. Dazu passend hatte van Gogh im September verkündet, dass er „[... ] Männer und Frauen mit diesem gewissen Ewigen malen [möchte], wofür früher der Heiligenschein das Symbol war und das wir durch das Leuchten, durch das Zittern und Schwingen unserer Farben zu geben versuchen."101

Zwei Jahre zuvor hatte er beim Anblick der Maris Stella, einer Darstellung der Gottesmutter in der Rolle der Schutzheiligen der Seefahrer mit ihren Attributen Kreuz und Anker, in einem Fenster der Kirche Sint-Andreas in Antwerpen, lobend die Farbwahl der „Gestalt der Heiligen Jungfrau, [als] hochgelb, weiß, orange "102 beschrieben

diesbezüglich zu Familienporträts niederländischer Maler des 17. Jahrhunderts, insbesondere Frans Hals, gesehen werden, die van Gogh höchstwahrscheinlich vertraut waren.

100 Zu dem Vergleich mit Altmeisterfamilienporträts S. Rathbone 2013, S. 101. Für das Interesse an der Ausführung von Köpfen und insbesondere Händen bei Altmeistergemälden vgl. Brief 547/439, 14.12.1885, an Theo, Erpel 1965, Bd. 3, S. 348-351.

Van Gogh erstellte nicht nur Studien von Händen nach Altmeistergemälden, sondern hatte immer wieder Studien von Händen gezeichnet, beispielsweise im Frühjahr 1885, im Vorfeld der weiter oben besprochenen Kartoffelesser. Studienblatt mit sieben Händen, Januar-Februar 1885, Kohlezeichnung, Maße unbekannt, Amsterdam, Van Gogh Museum, F 1360r, JH 619. Vgl. Rathbone 2013, S. 101 für die Verbindung zum Marientypus der Renaissance. Rathbone erwähnt bspw. Quentin Metsys (1466-1530), Madonna mit den Kirschen, 1520er Jahre, Öl auf Holz, 74,9 x 63,9 cm, Sarasota, The John and Mable Ringling Museum of Art (vgl. Abb. 84).

101 Brief 673/531, Arles, 3.9.1888, an Theo, zitiert nach Erpel 1965, Bd. 4, S. 137-140, S. $138 f$. Vgl. Druick/Zegers 2001, S. 227. Hier wird als Beispiel eine Madonnendarstellung mit Kind von Gentile da Fabriano (ca. 1370-1427) aufgeführt: Madonna mit Kind, Tempera auf Holz, 95,9 x 56,6 cm, Washington D.C., National Gallery of Art (vgl. Abb. 85).

102 Brief 551/443, Antwerpen, ca. 2.1.1886, an Theo, zitiert nach Erpel 1965, Bd. 3, S. 360-365, S. 361. Es handelt sich um Henri Dobbelaere (gestorben 1885), Stella Maris, 1866, Glasfenster, Antwerpen, Sint-Andries Kirche, (1889 zerstört). Vgl. Druick/Zegers 2001, S. 227 und Anmer- 
(vgl. Abb. 86). Auch dieses Vorbild könnte ihn bei der Zusammenstellung der Farben Gelb für den Hintergrund und Weiß für das Kleid beeinflusst haben. Doch auch die mit den Attributen der Maris Stella verbundene Symbolik von Glaube (Kreuz) und Hoffnung (Anker) könnte bei der Entwicklung seines Bildtypus von Mutter mit Kind und einer damit einhergehenden ermutigenden Botschaft eine Rolle gespielt haben, die in eigener Interpretation auch van Gogh auszudrücken gedachte. ${ }^{103}$

Denn schließlich kehrte er nach weiteren Fassungen von Porträts des Vaters zur Mutter zurück und begann mit den als La Berceuse bezeichneten Porträts (vgl. Abb. 87 u. 88). ${ }^{104}$ An den befreundeten Maler Arnold Koning (1860-1945) schickte er eine ausführliche Beschreibung, die wertvolle Hinweise für die Interpretation des Sujets liefert:

Es ist eine grün gekleidete Frau (Oberkörper olivgrün und der Rock blasses Veroneser Grün). Ihr Haar ist ganz orange und in einen Zopf geflochten. Die Gesichtsfarbe ist zu chromgelb gesteigert, natürlich mit einigen gebrochenen Tönen, um zu modellieren. Die Hände, die den Wiegestrick halten, desglei-

kung 3 zu diesem Brief in der Online-Ausgabe der Briefe, abgerufen unter: http://vangoghletters. $\mathrm{org} / \mathrm{vg} / \mathrm{letters} / \mathrm{let} 551 /$ letter.html\#.

103 Vgl. Druick/Zegers 2001, S. 228.

104 Zunächst hatte er noch drei sich ähnelnde Einzelporträts des Säuglings vor hellgrünem Hintergrund gemalt und auch noch die Porträts der Söhne Camille und Armand angefertigt: Porträt von Marcelle Roulin, Dezember 1888, Öl auf Leinwand, 35 x 24,5 cm, Amsterdam, Van Gogh Museum, F 441, JH 1641; Porträt von Marcelle Roulin, Dezember 1888, Öl auf Leinwand, $34,3 \times 24,5$ cm, Privatsammlung, F441a, JH 1640 u. Porträt von Marcelle Roulin, 1888, Öl auf Leinwand, 35 x 23,9 cm, Washington, D.C., National Gallery of Art, F 440, JH 1639. Bei den Porträts der Söhne handelt es sich um: Porträt von Camille Roulin, November-Dezember 1888, Öl auf Leinwand, 40 x 32,5 cm, Amsterdam, Van Gogh Museum, F 538, JH 1645 u. Porträt von Camille Roulin, „répétition“, November-Dezember 1888, Öl auf Leinwand, 43,2 x 34,9 cm, Philadelphia Museum of Art, F 537, JH 1644. Um das Jahr 1895 kaufte der Kunsthändler Ambroise Vollard mehrere der Roulin Porträts auf. Vgl. Rathbone 2013, S. 107. Es ist möglich, dass van Gogh ein drittes Porträt Camilles anfertigte, das sich stilistisch jedoch deutlich von den beiden anderen Porträts unterscheidet. In der Literatur ist die Zuordnung zu Camille Roulin umstritten. Bei dem in Frage stehenden Werk handelt es sich um Der Schuljunge (Camille Roulin?), Anfang Dezember 1888, Öl auf Leinwand, 63,5 x 54 cm, Sao Paulo, Museu de Arte de Sao Paulo, F 665, JH 1879. Hulsker identifizierte den Jungen als Camille, de la Faille jedoch nicht. Vgl. auch Rathbone 2013, S. 110. Bei den Porträts des älteren Sohnes handelte es sich um Porträt von Armand Roulin, November 1888, Öl auf Leinwand, 66 x 55 cm, Essen, Museum Folkwang, F 492, JH 1642 u. Porträt von Armand Roulin, November 1888, Öl auf Leinwand, 66 x 55 cm, Rotterdam, Museum Boijmans Van Beuningen, F 493, JH 1643.

$\mathrm{Zu}$ den Werken der Berceuse zählen: La Berceuse (Porträt Madame Roulins), Dezember 1888Januar 1889, Öl auf Leinwand, 91 x 72 cm, Otterlo, Kröller-Müller Museum, F 504, JH 1655; La Berceuse (Porträt Madame Roulins), Januar 1889, Öl auf Leinwand, 92,7 x 73,7 cm, New York, The Metropolitan Museum of Art, F 505, JH 669; La Berceuse (Porträt Madame Roulins), Januar 1889, Öl auf Leinwand, 92,7 x 73,8 cm, The Art Institute of Chicago, F 506, JH 1670; La Berceuse (Porträt Madame Roulins), März 1889, Öl auf Leinwand, 91 x 71,5 cm, Amsterdam, Stedelijk Museum, F 507, JH 1672 u. La Berceuse (Porträt Madame Roulins), Februar-März 1889, Öl auf Leinwand, 92,7 x 72,7 cm, Boston, Museum of Fine Arts, F 508, JH 1671. 
chen. Der Hintergrund ist unten Zinnober (er stellt einfach einen Fliesen- oder Ziegelfußboden dar). An der Wand eine Tapete, die ich natürlich im Zusammenhang mit den übrigen Farben berechnet habe. Diese Tapete ist blaugrün mit rosa Dahlien und mit Orange und Ultramarin getüpfelt. [...] Ob ich mit Farbe ein Wiegenlied gesungen habe, überlasse ich den Kritikern [...]. ${ }^{105}$

Diese „Sub“-Serie innerhalb der Roulin-Familienserie hat in der Literatur große Resonanz gefunden, und mittlerweile dazu geführt, dass für wenige andere Werke van Goghs vergleichbar viele Interpretationsansätze formuliert worden sind. Darüber hinaus sind im Laufe der Zeit, was die Chronologie der verschiedenen Fassungen angeht, viele Vorschläge diskutiert worden. ${ }^{106}$ An dieser Stelle sei kurz auf die Entstehungsgeschichte eingegangen, da sie Rückschlüsse auf van Goghs Motivation hinsichtlich der neuerlichen Porträts der Mutter zulassen.

Van Gogh begann mit dem ersten Portrait Madame Roulins im Dezember 1888 und setzte seine Arbeit daran erst im Januar, nach dem Zwischenfall an Weihnachten, der zu Gauguins Abreise führte, fort. ${ }^{107}$ Ende Januar beschreibt van Gogh das Werk ausführlich seinem Freund Arnold Koning im eingangs zitierten Brief, wobei insbesondere der Hinweis, dass es sich bei den Blumen auf der Tapete im Hintergrund um Dahlien handelt, bedeutsam für die Chronologie ist. ${ }^{108}$ In späteren Briefen über die nachfolgenden Varianten spricht van Gogh nur noch allgemein über Blumen, und es lässt sich diesbezüglich beobachten, dass die naturalistische Ausarbeitung der Blumen im Laufe der Bildersequenz deutlich abnimmt. Erinnern

105 Brief 740/ 571a, Arles, 22.01.1889, an Arnold Koning, zitiert nach Erpel 1968, Bd. 5, S. 316317, S. 317.

106 Vgl. Rathbone 2013, S. 119. Für die Ausstellungen zu van Goghs Wiederholungen in Washington und Cleveland 2013-2014 wurde durch intensive technische Untersuchungen in Verbindung mit den überlieferten Informationen aus den Briefen van Goghs nicht nur eine schlüssige Reihenfolge propagiert, an deren Anfang das Porträt aus dem Kröller-Müller Museum steht (1), gefolgt von der Version aus dem New Yorker Metropolitan Museum of Art (2) sowie den Kopien aus dem Art Institute of Chicago (3), dem Stedelijk (4) und dem Bostoner Museum of Fine Arts (5), sondern auch auf eindringliche Weise van Goghs Wiederholungspraxis mit den Änderungen von Bild zu Bild beleuchtet und nachvollziehbar gemacht. Vgl. Rathbone 2013, S. 118-139 und technische Anmerkungen Steeles, S. 130-138. Diese Reihenfolge widerspricht der Neuedition der Briefe van Goghs, die sich ihrerseits auf Hoermann Listers 2001 publizierte Meinung stützen, dass die Version aus Boston am Anfang der Serie stehe und das Werk aus Otterlo zuletzt entstanden sei. Rathbone und Steele widerlegen dies schlüssig. Vgl. Hoermann Lister 2001, S. 62-82 sowie Anmerkung 12 zu Brief 822/B 21, abgerufen unter: http://vangoghletters.org/vg/letters/let822/letter.html\#.

107 An Gauguin schrieb er am 21. Januar des neuen Jahres, dass er die Arbeit an einem Porträt Madame Roulins wieder aufgenommen habe, das im Bereich der Hände aufgrund seines Unfalls unvollendet geblieben sei. Vgl. Brief 739, in dieser Fassung nicht in Erpel, Arles, 21.1.1889, an Paul Gauguin: „Aujourd'hui j'ai recommencé la toile que j'avais peinte de mme Roulin, celle que pour cause de mon accident était restée à l'etat vague pour les mains." Zitiert nach der Online Edition der Briefe, abgerufen unter: http://vangoghletters.org/vg/letters/let739/letter.html\#

108 Vgl. Brief 740/ 571a, Arles, 22.01.1889, an Arnold Koning, zitiert nach Erpel 1968, Bd. 5, S. 316-317. 
die Blumen in der zweiten Fassung noch an Dahlien, werden sie im Verlauf der Bilderserie immer schematischer und abstrahierter. ${ }^{109}$

Van Gogh malte Mitte-Ende Januar 1889 die zweite Fassung, heute in New York, die die größten Ähnlichkeiten mit dem ersten Porträt aufweist, obschon erkennbar ist, dass van Gogh Konturen, wie die der Kordel und einiger Blumen, nun in kräftigem Rot malte, um einen Komplementärkontrast zum Grün des Rocks und der Tapete zu erzeugen und sich damit von der vergleichsweise naturalistischen Wiedergabe der vorherigen Version entfernte. Dass die Kordel nun in leuchtender Farbe dargestellt ist, könnte darin begründet sein, dass stärker auf ihre wichtige Funktion als Attribut für Madame Roulins Mutterrolle hingewiesen werden sollte (Abb. 93).

Van Gogh war mit der Haltung der Hände in der ersten Version, in der der rechte Arm unnatürlich nach unten einknickt und die Kordel sehr weit unten platziert ist, so dass es scheint als halte Madame Roulin die Kordel gar nicht richtig, unzufrieden. Infolgedessen korrigierte er dieses, für die Bildaussage so bedeutungsvolle Motiv, in der zweiten Fassung, so dass nun die rechte Hand auf der linken liegt und deutlich die rot umrandete Kordel hält. Diese Lösung wurde von van Gogh bei der vierten Variante Ende Februar-Anfang März leicht modifiziert, indem nun die linke Hand über der rechten, die die Kordel hält, ruht (Abb. 94). ${ }^{110}$ Zur Erläuterung

109 Auch andere Aspekte, wie die Ausarbeitung des Mieders im Halsbereich oder des Eherings, die in keiner Fassung so spezifisch sind wie in der ersten aus dem Kröller-Müller Museum, lassen die Verarbeitung von tatsächlich am Modell gesehenen Eigenheiten bei der ersten Fassung vermuten. Die Simplifizierungen bei den später im Atelier entstandenen Kopien deuten dagegen eher auf die Repetition von generischen Attributen hin. Vgl. Rathbone 2013, S. 126f. In der Literatur ist auch die Frage diskutiert worden, ob aufgrund der Ähnlichkeit zwischen dem im Herbst mit Gauguin entstandenen Porträt überhaupt ein einziges der Porträts nach dem Leben gemalt worden sei. Rathbone 2013, S. 105: „The similarity between the portrait of Augustine Roulin in Philedelphia ... and the head of Madame Roulin in La Berceuse has been noted by scholars." Vgl. Auch Hoermann Lister 2001, S. 63-83. Mehrere Briefstellen zeigen jedoch eindringlich, dass Madame Roulin ihm tatsächlich noch einmal Porträt saß, bspw. Brief 740/ 571a, Arles, 22.01.1889, an Arnold Koning, zitiert nach Erpel 1968, Bd. 5, S. 316-317. Vgl. dazu insbesondere Rathbone2013, S. 126f. u. Fußnote 16. Erkennbare Spuren von Kohleunterzeichnungen in mehreren Bereichen der Komposition lassen die Vermutung aufkommen, dass van Gogh beim Malen vor dem Modell zunächst die Komposition skizzierte, bevor er mit dem Ausarbeiten in Öl begann. Vgl. Rathbone 2013, S. 127 u. Fußnote 18. Die Vermutung der Kohleunterzeichnung ist durch Infrarotreflektographie nicht bestätigt worden. Dies kann jedoch an der Fehlerquote der Untersuchungsmethode liegen, die manche Pigmente hell oder dunkel erscheinen lässt. Vgl. Technische Anmerkungen Elizabeth Steeles bei Rathbone 2013, S. 130 u. Fußnote 35.

110 Vgl. Rathbone 2013, S. 127f. u. Technische Anmerkungen Elizabeth Steeles bei Rathbone 2013, S. 134. Es ist mit bloßem Auge erkennbar, dass van Gogh auch die Hände und den rechten Ärmel der Stedelijk Fassung mehrfach überarbeitete. Nach mehreren Anläufen entschied er sich in der vierten Fassung schlussendlich wieder für die ursprüngliche Haltung der Hände aus dem allerersten Werk, linke Hand auf rechter Hand aufliegend, die er auch für das letzte Werk der Serie, der Ende Februar-Anfang März entstandenen fünften Fassung, heute in Boston, beibehalten sollte. Dass van Gogh mit der vierten Fassung unzufrieden war, könnte ihn dazu verleitet haben, sie im Gegensatz zu den vier anderen Porträts unsigniert zu lassen. Die anderen Werke hatte er entweder mit seinem Namen oder gar mit Ort und Datum, wie bei der verschenkten zweiten Fassung, oder 
seiner Absichten schrieb van Gogh seinem Bruder am 29. März über die fünfte und letzte Fassung des Porträts:

Und nun mache ich mich zum fünften Mal an meine „Berceuse“. Wenn Du sie siehst, wirst Du mir recht geben, daß es weiter nichts ist als ein Farbdruck aus dem Kaufladen, und dabei ist es nicht mal photographisch richtig in den Proportionen oder in irgendetwas sonst. Aber ich will ja ein Bild machen, wie es ein Seemann, der nichts vom Malen versteht, sich vorstellen würde, wenn er auf hoher See an eine Frau auf dem Land denkt. ${ }^{111}$

Van Gogh hatte bereits in einem Brief vom 21. Januar an Gauguin ausgeführt, welche tröstende Wirkung La Berceuse - eine "petite musique de couleur d'ici“ ${ }^{112}$ haben könne. ${ }^{113}$ Das Symbol der Wiege hatte van Gogh schon längere Zeit beschäftigt. Mehrere Jahre zuvor hatte er sich in einem Brief sehr berührt von der Beziehung zwischen Mutter und Kind gezeigt, als seine damalige Lebensgefährtin, die Prostituierte Sien, während ihrer acht Monate dauernden Beziehung mit ihm, im Juli 1882 ein Kind zur Welt brachte. Mit Blick auf die Wiege bemerkte er: „Dieses [...] Möbel kann ich nicht ohne Rührung ansehen, denn es ist eine starke, mächtige Gemütserregung, die den Menschen ergreift, wenn er neben der Frau, die er liebt, gesessen hat, mit einem Kindchen in der Wiege daneben. Und war es auch im Krankenhaus, wo sie [Sien] lag und ich bei ihr saß, es ist immer die ewige Poesie der Christnacht mit dem Kind im Stall, wie die alten holländischen Maler es aufgefaßt haben, und Millet und Breton - doch ein Licht im Dunkel, eine Helligkeit

alternativ mit „La Berceuse“ beschriftet. Steele begründet dies mit der Unzufriedenheit darüber, dass Madame Roulin die New Yorker Fassung bereits an sich genommen hatte und somit van Gogh die Vorlage mit der geänderten Handhaltung gefehlt habe. Aufgrund dieser Unzufriedenheit entschied sich van Gogh wohl bei der fünften Kopie für die Fassung aus Chicago als Vorlage. Brief 753/582, Arles, 29.3.1889, an Theo, zitiert nach Erpel 1965, Bd. 4, S. 258-260, S. 259. Wie Rathbone betont, ging van Gogh für die fünfte Variante mit einem vorgefassten Bild im Kopf ans Werk, das sich im Laufe der vergangenen Wochen bei der Beschäftigung mit dem Thema entwickelt hatte. Im Malprozess ließ er nun bereits zu Beginn Platz für die Blumen, um sie an den gleichen Positionen wie in den vorher entstandenen Werken zu platzieren. Gleichwohl wirken die Blumen, wie auch das Hintergrundmuster, jetzt im Umkehrschluss sehr schematisch und skizziert. Waren besonders in den ersten zwei Fassungen die Blumen noch dreidimensional ausgearbeitet und stimmig mit dem Hintergrundmuster verbunden, schweben sie bei der letzten Variante flach und unverbunden darüber. Ähnliche Beobachtungen lassen sich bei dem mit raschem Duktus ausgearbeiteten Rock machen, der deutlich weniger Plastizität als noch jener aus der zweiten Fassung aufweist.

112 Brief 745/576, Arles, 3.2.1889, an Theo, zitiert im frz. Original nach der Online-Ausgabe der Briefe, abgerufen unter: http://vangoghletters.org/vg/letters/let745/letter.html.

113 Vgl. Brief 739, in dieser Fassung nicht in Erpel, Arles, 21.1.1889, an Paul Gauguin: „Et je crois que si on plaçait cette toile telle quelle dans un bateau de pêcheurs même d'Islande, il y en aurait qui sentiraient là-dedans la berceuse. "Zitiert nach der Online Edition der Briefe, abgerufen unter: http://vangoghletters.org/vg/letters/let739/letter.html. Auf die weiteren Hintergründe wird an späterer Stelle eingegangen. 
mitten in finsterer Nacht. " ${ }^{114}$ Auch damals verknüpfte er die Wiege bereits mit dem Gefühl des Trostes, berichtete er doch Theo im gleichen Brief, dass er über der Wiege „Bilder [...] aufgehängt [habe], [...] lauter besonders schöne, [unter anderem] den ,Christus Consolator" von Scheffer"115.

An anderer Stelle beschreibt er genauer die angestrebte Wirkung von La Berceuse, die Männern auf hoher See als „Farbenmusik“116 Trost spenden sollte, „als würden sie eingewiegt, als hörten sie wieder ihr eigenes Wiegenlied“117. Damit vergleicht van Gogh sein Schaffen auch mit dem von Komponisten: „...Ach mein lieber Freund, aus der Malerei das zu machen, was schon vor uns die Musik von Berlioz und Wagner bedeutet ... eine Kunst des Trostes für zerrissene Herzen!"118 Wiederholt verweist er auf die mögliche heilende Wirkung der Musik: „Eines Tages wird vielleicht jeder Mensch eine Neurose haben, den Horla, den Veitstanz oder was anderes. Aber gibt es denn kein Gegengift? In Delacroix, in Berlioz und Wagner?"119

Van Gogh war, was die Verbindung zu den Seefahrern anging, von literarischen Quellen beeinflusst, beispielsweise davon, was Pierre Loti (1850-1923) in seinem Roman Pêcheur d'Islande (1886) über die Gewohnheit der Fischer, das Bild eines Heiligen auf ihren Booten aufzuhängen, geschrieben hatte. Darüber hinaus werden der See gegen Ende von Lotis Romans mütterliche Eigenschaften zugeschrieben, wenn sie mit einer Mutter, die ihr Kind wiegt, verglichen wird. Van Gogh diskutierte dies mit Gauguin, dem der Roman ebenfalls vertraut war und der selbst ein erfahrener Seefahrer war, ausführlich. ${ }^{120}$

Dass van Gogh im Zuge der Wiederholungen von La Berceuse in seinem Brief vom 29. März von einem „Farbdruck aus dem Kaufladen“ spricht, verweist auf das gedankliche Konzept, ein einfaches Bild zu schaffen, das allen Menschen, unabhängig von Kaufkraft, Hintergrundwissen und ästhetischer Schulung, zugänglich war; zudem sollte es gefallen und Trost spenden. Dies hatte er Jahre zuvor, inspiriert von den englischen Druckgrafiken, schon einmal versucht. ${ }^{121}$ Wie Ary Scheffers

114 Brief 245/213, Den Haag, 6.-7.7.1882, an Theo, zitiert nach Erpel 1965, Bd. 2, S. 38-40, S. 38. Auf den Brief in diesem Kontext verweist Rathbone 2013, S. 117, Fußnote 3.

115 Brief 245/213, Den Haag, 6.-7.7.1882, an Theo, zitiert nach Erpel 1965, Bd. 2, S. 38-40, S. 38.

116 Brief 745/576, Arles, 3.2.1889, an Theo, zitiert nach Erpel 1965, Bd. 4, S. 245-248, S. 245.

117 Brief 743/574, Saint-Rémy, 28.1.1889, an Theo, zitiert nach Erpel 1965, Bd. 4, S. 240-243, S. 240.

118 Brief 739/in anderer Fassung 573a, 21.1.1889, an Paul Gauguin, zitiert nach Erpel 1968, Bd. 5, S. 308-309. Dass van Gogh Berlioz und Wagner im gleichen Satz erwähnte, könnte durch Camille Benoits Buch zu erklären sein, das einen Aufsatz Wagners über Berlioz enthielt. Vgl. Fußnote 6 der Online-Ausgabe der Briefe, unter: http://vangoghletters.org/vg/letters/let739/letter.html. Der Artikel L'Amour dans la musique von Camille Bellaigue, den van Gogh zusätzlich las, erwähnte Berlioz ebenfalls mehrfach. Vgl. Veldhorst 2015, S. 52.

119 Brief 743/574, Arles, an Theo, 28.1.1889, Erpel 1965, Bd. 4, S. 240-243, S. 243.

120 Van Gogh berichtet davon in Brief 743/574, an Theo, 28.1.1889, Erpel 1965, Bd. 4, S. 240-243, S. 240.Vgl. Pickvance 1884, S. 248 und auch die Anmerkungen zu Brief 739 an Gauguin in der Online Edition der Briefe, abgerufen unter: http://vangoghletters.org/vg/letters/let739/letter.html.

121 Vgl. Rathbone 2013, S. 129. 
tröstender Christus Consolator (Abb. 79), der durch die unzähligen druckgraphischen Reproduktionen im 19. Jahrhundert große Beliebtheit erlangt hatte, sollte La Berceuse als „modern madonna" 122 die Herzen der Menschen auf eine Art und Weise erreichen, die vormals religiösen Werken und der Religion selbst vorbehalten war.

Über die Jahre drückte van Gogh immer wieder seine Hoffnung aus, dass seine Werke eine tröstliche Wirkung auf ihren Betrachter haben mögen, so beispielsweise Ende Januar 1889 als weitere Wiederholungen von La Berceuse entstanden, im gleichen Brief, in dem er sich vorgestellt hatte, zwei seiner großen Trost-Motive zu einem Polyptychon zu kombinieren: dabei sollte das Porträt von La Berceuse von zwei Fassungen der Sonnenblumen flankiert werden, damit diese „zu beiden Seiten [wie] Fackeln oder Kandelaber “123 wirkten. Es geht dabei um die Selbstvergewisserung im Hinblick auf den „Nutzen“ und Sinn des eigenen Tuns. Der Trostbedürftige findet Trost darin, etwas Tröstliches für die Anderen zu schaffen. Mit seiner großen Fähigkeit der Selbstreflexion schrieb er Ende Januar 1889 an Theo:

Und noch einmal - entweder sperrt mich gleich in eine Irrenzelle, ich werde mich nicht dagegen wehren, falls ich mich doch täuschen sollte - oder laßt

122 Kōdera 1990, S. 48.

123 Brief 743/574, Arles, an Theo, 28.1.1889, Erpel 1965, Bd. 4, S. 240-243, S. 240. Da van Gogh wiederholt von der Familie als Einheit sprach, liegt es nahe, zu vermuten, dass er sie im Zuge der bei der Décoration erprobten Ordnungsprinzipien auch gemeinsam auf einer Wand gruppieren würde. Nicht nur, da die Mutter ,ideell Zentrum der Familie“ (Dorn 1990, S. 447) sei, sondern auch aufgrund des einzigen Querformats, vermutete Dorn hinsichtlich der Anordnung bei einer möglichen Hängung, dass das Porträt der sitzenden Mutter in der Mitte zu verorten wäre, flankiert von je zwei hochformatigen Porträts auf beiden Seiten ihres Ehemannes und der drei Kinder. Die Hintergrundfarben der hochformatigen Porträts der beiden Söhne links und rechts außen würden dabei einen Komplementärkontrast zwischen Grün-Rot erzeugen. Die Gelbtöne der Hintergründe der Porträts von Vater und Tochter innenliegend wären dem Hintergrund des Porträts der Mutter ähnlich. (Vgl. Dorn 1990, S. 447 für eine mögliche Reihung von fünf Porträts mit dem querformatigen Porträt der Mutter in der Mitte (F 493, JH 1643-F434, JH 1647-F 503, JH 1646-F 491, JH 1638-F 665, JH 1879) u. Tafel 8, S. 616f.) Dorn sah dabei „[e]in Triptychon mit gelben und orangefarbenen Fonds, flankiert von den beiden Söhnen und so eingespannt zwischen einander steigernde Eckwerte" Dorn 1990, S. 447. Van Goghs Porträtserie weist sehr kohärente gestalterische Binnenstrukturen auf. Nur für die als Pendants konzipierten Porträts der Eltern wählte van Gogh Kniestücke und sonst für alle Kinderporträts Bruststücke. Bis auf Madame Roulins erstes Porträt handelt es sich durchweg um Hochformate. Die Hintergrundfarben der Kinderporträts sind durchgehend monochrom und in der Mehrzahl in Primärfarben gehalten, die ihrerseits starke Kontraste zur Kleidung der in den Bildern dargestellten Personen oder aber auch innerhalb der einzelnen Bilder der Serie herstellen. Dies geht einher mit van Goghs großer Simplifizierung des Darstellungsraumes und dem weitgehendem Verzicht von geographischen oder häuslichen Kontexten, Möbeln sowie anderen persönlichen Attributen. Ausnahmen sind neben dem Doppelporträt von Mutter und Baby aus Philadelphia auch hier wieder die Einzelporträts der Eltern, die nicht nur deutlich sichtbar Mobiliar in die Darstellung mit einbeziehen, das im Hinblick auf La Berceuse und die Kordel für eine weitere Bedeutungsebene steht, sondern sich auch durch die korrespondierenden geblümten Tapeten auszeichnen (bei Joseph Roulin die zwei letzten Varianten aus Philadelphia und Otterlo). Zudem ist Joseph Roulin klar erkennbar in seiner Berufsuniform dargestellt, die ihn als hart arbeitenden Bürger ausweist. 
mich mit all meinen Kräften arbeiten [...]. Wenn ich nicht verrückt bin, wird einst die Stunde kommen, wo ich Dir schicke, was ich Dir von Anfang an versprochen habe. Vielleicht werden meine Bilder unglücklicherweise zerstreut werden, aber Du wenigstens sollst die Gesamtheit dessen sehen, was ich will, und wirst hoffentlich einen tröstenden Eindruck davon haben. ${ }^{124}$

In der Darstellung der Berceuse kommen verschiedene künstlerische Entwicklungsstränge der vorherigen Jahre zusammen: der bereits fünf Jahre zuvor im Zuge der Beschäftigung mit den Übertragungen englischer Drucke formulierte Wille, Kunst seriell zu produzieren, einfache Menschen zu erreichen und insbesondere im Hinblick auf eine gesteigerte Empfindsamkeit bei der Herstellung von Kunst, diese Aspekte zu vereinigen, um - und dies ist wohl mit das wichtigste Kriterium - den Menschen Trost zu spenden. Diese Aspekte kulminierten schließlich in der Serie des ummauerten Feldes, die er wenige Monate später in Saint-Rémy beginnen sollte, bei der er aus den allegorischen Darstellungen des Schnitters und Kornfeldes als Metaphern für das menschliche Leben Trost für sich selbst in einer großen Krise gewinnen konnte. ${ }^{125}$

Im Hinblick auf die Landschaft der Provence, die er im Ganzen zu fassen suchte, sah van Gogh deutlich seine weiteren Aufgaben; im Herbst des gleichen Jahres erläuterte er: „Es lohnt nicht, von irgendwelchen meiner jetzigen Arbeiten zu reden. Wenn ich zurück bin, ergibt sich allenfalls eine Gesamtheit von ,Eindrücken aus der Provence'; [...] ich [muss] noch die Ölbäume, die Feigenbäume, die Weingärten, die Zypressen malen [...], lauter charakteristische Dinge, und auch die Alpinen müssen noch stärker charakterisiert werden. ${ }^{126}$ An diesem Vorhaben, insbesondere mit Fokus auf die Ölbäume, Zypressen und Alpinen, arbeitete van Gogh dann auch in Saint-Rémy mit großem Einsatz weiter.

Mit Humor versuchte er im Frühling 1889 sich selbst und seinem Bruder gut zuzureden, und wieder kam der Malerei der zentrale Aspekt der Vermittlung von Trost zu: „Du kannst Dir ja wohl denken, daß ich mir nicht gerade das Verrücktsein ausgesucht hätte, wenn ich hätte wählen können, aber hat man erst mal so eine Geschichte, so kann man sie wenigstens nicht mehr kriegen. Und außerdem gibt es vielleicht noch den Trost, daß man ein bißchen dabei weitermalen kann." ${ }^{127}$

Auch wenn bei La Berceuse und der wenig später in Saint-Rémy begonnenen Serie des ummauerten Feldes die Vermittlung von Trost ein zentrales Thema ist, unterscheidet sich die Darstellung des immer wieder neu beginnenden Zyklus der Natur in vielerlei Hinsicht deutlich von der seriell zu vervielfältigenden La Berceuse. Van Gogh war zudem auch nicht zufrieden mit der Art und Weise, wie er das Bild der wiegenden Mutter konzipiert hatte. Im Dezember 1889 schrieb er deswegen an Bernard:

124 Brief 743/574, Arles, an Theo, 28.1.1889, Erpel 1965, Bd. 4, S. 240-243, S. 241.

125 Vgl. Brief 800/604, Saint-Rémy, 5./6.9.1889, an Theo, zitiert nach Erpel 1965, Bd. 4, S. 308315, S. 310 u. 314.

126 Brief 808/609, Saint-Rémy, 5.10.1889, an Theo, zitiert nach Erpel 1965, Bd. 4, S. 329-331, S. 331.

127 Brief 763/585, Arles, an Theo, um 21.4.1889, Erpel 1965, Bd. 4, S. 263-266, S. 266. Auf diesen Brief verweist Jansen 2003, S. 20. 
Als Gauguin in Arles war, habe ich mich, wie Du weißt, ein- oder zweimal zu einer Abstraktion hinreißen lassen: in der ,Berceuse ' [...] und damals erschien mir die Abstraktion ein verlockender Weg. Aber das ist verhextes Land, mein Guter! Und bald steht man vor einer Mauer. ${ }^{128}$

Van Gogh war nach Gauguins Abreise - und dies könnte als Motivation für die Serie des ummauerten Feldes, also der Hinwendung zu einem konkreten, landwirtschaftlichen Thema, von großer Bedeutung sein - zu der Überzeugung gelangt, dass „einzig die Nähe zum erlebten Motiv [...] Garant [...] der neuen Kunst und damit ihrer Identität stiftenden Funktion [sein konnte]. "129 Van Gogh hatte nach eigener Aussage viel von Delacroix' Haltung zum Malen aus dem Gedächtnis gelernt und beneidete durchaus die Freunde in der Bretagne, die nach dem Gedächtnis arbeiteten oder Kompositionen gar frei erfanden. ${ }^{130}$ Dennoch sollte für ihn in der Zeit nach Gauguins katastrophal endendem Besuch in Arles die Erkenntnis maßgeblich werden, dass er ohne Modell nicht arbeiten konnte:

Nicht, daß ich nicht der Natur einfach den Rücken kehre, wenn ich eine Studie in ein Bild verwandle, indem ich vereinfache und vergrößere und die Farben ins Gleichgewicht bringe, aber was die Form anlangt, habe ich große Angst, mich vom Möglichen und Richtigen zu entfernen. [...] Ich übertreibe, manchmal ändere ich am Motiv; aber ich erfinde eben nicht das ganze Bild, im Gegenteil, ich finde es fertig vor, aber es muß aus der Natur herausgeschält werden. ${ }^{131}$

Van Gogh gab hier eine schlüssige Beschreibung seiner Arbeitsweise in Saint-Rémy. Er verwarf die Abstraktionen und war bei der Motivfindung stark der ihn umgebenden Wirklichkeit in und außerhalb der Anstalt verpflichtet. Er malte oder zeichnete in der Regel zunächst vor dem Gegenstand, was seine Aussage nachvollziehbar macht, dass er die Bilder nicht „erfinde“, sondern fertig in der Natur „finde“ und sie „herausschälen“ müsse. Gleiches galt für die Übertragung des Bildgegenstandes, den er „vereinfache“ und „vergrößere“ und dessen „Farben [er] ins Gleichgewicht bringe“. 132

128 Brief 822/B 21, Saint-Rémy, um 26.11.1889, an Émile Bernard, zitiert nach Erpel 1968, Bd. 5, S. 291-295, S. 292.

129 Schneede 1989, S. 14.

130 „Er [Delacroix] behauptete, die besten Bilder mache man aus dem Kopf. Par cœur [auswendig]!“ Brief 496/403, Nuenen, 28.4.1885, an Theo, zitiert nach Erpel 1965, Bd. 3, S. 253-255, S. 254. Kursiv gedrucktes im Originalbrief unterstrichen. Vgl. Robinson 2013, S. 12.

131 Brief 698/ B 19, Arles, ca. 5.10.1888, an Émile Bernard, zitiert nach Erpel 1968, Bd. 5, S. 285 288, S. 287.

132 Diese Schritte sind nicht nur auf inhaltlicher, sondern auch auf formaler Ebene entscheidend: Mit beispielsweise der Verwendung intensiverer Farbkontraste innerhalb von Wiederholungen, besonders bei dem für den Ausdruck von Trost so wichtigen Kornfeld, der Schnitter, das er im Laufe weniger Monate gleich dreimal malte, gelang es ihm im Zuge der Wiederholungen, inhaltliche Pointierungen [Akzentuierungen] zu setzen. 



\section{Das Jahr in Saint-Rémy}

\subsection{Der Zyklus des ummauerten Kornfeldes}

In Saint-Rémy war van Gogh sofort berührt vom Ausblick aus seinem Fenster über die provenzalische Landschaft - das heißt genauer von dem Motiv des ummauerten Feldes. Die Landschaft erschien ihm nicht nur „à la van Goyen “" ihn auch an Werke von Daubigny und Rousseau, in denen jene „die ganze Innigkeit ausgedrückt [haben...], die ganze Stille und Größe, und sie haben ein so herzbewegendes, so persönliches Empfinden hineingemalt. Solche Gemütsstimmungen sind mir durchaus nicht zuwider." ${ }^{2}$

Aus Saint-Rémy schrieb van Gogh seiner Schwester im Januar 1890 einen ähnlich gestimmten Brief: „Ach, was den Unterschied zwischen der Großstadt und dem Lande betrifft - was für ein Meister ist doch Millet! Dieser so weise, so gefühlsstarke Mann malt das Land in einer Weise, daß man es sogar in der Stadt immer noch fühlt. Und dann hat er etwas so Einzigartiges und durch und durch Gutes, daß es einen tröstet, seine Werke zu betrachten, und man fragt sich, ob er sie mit Absicht so gemalt hat, um uns zu trösten. " ${ }^{3}$ Diese Kriterien waren für van Gogh in SaintRémy zu seinem Paradigma geworden, und von ihnen leitete er seine Aufgaben als Künstler ab.

Brief 776/592, Saint-Rémy, ca. 23.5.1889, an Theo, zitiert nach Erpel 1965, Bd. 4, S. 279-284, S. 281.

2 Brief 777/593, Saint-Rémy, zw. 31.5. u. 6.6. 1889, an Theo, zitiert nach Erpel 1965, Bd. 4, S. 284-286, S. 285.

3 Brief 841/W 19, Saint-Rémy, 20.1.1890, an Willemien, zitiert nach Erpel 1968, Bd. 5, S. 75-77, S. 76. 


\subsubsection{Der Zyklus: eine Bestandsaufnahme}

Die in Saint-Rémy entstandenen Werke müssen im Kontext der vorherigen Auseinandersetzung mit der Feldarbeit und der Entwicklung seiner eigenen Ikonographie gesehen werden. Mehrere traditionelle Kalendermotive mit arbeitenden Bauern, wie das Mähen des Korns, das Wegtragen der Garben oder das Pflügen vor der Neuaussaat, lassen sich in van Goghs Zyklus in Saint-Rémy finden. ${ }^{4}$ Darüber hinaus hielt van Gogh das Feld ohne Staffagefiguren über das Jahr hinweg in den unterschiedlichen Stadien des Kornwachstums fest, beginnend mit dem noch grünen Feld im Frühling, über das goldene Korn im Sommer, hin zum brachliegenden Feld im Winter. Auch erscheint das Feld in Darstellungen unterschiedlicher Tageszeiten (Morgen, Mittag, Nacht) und Witterungslagen (bei Sonnenschein, bewölktem Himmel, bei Wind und im Regen), die die ganze Bandbreite der Natur- und Wetterphänomene abbilden. Anhand der nachfolgenden Aufstellung sei dies in übersichtlicher Form dargestellt.

\begin{tabular}{|l|l|l|}
\hline Werk & Station im Jahreskreis & Wetter u. Tageszeit \\
\hline $\begin{array}{l}\text { Kornfeld, nach dem } \\
\text { Unwetter, Juni 1889, } \\
\text { sowie in der „réduction“ } \\
\text { (Abb. 1 u. 2) }\end{array}$ & grünes Frühlingsfeld & $\begin{array}{l}\text { heiteres Wetter, Mittag } \\
\text { oder Nachmittag }\end{array}$ \\
\hline $\begin{array}{l}\text { Kornfeld, Ende Mai oder } \\
\text { Anfang Juni 1889 } \\
\text { (Abb. 3) }\end{array}$ & $\begin{array}{l}\text { grünes Frühlingsfeld, } \\
\text { Korn färbt sich gelb, } \\
\text { Mohnblumen blühen }\end{array}$ & $\begin{array}{l}\text { Sonnenschein, } \\
\text { Vormittag }\end{array}$ \\
\hline $\begin{array}{l}\text { Kornfeld, der Schnitter, } \\
\text { „étude“, Juni-Juli 1889, } \\
\text { sowie in den zwei } \\
\text { weiteren Fassungen } \\
\text { (Abb. 4, 5 u. 6) }\end{array}$ & Erntethema (Schnitter) & $\begin{array}{l}\text { Sonnenschein, } \\
\text { Vormittag }\end{array}$ \\
\hline $\begin{array}{l}\text { Kornfeld, Mondaufgang, } \\
\text { Juli 1889 (Abb. 7) }\end{array}$ & $\begin{array}{l}\text { Erntethema (abgeerntetes } \\
\text { Feld) }\end{array}$ & Nacht \\
\hline $\begin{array}{l}\text { Gepflügte Äcker, Ende } \\
\text { August, vor 2.9.1889 } \\
\text { u. Gepflügte Äcker, } \\
\text { Morgenlicht, September } \\
\text { 1889, (Abb. 8 u. 9) }\end{array}$ & $\begin{array}{l}\text { Pflügen vor der } \\
\text { Neuaussaat }\end{array}$ & Sonnenschein, \\
Vormittag \\
\hline
\end{tabular}

4 In Kalenderminiaturen in Stundenbüchern (vgl. Ernteszene, August, fol. 9v, Simon Bening (1483 od. 1484-1561), München-Montserrat Stundenbuch (oder Flämischer Kalender), Brügge, erste Hälfte 16. Jh., Bayerische Staatsbibliothek, München, cod. lat. 23 638) oder beispielsweise bei Bruegels Kornernte) ist das Mähen und das Zusammenbinden der Garben normalerweise Teil des gleichen Motivs. 


\begin{tabular}{|l|l|l|}
\hline $\begin{array}{l}\text { Ummauertes Feld mit } \\
\text { Bauern, Oktober 1889 } \\
\text { (Abb. 10) }\end{array}$ & $\begin{array}{l}\text { Erntethema (Bauer mit } \\
\text { Korngarbe) }\end{array}$ & $\begin{array}{l}\text { Heiteres Wetter, Mittag } \\
\text { oder Nachmittag }\end{array}$ \\
\hline $\begin{array}{l}\text { Kornfeld, Blick auf die } \\
\text { Kirche von Saint-Paul- } \\
\text { de-Mausole, Herbst 1889 } \\
\text { (Abb. 11) }\end{array}$ & $\begin{array}{l}\text { Feld liegt brach, Herbst- } \\
\text { thema }\end{array}$ & $\begin{array}{l}\text { Heiteres Wetter, wohl } \\
\text { Nachmittag }\end{array}$ \\
\hline $\begin{array}{l}\text { Ummauertes Feld, Regen, } \\
\text { November 1889 (Abb. 12) }\end{array}$ & $\begin{array}{l}\text { Herbstthema, } \\
\text { brachliegendes Feld }\end{array}$ & $\begin{array}{l}\text { Regenwetter, Tageszeit } \\
\text { unbestimmbar }\end{array}$ \\
\hline $\begin{array}{l}\text { Kornfeld, Sonnenaufgang, } \\
\text { November 1889 (Abb. 13) }\end{array}$ & $\begin{array}{l}\text { Herbstthema, } \\
\text { brachliegendes Feld }\end{array}$ & Sonnenschein, Morgen \\
\hline $\begin{array}{l}\text { Ummauertes Feld mit den } \\
\text { Alpillen im Hintergrund, } \\
\text { Januar-Februar 1890 } \\
\text { (Abb. 14) }\end{array}$ & $\begin{array}{l}\text { Frühlingsauftakt, blühende } \\
\text { Bäume }\end{array}$ & Heiteres Wetter, Mittag (?) \\
\hline $\begin{array}{l}\text { Diverse Zeichnungen des } \\
\text { Sämann, bspw. ummauertes } \\
\text { Feld mit Sämann im Regen, } \\
\text { März-April 1890, } \\
\text { (Abb. 24 u. 25) }\end{array}$ & Neuaussaat & $\begin{array}{l}\text { Regenwetter, Tageszeit } \\
\text { unbestimmbar }\end{array}$ \\
\hline $\begin{array}{l}\text { Kornfeld, Mai 1890 } \\
\text { (Abb. 15) }\end{array}$ & grünes Frühlingsfeld & $\begin{array}{l}\text { heiteres Wetter, früher } \\
\text { Morgen }\end{array}$ \\
\hline
\end{tabular}

\subsubsection{Der Farbkreislauf}

Bezüglich der Gliederung lässt sich bei den Ansichten des ummauerten Feldes auch das Konzept des Farbkreises erkennen, das van Gogh 1884 entwickelt hatte. Statt für die einzelnen Monate hatte er allerdings einen Jahreszeitenzyklus konzipiert, das heißt den Jahreszeiten bestimmte Farbkombinationen zugeordnet. Das frische Grün von Kornfeld, nach dem Unwetter (Abb. 1) und Kornfeld (Abb. 15) aus dem Mai 1890 sowie die kleine Ölstudie mit den blühenden Bäumen, Ummauertes Feld mit den Alpillen im Hintergrund (Abb. 14), bilden den Frühling ab, ganz so, wie van Gogh es fünf Jahre zuvor charakterisiert hatte: „Der Frühling ist zartes, grünes junges Korn und rosa Apfelblüten [...]." Die Erntebilder Kornfeld, Mondaufgang (Abb. 7) und die dritte Wiederholung von Kornfeld, der Schnitter hingegen bezeichnen mit ihrem intensivem Kontrast von orange-gelbem und orange-goldenem Korn und

Brief 451/372, Nuenen, ca. 2.7.1884, an Theo, zitiert nach Erpel 1965, Bd. 3, S. 181-183, S. 182. 
blauem Himmel den Sommer: „Wenn nun der Sommer den Gegensatz von blauen Tönen gegen ein Element von Orange im Goldbronzeton des Korns ist [...]."6

Die zwei Fassungen von Gepflügte Äcker (Abb. 8 u. 9), aber auch Ummauertes Feld mit Bauern (Abb. 10) zeigen den von van Gogh dem Herbst zugewiesenen komplementären Farbkontrast von Gelb und Violett. Im Oktober wies er seinen Bruder zudem auf die Komplementarität hinsichtlich der Farbigkeit des letztgenannten Werkes mit Kornfeld, der Schnitter (Abb. 4, 5 u. 6) hin:

Es ist wieder eine herbe Studie, und statt fast ganz gelb zu sein, ist es ein fast ganz violettes Bild. Gebrochene und neutrale Violetts. Ich schreibe es Dir, weil ich glaube, es ergänzt den ,Schnitter' [...] Sobald das Bild [Ummauertes Feld mit Bauern ${ }^{7}$ trocken ist, schicke ich es Dir [...]. Ich bitte Dich sehr, wenn sich jemand die Studien ansieht, so zeige die beiden Bilder zusammen wegen des Gegensatzes der Komplementärfarben. ${ }^{8}$

Einzig für den Winterkontrast „Schnee mit [...] schwarzen Silhouetten“ lässt sich im Zyklus des ummauerten Feldes kein entsprechendes Werk ermitteln. Dies ist wohl durch van Goghs Wunsch zu erklären, kräftige Farben zu verwenden. Bereits zu Beginn seines Aufenthalts in Arles hatte van Gogh durch den Gebrauch leuchtender Farben nicht nur den künstlerischen Anforderungen seiner Zeit, wie er sie sah, genügen wollen - „der Maler der Zukunft ist ein Kolorist, wie es noch keinen gegeben hat. “9 -, sondern sich auch darum bemüht, durch seine Farbwahl „Heiterkeit [...] Glück, Hoffnung und Liebe "10 auszudrücken. Er vertrat die Auffassung, „daß im Süden eine neue Koloristen-Schule Wurzel fassen wird,“ denn er gewann „mehr und mehr [den Eindruck], daß die im Norden mehr Wert auf geschickte Pinselführung und den sogenannten malerischen Effekt legen als auf das Bestreben etwas durch die Farbe selbst auszudrücken. "11

6 Brief 451/372, Nuenen, ca. 2.7.1884, an Theo, zitiert nach Erpel 1965, Bd. 3, S. 181-183, S. 182.

7 Ummauertes Feld mit Bauern, Oktober 1889, Öl auf Leinwand, 73 x 92 cm, Indianapolis Museum of Art, F 641, JH 1795.

8 Brief 810/610, Saint-Rémy, ca. 8.10.1889, an Theo, zitiert nach Erpel 1965, Bd. 4, S. 332-334, S. 332 .

9 Brief 604/482, Arles, 4.5.1888, an Theo, zitiert nach Erpel 1965, Bd. 4, S. 39-41, S. 40. Vgl. für diesen Brief auch Homburg 2001, S. 36.

10 Brief 678/W 7, Arles, 9. u. 14.9. 1888, an Willemien, zitiert nach Erpel 1968, Bd. 5, S. 51-54, S. 53. Vgl. für diesen Brief auch Noll 1996, S. 70.

11 Brief 707/555, Arles, 17.10.1888, an Theo, zitiert nach Erpel 1965, Bd. 4, S. 199-202, S. 200. Vgl. für diesen Brief auch Homburg 2001, S. 39. 


\subsubsection{Landwirtschaftliche Motive im Jahreskreis}

\subsubsection{Der Schnitter}

Den so wichtigen und häufig zu Papier und auf die Leinwand gebrachten Sämann stellte van Gogh im Zyklus des ummauerten Feldes nur im Frühjahr 1890, bald vor seiner Abreise nach Auvers, in mehreren Zeichnungen mit unterschiedlicher kompositorischer Anlage dar. Ob er in Saint-Rémy auch eine Version des Sämanns in Öl plante, ist nicht abschließend geklärt. Der komplementäre Schnitter war dagegen so wichtig, dass er in drei Ausführungen vorliegt, weswegen der Schwerpunkt der Untersuchung auf dieses Motiv gelegt wird. Doch auch der Pflüger nimmt im Gesamtwerk van Goghs eine tragende Rolle ein und, da er in Saint-Rémy zweifach auftaucht, soll er ebenfalls ausführlich besprochen werden.

Schnitter und Sämann, deren Semantik für ihn wesentlich durch die Bibel geprägt ist, gehören insgesamt zu den häufigsten landwirtschaftlichen Figuren in van Goghs Werk. Van Gogh war mit den einschlägigen Gleichnissen und Bibelstellen bestens vertraut und reflektierte sie häufig in seinen Briefen. Im September 1877 schrieb er mit Bezug auf Galater 6, 7-8: „Denn was der Mensch säet, das wird er ernten, und wer den Geist säet, der wird von dem Geist das ewige Leben ernten. “12 Fünf Jahre später, und nach seiner Entscheidung, Künstler zu werden, hatte van Gogh das Sämann-Schnitter-Thema umgemünzt: „Das Studienmachen betrachte ich als Säen, und das Bildermachen ist Ernten. "13 Immer wieder tauchen entsprechende Analogien in Abwandlung auf. In einem Brief an seine Schwester aus dem Oktober 1887 verglich er die Menschen mit Getreidekörnern. „In jedem gesunden, natürlichen Menschen steckt wie im Samenkorn Keimkraft. - Und das natürliche Leben ist also Keimen. Was die Keimkraft im Samenkorn, das ist die Liebe in uns. " ${ }^{14}$

Aus diesem Grund überrascht es wenig, dass van Gogh seinen Bruder, unmittelbar nach seiner Entscheidung, Künstler zu werden, gebeten hatte, ihm Millets Serie Die Feldarbeiten zu schicken, die auch zwei Darstellungen von Schnittern enthielt, die er zu kopieren beabsichtigte. ${ }^{15}$ Van Gogh kopierte oder diskutierte über die Jahre hinweg immer wieder unterschiedliche Erntedarstellungen mit Schnittern, neben denen von Millet zum Beispiel auch mehrere von Lhermitte, über deren Bedeutung er im Oktober 1885 bemerkte: „In den Arbeiten von Millet, von Lhermitte ist auch alle Wirklichkeit gleichzeitig Symbol. Sie sind etwas anderes, als was man Realisten

12 Brief 131/110, Amsterdam, 18.9.1877, an Theo, zitiert nach Erpel 1965, Bd. 2, S. 144-148, S. 146. Vgl. Kōdera 1990, S. 67 u. Fußnote 234. Hinweis auf Galater auch in Fußnote 21 dieses Briefs, abgerufen aus der Online-Ausgabe der Briefe, unter http://vangoghletters.org/vg/letters/ let131/letter.html.

13 Brief 266/233, Den Haag, 18.9.1882, an Theo, zitiert nach Erpel 1965, Bd. 2, S. 100-102, S. 102.

14 Brief 574/W 1, Paris, Ende Oktober, an Willemien, zitiert nach Erpel 1968, Bd. 5, S. 32-36, S. 32. Vgl. für diesen Brief auch Kendall 2015, S. 127.

15 Vgl. Brief 156/134, Cuesmes, 7.9.1880, an Theo, Erpel 1965, Bd. 1, S. 210-211. Auf diesen Brief verweist Robinson 2013, S. 19. 
nennt. " ${ }^{16}$ Insbesondere bei Millet ist die allegorisch-religiöse Auffassung dieser Motive unmittelbar vorgeprägt.

Sind aus der Zeit bis 1884 nur zwei Werke van Goghs mit Schnittern bekannt, springt die Zahl 1885 schlagartig auf mindestens 14. Aufgrund der symbolischen Verknüpfung des Schnitters mit dem Tod, vermutet Kōdera, dass die hohe Zahl durch das Ableben des Vaters im März 1885 erklärt werden könnte. Unterstützt wird diese Hypothese dadurch, dass van Gogh nach vielen Darstellungen des zu dem Schnitter komplementären Sämanns bis 1884 im darauf folgenden Jahr keinen einzigen Sämann anfertigte. Aus den Jahren in Paris ist keine Darstellung des Schnitters von van Gogh bekannt. Erst der Umzug in die Provence im Frühjahr 1888 ließ ihn dieses Thema wieder aufgreifen und beschäftigte ihn bis zu seinem Tod in Auvers zwei Jahre später. ${ }^{17}$

Erkenntnisse über van Goghs Assoziationen mit dem dialektischen SämannSchnitter-Motiv liefert seine Auseinandersetzung mit dem 1862 entstandenen Trauerzug durchs Kornfeld des niederländischen Malers und Radierers Jacobus Jan van der Maaten (1820-1879) - ein weiteres bedeutsames Werk, das er, noch vor seiner Entscheidung, Künstler zu werden, kennen- und schätzen gelernt hatte. ${ }^{18}$ Van Gogh berichtete 1877 aus Amsterdam, dass sein Vater dieses Bild in einer Predigt anlässlich einer Beerdigung im Zusammenhang mit Abschnitten aus der Bibel erwähnt habe, die Christi Auferstehung, das ewige Leben und landwirtschaftliche Metaphern, wie das Gleichnis vom Wachsen der Saat (Markus 4, 26-29), zum Inhalt hatten. ${ }^{19}$

Dargestellt ist eine Prozession dunkel gekleideter Personen, die der Betrachter nur von hinten sieht, durch ein reifes Kornfeld, zu einer kleinen Ortschaft in der Ferne, in deren Mitte sich eine die umliegenden Häuser überragende Kirche befindet. An der Spitze des Zuges lassen sich die Umrisse des Sarges erahnen. Zu sehen ist eine typisch niederländische Flachlandschaft mit tiefliegendem Horizont, die sich über die ganze Bildbreite erstreckt und von einem hohen Himmel überfangen wird, der fast zwei Drittel des Bildraumes einnimmt. Der Feldweg führt auf die Kirche zu, die sich nicht nur im Fluchtpunkt, sondern auch exakt in der Mittelachse des

16 Brief 533/425, Nuenen, 4.10.1885, an Theo, nach Erpel, Bd. 3, S. 306-307, S. 307. Léon Augustin Lhermitte (1844-1925), La moisson, 1874, Carcassonne, Musée des Beaux-Arts u. La moisson, 1883, Saint Louis, Washington University Gallery of Art. Beide Werke erwähnte van Gogh in Brief 484/395, Nuenen, 2.3.1885, an Theo, Erpel 1965, Bd. 3, S. 236-238, S. 237.

17 Vgl. Kōdera 1990, S. 137.

18 Vgl. Brief 37/30, Paris, 6.7.1875, an Theo, Erpel 1965, Bd. 1, S. 33-34, S. 33 u. Brief 36/29, Paris, 29.6.1875, an Theo, Erpel 1965, Bd. 1, S. 32-33. Auf diese Briefe verweist auch Greer 2003, S. 68. Sowohl er als auch sein Vater besaßen Reproduktionen davon. Die Lithographie hatte van der Maaten selbst angefertigt. Sie erschien in Kunstkronijk, Bd. 3, 1862, no. 20, S. 78-79 (heute eine Ausfertigung im Van Gogh Museum), vgl. Fußnote 2 zu Brief 36/29 in der Online-Ausgabe der Briefe, abgerufen unter: http://vangoghletters.org/vg/letters/let036/letter.html\#.

19 In der Predigt wurden laut van Gogh 1. Thessalonicher 4, 13-18 u. 5, 1-10, Markus 4, 26-29, Johannes 12, 24 u. 1. Korinther 15, 35-38, 40-58 erörtert. Vgl. Brief 128/in dieser Fassung nicht in Erpel, Amsterdam, 27.8.1877, abgerufen in derOnline-AusgabederBriefe, unterhttp://vangoghletters.org/ vg/letters/let128/letter.html\#. 
Bildes befindet und deren spitzer Turm sich zusätzlich als Silhouette vor dem lichten Horizont abhebt. Rechts von der Prozession ist im Vordergrund ein einzelner kleiner Schnitter dargestellt, der seine Sense geschultert hat und seine Aufgabe unterbrochen hat - eine Aufgabe, die allein zu bewältigen aufgrund der Größe des Feldes fast unmöglich erscheint. Dadurch wird impliziert, dass die Arbeit des Menschen in der sich zyklisch wandelnden Natur niemals endet („Im Schweiße deines Angesichts wirst du dein Brot essen, bis du zurückkehrst zur Erde, denn von ihr bist du genommen. Denn Staub bist du, und zum Staube wirst du zurückkehren!“ Genesis 3, 19). Darüber hinaus lassen die geringe Figurengröße der Teilnehmer der Prozession und die des Schnitters die Bedeutung des menschlichen Elements in der Weite der Landschaft, unter dem hohen Himmel geringfügig erscheinen. Bedeutsam ist nun aber, dass augenscheinlich eine Beziehung zwischen dem Leichenzug, das heißt dem hier zu Grabe getragenen Toten, und der Arbeit des Schnitters hergestellt ist.

Van Gogh schenkte M. B. Mendes da Costa, seinem Lehrer für Latein und Griechisch in Amsterdam, eine druckgraphische Reproduktion dieses Werkes, das er für ihn auf beiden Seiten mit assoziativen Anmerkungen versehen hatte (Abb. 89). Wie van Gogh es durch seinen Vater und dann durch seinen Onkel Stricker gelernt hatte, fügte er gemäß der Praxis der „bijschriften-poëzie“ an den Bildrändern thematisch ergänzende christliche und profane Texte hinzu, um die Bildaussage zu erweitern, die ihrerseits entscheidend zum Verständnis beitragen, wie van Gogh den Trauerzug durchs Kornfeld interpretierte. Diese umfassen unterhalb des Bildes lateinische Zitate aus der Bibel, unter anderem diejenigen zum Sämann und zur Ernte (beispielsweise das Gleichnis vom Wachsen der Saat; Markus 4, 26-29), die sein Vater bereits in seiner Predigt in Zusammenhang mit eben diesem Bild zitiert hatte, und Abschnitte über die Auferstehung aus dem Evangelium des Johannes. ${ }^{20}$

Auszüge aus dem Choral „De Hoop der Zaligheid“ (dt. „Die Hoffnung auf Erlösung “) aus dem Gesangbuch der Niederländisch Reformierten Kirche, die das Bild auf der linken Seite flankieren, beziehen sich ebenfalls auf die Arbeit eines müden Bauern und die Hoffnung auf Erlösung - eine Hoffnung, die alle Mühen des Lebens erleichtere und den Schmerz lindere. ${ }^{21}$ Die Auswahl dieser Texte zeigt deutlich, dass van Gogh aus van der Maatens Motiv, trotz dessen insgesamt eher düsterer Atmosphäre und der Darstellung des Schnitters, dessen Arbeit mit dem Tod parallelisiert

20 Bei den Bibelstellen unterhalb des Bildes handelte es sich um Johannes 5, 24-25, 28-29 und Johannes 12, 24-25, Markus 4, 26-29 sowie Lukas 9, 24. Vgl. Kōdera 1990, S. 13f. Das Original befindet sich in der Universiteitsbibliotheek, Amsterdam (Ms. XIII C 13a), der es Mendes da Costa vermachte.

21 Es handelte sich um Nummer 189 aus dem Gesangbuch. Van Gogh zitierte nur die erste und sechste Strophe des Chorals und sie variieren leicht von der gedruckten Fassung, so dass vemutet werden kann, dass er sie aus dem Kopf niederschrieb. „Zoo bly de landman moe van 't ploegen | De neigende avondscheemering groet $\mid$ Zoo bly zien wij na al ons zwoegen | Dat onze dag ten einde spoedt | Niet eeuwig zal de hope kwijnen | Die naar het uur de ruste smacht | Maar 't oogenblik zal eens verschijnen | Zoo lang hier hijgend ingewacht | Die hoop kan alle leed verzachten | Komt reisgenoten 't hoofd omhoog | Voor hen die 't heil des Heeren wachten | Zijn bergen vlak en zeeën 
ist, den Glauben auf die Auferstehung abzuleiten vermochte. Hinweise für diese Lesart lassen sich auch im Bild ermitteln, denn der lichte Horizont, vor dem sich die Kirche, die ihrerseits aufgrund ihres weit in den Himmel hineinragenden Turmes eine Verbindung zwischen irdischer und himmlischer Zone herstellt, so deutlich abhebt, kann dabei als ein Zeichen der Hoffnung, der Verheißung auf ein Leben nach dem Tod gedeutet werden.

Verse des amerikanischen Dichters Henry Wadsworth Longfellow (1807-1882), aus dessen Gedicht Afternoon in February, das, ähnlich wie der Choral und van der Maatens Werk, eine Verbindung zwischen einer Landschaft und dem Tod herstellt, schrieb van Gogh auf der rechten Bildseite nieder: „The day is ending | The night descending | The marsh is frozen | The river dead. [...] And through the meadows | Like fearful shadows | Slowly passes a funeral train. "22 Bedeutsam sind dabei Longfellows Beschreibungen der Natur im Winter, der Tageszeit, der Witterungsverhältnisse und der Landschaftsmotive, die alle als Todesmetaphern zu interpretieren sind und aus van Goghs Sicht van der Maatens Darstellung ergänzen - ein wichtiger Anhaltspunkt bei der Frage, in welchem Sinne van Gogh in späteren Jahren Landschaftsdarstellungen symbolisch begreifen konnte bzw. verstanden wissen wollte. ${ }^{23}$

Longfellows Gedicht muss van Gogh besonders geschätzt haben, hatte er es doch bereits im Jahr zuvor in das Gästebuch von Anne Slade-Jones, der Ehefrau des Pastors Thomas Slade-Jones, übertragen, als er mit der Familie in Isleworth lebte. Neben dem Gedicht von Longfellow schrieb er in das Gästebuch, unter anderem, Psalmen und vier Gedichte von Friedrich Rückert nieder und klebte auf der folgenden Seite des Gästebuchs eine Reproduktion von Paul Delaroches (1797-1856) Christus im Garten Gethsemane ein, das weitere Rückschlüsse auf van Goghs Ver-

droog | Zaligheid niet af te meten | Vreugd die alle smart verbant | Eens is de vreemdlingschap vergeten | En wij wij zijn in 't vaderland“ (Kōdera 1990, S. 13f.).

„Froh wie der Bauer, müde vom Pflügen | Die Abenddämmerung grüßt | Sind wir, nach all der Arbeit und Mühen | Zu sehen, dass sich der Tag dem Ende zuneigt | Unsere Hoffnung auf die Stunden der Ruhe | Soll nie ermatten | Aber der Augenblick | Keuchend so lange herbeigesehnt, soll eintreffen | Die Hoffnung kann all unseren Schmerz lindern | Kommt, Reisende, hebt Eure Hände in die Höhe | Für die, die der Erlösung des Herrn harren | Sind Berge flach und die Meere trocken | Unermessliche Freude | Entzündet sich, die alle Schmerzen vertreibt | Unsere Entfremdung wird vergessen sein | Und wir werden in unserer Heimat sein" (eigene Übersetzung). Als Quelle könnte dieses Gesangbuch gedient haben: Het boek der Psalmen nevens de Gezangen bij de Hervormde Kerk van Nederland, Amsterdam 1825, S. 310f., Choral 189, „De Hoop der Zaligheid“. Wie Kōdera hervorhebt, befindet sich diese Ausgabe in der Sammlung der Familie van Gogh (heute im Van Gogh Museum), aber es ist nicht abschließend gesichert, ob van Gogh auch genau diese Ausgabe verwendete. Vgl. Kōdera 1990, S. 13f. u. Fußnote 20 für weitere Informationen und eine Überstzung in das Englische.

22 Zitiert nach Dokument mit Abschriften von Gedichten, RM03/nicht in Erpel, wohl London, Dezember 1874-März 1876, abgerufen in der Online-Ausgabe der Briefe, unter http://vangoghletters. org/vg/letters/RM03/letter.html\#n-3. Vgl. für das Gästebuch von Anne Slade-Jones Kōdera 1990, S. 14 u. Fußnote 21 sowie Pabst 1988, S. 60-61 u. 69. Es ist nicht abschließend ermittelt, ob das Bild tatsächlich von van Gogh eingeklebt worden war.

23 Vgl. Greer 2003, S. 68f. 
knüpfungen unterschiedlicher Text- und Bildquellen zu der Thematik des Todes zulässt.

Von welcher zentralen Bedeutung der Schnitter in Saint-Rémy für van Gogh war, lässt sich nicht nur anhand der Briefe verstehen, sondern auch durch den Entstehungsprozess des durch van Goghs Wiederholungspraxis „étude“ - „tableau“ „réduction" in drei sich ähnelnden, aber letztlich doch voneinander abweichenden Fassungen vorliegende Kornfeld, der Schnitter nachvollziehen. Von keinem Motiv des Zyklus liegen ähnlich viele Fassungen vor.

Die Unterschiede im Bereich des Feldes der jeweiligen Varianten bestehen wesentlich in Änderungen der für das Sujet wichtigsten Bildbestandteile, namentlich des Schnitters, des Feldes und der Mauer, und zeigen an, dass van Gogh von Version zu Version um eine deutlichere inhaltliche Akzentuierung bemüht war: Die begrenzende Mauer wird von Werk zu Werk immer deutlicher hervorgehoben und die große Korngarbe, die in der „étude“ noch prominent im Vordergrund platziert war, ist in den zwei Wiederholungen verschwunden, um freie Sicht auf den Schnitter zu gewähren. Stattdessen ist der Bereich des noch nicht abgeernteten Feldes größer als zuvor.

Dadurch ergeben die Schnittkante des noch stehenden Korns und die diagonal angeordnete Bergkette gemeinsam eine Keilformation, deren Spitze wohl absichtlich und bedeutungsvoll wie ein Pfeil direkt auf den Schnitter weist. ${ }^{24}$ Diese kompositorische Hervorhebung des Schnitters fehlte in der ersten Fassung noch gänzlich. Da der Schnitter bei der ersten Version im gleichen Ton wie das Feld gemalt war, löst er sich vielmehr darin nahezu auf. Neben der kompositorischen Veränderung der Bilder konturierte van Gogh den Schnitter in der zweiten Fassung zunächst mit schwarzem Pinselstrich entschiedener und hob ihn zusätzlich mit stumpferem Gelb vom leuchtenden Feld ab. In der dritten Fassung steigerte er diese farbliche Hervorhebung noch weiter.

Wie eingangs dargestellt, war van Goghs zunächst intensiver Bibelglaube, vor allem im Zeitraum 1876-1879, als er sich bemühte, als Geistlicher zu arbeiten, in der Folge einem „Bewusstsein von etwas Höherem und de[m] Glauben daran ${ }^{\prime}-[\ldots$,das] sich auf den ewigen Kreislauf der Jahreszeiten gründete“25, gewichen. Van Gogh war jedoch kein Pantheist, der Gott in der Natur fand. Die Natur hatte tatsächlich „nur" einen Verweischarakter auf jene „quelque chose là-haut“. Mitte der 1880er Jahre schrieb van Gogh, als er mit dem Stellenwert der Religion, und insbesondere mit seinem Vater als einem Vertreter der Amtskirche, rang, in Hinblick auf den alten Kirchturm von Nuenen, den er in der Bildflucht einer der Fassungen der Weber integriert hatte: „Und nun sagt mir die alte Ruine, wie ein Glaube und eine Religion

24 Vgl. Hansen 2002, S. 90.

25 Bakker 2010, S. 196. Zitiert wird Brief 333/277, Den Haag, 29.3. u. 1.4.1883, an Theo, zitiert nach Erpel 1965, Bd. 2, S. 230-234, S. 232. Den Ausspruch „quelque chose là-haut" verwendet van Gogh immer wieder in seinen Briefen. 
vergehen - obgleich sie festgegründet waren, wie dagegen das Leben und Sterben der Bauern das gleiche ist und bleibt, ein stetes Aufsprießen und Verwelken wie bei dem Gras und den Blumen, die auf diesem Kirchhofsboden wachsen. Les réligions passent, Dieu demeure [...]. ${ }^{\text {"26 }}$ Van Gogh ging von einer Vergänglichkeit der Religionen aus und die Kirche sah er am Ende. Nicht vergänglich war für ihn jene "quelque chose là-haut".

Etwa drei Jahre später berichtete van Gogh seinem Bruder aus Arles, dass er einen Artikel über Tolstois Beschäftigung mit der Religion gelesen habe. Infolgedessen drückte er seine Hoffnung aus, „daß, ganz abgesehen von heftigen, aufrührerischen Revolutionen, auch eine innerliche, geheime Revolution in den Menschen vor sich gehen werde, aus der eine neue Religion geboren werden wird oder vielmehr etwas ganz Neues, das keinen Namen hat, das aber dieselbe Wirkungskraft haben wird, zu trösten und das Leben möglich zu machen, wie früher die christliche Religion. "

Die Natur bot van Gogh in Saint-Rémy „[i]n dieser Lage unerfüllter Sehnsucht und zweifelndem Verlangen nach einem Lebensfundament [...] als Ausfluß, Spiegel in sinnbildlicher Weise jener unsichtbaren höheren Macht zuletzt Hoffnung und

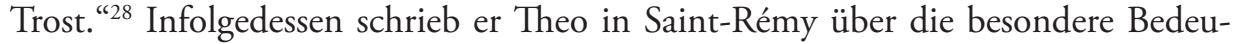
tung des Schnitters für ihn:

[...] ein Schnitter; die Studie ist ganz gelb schrecklich dick aufgetragen, aber das Motiv ist schön und einfach. Ich sehe in diesem Schnitter - einer unbestimmten Gestalt, die in sengender Hitze wie der Teufel dreinhaut, um mit der Arbeit fertig zu werden -, ich sehe in ihm ein Bild des Todes in dem Sinne, daß die Menschen das Korn sind, das er niedersichelt. Es ist also, wenn man will, das Gegenstück zu dem Sämann, den ich früher versucht habe. ${ }^{29}$

Den Schnitter als Verkörperung des Todes aufzufassen, hat in der bildenden Kunst eine lange Tradition. Sie findet sich häufig in der mittelalterlichen Buchmalerei, besonders in Stundenbüchern zu Beginn des Totenoffiziums - Gebeten, die zum Gedenken von Verstorbenen gesprochen wurden - und dort beispielsweise um 1475 in einer Jean Fouquet (um 1420-zw. 1478-1481) zugeschriebenen Illumination für

26 Brief 507/411, Nuenen, ca. 9.6.1885, an Theo, zitiert nach Erpel 1965, Bd. 3, S. 275-278, S. 276. Dt. „Die Religionen vergehen, Gott bleibt.“ Dies war ein Zitat Victor Hugos, der zwei Wochen vorher verstorben war. Vgl. auch Anmerkung 2 zu diesem Brief in der Online-Ausgabe der Briefe, abgerufen unter: http://vangoghletters.org/vg/letters/let507/letter.html\#. Noll glaubt bei dieser Beschreibung des Kirchturms nicht an die Vergänglichkeit der Religion, sondern vielmehr, dass dieser positiv konnotiert und als Sinnbild von "quelque chose là-haut" zu verstehen sein könnte, „als ein religiöses Denkmal und Hinweis auf Gott, in dessen Angesicht und unter dessen Schirm und Schutz die alltägliche Arbeit geschieht." Noll 1994, S. 67.

27 Brief 686/542, Arles, 23. o. 24. September 1888, an Theo, zitiert nach Erpel 1965, Bd. 4, S. 169174, S. 172f. Vgl. für diesen Brief und die Verbindung zu Tolstoi auch Noll 1996, S. 67.

28 Noll 1996, S. 67. Wie Noll eindringlich hinweist, handelt es sich dabei jedoch nicht um eine pantheistische Auffassung.

29 Brief 800/604, Saint-Rémy, 5./6.9.1889, an Theo, zitiert nach Erpel 1965, Bd. 4, S. 308-315, S. 310 . 
das sogenannte de Veauce-Stundenbuch, die den Sensenmann als lächelndes Skelett neben bereits niedergestreckten Menschen zeigt (Abb. 90). ${ }^{30}$

Van Gogh könnte durch Millets Darstellung von La Mort et le bûcheron beeinflusst gewesen sein, bei dem ein Sensenmann, basierend auf einer gleichnamigen $\mathrm{Fa}$ bel von Jean de La Fontaine (1621-1695), einen alten Holzfäller von hinten packt und mit sich zieht (Abb. 91). ${ }^{31}$ Van Gogh war de la Fontaines Geschichte über die Mühsal des Lebens und die Erlösung durch den Tod vertraut, da sein Onkel Stricker sie in eine seiner Predigten über das Buch der Sprüche 15, 24 („Einen Lebenspfad zur Höhe gibt es für den Klugen, damit er der Totenwelt drunten entgeht") integriert und dadurch eine allegorisch-religiöse Interpretation entwickelt hatte. In einem Brief vom August 1877 zitierte van Gogh die Fabel, an deren Ende es heißt: „Le trépas vient tout guérir [Der Tod kommt, um alles zu heilen]“, in voller Länge im französischen Original. ${ }^{32}$

Hinsichtlich der Verbindung zur Feldarbeit könnte van Gogh auch durch einen in dem von ihm geschätzten Magasin Pittoresque veröffentlichten Holzstich, der den Schnitter als Skelett mit Sense darstellt, inspiriert gewesen sein (Abb. 92). Der das Feld niedermähende Sensenmann wird überfangen von der Inschrift „Le ciel sourit | Le champ fleurit | La mort moissone... [dt. Der Himmel lächelt | Das Feld blüht | Der Tod mäht] “.33

Dies könnte van Gogh zu der Aussage geführt haben, dass der Tod kein Übel bedeute: „Aber dieser Tod hat nichts Trauriges, das geht bei hellem Tageslicht vor sich, mit einer Sonne, die alles in feinem Goldlicht überflutet. [...] Uff - der "Schnitter“ ist fertig, [...] - es ist ein Abbild des Todes, so wie das große Buch der Natur uns von ihm spricht - aber was ich anstrebe, ist das ,beinah lächelnd'[...]." ${ }^{34}$ Ebenso möglich ist, dass van Gogh den Aspekt des ,beinah lächelnd' im Angesicht des Todes aus einem Artikel des französischen Autors Théophile Silvestre (1823-1876) über Delacroix abgeleitet hatte, in dem jener den Tod des Malers als sehr friedlich be-

30 Jean Fouquet (ca. 1420-1478?) zugeschrieben, Der Tod, , sog. de Veauce-Stundenbuch, Amsterdam, Bibliotheca Philosophica Hermetica, BPH 74, folio 120; u.a. auch Sotheby's London, Auktion 6.7.2000, Los 38. Vgl. Schaefer 1994, S. 260-262.

31 Jean-François Millet (1814-1875), Der Tod und der Holzfäller, 1859, Öl auf Leinwand, Maße unbekannt, Ny Carlsberg Glyptothek, Kopenhagen. Vgl. für die Verbindung zu van Gogh auch Heugten/Consibee/van Tilborgh 1989, S. 78.

32 Brief 127/106, Amsterdam, 18.8.1877, an Theo, zitiert nach dem Originalbrief, abgerufen in der Online-Ausgabe der Briefe, unter: http://vangoghletters.org/vg/letters/let127/letter.html\#.

33 Vgl. Holzstich nach Neurather, in Magasin Pittoresque, 19.12.1851, S. 257, abgebildet in van Heugten/Consibee/van Tilborgh 1989, S. 78. Es ist überliefert, dass van Gogh diese Ausgabe des Magazins besaß, denn in Brief 309/R 21, Den Haag, 8.2.1883, an van Rappard, Erpel 1968, Bd. 5, S. 157-160, S. 158, schrieb er über einen andere Darstellung daraus. Vgl. auch Anmerkung 4 aus der Online-Ausgabe der Briefe, abgerufen unter: http://vangoghletters.org/vg/letters/let309/ letter.html.

34 Brief 800/604, Saint-Rémy, 5./6.9.1889, an Theo, zitiert nach Erpel 1965, Bd. 4, S. 308-315, S. 310 u. 314 . 
schrieb. Van Gogh übernahm die Wortwahl eins zu eins: „Ainsi mourut presqu'en souriant Eugène Delacroix [So starb, beinahe lächelnd, Eugène Delacroix]“35.

Mehrfach deutete van Gogh in Saint-Rémy seinen Geschwistern seine Verzweiflung und Hoffnungslosigkeit an: „Viele Tage lang war ich vollkommen verwirrt wie in Arles, genauso, und es ist anzunehmen, daß diese Anfälle auch in Zukunft wiederkommen; das ist entsetzlich. [...] Ich sehe keine Möglichkeit mehr, Mut oder Hoffnung zu schöpfen [...]." ${ }^{36}$ Kurz zuvor hatte er in einem Brief an seine Schwester zum Ausdruck gebracht, wie sehr er mit dem Sinn des Lebens und dem Fehlen von Gewissheiten haderte: „Wir kennen das Leben nicht, wir haben keine Ahnung von seinen Untergründen, wir leben eben in einer Zeit, da alle Welt sinnlos durcheinanderschwatzt und alles zu wanken scheint [...]. Aber jeder Gedanke an ein geregeltes Leben, jeder Gedanke, in uns selbst und in anderen schöne Gedanken und Gefühle zu wecken, muß notwendigerweise als reine Utopie vorkommen [...] Was kann man weiter tun, wenn man alles bedenkt, was wir nicht verstehen, als die Kornfelder betrachten. " ${ }^{37}$

Als der Bruder Cornelis (1867-1900) im Sommer 1889 nach Südafrika aufbrach, schrieb van Gogh Theo einen Brief, in dem der Schwerpunkt auf dem Schmerz, den er empfand, und auf seiner Unfähigkeit, den Sinn des Weltgeschehens zu verstehen, liegt. Einzig die Kornfelder erschienen ihm als Möglichkeit der Flucht davor:

Drüben kann man sich freimachen vom Einfluß unserer Großstädte, die so alt sind, wo alles so unsinnig ist und zu schwanken scheint - das ist der große Unterschied gegen Europa. Statt daß man sieht, wie Lebenskraft und angeborene Energie sich in leerem Geschwätz verflüchtigen, kann man vielleicht fern von Leiden lernen ohne zu klagen, den Schmerz ohne Widerwillen hinzunehmen - gerade dabei kann einem leicht schwindlig werden; und doch überkommt uns manchmal eine dunkle Ahnung, daß wir vielleicht auf der anderen Seite des Lebens ein Daseinsrecht des Schmerzes erkennen, der, von hier aus gesehen, zuweilen den ganzen Horizont so beherrscht, daß er uns wie eine hoffnungslose Sintflut vorkommt. Wie sich das alles zueinander verhält, davon wissen wir sehr wenig, und wir tun besser daran, ein Kornfeld anzuschauen, auch wenn es nur ein gemaltes ist. ${ }^{38}$

35 Brief 526/R 58, Nuenen, zw. 8.-15.9.1885, an van Rappard, zitiert nach Erpel 1968, Bd. 5, S. 236-238, S. 237. Übersetzung ebenfalls bei Erpel. Hinweis auf diesen Brief in Fußnote 28 zu Brief 800/604, abgerufen aus der Online-Ausgabe der Briefe, unter: http://vangoghletters.org/vg/ letters/let800/letter.html.

36 Brief 797/601, Saint-Rémy, 22.8.1889, an Theo, zitiert nach Erpel 1965, Bd. 4, S. 301-302, S. 301.

37 Brief 785/W 13, Saint-Rémy, 2.7.1889, an Willemien, zitiert nach Erpel 1968, Bd. 5, S. 63-65, S. 63f. Vgl. für diesen Brief auch Noll 1994, S. 128f.

38 Brief 784/597, Saint-Rémy, zw. 25.6.1889 u. 5.7.1889, an Theo, zitiert nach Erpel 1965, Bd. 4, S. 294-297, S. 297. 
Gute zwei Wochen später versuchte sich van Gogh mit seinen Farben zu vergiften, woraufhin ihm das Malen vorerst untersagt wurde - eine Maßnahme, die ihm nicht zusagte, da „die Arbeit an meinen Bildern eigentlich zu meiner Genesung nötig ist, denn die Tage jetzt, wo ich nichts tue [...], sind mir beinah unerträglich. ${ }^{~} 39$ Nach seinem gescheiterten Traum vom „Atelier des Südens“, der ein Familienersatz werden sollte, war für van Gogh in einer Welt, in der für ihn wichtige Fundamente, wie die Lehren der Kirche ins Wanken geraten waren, die Hinwendung zur Natur und die Beschäftigung mit ihrem „ewigen“, beständig sich wiederholenden Rhythmus, der einzig verbliebene Trost. ${ }^{40}$ Seiner Schwester erklärte er im Juli 1889, wie die Gesetzmäßigkeit, mit der sich der Zyklus der Natur vollzieht, auf das menschliche Leben zu beziehen sei. Auch die Symbolik des Schnitters interpretiert er in diesem Brief:

[Den Kornfeldern] ergeht es wie uns, denn sind wir, die wir von Brot leben, nicht selber zu beträchtlichem Teil Korn, sollten wir uns nicht damit abfinden, zu wachsen wie eine Pflanze, unfähig uns zu bewegen und zu erlangen, was unsere Phantasie oft sich wünscht - und hingemäht zu werden, wenn wir reif sind wie das Korn? ${ }^{41}$

Gerade wenn van Gogh mit dem Schnitter den Tod meinte, sollte damit kein Schrecken verbunden sein, vielmehr knüpfte sich an die Darstellung des Korns als Metapher für den Menschen - weiterhin in Beziehung zu den biblischen Gleichnissen ein Trost. ${ }^{42}$ Die Beschäftigung mit der Natur und das Malen von Landschaftsbildern bot ihm dadurch die Möglichkeit, Kraft für sich selbst zu schöpfen und Hoffnung auszudrücken. Bis zuletzt war es seine Absicht, in seinen Landschaftsbildern immer wieder zu zeigen, was das Land „an Gesundem und Stärkendem“ “43 birgt.

Seinem Bruder erklärte er, welche positive Wirkung die Arbeit mit diesem Sujet auf ihn habe und dass die Natur ihm den gleichen Halt bieten könne, wie das Leben im Schoß einer Stabilität und Sicherheit gewährenden Familie: „Und weißt Du, was ich hoffe, da ich nun überhaupt wieder zu hoffen angefangen habe - daß die Familie Dir werden wird, was mir die Natur ist, die Erdschollen, das Gras, das gelbe Korn,

39 Brief 797/601, Saint-Rémy, 22.8.1889, an Theo, zitiert nach Erpel 1965, Bd. 4, S. 301-302, S. 301. Für den Suizidversuch wird der 16.oder 17.7. angenommen. Für das Datum vgl. die Kommentierung zu Brief 793/T 13, Paris, 29.7.1889, Theo v. Gogh an Vincent, auf der Internetseite des van Gogh Museums: http://vangoghletters.org/vg/letters/let793/letter.html. Bzgl. der versuchten Vergiftung vgl. das Telegramm von Jo van Gogh-Bonger an ihre Schwester Mien im Kommentar zu Brief 794/T 14, Paris, 4.8.1889, Theo v. Gogh an Vincent, auf der Internetseite des van Gogh Museums: http://vangoghletters.org/vg/letters/let794/letter.html.

$40 \quad$ Vgl. Noll 1994, S. 129.

${ }_{41}$ Brief 785/W 13, Saint-Rémy, 2.7.1889, an Willemien, zitiert nach Erpel 1968, Bd. 5, S. 63-65, S. $64 f$.

42 Vgl. Bakker 2010, S. 197.

43 Brief 898/649, Auvers, ca. 10.7.1890, zitiert nach Erpel 1965, Bd. 4, S. 388-389, S. 389. 
der Bauer [...]. “44 Infolgedessen wird deutlich, dass die zyklische Natur mit ihrem „unveränderlichen Rhythmus, der auf eine höhere Gesetzmäßigkeit und Ordnung, gewissermaßen auf eine ,prästabilierte Harmonie‘ zu verweisen schien, [...] Hoffnung auf „quelque chose là-haut“ und auf eine jenseitige Existenz geben [konnte], in der sich alle unbewältigten quälenden Fragen des Lebens lösen würden. " ${ }^{45}$ Entscheidend für van Goghs Verständnis von „quelque chose là-haut“ ist die sich darin ausdrückende Unbestimmtheit seiner religiösen Vorstellungen und Hoffnungen.

Ergänzt wird die Interpretation des Kornfeldes mit dem Schnitter durch die im Oktober 1889 entstandene Ansicht Ummauertes Feld mit Bauern (Abb. 10), die einen Bauern beim Forttragen einer Korngarbe zeigt, und über die van Gogh seinem Bruder mitteilte:

Ich komme eben mit einem Bild nach Hause, an dem ich seit einiger Zeit arbeite - es ist dasselbe Feld wie beim ,Schnitter'. [...] Ich schreibe es Dir, weil ich glaube es ergänzt den ,Schnitter ' und macht deutlicher, was der ist. Denn der ,Schnitter' scheint zufällig gemacht, und dies daneben wird ihn ins Gleichgewicht bringen. ${ }^{46}$

Wie van Gogh andeutete, beabsichtigte er hierbei eine andersartige und ergänzende Darstellung des Todes, die der Darstellung des Schnitters farblich und inhaltlich gegenüberstand. Im Gegensatz zu dem Schnitter aus den drei Varianten von Kornfeld, der Schnitter, der „in sengender Hitze wie der Teufel dreinhaut “47, handelt es sich um einen Bauern, der achtsam das Korn aufliest und davonträgt - das Motiv des Zusammenbindens und Wegtragens der Ähren findet sich in vielen Erntedarstellungen Millets (vgl. Abb. 26) und Lhermittes ${ }^{48}$-, so dass möglicherweise eine Verbindung zu dem Gleichnis vom Unkraut unter dem Weizen (Mt. 13, 24-30) gesehen werden kann, das von einem fürsorglichen Bauern handelt und in seiner allegorischen Bedeutung auf die Scheidung der Seligen und der Verdammten beim Jüngsten Gericht zu beziehen ist. ${ }^{49}$ Wie Thomas Noll aufzeigt, erhält der Tod dadurch ein hoffnungsvolles Antlitz, da er „den Menschen aus dem Elend dieser Welt

44 Brief 800/604, Saint-Rémy, 5./6.9.1889, an Theo, zitiert nach Erpel 1965, Bd. 4, S. 308-315, S. 314.

45 Noll 1994, S. 129.

46 Brief 810/610, Saint-Rémy, ca. 8.10.1889, an Theo, zitiert nach Erpel 1965, Bd. 4, S. 332-334, S. 332 .

47 Brief 800/604, Saint-Rémy, 5./6.9.1889, an Theo, zitiert nach Erpel 1965, Bd. 4, S. 308-315, S. 310 .

48 Vgl. Adrien Lavieille (1848-1920) nach Jean-François Millet (1814-1875), Les travaux des champs, Serie von 10 Holzschnitten, 1853, Amsterdam, Van Gogh Museum. Léon Augustin Lhermitte (1844-1925), La moisson, 1883, Saint Louis, Washington University Gallery of Art. Dieses Werk erwähnte van Gogh in Brief 484/395, Nuenen, 2.3.1885, an Theo, Erpel 1965, Bd. 3, S. 236-238, S. 237.

49 Vgl. für das Aufzeigen dieser Interpretation Noll 1994, S. 131. 
in eine bessere jenseitige Existenz versetzt [...]. " ${ }^{50}$ Dementsprechend sei der Bauer mit „quelque chose là-haut“ in Beziehung zu setzen.

Joan Greer wies anschaulich auf die verschiedenen Bedeutungs- und Assoziationsebenen des Schnitters und Sämanns hin, die zunächst einen Bauern bei der Arbeit im Feld präsentieren. Aber der Bauer stehe auch für den Künstler selbst und weise indirekt - durch die Verbindung zur biblischen Sämann-Parabel und dem Gleichnis vom Unkraut - auf den Zusammenhang zwischen der Aufgabe des Künstlers, durch seine Arbeit Trost zu spenden, auf der einen Seite und von Christus sowie dem fürsorglichen Bauer auf der anderen Seite, hin. ${ }^{51}$

\subsubsection{Der Pflüger}

Van Gogh schien tatsächlich Trost beim Malen und dabei insbesondere durch die Beschäftigung mit dem Sujet des ummauerten Kornfeldes zu finden, denn zwei Wochen, nachdem er sich beklagt hatte, dass man ihm nach seinem missglückten Selbsttötungsversuch ${ }^{52}$ untersagt hatte zu malen, ${ }^{53}$ konnte er seinem Bruder berichten, dass es ihm etwas besser gehe: „Gestern habe ich wieder angefangen, ein bißchen zu arbeiten - eine Sache, die ich von meinem Fenster aus sehe - ein gelbes Stoppelfeld, das umgepflügt wird, der Gegensatz der violetten, umgepflügten Erde zu den gelben Stoppelstreifen, Berge im Hintergrund. " ${ }^{54}$ Van Gogh bezog sich in seinem Brief auf Gepflügte Äcker (Abb. 8), ${ }^{55}$ das nun nach dem Erntebild Kornfeld, der Schnitter den nächsten Schritt im Jahreskreis zeigte: das Umpflügen des Feldes für die Neuaussaat. Es dürfte vielleicht nicht zu weit gegriffen sein, diese landwirtschaftliche Tätigkeit mit positiven Konnotationen der Vorbereitung für einen Neuanfang gleichzusetzen. ${ }^{56}$

Der Vorgang des Umpflügens oder Umgrabens hatte schon seit langer Zeit eine große Faszination auf van Gogh ausgeübt und diese ebbte auch bis zum Ende seines Lebens nicht ab. ${ }^{57}$ Lässt sich der Pflüger über das Gesamtwerk gerechnet in 20 Dar-

\footnotetext{
50 Noll 1994, S. 131.

51 Vgl. Greer 2001, S. 108.

52 Vgl. das Telegramm von Jo van Gogh-Bonger an ihre Schwester Mien im Kommentar zu Brief 794/T 14, 4.8.1889, Theo v. Gogh an Vincent, abgerufen in der Online-Ausgabe der Briefe, unter http://vangoghletters.org/vg/letters/let794/letter.html.

53 Vgl. Brief 797/601, Saint-Rémy, 22.8.1889, an Theo, zitiert nach Erpel 1965, Bd. 4, S. 301-302, S. 301.

54 Brief 798/602, Saint-Rémy, 2.9.1889, an Theo, zitiert nach Erpel 1965, Bd. 4, S. 302-306, S. 302.

55 Gepflügte Äcker, Ende August 1889, Öl auf Leinwand, 49 x 62 cm, Privatbesitz (Christie’s NY, Auktion 15004, Los 28A, 13.11.2017), F 625, JH 1768.

56 Vgl. Christie’s NY, Auktion 15004, Los 28A, 13.11.2017, Katalogisierung abgerufen unter http:// www.christies.com/lotfinder/paintings/vincent-van-gogh-laboureur-dans-un-champ-6108742details.aspx?from=salesummary\&intObjectID $=6108742 \&$ lid $=1$.

57 Da das Land um Zundert nicht besonders fruchtbar war, wird van Gogh bereits seit seinen Kindertagen das Bild des Bauern beim Graben vertraut gewesen sein. Vgl. Stolwijk 2015, S. 36.
} 
stellungen ermitteln, sind für die Grabenden 85 Beispiele bekannt. ${ }^{58}$ Es ist anhand der Einführung deutlich geworden, dass das Motiv des Pflügers seit Jahrhunderten in den Darstellungen von Monatsbildern oder von Jahreszeiten üblich ist. Als Anregung für van Gogh können jedoch ganz spezifische ikonographische und literarische Quellen namhaft gemacht werden. Wichtig ist dabei, dass für van Gogh besonders das dem Pflügen verwandte Motiv der Grabenden von Bedeutung war. Unmittelbar kannte er dies sehr wahrscheinlich aus seiner Heimat Zundert, wo der Boden sehr schwer zu bearbeiten war. Wie van Gogh auch in Sensiers Millet-Biographie erfuhr, mussten die Bauern überall dort ihre Arbeit mit dem Spaten verrichten, wo das Gelände zu uneben oder der Boden zu hart für den vom Pferd gezogenen Pflug war. Bei Sensier wird in diesem Kontext für die ausgesprochen Schweiß treibende Arbeit zudem - und nicht unüblich für dieses Sujet - Genesis 3, 19, über die Vertreibung der Menschen aus dem Paradies, zitiert: „Tu mangeras ton pain à la sueur de ton front [Im Schweiße deines Angesichts wirst du dein Brot essen]. “59

Trotz des an sich ähnlichen Vorgangs beim Umgraben und dem Pflügen bestehen jedoch entscheidende inhaltliche Unterschiede zwischen den zwei Motiven, die anhand von van Goghs Auseinandersetzung mit dem Pflüger deutlich werden. ${ }^{60}$ Noch vor seiner Entscheidung, Künstler zu werden, hatte er 1877 über den Pflüger geschrieben und dabei aus einem Gedicht Henry Wadsworth Longfellows zitiert: „,Wer seine Hand an den Pflug leget, der sehe nicht zurück' und ,sei ein Mann“"61. Dies war seinerseits aus Lukas 9, 61-62 abgeleitet: „Und ein andrer sprach: Herr, ich will dir nachfolgen; aber erlaube mir zuvor, dass ich Abschied nehme von denen, die in meinem Hause sind. Jesus aber sprach zu ihm: Wer die Hand an den Pflug legt und sieht zurück, der ist nicht geschickt für das Reich Gottes." Auch Eliza Laurillard zitiert diese Bibelstelle im ersten Kapitel seines Werkes Met Jezus in de natuur und betont das Vorwärtsstreben des Pflügers, der sich nicht umdreht, weil er fokussiert auf das Kommende blickt. Laurillard fasst dies in seiner Predigt „Hand aan den ploeg, zoo zal 't God vorderen [...] mits het oog steeds vooruit blijve zien“ [Hand an den Pflug, so wird es Gott voranbringen ... vorausgesetzt, dass der Blick immer nach vorne gerichtet ist]"62 zusammen. Wie Kōdera hinsichtlich der Inter-

58 Vgl. Kōdera 1990, S. 69 u. Appendix 1.

59 Sensier 1881, S. 130. Hinweis durch Kōdera 1990, S. 69 u. Fußnote 241. Es ist überliefert, dass Millet seinerseits von Hans Holbeins Druckgrafik Der Pflüger und der Tod (veröffentlicht in Les simulachres et historiées faces de la mort, Lyon 1538) inspiriert war. Unterhalb des Holzschnitts wird ebenfalls auf den Vers aus Genesis verwiesen.

60 Vgl. Kōdera 1990, S. 72.

61 Brief 126/105, Amsterdam, 5.8.1877, an Theo, zitiert nach Erpel 1965, Bd. 1, S. 134-137, S. 135. Van Gogh zitiert im Original auf Niederländisch. Das Zitat Longfellows ist ursprünglich dem Gedicht „My lost youth“ (Strophe 8) entnommen, erschienen in Birds of passage, 18861891, vol. 3, S. 41-44, vgl. für diese Angabe Anmerkung 19 zu diesem Brief aus der Online-Ausgabe der Briefe, abgerufen unter: http://vangoghletters.org/vg/letters/let126/letter.html.

62 Eigene Übersetzung. Das ausführliche Zitat lautet: „Zoo, Jezus! hebt Gij geploegd. ,Vooruit!' was uwe leus, ,Recht' was uw regel, en Gij keekt niet om naar wie een kroon vlochten [...] Een spreekwoord zegt: ,Hand aan den ploeg, zoo zal 't God vorderen'. Maar dat vul ik nu aan met deze 
pretation von van Goghs Pflügern treffend hervorhebt, war diese mehr auf die eigene Person gemünzte Bedeutung wie auch die biblische relevant. ${ }^{63}$

Verschiedene Darstellungen von pflügenden Bauern sind im Werk van Goghs überliefert. So beispielsweise die Skizze Pflügender Bauer mit Bäuerinnen aus dem Oktober 1883 (Abb. 93). Über die Entstehung der Zeichnung und das, was das Motiv ihm bedeutete, schrieb van Gogh: „Ich bin heute hinter den Pflügern hergelaufen, die ein Kartoffelfeld umpflügten; hinter ihnen her gingen Frauen, um ein paar übriggebliebene Kartoffeln aufzulesen. [...] ach es ist so eigenartig und so still, so friedlich. Ich kann kein anderes Wort dafür finden als Frieden. "64

1885 erschienen im Monatsrhythmus Léon-Augustin Lhermittes Les Mois rustiques als Supplement der Zeitschrift Le Monde illustré - eine der Publikationen, die van Gogh oft las. In dieser Serie, bestehend aus zwölf Motiven, sind in den jeweiligen Monatsbildern Szenen des ländlichen Lebens, dabei landwirtschaftliche Tätigkeiten, aber auch religiöse Festtage oder Personen, die mit dem entsprechenden Monat verknüpft sind, dargestellt. Van Gogh erhielt Anfang April 1885 die Blätter für die Monate März und April (vgl. Abb. 63 u. 64). Ist im Märzbild das für den Frühling traditionelle Sujet des Pflügens (Le Labourage) thematisiert, bei dem in harter menschlicher und tierischer Arbeit die Neuaussaat vorbereitetet wird, wählte Lhermitte für den Folgemonat eine Szene mit einer Mutter und ihren zwei Kindern bei der Arbeit im Garten (Le Jardinage). ${ }^{65}$ Während die Mutter mit einem Spaten den Boden aushebt, überfliegt den Garten - wie bereits das gepflügte Feld - eine Schar Schwalben, denen sie, ihre Beschäftigung unterbrechend, mit ihrem Blick folgt. Wie die zurückkehrenden Zugvögel zeigen die Obstbäume, die den bescheidenen Garten säumen, die Jahreszeit an. Die Bäume stehen in Blüte und unterstreichen damit die Bedeutung des Frühlings als eine Zeit des Aufbruchs und des Versprechens auf reifende Früchte.

Van Gogh hielt seine Begeisterung für die Drucke nicht zurück und verglich die Darstellungen Lhermittes mit denen Millets, wobei bei der Beurteilung der künstlerischen Leistung ethische Gesichtspunkte einen großen Stellenwert einnahmen: „Es kommt nur darauf an, wieviel Leben und Leidenschaft ein Künstler in seiner Figur auszudrücken vermag [...]. Und die Bauern von Lhermitte, Millet, sind ge-

gedachte: ,mits het oog steeds vooruit blijve zien“." Laurillard 1881, S. 11-13. Vgl. Kōdera 1990, S. 68 u. Fußnote 238.

63 Vgl. Kōdera 1990, S. 68.

64 Brief 397/333, Nieuw-Amsterdam, ca. 16.10.1883, zitiert nach Erpel 1965, Bd. 3, S. 43-50, 47. Van Gogh skizzierte das Motiv in diesem Brief: Pflügender Bauer mit Bäuerinnen, Tinte, Amsterdam, Van Gogh Museum, F-, JH 412.

65 Léon-Augustin Lhermitte (1844-1925), Le Labourage, Darstellung des Monats März aus der Serie Les Mois rustiques, druckgraphische Reproduktion publiziert in Le Monde illustré, 28.03.1885, Paris 1885, nach S. 210 sowie ders. Le Jardinage, Darstellung des Monats April aus der Serie Les Mois rustiques, druckgraphische Reproduktion publiziert in Le Monde illustré, 25.04.1885, Paris 1885, nach S. 274. 
rade wegen ihres Lebens so schön. "66 Van Gogh würdigte Lhermittes Motive auch wegen ihrer Sujets, stellten sie doch das Landleben, aber auch den Rhythmus der Jahreszeiten dar - Bilder, die durch die günstigen Reproduktionen in den Zeitschriften allgemein zugänglich und thematisch leicht verständlich waren, insbesondere für Personen, die in den Bildern dargestellt waren. ${ }^{67}$ Über das Aprilbild, das aufgrund der grabenden Bäuerin einen besonderen Stellenwert für van Gogh einnahm, schrieb er an Theo: „Die Frau mit dem Spaten von Lhermitte, wie lebt das, wie echt ist das: wie von einem Bauern gemacht, der malen kann, es ist meisterhaft. Ich an Deiner Stelle würde von den Lhermittes viele Exemplare kaufen und sie zehn Jahre lang aufheben. Denn es sind Meisterwerke, die man auf diese Art für seine fünfzig Centimes bekommt." 68

Relevant für die positive Deutung des Pflügers und seiner Arbeit in Saint-Rémy als Vorbereitung für die Neuaussaat ist in diesem Zusammenhang auch van Goghs malerische Umsetzung in den zwei Ausführungen zu diesem Thema. Bei Gepflügte Äcker (Abb. 8) von Ende August ist das Feld seitlich offen und nur längs durch den Bildraum von der Mauer begrenzt, die in diesem Fall sehr weit in den Bildraum nach hinten gerückt und nur als ein flaches, schmales Band erscheint, das weit davon entfernt ist, eine räumliche oder gar psychologische Barriere darzustellen. Das Feld selbst erstreckt sich dadurch so tief in den Bildraum wie in keiner anderen Ansicht zuvor. In der Bildmitte treibt ein einsamer Pflüger sein Pferd über einen gelb hervorgehobenen Streifen Erde. Die Bäume auf der linken Bildseite, an deren Stelle in Wirklichkeit ein Olivenhain war, das nah an die Mauer herangerückte Haus auf der rechten Seite und insbesondere die geschrumpften Alpillen am rechten Rand zeigen, dass van Gogh sich verschiedentlich Freiheiten bei der Wiedergabe der sichtbaren Wirklichkeit nahm. ${ }^{69}$

Das in der Folge von Gepflügte Äcker abgeleitete Werk Gepflügte Äcker, Morgenlicht (Abb. 9) ist in vielen kompositorischen Aspekten seinem Vorläufer sehr ähnlich, doch verzichtet van Gogh nun sogar gänzlich auf die Mauer und platzierte in der zentralen Bildflucht zwei Windmühlen, eine große und eine kleine, jeweils wie thronend auf den Scheitelpunkten zweier Hügel - verklärende Reminiszenzen an seine holländische Heimat. Die Mühlen zeigen, neben dem bereits zitierten Vergleich der Landschaft vor seinem Fenster mit van Goyen, wie van Gogh „charakteristische Motive der niederländischen Landschaft [...] in französischen Land-

66 Brief 500/406, Nuenen, 4.u. 5.5.1885, an Theo, zitiert nach Erpel 1965, Bd. 3, S. 261-265, S. 262. Vgl. auch Noll 1994, S. 61.

67 Vgl. Greer 2018, S. 77.

68 Brief 500/406, Nuenen, 4.u. 5.5.1885, an Theo, zitiert nach Erpel 1965, Bd. 3, S. 261-265, S. 262.

69 Dass der Betrachterstandpunkt auf Bodenniveau sei, das Bild aber im Zimmer van Goghs gemalt worden sein muss, lässt Pickvance zusätzlich zu den anderen Aspekten zu dem Schluss kommen, dass Gepflügte Äcker aus der Erinnerung gemalt worden sein muss. Vgl. Pickvance 1986, S. $124 \mathrm{f}$. 
schaften entdeckte oder in sie hineinsah. "“0 Kein anderes Bild aus der Serie ist von einer solchen Weite, Flach- und Offenheit, entscheidenden Charakteristika „typisch niederländische[r] Landschaftsauffassung ", ${ }^{71}$ geprägt. Im Vorjahr hatte er aus Arles seinem Bruder bezüglich der Assoziationen der von ihm so geschätzten heimatlichen Landschaft geschrieben: „Hier erinnert, abgesehen von der stärkeren Farbe, alles an Holland, alles ist flach, aber es kommt einem mehr das Holland Ruysdaels und Hobbemas und Ostades in den Sinn als das heutige Holland. “72

\subsection{Religiöse Malerei vs. Natur: die Serie der Olivenhaine in Saint-Rémy}

Das zweite große Thema, das van Gogh in Saint-Rémy parallel zum ummauerten Kornfeld beschäftigte, war die Darstellung der nahe der Anstalt gelegenen Olivenhaine im Jahresverlauf. Aufgrund vieler Parallelen zu den Ansichten des ummauerten Feldes vor seinem Fenster ist es wichtig, diesen Themenkomplex ebenfalls zu beleuchten. Begonnen zwar im Juni, aber maßgeblich im November und Dezember entstanden, malte van Gogh mehr als 15 Bilder von Olivenhainen in Saint-Rémy, elf davon im französischen Standardmaß „Toiles de 30“. Wie auch beim ummauerten Feld strebte van Gogh jedoch nicht ausschließlich die Abbildung der sich im Jahreskreis wandelnden Natur an, sondern auch die Visualisierung weiterer, assoziativer Bedeutungsebenen, die er aus der Natur ableitete. Die Auseinandersetzung mit der Serie der Olivenhaine wirft, analog zu dem zeitgleich gemalten Zyklus des ummauerten Feldes, ein weiteres Licht auf die Verbindung zwischen der Vermittlung von Empfindungen, der Bedeutung der Natur und der Darstellung religiöser Sujets.

Van Gogh hatte Mitte Juni zunächst mit mehreren Ansichten von Olivenhainen begonnen, die farblich, ähnlich wie Kornfeld, nach dem Unwetter, ${ }^{73}$ dem Auftakt der Serie des ummauerten Feldes, von eher frisch-klaren Blau-Grün- und Weißtönen dominiert sind, die van Gogh einander gegenüberstellte. ${ }^{74}$ Vordergründig

70 Bürgi/Zimmer/Feilchenfeldt 2009, S. 17 u. besonders Blotkamp 2009, 67. In der Literatur ist aufgrund der zwei Mühlen und der ähnlichen kompositorischen Anlage ein überzeugender Vergleich zu der im vorherigen Sommer in Arles entstandenen Federskizze Landschaft mit Alphonse Daudets Mühle aufgezeigt worden. Landschaft mit Alphonse Daudets Mühle, Juli 1888, Bleistift, Rohrfeder, braune Tinte auf Papier, Van Gogh Museum, Amsterdam, F 1496, JH 1496, Vgl. Hansen 2002, S. 94.

71 Bürgi/Zimmer/Feilchenfeldt 2009, S. 17.

72 Brief 630/502, Arles, an Theo, 23.6.1888, zitiert nach Erpel, Bd. 4, S. 77. Auf diesen Brief verweist auch Blotkamp 2009, 75.

73 Kornfeld, nach dem Unwetter, Juni 1889, Öl auf Leinwand, 70,5 x 88,5 cm, Kopenhagen, Ny Carlsberg Glyptothek, F 611, JH 1723.

74 Olivenhain, Saint-Rémy, Mitte Juni, Öl auf Leinwand, 72 x 92 cm, Otterlo, Kröller-Müller Museum, F 585, JH 1758; Olivenhain, Saint-Rémy, Juni-Juli, Öl auf Leinwand, 73,1 x 93,1 cm, Kansas City, The Nelson Atkins Museum of Art, F 715, JH 1759; Olivenbäume mit Alpillen im Hintergrund, Saint-Rémy, Juni 1889, Öl auf Leinwand, 72,5 x 92 cm, New Zork, Museum of Modern Art, 
fallen auch Ähnlichkeiten mit dem Auftakt seiner Arbeiten im Vorjahr in Arles, mit der Serie der blühenden Obstbäume, auf. Anders jedoch als die in der Pracht des Frühlings großen Optimismus verbreitende Obstblüte ist die durch die knorrigen Olivenbäume vermittelte Stimmung weitaus weniger überschwänglich. ${ }^{75}$ Van Gogh schrieb entsprechend in einem Brief an seine Schwester eher neutral von einer sommerlichen Landschaft, „die einen Ölbaumgarten mit graugrünem Laub darstellt, in der Farbe etwa wie die Weiden, die Schlagschatten violett auf sonnenbeschienenem Sand. "76 Seinem Bruder erläuterte er Ende September seinen Versuch, in einem Bild mit Olivenbäumen „die Stunde wiederzugeben, wo man die grünen Rosenkäfer und die Zikaden in der Hitze herumfliegen sieht. "77 In manchen Fassungen ist die Sonne nicht direkt zu sehen, aber wie kraftvoll sie im provenzalischen Hochsommer auf die Bäume herabscheint, wird durch das sonnendurchflutete Licht und die großen blauen Schlagschatten der Baumkronen auf dem Boden in einer Ansicht aus dem Juni-Juli mehr als deutlich (vgl. Abb. 20). ${ }^{78}$

Anders als bei normalen Laubbäumen zeigen die Blätter von Olivenbäumen über das Jahr hinweg wenig farblichen Wechsel. Dadurch werden andere gestalterische Faktoren bei der Darstellung der Veränderungen im Jahreskreis maßgeblich. Die unerbittlich niederscheinende Nachmittagssonne griff van Gogh beispielsweise in den später im Herbst entstandenen Varianten, so beispielsweise in Olivenbäume mit gelbem Himmel und Sonne, erneut auf (vgl. Abb. 21). Hierbei erzeugt der gelbgolden leuchtende Himmel mit den blau-grauen Bergen ebenso starke Farbkontraste wie die blauen Schlagschatten der Baumkronen auf dem rostroten Boden. ${ }^{79}$ Anders als noch in Kornfeld, Sonnenaufgang, ${ }^{80}$ dem anderen Werk aus dem Herbst mit großer scheibenförmiger Sonne, in dem van Gogh „Ruhe [... und] einen tiefen Frieden" ${ }^{\prime 11}$ ausdrücken wollte, zeigte er nun in aller Deutlichkeit das vom trocke-

F 712, JH 1740 u. Olivenbäume, Saint-Rémy, Juni 1889, Öl auf Leinwand, 49 x 63 cm, Edinburgh, National Gallery of Scotland, F 714, JH 1858.

75 Vgl. Walther/Metzger 2015, S. 521.

76 Brief 780/W 12, Saint-Rémy, an Willemien, 16.6.1889, zitiert nach Erpel 1968, Bd. 5, S. 61-62, S. 61. In der Online-Ausgabe der Briefe wird vermutet, dass es sich bei dem beschriebenen Werk um die relativ abstrahierten Olivenbäume, F 714, JH 1858, handeln könnte.

77 Brief 805/607, Saint-Rémy, ca. 20.9.1889, an Theo, zitiert nach Erpel 1965, Bd. 4, S. 322-327, S. 325. In der Online-Ausgabe der Briefe wird vermutet, dass es sich um Olivenhain, F 715, JH 1759, handelt. Vgl. dort Fußnoten 23 u. 27, abgerufen unter http://vangoghletters.org/vg/letters/ let805/letter.html.

78 Vgl. Pickvance 1986, S. 100. Nur indirekt zu erahnen ist die Sonne bei Olivenhain, Saint-Rémy, Juni-Juli, Öl auf Leinwand, 73,1 x 93,1 cm, Kansas City, The Nelson Atkins Museum of Art, F 715, JH 1759.

79 Olivenbäume mit gelbem Himmel und Sonne, Saint-Rémy, November 1889, Öl auf Leinwand, 73,7 cm x 92,7 cm, The Minneapolis Institute of Art, F 710, JH 1856.

80 Kornfeld, Sonnenaufgang, November 1889, Öl auf Leinwand, 71 x 90,5 cm, Privatsammlung, F 737, JH 1862.

81 Brief 822/B 21, Saint-Rémy, um 26.11.1889, an Émile Bernard, zitiert nach Erpel 1968, Bd. 5, S. 291-295, S. 293 f. 
nen und heißen Hochsommer versengte Gras. Fast alle diese im Spätsommer und Herbst entstandenen Ansichten von Olivenbäumen sind von Farbkontrasten mit leuchtenden Farben, wie Orange-Rot, Ocker, Gelb und Grün, dominiert. ${ }^{82}$

Ende September hatte van Gogh seinem Bruder mit Enthusiasmus von der lokalen Bedeutung der Olivenhaine sowie den Herausforderungen, die mit dem Malen der Bäume einhergehen, berichtet. ${ }^{83}$ Anfang Oktober empfahl er auch Bernard eine Auseinandersetzung mit dem Thema, „wenn man den eigentlichen Charakter herausschälen und nicht nur etwas unbestimmt Erlebtes, sondern ein Stück wirkliche Provence wiedergeben will. Um das zu erreichen, muß man sich tüchtig anstrengen und hart arbeiten, [...] denn es geht darum, der Sonne und dem blauen Himmel ihre Gewalt und Leuchtkraft zu geben und dem ausgedörrten, schwermütigen Gelände seinen feinen Thymianduft. Die Ölbäume hier, mein Guter, das wäre etwas für Sie. [...] Silber auf orangefarbenem oder violettem Boden, unter der großen weißen Sonne. ${ }^{84}$ In den im Dezember entstandenen Fassungen stellte van Gogh in mindestens vier Bildern mit dem Fokus auf der Olivenernte den nächsten und abschließenden Schritt im Jahreskreis der Olivenbäume dar und entwickelte wieder kräftige komplementäre Farbkontraste, beispielsweise von Rot und Grün in dem Werk Olivenpflücker (vgl. Abb. 22). ${ }^{85}$

Für das weitere Verständnis von van Goghs Olivenhainen ist eine Einordnung in den Entstehungskontext bedeutsam, denn begleitet und mitbestimmt wurde die Entwicklung der Serie von einer Diskussion mit Bernard und Gauguin, die sich ihrerseits jeweils mit dem Thema Christus am Ölberg beschäftigten. Sie entwickelten dabei religiöse Sujets, die zwar nicht auf direkten Naturbeobachtungen basierten, ihre Werke folgten aber mit der Darstellung Christi und der anderen Personen der

82 Olivenhain, Saint-Rémy, November 1889, Öl auf Leinwand, 74 x 93 cm, Göteborgs Konstmuseum, F 586, JH 1854; Olivenhain, Saint-Rémy, November 1889, Öl auf Leinwand, 72,7 x 92,1 cm, New York, The Metropolitan Museum of Art, F 708, JH 1855; Olivenhain, Saint-Rémy, November-Dezember 1889, Öl auf Leinwand, 73 x 92 cm, Amsterdam, Van Gogh Museum, F 707, JH 1857; Weißes Bauernhaus zwischen Olivenbäumen, Saint-Rémy, Dezember 1889, Öl auf Leinwand, 70 x $60 \mathrm{~cm}$, Privatbesitz, F 664, JH 1865 u. Hütten zwischen Olivenbäumen und Zypressen, Saint-Rémy, Dezember 1889, Öl auf Leinwand, 45,5 x 60 cm, Privatbesitz, F 623, JH 1873.

83 Vgl. Brief 806/608, Saint-Rémy, 28.9.1889, nach Erpel 1965, Bd. 4, S. 328-329, S. 329. Auf diesen Brief weist Greer 2001, S. 108 hin.

84 Brief 809/B20, Saint-Rémy, 8.10.1889, an Bernard, zitiert nach Erpel 1968, Bd. 5, S. 289-291, S. 289f. Wie häufig bei van Goghs Briefen festzustellen, ist nicht klar, ob es sich um eine Beschreibung der Natur oder eines seiner Werke handelt.

85 Olivenhain mit pflückenden Figuren, Saint-Rémy, Dezember 1889, Öl auf Leinwand, 73 x 92 cm, Otterlo, Kröller-Müller Museum, F 587, JH 1853; Olivenpflücker, Saint-Rémy, Dezember 1889, Öl auf Leinwand, 73 x 92 cm, Privatbesitz, F 654, JH 1868; Olivenpflücker, Saint-Rémy, Dezember 1889, Öl auf Leinwand, 72,4 x 89,9 cm, New York, The Metropolitan Museum of Art, F 655, JH 1869 u. Olivenpflücker, Saint-Rémy, Dezember 1889, Öl auf Leinwand, 73 x 92 cm, Washington, National Gallery of Art, F 656, JH 1870. 
biblischen Überlieferung, nach der Jesus in der Nacht vor seiner Kreuzigung im Garten Gethsemane betete und, von Angst vor dem Tod ergriffen wurde. ${ }^{86}$

Van Gogh erhielt im November eine Skizze von Gauguins sowie eine photographische Reproduktion von Bernards Werk, die beide auf große Ablehnung seinerseits stießen. ${ }^{87}$ Gauguin porträtierte sich selbst prominent im Bildvordergrund als Christus mit gesenktem Haupt - leicht verfremdet zwar mit rotem Haar und Bart -, aber dennoch aufgrund der Gesichtszüge klar zu identifizieren, während im Hintergrund des Gartens der Verräter Judas und die Soldaten herankommen. Es wird allgemein angenommen, dass Gauguin damit eine Parallele zwischen seinem Kampf um Anerkennung als Künstler und dem Leiden Christi herstellen wollte (Abb. 97). ${ }^{88}$ Bernards Fassung, die Theo gesehen und seinem Bruder als „Christus mit rotem Haar, daneben ein gelber Engel“ beschrieben hatte, war durch die gelängten Figuren (laut Theo „lächerlich“89 in ihrer Ausformung), die Hinzunahme des Engels und die Vernachlässigung einer schlüssigen perspektivischen Anlage deutlich weniger noch als Gauguins Werk einer unmittelbaren Naturschilderung verpflichtet (Abb. 98). Anders als Gauguin hatte Bernard jedoch nicht beabsichtigt, sich selbst abzubilden, sondern fügte stattdessen ein Porträt Gauguins zwischen den Soldaten, auf der rechten Seite, ein. Es wird diskutiert, ob Bernard ihm dadurch die Rolle des Judas zuweisen wollte, möglicherweise aufgrund des „Verrats“ an ihrem gemeinsamen Freund van Gogh und dessen Plänen für die Künstlergemeinschaft im Süden, infolge des gescheiterten Besuchs in Arles. In dieser Lesart wäre der rothaarige Christus als van Gogh zu identifizieren. ${ }^{90}$

Van Gogh hatte selbst in Arles im Vorjahr zwei Ansichten eines Garten Gethsemane mit Figuren gemalt, war jedoch mit ihnen unzufrieden und kratzte sie wieder von der Leinwand, weil ihm bereits zu diesem Zeitpunkt die Entwicklung einer eigenen religiösen Szene mit Figuren nicht behagte. ${ }^{91}$ Infolgedessen warf er seinen Freunden - im Anschluss an die Diskussion über eine Malerei aus dem Gedächtnis - vor, mit ihrer Form der figürlichen religiösen Malerei „[s]chablonenhafte“ Motive

86 Gethsemane (aramäisch „Ölkelter") beschreibt eine Örtlichkeit am Ölberg. Vgl. Küchler, Max: Get(h)semani, in: Lexikon für Theologie und Kirche, Bd. 4, 1995, Sp. 607. Vgl. für die Todesangst und Verhaftung Mk 14, 32 u. Mt 26, 36, für die Interpretation Bösen 1994, S. 140f. Vgl. bspw. für die Symbolik des Ortes auch Früchtel 1994, S. 469f., wo darauf hingewiesen wird, dass Jesus zunächst auf den Ölberg geht und dann hinab nach Gethsemane, also eine geographische Unterscheidung bestehe.

87 Paul Gauguin (1848-1903), Christus im Garten Gethsemane, 1889, Öl auf Leinwand, 72 x 90 cm, Norton Museum of Art, West Palm Beach sowie Émile Bernard (1868-1941), Christus am Ölberg,1889, Öl auf Leinwand, Maße und derzeitiger Aufenthaltsort unbekannt.

88 Vgl. Greer 2001, S. 110 u. Druick/Zegers 2001, S. 291. In dieser Zeit schien die Fortsetzung von Theos finanzielle Unterstützung für Gauguin fraglich.

89 Beide Zitate Brief 819/T 20, Paris, 16.11.1889, Theo an Vincent, zitiert nach Erpel 1968, Bd. 6, S. 27-28, S. 28.

90 Vgl. Greer 2001, S. 110 u. Druick/Zegers 2001, S. $306 f$.

91 Vgl. Brief 685/540, Arles, 21.9.1888, an Theo, zitiert nach Erpel 1965, Bd. 4, S. 163-164, S. 164. Auf diesen Brief weist Dorn 1991, S. 69 hin. 
zu schaffen, die „abscheulich“92 seien. Van Gogh äußerte nicht nur harsche Kritik an der Art, wie Gauguin und Bernard mit ihrer Darstellung Christi zu höchst idiosynkratrischen und nicht-naturalistischen Lösungen des Gethsemane-Stoffes gelangt waren, die seiner Meinung nach keinen künstlerischen Fortschritt darstellten, sondern verteidigte auch seinen eigenen auf Naturbeobachtung basierenden Ansatz bei dem Motiv des Olivenhains, der auch für die Ansichten des ummauerten Feldes gilt:

Versteh mich recht, mir geht es nicht darum, etwas Biblisches zu machen ich habe an Bernard und auch an Gauguin geschrieben, meiner Ansicht nach sei es unsere Pflicht zu denken und nicht zu träumen, und daher sei ich beim Anblick ihrer Arbeiten erstaunt gewesen, daß sie sich in dieser Hinsicht so gehenließen. [...] Sie haben so was von einem Traum oder Albdruck an sich [...]. Um das loszuwerden, habe ich an diesen klaren, kalten Tagen, aber bei schönem Sonnenschein, von früh bis abends in den Obstgärten herumgepinselt $[\ldots] \cdot{ }^{93}$

Gauguins und Bernards Auseinandersetzung mit dem Gethsemane-Thema hatte wenig mit den bewegenden, und wie van Gogh annahm, tief empfundenen religiösen Gemälden von beispielsweise Rembrandt oder Delacroix gemeinsam, über die er Bernard im Juni 1888 geschrieben hatte, dass diese Christus überzeugend, und so wie er ihn sich selbst auch vorstellte, visualisiert hatten. Hätten sich Gauguin und Bernard an einer solchen Form der Darstellung orientiert, wäre van Goghs Kritik vermutlich nicht so scharf ausgefallen. ${ }^{94}$ Der entscheidende Aspekt ist jedoch, dass van Gogh davon ausging, dass es in seiner Zeit überhaupt nicht mehr möglich sei, Christus darzustellen, wie noch Delacroix es konnte.

Aufschlussreich für das Verständnis von van Goghs eigenen künstlerischen Absichten, im Gegensatz zu seinen Freunden, ist ein Brief von Ende November, in dem er auf die regionale Bedeutung der Olivenhaine eingeht; seinem Bruder schreibt er, dass diese zusammen mit den Zypressen für die Provence das bedeuteten, was die Weiden für die Niederlande sind:

Ölbäume gibt es von ganz verschiedener Gestalt, wie unsere Weide oder Kopfweide im Norden. Du weißt ja, Weiden sind sehr malerisch; zwar scheinen sie eintönig, aber sie geben der Landschaft ihr Gepräge. Und was bei

92 Beide Adjektive ebenfalls aus Brief 822/B 21, Saint-Rémy, um 26.11.1889, an Émile Bernard, zitiert nach Erpel 1968, Bd. 5, S. 291-295, S. 292. Paul Gauguin (1848-1903), Christus im Garten Gethsemane, 1889, Öl auf Leinwand, 72 x 90 cm, Norton Museum of Art, West Palm Beach u. Émile Bernard, Christus am Ölberg, 1889, Öl auf Leinwand, Maße und derzeitiger Aufenthaltsort unbekannt. Ersteres sah van Gogh in Form einer Skizze und letzteres als photographische Reproduktion Vgl. auch Greer 2001, S. 110.

93 Brief 823/615, Saint-Rémy, 26.11.1889, an Theo, zitiert nach Erpel 1965, Bd. 4, S. 340-342, S. 340. Pickvance 1986, S. 161 verweist auf diesen Brief.

94 Vgl. Brief 632/B 8, Arles, 26.6.1888, nach Erpel 1968, Bd. 5, S. 261-265, S. 261. Vgl. auch Druick/Zegers 2001, S. 308 u. Brief 820/614, Saint-Rémy, 19.11.1889, an Theo, nach Erpel 1965, Bd. 4, S. 337-340, S. 338. 
uns zuhause die Weide ist, das sind hier die Ölbäume und Zypressen. Was ich gemacht habe, ist ein wenig hart und [...] grober Realismus, aber es hat wenigstens etwas Ländliches und riecht nach Erde. ${ }^{95}$

Er äußert weiterhin die Hoffnung darauf, dass Theo durch seine Olivenhaine „eine Reihe provençalischer Studien [... bekomme], die wirklich durchempfunden sind und sich [...] mit unseren fernen Erinnerungen an unsere Jugend in Holland verknüpfen"96. Die Weiden hatten für van Gogh seit Kindertagen eine besondere Bedeutung. Wie viele andere Naturmotive hatte er sie häufig anthropomorphisiert und sprach an anderer Stelle beispielsweise von „einem toten Kopfweidenstamm [...] ganz allein und trübselig [...]. "97 Genauso sah er allgemein „in Bäumen [...] Ausdruck und gewissermaßen eine Seele. So hat eine Reihe Kopfweiden manchmal etwas von einer Prozession von Weisenmännern. "98

Van Goghs sinnbildliche Wahrnehmung der Natur und seine Absicht, bestimmte Vorstellungen und Gefühle bei deren Wiedergabe zum Ausdruck zu bringen, ließ sich bereits in der 1882 entstandenen Zeichnung der mächtigen Baumwurzeln im Sandboden ablesen (Les Racines, Abb. 48), als er „versucht[e], in die Landschaft dasselbe Gefühl zu legen wie in die Figur [Sorrow]. Das gleichsam krampfhafte und leidenschaftliche Sich-fest-Wurzeln in der Erde und das Halb-losgerissen-Sein durch die Stürme.“ Er betonte darüber hinaus, dass er gleichzeitig „bestrebt war, der Natur, die [... er] vor [... sich] hatte, treu zu sein, ohne dabei zu philosophieren "99.

Auch mit den ebenfalls im Brief vom November 1889 erwähnten Zypressen hatte van Gogh sich seit seiner Ankunft im Süden sehr intensiv beschäftigt (Kōdera zählt insgesamt 65 Bilder mit Zypressen). ${ }^{100}$ Insbesondere im Herbst 1889 entstanden in Saint-Rémy Ansichten, bei denen die schlanken dunklen Bäume prominent im Bildraum, und leuchtend vor dem hellblauen Himmel, platziert sind. ${ }^{101}$ In einem Brief an Albert Aurier beschreibt van Gogh die regionale Bedeutung des Baumes, aber auch die emotionale Wirkung, die die dunklen Zypressen auf ihn ausübten. ${ }^{102}$

95 Brief 823/615, Saint-Rémy, 26.11.1889, an Theo, zitiert nach Erpel 1965, Bd. 4, S. 340-342, S. 340. Pickvance 1986, S. 161 verweist auf diesen Brief.

96 Brief 829/617, Saint-Rémy, 26.11.1889, an Theo, zitiert nach Erpel 1965, Bd. 4, S. 342-344, S. 343. Auf diese zwei Briefe weist Greer 2001, S. 108f. hin.

97 Brief 251/220, Den Haag, 26.7.1882, an Theo, zitiert nach Erpel 1965, Bd. 2, S. 63-68, S. 64. Stolwijk 2003, S. 27 verwendet den treffenden Begriff „,anthropomorphised“.

98 Brief 292/242, Den Haag, 10.12.1882, an Theo, zitiert nach Erpel 1965, Bd. 2, S. 125-128, S. 127. Auf diesen Brief verweist Stolwijk 2003, S. 27.

99 Brief 222/195, Den Haag, 1.5.1882, an Theo, zitiert nach Erpel 1965, Bd. 1, S. 368-371, S. 368f. Bei dem angesprochenen Werk handelte es sich um Les Racines, April-Mai 1882, Bleistift, schwarze Kreide, Tinte, braune und graue Lavierung sowie deckende Aquarellfarben auf Papier, 51,5 x 70,7 cm, Otterlo, Kröller-Müller Museum, F 933r, JH 142.

100 Vgl. Kōdera 1990, S. 146.

101 Bspw. Zypressen mit untergehender Sonne, Anfang Dezember 1889, Öl auf Leinwand, $92 \times 73 \mathrm{~cm}$, Kröller-Müller Museum, Otterlo, F 652, JH 1843)

102 Vgl. Brief 853/626a, Saint-Rémy, 9./10.2.1889, an Albert Aurier, zitiert nach Erpel 1968, Bd. 5, S. 326-328, S. 327f. 
Anhand anderer Äußerungen bezüglich der Bedeutung von Zypressen, so nennt er sie in einem Brief beispielsweise „funèbre cyprès" ${ }^{103}$, kann eine Verknüpfung van Goghs mit der seit Jahrhunderten gängigen symbolischen Aufladung der Zypresse als Baum des Todes abgeleitet werden. ${ }^{104}$ Wie Noll jedoch eindringlich warnt, sei es eine „leichtfertige Vergröberung“, alle Darstellungen von Zypressen als Sinnbilder des Todes zu interpretieren. ${ }^{105}$ Ähnlich wie für die Weiden oder auch die Zypressen entwickelte er für die Stimmung, die durch die Olivenbäume und den farblichen Kontrast, den ihre Blätter mit dem roten Boden eingehen, eine eigene Interpretation.

Van Gogh schuf eine Ansicht des Gartens von St. Paul in der Heilanstalt (Abb. 94), um zu zeigen, und dies ist auch auf Ansichten der Olivenhaine zu übertragen, dass „man den Eindruck von Angst auch hervorrufen kann, ohne gleich auf den historischen Garten Gethsemane abzuzielen"106. Van Gogh verstand seinen Garten als Alternative zu den Darstellungen der Freunde und beschreibt in einem Brief an Bernard die künstlerischen Mittel, mit denen er Gefühle auszudrücken gedachte. Zunächst erwähnt er im Brief ein kleines Tafelbild Giottos, das er zusammen mit Gauguin in Montpellier gesehen hatte, „den Tod irgendeiner braven Heiligen“, um dann auf die Empfindungen hinzuweisen, die er bei der Betrachtung empfindet: „Der Ausdruck von Schmerz und Verzückung darauf ist so menschlich, daß man mag man noch so sehr im neunzehnten Jahrhundert sein - das Gefühl hat, als wäre man dabei - so stark teilt sich einem die Erregung mit." ${ }^{107}$ Im Brief folgt sodann die Beschreibung des Gartens von St. Paul, durch die ersichtlich wird, wie van Gogh die Natur anthropomorphisiert, und zwar indem er aus ihrer herbstlichen Erscheinung menschliche Gefühle ableitet - hier vor allem das Gefühl von Beklommenheit und Angst:

Dieser Parkrand ist mit großen Kiefern bepflanzt, Stämme und Äste sind ockerrot, das Grün der Nadeln hat durch die Beimischung von Schwarz etwas Düsteres [im Original deutlicher auf die menschliche Empfindung gemünzt,

103 Brief 692/541, Arles, ca. 27.9.1888, an Theo, Erpel 1965, Bd. 4, S. 165-167, S. 165, dort als „düstere Zypresse“ übersetzt. Auf diese Briefstelle verweist Noll 1994, S. 136.

104 Vgl. bspw. „Zypresse“, in: Meyers großes Taschenlexikon, Bd. 25, 1999, S. 349. Dort heißt es weiter: „In der Antike und im MA wurden Holz, Zweige und Zapfen vielfach medizinisch verwendet. Der Rauch verbrannter Zweige galt als Abwehrmittel gegen böse Geister und Seuchen." Vgl. auch „Cypress“, in: Hall's Dictionary of Symbols, 1996, S. 89: „Since antiquity, a symbol of death and of life beyond the tomb."

105 Noll 1994, S. 131f.

106 Brief 822/B 21, Saint-Rémy, um 26.11.1889, an Émile Bernard, zitiert nach Erpel 1968, Bd. 5, S. 291-295, S. 294. Bei dem Werk handelt es sich um Der Garten von St. Paul, November 1889, Öl auf Leinwand, 71,5 x 90,5 cm. Van Gogh Museum, Amsterdam, F 659, JH 1850.

107 Beide Zitate aus Brief 822/B 21, Saint-Rémy, um 26.11.1889, an Émile Bernard, zitiert nach Erpel 1968, Bd. 5, S. 291-295, S. 293. Im Dezember 1888 waren van Gogh und Gauguin nach Montpellier gereist, wo sie im Musée Fabre Der Tod und die Himmelfahrt der Jungfrau sahen, das zu dieser Zeit noch Giotto zugeschrieben gewesen war. Vgl. auch Kommentar 17 in der OnlineAusgabe der Briefe zu diesem Brief, abgerufen unter: http://vangoghletters.org/vg/letters/let822/ letter.html\#. 
durch das franz. „attristé" - betrübt]. [...] Der erste Baum ist ein gewaltiger Stamm, aber vom Blitz getroffen und abgesägt. [...] Dieser düstere Riese, wie ein stolzer Besiegter - wenn man ihn als ein lebendes Wesen betrachtet -, steht im Gegensatz zu dem blassen Lächeln einer letzten Rose an dem welkenden Strauch vor ihm. Unter den Bäumen leere Steinbänke, düsteres Buchsgebüsch [...] Ein Sonnenstrahl, der letzte Widerschein, erhöht den dunklen Ocker bis zu leuchtendem Orange. [...] Du wirst verstehen, diese Verbindung von rotem Ocker, von Grün, verdüstert durch Grau [im Original wieder der Verweis auf die Empfindung: „de vert attristé de gris“ - Grün betrübt durch Grau], die schwarzen Striche, welche die Konturen bilden, dies alles bringt ein wenig dieses „Schwarz-Rot“ genannte Angstgefühl hervor, unter dem manche meiner Unglücksgefährten häufig zu leiden haben. Und das Motiv des großen, vom Blitz getroffenen Baumes, das kränklich rosagrüne Lächeln der letzten Herbstblume verstärkt diese Vorstellung noch. ${ }^{108}$

Van Gogh lädt die Farben mit suggestiven Qualitäten auf, die in Ihrem Zusammenspiel - dabei kann es sich um eine Reduzierung oder eine Intensivierung durch entsprechende Kontraste handeln - Stimmungen erzeugen. Im Garten von St. Paul verbindet van Gogh mit dem Farbkontrast Schwarz-Rot-Grün, zu sehen bei dem roten Boden, den grünen Nadeln, den roten Baumstämmen, und den massiven dunklen Konturen, die sie einrahmen, Angstgefühle, und er versteht den rosa-grünen Farbkontrast der Blumen auf der rechten Bildseite als „kränklich“. ${ }^{109}$ Diese, ein Angstgefühl hervorrufende Gegenüberstellung „von rotem Ocker, von Grün, verdüstert durch Grau" und schwarzen Konturen, tritt in einer Vielzahl der im Herbst entstandenen Olivenhaine auf. ${ }^{110}$

Neben den Farbkontrasten ist jedoch auch der Pinselduktus bemerkenswert. Im Garten von St. Paul ist der gesamte untere Bildbereich flächig von der intensivockerroten Erde bedeckt, die den grünen Zweigen der Kiefern, die van Gogh mit kurzen, dabei geschwungenen, und in der Mehrzahl vertikal ausgerichteten Pinselstrichen darstellt, gegenübersteht. Im Hintergrund hüllt die soeben untergegan-

108 Brief 822/B 21, Saint-Rémy, um 26.11.1889, an Émile Bernard, zitiert nach Erpel 1968, Bd. 5, S. 291-295, S. 294. Die deutsche Übersetzung ist hier hinsichtlich der Äußerung „das Grün der Nadeln hat durch die Beimischung von Schwarz etwas düsteres." etwas ungenau, betont van Gogh doch im Original „au feuillage vert attristé [betrübt] par un mélange de noir.“ Vgl. Originalfassung des Briefs, abgerufen aus der Online-Ausgabe der Briefe, unter: http://vangoghletters. org/vg/letters/let822/letter.html\#.

109 Kompositorisch wirkt der Garten von St. Paul aufgrund der einfassenden Mauer und des Gebäuderiegels äußerst geschlossen. Dieser Effekt wird durch die Nahsichtigkeit - die Bäume im Vordergrund sind durch den oberen und linken Bildrand beschnitten -, verstärkt, so dass der Eindruck entsteht, dass der Betrachter direkt im Bildraum stehe.

110 Besonders stark ist der Kontrast zwischen den in schweren Konturen gefassten Stämmen der Variante, die sich heute im Minneapolis Institute of Arts befindet. Olivenbäume mit gelbem Himmel und Sonne, Saint-Rémy, November 1889, Öl auf Leinwand, 73,7 cm x 92,7 cm, The Minneapolis Institute of Art, F 710, JH 1856. 
gene, und bereits nicht mehr sichtbare Herbstsonne den blauen Himmel in ein Licht, das von Orange zu hellem Gelb changiert. Durchdrungen wird der obere Bereich des Himmels und das Blätterwerk von einer Vielzahl kleiner weißer Pinselstriche, die nicht nur den Eindruck gleißenden Lichts, sondern in Kombination mit den geschwungenen Zweigen auch eine große Unruhe in der oberen Bildhälfte erzeugen. Der tupfende Duktus, der, wie auch die Gegenüberstellung der ungemischten Farben, deutlich auf die Beschäftigung mit Seurat und die Lektüre von Farbtheoretikern wie Blanc, verweist, findet sich in mehreren Ansichten der Olivenhaine, besonders bei derjenigen, die sich heute im Metropolitan Museum in New York befindet, bei der die vielen weißen Punkte im Bereich des Himmels die flirrend heiße Atmosphäre erzeugen, von der van Gogh wiederholt spricht (Abb. 96). ${ }^{111}$ Auch die Überlegungen zum Verhältnis von Farbe zu Musik, die van Gogh seit dem Sommer 1884 immer wieder beschäftigt hatten und ihn erkennen ließen, dass, wie in der Musik durch die Modulation von Tönen und ihre jeweiligen harmonischen Beziehungen, auch in der Malerei durch die Modifizierung der Farben und ihre Gegenüberstellungen entsprechend starke oder schwache Effekte erzielt werden können, wurden in Saint-Rémy wieder relevant.

Als Gegenstück zu dem Garten von St. Paul verstand van Gogh das im November entstandene Kornfeld, Sonnenaufgang (Abb. 13), das die gerade aufgegangene Wintersaat vor einer großen, strahlend goldenen Sonnenscheibe zeigt, und in dem van Gogh „Ruhe [... und] einen tiefen Frieden "112 ausdrücken wollte. Auch hier finden sich, über den Bildraum verteilt, viele kurze, weiße und leuchtend gelbe Striche, mit denen van Gogh die Sonnenstrahlen auf dem Feld visualisiert. Er hatte sich auf dieses Werk bezogen, als er Bernard mitteilen wollte, „daß es nicht nötig ist, wenn man ein tröstendes, sanftes Motiv geben will, die Persönlichkeiten der Bergpredigt darzustellen"113, wenn dies auch nach der Natur und durch symbolisch aufgeladene Landschaftsbilder unter Verwendung suggestiver Farben erreicht werden könne. Im Kontrast dazu steht die Ansicht des ummauerten Feldes aus dem Juni (Abb. 3), ${ }^{114}$

111 Olivenhain, Saint-Rémy, November 1889, Öl auf Leinwand, 72,7 x 92,1 cm, New York, The Metropolitan Museum of Art, F 708, JH 1855. Vgl. Brief 805/607, Saint-Rémy, ca. 20.9.1889, an Theo, zitiert nach Erpel 1965, Bd. 4, S. 322-327, S. 325 für die Aussage über die Hitze.

112 Brief 822/B 21, Saint-Rémy, um 26.11.1889, an Émile Bernard, zitiert nach Erpel 1968, Bd. 5, S. 291-295, S. 293f. Kornfeld, Sonnenaufgang, November 1889, Öl auf Leinwand, 71 x 90,5 cm, Privatsammlung, F 737, JH 1862.

113 Brief 822/B 21, Saint-Rémy, um 26.11.1889, an Émile Bernard, zitiert nach Erpel 1968, Bd. 5, S. 291-295, S. 294. Auf diesen Brief weist Jansen 2003, S. 23 hin.

114 Kornfeld, Ende Mai oder Anfang Juni 1889?, Öl auf Leinwand, 72 x 92 cm, Otterlo, KröllerMüller Museum, F 720, JH 1728. Die zeitliche Einordnung dieses von van Gogh nicht datierten Werkes ist nicht unumstritten. Es könnte bereits Ende Mai 1889 entstanden sein (vgl. Vellekoop/ Zwikker 2007, S. 392 u. Datierung des Kröller-Müller Museums, bspw. im Online Katalog der Sammlung, abgerufen unter https://krollermuller.nl/en/vincent-van-gogh-enclosed-wheat-fieldwith-rising-sun). Es wird verschiedentlich auch in den Mai des Folgejahres datiert, bspw. durch Hansen aufgrund inhaltlicher und stilistischer Beweggründe. Hansen weist jedoch auch auf die Möglichkeit einer Entstehung im Jahr 1889 hin (vgl. Hansen 2002, S. 102f.). Die Datierung 
die durch die extrem steile Aufsicht auf das Feld, das unter dem Betrachter nach links wegzukippen scheint, charakterisiert ist. Darüber hinaus erhält die diagonal in die rechte Bildecke verlaufende Mauer durch dunkle Konturen und Schatten eine besondere Präsenz und Prägnanz. ${ }^{115}$ Der intensiv gelb gefärbte Himmel, der nur einen schmalen Streifen in der oberen linken Bildhälfte einnimmt, ist im Vergleich zu anderen Ansichten stark zurückgedrängt. Zwischen roten Farbtupfern, die auf dem grünen Feld Klatschmohn andeuten, entstehen Komplementärkontraste. Ebenso stark ist der Farbkontrast zwischen den blauen Hügeln und dem gelben Himmel.

Folglich geht es für van Gogh darum, durch Form und suggestive Farben sowie deren Gegenüberstellung, folglich das, was Blanc über Delacroix als „'orchestration des couleurs " 116 bezeichnet hatte, in den Olivenhainen eine Wirkung zu erreichen, die, ohne dass Christus selbst dargestellt ist, eine Empfindung der Angst Christi am Ölberg vermittelt bzw. diese Angst zum Ausdruck bringt. Dies gelingt van Gogh durch die künstlerische Interpretation des Naturmotivs. Van Gogh verglich sich dahingehend auch mit Millet, der trotz christlicher Prägung so gut wie nie biblische Bilder gemalt habe. ${ }^{117}$

Eine sich in ihrer Komposition, dem Duktus und der Farbwahl grundsätzlich von dem Garten von St. Paul unterscheidende Landschaft ist Olivenbäume mit Alpillen im Hintergrund (Abb. 95), die von intensiven Blautönen im Kontrast mit Weiß, blassem Grün und gebrochenem Gelb, dominiert wird. ${ }^{118}$ Im Gegensatz zu dem Garten von St. Paul ist dieser Olivenhain wesentlich ausgewogener in der kompositorischen Anlage und zurückhaltender hinsichtlich der Farbkontraste. Der Betrachter überblickt in leicht erhobener Position einen Olivenhain mit gräulichgrünen Blättern, hinter dem sich die in tief dunkelblauen Farbtönen gefassten Alpillen im Hintergrund erheben. Diese werden von einem um eine Nuance helleren, in gleichmäßigem Duktus aufgetragenen blauen Himmel überfangen, auf den eine große leuchtend weiße Wolke aufgezogen ist, die von gebrochenem Gelb umrandet ist und dadurch einen Kontrast zum umliegenden Blau erzeugt. Statt der getupften und kurzen Pinselstriche vermitteln sanft gewellte Linien des hügeligen Terrains im Vordergrund, aber auch die geschwungenen Stämme der Olivenbäume, die abge-

des Kröller-Müller Museums auf Ende Mai 1889 muss auch hinsichtlich der Feldfarbe diskutiert werden, die hier bereits mehr gelbes und damit reifes Korn als bei Kornfeld, nach dem Unwetter zeigt. Van Gogh malte bereits Ende Juni, Anfang Juli mit F 617, JH 1753 das erste Erntebild.

115 Vgl. Hansen 2002, S. 102. Bei der Beschreibung eines anderen Werkes aus Saint-Rémy hatte er bezüglich der dunklen Konturen von einem Angstgefühl gesprochen, das diese auslösen könnten. Vgl. Brief 822/B 21, Saint-Rémy, um 26.11.1889, an Émile Bernard, zitiert nach Erpel 1968, Bd. 5, S. 291-295, S. 293. Bei dem Werk handelt es sich um Der Garten von St. Paul, November 1889, Öl auf Leinwand, 71,5 x 90,5, Amsterdam, Van Gogh Museum, F 659, JH 1850. Vgl. für die extreme Diagonalität auch Tralbaut 1970, S. 100-102.

116 Blanc, Les Artistes de mon Temps 1876, S. 28.

117 Vgl. Brief 822/B 21, Saint-Rémy, um 26.11.1889, an Émile Bernard, nach Erpel 1968, Bd. 5, S. 291-295, S. 294.

118 Olivenbäume mit Alpillen im Hintergrund, Saint-Rémy, Juni 1889, Öl auf Leinwand, 72,5 x $92 \mathrm{~cm}$, New York, Museum of Modern Art, F 712, JH 1740. 
rundeten Hügel des Gebirgszugs, und die bauchig-runde Wolke den Eindruck von Ruhe.

Van Gogh erklärte seinem Bruder bezüglich dieses Bildes und der zur gleichen Zeit entstandenen Sternennacht, dass sie „keine Rückkehr zur Romantik oder zu religiösen Ideen [... sind]. Aber auf dem Wege über Delacroix kann man, mehr als es den Anschein hat, durch die Farbe und ein eigenwilligeres Zeichnen als photographische Genauigkeit die Natur auf dem Lande ausdrücken, die reiner ist als die Vorstadt und die Kneipen von Paris. "119 Etwas weiter im gleichen Brief fügt van Gogh erläuternd an, dass er, Gauguin und Bernard sich vielleicht nicht mit ihrer Kunst durchsetzen würden, aber trotzdem für etwas Gutes in der Malerei stehen könnten: „um zu trösten oder eine trostreichere Malerei vorzubereiten. “ ${ }^{120}$ Aus diesem Kommentar könnte eine Interpretation des Olivenhaines, insbesondere in der vorliegenden Ausführung mit dem zurückgenommenen Farbschema Grün-Blau-Weiß-Gelb, abgeleitet werden, die vom Ausdruck der Angst, der durch die ungleich schärferen Rot-Grün-Komplementärkontraste in Verbindung mit schwarzen Konturen ausgedrückt werden sollte, abweicht, und stattdessen auf den Aspekt des Trostes verweist.

Unbestritten ist, dass das Gethsemane-Thema im Evangelium nach Lukas insbesondere auch für das Spenden von Trost steht: „Da erschien ihm ein Engel vom Himmel und gab ihm (neue) Kraft." ${ }^{121}$ Jesus wird gestärkt durch das Gebet und, befreit von der Angst, legt er sein Leben in die Hände seines Vaters. In der ikonographischen Tradition ist insbesondere diese Schilderung des Gebets am Ölberg im Lukasevangelium vielfach wiedergegeben worden. Auch der von van Gogh geschätzte Ary Scheffer folgt 1839 in seiner Darstellung von Christus im Garten Gethsemane dieser Überlieferung (Abb. 99). Van Gogh besaß eine Reproduktion dieses Werkes, die er über seinem Schreibtisch aufhängte. ${ }^{122}$

Dass van Gogh sich mit dieser Überlieferung des Gebetes am Ölberg auseinandergesetzt hatte, zeigt seine Bemerkung zu der missglückten Gethsemane-Studie aus dem Vorjahr, die einen Engel beinhaltete, der, wie aus dem Lukasevangelium über-

119 Brief 782/595, Saint-Rémy, 18.6.1889, an Theo, zitiert nach Erpel 1965, Bd. 4, S. 289-292, S. 290. Sternennacht, Saint-Rémy, Juni 1889, Öl auf Leinwand, 73 x 92 cm, New York, Museum of Modern Art, F 612, JH 1731.

120 Brief 782/595, Saint-Rémy, 18.6.1889, an Theo, zitiert nach Erpel 1965, Bd. 4, S. 289-292, S. 290.

121 Lukas 22, 43.

122 „Die zwei Drucke, Christus Consolator', die ich von Dir bekommen habe, hängen in meiner Stube - ich sah die Bilder im Museum, und auch von Scheffer: ,Christus in Gethsemane', das kann man nie vergessen." Brief 101/84, Dordrecht, 21.1.1877, an Theo, zitiert nach Erpel 1965, Bd. 1, S. 98-99, S. 98. Vgl. für diesen Brief auch Veldhorst 2015, S. 98. Bei den Werken handelte es sich um Reproduktionen von Gemälden Ary Scheffers (1795-1858), Christus in Gethsemane, 1839, Dordrechts Museum u. Christus Consolator, 1837, Amsterdam, Van Gogh Museum (Leihgabe des Amsterdams Historisch Museum). Vgl. Online-Ausgabe der Briefe, Fußnote 7, abgerufen unter http://vangoghletters.org/vg/letters/let101/letter.html.

Vgl. für andere Beispiele auch Albrecht Dürers (1471-1528) Variante für seine zwölfteilige Große Passion (1496-1497, Holzschnitt, ca. 38,9 x 27,6 cm, u.a. London, Victoria und Albert Museum). 
liefert ist, gesandt war, um Jesus neue Kraft zu geben: „Zum zweiten Mal habe ich eine Studie, Christus mit dem Engel auf dem Ölberg, abgekratzt. Weil ich hier richtige Ölbäume vor Augen habe; aber ich kann oder vielmehr will nicht mehr ohne Modelle malen, doch habe ich das farbig im Kopf, die Sternennacht, die Gestalt Christi blau, allerstärksten Blaus, und der Engel ein gebrochenes Zitronengelb." ${ }^{23}$ Van Goghs Kommentar zeigt, dass ihm bereits zu diesem Zeitpunkt die eigene bildliche Entwicklung der religiösen Szene mit Figuren nicht behagte. Aufschlussreich ist jedoch, dass sich in diesen Fassungen, die mit dem Engel das Motiv des Trosts enthalten, genau die Farben - tiefes Blau und gebrochenes Gelb -, wie in Olivenbäume mit Alpillen im Hintergrund (Abb. 95) finden.

\subsection{Trost durch Kopien: der Kreis schließt sich}

Im September 1889, während einer Phase, in der van Gogh infolge eines neuerlichen Anfalls das Anstaltsgelände nicht verlassen konnte, begann er mit dem Kopieren unterschiedlicher Vorlagen. Auffällig ist, dass van Gogh nicht nur Bilder aus dem landwirtschaftlichen Themenkreis kopierte, sondern auch religiöse Sujets. Er fertigte mit den zwei zusätzlichen Fassungen von Kornfeld, der Schnitter und jeweils einer ergänzenden Ausführung von Gepflügte Äcker und Kornfeld, nach dem Unwetter, Kopien eigener Werke an, die die Bedeutung der Sujets akzentuierten, und kam auch wieder auf zwei seiner großen Vorbilder, Millet und Delacroix, zurück, die er bewunderte und deren Kompositionen er nun mit seinen gestalterischen Mitteln neu interpretierte.

Als sich van Gogh von seinem Anfall erholte und sein Zimmer noch nicht wieder verließ, wandte er sich zunächst Millets Serie der Feldarbeiten zu - zehn Darstellungen von Bauern bei unterschiedlichen landwirtschaftlichen Tätigkeiten, die ihm als nichtkolorierte druckgraphische Reproduktionen von Jacques-Adrien Lavieille vorlagen. Es ist im Zusammenhang der parallel entstehenden und thematisch verwandten Serie des ummauerten Feldes sicherlich kein Zufall, dass er sich gerade mit dem Thema der Feldarbeiten beschäftigen wollte. Letztlich war es aber auch eine praktische Maßnahme, in einer Zeit, in der er keine Modelle hatte oder neue Landschaftsmotive verarbeiten konnte, sich in der Wiedergabe der menschlichen Figur zu üben und mit Farben zu experimentieren. Ende September schrieb er an seinen Bruder: „Ich habe jetzt sieben Kopien von Millets zehn ,Feldarbeiten'. Ich versichere Dir, Kopieren interessiert mich ungemein, und da ich zur Zeit keine Modelle habe, bedeutet es, daß ich die Figur nicht aus den Augen verliere. "124

Der Schnitter, den van Gogh nur wenige Wochen zuvor bei der Arbeit im Kornfeld vor seinem Fenster gemalt hatte, ist in den Travaux des champs zweimal vertreten, sowohl in gebückter Haltung mit Sichel als auch aufrecht stehend mit Sense.

123 Brief 685/540, Arles, 21.9.1888, an Theo, zitiert nach Erpel 1965, Bd. 4, S. 163-164, S. 164. Auf diese beiden Briefe weist Dorn 1991, S. 69 hin. 
Van Gogh kopierte beide Varianten. ${ }^{125}$ In einem Brief beschreibt er den Prozess der Umwandlung von der druckgraphischen Vorlage in ein Ölgemälde: „Eher ist es wie ein Übersetzen in eine andere Sprache - als übersetze man die Hell-DunkelWirkungen des Schwarz-Weiß in die Sprache der Farben. "126 In einem anderen Brief erläutert er ausführlich, wie er die monochromen Vorlagen mit Leben füllt und welche Freude ihm das Kopieren und Übertragen in eine neue Darstellungsform bereitet. Wieder sind die Verwendung suggestiver Farben und deren Gegenüberstellung von entscheidender Bedeutung für die Vermittlung der Bildaussage:

Ich stelle das Schwarz-Weiß von Delacroix oder von Millet oder die SchwarzWeiß-Wiedergabe nach ihren Sachen als Motiv vor mich hin. Und dann improvisiere ich darüber in Farbe, doch versteh mich recht - ich bin nicht ganz ich, sondern suche Erinnerungen an ihre Bilder festzuhalten - aber diese Erinnerung, der ungefähre Zusammenklang der Farben, die ich gefühlsmäßig erfasse, auch wenn es nicht genau die richtigen sind - das ist meine eigene Interpretation. ${ }^{127}$

Hinsichtlich des Schnitters (Abb. 100) mit der Sense lässt sich exemplarisch beobachten, wie van Gogh die Vorlagen „übersetzt“. Van Gogh behält zunächst Millets Komposition der prominent ins Zentrum gerückten Gestalt des Schnitters bei, der dem Betrachter den Rücken zugewendet hat, während er mit der Sense das Korn niedermäht. Van Gogh interpretiert die Vorlage jedoch durch den Pinselduktus, die leuchtenden Farben und die intensiven Farbkontraste vollkommen neu, so dass in ihrem Charakter eigenständige Werke entstehen. Die Gegenüberstellung von intensiven Gelb- und Blautönen in ihren jeweiligen Abstufungen, zuvorderst bei Feld und Himmel, aber auch innerhalb der Figur des Schnitters, dominiert das Bild. Dazu leuchten der gelbe Arbeitsmantel und der Hut des Schnitters vor dem strahlend blauen Himmel, der in einzelnen Bereichen in dem gleichen Duktus von kurzen Pinselstrichen gemalt ist, der in pastosem Farbauftrag dem Feld die Struktur des noch stehenden Korns verleiht.

Etwas später schrieb van Gogh seinem Bruder nicht nur, dass er zufrieden mit dem Ergebnis sei, sondern auch, was ihn motiviert habe, die Drucke in Gemälde zu übertragen: „Du wirst überrascht sein, wie die ,Feldarbeiten“ durch die Farbe wirken, es ist eine sehr feinempfundene Serie von ihm. Was ich darin suche und warum es mir gut scheint, diese Sachen zu kopieren, will ich Dir zu sagen versuchen. Von uns Malern wird immer verlangt, wir sollten selber komponieren und nur Kompositeure

125 Der Schnitter mit Sichel (nach Millet), September 1889, Öl auf Leinwand, 44 x 33 cm, Van Gogh Museum, Amsterdam, F 687, JH 1782 u. Der Schnitter (nach Millet), September 1889, Öl auf Leinwand, 43,5 x 25 cm, Privatbesitz, zuletzt Christie's London, Auktion 14239, 27.06.2017, Los 6, F 688, JH 1783.

126 Brief 839/623, Saint-Rémy, um 13.1.1890, an Theo, zitiert nach Erpel 1965, Bd. 4, S. 351-354, S. 351.

127 Brief 805/607, Saint-Rémy, 6.9.1889, an Theo, zitiert nach Erpel, Bd. 4, S. 322-327, S. 325. 
sein." ${ }^{128}$ Wie bereits mehrfach zuvor verweist van Gogh wieder auf die Verbindung zwischen Malerei und Musik, die, wie bereits bei La Berceuse, mit der Vermittlung von Trost durch Kunstwerke in Zusammenhang steht:

Gut - aber in der Musik ist es nicht so - wenn jemand Beethoven spielt, da gibt er seine persönliche Interpretation dazu - in der Musik und besonders im Gesang ist die Interpretation eines Komponisten eine Sache für sich, und es ist nicht unbedingt erforderlich, daß nur der Komponist seine eigenen Kompositionen spielt. Gut - aber besonders jetzt, wo ich krank bin, suche ich etwas mir zum Trost und Freude zu machen. ${ }^{129}$

Auch Paul-Edmé le Rats Radierung nach Millets Sämann kopierte van Gogh in zwei Fassungen, zunächst Anfang November und dann Ende Januar 1890. ${ }^{130}$ Diese Kopien schlagen eine Brücke zu den Anfängen von van Goghs künstlerischer Arbeit, als er sich durch das Kopieren dieses Druckes schulte (Abb. 27 u. 28). Im Gegensatz zu den Kopien nach den druckgraphischen Vorlagen Lavieilles sind die zwei Varianten des Sämanns wesentlich gedämpfter hinsichtlich der Wahl der Farben und der Kontraste. Auch mit dem Duktus der kurzen Pinselstriche, vor allem bei der Fassung aus dem Januar 1890, scheint sich van Gogh an die Linienführung der radierten Vorlage angelehnt zu haben. Noll versteht sie als „Hommage“ van Goghs an sein Vorbild Millet. ${ }^{131}$

Der Sämann wurde für van Gogh im Frühling 1890 nicht nur bei der Anfertigung von Kopien wieder relevant, sondern auch hinsichtlich eigener Motive, so dass er ihn im März und April in mehreren Skizzen bei der Aussaat, und zumindest in zwei Beispielen dabei auf dem ummauerten Feld vor seinem Fenster, festhielt (Abb. 24 u. 25). ${ }^{132}$ Die Art der Darstellung des Niederschlags in diesen beiden Fassungen erinnert an Ummauertes Feld, Regen aus dem November und dabei an die Übertragungen des strichartigen Regens, der wie erwähnt aus japanischen Farbholzschnitten abgeleitet war. Ob van Gogh im Frühling 1890 eine neue, eigene Komposition des Sämanns in einem Gemälde plante, ist nicht überliefert, aber es ist angesichts der künstlerischen Auseinandersetzung anzunehmen. Zudem hatte er noch in Arles

128 Brief 805/607, Saint-Rémy, 6.9.1889, an Theo, zitiert nach Erpel, Bd. 4, S. 322-327, S. 324.

129 Brief 805/607, Saint-Rémy, 6.9.1889, an Theo, zitiert nach Erpel, Bd. 4, S. 322-327, S. 324.

130 Der Sämann (nach Millet), November 1889, Öl auf Leinwand, 64 x 55 cm, Otterlo, KröllerMüller Museum, F 689, JH 1836 u. Der Sämann (nach Millet), Januar 1890, Öl auf Leinwand, $81 \times 65 \mathrm{~cm}$, Privatsammlung, JH 690, JH 1837.

131 Vgl. Noll 1994, S. 149.

132 Ummauertes Feld mit Sämann im Regen, März-April 1890, Bleistift und schwarze Kreide auf Papier, 23,5 x 31,5 cm, Essen, Museum Folkwang, F1550, JH1897 u. Sämann im Regen, März-April 1890, Bleistift auf Papier, 23,9 x 27,3cm, Amsterdam, Van Gogh Museum, F 1551r, JH1898. Die Parallelen zu Ummauertes Feld, Regen, November 1889, 73,5 x 92,5 cm, Öl auf Leinwand, Philadelphia Museum of Art, F 650, JH 1839 sind auch bei den tiefen Ackerfurchen zu erkennen. 
konstatiert, dass das, „was nach Millet und Lhermitte noch zu tun bleibt, das ist -der Sämann mit Farbe und in großem Format." ${ }^{133}$

Im Zuge der Besinnung auf Motive aus dem landwirtschaftlichen Themenkreis, die ihn bereits seit seiner Zeit in Holland beschäftigt hatten, wurde auch das Thema der Grabenden wieder bedeutsam. Van Gogh hatte die mit dem Spaten mühsam grabenden Bauern zwar nicht im Kontext der ummauerten Felder dargestellt, doch tauchte dieses Sujet schließlich auch in Saint-Rémy in Form von Kopien auf, die ebenfalls auf van Goghs künstlerische Anfänge verweisen, hatte er doch bereits im Oktober 1880 Zwei grabende Männer nach einem Gemälde Millets gezeichnet. ${ }^{134}$ Diese Vorlage übertrug van Gogh im Oktober 1889 schließlich in ein eigenes Ölgemälde. Im Frühjahr 1890, kurz vor seiner Rückkehr in den Norden, entstanden weitere Werke von grabenden Bauern in Öl sowie in Form von Skizzen auf Papier. ${ }^{135}$

Aufgrund des Zeitpunktes, der mit dem Rückzug aus der Provence, die van Gogh mit so viel Hoffnung auf seine persönliche Entwicklung und mit künstlerischen Plänen verknüpft hatte, zusammenfiel, und dadurch, dass nach mehreren Jahren schlagartig wieder viele Darstellungen von grabenden Bauern entstanden, die, wie beispielsweise bei Sensier, häufig mit Genesis 3, 19, und den aus dem Paradies vertriebenen Menschen in Verbindung gebracht werden, die im Schweiße ihres Angesichts ihr Brot verdienen müssen, vergleicht Kōdera die Grabenden in van Goghs Werk mit „an ominous Leitmotiv in a score of music, this theme of banishment from Paradise and its variants constantly reemerges during the tragic moments in Van Gogh's career. “136

Dass sich van Gogh in Saint-Rémy wieder so intensiv dem landwirtschaftlichen Themenkreis zuwandte, wird auch als Rückbesinnung auf seine ursprüngliche Aufgabe als „Bauernmaler" interpretiert, als der er sich im April 1885 im Anschluss an sein Vorbild Millet bezeichnet hatte. ${ }^{137}$ Damals war es ihm wichtig gewesen, „die Bauern [so zu] malen, [... dass] man selber einer von ihnen ist und fühlt und denkt wie sie, indem man nichts anderes sein kann, als man ist. ${ }^{\text {138 }}$

133 Brief 629/501, Arles, 21.6.1888, zitiert nach Erpel 1965, Bd. 4, S. 74-76, S. 75. Vgl. auch Noll 1994, S. 149.

134 Zwei grabende Männer (nach Millet), November 1880, Bleistift und Kohle, 37 x 62 cm, KröllerMüller Museum, Otterlo, F 829, JH D. Van Gogh übertrug das Gemälde nach einer Photographie.

135 Vgl. Brief 816/613, Saint-Rémy, ca. 3.11.1889, an Theo, Erpel 1965, Bd. 4, S. 336-337, S. 336. Theo hatte seinem Bruder diverse Druckgraphiken nach Werken Millets geschickt. Zwei grabende Männer (nach Millet), Oktober 1889, Öl auf Leinwand, 72 x 92 cm, Stedelijk Museum, Amsterdam, F 648 JH 1833. Ein Beispiel für eine selbst entwickelte Zeichnung von Grabenden aus dem Frühjahr 1890 ist Zypressen mit vier Bauern, die im Feld arbeiten, Februar 1890, schwarze Kohle, 32 x 23,5 cm, Museum Folkwang, Essen, F 1539, JH 1889.

136 Kōdera 1990, S. 78. Vgl. Sensier 1881, S. 130.

137 Vgl. Noll 1994, S. 147f. Vgl. Brief 493/400, Nuenen, 13.4.1885, an Theo, nach Erpel 1965, Bd. 3, S. 246-248, S. 247 für die Bezeichnung als „Bauernmaler“.

138 Brief 497/404, Nuenen, 30.4.1885, an Theo, zitiert nach Erpel 1965, Bd. 3, S. 255-259, S. 255. 
Doch nicht nur Sämann, Schnitter und die Grabenden tauchen in Saint-Rémy wieder auf, sondern auch das Motiv von Trauernder alter Mann („At Eternity's Gate") (Abb. 33), das er im Mai 1890 nach seiner eigenen Lithographie nun in Öl auf Leinwand übertrug (Abb. 102). ${ }^{139}$ Wie bereits dargelegt, hatte van Gogh 1882 hinsichtlich des Motivs mit dem alten Mann, der zusammengesunken neben einem brennenden Kamin sitzt, und seinen Kopf auf die Hände gestützt hat, 1882 noch erläutert, dass er dabei „die Existenz von ,quelque chose là-haut', [...] das Dasein eines Gottes und einer Ewigkeit "140 fühlte. Der in Trauernder alter Mann vermittelte Aspekt der Endlichkeit des irdischen Daseins - „Am Tor zur Ewigkeit“ - und der Hoffnung auf ein Leben danach, könnten ihn, zusätzlich zu den Zyklusdarstellungen der Natur, aus denen er ebenfalls die Hoffnung auf eine höhere Ordnung und ein Leben im Jenseits abzuleiten vermochte, dazu bewogen haben, sich in der Zeit in Saint-Rémy wieder diesem tröstlichen Motiv zuzuwenden. ${ }^{141}$

Die ersten Kopien religiöser Sujets entstanden nach der Pietà von Delacroix, die er im September nach einer druckgraphischen Reproduktion zweimal in Öl, in unterschiedliche Leinwandgrößen, übertrug. ${ }^{142}$ Entstand die kleinere Variante, die eine eher gedämpfte Farbpalette aufweist, um die Lithographie der Pietà zu ersetzen, die während seiner Krankheit beschädigt worden war, zeigt die größere Fassung mehr Freiheiten van Goghs, vor allem bei dem pastosen Farbauftrag und bei der Wahl der Farben, von Gelb und Blau/Violett, die er in der Tradition von Delacroix' Lehre der Farbkontraste angewandt hatte (Abb. 101). ${ }^{143}$ In großer Ausführlichkeit beschrieb van Gogh seiner Schwester, die das Sujet nicht kannte, die Komposition und die Wahl der Farben: „Am Eingang einer Grotte liegt, die Hände nach vorn auf der linken Seite, der schlaffe Leichnam, und die Frau dahinter. Es ist der Abend nach einem Gewitter, und diese todtraurige, blaugekleidete Gestalt - ihre wogenden

139 Trauernder alter Mann („At Eternity’s Gate“), Mai 1890, Öl auf Leinwand, $80 \mathrm{~cm}$ x 64 cm, Otterlo, Kröller-Müller Museum, F 702, JH 1967.

140 Brief 288/248, Den Haag, 26.u.27.11.1882, an Theo, zitiert nach Erpel 1965, Bd. 2, S. 138-143, S. 140 .

141 Vgl. Noll 1994, S. 148, Fußnote 148. Hulsker beschreibt es als Erinnerung an die lange vergangene Zeit in Den Haag als zunächst eine Zeichnung und dann eine Lithographie nach der englischen Vorlage entstanden waren. Hulsker hält es für unwahrscheinlich, dass van Gogh siebeneinhalb Jahre später in der Lage war, das Gemälde anzufertigen, ohne dass ihm die Lithographie vorlag. Vgl. Hulsker 1984, S. $444 \mathrm{f}$.

142 Pietà (nach Delacroix), 1889, Öl auf Leinwand, 73 x 60,5 cm, Amsterdam, van Gogh Museum, F 630, JH 1775, u. Pietà (nach Delacroix), 1889, Öl auf Leinwand, 42 x 34 cm, Rom, Collezione Vaticana d'Arte Religiosa Moderna, F 757, JH 1776. Beide nach einem Druck von Célestin Nanteuil-Leboeuf, Pietà (nach Eugène Delacroix), c. 1850, Lithographie, Maße unbekannt, Amsterdam, van Gogh Museum.

143 Vgl. zu van Goghs Kopie der Pietà auch ausführlich Homburg 1996, S. 71. 
Gewänder flattern im Wind - hebt sich von einem Himmel ab, an dem violette, goldgeränderte Wolken dahintreiben. " ${ }^{144}$

Neben der Herausforderung, das Werk von Delacroix mit seinen eigenen gestalterischen Mitteln neu zu interpretieren, waren die in der Pietà vermittelten Empfindungen ein weiterer Beweggrund für van Goghs Beschäftigung. ${ }^{145}$ In betont selbstkritischer Manier betonte er, dass die Kopie, die er seiner Schwester schicken wollte, ,in keinerlei Hinsicht von Wert [sei]“, dass sie jedoch daran erkennen könne, „daß Delacroix die Züge einer Mater Dolorosa nicht in der Art von römischen Statuen zeichnet; sondern das fahle Antlitz, der irre, bestürzte Blick eines durch Angst, Tränen und Nachtwachen erschöpften Menschen erinnert eher an Germinie Lacerteux. "146 Wie Homburg aufzeigt, verweist dieser Vergleich auf Kommentare von Charles Blanc, der seinerseits in Les Artistes de mon Temps darauf hingewiesen hatte, dass Delacroix die Pietà in der Kirche von Saint-Denis du Saint-Sacrement im Marais nicht im Sinne der akademischen Tradition gemalt, sondern dass er die Szene mit überzeugend dargestellten Emotionen näher an den Betrachter herangerückt hatte, der dadurch unmittelbar mit der Mater dolorosa und der Klage über ihren Sohn konfrontiert war: „Ah! cette immense douleur n'est point contenue et drapée à la manière antique, et la pitié qu'inspire le cadavre de ce fils tant pleuré n'est point tempérée à dessein par les convenances d'une philosophie qui fut sublime, mais qui n'est plus la nôtre; au contraire c'est un désespoir qui éclate et s’abandonne come s'il était sans témois[...]." ${ }^{147}$

Van Goghs Hinweis, dass ihn seine Muttergottes an Germinie Lacerteux, eine arme junge Frau vom Land, die in Paris den Versuchungen der Großstadt erliegt, aus dem gleichnamigen Roman von Jules and Edmond de Goncourt von 1865, erinnere, verdeutlicht, wie wichtig es ihm war, eine Vorlage zu kopieren, in der durch die Protagonistin Gefühle vermittelt werden, die nicht akademisch-stilisiert dargestellt, sondern tief empfunden sind und aus dem wirklichen Leben einer menschlichen Maria stammen, die „in einer großen, verzweifelten Gebärde die leeren Arme nach vorn [streckt], und man sieht ihre Hände, die guten, festen Hände einer Arbeiterin. " 148

Im Mai des Folgejahres malte van Gogh eine Kopie von Der barmherzige Samariter nach Delacroix, wieder mit intensiven Farben und Kontrasten, vor allem aus Blau und Gelb. Wie bereits bei der Pietà übersetzte van Gogh das Liniennetz der druckgraphischen Vorlage in einen pastosen Farbauftrag mit kräftigen, länglich-ge-

144 Brief 804/ W 14, Saint-Rémy, 19.09.1889, an Willemien, zitiert nach Erpel 1968, Bd. 5, S. 6568, S. 66.

145 Vgl. Homburg 1996, S. 72.

146 Brief 804/ W 14, Saint-Rémy, 19.09.1889, an Willemien, zitiert nach Erpel 1968, Bd. 5, S. $65-$ 68, S. 66.

147 Blanc 1876, S. 80. u. Homburg 1996, S. 63f. u. 72 für den Hinweis auf Blanc in diesem Zusammenhang.

148 Brief 804/ W 14, Saint-Rémy, 19.09.1889, an Willemien, zitiert nach Erpel 1968, Bd. 5, S. 6568, S. 66. 
schwungenen Pinselstrichen. ${ }^{149}$ Außerdem entstand eine Kopie der Auferweckung des Lazarus nach Rembrandt. Nur bei dieser Übertragung wich van Gogh kompositorisch von der Vorlage ab, und statt die gesamte Szene wiederzugeben, stellte er unter Verzicht auf die Christusfigur nur einen Ausschnitt dar: Lazarus, der sich aus seinem Grab erhebt und seine Schwestern Martha und Maria, in ihrem Zustand von Entsetzen und Überraschung. ${ }^{150}$ Dass van Gogh Lazarus mit einem rötlichen Bart darstellte, könnte, wie häufig vermutet wird, ein Selbstporträt andeuten. Aus diesem Grund wird die Wahl des Sujets mit der im Frühling getroffenen Entscheidung, wieder zurück in den Norden zu gehen, verknüpft und, auf van Gogh übertragen, als Ausdruck der Hoffnung auf Genesung und einen Neuanfang, interpretiert. ${ }^{151}$

Van Goghs Kopien religiöser Sujets sind insbesondere relevant, da sie zeigen, dass er trotz der vehementen Kritik an den religiösen Werken von Gauguin und Bernard nicht grundsätzlich solche Sujets ablehnte, sich jedoch - wie anhand der zwei abgekratzten Gethsemane-Studien deutlich wird - offensichtlich nicht imstande fühlte, eigene Kompositionen zu entwickeln, die seinen Vorstellungen genügten. Stattdessen hielt er sich an die Werke älterer Meister, wie Delacroix und Rembrandt, was ihn nicht dem Druck aussetzte, Neues zu entwickeln, die ihm jedoch erlaubten, Motive, die für ihn von Bedeutung waren, in seinem eigenen Stilidiom zu gestalten und damit gleichsam sich anzueignen. In einem Brief aus dem Januar 1890 werden jedoch auch weitere Motive für seine Kopien ersichtlich. So hielt van Gogh fest, dass seine Kopien „aus ganz tiefer und aufrichtiger Bewunderung für Millet entstanden sind“ und er durch seine Interpretationen „die Arbeit eines Millet dem großen allgemeinen Publikum zugänglicher" ${ }^{\text {"152 }}$ machen wollte, folglich durch seine Kopien zu weiterer Verbreitung verhelfen konnte. ${ }^{153}$

Noll erkennt bei der „Hinwendung zu den [... religiösen] Bildern [...] das nach wie vor ungestillte Verlangen van Goghs nach religiösem Trost." Gleichzeitig bestehe eine Verbindung zwischen van Goghs Unfähigkeit „traditionellen christlichen Themen überzeugenden und das heißt zeitgemäßen Ausdruck zu verleihen - sowenig wie es ihm trotz aller Sehnsucht nach Religion, trotz seiner Verehrung Christi gelang, eine ,traditionelle ungebrochene Heilsgewißheit zu erlangen." ${ }^{154}$

149 Der barmherzige Samariter (nach Delacroix), Saint-Rémy, Mai 1890, Öl auf Leinwand, 73 x 60 cm, Kröller-Müller Museum, Otterlo, F 633, JH 1974.

150 Auferweckung des Lazarus (nach Rembrandt), Saint-Rémy, Mai 1890, Öl auf Papier, 50 x 65 cm, Van Gogh Museum, Amsterdam, F 677, JH 1972.

151 Vgl. Homburg 1996, S. $76 f$.

152 Brief 839/623, Saint-Rémy, um 13.1.1890, an Theo, zitiert nach Erpel 1965, Bd. 4, S. 351-354, S. 351 .

153 Vgl. Noll 1994, S. 146.

154 Noll 1994, S. 146. 


\section{Im Vergleich: Monets Getreideschober und Cézannes Ansichten der Montagne Sainte-Victoire}

\subsection{Monets Serie der Getreideschober in Giverny}

Van Goghs Serien - und namentlich die Darstellungen des ummauerten Feldes lassen sich in ihrer Eigenheit nochmals genauer fassen durch einen Vergleich mit Claude Monets Serie der Getreideschober und Paul Cézannes Ansichten der Montagne Sainte-Victoire. ${ }^{1}$

Monet hatte nach der Ernte des Spätsommers 1890 begonnen, wiederholt das an sein Haus in Giverny angrenzende Feld zu malen (vgl. Abb. 104). Er richtete dabei den Blick nach Südwesten und stellte bis Frühjahr 1891 in mindestens 24 Gemälden die auf dem Feld errichteten kegelförmigen Getreideschober dar. Der Winter 1890/91 war, wie Wetteraufzeichnungen zu entnehmen ist, „ein denkwürdiges meteorologisches Ereignis“2 mit anhaltender, aber nicht zu großer Kälte, Sonnenschein und leichten Schneefällen: Bedingungen, die Monet die Arbeit im Freien ermöglichten, so dass er auf mehreren Leinwänden gleichzeitig malte, um „vor allem die Eindrücke dieser prachtvollen Winterszenen festzuhalten“3. In

$1 \quad$ Serien waren im 19. Jahrhundert keine unübliche visuelle Ausdrucksform. Die dreizehn Paysages de Mer Gustave Courbets von 1867, Edgar Degas 1886 anlässlich der letzten Impressionistenausstellung gezeigte Gruppe formal ähnlicher Pastelle mit Frauen bei der Toilette oder Serien von Camille Pissarro seien als Beispiele genannt. Im Jahr 1889 wurden anlässlich der Pariser Weltausstellung die bei vielen Künstlern beliebten Hundert berühmte Ansichten von Edo Utagawa Hiroshiges aus dem Jahr 1857 ausgestellt. Monet war direkt von den Serien japanischer Farbholzschnitte beeinflusst. Vgl. Boehm 2017, S. 138.

2 Wildenstein 2010, S. 276.

3 Claude Monet, übersetzt u. zitiert bei Wildenstein 2010, S. 276. 
dieser Zeit entstanden mindestens sieben Ansichten der Getreideschober, die von Schnee bedeckt sind (vgl. Abb. 103). ${ }^{4}$ Die übrigen Werke zeigen zu unterschiedlichen Tageszeiten entweder einen oder zwei Getreideschober aus mehr oder weniger großer Entfernung. Auffallend ist die Ähnlichkeit der Werke untereinander hinsichtlich ihrer Komposition: eine formal und in ihren Charakteristika reduzierte Landschaftsdarstellung, in welcher der Getreideschober zentraler Bildgegenstand ist (vgl. Abb. 105).

Die Meules, fin de l'été, effet du matin (Abb. 105) zeigen zwei Getreideschober im kühlen morgendlichen Licht. ${ }^{5}$ Das Feld leuchtet auf der von der Sonne beschienenen Seite im Wechsel von weißen und goldbraunen Halmen sowie hellvioletten und hellgrünen Schichten des Ackerbodens darunter. Daneben stehen die verschatteten Zonen der Schober und des Ackers in dunklem Orange sowie Violett- und Blautönen. Das Wechselspiel zwischen ungleichmäßigen, kurzen und tupfenden Pinselstrichen erzeugt einen gleichmäßig flimmernd-flirrenden Gesamteindruck.

Bei Meules au soleil, midi zeigt Monet dagegen die Schober in der Mittagssonne, so dass im Vergleich alle Farben eine Nuance heller wirken (Abb. 106). ${ }^{6}$ Der linke Bildbereich ist in helles, fast gleißendes Licht gehüllt. Das Feld erscheint in hellem Gelb, Grün und Violett und die Farben der Schattenzonen sind weniger intensiv als am Morgen. Das Gegenlicht erzeugt starke Kontraste der Schober vor dem Hintergrund zwischen hell und dunkel, wohingegen sich die Formen im abschwächenden, dunstigen Licht der tief stehenden Abendsonne von Meules, fin de l'été, effet du soir (Abb. 107) aufzulösen scheinen. ${ }^{7}$ Bei den Winterbildern, beispielhaft sei hier Meule, effet de neige, temps couvert (Abb. 108) genannt, stehen die warmen, erdigen Farben des Schobers in scharfem Kontrast zum Weiß des Schnees und dem bläulichen Licht, in das die Wintersonne das Feld taucht. ${ }^{8}$

Anders als lange Zeit kolportiert, handelte es sich nicht um Heuhaufen, sondern mit dem Getreideschober - französisch „Meule“ - um eine für die Normandie typische Form der Lagerung, in der Getreide den Winter über aufbewahrt und frisch gehalten wurde. Getreideschober wurden vor Monet häufig in der französischen Landschaftsmalerei des 19. Jahrhunderts dargestellt (vgl. Abb. 62), „doch liefer-

4 Dazu gehören: W 1274, W 1275, W 1276, W 1277, W 1278, W 1279, W 1281, W 1282 (?) sowie W 1283. Für die Werke Claude Monets wurde das Werkverzeichnis Daniel Wildensteins (Wildenstein, Daniel: Monet oder der Triumph des Impressionismus, Köln 2010 („W“ Nummern) verwendet.

5 Claude Monet (1840-1926), Meules, fin de l'été, effet du matin, 1891, Öl auf Leinwand, 60,5 x 100,5 cm, Paris, Musée d'Orsay, W 1266.

6 Claude Monet (1840-1926), Meules au soleil, midi, 1890, Öl auf Leinwand, 65,6 x 100,6 cm, Canberra, National Gallery of Australia, W 1271.

7 Claude Monet (1840-1926), Meules, fin de l'été, effet du soir, 1890-1891, Öl auf Leinwand, 60 x $100 \mathrm{~cm}$, Art Institute of Chicago, W 1269.

8 Claude Monet (1840-1926), Meule, effet de neige, temps couvert, 1891, Öl auf Leinwand, 66 x 93, Art Institute of Chicago, W 1281. Diese Werke diskutiert Heinrich, da sie in der Ausstellung der Hamburger Kunsthalle gezeigt werden konnten. Vgl. Heinrich 2001, S. 17. 
ten sie meist den Hintergrund für anekdotische Szenen oder dienten als Requisite einer Fruchtbarkeitsallegorie; Hauptdarsteller waren sie bis dahin nicht. "9 An diese reiche Darstellungstradition des ländlichen Lebens, die in Frankreich bis auf die Monatsbilder in Stundenbüchern oder in romanischen Kirchen zurückweist und im 19. Jahrhundert von den Barbizon-Malern und zahlreichen anderen Malern aufgegriffen wurde, schließt Monet mit der Wahl dieses Motivs an. Jedoch ist die Arbeit der Bauern oder gar deren Armut, auf die Maler wie Breton und Millet vielfach hinweisen, nicht Gegenstand von Monets Serie. ${ }^{10}$ Paul Hayes Tucker erklärt in seinem Aufsatz zu Monets Serien, dass die Getreideschober „breathe the air of contentment. For this is the countryside that fulfills all promises, the rural France that is wholesome and fecund, reassuring and continuos." ${ }^{11}$

Wenn die harte Arbeit der Bauern nicht mehr Bildgegenstand war, welche künstlerischen Anliegen verfolgte Monet stattdessen mit seinen Landschaftsbildern, die in Variation immer wieder das gleiche Sujet zeigen? Für die Beantwortung dieser Frage ist ein Blick zurück auf die Grundlagen und die Anfänge der Freilichtmalerei in Frankreich unerlässlich, denn bereits Pierre-Henri de Valenciennes hatte, wie erwähnt, in seiner Schrift Élemens de perspective practique (1799/1800) empfohlen, Objekte zu unterschiedlichen Tageszeiten zu malen, um die Veränderungen zu studieren, die das wechselnde Licht und die unterschiedlichen Witterungsverhältnisse bewirken: „Il est bon peindre la même vue à différents heures du jour, pour observer les différences que produit la lumière sur les formes. Les changemens sont si sensibles et si étonnans, qu'on a peine à reconnaître les mêmes objets. "12 Allein 140 Ölskizzen von de Valenciennes, entstanden 1782-1784, sind im Louvre aufbewahrt, in denen dieser vielfach die gleichen landschaftlichen Motive unter wechselnden Lichtverhältnissen und zu unterschiedlichen Tageszeiten abbildet. Die Studien sind dabei durch die Darstellung des Unscheinbar-Alltäglichen und Zufälligen geprägt, das er unter Verzicht auf sonst übliche Vordergrundpartien dicht an den Betrachter heranrückt. De Valenciennes war auch um eine Ordnung und einen Zusammenhang dieser Skizzen untereinander bemüht, die dadurch zum Ausdruck kam, dass er manche paarweise nebeneinander anordnete. ${ }^{13}$

Die Erscheinungen des wechselnden Lichtes zu studieren, war für die Impressionisten im zweiten Drittel des 19. Jahrhunderts bereits keine neue Aufgabe mehr, sondern die Praxis eines jeden akademisch ausgebildeten Malers geworden. Daran hatte de Valenciennes, der 1812 als Professor an die École des Beaux-Arts berufen worden war, selbst großen Anteil als er 1817 auf die Einrichtung eines „Prix de Rome“ speziell für die Landschaftsmalerei hinwirkte, wobei die Studenten

$9 \quad$ Heinrich 2001, S. 16.

10 Vgl. Hayes Tucker 1989, S. 37.

11 Hayes Tucker 1989, S. 37.

12 De Valenciennes 1800, S. 409. Vgl. auch Busch 1997, S. 233-240 und die Einführung zu de Valenciennes Schrift.

13 Vgl. Busch 1997, S. 237 u. insbesondere Baumann 2004, S. 16 bzgl. der neuartigen Charakteristika. 
eine Landschaftsskizze und eine vor der Natur angefertigte Baumstudie einreichen mussten. Die ersten drei Jahre des vierjährigen Aufenthaltes in Rom verbrachten die Stipendiaten vor allem mit Studien nach der Natur, ehe sie im vierten Jahr dazu gelangten, ideale Landschaften mit historischen Sujets („paysages historiques“) zu komponieren.

Das Studium der sichtbaren Wirklichkeit war dementsprechend kein Selbstzweck, sondern diente dazu, naturnahe - nicht naturgetreue - ideale Landschaften zu schaffen. Auch wenn de Valenciennes' Anweisungen sich noch auf Ölskizzen, nicht auf vollendete Kompositionen bezogen, und für ihn die in der Natur entstandenen „études" Studienmaterial keine vollwertigen Bilder darstellten, wurde der Malerei in der Natur, vor dem Motiv, doch ein immer größerer Stellenwert beigemessen. ${ }^{14}$

De Valenciennes' Schüler Jean Baptiste Deperthes (1761-1833) folgte seinem Lehrer hinsichtlich der Bedeutung der Ölskizze nach der Natur und geht in seinem Traktat Théorie du paysage (1818), das auf die Gewinner des Rompreises großen Einfluss ausübte, gar einen Schritt weiter, indem er die realistische Landschaft („paysage champêtre“) der klassischen „idealen Landschaft“, die sich von Nicolas Poussin (1594-1665) und Claude Lorrain (1600-1682) herleitet, gleichstellte. ${ }^{15}$ Wie Werner Busch festhält, war es damit de Valenciennes' Verdienst, dass die „Bilderfindung [...] nicht mehr primär ideengespeist [ist], [sie] entspringt nicht mehr allein dem künstlerischen Genius, sondern ist Resultat abgeleiteter Naturkenntnis. Erst danach setzt die Intellektualisierung der Landschaft durch Bildungsverweise ein. " ${ }^{16}$

Die Ideen von de Valenciennes auch auf "tableaux“ zu übertragen und damit die Landschaftsdarstellung „en plein air“ als vollwertig zu erachten, setzte erst mit den Freilichtmalern der Schule von Barbizon seit dem zweiten Drittel des 19. Jahrhunderts ein - an die die Impressionisten nahtlos anschlossen -,als beispielsweise Théodore Rousseau (1812-1867), Charles-François Daubigny (1817-1878) und Jean-Baptiste-Camille Corot (1796-1875) Werke ausstellten, die unter anderem das gleiche Motiv - die Wiedergabe der Natur in unidealisierter, schlichter Weise - zu unterschiedlichen Tageszeiten zeigten. ${ }^{17}$ Die Verbindung ist dabei unmittelbar zu de Valenciennes herzustellen, hatten doch Corots Lehrer Jean-Victor Bertin (1767-1842) und Achille-Etna Michallon (1796-1822) ihrerseits bei ihm studiert. Letzterer war gar der erste Gewinner des Rompreises für Landschaftsmalerei im Jahre 1817.

14 Vgl. Busch 1997, S. 238.

15 Vgl. Busch 1997, S. 239. Jean Baptiste Deperthes: Théorie du paysage ou considerations générales sur les beautés de la nature que l'art peut imiter [...], Paris 1818.

Der Begriff der „paysage champêtre“ stammt von Roger de Piles (1635-1709), der diese 1708 in seiner Schrift Cours de peinture par principes von der "paysage historique" unterscheidet.

16 Busch 1997, S. 239.

17 Vgl. Baumann 2004, S. 21f. Vgl. auch Heinrich 2001, S. 14 und dort den Hinweis auf Pierre Henri de Valenciennes, Eléments de perspectives pratique à l'usage des artistes, Paris 1800. 
In der vom offiziellen akademischen Diskurs bestimmten Wahrnehmung hatten lange Zeit große Vorbehalte gegenüber der realistischen Landschaftsmalerei bestanden, galt die bloße Wiedergabe der sichtbaren Natur - noch dazu im Freien, statt im Atelier - doch bis weit in die zweite Hälfte des 19. Jahrhunderts oft als schlicht unanständig und vulgär. ${ }^{18}$ Waren Corots Romstudien in den 1820er und 1830er Jahren in der französischen Öffentlichkeit noch auf Ablehnung gestoßen, begann sich mit dem Salon von 1849 die Wahrnehmung hinsichtlich seiner Landschaftsbilder langsam zum Positiven zu verändern, obschon weiter Vorbehalte gegenüber der Gestaltung vorherrschten. ${ }^{19}$ Die spontanen Ölskizzen Corots, die dieser in der Natur vor dem Motiv malte, wurden zwar nicht in den Salons gezeigt, dass sie dennoch auf die nachfolgende Malergeneration außerordentlich großen Einfluss ausübten, zeigt sich dadurch, dass sie nach seinem Tod von vielen Malerkollegen, beispielsweise Degas, erworben wurden und auch in die Sammlung des Louvre übergingen. Sie waren bei den Impressionisten und Kritikern, wie Émile Zola, weitaus beliebter und übten größeren Einfluss aus als die späteren lyrischen Landschaften Corots. ${ }^{20}$

Gustave Courbet, der aufgrund seiner revolutionär neuen Sujets und deren Darstellung immer wieder den Widerstand der Behörden und der öffentlichen Meinung provozierte, malte ab Ende 1869 in Étretat, einem kleinen Fischerdorf in der Normandie, wo vor ihm bereits Delacroix gearbeitet hatte, rund 60 Meereslandschaften und Strandbilder, in denen er seine Kritik an der traditionellen Landschaftsmalerei zum Ausdruck brachte. 1855 hatte er in seinem Manifest „Le Réalisme“ postuliert, dass es sein Wille sei, seine Zeit auf eine eigene Art und Weise und nach seinem eigenen Empfinden darzustellen. ${ }^{21}$ Statt das Meer auf eine erhaben-idealisierte Art und Weise zu visualisieren, fasst Courbet einen scheinbar beliebig wirkenden Küstenabschnitt und lässt den Betrachter die mit grobem Pinselduktus erfasste volle Wucht der tosenden Brandung erahnen. Fasziniert von den Kräften der Natur stellt er wiederholt die anrollenden Wellen in wechselnden Bildausschnitten und zu unterschiedlicher Tageszeit dar. ${ }^{22} 20$ Jahre vor Monets Anfängen des seriellen Arbeitens, motiviert durch impressionistische Bildparadigmen, ist Courbets dem

18 Vgl. Busch 1997, S. 238 u. bspw. Clark 1986, S. 164f. mit dem Verweis auf die Aussagen des Grafen Alfred de Nieuwerkerke (1811-1892), einem der einflussreichsten Kulturpolitiker zu Zeiten Napoleons III., und die Entscheidung Courbets den Salon zu meiden und seine Werke separat auszustellen. Insbesondere Gustave Courbet erlebte die harte Haltung am eigenen Leib als er vom Salon zurückgewiesen wurde und stattdessen 1855 eine eigene Ausstellung organisierte, bei der er vierzehn Landschaftsbilder zeigte. An dieser Stelle sei natürlich auch auf Manet verwiesen.

19 Vgl. Busch 1997, S. 238.

20 Vgl. Langmuir 2006, S. 278f. u. Baumann 2004, S. 30 u. 32. Fast einhellig wurden die späteren, lyrischen Landschaften Corots von den Impressionisten abgelehnt.

21 Das Manifest Courbets ist online verfügbar, beispielsweise auf der Internetseite des Musée d'Orsay, abgerufen unter: http://www.musee-orsay.fr/fr/collections/dossier-courbet/courbet-sexprime. html?cHash=c578ddfcff.

22 Vgl. bspw. Gustave Courbet (1819-1877), Die Welle, 1869, 63 x 91,5 cm, Frankfurt, Städel Museum. Vgl. die Katalogisierung des Werkes, abgerufen auf der Internetseite des Museums, unter: http://www.staedelmuseum.de/de/sammlung/die-woge-1869. 
Realismus verpflichtete Serie als ein wichtiger Wegbereiter der Landschaftsmalerei für Monets serielle Kunst zu verstehen.

Monet wuchs in Le Havre auf und begann an den Stränden der Normandie zu malen, wo er, vor allem beeinflusst durch Eugène Boudin, sein Bekenntnis zur plein-air Malerei entwickelte. 1860 schrieb sich Monet in Paris an der Académie Suisse ein, einem unabhängigem Atelier, das vor ihm bereits Delacroix, Corot und Courbet besucht hatten, und wo er auf Camille Pissarro traf, von dem er später berichtete, dass dieser wie Corot gearbeitet habe. Für Delacroix äußerte er nach dem Besuch einer Retrospektive große Bewunderung. Dort hatte er unter anderem dessen erstes bedeutendes Werk Die Dante-Barke von 1822 gesehen, bei dem Delacroix' neuartige Farbbehandlung Anwendung fand. ${ }^{23}$

Im Jahr darauf folgte er der Einberufung zum Militär und, beeinflusst von den Erzählungen eines Freundes vom Dienst in den Kolonien unter der afrikanischen Sonne, entschied er sich für eine Einheit in Algerien. Wie für Delacroix, dessen Kolorismus unter anderem von einem Marokkobesuch 1832 beeinflusst worden war, machten das dortige Licht und die Farben auch auf Monet einen großen Eindruck. Im Atelier von Charles Gleyre, das er ab 1862 nach seiner Entlassung aus dem Militärdienst besuchte, traf er auf Frédéric Bazille (1841-1870), Alfred Sisley (1839-1899) und Pierre-Auguste Renoir (1841-1919). Mit den neuen Künstlerfreunden brach er 1863 nach Chailly-en-Bière auf, um dort im Wald von Fontainebleau, keine zwei Kilometer von Barbizon, im Freien zu malen. ${ }^{24}$ Zwei Jahre später beabsichtigte er, beeinflusst von Manets Déjeuner sur l'herbe, das 1863 für großes öffentliches Aufsehen gesorgt hatte, in Chailly seine ebenfalls großformatige Variante eines „Frühstücks im Grünen“" zu malen. Anders als Manet, der für zeitgenössische Betrachter auf anstößige Art und Weise eine Bildidee der Renaissance adaptiert hatte, war Monets Gemälde, auf dem eine Personengruppe beim Picknick - unter anderem sein Freund Bazille - in Lebensgröße und zeitgenössischer Kleidung dargestellt werden sollten, vergleichsweise wenig provokativ. Mit Manet gemein hatte das Sujet jedoch die Darstellung einer Szene des alltäglichen, modernen Lebens, anstelle von historisierenden oder romantischen Themen. Das Projekt scheiterte nach Studien letztlich aus finanziellen, aber auch künstlerischen Gründen, die jedoch ein Schlaglicht auf die Fragen werfen, mit denen sich Monet intensiv befasste: Dabei sind vorrangig die Lichteffekte zu nennen, insbesondere das Licht, das durch die Blätter der Baumkronen fällt, sowie die Verteilung von Licht- und Schatten, wobei die zunächst entstandene Studie eine große Spontaneität aufweist. ${ }^{25}$

23 Eugène Delacroix (1798-1863), Dante und Vergil in der Unterwelt, 1822, Öl auf Leinwand, 189 x $246 \mathrm{~cm}$, Paris, Louvre. Vgl. Wildenstein 2010, S. 26f. dort auch das Zitat Monets über Corot.

24 Vgl. Wildenstein 2010, S. 46.

25 Vgl. Wildenstein 2010, S. 60. Schwierigkeiten bereitete Monet die Übertragung von der Skizze auf das Monumentalwerk, insbesondere die Bewahrung der Spontaneität. Ein Fragment befindet sich im Musée d'Orsay. Claude Monet (1840-1926), Le déjeuner sur l'herbe, 1865-1866, Öl auf Leinwand, 248 x $217 \mathrm{~cm}$, Musée d'Orsay. Vgl. auch die Katalogisierung des Werkes, abrufbar auf der Internetseite des Museums, unter: http://www.musee-orsay.fr/fr/collections/ 
Wenig später entstand das Gemälde Femmes au jardin. Monet hatte für die Darstellung der vier Frauen ein Großformat gewählt, das traditionell für Historienbilder reserviert war. Seine vorrangige Zielsetzung war es, die Figuren in eine atmosphärische Landschaftsdarstellung zu integrieren. Auf dem Salon 1867 wurde das Werk abgelehnt. Als Grund für die Zurückweisung der Femmes au jardin nannte die Jury die vollkommene Abwesenheit eines Bildgegenstandes oder narrativen Elements und die deutlich sichtbaren Pinselstriche, die als Zeichen von Nachlässigkeit und Unvollständigkeit interpretiert wurden. ${ }^{26}$

Als Monet 1869 mit Renoir in La Grenouillère arbeitete, wo er seine leuchtende Malweise aus kurzen und lebhaften Pinselstrichen und fragmentarischen Formen entwickelte, hatte er das Interesse an figürlicher Malerei nahezu vollkommen verloren, das er Anfang der 1860er nach seinen ersten Reisen nach Paris entwickelt hatte und fertigte fast ausschließlich Landschaften an. Wichtige Eindrücke gewann Monet auch 1870/71 durch seinen kriegsbedingten Aufenthalt in London als er die Werke der zwei Generationen älteren englischen Landschaftsmaler John Constable (1776-1837) und William Turner (1775-1851) kennenlernte. Waren Constables charakteristischer Duktus und seine Farbdifferenzierungen anregend, konnte Monet in Turners Bildern sehen, wie dieser den Eindruck des Gesehenen unter bestimmten Licht- und Witterungsverhältnissen anstrebte. ${ }^{27}$

Im Jahr 1874 fand schließlich die erste Gruppenausstellung der sogenannten „Société Anonyme des Artistes Peintres, Sculpteurs, Graveurs etc.“ statt, bei der Monet und andere Künstlerfreunde, unter ihnen Paul Cézanne, Edgar Degas, Armand Guillaumin (1841-1927), Berthe Morisot (1841-1919), Camille Pissarro (18301903), Renoir und Alfred Sisley (1839-1899), im ehemaligen Studio des Photographen Nadar (Gaspard-Félix Tournachon, 1820-1910) als Gegenveranstaltung zum Salon ihre Werke der Öffentlichkeit zugänglich machten. Die erste Ausstellung fand unmittelbaren Widerhall in der Presse und führte infolge der sarkastischen Kommentare des Kritikers Louis Leroy bezüglich der von Monet als Impression, soleil levant betitelten Ansicht des Hafens von Le Havre zu der Bezeichnung der Kunstströmung mit ihren eigentlichen Namen, der sich trotz der anfänglichen negativen Konnotation langsam etablierte. ${ }^{28}$ Der Kunstkritiker Jules-Antoine Castagnary

oeuvres-commentees/recherche/commentaire_id/le-dejeuner-sur-lherbe-18301.html?no_cache=$1 \& \mathrm{cHash}=5820832 \mathrm{c} 25$.

26 Claude Monet (1840-1926), Femmes au jardin, um 1866, Öl auf Leinwand, 255 x 205 cm, Paris, Musée d'Orsay. Vgl. auch die Katalogisierung des Werkes, abrufbar auf der Internetseite des Museums, unter: http://www.musee-orsay.fr/en/collections/works-in-focus/painting/commentaire_id/frauen-im-garten-5636.html?tx_commentaire_pi1\%5BpidLi\%5D=509\&tx_commentaire_pi $1 \% 5 \mathrm{Bfrom} \% 5 \mathrm{D}=841 \& \mathrm{cHash}=$ adc95a24b6. Vgl. auch Wildenstein 2010, S. 63 für weitere Informationen hinsichtlich der geplanten gemeinsamen Ausstellung als Alternative zum Salon.

27 Vgl. Wildenstein 2010, S. 86f.

28 Claude Monet (1840-1926), Impression, soleil levant, 1872, Öl auf Leinwand, 48 x 63 cm, Paris, Musée Marmottan Monet, W 263. Die als fiktiver Dialog verfasste Kritik erschien am 25.4.1874 in der Zeitschrift Le Charivari. 
schrieb wenige Tage nach der Veröffentlichung von Leroys Artikel wohlwollender über die Ausstellung und seine Besprechung scheint der erste ernsthafte Versuch gewesen zu sein, den Impressionismus zu definieren: „Si l'on tient à les caractériser d'un mot qui les explique, il faudra forger le terme nouveau d'impressionnistes. Ils sont impressionnistes en ce sens qu'ils rendent non le paysage, mais la sensation produite par le paysage. Le mot même est passé dans leur langue: ce n'est pas paysage, c'est impression que s'appelle au catalogue le Soleil levant de M. Monet. Par ce côté, ils sortent de la réalité et entrent en plein idéalisme. ${ }^{29}$ Wie Richard Shiff festhält, hatte Castagnary bereits seit dem Salon von 1863 das ehrliche und direkte Malen nach dem Gegenstand als Charakteristikum einer modernen Malerei in einer fortschrittlichen Gesellschaft propagiert. ${ }^{30}$ Castagnarys Äußerungen zeigen, dass er sich mit den technischen, philosophischen und psychologischen Dimensionen der neuen Malerei auseinandergesetzt und infolgedessen wichtige Charakteristika erkannt hatte: Er diskutiert den Einfluss der persönlichen Wahrnehmung der Künstler und stellt fest, dass das subjektive Empfinden der Natur für den Prozess der Bildfindung - der Darstellung eines Eindrucks - entscheidend war. ${ }^{31}$

John Rewald greift in seiner History of Impressionism Castagnarys Definition auf und bemerkt hinsichtlich der Frage nach der Beziehung zum Realismus, dass die Impressionisten „renounced even the pretense of creating reality. Rejecting the objectivity of realism, they had selected one element from reality - light - to interpret all of nature [...] the impressionists [...] knew that they had accomplished a great step forward in the representation of nature. " 32 Rewald schlussfolgert daraus, dass der Erfolg der Impressionisten auf „the careful observation of colored light appearing in a scene at a particular moment ${ }^{\text {" }} 33$ beruht. Shiff wirft richtigerweise die Frage auf, ob aus Rewalds Erklärung abzuleiten sei, dass das Licht Teil einer objektiv und für jedermann wahrnehmbaren Wirklichkeit ist, und inwiefern diese Auffassung von einem konventionellen Realismus abweicht. ${ }^{34}$ Waren zwar die Impressionisten weiterhin, wie in der Tradition der Realisten, bemüht, die Natur direkt abzubilden, stellt doch das subjektive Element das Castagnary „idéalisme“ nennt, - d.h. die Art und Weise, wie Landschaft individuell empfunden und abgebildet wird, beispielsweise durch eine skizzenhafte Ausführung einer „impression“- einen wichtigen Unterschied zu der Vorgängergeneration der Realisten dar, die eine ehr-

29 Castagnary, Jules-Antoine: Exposition du boulevard des Capucines-Les impressionnistes, in: Le Siècle, Bd. 39, Nr. 15126, 29.04.1874, S. 3, Sp. 5.

30 Vgl. Shiff 1984, S. 3.

31 Shiff weist auf Unklarheiten in Castagnarys Definition hin, „since he alludes to a distinction between a natural world, the landscape' that exists independently of one's perception or experience of it, and the sensation produced 'by this landscape. Is this sensation available for all to have? Or is the landscape necessarily seen differently by different artists? Does the new ,impressionism ' depart from ,naturalism'?" Shiff 1984, S. 3.

32 Rewald 1961, S. 330.

33 Rewald 1961, S. 338.

34 Vgl. Shiff 1984, S. 4. 
liche Abbildung, beispielsweise der ländlichen Arbeitswelt, anstrebte. Shiff fasst zusammen, dass für viele Künstler und Kritiker der Impressionismus sowohl objektiv, hinsichtlich der Gegebenheit des Bildgegenstandes, als auch subjektiv, infolge der individuellen künstlerischen Interpretation, sein konnte. ${ }^{35}$

Aufgrund der Vielzahl von Künstlern, die auf den Ausstellungen der Impressionisten vertreten waren - bis zur achten Gruppenausstellung im Jahr 1886 hatten 57 unterschiedliche Maler teilgenommen -, ist eine Definition der Kunst, die unter dem Begriff Impressionismus firmierte, mit Schwierigkeiten verbunden. Dennoch kann anhand von Monets Landschaftsbildern, die seit den 1870er Jahren entstanden, ein Paradigma für den Impressionismus abgeleitet werden. ${ }^{36}$

Bereits 1874 ist bei Monet die Tendenz zu erkennen, Motive wiederholt zu verschiedenen Tageszeiten erfassen zu wollen, als er die Straßenbrücke von Argenteuil sieben Mal und die Eisenbahnbrücke, die die Seine flussaufwärts von Argenteuil überspannt, vier Mal malte. In einer Ansicht der Sraßenbrücke von Argenteuil, die sich heute im Musée d'Orsay befindet, ankern drei Segelboote im Vordergrund, die parallel nebeneinander angeordnet sind. Die Brücke ist nur ausschnitthaft am rechten Bildrand zu sehen. Die Effekte des Lichts auf den Bootmasten und deren Spiegelung auf dem Wasser geben Monet die Möglichkeit zu Komplementärkontrasten von Orange und Blau, die den Eindruck des glitzernden Lichts verstärken. Unterschiedlich bearbeitete Flächen stehen sich im Bild gegenüber: Die Abgrenzungen der fein-strukturierten Bildelemente, wie der Segelboote und der Brücke, sind klar und solide gefasst, dagegen ist das Wasser im Bildmittelgrund durch bewegte Pinselstriche charakterisiert, die die Reflektionen des Lichts visualisieren. ${ }^{37}$ Die unterschiedlichen Ansichten der Brücken können durch die wiederholte Auseinandersetzung mit dem gleichen Thema zu wechselnden Tageszeiten - trotz der unterschiedlichen Betrachterstandpunkte und Kompositionen - zumindest als indirekte Vorläufer für die Serie der Getreideschober gelten.

Als weiterer Vorläufer für die Serie der Getreideschober kann auch die Motivreihe des Pariser Bahnhofs Saint-Lazare aus den Jahren 1876 und 1878 verstanden werden, die mit ihrem Fokus auf den wechselnden Wirkungen des Lichts in der Bahnhofshalle und den aufsteigenden Dampfwolken an Turners Werk Rain, Steam, and Speed-The Great Western Railway von 1844 erinnert. ${ }^{38}$ Obwohl Monet noch den Standort wechselte und darüber hinaus - je nach Bildgegenstand - den Pinselduktus variierte und damit noch weit von der Systematik, der Gleichförmigkeit und

35 Vgl. Shiff 1984, S. 4f. „For many artists and critics, impressionist painting seemed both objective and subjective." Zitiert aus Shiff 1984, S. 5.

36 Vgl. auch Coyle 2009, S. 86 für die Charakteristika des Impressionismus.

37 Claude Monet (1840-1926), Die Brücke von Argenteuil, 1874, Öl auf Leinwand, 60,5 x 80 cm, Paris Musée d'Orsay. Vgl. auch die Katalogisierung auf der Internetseite des Musée d'Orsay, abgerufen unter: http://www.musee-orsay.fr/en/collections/index-of-works/notice.html?no_cache=18 nnumid $=1297$.

38 William Turner (1775-1851), Rain, Steam and Speed - The Great Western Railway, 1844, Öl auf Leinwand, $91 \times 121,8 \mathrm{~cm}$, London, National Gallery. 
Geschlossenheit der Serie der Getreideschober entfernt ist, kann doch bereits konstatiert werden, dass für Monet bei den Bahnhofsansichten nicht die Schilderung der Züge oder der Reisenden von Bedeutung ist, sondern die Wirkungen des Lichts und der Farben zu unterschiedlichen Zeitpunkten der entscheidende Bildgegenstand sind. ${ }^{39}$ Wie viele andere Künstler seiner Zeit war auch Monet unmittelbar von den japanischen Holzschnittserien, beispielsweise Hiroshiges (Hundert berühmte Ansichten von Edo, 1857) oder Hokusais 36 Ansichten des Berges Fuji (18311834), bei dem auf allen Blättern der heilige Berg in unterschiedlichen Zusammenhängen und Kompositionen zu sehen ist, beeinflusst. ${ }^{40}$

In den 1880er Jahren reiste Monet extensiv und malte unter anderem in Étretat wiederholt die charakteristischen Felsformationen. Zwischen 1883 und 1886 zog es Monet jedes Jahr in das Seebad in der Normandie, und er schuf dort fast 50 Gemälde, darunter 20 Ansichten des Strandes und der außergewöhnlichen Klippen. Auch diese Ansichten, in denen Monet wiederholt zu unterschiedlichen Tageszeiten den Eindruck des Lichts auf den Felsen, aber auch die Reflexionen des Lichts und die Spiegelungen der Gesteinsformationen auf dem Wasser zeigt, künden die Serien, die wenige Jahre später entstehen sollten, an. Wie bereits bei den Bahnhöfen variierte Monet jedoch noch das Motiv und den Bildausschnitt. ${ }^{41}$

Ein Jahr vor der Entstehung der Getreideschober reiste Monet in eine abgelegene Region im Zentralmassiv und malte dort wiederholt, in 24 Fassungen, Felsformationen am Fluss Creuse. Anders als noch bei den zuvor angesprochenen Werkgruppen ist hier nun bereits die Tendenz der Vereinheitlichung zu erkennen, zeigen doch zehn Ansichten fast genau den gleichen Blickwinkel und die gleiche Komposition. Viele der Bilder weisen eine dunklere Farbpalette auf und fangen die Lichtsituationen am späten Nachmittag oder in den frühen Abendstunden, direkt nach dem Untergang der Sonne, ein, wenn die letzten Sonnenstrahlen den Himmel in ein rosa-rotes Licht tauchen. ${ }^{42}$ Andere Ansichten geben die Stimmung unter einem grauen Himmel wieder. Auch die Kargheit der Landschaft, die sich durch nackte Felsen, den sich durch das Tal schlängelnden Fluss und Hügel nahezu ohne Vegetation im Hintergrund auszeichnet, weist auf die formale Einfachheit der Getreideschober hin. Hayes Tucker schlägt infolgedessen vor, diese Gruppe als Monets erste Serie zu bezeichnen. ${ }^{43}$

39 Vgl. Heinrich 2001, S. 15.

40 Vgl. Boehm 2017, S. 138. Wo genau Monet mit den Holzschnitten zum ersten Mal in Kontakt kam (Le Havre, Paris, Zaandam, Amsterdam oder London), ist nicht klar. Vgl. Wittgenstein 2010, S. 100.

41 Vgl. exemplarisch Claude Monet (1840-1926), Etretat, la Manneporte, reflets sur l'eau, um 1885, Öl auf Leinwand, 65,8 x 81,5 cm, Paris, Musée d'Orsay oder Etretat, la Manneporte, 1883, Öl auf Leinwand, 65,4 x 81,3 cm, New York, The Metropolitan Museum of Art. Letzteres zeigt den charakteristischen Felsen in Nahsicht.

42 Vgl. bspw. Claude Monet (1840-1926), Creusetal, Grauer Tag, 1889, Öl auf Leinwand, 65,5 x $81,2 \mathrm{~cm}$, Boston, Museum of Fine Arts.

43 Hayes Tucker 1989, S. 43. 
Bei der Serie der Getreideschober manifestierte sich eine Entwicklung Monets hin zu einer Ausdrucksform, „die der Summe der einzelnen Eindrücke gerecht wird.“44 Monet selbst soll, laut den Aufzeichnungen des holländischen Autors W.G. Byvanck (1848-1925), während der Ausstellung bemerkt haben, „dass die [Werke] ihren vollen Wert erst durch den Vergleich mit den anderen und als Teil der ganzen Serie erhalten. ${ }^{\text {" } 55}$ Die Serie, welche die Getreideschober zwar zu unterschiedlichen Jahresund Tageszeiten zeigt, aber aufgrund der Wiederholung der Motive, ihrer Kompositionen und anderer formaler Aspekte in sich sehr geschlossen wirkt, könne demnach nicht nur „ein aufrichtiges Bild des sich in seiner äußeren Erscheinung ständig ändernden Gegenstands [...] geben, sondern auch die Aufzeichnung verstreichender Zeit. " ${ }^{46}$ Die Einzelwerke, die den Augenblick in seiner jeweiligen Erscheinung - auf die subjektive Art und Weise, wie Monet sie wahrnahm - festhalten, werden so zu Teilen des Gesamtzusammenhangs der Serie: einer Fixierung der flüchtigen atmosphärischen Erscheinungen im Laufe der Zeit. ${ }^{47}$

Monet hatte sich 1890 von seinem Händler Paul Durand-Ruel (1831-1922) das Recht einräumen lassen, Einzelausstellungen ausrichten zu dürfen, bei denen er geschlossene Serien - erst die Serie der Getreideschober, dann die Pappeln und schließlich die Kathedralen - präsentieren konnte. Monet bereitete die Präsentation seiner Werke akribisch vor und 15 der 22 für die Ausstellung ausgewählten Werke zeigten Getreideschober. ${ }^{48}$ Trotz der überlieferten Werkliste ist nicht genau bekannt,

44 Heinrich 2001, S. 18. Vgl. auch Klein 1998, S. 124.

45 W.G.C. Byvanck: Un Hollandais à Paris en 1891, in: Anatole France, Sensations de litérature et d'art, Paris 1892. Zitiert nach der deutschen Übersetzung bei Heinrich 2001, S. 18.

46 Heinrich 2001, S. 18.

47 Vgl. Heinrich 2001, S. 19.

48 Vgl. Moffett 1984, S. 152 f.

War die Generation von Malern vor den Impressionisten, wie Courbet und die Freilichtmaler in Barbizon, noch fast ausschließlich auf private Auftraggeber angewiesen - und in Courbets Fall stellte die Unabhängigkeit von staatlichen Kommissionen ein wichtiges persönliches Ziel dar -, fiel die Entwicklung des Impressionismus mit dem Aufkommen des modernen Kunstmarktes zusammen, der sich nicht nur durch die immer beliebter werdenden Auktionen im Hôtel Drouot auszeichnete, sondern auch durch ein sich entwickelndes enges Netzwerk von Verbindungen zwischen Händlern, die die Kunst taxierten und verkauften, sowie Kritikern, die die Kunst interpretierten und förderten. Wurden die Impressionisten zunächst noch vorrangig durch Freunde und Familie unterstützt, nahm sich ihrer ab Anfang der 1870er Jahre zuerst der Händler Paul DurandRuel an. Ihm gelang es nach und nach den Käuferkreis so zu erweitern, dass ab den 1880er Jahren die Impressionisten ihre Werke nicht mehr in unabhängigen Ausstellungen, sondern mehr und mehr in Privatgalerien ausstellten und verkauften. Der Einfluss der Käufer wirkte sich merklich auf die künstlerische Sprache der Impressionisten aus und förderte dadurch auch eine ablehnende Haltung dieser Kommerzialisierung bei neo-impressionistisch arbeitenden Künstlern zutage (Vgl. Rubin 2001, S. 331f. u. insbesondere zu Durand-Ruel den sehr ausführlichen Katalog: Inventing Impressionism. Paul Durand-Ruel and the Modern Art Market).

Neben Renoir und Degas wusste Monet das System am besten für sich zu nutzen und wurde so neben ihnen zu einem der wirtschaftlich erfolgreichsten Künstler. Infolgedessen musste er sich 
wie Monet die Hängung und damit Beziehungen der Werke untereinander konzipierte. Die Liste zeigt jedoch, dass Monet Werke unterschiedlicher Tageszeit, Jahreszeit und Lichtstimmung und dabei Ansichten aus der Entfernung oder in Nahsicht sowie Werke, die entweder zwei oder nur einen Schober zeigen, vorgesehen hatte. Mit der Auswahl wird deutlich, dass Monet um malerische Vielfalt der Stimmungen und Darstellungsvarianten der Schober bemüht war. ${ }^{49}$

Über seine Arbeit an den Meules und das, was er bei den unterschiedlichen Ansichten darzustellen beabsichtigte, hatte er im Oktober 1890 an seinen Freund Gustave Geffroy (1855-1926) geschrieben:

Je deviens d'une lenteur à travailler qui me désespère, mais plus je vais, plus je vois qu'il me faut beaucoup travailler pour arriver à rendre ce que je cherche, „l'instantanéité", surtout l'enveloppe, la même lumière répandue partout $\left[\ldots . . .^{50}\right.$

Bei den Termini der „instantanéite““ (dt. „Augenblicklichkeit“) und des „enveloppe“ (dt. „Hülle“) handelt es sich um Schlüsselbegriffe für das Verständnis der Serie. Monet soll sich gewünscht haben, blind geboren zu sein, um dann plötzlich sehen zu können und so einen unvoreingenommenen Blick auf die Dinge zu haben. ${ }^{51}$ Monet ging infolgedessen bei der Suche nach instantanéité davon aus, dass der erste Blick auf ein Motiv der ehrlichste sei. Ein Umstand, der - möglicherweise in der Rückschau von Monet etwas überspitzt dargestell $t^{52}$ - dazu geführt haben soll, dass er entsprechend den atmosphärischen Veränderungen zwischen mehreren

im Vorfeld der geplanten Ausstellung der Serie der Getreideschober im Mai 1891 in der Galerie Durand-Ruel in Paris der Kritik stellen, zu kommerziell zu malen. Camille Pissarro formulierte dies in einem Brief an seinen Sohn Lucien: „Ich weiß nicht, wieso es Monet nicht peinlich ist, sich diesen ständigen Wiederholungen zu unterziehen - aber da siehst Du mal wieder, welch schreckliche Konsequenzen der Erfolg haben kann!“ (Brief vom 9.4.1891, in: Camille Pissarro: Lettre à son fils Lucien, hg. v. John Rewald, Paris 1950, S. 230f, zitiert in der Übersetzung bei Heinrich 2001, S. 13.) Auch Pissarro erkannte schnell, dass eine Reduktion auf eine rein kommerzielle Absicht, also dem Ausnutzen einer „economy of scale“ (Klein 1998, S. 127 nutzt diesen Ausdruck im Zusammenhang mit Monets Serien) bei der Entwicklung von Motiven mit großer Absatzfähigkeit, der Komplexität der Serie nicht ausreichend gerecht wurde: „Gestern wurde die Ausstellung von Monet bei Durand eröffnet. Ich bin mit verbundenen Augen dorthin gegangen, und ich konnte nicht anders, als mit einem Blick die wunderschönen Sonnenuntergänge von Monet zu sehen. Er ist mir sehr lichtvoll und meisterhaft vorgekommen - unanfechtbar. [...] Er ist wirklich ein großer Künstler." (Brief vom 5.5.1891, in: Camille Pissarro: Lettre à son fils Lucien, hg. v. John Rewald, Paris 1950, S. 237, zitiert in der Übersetzung bei Heinrich 2001, S. 13.)

49 Vgl. Heinrich 2001, S. 18.

50 Claude Monet an Gustave Geffroy, 7.10.1890, zitiert nach Geffroy 1922, S. 189.

51 Vgl. Görgen 2001, S. 47.

52 Vgl. Moffett 1984, S. 146. Aufgrund von Pentimenti wird angenommen, dass Monet mehrfach Korrekturen an Werken vorgenommen hat und diese bei weitem nicht so spontan entstanden sein können, wie von ihm beschrieben. Vgl. Hayes Tucker 1989, S. 89f. u. Moffett 1984, S. 147. 
Leinwänden hin- und hereilte, um die wechselnde Erscheinung des Motivs in einem bestimmten Moment einzufangen. ${ }^{53}$

Wie Christoph Heinrich ausführt, ist der Aspekt der enveloppe, der „Sphäre um den Gegenstand, eine Umhüllung aus sich in der Luft brechendem Licht ${ }^{\text {“54, }}$ noch bedeutender für die Serie der Getreideschober, da Monet, im Unterschied zu früheren Werken, die Faktur einheitlich jeweils einen „dichten Teppich aus atmosphärischen Nuancen" ${ }^{\text {"55 }}$ bilde. Die Getreideschober in ihrer relativ gleichmäßigen Beschaffenheit sind so zu Projektionsflächen und Anschauungsobjekten für Veränderungen von Licht und Schatten im Laufe der Zeit geworden, die den Gegenstand sekundär und letztlich austauschbar werden lassen. Entsprechend haben die Getreideschober weder eine politische noch eine sozialkritische Bedeutung, die ihnen sonst in der französischen Malerei des 19. Jahrhunderts beigemessen wurde. ${ }^{56}$

Boehm argumentiert, dass instantanéité und enveloppe nichts bezeichneten, „was im Bilde passiert, sondern eine Präsentationsform des Bildganzen eine Zeitigung des Bildes insgesamt sind. [...] Sie führ[en] alles Sichtbare als plötzlich und instabil vor, aber nicht im Sinne der Vergänglichkeit. Momentaneität meint auch nicht die Mitte zwischen Vergangenheit und Zukunft. Sie meint eine Zeit ohne Verlauf. Der Augenblick steht, er verewigt sich auf merkwürdige Weise. Die Fülle zeitlicher Irritationen über das ganze Bild hin mündet in Zeitlosigkeit, in den $\mathrm{Zu}$ stand der unendlichen Wiederholung des gleichen Augenblicks, in der Ruhe und Dauer allerdings nicht einkehren. "57 Folglich werden Fragilität und zeitliche Instabilität abgebildet, dabei aber keine Vergänglichkeit intendiert. Boehm nennt den dargestellten Moment auch „die stehende Sekunde, die sich unter den Bedingungen dieser Malerei ,verewigt'. " 58

Wichtig ist der Verweis auf die Bedeutung der Serie der Meules sowie der danach entstandenen Serien der Pappeln und der Kathedralen für die Entwicklung der abstrakten Kunst. In Bezug auf die Erklärung Wassily Kandinskys (1866-1944), er habe vor einem in Nahsicht gemalten Getreideschober Monets gestanden und zunächst das Motiv nicht erkannt, ${ }^{59}$ wird argumentiert, dass Monet durch die Nahsicht die Räumlichkeit der Bildanlage und die Plastizität des abgebildeten Gegenstandes hinter die Darstellung der Struktur des Getreideschobers und des Erdbodens, genauer: hinter die Faktur des Gemäldes gestellt habe, ${ }^{60}$ die „als licht-

\footnotetext{
53 Vgl. Wildenstein 2010, S. 275.

54 Heinrich 2001, S. 16.

55 Heinrich 2001, S. 16.

56 Vgl. Moffett 1984, S. 143.

57 Boehm 1988, S. 49.

58 Boehm 2017, S. 141.

59 Es soll sich um die Ausstellung der Impressionisten 1896 in Moskau handeln, bei der Meule au soleil, 1891, Öl auf Leinwand, 60 x 100 cm, Kunsthaus Zürich, W 1288, gezeigt wurde, vgl. Heinrich 2001, S. 20.

60 Vgl. Heinrich 2001, S. 20.
} 
volles, in horizontale Bänder eingespanntes Gewebe “61 eine eigene, gar übergeordnete Bedeutungsqualität erfahre. Boehm erkannte in Monets flirrender Malweise eine „Optik der latenten Unschärfe“62. Monet schaffe zwar Räumlichkeit und stelle die Landschaft und die Schober als solche klar erkennbar dar, gleichzeitig bleibe alles unscharf, einzelne Bildbereiche könnten nicht voneinander unterschieden werden. „Mit der Optik der Unschärfe verschwindet das Sujet nicht, aber es ist viel mehr Anlass als Ziel des Bildes. Das Sichvordrängen der malerischen Mittel [...] gibt dem Bild den Charakter einer Erscheinung [,impression"]. "“3 Bei Monets Bildern handele es sich nicht mehr um ,in sich geschlossene Gebilde [Einzelwerke] mit einem Zentrum kompositioneller, perspektivischer oder sonstiger Art. Es sind eher Konstellationen denn Kompositionen." ${ }^{46}$

Einen Schritt weiter ging Monet bei der anschließenden Serie der Pappeln, bei der er das Motiv der Baumreihe am Fluss zu einer regelmäßigen Gitterstruktur reduzierte. Die dabei entstandene „Matrix “65 ist laut Heinrich statisch und werde von Monets „lebendigem Pinselduktus umhüllt, und so werde die Naturstruktur zu einem Gitter, in dem sich die farblichen Nuancen des ständig verändernden Lichts verfangen. “66 Monet sei losgezogen, „um das unterschiedliche Licht vor dem Motiv

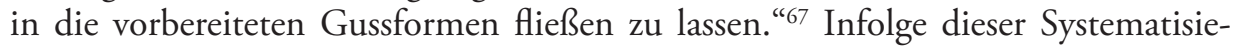
rung Monets entsteht der Eindruck, dass der abgebildete Gegenstand als Objekt an Bedeutung verliert und nur noch als - vermeintlich austauschbarer - Träger (,enveloppe“) der atmosphärischen Erscheinungen figuriert. Dies lässt sich in Steigerung auch bei den Kathedralbildern feststellen. Die Bedeutung der Kathedrale als religiöses Gebäude tritt dabei in den Hintergrund - Monet stellt das Kreuz nur sehr schemenhaft und zurückhaltend dar -, und die Fassade fungiert nunmehr als Folie für die Effekte des Lichts und der Atmosphäre. Der Kunstkritiker Léon Bazalgette (1873-1928) bezeichnet die Kathedralen in seinem Buch L'Esprit Nouveau von 1898 aus diesem Grund als „saine, franche, vitale, réaliste, vivante“"68; Monet habe das Gebäude als „fragment de nature, suivant la réalité, non suivant le dogme“69 aufgefasst. Monet zieht damit die letzten Konsequenzen aus den Zielen des Impressionismus; gegenüber der Erscheinung des Gegenstandes - ja dem Erscheinungshaften und dessen Bedingungen - rückt der Gegenstand selbst in die zweite Reihe, ohne aber ganz und gar preisgegeben zu werden. Aus diesem Grund schlussfolgerte Bazalgette hinsichtlich der Bedeutung Monets für die moderne Kunst: „S'il y a vraiment

\footnotetext{
Heinrich 2001, S. 20.

Boehm 2017, S. 140.

Boehm 2017, S. 141.

Boehm 2017, S. 141.

Heinrich 2001, S. 21.

Heinrich 2001, S. 21.

Heinrich 2001, S. 21.

Bazalgette 1898, S. 389.

Bazalgette 1898, S. 376.
} 
un art modern [...] un art qui se rattache à la pensée d'aujourd'hui, le peintre des cathédrales en est, à tous les points de vue, l'un des représentants. "70

Klein nennt die Serien der Getreideschober und der Pappeln aus etwas anderen Gründen ebenfalls „paradigmatic of the Modernist series [...] In these series, the artist's vision, will and personal experience generate the variations on the single unifying motif. There is no story or cycle. These modern series have neither beginning nor end. Their extension is potentially infinite, so any limits are arbitrary. Since there is no narrative or other progression, no particular sequence is prescribed." ${ }^{1}$ Daraus kann gefolgert werden, dass Monet durch die Vielzahl der Momente, die er fixiert, die Erfassung einer Totalität des Erscheinungshaften, die auf die Erfassung der Wirklichkeit „an sich“ abzielt, zu erreichen suchte.

Boehm kommt zu einem ähnlichen Ergebnis, wenn er feststellt, dass, „[w]enn sich die künstlerische Aufgabe nicht mehr mittels eines organischen [d.h. konventionellen] Bildgefüges stellen und - im Falle des Gelingens - auch lösen lässt, dann ist sie überhaupt nicht mehr auf einen einzigen Versuch zu beschränken und auf ein Ziel auszurichten. Sie muss [...] wiederholt werden. Das nächste Bild tritt in die gleiche Aufgabe ein und gibt ihr neuen Ausdruck. [...] Die Substanz des einzigen Werkes verwandelt sich in die Struktur einer Serie, deren Glieder durch Wiederholung verbunden sind."72

Als Monet das erste Mal über die Serie der Getreideschober schrieb, nannte er sie „une série d'effets“"73, die Bezeichnung „Meules“ setzte er nur ergänzend in Klammern dahinter. Dies veranschaulicht, worauf es Monet primär ankam: Effekte des Lichtes, nicht die Wiedergabe eines landwirtschaftliches Motivs. Neben dieser positivistischen Bedeutungsebene der „visible truths ${ }^{\text {“74 }}$ wies Monet allerdings auch darauf hin, dass er bei der Serie der Getreideschober ausdrücken wollte, was er fühle: „Enfîn je suis de plus en plus enragé du besoin de rendre ce que j’éprouve et fais [was ich empfinde]. "75 Es ist nicht einfach, zu bestimmen, was Monet damit ausdrücken wollte. Deutlich wird jedoch, dass er beabsichtigte, neben dem Sichtbaren eine subjektive Bedeutungsebene abzubilden. Es ist möglich, dass es sich bei der Augenblicklichkeit nicht nur um ein zeitliches Moment handeln sollte, sondern mehr um eine „extended perceptual experience reaching more widely [...] into the psychological structure of life. "76 Hayes Tucker zufolge verweist Monet mit dem Verb „éprouver“ auf eine „heightened awareness of knowledge and emotion that is

$\overline{70}$ Bazalgette 1898, S. 390. Hayes Tucker argumentiert, dass Bazalgette ein guter Freund Geffroys war und den Aufsatz mit ihm diskutiert haben könnte. Er schickte darüber hinaus eine Ausfertigung an Monet. Vgl. Hayes Tucker 1989, S. 296, dort Fußnote 59.

71 Klein 1998, S. 124.

72 Boehm 2017, S. 142.

73 Claude Monet an Gustave Geffroy, 7.10.1890, zitiert nach Geffroy 1922, S. 189.

74 Vgl. Moffett 1984, S. 145.

75 Claude Monet an Gustave Geffroy, 7.10.1890, zitiert nach Geffroy 1922, S. 189.

76 Moffett 1984, S. 145. Moffett zitiert seinerseits George Heard Hamilton: Claude Monet's Paintings of Rouen Cathedral, London 1960, S. $18 f$. 
stored in the depths of one's unconscious as well as to what one sees and feels in the present."

Auch Byvancks Äußerungen lassen auf seine subjektiven Erfahrungen während des Ausstellungsbesuchs schließen. Er erklärt mit Nachdruck, dass der Betrachter wegen der großen Vielfalt der dargestellten Farben ein Gefühl großer Freude empfinde. ${ }^{78}$ Gustave Geffroy setzt die Serie der Getreideschober ebenfalls mit Gefühlszuständen gleich. Zur Ausstellung der Meules bei Durand-Ruel war mit Genehmigung Monets ein Essay von ihm erschienen, der den Künstler „auch als Maler des Unsichtbaren, als Poeten einer höheren Realität feierte. " ${ }^{79}$ Geffroy erkennt im Hinblick auf die Pappeln und Monets Darstellung des beständigen Wechsels der Erscheinungen, die eine „Gesamtheit der Empfindungen" ${ }^{80}$ erzeuge, ein metaphysisches Element. Daraus folgert er, dass Monet beabsichtigt habe, „figurer par une arabesque le visage de l'univers, de réunir toutes choses dans la pure incandescence de la clarté solaire. “81 In seinem bedeutenden Vortrag „The decorative and the natural in Monet's Cathedrals" diskutiert Robert Herbert die Frage, ob Monet in den Kathedralbildern eine neue Form von Pantheismus präsentiere. ${ }^{82}$

Viele Beobachtungen, die Geffroy angesichts der Meules machte, decken sich mit den ein Jahr später aufgestellten Regeln des symbolistischen Manifests Albert Auriers. ${ }^{83}$ Es ist zwar überliefert, dass Monet keine Neigung zu kunsttheoretischen Reflexionen hatte, doch ist auch bekannt, dass er zumindest die symbolistischen Autoren, wie Stéphane Mallarmé (1842-1898) und Joris-Karl Huysmans (1848-1907), las und sich im Umfeld symbolistischer Künstler in Paris aufhielt. ${ }^{84}$ Infolgedessen kann festgehalten werden, dass die Meules „als Werkgruppe eine höhere Idee [vertreten], nämlich die eines Zusammenklangs des Universums und [sie] drücken diese Idee in einer klaren, einprägsamen Form aus - der Form der Serie, in der jedes Bild sich auf ein anderes bezieht und [sich] mit einem anderen vergleichen lässt. Sie sind subjektiv, denn der Gegenstand wird nicht als Objekt, sondern als eine Folge von subjektiv wahrgenommenen Zeichen betrachtet [...]. " ${ }^{85}$ Noll erkennt, dass sich „in den Serien ein wie auch immer im einzelnen bestimmter Glaube an eine ,kosmische Harmonie “" 86 ausdrücke. So ist laut Heinrich die Serie der Meules ein Wendepunkt im Werk Monets, mit der es ihm gelungen sei, seinen Kritikern zu beweisen, dass er nicht einem überkommenen,

\footnotetext{
$77 \quad$ Hayes Tucker 1989, S. 95.

78 W.G.C. Byvanck: Un Hollandais à Paris en 1891, in: Anatole France, Sensations de litérature et d'art, Paris 1892, S. 176. Hinweis auf diesen Aspekt bei Moffett 1984, S. 152.

79 Heinrich 2001, S. 19.

80 Im Original „le total de sensations“, Vgl. Geffroy 1922, S. 300.

81 Geffroy 1922, S. 300.

82 Vgl. Herbert 1984, S. 169.

83 Vgl. Albert Aurier: Paul Gauguin oder der Symbolismus in der Malerei, in: Mercure de France, Februar 1892.

84 Vgl. Moffett 1984, S. 150.

85 Heinrich 2001, S. $19 \mathrm{f}$.

86 Noll 1994, S. 130, dort Fußnote 639.
} 
positivistisch arbeitenden Impressionismus anhänge, sondern in der Lage sei, äußerlich Wahrnehmbares und gleichzeitig Emotionen und poetische Inhalte abzubilden. ${ }^{87}$

\subsection{Paul Cézanne und die Ansichten der Montagne Sainte-Victoire}

Augenblick der Ewigkeit. - Das Gebüsch war gelber Ginster, die Bäume waren vereinzelte braune Föhren, die Wolken erschienen durch Erddunst bläulich, der Himmel [...] war blau. Ich war stehengeblieben auf einer Hügelkuppe der Route Paul Cézanne, die von Aix-en-Provence ostwärts zum Dorf Le Tholonet führt. (Peter Handke, Die Lehre der Sainte-Victoire) ${ }^{88}$

Die Darstellung des östlich seiner Geburtsstadt Aix-en-Provence gelegenen und sich markant aus der Umgebung erhebenden Kalksandsteingebirges der Sainte-Victoire, dessen höchster Gipfel, der Pic des Mouches, eine Höhe von mehr als 1.000 Meter erreicht, sollte Paul Cézanne zunächst in unregelmäßigen Abständen und dann, in den letzten Jahren bis zu seinem Tode im Jahr 1906, immer intensiver verfolgen. Mit etwa 60 Versionen in unterschiedlichen Techniken gehört die Montagne Sainte-Victoire zu den Motiven in seinem Werk, denen sich Cézanne am häufigsten widmete. ${ }^{89}$ Im Unterschied zu dem auf etwa ein Jahr zu begrenzenden Entstehungszeitraum der Serien van Goghs und Monets entstanden Cézannes Werke über sein ganzes Leben hinweg und sind zudem nicht auf einen bestimmten Blickwinkel oder eine sich wiederholende Komposition festgelegt. Stattdessen „umkreiste“ Cézanne sein Motiv über Jahrzehnte und schuf Ansichten, die das Gebirge aus verschiedenen Himmelsrichtungen, von wechselnden Standorten, und aus unterschiedlichen Blickwinkeln und Entfernungen zeigen.

Cézanne begann sehr früh, sich für die hügelige Landschaft um Aix zu interessieren und stellte diese, nicht lange nach seiner Entscheidung, Künstler zu werden, um 1862 in der kleinen „plein air“-Ölskizze Paysage de la campagne d'Aix à la tour de César dar, die in ihrer Tonalität und mit den sanft geschwungenen Hügeln, den einzeln verstreuten Pinien und der lichten Atmosphäre deutliche Einflüsse Corots, aber besonders des Aixer Malers François-Marius Granet (1775-1849) aufweist, dessen Werke im örtlichen Musée Granet Cézanne seit Kindertagen kannte. ${ }^{90}$ Dort

87 Vgl. Heinrich 2001, S. 20.

88 Handke 1980, S. 10.

89 Insgesamt handelt es sich um ca. 60 Gemälde, Zeichnungen und Aquarelle, vgl. Boehm 1988, S. 25. Für die Zählung und Einordnung der Werke Paul Cézannes wurde John Rewalds Werkverzeichnis (Morton, Robert (Hg.): The Paintings of Paul Cézanne. A Catalogue Raisonné by John Rewald in Collaboration with Walter Feilchenfeldt and Jayne Warman, Bd. 1 (Textband) u. 2 (Abbildungen), New York 1996) verwendet („R“ Nummern).

90 Paul Cézanne (1839-1906), Paysage de la campagne d'Aix à la tour de César, um 1862, Öl auf Leinwand, 19 x 30 cm, Aix-en-Provence, Musée Granet, R 24. Vgl. für die Verbindung zu François- 
hatte er auch gesehen, dass Granet in einer Vielzahl seiner Landschaftsbilder im Hintergrund die Montagne Sainte-Victoire als Silhouette abgebildet hatte (vgl. Abb. 113b). ${ }^{91}$

Bereits in den Anfangsjahren malte Cézanne, wenn er aus Paris nach Aix zurückkehrte, häufig Landschaften, in denen die Montagne Saint-Victoire wie bei Granet im Hintergrund erscheint. Am 14. April 1878 hatte Cézanne an seinen Freund Émile Zola geschrieben: „Wenn man im Zuge am Landsitz von Alexis vorbeifährt, entfaltet sich gegen Osten ein begeisterndes Motiv: Saint-Victoire und die Felsen, die Beaurecueil überragen. Ich sagte: ,Welch ein schönes Motiv'[...]. ${ }^{\text {"92 }}$ Cézanne hatte sich in seiner Aussage wohl auf den Mont de Cengle bezogen, einem niedrigen Ausläufer auf der Südseite der Montagne Saint-Victoire, den er erstmals 1867-1870 mit den davor liegenden Fabrikgebäuden und einem Eisenbahndurchschnitt durch das Tal gemalt hatte. ${ }^{93}$

In Baigneurs au Repos von 1876-1877 stellt die in hellen Beige- und Grautönen gefasste Sainte-Victoire im Hintergrund eine Kulisse für die sich auf dem kräftigen Grün des Rasens im Vordergrund räkelnden Badenden dar (Abb. 109). ${ }^{94}$ Dem ähnlich ist Cézannes 1878-1879 entstandene Ansicht Vers la Montagne Sainte-Victoire (Abb. 110), die als eine der ersten die Sainte-Victoire - mit dem Mont de Cengle auf der rechten Seite - in dominierender Bildposition und mit freiem Bildvordergrund zeigt und damit als Auftakt jener Werke gelten kann, bei denen das Gebirge nicht mehr nur als Hintergrundmotiv fungiert, sondern zunehmend eine dominierende Position einnimmt. ${ }^{95}$

Nachdem Cézanne zwischen 1874 und 1877 mit den Impressionisten ausgestellt hatte, zog er 1881 zurück nach Aix, um seine eigene künstlerische Sprache zu entwickeln. Ungefähr zwei Jahre später entstand eine Ansicht vom Grundstück seiner Schwester aus, La Montagne Sainte-Victoire Vue de Bellevue (Abb. 111), das sich südwestlich von Aix, nahe dem väterlichen Anwesen „Jas de Bouffan“, befand. ${ }^{96}$ Von

Marius Granet Rewald 1996, Bd I, S. 72 u. Tompkins Lewis 2000, S. 46, die dessen Paysage de la campagne d'Aix (ca. 1840, Öl auf Leinwand, 27,2 x 35,1 cm, Aix-en-Provence, Musée Granet) nennt.

${ }_{91}$ Vgl. bspw. Francois-Marius Granet (1775-1849), Sainte-Victoire vue d'une cour de ferme au Malvalat, Datum unbekannt, Öl auf Leinwand, 33 x41 cm, Aix en Provence, Musee Granet.

92 Brief XLVII, 14.4.1878, P. Cézanne an Émile Zola, zitiert nach Rewald 1979, S. 151-152, S. 151.

93 Vgl. Rewald 1996, Bd. 1, S. 113 u. 264f. Paul Cézanne (1839-1906), Usines près du Mont de Cengle, 1867-1869, Öl auf Leinwand, 41 x 55 cm, Privatsammlung, R 132 u. La Tranchée avec la Montagne Sainte-Victoire (Der Bahndurchstich), um 1870, Öl auf Leinwand, 80,4 x 129,4 cm, München, Neue Pinakothek, R 156.

94 Paul Cézanne (1839-1906), R 261.

95 Paul Cézanne (1839-1906), Vers la Montagne Sainte-Victoire, 1878-79, Öl auf Leinwand, 45 x 53,3 cm, Barnes Foundation, Merion (Pennsylvania), R 397. Vgl. Rewald u.a. Bd I 1996, S. 265. Dittmann dagegen argumentiert, dass der Auftakt der Serie später erfolgt sei, mit dem Werk La Montagne Sainte-Victoire Vue de Bellevue, R 511.

96 Paul Cézanne (1839-1906), La Montagne Sainte-Victoire Vue de Bellevue, 1882-85, Öl auf Leinwand, 65 x 81,7 cm, Metropolitan Museum of Art, New York, R 511. 
dort hatte Cézanne einen freien Blick auf die Montagne Sainte-Victoire, vor der sich das Tal des Flusses Arc mit einem markanten Aquädukt ausbreitete. Cézanne inszenierte den Blick mithilfe von zwei sich wie zufällig für die Sichtachse öffnenden Bäumen auf den am Horizont liegenden Berg. In Anlehnung an die Prinzipien der Farbperspektive staffelte er den Tiefenraum: vorne mit akzentuiertem, vertikalschraffierendem Duktus die dunkelgrünen Blätter der flankierenden Baumkronen vor dem graublauen Himmel, im Mittelgrund ockerfarbene und hellgrüne Felder und Häuser mit beigefarbenen Dächern, hinter denen der Berg in stumpfem GrauBeige steil im Hintergrund aufragt und sich in der Ferne vor dem fast gleichfarbigen Himmel optisch kaum noch abheben kann. Durch diese Dunkel-Hell Staffelung und die zunehmende Unschärfe werden - trotz der gleichbleibend kräftigen Farbwerte - auch Anklänge an eine Luftperspektive sichtbar. Cézanne war bei dieser frühen Variante der Montagne Sainte-Victoire noch darauf bedacht, seinen Gegenständen mit dunklen Konturen eine bestimmte Form zu geben, wie beispielsweise den Baumstämmen, dem Aquädukt oder dem Berg. ${ }^{97}$

Ein ähnliches Ziel verfolgte Cézanne bei der wenig später entstandenen Ansicht Les Marronniers du Jas de Bouffan en Hiver, bei der die Sainte-Victoire nur schemenhaft im Hintergrund als grau-blaue Silhouette hinter den im Garten des väterlichen Hauses in zwei Reihen stehenden Kastanienbäumen erkennbar ist (Abb. 112). Wieder arbeitete Cézanne mit den Mitteln der Farbperspektive, um Räumlichkeit zu erzeugen. Die im Vordergrund verlaufende Allee der Bäume mit ihren dunklen Stämmen und Ästen hebt sich deutlich von den dahinterliegenden winterlichen Grau- und Blautönen des Himmels und der Sainte-Victoire ab. Zugleich bedeutet deren bildparalleler Verlauf einen Verzicht auf die Erschließung des Bildraumes; vielmehr verklammern die bis zum Bildrand aufsteigenden Stämme alle Raumzonen und binden sie an die Bildfläche. Cézanne will Raum und Fläche verbinden; Raum soll evoziert werden, zugleich aber die Bildfläche nicht illusionistisch negiert sein.

Bereits deutlich abstrahierter ist die zwischen den Jahren 1896-98 entstandene Variante aus der St. Petersburger Eremitage (Abb. 115), welche den Berg von der Route du Tholonet aus, nahe des in der Region bekannten Château Noir, zeigt. ${ }^{98}$ Mehr noch als bei vorherigen Ansichten rückt Cézanne den Berg näher an den Betrachter heran; der Berg erstreckt sich dadurch dominierend über die gesamte Bildbreite. Cézanne gestaltet die Landschaft nun weniger noch als zuvor in naturalistischer Weise. Die leuchtenden Farben - das Ocker des Hangs im Vordergrund, das helle Graublau des Bergs und die Grüntöne der Vegetation - ergeben starke Kontraste. Zudem verwendet er einen gleichmäßig dünnen Farbauftrag und

${ }_{97}$ Vergleichbar mit diesem Werk sind aufgrund des Blickwinkels, der rahmenden Vegetation, des Farbschemas und Abstraktionsgrades beispielsweise die Varianten La Montagne Sainte-Victoire au Grand Pin, 1886-87, Öl auf Leinwand, 66 x 90 cm, The Courtauld Institute, London, R 599 und La Montagne Sainte-Victoire, um 1890, Öl auf Leinwand, 62 x 92 cm, Musée d'Orsay, Paris, R 698.

98 Paul Cézanne (1839-1906), La Montagne Sainte-Victoire au dessus de la Route du Tholonet, 1896-98, Öl auf Leinwand, 78 x 98 cm, Eremitage, St. Petersburg, R 899. 
vielfach parallelisierte Pinselstriche, die von der Struktur der dargestellten Gegenstände abstrahieren, und zwischen denen an manchen Stellen die weiße Leinwand sichtbar bleibt; beispielsweise werden die Büsche und Baumkronen nur noch mit nebeneinander gesetzten, unterschiedlichen Farbfeldern („Modulen“) angedeutet. ${ }^{99}$ In gleicher Weise bildet Cézanne die Abstufungen des Berges durch gleich gerichtete Pinselstriche in dunkleren Blautönen sowie vereinzelt mit dünnen Konturen ab.

Nach der Jahrhundertwende entstanden verschiedene Ansichten nördlich von Aix, von Les Lauves aus, wo sich Cézanne nach 1902 ein Atelier errichten ließ. Der Blick öffnet sich von dort aus weit über das Tal, an dessen Horizont die Montagne Sainte-Victoire trapezförmig emporsteigt. ${ }^{100}$ Die Werke, die Cézanne in seinen letzten Jahren vom Berg malte, zeigen deutliche Veränderungen zu den in den zwei Jahrzehnten vorher entstandenen Varianten. Der Blick ist jetzt frei auf den Berg: ohne rahmende Bäume, Figuren oder Architektur. Alles Nebensächliche wird ausgespart. Der Berg ragt aus der flachen Umgebung hervor und ist zum unbestrittenen Protagonisten avanciert. Konnte bei dem Werk in St. Petersburg (Abb. 113) noch relativ zweifelsfrei die Bedeutung der einzelnen Farbflächen bestimmt werden, so löst Cézanne diesen Zusammenhang zunehmend auf. Einhergehend mit einer deutlich dunkleren und kostrastreicheren Farbpalette gestaltet er nun ausschließlich fragmentarische, abstrahierte Farbflächen, die nur noch im Gesamteindruck die abgebildete Landschaft konstituieren. Cézanne bezeichnete diese Farbflächen als „taches“101. In freier Übertragung des wahrgenommenen Natureindrucks durchziehen dunkle schraffierte Farbflecken die Landschaft; das Grün der Felder und Bäume findet seine Entsprechungen in grünen Schraffuren im Himmel (vgl. Abb. 114 u. 115). ${ }^{102}$

Durch die Aufzeichnungen Émile Bernards ist überliefert, was Cézanne mit der Verwendung der Farbflecken beabsichtigte: „Die Natur lesen, heißt, sie durch den Schleier der Interpretation mittels farbiger Flecken sehen, die nach einem Harmoniegesetz aufeinander folgen. Diese großen Mischfarben lassen sich durch die Modulation analysieren." 103

Ist der Bildeinstieg bei der Variante aus dem Nelson Atkins Museum in Kansas ${ }^{104}$ noch eindeutig über die Wiese im Vordergrund möglich, mit einer daran anschließenden klaren Staffelung des Tiefenraums - obwohl nur über die Farb-, nicht die Linearperspektive -, wird der Aspekt der Dreidimensionalität und einer plausiblen räumlichen Struktur zunehmend vernachlässigt: Der Vordergrund ist bei der Baseler Version (Abb. 114) in einer scheinbar chaotischen Auflösung begriffen. Das Grün -

\footnotetext{
99 Vgl. zur „Modulation“ bspw. Kurz 2003, S. 150.

100 Vgl. Dittmann 2005, S. 116.

101 Cézanne nach Joachim Gasquet, , in: Conversations avec Cézanne, Paris 1978, S. 109.

102 Bspw. Paul Cézanne (1839-1906), Le Mont Sainte-Victoire vu des Lauves, 1902-6, Öl auf Leinwand, 63,5 x $83 \mathrm{~cm}$, Zürich Kunsthaus, R 916.

103 Cézanne nach Emile Bernard, in: Gespräche mit Cézanne, Zürich 1982, S. 54. Auf dieses Zitat verweist Kurz 2003, S. 120.

104 Paul Cézanne (1839-1906), Le Mont Saint-Victoire vu des Lauves, 1902-6, Öl auf Leinwand, 65 x 81,3, Nelson Atkins Museum of Art, Kansas City, R 913.
} 
wo handelt es sich um Bäume, wo um Felder? - erstreckt sich nicht mehr nur in der Ebene vor dem Berg, sondern hat jetzt auch den Himmel erreicht, so dass sich diese zwei Zonen vereinigen. Zudem erstrahlt der Berg wie ein angeleuchteter Saphir im leuchtenden Blau des Himmels, das in kleinen bläulichen Farbflächen in den Bildvordergrund herabzuregnen scheint und damit die Gliederung der Bildgründe vollends aufhebt. ${ }^{105}$ Cézanne erklärte diesen Vorgang mit der Notwendigkeit, „in unsere durch die roten und gelben Farbtöne wiedergegebenen Lichtvibrationen eine genügende Menge von Blau zu mischen, um die Luft fühlbar zu machen. "106 Anders als die Impressionisten wollte er jedoch damit nicht die atmosphärische Erscheinung des Gegenstands darstellen, sondern den Gegenstand, die Natur - den Berg - selbst.

Das Werk aus dem Puschkin-Museum - mutmaßlich eine der letzten Ansichten aus Les Lauves - zeigt in leichter Variation ebenfalls die Auflösung einer geordneten Struktur im Vordergrund und die Verbindung der - gegenständlich zu unterscheidenden - verschiedenen Bildebenen in der Fläche (vgl. Abb. 114): Die aus ihrem ursprünglichen Zusammenhang gelösten grünen Farbfelder aus dem Vordergrund finden sich wie bei der Baseler Variante auch hier sowohl am Berg als auch im Bereich des Himmels wieder. ${ }^{107}$ So verbindet der Berg, bestehend aus den jeweiligen Farbfeldern der umgebenden Bereiche, die verschiedenen räumlichen Ebenen, und Cézanne gelingt die angestrebte „Vergegenwärtigung einer übernatürlichen Einheit aller Dinge der Natur, der Bäume, der Ebene, des Berges, des Himmels [...]. " ${ }^{108}$

Cézanne folgte dem Paradigma der Impressionisten - einer Malerei vor dem Motiv -, doch unterscheidet er sich grundlegend von den Impressionisten in seinen Zielen. Wie verschiedentlich überliefert, wollte er „aus dem Impressionismus etwas Solides und Dauerhaftes" ${ }^{109}$ machen, indem er bei einem Sujet wie dem des Berges die Darstellung des flüchtigen Augenblicks überwand. Sein Ziel war jedoch nicht, „die flüssige impressionistische Bildform einzufrieren. “110 Vielmehr strebte er nach einer Synthese zwischen Veränderung und Dauer als die zwei Seiten des gleichen sichtbaren Sachverhalts an. ${ }^{11}$ Dass dabei die Wahl auf einen Berg fiel, war kein Zufall, steht dieser doch wie kaum etwas anderes für Massivität, Permanenz, Unbeweglichkeit und Unveränderlichkeit, aber gleichzeitig in seinem geologischen Entstehungsprozess auch für das genaue Gegenteil: große Turbulenzen, Eruptionen,

105 Paul Cézanne (1839-1906), Le Mont Saint-Victoire vu des Lauves, 1904-6, Öl auf Leinwand, $60 \times 72 \mathrm{~cm}$, Kunstmuseum Basel, R 931.

106 Brief CXCIV, 15.4.1904, P. Cézanne an Émile Bernard, zitiert nach Rewald 1979, S. 280 - 281, S. 281.

107 Paul Cézanne (1839-1906), Le Mont Saint-Victoire vu des Lauves, 1904-6, Öl auf Leinwand, 60 x $73 \mathrm{~cm}$, Puschkin-Museum, Moskau, R 932.

108 Vgl. Dittmann 2005, S. 116.

109 Cézanne wenige Monate vor seinem Tod zu Maurice Denis, zitiert nach: Doran, Michael (Hg.): Gespräche mit Cézanne, Zürich 1982, S. 207.

110 Boehm 1988, S. 52.

111 Vgl. Boehm 1988, S. 52. 
Auffaltungen, Brüche und nicht zu bändigende Naturgewalten. ${ }^{112}$ Dabei haben in Cézannes Malprozess die für Monet noch grundlegenden zeitlichen Determinanten der instantanéité, aber auch der enveloppe, keine Bedeutung mehr, da Cézanne bewusst auf Merkmale der Augenblicksbestimmung - beispielsweise die Angabe der Tageszeit oder der Witterung durch entsprechendes Licht - verzichtete.

Während Monet eher gleichmäßig feine - häufig als „Hlirrend“ bezeichnete Pinselstriche - bei einem körnigen, pastosen Farbauftrag - einsetzte, die sich in der Summe zum Bildgegenstand formen, dadurch ihrerseits undifferenzierbar werden und der „Landschaft den Charakter einer Erscheinung " ${ }^{113}$ verleihen, hat Cézannes breiterer und flächenhafterer Duktus - sein Arrangieren von Farben in Modulen - eine völlig gegensätzliche Körperlichkeit und Formgebung zur Folge. Cézannes Farbflecken ergeben zwar auch erst in der Gesamtheit das Bild einer Landschaft, doch sind sie gröber und massiver und verbinden sich nie ,zugunsten der Dichte eines farbigen Schleiers, " ${ }^{114}$ vielmehr bleiben sie als einzelne Farbflächen unterscheidbar und in ihrer Materialität und Individualität wahrnehmbar.

Cézannes Haltung zur Natur wird anhand zweier Bemerkungen deutlich, die aus Gesprächen mit seinem Freund, dem Schriftsteller Joachim Gasquet (18731921), überliefert sind: „Die Natur ist nicht an der Oberfläche. “ Und: „Die Natur ist immer dieselbe aber von ihrer sichtbaren Erscheinung bleibt nichts bestehen. "115 Aus diesem Grund wollte Cézanne die Natur „durch sorgfältige Arbeit erkennen lernen, ihr Wesen mit den Mitteln der Malerei erforschen“116, sie „realisieren“, wie er sein Vorhaben nannte. Wie Bertram Schmidt ausführt, hatte Cézanne das Verständnis von „Realisierung“"von Delacroix übernommen und es ist gekennzeichnet durch drei wichtige Charakteristika: „1. Die Realisierung hat ein unerreichbares Ziel. 2. Der kontinuierliche Fortschritt in der Arbeit des Malers wird gerade durch die Unerreichbarkeit des Zieles ermöglicht. 3. Der Maler kann und muß von seinem Verlangen, das Ziel zu erreichen, also von seiner Arbeit, besessen sein." ${ }^{117}$

Dabei war sich Cézanne auch bewusst, dass die Wirklichkeit, d.h. die Natur oder das Modell, nicht kopierbar war und sie „aus den Möglichkeiten der Malerei neu erzeugt werden “118 mussten. Das Motiv, so formuliert Boehm treffend, sei „eine Manifestation dieses Prozesses, Ergebnis, nicht Ausgangspunkt der Malerei. Ge-

112 Die Sainte-Victoire hatte zudem für Cézanne aufgrund seiner eigenen intensiven emotionalen Verbindung zu seiner heimatlichen Provence, aus der der Berg so prominent als Monolith herausragt, eine besondere Bedeutung. Im Angesicht des permanenten Wandels, dem das Leben unterworfen ist, strahlte der Berg auf Cézanne Ruhe und Beständigkeit aus.

113 Boehm 1988, S. 47.

114 Boehm 1988, S. 51.

115 Zitiert nach Gespräche mit Cézanne, Zürich 1982, S. 136 u. S. 153. Auf dieses Zitat verweist Boehm 1988, S. 98.

116 Boehm 1988, S. 43. Es ist wichtig, dass Cézanne sich mit seiner Malerei mit der Wirklichkeit auseinandersetzen und dies nicht nur auf ästhetische Lösungen beschränken wollte. Vgl. Boehm 1988, S. 118.

117 Schmidt 2004, S. 124. Hier auch der Hinweis auf Delacroix.

118 Boehm 1988, S. 118. 
hörte zu [... der Landschaftsmalerei] stets die reale oder ideale Ansicht, der Blick auf die Oberfläche der Dinge mit dem Ziel der Schilderung charakteristischer Eigenschaften, so zeigt uns die Montagne ganz im Gegenteil, daß die Natur nichts ist, was schon vorliegt, sondern etwas, das sich bildet, das ,wird', wenn es Dasein beansprucht." 119

Cézanne wollte zunächst das Sichtbare vor seinen Augen abbilden - nicht Metaphysisches oder Allegorisches -, zugleich aber suchte er die Landschaft mit seinen eigenen Mitteln neu aufzubauen und dabei auszudrücken, was er empfand. In einem Brief schrieb er: „Im Maler gibt es zwei Dinge: das Auge und das Gehirn, beide müssen sich gegenseitig helfen: Man muß an ihrer gegenseitigen Entwicklung arbeiten; am Auge durch das Sehen nach der Natur, am Gehirn durch die Logik der geordneten Empfindungen, welche die Ausdrucksmittel liefert. "120 Martina Kurz schreibt in diesem Zusammenhang von der „dialektische[n] Spannung der Bildgenese Cézannes“, die dadurch zum Ausdruck komme, dass „,[d]as künstlerische Subjekt mit seinen individuellen Empfindungen, [...] diese Empfindungen [zugleich auch] zu objektivieren und vor allem zu ordnen versucht." 121

An den jungen Schriftsteller Louis Aurenche (1877-1952?) schrieb Cézanne Anfang 1904, dass „ein starkes Empfinden für die Natur [...] die notwendige Grundlage aller künstlerischen Gestaltung [... ist und, dass] die Kenntnis der Mittel, unsere künstlerische Empfindung zum Ausdruck zu bringen, nicht weniger wesentlich ist und [...] sich nur durch sehr lange Erfahrung erwerben läßt. " ${ }^{222}$ Das Erlangen dieser Erfahrung und der entsprechenden Fähigkeiten war nur auf dem harten Weg der wiederholten Beschäftigung mit dem gleichen Motiv möglich, wie er Bernard wenig später mitteilte: „Ich arbeite sehr langsam, da die Natur sich mir sehr vielgestaltig darbietet und es unablässig gilt, Fortschritte zu machen. Man muß sein Modell gut betrachten und sehr richtig empfinden und sich außerdem noch mit Kraft und Gewähltheit ausdrücken. " ${ }^{123}$ Wenige Wochen später wiederholte er diese Maxime in einem weiteren Brief an Bernard: „Man muß das, was man vor sich hat, durchdringen und beharrlich fortfahren [...]." ${ }^{124}$ Im Oktober 1904, etwa ein halbes Jahr später, hatte seine Bemerkung an den französischen Maler Charles Camoin (1879-1965) bereits einen leichten Beigeschmack von Resignation: „Das Erfassen des Modells und seine Realisierung gelingen dem Künstler manchmal nur sehr langsam." 125

\footnotetext{
119 Boehm 1988, S. 101.

120 Zitiert nach Gespräche mit Cézanne, Zürich 1982, S. 54. Auf dieses Zitat verweist Kurz 2003, S. 149.

121 Beide Zitate hier aus Kurz 2003, S. 149.

122 Brief CXCII, 25.1.1904, P. Cézanne an Louis Aurenche, zitiert nach Rewald 1979, S. 279.

123 Brief CXCV, 12.5.1904, P. Cézanne an Émile Bernard, zitiert nach Rewald 1979, S. 281-282, S. 282.

124 Brief CXCVI, 26.5.1904, P. Cézanne an Émile Bernard, zitiert nach Rewald 1979, S. 283.

125 Brief CCII, 11.10.1904, P. Cézanne an Charles Camoin, zitiert nach Rewald 1979, S. 287.
} 
Paul Cézanne verstarb am 22. Oktober 1906 in Aix. Gute sechs Wochen vorher hatte er seinem Sohn Paul gestanden, „daß bei mir die Realisierung meiner Empfindungen immer sehr mühselig ist. Ich kann nicht die Intensität erreichen, die sich mir vor meinen Sinnen entwickelt, ich besitze nicht jenen wundervollen Farbenreichtum, der die Natur belebt. " ${ }^{126}$ Noch eine Woche vor seinem Tod bestellte er bei seinem Sohn ,zwei Dutzend Marderhaarpinsel“127 und beschwerte sich am 17. Oktober schriftlich bei einem Farbenhändler über eine ausbleibende Lieferung und forderte „[e]ine Antwort bitte, und zwar schleunigst schnell!“"128

Aus dem Verständnis, dass das Sehen und die „Realisierung“ der Natur trotz intensiven Ringens niemals abgeschlossen waren, dass in diesem unerreichbaren Ideal jedoch die Motivation lag, sich immer weiter dem Ziel anzunähern, folgte für Cézanne „die wiederholte Rückkehr zum gleichen optischen Sachverhalt, [die] Arbeit in Werkgruppen und Serien" ${ }^{129}$. Es bedeutete dies über Jahrzehnte eine Rückkehr zum immer gleichen Motiv, die sich nicht nur in 34 Versionen in Öl auf Leinwand niederschlug, sondern auch in 26 Zeichnungen und Aquarellen. ${ }^{130}$

\subsection{Vergleich der Serien}

Die Untersuchungen haben gezeigt, dass van Gogh, Monet und Cézanne sich wiederholt mit Landschaftsmotiven auseinandersetzten, die für sie einen wichtigen persönlichen Stellenwert besaßen: van Gogh, der sich als „Bauernmaler“131 sah, mit dem sich wandelnden Kornfeld vor seinem Anstaltszimmer, Monet mit den Getreideschobern auf dem Feld neben seinem Haus in Giverny und Cézanne mit der Montagne Sainte-Victoire, jenem Motiv, das ihn lebenslang beschäftigte.

Ein erstes wichtiges Kriterium für den Vergleich ist das Verständnis der verschiedenen Ansichten als Serien sowie die Verknüpfung der Werke miteinander, die sich trotz gewisser Parallelen bei van Gogh, Monet und Cézanne grundlegend unterscheiden. Van Gogh stellte im Laufe des Jahres in Saint-Rémy in immer neuen Varianten das gleiche Feld dar, indem er den Blickwinkel, das Gefälle, die Beschaffenheit der Mauer, die Figuren, d.h. die Staffage, die Wiedergabe der Tages- und

126 Brief CCXXIII, 11.10.1904, P. Cézanne an seinen Sohn Paul, zitiert nach Rewald 1979, S. $304-$ 305, S. 304.

127 Brief CCXXXI, 15.10.1906, P. Cézanne an seinen Sohn Paul, zitiert nach Rewald 1979, S. 312 313, S. 312.

128 Brief CCXXXII, 17.10.1906, P. Cézanne an einen Farbenhändler, zitiert nach Rewald 1979, S. 313. Aus den Aufzeichnungen von Cézannes Schwester Marie geht hervor, dass der Maler kurz danach trotz Regens über Stunden im Gelände geblieben war, um zu malen und, nachdem er dort voller Erschöpfung zusammengebrochen war, auf einem Wäschereikarren nach Hause gebracht werden musste und schließlich zwei Tage später starb. Vgl. Brief 20.10.1906, Marie Cézanne an den Sohn Paul, nach Rewald 1979, S. 313.

129 Boehm 1988, S. 27. Vgl. auch Schmidt 2004, S. 124 für die Begriffsbedeutung der „Realisierung“.

130 Vgl. Boehm 1988, S. 25.

131 Brief 493/400, Nuenen, 13.4.1885, an Theo, zitiert nach Erpel 1965, Bd. 3, S. 246-248, S. 247. 
Jahreszeiten sowie das Wetter, aber auch den Pinselduktus, die Leinwandgröße und das Format variierte. In der Literatur werden die Ansichten des ummauerten Feldes trotz allem - wohl in Ermangelung einer allgemein gültigen Definition von Bilderserien - häufig einfach als Serie zusammengefasst. ${ }^{132}$ Dies allein wird den Werken jedoch nicht gerecht - zumal auch van Gogh selbst nicht den Begriff der Serie für das ummauerte Feld verwendete, möglicherweise, weil ihm der Terminus Ende der 1880er Jahre eher im Sinne der impressionistischen Bilderreihe vertraut war. Ein Brief an seinen Bruder, geschrieben in Saint-Rémy im September 1889, deutet in etwa auf das, was Monet gute anderthalb Jahre später bei den Getreideschobern hinsichtlich der Effekte des Lichtes zu erreichen suchte. Van Gogh berichtete Theo von einer Studie, die er von einer Felsenschlucht in den Alpillen angefertigt hatte und dass er sicher sei, davon eine ganze Serie anfertigen zu können, um die Lichteffekte auf den Bäumen und Felsen im Sonnenuntergang - „ganz violett" - festzuhalten. ${ }^{133}$ Dies entspricht seinen Äußerungen im Vorjahr in Arles, wo er in Briefen an Theo bei den Bildern blühender Obstgärten mehrfach von zusammenhängenden „Serien“134 geschrieben hatte. Dabei spielte für van Gogh der Umstand, dass es sich um eine Station im Jahreskreis handelte, den er ebenfalls abbilden wollte, bei der Klassifikation als Serie eine größere Rolle als die Farbigkeit der Werke.

In einer kritischen Abwägung der verschiedenen Definitionsversuche von serieller Kunst lassen sich van Goghs Ansichten des ummauerten Feldes klassifizieren. Die einzelnen Werke zeigen zwar alle das gleiche Sujet und erfüllen, bei aller gegebenen Variation, demnach Boehms Maßgabe, „dass sich eine Serie von Bildern durch ein gemeinsames Thema ausbilde[... $]^{“ 135}$. Gleichzeitig weist Boehm aber auch darauf hin, dass es wichtig sei, den Unterschied zwischen Variationen eines Themas und Wiederholungen zu verstehen. „Variationen haben untereinander keinen direkten Bezug, sondern sie beziehen sich untereinander nur dadurch, dass sie am gleichen Thema partizipieren. Spricht man dagegen von Iteration [,Wiederholung“], so ist damit ausdrücklich die Verbindung gemeint, welche die Glieder einer Serie vereint. "“136 Boehms Ansatz lässt sich sehr gut auf van Gogh übertragen. Das übergeordnete Thema ist der Jahreskreis, der sich an dem ummauerten Feld vor van Goghs Fenster manifestiert, an dem alle Werke partizipieren und der ihn zu monatlichen Variationen des gleichen Sujets anregte. Dadurch, dass van Gogh jedoch viele An-

132 So beispielsweise im Katalog der Ausstellungen in Bremen und Basel.

133 Vgl. Brief 810/610, Saint-Rémy, ca. 8.10.1889, an Theo, zitiert nach Erpel 1965, Bd. 4, S. 332 334, S. 333. Bei dem entsprechenden Werk handelte es sich um Felsenschlucht, 1889, Öl auf Leinwand, 73 x $92 \mathrm{~cm}$, Boston, Museum of Fine Arts, F 662, JH 1804. Zu diesem Vorhaben sollte es jedoch nicht mehr kommen.

134 Vgl. Brief 601/479, Arles 25.4.1888, an Theo, zitiert nach Erpel 1965, Bd. 4, S. 31-33, S. 32 sowie Brief 608/486, Arles, 10.5.1888, an Theo, zitiert nach Erpel 1965, Bd. 4, S. 45- 46, S. 46. Auf beide Briefe weist Zimmer 2009, S. 107 hin.

135 Boehm 2017, S. 143. Es handelt sich hier um einen Sammelband von Aufsätzen Boehms. Der Aufsatz erschien zuerst 1988 und wird immer wieder zitiert, bspw. bei Heinrich 2001, S. 7-12.

136 Boehm 2017, S. 143. 
sichten vom gleichen Standpunkt aus malte, weisen diese beispielsweise hinsichtlich der Komposition auch iterative Elemente auf, die auf eine Auffassung als Serie verweisen können.

Ähnlich wie Coplans und Boehm argumentiert Annabelle Görgen, dass den Bildern (oder Bildelementen) einer Serie „eine durchschaubare Struktur innewohnen muss, die sich im nächsten Angang wiederholen [... lässt]. " Diese durchschaubare Struktur ist zweifelsohne das ummauerte Feld. Wichtig sei dabei laut Görgen, dass „die Wiederholung [...] nicht nur additiv [geschieht], Bildelemente können [vielmehr] regelmäßig abgewandelt wiederkehren, bis hin zu ihrem Gegensatz. ${ }^{\text {"137 Mit }}$ dieser Erklärung kommt Görgen der Definition von Kopien aus dem Dictionnaire de l'Académie des Beaux-Arts, ${ }^{138}$ die van Gogh mit großer Wahrscheinlichkeit kannte, sehr nahe, wo primär unter Kopien jene zusätzlichen Versionen eines Werkes zu verstehen sind, die durch den gleichen Künstler als Variationen nach seinem eigenen Werk gemalt wurden und im französischen als „répétitions“ bezeichnet werden. Entscheidend ist, dass sich jede weitere Version von der Ursprungsfassung unterscheidet. Der Begriff „répétition“ war zum ersten Mal in zwei Briefen van Goghs an seinen Bruder im April 1888 gefallen, als er Theo wissen ließ, dass er gerne weitere Versionen zweier neuer Werke erstellen wollte. Zu dieser Zeit war van Gogh damit beschäftigt, den Jahreskreis der Natur anhand mehrerer Bilderserien abzubilden und wendete viel Energie auf die Darstellung der blühenden Obstbäume auf. ${ }^{139} \mathrm{Zu}$ sammen können diese Wiederholungen des gleichen Sujets eine Serie konstituieren.

In Hinblick auf die von van Gogh verwendete Terminologie war es auch wichtig, zu verstehen, dass zumindest in Saint-Rémy die von ihm als „répétitions“ seiner eigenen Werke bezeichneten Bilder Ergebnis eines künstlerisches Konzepts waren, das ihm die Möglichkeit der Revision seiner eignen Werke erlaubte. Daraus hatte sich die auch bei den Ansichten des ummauerten Feldes angewandte Begriffstrias „étude“ - „tableau“ - „reduction“ für seine Wiederholungen entwickelt. Die zusätzlichen Fassungen von Kornfeld, der Schnitter aus Saint-Rémy ermöglichten es, durch die jeweiligen Änderungen van Goghs gestalterische Absichten besser nachzuvollziehen.

In ihrem Aufsatz verweist Görgen zudem, wie bereits von John Klein aufgezeigt, auf den Aspekt der Temporalität seriellen Arbeitens, denn der „periodische Wechsel in der Zeit setzt Rückblick und Vorschau voraus. Er führt zum Rhythmus, einer

137 Beide Zitate Görgen 2001, S. 45.

138 „Les copies [...] sont là de simples répétitions, reconaissables souvent à quelque variante qu’y a introduite à dessein le maître lui-même.“ „copie“, in: Dictionnaire de l'Académie des Beaux-Arts, Bd. 4, Paris 1884, S. 262-265. Vgl. auch Mainardi 2000, S. 63.

139 Vgl. Brief 595/476, Arles, 11.4.1888, an Theo, nach Erpel 1965, Bd. 4, S. 27-28, S. 27 sowie Brief 597/477, Arles, 13.4.1888, an Theo, nach Erpel 1965, Bd. 4, S. 28-29, S. 28. Bei den Werken handelte es sich um Die Brücke von Langlois, 1888, Öl auf Leinwand, 53,4 x 64 cm, Otterlo, Kröller-Müller Museum, F 397, JH 1368 u. Blühender Pfirsichbäum (Souvenir de Mauve), März 1888, Öl auf Leinwand, 73 x 59,5 cm, Otterlo, Kröller-Müller Museum, F 394, JH 1379. 
gleichmäßig gegliederten Bewegung, deren Gestalt eine Ordnung bildet. "140 Auch John Kleins Definition von Serien, die explizit den Aspekt des Allegorischen und der zyklischen Darstellungen erwähnt, war in dieser Hinsicht hilfreich. „The traditional agent of unity in a series of paintings is the subject matter, the traditional form of this agency is liturgical, narrative, allegorical, or cyclical, among other iconographic frameworks. Each of these frameworks has an internal logic, so that the meaning of the individual works in a series is mutually reinforcing. "141 Bei Van Gogh leitet dieser Gedanke auf den Jahreskreis des Feldes vor seinem Fenster über. Es handelt sich bei den Ansichten des ummauerten Feldes nicht bloß um additive Elemente einer Reihe ohne „Zielbild“142, sondern vielmehr um einen geschlossenen Zyklus, geprägt durch Interkonnektivität in Inhalt und Struktur, in dem bereits jedes einzelne Werk die Funktion eines vollwertigen Zielbildes - der Repräsentation einer Station im Jahreskreis - übernimmt. Besonders deutlich ist dies bei jenen Ansichten mit Figuren geworden, die auf Gleichnisse verweisen. Die einzelnen Ansichten fügen sich darüber hinaus in ihrer Gesamtheit zu einem Kreislauf zusammen. Die Abbildung des Jahreskreises der Natur anhand des Kornfeldes vor van Goghs Fenster stellt damit eine klar strukturierte, zyklische Serie dar, in der die einzelnen Bilder, in ihrer Funktion als Repräsentation einzelner Stationen im Jahreskreis, miteinander korrespondieren und zusätzlich in der Summe ,a differentiated whole “143 ergeben. ${ }^{144}$

Einzig Monet äußerte sich zu seinen Ansichten der Getreideschober dezidiert als geschlossene Serie. Deutlich wurde dies anhand des von ihm für die Ausstellung bei Durand-Ruel ausgearbeiteten Konzeptes, das darauf abzielte, dem Betrachter ein Ganzes zu vermitteln, das sich aus den Einzelteilen konstituiert. ${ }^{145}$ So verliert das Einzelbild zugunsten des Gesamteindrucks an Bedeutung. Boehm konstatiert, dass es sich bei Monets Getreideschobern nicht mehr um „in sich geschlossene Gebilde [Einzelwerke] mit einem Zentrum kompositioneller, perspektivischer oder sonstiger Art [handelt]. Es sind eher Konstellationen denn Kompositionen [...]." ${ }^{146}$

Cézannes Werke werden zwar ebenfalls aufgrund des gleichen Bildgegenstands als Serie verstanden, doch ist ihre Verknüpfung untereinander durch ihren über mehrere Jahre andauernden Entstehungsprozess und die wechselnden Blickwinkel auf den Berg und die stilistischen Veränderungen hin zu der Malerei in „taches“

\footnotetext{
140 Görgen 2001, S. 45.

141 Klein 1998, S. 123.

142 Boehm 2017, S. 138.

143 Coplans 1968, S. $10 \mathrm{f}$.

144 Auch durch van Goghs weit gefasstes Verständnis hinsichtlich übergeordneter Werkzusammenhänge - sei es über das Motiv, das Format, die Komposition oder die Farbigkeit - das ihn beispielsweise Kornfeld, Sonnenaufgang sowohl als Gegensatz zu Irrenhausgarten in Saint-Rémy als auch für das Polyptychon für die Ausstellung in Brüssel auswählen ließ, behaupteten die Werke ungeachtet der Einbettung in den Zyklus des Jahreskreises ihren Einzelcharakter deutlicher als die sich inhaltlich und formal stark ähnelnden Werke Monets.

145 Vgl. Heinrich 2001, S. 18.

146 Boehm 2017, S. 141.
} 
wesentlich ungebundener. Wichtigste Klammer ist Cézannes Wille, das Motiv der Montagne Sainte-Victoire zu erfassen - das zuerst noch wie zufällig im Hintergrund seiner Bilder erscheint, zuletzt aber zunehmend prominent und unter Verzicht von Nebenmotiven herausgestellt wird. Dadurch ist bei Cézanne durch eine Schärfung und Akzentuierung der bildnerischen Mittel eine klare künstlerische Progression zu erkennen. Monets wie aus einem Guss entstandene Serie weist einen solchen Entwicklungsprozess nicht auf. Wie Schmidt hervorhebt, verbindet Monet und Cézanne gleichzeitig jedoch eine Abkehr vom hierarchischen akademischen Bildbegriff, bei dem konventionelle bildnerische Mittel, wie die Positionierung der Gegenstände im Bild nach Wichtigkeit, die Abstufung des Bildraumes durch unterschiedliche perspektivische Mittel (Linear-, Farb- und Luftperspektive), die Verwendung von Helldunkel und die Beschränkung von Farben auf wichtige Bildgegenstände, zurücktreten. Stattdessen findet eine Differenzierung innerhalb des Bildes meist lediglich nur noch über die Farben statt. Laut Schmidt erzeugt die ,gleichmäßige Farbintensität [...] farbige, flächige Overall-Strukturen [...]. Die Abwesenheit von Differenzierung im traditionellen Sinn soll [...] die Abwesenheit von Überlegung, von Machen überhaupt bedeuten. Die Gemälde sollen also als nicht gemacht, sondern unmittelbar aus der Erfahrung der Natur und aus persönlicher Emotion geschöpft erscheinen. "147 Bei van Gogh ist zwar auch die gleichmäßige Farbintensität zu erkennen, gleichzeitig ist er jedoch bei den ummauerten Feldern weiterhin einer nachvollziehbaren Tiefenstaffelung verpflichtet, unterstützt durch entsprechende Bildelemente, sei es beispielsweise durch die Mauer oder durch Ackerfurchen, die fluchtpunktartig in die Bildtiefe verlaufen (vgl. Abb. 2, 8 u. 9). Anders als Monet und Cézanne unterstreicht van Gogh Differenzierungen zwischen Gegenständen im Bild häufig durch dunkle Konturen.

Ein wesentliches Element des Vergleiches ist das Naturverständnis und die jeweilige Wahrnehmung der Landschaft als Bildsujet und die Frage, wie die Künstler diese in Ihren Werken umsetzten und was sie damit beabsichtigten. Alle drei Künstler waren bei der Motivfindung stark der sichtbaren Wirklichkeit verpflichtet und skizzierten und malten hauptsächlich in der Nachfolge von de Valenciennes und der Barbizon-Maler „en plein air“, wobei der Bildgegenstand zugleich in je eigener Weise interpretiert wurde. Auch wenn sie „die subjektive Auffassung der sichtbaren Welt, der Landschaftsmalerei als Trägerin geistiger Inhalte "148 verbindet, unterscheiden sie sich in den Schlüssen, die sie daraus zogen, fundamental. Van Gogh ging es in Saint-Rémy darum, durch die künstlerische Interpretation des Naturmotivs, also durch suggestive Form und Farbe in den Landschaftsbildern, einen Ausdruck zu erreichen. Dieser fußt auf der zyklischen Darstellung des Kornfelds „als gleichnishafte Schilderung vom Lebensschicksal der Menschen " 149 - inhaltlich verknüpft mit dem spirituellen Glauben an „quelque chose là-haut“, dem „Bewusstsein von

147 Schmidt 2004, S. 129.

148 Noll 1994, S. 130, Anm. 639.

149 Noll 1994, S. 130, Anm. 639. 
etwas Höherem“"150, das sich auf den ewigen Kreislauf der Jahreszeiten und der daraus abgeleiteten Verbindung „der Natur in ihrer ,ewigen“ Ordnung und harmonischen Gefügtheit" ${ }^{151}$ gründet. Noll vermutet, dass „die tiefere Bedeutung [... der von van Gogh dargestellten] Arbeitenden [...] in der Schilderung des in jedem Sinne natürlichen, ursprünglichen Lebens zu suchen sein [wird]; in der typischen Darstellung des Menschen als Sämann, Grabenden, Pflügenden etc., des Menschen in seiner ,conditio humana', der sein Brot, im Schweiße seines Angesichts essen`soll, eingebunden in eine ,ewige', von Gott geschaffene Natur, in welcher Arbeit, von den Gleichnisreden Jesu mit einem höheren Sinn erfüllt, sinnbildliche Bedeutung erlangt. "152

Damit steht van Gogh Monets vorrangig positivistischer Wahrnehmung der Natur gegenüber, die maßgeblich auf atmosphärische Veränderungen und entsprechende Aspekte der sichtbaren Wirklichkeit konzentriert war. Dass Monet primär auf die Effekte des Lichtes und der Witterung und nicht auf die Wiedergabe eines landwirtschaftliches Motivs abzielte, wird neben der Umsetzung in den Bildern dadurch deutlich, dass er, als er das erste Mal über die Serie der Getreideschober schrieb, sie dezidiert „une série d'effets“153 nannte, die Bezeichnung „meules“ nur ergänzend in Klammern hinter den Titel anfügte. Monet suchte die enveloppe, die „Sphäre um den Gegenstand, eine Umhüllung aus sich in der Luft brechendem Licht" ${ }^{\text {"154, }}$, bildlich zu erfassen, und bildete dafür in den Ansichten der Meules die Faktur einheitlich als eine „dichten Teppich aus atmosphärischen Nuancen“155, der die Getreideschober in ihrer relativ gleichmäßigen Beschaffenheit zu Projektionsflächen und Anschauungsobjekten für Veränderungen von Licht und Schatten im Laufe der Zeit werden ließ. ${ }^{156}$ Dabei bleibt der Bildgegenstand unscharf und einzelne Bildbereiche können und sollen nicht voneinander unterschieden werden. „Mit der Optik der Unschärfe verschwindet das Sujet nicht, aber es ist viel mehr Anlass als Ziel des Bildes. Das Sichvordrängen der malerischen Mittel [...] gibt dem Bild den Charakter einer Erscheinung [„,impression“]. “157 Dadurch gelang es Monet, mittels einer partiellen Loslösung vom Gegenstand, die letzten Konsequenzen aus den künstlerischen Zielen des Impressionismus zu ziehen. Auch der Aspekt der Wahrnehmung Monets, das Empfinden („éprouver“) und sein Wunsch, „im beständigen Wechsel der Erscheinungen eine [...] Einheit in der Vielfalt [und damit möglicherweise] „eine ,kosmische Harmonie“ auszudrücken“" ${ }^{158}$, liegen auf einer anderen inhaltlichen Ebene als van Goghs Absichten.

\footnotetext{
150 Brief 333/277, Den Haag, 29.3. u. 1.4.1883, an Theo, zitiert nach Erpel 1965, Bd. 2, S. 230234, S. 232. Vgl. auch Bakker 2010, S. 196.

151 Noll 1996, S. 67.

152 Noll 1994, S. 64.

153 Claude Monet an Gustave Geffroy, 7.10.1890, zitiert nach Geffroy 1922, S. 189.

154 Heinrich 2001, S. 16.

155 Heinrich 2001, S. 16.

156 Vgl. Heinrich 2001, S. 17.

157 Boehm 2017, S. 141.

158 Noll 1994, S. 130, Anm. 639.
} 
Dadurch lässt sich eine Entwicklung, beginnend bei de Valenciennes' Freilichtskizzen hin zu Monets Serien, erkennen, die „das zunehmende Absinken des dargestellten Gegenstandes in die Bedeutungslosigkeit [zeigt, die bei den] Heuhaufen Monets [...] zu einem ersten Höhepunkt geführt worden ist, bis es in der abstrakten Kunst zum totalen Triumph des ,Wie über das ,Was' gekommen ist." 159

Obwohl Cézanne sich wie die anderen beiden Künstler grundsätzlich zunächst der sichtbaren Wirklichkeit verpflichtet fühlte, zog er andere Konsequenzen daraus. Er vertrat die Ansicht, dass die Landschaft nicht durch eine naturalistisch genaue Wiedergabe zu erfassen war, sondern „aus den Möglichkeiten der Malerei neu erzeugt werden "160 müsse. Cézanne nannte diesen Vorgang ,realisieren“, der nicht nur die äußere Fertigstellung des Gemäldes beschreibt, sondern bei dem noch viel wichtiger das Motiv selbst „eine Manifestation dieses Prozesses“161 darstellt, und durch den er die inneren Zusammenhänge der Natur verstehen lernen konnte wenngleich dieses Streben niemals seinen Abschluss finden konnte.

Wie bei den Impressionisten besteht auch bei Cézannes Bildgenese eine Dialektik zwischen Subjektivität und Objektivität - hier: die Spannung zwischen „künstlerische[m] Subjekt mit seinen individuellen Empfindungen, [... und dem Streben, diese Empfindungen] zu objektivieren und vor allem zu ordnen "162. Cézanne hatte dies anschaulich mit seinen eigenen Worten beschrieben: „Im Maler gibt es zwei Dinge: das Auge und das Gehirn, beide müssen sich gegenseitig helfen: Man muß an ihrer gegenseitigen Entwicklung arbeiten; am Auge durch das Sehen nach der Natur, am Gehirn durch die Logik der geordneten Empfindungen, welche die Ausdrucksmittel liefert. "163 Wie Monet, den bei seinen Serien das Streben nach der Fixierung einer größtmöglichen Zahl und Variation der Erscheinungen antrieb, um eine „Einheit in der Vielfalt" auszudrücken, meinte auch Cézanne, dass sein Ziel nur durch die wiederholte Darstellung desselben Motivs zu erreichen sei. Dieses Streben wird durch eine zunehmende Fokussierung auf die Montagne Sainte-Victoire, bei einer zunehmenden Aussparung von allem Nebensächlichen, augenfällig. Verbunden mit einer deutlich dunkleren und kontrastreicheren Palette gestaltete Cézanne bald ausschließlich fragmentarische, abstrahierte Farbflächen (,taches"), die nur noch im Gesamteindruck die abgebildete Landschaft konstituieren. ${ }^{164}$ In freier Übertragung des wahrgenommenen Natureindrucks durchziehen diese durchmischten "taches“ die Landschaft; das Grün der Felder und Bäume findet seine Entsprechungen in grünen Flecken im Himmel (vgl. Abb. 114 u. 115). ${ }^{165}$ Cézanne wollte, wie er Ber-

159 Baumann 2004, S. 16

160 Boehm 1988, S. 118.

161 Boehm 1988, S. 101.

162 Kurz 2003, S. 149.

163 Zitiert nach Gespräche mit Cézanne, Zürich 1982, S. 54. Auf dieses Zitat verweist Kurz 2003, S. 149 .

164 Cézanne nach Joachim Gasquet, , in: Conversations avec Cézanne, Paris 1978, S. 109.

165 Bspw. Paul Cézanne (1839-1906), Le Mont Sainte-Victoire vu des Lauves, 1902-6, Öl auf Leinwand, 63,5 x 83 cm, Zürich Kunsthaus, R 916. 
nard mitteilte, mit der Verwendung der Farbflecken etwas durch und durch Subjektives erreichen: „Die Natur lesen, heißt sie durch den Schleier der Interpretation mittels farbiger Flecken sehen, die nach einem Harmoniegesetz aufeinander folgen. Diese großen Mischfarben lassen sich durch die Modulation analysieren."166

Anders als Monet verzichtete Cézanne dabei jedoch bewusst auf die Abbildung atmosphärischer Aspekte, so dass Tages- oder Jahreszeiten im Sonnenlicht der Provence unbestimmbar blieben. Wie verschiedentlich überliefert, wollte er „aus dem Impressionismus etwas Solides und Dauerhaftes "167 machen, indem er bei einem Sujet wie dem des Berges die Wiedergabe des flüchtigen Augenblicks überwand und stattdessen die Darstellung zugleich von Veränderung und Dauer erreichte. ${ }^{168}$ Dafür steht der Berg symptomatisch, der sich nach großen tektonischen Bewegungen seit Millionen von Jahren nicht verändert hat. Im Gegensatz dazu ging es bei den landwirtschaftlichen Motiven van Goghs und Monets um den Wechsel des Lichts und der Witterung bzw. die jahreszeitlich bedingten Veränderungen eines Kornfeldes; dies, um weitere Impression einzufangen (Monet) oder dem Zyklus eine weitere Station vom Werden und Vergehen hinzuzufügen.

Dadurch ist hinsichtlich des Aspekts der Zeitlichkeit besonders van Gogh mit seiner klar definierten und begrenzten zyklischen Darstellungsform nur bedingt mit Cézanne zu vergleichen. In dem Verständnis, dass das Sehen und damit die „Realisierung“ der Montagne Sainte-Victoire durch die eigene menschliche Beschränkung niemals zum Ziel kommen konnte, ist Cézannes Serie - wie auch die von Monet mit der Wiedergabe einer potenziell unendlichen Zahl an atmosphärischen Erscheinungen - nicht zyklisch, sondern linear und damit nicht abzuschließen - so wie auch der menschliche Erkenntnisprozess zu keinem Ende gelangt. Van Goghs Serie der ummauerten Felder hingegen wäre ohne die sich jahreszeitlich wandelnde Gestalt des Feldes - die unvermeidlich wie auch das menschliche Leben mit Anfang und Ende verknüpft ist - nicht denkbar. Nichtsdestoweniger vermittelte gerade der Aspekt „der Natur in ihrer ,ewigen' Ordnung "169 und der Regeneration im neuen Jahr van Gogh besonderen Trost. Dies weist trotz klarem Anfang und Ende des Zyklus auf eine zusätzliche zeitliche Komponente hin, die van Gogh mit dem Sujet verband. Den Wandel der Natur verfolgte auch Monet; doch geht es hier um den Wechsel und die Vielfalt der Erscheinungen, nicht um die Ordnung und den Rhythmus der Natur. Vor allem fehlt bei Monet der Aspekt des Sinnbildlichen und Gleichnishaften der Natur, auch wenn bei seinen Serien eine Art von Pantheismus eine Rolle spielen mag. Ein religiöser Aspekt wäre damit allerdings bei Monet nicht anders als bei van Gogh zu konstatieren; und auch Cézannes Bemühen, gleichsam

\footnotetext{
166 Cézanne nach Emile Bernard, in: Gespräche mit Cézanne, Zürich 1982, S. 54. Auf dieses Zitat verweist Kurz 2003, S. 120.

167 Cézanne wenige Monate vor seinem Tod zu Maurice Denis, zitiert nach: Doran, Michael (Hg.): Gespräche mit Cézanne, Zürich 1982, S. 207.

168 Vgl. Boehm 1988, S. 52.

169 Noll 1996, S. 67.
} 
hinter das Erscheinungshafte zum Wesenhaften seines Motivs vorzudringen, beinhaltet womöglich ein religiöses Element (Cézanne war gläubiger Katholik).

So unterschiedlich das Moment des Seriellen und so unterschiedlich jeweils die stilistische Form erscheint, treffen in diesem Punkt die Künstler zusammen: Die Natur, ihr Wandel im Jahreslauf und die an Licht und Atmosphäre sich knüpfenden natürlichen Bedingungen des Erscheinungshaften gewinnen eine Bedeutung, die über das Anschauliche hinausweist. 


\section{Fazit}

Bereits sehr früh ist bei van Gogh die Absicht zu erkennen, durch Wiederholungen oder Variationen eines Motivs dessen zentrale Aspekte oder dessen Charakter gänzlich erfassen oder vermitteln zu wollen, schließlich Werkgruppen zu schaffen, „die zusammen eine Art Ganzes bilden“1. Angefangen bei den Kopien der Feldarbeiten Millets, an denen er sich schulte, dann auch bald bei eigenen Sujets, wie den Stadtansichten Den Haags für seinen Onkel, deren übergeordnetes Thema die Lebensverhältnisse der unteren Bevölkerungsschichten ist, schließlich bei seinem Wunsch, als Illustrator ein größeres Publikum zu erreichen. Als er in diesem Zusammenhang 1882 das Medium der Lithographie kennenlernte, war er begeistert von den Möglichkeiten der Druckgraphik, die es ihm ermöglichte, „mal eine richtige Serie zu machen. "2 Das übergreifende Thema dieser gedruckten Serie sollte, ähnlich wie bereits in Den Haag, die Darstellung von „Arbeitertypen [...], Säer, Grabende,

1 Brief 292/242, Den Haag, 10.12.1882, an Theo, zitiert nach Erpel 1965, Bd. 2, S. 125-128, S. 127. Hulsker bezeichnet die danach entstandenen Lithographien als "Serie“. Vgl. Hulsker 1980, S. 66. Van Gogh spricht im Brief auf Niederländisch von "geheel“ = Ganzes.

2 Brief 283/245, Den Haag, 16. oder 17.11.1882, an Theo, zitiert nach Erpel 1965, Bd. 2, S. 132 133, S. 133. Hinweis durch Zimmer 2009, S. 96. 
Holzhauer, Pflüger, [eine] Waschfrau, dazwischen auch mal eine Kinderwiege oder ein[...] Waisenmann“3, sein.

Aber auch bei der Auseinandersetzung mit den Webern war die wiederholte Darstellung des gleichen Sujets mit sozialen Aspekten verbunden, wollte er doch, angeregt durch die Lektüre von sozialkritischen Werken, wie Silas Marner, auf das Schicksal der Weber aufmerksam machen. Sowohl bei der Entstehung der RoulinSerie als auch bei dem Jahreskreis der Natur in Arles wurde ein vielschichtiges und über die Jahre gewachsenes Geflecht von unterschiedlichen Themenkomplexen und Absichten evident, auf dem van Gogh in den Ansichten des ummauerten Feldes unmittelbar aufbaute: die Darstellung des Zyklus der Natur, die damit verbundene Vermittlung von Trost und die Verwendung suggestiver Farben.

Es ist deutlich geworden, dass van Gogh bereits lange vor seiner Entscheidung, Künstler zu werden, dem Aspekt des zyklisch-wiederholten Werdens und Vergehens der Natur als Analogie für das Leben einen großen Stellenwert beigemessen hatte, verglich er doch schon in seiner ersten Predigt 1876 in England das Leben mit einer Serie von Jahreszeiten und wies auf die Natur des christlichen Lebens hin. ${ }^{4}$

Anknüpfend an van Goghs Aussage, dass er bei der Entwicklung des Zyklus, ähnlich wie sein Vorbild Millet, von alten Bauernkalendern („vieil almanach de campagne" $)^{5}$ inspiriert gewesen sei, ließ sich eine inhaltliche Verbindungslinie zu den Kalenderbildern in Stundenbüchern und Almanachen aufzeigen, die van Gogh aus seiner Zeit im Kunsthandel und durch die Lektüre von Kunstjournalen gekannt haben wird, die ihrerseits an eine jahrhundertealte Darstellungstradition in der westlichen Kunst anknüpften, in der zum Teil auch Pieter Bruegel d.Ä. mit seinem Jahreszeitenzyklus steht, der auf nachfolgende Generationen großen Einfluss ausübte. Darstellungen des Kreislaufs der Natur finden sich seit der Antike und konnten, „einerseits im Zusammenhang der Jahreszeitenthematik, andererseits in einem an den Monaten orientierten kalendarischen Kontext" ${ }^{\text {} 6}$ stehen.

Van Gogh kannte sowohl religiös aufgefasste zyklische Darstellungen der Natur, wie Poussins zwischen 1660-1664 entstandener Zyklus in Form einer allegorie réelle mit typologischen Bezügen, als auch Jahreszeitenzyklen und Monatsdarstellungen

3 Brief 289/249, Den Haag, 1.12.1882, an Theo, zitiert nach Erpel 1965, Bd. 2, S. 143-147, S. 144.

4 Vgl. Abschrift der Predigt in Brief 79/79a, Isleworth, 3.11.1876, an Theo, zitiert nach Erpel 1968, Bd. 6, S. 335-340, S. 335 u. 339. Es ist wichtig hervorzuheben, dass das Einzelleben nicht zyklisch, sondern linear ist: von Geburt zum Tod. Dass van Gogh mit der Regeneration der Natur wohl das Moment der Auferstehung verband, erlaubt auch nicht, das menschliche Leben zyklisch zu nennen. Das Leben der Menschheit ist insgesamt dagegen sehr wohl zyklisch zu nennen: eine Generation stirbt, die nächste folgt darauf etc.

5 Brief 628/B 7, Arles, 19.6.1888, an Émile Bernard, zitiert nach Erpel 1968, Bd. 5, S. 257-261, S. 258. Van Gogh äußerte sich in Bezug auf Louis Anquetins, Die Ernte (Mäher zur Mittagszeit), 1887, Privatsammlung, vgl. Online-Ausgabe der Briefe, abgerufen unter: http://vangoghletters. $\mathrm{org} / \mathrm{vg} /$ letters/let628/letter.html\#. Sensier hatte hinsichtlich Millets Inspiration für die Jahreszeitenbilder ebenfalls den „calendrier de la vie agricole“ erwähnt. Zitiert aus Sensier 1881, S. 362.

6 Divjak/Wischmeyer, Bd. 1, 2014, S. 157. 
der bäuerlichen Arbeit von Millet und Lhermitte. Dabei übte vor allem Millets Jahreszeitenzyklus für den Sammler Jacques Hartmann, bei dem dieser Szenen aus dem Bauernleben mit dem Symbolismus der vier Jahreszeiten verbunden hatte, einen großen Einfluss aus. Davon beeindruckt konzipierte van Gogh 1884 für den Juwelier Hermans Allegorien der Jahreszeiten mit bäuerlicher Arbeit. In Arles griff er, nach den Eindrücken seines Aufenthaltes in Paris, ein Jahre zuvor entwickeltes Konzept wieder auf, die Jahreszeiten mit entsprechenden Farben und Farbgegenüberstellungen zu assoziieren. Darauf aufbauend entwickelte er nach seiner Ankunft in Saint-Rémy mit großer Regelmäßigkeit Monat für Monat neue Ansichten des sich wandelnden ummauerten Feldes, die sich in ihrer Gesamtheit zu einem Zyklus zusammenfügen lassen.

Da die Landschaft für van Gogh „in dieser zutiefst niederländischen Bildtradition wichtiger Bedeutungsträger" ${ }^{\text {" }}$ geworden war, lag der Fokus der Untersuchung auf der Frage nach van Goghs Haltung zur Natur. Aufgewachsen auf dem Land, in enger Verbundenheit mit der Natur, war van Gogh bereits sehr früh sensibilisiert für die Natur und das ländliche Leben, sei es die bäuerliche Arbeit oder seien es die Nöte der ländlichen Bevölkerung, derer er sich später, inspiriert durch seine Vorbilder, Breton, Millet, oder die Maler der Haager-Schule, um nur einige wenige zu nennen, selbst als Künstler annahm, um Werke zu schaffen, die „deutlicher [sprechen] als die Natur selbst. ${ }^{\text {"2 }}$

Zunächst war seine Haltung zur Natur jedoch noch deutlich von den Schriften der Prediger und Theologen, beispielsweise Spurgeon und Laurillard, geprägt, die er in den 1870er Jahren studiert hatte und die ihn die Natur mit religiös-symbolischen Inhalten aufladen ließen. ${ }^{3}$ Daher konnte nicht nur die inhaltliche Bedeutung der Landschaftsmalerei für van Gogh entschlüsselt werden, die Bedeutung der Motive der Feldarbeit und im Besonderen des Pflügers und des Schnitters, sondern auch ein Wandel von van Goghs Naturwahrnehmung - was insbesondere deutlich geworden ist bei der Serie der Olivenhaine - und eine Fokussierung auf weitere inhaltliche Motive verständlich werden. Van Goghs Landschaften weisen bei aller Verpflichtung gegenüber der Malerei vor dem Motiv, in der Natur, die er immer wieder, und insbesondere nach dem Scheitern der „Abstraktionen“ in Folge von Gauguins Besuch in Arles, betonte, inhaltliche Anleihen an die „paysage historique“ und die „Intellektualisierung der Landschaft durch Bildungsverweise“ ${ }^{4}$ auf.

Zimmer 2009, S. 99.

Brief 152/130, Wasmes, ca. 19.6.1879, an Theo, zitiert nach Erpel 1965, Bd. 1, S. 194-197, S. 196. Neben Rembrandt kann als Beispiel auch Jacob van Ruisdael (1628/29-1682) aufgeführt werden, bspw. dessen Werk Der Busch (1647-50, Öl auf Leinwand, 68 x $82 \mathrm{~cm}$, Paris, Louvre. Vgl. Brief 361/299, Den Haag, 11.7.1883, Erpel 1965, Bd. 2, S. 295-301, S. 295.

$3 \quad$ Vgl. Anmerkung 2 zu Brief 104/87, Dordrecht, 28.2.1877, an Theo, abgerufen aus der OnlineAusgabe der Briefe, unter http://vangoghletters.org/vg/letters/let104/letter.html für den Hinweis auf Spurgeon.

Busch 1997, S. 239. 
Dabei wurde nach einer Rückschau auf van Goghs religiöse Prägung und seinen beruflichen Werdegang, insbesondere vor seiner Entscheidung, als Künstler zu arbeiten, deutlich, dass er das Feld und die darauf arbeitenden Bauern auch mit bestimmten Vorstellungen verknüpfte. Das ummauerte Feld vor seinem Fenster wurde im Jahr 1889-1890 damit zum Schauplatz seiner Beschäftigung mit dem Rhythmus der Natur, dem Zyklus von Wachsen, Gedeihen, der Ernte/dem Tod und einem neuen Anfang im darauffolgenden Jahr - dies alles im Zusammenhang mit religiösen Konnotationen, die vor dem Hintergrund der biblischen Gleichnisse evident wurden. Dies ließ ihn die zyklische Darstellung des Kornfelds „als gleichnishafte Schilderung vom Lebensschicksal der Menschen" ${ }^{5}$ verstehen. Mit dem erneuten Aufgreifen der agrarischen Thematik des Schnitters, Pflügers und Sämanns in SaintRémy schloss van Gogh inhaltlich einen Kreis, den er mit den ersten Darstellungen der Feldarbeiten nach Millet im Herbst 1880 und seiner späteren Definition und Zielsetzung als „Bauernmaler" begonnen hatte.

Möglicherweise ein wenig dem Zufall der Chronologie seines Aufenthaltes geschuldet, stellte van Gogh in Saint-Rémy einen ganzen Jahreszeitenzyklus dar, der nicht mit dem trüben Winter oder mit der Ernte und dem damit verknüpftem Thema des Todes durch den Schnitter endete, sondern mit dem Frühling und dem noch jungen Grün des neu bestellten Feldes. In der Nervenheilanstalt vermochte ihm angesichts eines Kornfeldes vor seinem Fenster der Kreislauf von Werden und Vergehen in der Natur als Metapher für das menschliche Leben Trost spenden, insofern er auf eine „höhere“ Ordnung verwies.

Die Vermittlung von Trost beschäftigte van Gogh, wie auch in den Jahren zuvor, in Saint-Rémy immer wieder. Analog zu seiner religiösen und intellektuellen Sozialisierung, an der zunächst sein Vater und sein Onkel Stricker mit ihrer jeweiligen theologischen Ausrichtung entscheidenden Anteil hatten, konnte eine nähere Betrachtung aufzeigen, inwiefern für ihn Trost und landwirtschaftliche Sujets miteinander verknüpft waren. Als eines der zentralen Themen des Zyklus kam der Trost nicht nur durch Einzelwerke und ihre allegorischen Darstellungen zum Ausdruck, sei es mit dem Schnitter, der einen "beinah lächelnden“ Tod bedeutet oder mit dem Pflüger, der die Neuaussaat vorbereitet, sondern auch in der Gesamtheit der zyklischen Darstellung des Feldes und der damit einhergehenden Vermittlung eines steten Neubeginns.

Deutlich wurde im Zusammenhang mit der parallel entstandenen Serie der Olivenhaine, wie sehr van Gogh darauf bedacht war, Trost auszudrücken, ohne auf religiöse Sujets zurückgreifen zu müssen. Die Beschäftigung mit den Olivenhainen warf daher ein zusätzliches Schlaglicht darauf, wie sich van Goghs Haltung zur Religion in den Jahren nach seiner Abkehr von der Kirche verändert hatte. Van Gogh wollte im Gegensatz zu Bernards und Gauguins höchst idiosynkratrischen und nicht-naturalistischen Lösungen des Gethsemane-Stoffes, die seiner Meinung nach keinen künstlerischen Fortschritt darstellten, durch Form und suggestive Farbe

Noll 1994, S. 130, Anm. 639. 
in den Olivenhainen eine Wirkung erreichen, die ohne die Darstellung Christi doch dessen Angst und Not beim Gebet am Ölberg zum Ausdruck bringt.

Der Vergleich mit den fast zeitgleich entstandenen Serien Claude Monets und Paul Cézannes förderte nur wenige Gemeinsamkeiten, darunter die Verpflichtung gegenüber der sichtbaren Wirklichkeit bei der Motivfindung und die Freilichtmalerei, dafür viele grundlegende Unterschiede zutage. Diese betrafen die Motivation und die Konzeption einer vielfachen Wiederholung des gleichen Sujets und die daraus abgeleitete, individuelle Form serieller Bildschöpfung, die subjektive Auffassung der Landschaft und die daraus resultierende Rolle der Landschaft, sei es als Folie für unterschiedliche Effekte (Monet), im zyklischen Wandel als Metapher für das menschliche Werden und Vergehen (van Gogh) oder als Ergebnis der Synthese zwischen Veränderung und Dauer, die der Maler ergründen und zu realisieren versuchen muss (Cézanne).

Die jeweilige stilistische Form, die bei allen drei Malern entscheidender Bestandteil der Bildaussagen ist, wurde dabei hinsichtlich ihrer Wirkung analysiert und in den zeitlichen Kontext gesetzt. Die Wahl der einzelnen Themenkomplexe ließ sich häufig aus den jeweiligen Künstlerbiographien und den daraus erkennbaren Zielsetzungen und Motiven sowie den Entstehungskontexten erklären. Wie bei van Gogh waren auch die vielfältigen Aussagen Monets und Cézannes, in eigenen Briefen und Dokumenten oder überliefert in Aufzeichnungen anderer zu ihren Werken, ein entscheidender Schlüssel zum Verständnis der einzelnen Serien. 



\section{Quellen- und Literaturverzeichnis}

\section{Werkverzeichnisse}

FAILLE, Jacob Baart de la: Vincent van Gogh. The Complete Works on Paper, Cata-logue Raisonné, San Francisco 1992.

FEILCHENFELDT, Walter: Vincent van Gogh. Die Gemälde 1886-1890. Händler, Sammler, Ausstellungen. Die Frühen Provenienzen, Wädenswill 2009.

HULSKER, Jan: The New Complete van Gogh. Paintings, Drawings, Sketches, Amsterdam u. Philadelphia 1984.

Morton, Robert (Hg.): The Paintings of Paul Cézanne. A Catalogue Raisonné by John REWALD in collaboration with Walter FEILCHENFELDT and Jayne WARMAN, Bd. 1 (Textband) u. 2 (Abbildungen), New York 1996.

VELLEKOOP, Marie u. Roelie ZWIKKER: Vincent van Gogh. Drawings. Arles, Saint-Rémy \& Auvers-sur-Oise. 1888-1890, Van Gogh Museum, Bd. 4, Amsterdam 2007.

WALTHER, Ingo F. u. METZGER, Rainer: Vincent van Gogh. Sämtliche Werke, Bd. 2, Arles, Februar 1888-Auvers-sur-Oise, Juli 1890, Köln 1989.

WALTHER, Ingo F. u. METZGER, Rainer: Vincent van Gogh. Sämtliche Werke, Köln 2015.

WILDENSTEIN, Daniel: Monet oder der Triumph des Impressionismus, Köln 2010 (zweite Ausgabe).

WILDENSTEIN, Daniel: Gauguin. A savage in the making, Catalogue Raisonné of the Paintings 1873-1888, Bd. 1 u. 2, Paris u. Mailand 2002.

WILDENSTEIN, Georges: Gauguin. Catalogue Raisonné, Paris 1964.

WRIGHT, Christopher: Poussin. Paintings, A Catalogue Raisonné, London 2007.

\section{Quellen und frühe Zeugnisse}

AURIER, Gabriel-Albert: Les Isolés. Vincent van Gogh, in: Mercure de France, Januar 1890, Heft 1, S. 24-29; dt. Übersetzung, in: Vincent van Gogh. Sämtliche Briefe, hg. v. Fritz Erpel, Bd. 6, Zürich 1968, S. 89-94.

BALZAC, Honoré de: La Comédie humaine. Études de moeurs. Scènes de la vie privée, Bd. 1, Paris 1842.

BAZALGETTE, Léon: L'Esprit Nouveau dans la Vie Artistique, Sociale et Religieuse, Paris 1898. 
BELLAIGUE, Camille: L'Amour dans la musique, in: Revue des Deux Mondes, LVIIIe Année, Troisième Période, Bd. 89, 15.9.1888, S. 305-347.

BENOÎT, Camille: Richard Wagner, musiciens, poètes et philosophes. Aperçus et jugements précédés de lettres inédites en France et traduits de l'Allemand pour la première fois, Paris 1887.

BLANC, M. Charles: Grammaire des Arts du Dessin, Architecture, Sculpture, Peinture. Paris 31876.

BLANC, M. Charles: Les Artistes de mon Temps. Paris 1876.

BUSCH, Werner (Hg.): Geschichte der klassischen Bildgattungen in Quellentexten und Kommentaren, Bd. 3, Landschaftsmalerei, Berlin 1997.

CASTAGNARY, Jules-Antoine: Exposition du boulevard des Capucines-Les impressionnistes, in: Le Siècle, Bd. 39, Nr. 15126, 29.04.1874, S. 3, Sp. 5.

Conversations avec CÉZANNE, hg. v. Michael DORAN, Paris 1978.

Gespräche mit CÉZANNE, hg. v. Michael DORAN, übersetzt von Jürg Bischoff, Zürich 1982.

Paul CÉZANNE. Briefe, hg. v. John Rewald, Zürich 1979.

DEPERTHES, Jean Baptiste: Théorie du paysage, ou, Considérations générales sur les beautés de la nature que l'art peut imiter et sur les moyens qu'il doit employer pour réussir dans cette imitation, Paris 1818.

DELACROIX, Eugène. Dictionnaire des Beaux-Arts, hg. v. Anne Larue, Paris 1996.

ELIOT, George: Silas Marner. The Weaver of Raveloe, Edinburgh u. London 1861.

FÉNÉON, Félix: Les impressionnistes en 1886, in: La Vogue, Paris 1886.

Paul GAUGUIN. Briefe und Selbstzeugnisse, hg. v. Kuno Mittelstädt, München 1970.

Ramblings of a Wannabe Painter [Racontars de rapin]. Paul GAUGUIN, hg. u. übersetzt v. Donatien Grau, New York 2016.

GEFFROY, Gustave: Claude Monet. Sa vie, son œuvre, Paris 1922.

HANDKE, Peter: Die Lehre der Sainte-Victoire, Frankfurt 1981.

KIERKEGAARD, Sören: Die Wiederholung, übersetzt, mit Einleitung und Kommentar, hg. v. Hans Rochol, Hamburg 2000.

LAURILLARD, Eliza: Met Jezus in de natuur, Amsterdam 1881.

LECOY DE LA MARCHE, A.: L'Académie de France a Rome. Correspondance inédite de ses Directeurs précédée d'une Étude historique, Paris 1874.

LOTI, Pierre: Pêcheur d'Islande, Paris 1908.

MENGS, Anton Raphael, Gedanken über die Schönheit und über Geschmack in der Malerei, Zürich 1771 (dritte Ausgabe).

MICHELET, Jules: La Femme, Paris 1860. 
MICHELET, Jules: Le Peuple, Paris 1846.

Vincent van Gogh's poetry albums, hg. v. Fieke PABST, Cahier Bd. 1, Zwolle 1988.

Quesne-van Gogh, Elisabeth Huberta du: Vincent van Gogh. Souvenirs personnels racontés par sa soeur, übersetzt von Gwénolée u. Bernard Zurcher, Paris 1982.

Rainer Maria RILKE. Über moderne Malerei, Zusammenstellung u. Nachwort v. Martina Kriessbach-Thomasberger, Frankfurt/Leipzig 2000.

SENSIER, Alfred: La Vie et l'Oeuvre de J.-F. Millet, Paris 1881.

SPURGEON, Charles Haddon: Teachings of nature in the Kingdom of Grace, London 1896.

VALENCIENNES, Pierre Henri de: Élemens de perspective pratique, à l'usage des artistes, suivis de réflexions et conseils à un elève sur la peinture, et particulièrement sur le genre du Paysage, Paris 1800.

Vincent VAN GOGH. Sämtliche Briefe, hg. v. Fritz Erpel, Bd. 1-6, Zürich 1965-1968.

ZOLA, Émile: Les Rougon-Macquart. La Curée, Bd. 2, Paris 1871.

\section{Sekundärliteratur}

\section{a. Sekundärliteratur über Vincent van Gogh}

ARNOLD, Matthias: Van Gogh und seine Vorbilder. Eine künstlerische Selbstfindung, München, New York 1997.

BAKKER, Nienke: On Rustics and Labourers. Van Gogh and „The People“, in: Van Goghs Musée imaginaire, hg. v. Chris Stolwijk, Sjraar van Heugten, Leo Jansen und Andreas Blühm (Ausst. Kat. Amsterdam, Van Gogh Museum 14. Februar-13. Juni 2003), London 2003, S. 87-98.

BAKKER, Nienke: Die Zyklen der Natur, in: Van Gogh. Der Künstler und seine Briefe, mit einem Vorwort von Nicholas Grimshaw (Ausst. Kat. London, Royal Academy of Arts, 23. Januar-18. April 2010), Köln 2010, S. 196-219.

BAKKER, Nienke: Ringen mit der Natur, in: Van Gogh. Der Künstler und seine Briefe, mit einem Vorwort von Nicholas Grimshaw (Ausst. Kat. London, Royal Academy of Arts, 23. Januar-18. April 2010), Köln 2010, S. 64-91.

BAKKER, Nienke, JANSEN, Leo und LUIJTEN, Hans: Van Goghs Briefe. Fenster zu einem Universum, in: Van Gogh. Der Künstler und seine Briefe, mit einem Vorwort von Nicholas Grimshaw (Ausst. Kat. London, Royal Academy of Arts, 23. Januar-18. April 2010), Köln 2010, S. 14-29. 
BAILEY, Martin: Young Vincent. The Story of Van Gogh's Years in England, London 1990.

BLOTKAMP, Carel: Ruisdael in der Provence, in: Vincent van Gogh. Zwischen Erde und Himmel. Die Landschaften, hg. v. Kunstmuseum Basel (Ausst. Kat. Basel, Kunstmuseum, 26. April-27. September 2009), Ostfildern 2009, S. 58-77.

BOEHM, Gottfried: Auge und Emotion-Van Goghs Land schaften, in: Vincent van Gogh. Zwischen Erde und Himmel. Die Landschaften, hg. v. Kunstmuseum Basel (Ausst. Kat. Basel, Kunstmuseum, 26. April-27. September 2009), Ostfildern 2009, S. 30-47.

BOIME, Albert: Vincent van Gogh, die Sternennacht. Die Geschichte des Stoffes und der Stoff der Geschichte, Frankfurt 1989.

BÜRGI, Bernhard, ZIMMER, Nina und FEILCHENFELDT, Walter: Zwischen Erde und Himmel-Van Goghs Landschaften. Eine Einführung, in: Vincent van Gogh. Zwischen Erde und Himmel. Die Landschaften, hg. v. Kunstmuseum Basel (Ausst. Kat. Basel, Kunstmuseum, 26. April-27. September 2009), Ostfildern 2009, S. 13-29.

CHETHAM, Charles Scott: The role of Vincent van Gogh's copies in the development of his art, New York 1976 (zugl. Camebridge (Mass.), Harvard University, Diss., 1960).

CHILDS, Elizabeth C.: Auf der Suche nach dem Atelier des Südens. Van Gogh, Gauguin und die Identität des Avantgardekünstlers, in: Vincent van Gogh und die Maler des Petit Boulevard, hg. v. Cornelia Homburg (Ausst. Kat. Saint Louis, Art Museum, 17. Februar-13. Mai 2001; Frankfurt, Städelsches Kunstinstitut und Städelsche Galerie, 8. Juni-2. September 2001), OstfildernRuit 2001, S. 115-154.

COYLE, Laura: Poesie der Felder und Wälder. Vincent van Gogh und die französische Landschaftsmalerei, in: Vincent van Gogh. Zwischen Erde und Himmel. Die Landschaften, hg. v. Kunstmuseum Basel (Ausst. Kat. Basel, Kunstmuseum, 26. April-27. September 2009), Ostfildern 2009, S. 78-95.

DERENTHAL, Ludger: „Die Erziehung des Auges“. Die serielle Photographie, das wissenschaftliche Experiment und Monets „Getreideschober“, in: Monets Vermächtnis. Serie, Ordnung und Obsession, hg. v. Uwe M. Schneede (Ausst. Kat. Hamburg, Kunsthalle, 28. September 2001-6. Januar 2002), OstfildernRuit 2001, S. 23-28.

DORN, Roland: Décoration. Vincent van Goghs Werkreihe für das Gelbe Haus in Arles, (Diss. phil. Mainz 1986) Hildesheim u.a. 1990.

DORN, Roland: Van Gogh, Gauguin und Richard Wagner, eine Étude auf das Jahr 1888, in: Die Symbolisten und Richard Wagner, hg. v. Wolfgang Storch u. Josef Mackert (Ausst. Kat. Berlin, Akademie der Künste, 15. August-29. September 1991 u. Brüssel, Maison du Spectacle-La Bellone, 7. Oktober-24. November 1991), Berlin 1991, S. 67-75. 
Van Gogh and Gauguin. Studio of the South, hg. v. Douglas W. DRUICK u. Peter Kort ZEGERS (Ausst. Kat. Chicago, The Art Institute, 22. September 2001-13. Januar 2002; Amsterdam, Van Gogh Museum, 9. Februar-2. Juni 2002), New York u. London 2001.

DUMAS, Ann: Das moderne Porträt, in: Van Gogh. Der Künstler und seine Briefe, mit einem Vorwort von Nicholas Grimshaw (Ausst. Kat. London, Royal Academy of Arts, 23. Januar-18. April 2010), Köln 2010, S. 126-153.

FEILCHENFELDT, Walter: Theo van Gogh als Sammler der Landschaftsbilder seines Bruders, in: Vincent van Gogh. Zwischen Erde und Himmel. Die Landschaften, hg. v. Kunstmuseum Basel (Ausst. Kat. Basel, Kunstmuseum, 26. April-27. September 2009), Ostfildern 2009, S. 48-57.

GRAETZ, H. R.: The Symbolic Language of Vincent van Gogh, London 1963.

GREER, Joan: „Christ, this Great Artist“ - Van Gogh's Socio-religious Canon of Art, in: Van Goghs Musée imaginaire, hg. v. C. Stolwijk, S. van Heugten, L. Jansen und A. Blühm (Ausst. Kat. Amsterdam, Van Gogh Museum 14. Februar-13. Juni 2003), London 2003, S. 61-72.

GREER, Joan E.: A modern Gethsemane: Vincent van Gogh's Olive Grove, in: Van Gogh Museum Journal 2001, hg. v. Van Gogh Museum Amsterdam, Zwolle 2001, S. 107-117.

GREER, Joan E.: „To everything there is a season“. The Rhythms of the Year in Vincent van Gogh's socio-religious worldview, in: Van Gogh and the Seasons, hg. v. Sjraar van Heugten (Ausst. Kat., Melbourne, National Gallery of Victoria, 28. April - 9. Juli 2017), Princeton 2018, S. 60-89.

HANSEN, Dorothee: Katalog der ausgestellten Werke, in: Van Gogh, Felder. Das Mohnfeld und der Künstlerstreit, hg. v. Wulf Herzogenrath u. Dorothee Hansen (Ausst. Kat. Bremen, Kunsthalle, 19. Oktober 2002-26. Januar 2003), Ostfildern-Ruit 2002, S. 53-145.

HANSEN, Dorothee: Vincent van Gogh - biographische Daten, in: Van Gogh, Felder. Das Mohnfeld und der Künstlerstreit, hg. v. Wulf Herzogenrath u. Dorothee Hansen (Ausst. Kat. Bremen, Kunsthalle, 19. Oktober 2002-26. Januar 2003), Ostfildern-Ruit 2002, S. 22-31.

HANSEN, Dorothee: Vincent van Goghs Felder. Ein Interview mit Roland Dorn, in: Van Gogh, Felder. Das Mohnfeld und der Künstlerstreit, hg. v. Wulf Herzogenrath u. Dorothee Hansen (Ausst. Kat. Bremen, Kunsthalle, 19. Oktober 2002-26. Januar 2003), Ostfildern-Ruit 2002, S. 32-51.

HEUGTEN, Sjraar van: Nature and the South. Arles and Saint-Rémy, 1888-90, in: Van Gogh and Nature, hg. v. Richard Kendall, Sjraar van Heugten u. Chris Stolwijk (Ausst. Kat. Williamstown, Clark Art Institute, 14. Juni-13. September 2015), New Haven, London 2015, S. 129-207. 
HEUGTEN, Sjraar van: The Dutch Years, 1880-85, in: Vincent Van Gogh. The Drawings, hg. v. John P. O’Neill u.a. (Ausst. Kat. Amsterdam, Van Gogh Museum, 1. Juli-18. September 2005; New York, The Metropolitan Museum of Art, 12. Oktober-31. Dezember 2005), New Haven, London 2005, S. $56-121$.

HEUGTEN, Sjraar van: Van Gogh in the Borinage. The Birth of an Artist, in: Van Gogh. The Birth of an Artist, hg. v. Sjraar van Heugten (Ausst. Kat. Mons, Musée des Beaux-Arts, 25. Januar-17 Mai 2015), New Haven, London 2015, S. 10-49.

HEUGTEN, Sjraar van: Working in black-and-white and colour. Van Gogh's regard for tonality and technique, in: Van Goghs Musée imaginaire, hg. v. Chris Stolwijk, Sjraar van Heugten, Leo Jansen und Andreas Blühm (Ausst. Kat. Amsterdam, Van Gogh Museum 14. Februar-13. Juni 2003), London 2003, S. 123-132.

Van Gogh. Colours of the North, Colours of the South, hg. v. Sjraar van HEUGTEN (Ausst. Kat. Arles, Fondation Vincent van Gogh Arles, 7 April-31 August 2014), Arles 2014.

Van Gogh. The Birth of an Artist, hg. v. Sjraar van HEUGTEN (Ausst. Kat. Mons, Musée des Beaux-Arts, 25. Januar-17 Mai 2015), New Haven, London 2015.

HEUGTEN, Sjraar van, Philip CONSIBEE u. Louis van TILBORGH: Catalogue. The Poetry of Country Life, in: Van Gogh \& Millet, hg. v. Louis van Tilborgh u. Sraar van Heugten: (Ausst. Kat. Amsterdam, Van Gogh Museum, 9. Dezember 1988-26. Februar 1989) Zwolle 1989, S. 27-84.

HOERMANN LISTER, Kristin: Tracing a transformation. Madame Roulin into La Berceuse, in: Van Gogh Museum Journal 2001, hg. v. Van Gogh Museum Amsterdam, Zwolle 2001, S. 62-82.

HOMBURG, Cornelia: The copy turns original. Vincent van Gogh and a new approach to traditional art practice (Oculi. Studies in the Arts of the Low Countries, Bd. 6) Amsterdam, Philadelphia 1996.

HOMBURG, Cornelia: Vincent van Goghs Avantgardestrategien, in: Vincent van Gogh und die Maler des Petit Boulevard, hg. v. Cornelia Homburg (Ausst. Kat. Saint Louis, Art Museum, 17. Februar-13. Mai 2001; Frankfurt, Städelsches Kunstinstitut und Städelsche Galerie, 8. Juni-2. September 2001), Ostfildern-Ruit 2001, S. 23-65.

IVES, Colta: Out of Line. How Van Gogh Made His Mark, in: Vincent Van Gogh. The Drawings, hg. v. John P. O’Neill u.a. (Ausst. Kat. Amsterdam, Van Gogh Museum, 1. Juli-18. September 2005; New York, The Metropolitan Museum of Art, 12. Oktober-31. Dezember 2005), New Haven, London, S. 3-19. 
JANSEN, Leo: Vincent van Gogh, active melancholic. A novice artist takes his stand, in: Van Gogh. The Birth of an Artist, hg. v. Sjraar van Heugten (Ausst. Kat. Mons, Musée des Beaux-Arts, 25. Januar-17 Mai 2015), New Haven, London 2015, S. 78-92.

JANSEN, Leo: Vincent van Gogh's Belief in Art as Consolation, in: Van Goghs Musée imaginaire, hg. v. Chris Stolwijk, Sjraar van Heugten, Leo Jansen und Andreas Blühm (Ausst. Kat. Amsterdam, Van Gogh Museum 14. Februar-13. Juni 2003), London 2003, S. 13-24.

JANSEN, Leo: Selbstaufopferung für die Kunst, in: The Real van Gogh. The Artist and His Letters, hier in der deutschen Übersetzung: Van Gogh. Der Künstler und seine Briefe, mit einem Vorwort von Nicholas Grimshaw (Ausst. Kat. London, Royal Academy of Arts, 23. Januar-18. April 2010), Köln 2010, S. 238-283.

KENDALL, Richard: Nature and the City. Paris, 1886-88, in: Van Gogh and Nature, hg. v. Richard Kendall, Sjraar van Heugten u. Chris Stolwijk (Ausst. Kat. Williamstown, Clark Art Institute, 14. Juni-13. September 2015), New Haven, London 2015, S. 87-127.

KENDALL, Richard, Sjraar van HEUGTEN u. Chris STOLWIJK: Introduction, in: Van Gogh and Nature, hg. v. Richard Kendall, Sjraar van Heugten u. Chris Stolwijk (Ausst. Kat. Williamstown, Clark Art Institute, 14. Juni-13. September 2015), New Haven, London 2015, S. 13-25.

KŌDERA, Tsukasa: Vincent van Gogh. Christianity versus nature (Oculi. Studies in the Arts of the Low Countries, Bd. 3; zugl. Diss. phil. Amsterdam 1988) Amsterdam, Philadelphia 1990.

KOLDEHOFF, Stefan: „Eben doch nur ein Künstler kleineren Stils“, in: 1912 Mission Moderne: Die Jahrhundertschau des Sonderbundes, hg. v. Barbara Schaefer (Ausst. Kat. Köln, Wallraf-Richartz-Museum, 31. August-30. Dezember 2012), Köln 2012, S. 70-87.

LUIJTEN, Hans: „Rummaging among my Woodcuts - Van Gogh and the Graphic Arts, in: Van Goghs Musée imaginaire, hg. v. Chris Stolwijk, Sjraar van Heugten, Leo Jansen und Andreas Blühm Chris Stolwijk, Sjraar van Heugten, Leo Jansen und Andreas Blühm (Ausst. Kat. Amsterdam, Van Gogh Museum 14. Februar - 13. Juni 2003), London 2003, S. 99-112.

MALO, Henri: Les Très Riches Heures du Duc de Berry, Paris 1945.

MEEDENDORP, Teio: Van Gogh's Topography - (A little bit) true to Nature, hg. v. Timothy Standring (Ausst. Kat. Denver, Art Museum 21. Oktober 201220. Januar 2013), New Haven 2012, S. 89-115.

MEIER-GRAEFE, Julius: Impressionisten. Guys, Manet, Van Gogh, Pissarro, Cezanne. Mit einer Einleitung über den Wert der französischen Kunst, München u.a. 1907.

MEIER-GRAEFE, Julius: Vincent, München 1912. 
MEIER-GRAEFE, Julius: Vincent van Gogh. Der Zeichner, Berlin 1928.

MEIER-GRAEFE, Julius: Vincent van Gogh. Der Roman eines Gottsuchers, Berlin u.a. 1932.

MOENS, Bart: Van Gogh in Brussels. A little-known but decisive stage in his early development as an artist, in: Van Gogh. The Birth of an Artist, hg. v. Sjraar van Heugten (Ausst. Kat. Mons, Musée des Beaux-Arts, 25. Januar-17 Mai 2015), New Haven, London 2015, S. 104-117.

MULLINS, Edwin: Van Gogh. The Asylum Year. London 2015.

NAIFEH, Steven u. Gregory WHITE SMITH: Van Gogh. The Life, London 2011.

NOLL, Thomas: Der große Sämann: Zur Sinnbildlichkeit in der Kunst von Vincent van Gogh, Worms 1994.

NOLL, Thomas: Van Gogh: Felder. Das Mohnfeld und der Künstlerstreit (Rezension Ausst. Kat.), in: Kunstchronik, hg. v. Zentralinstitut für Kunstgeschichte in München, 56. Jahrgang, Heft 7, Nürnberg 2003, S. 349-356.

NOLL, Thomas: Vincent van Gogh. Fischerboote am Strand, Frankfurt am Main, Leipzig 1996.

Van Gogh in Saint-Rémy und Auvers, hg. v. Ronald PICKVANCE (Ausst. Kat. New York, The Metropolitan Museum of Art, 25. November 1986-22. März 1987), New York 1986.

Van Gogh in Arles, hg. v. Ronald PICKVANCE (Ausst. Kat. New York, The Metropolitan Museum of Art, 18. Oktober-30 Dezember 1984), New York 1984.

POLLOCK, Griselda: On not seeing Provence. Van Gogh and the Landscape of Consolation, 1888-9, in: Framing France. The Representation of Landscape in France, hg. v. Richard Thomson, Manchester, New York 1998, S. 81-118.

RATHBONE, Eliza E.: Baby Marcelle Roulin, in: Van Gogh. Repetitions, hg. v. Eliza E. Rathbone, William H. Robinson, Elizabeth Steele u. Marcia Steele (Ausst. Kat. Washington D.C., The Phillips Collection, 12. Oktober 201326. Januar 2014; The Cleveland Museum of Art, 2. März-26. Mai 2014) New Haven, London 2013, S. 112-117.

RATHBONE, Eliza E.: Camille Roulin, in: Van Gogh. Repetitions, hg. v. Eliza E. Rathbone, William H. Robinson, Elizabeth Steele u. Marcia Steele (Ausst. Kat. Washington D.C., The Phillips Collection, 12. Oktober 2013-26. Januar 2014; The Cleveland Museum of Art, 2. März-26. Mai 2014), New Haven, London 2013, S. 106-111.

RATHBONE, Eliza E.: Madame Augustine Roulin and Baby Marcelle, in: Van Gogh. Repetitions, hg. v. Eliza E. Rathbone, William H. Robinson, Elizabeth Steele u. Marcia Steele (Ausst. Kat. Washington D.C., The Phillips Collection, 12. Oktober 2013-26. Januar 2014; The Cleveland Museum of Art, 2. März-26. Mai 2014), New Haven, London 2013, S. 100-105. 
REWALD, John: Von van Gogh bis Gauguin. Die Geschichte des Nachimpressionismus, Köln 1967.

ROBINSON, William H.: The Artist versus the Legend: Repetitions and Madness, in: Van Gogh. Repetitions, hg. v. Eliza E. Rathbone, William H. Robinson, Elizabeth Steele u. Marcia Steele (Ausst. Kat. Washington D.C., The Phillips Collection, 12. Oktober 2013-26. Januar 2014; The Cleveland Museum of Art, 2. März-26. Mai 2014), New Haven, London 2013, S. 8-15.

ROBINSON, William H.: On the Origins and Evolution of van Gogh's Repetitions, in: Van Gogh. Repetitions, hg. v. Eliza E. Rathbone, William H. Robinson, Elizabeth Steele u. Marcia Steele (Ausst. Kat. Washington D.C., The Phillips Collection, 12. Oktober 2013-26. Januar 2014; The Cleveland Museum of Art, 2. März-26. Mai 2014), New Haven, London 2013, S. 16-39.

ROBINSON, William H., Marcia STEELE u. Galina K. OLMSTED: Le Moulin de la Galette, in: Van Gogh. Repetitions, hg. v. Eliza E. Rathbone, William H. Robinson, Elizabeth Steele u. Marcia Steele (Ausst. Kat. Washington D.C., The Phillips Collection, 12. Oktober 2013-26. Januar 2014; The Cleveland Museum of Art, 2. März-26. Mai 2014), New Haven, London 2013, S. 50-57.

ROBINSON, William H., Marcia STEELE, H. Travers NEWTON u. Galina K. OLMSTED: The Bedroom, in: Van Gogh. Repetitions, hg. v. Eliza E. Rathbone, William H. Robinson, Elizabeth Steele u. Marcia Steele (Ausst. Kat. Washington D.C., The Phillips Collection, 12. Oktober 2013-26. Januar 2014; The Cleveland Museum of Art, 2. März-26. Mai 2014), New Haven, London 2013, S. 82-89.

SAUER, Martina: Cézanne - van Gogh - Monet. Genese der Abstraktion, (Diss. phil. 1999/2000) Bühl 1999/2000.

SCHNEEDE, Uwe M.: Van Gogh in St. Rémy und Auvers. Gemälde 1889/1890, München 1889.

SCHNEEDE, Uwe M.: Vincent van Gogh. Leben und Werk, München 2003.

SILVERMAN, Debora: Van Gogh and Gauguin, The Search for Sacred Art, New York 2000.

SILVERMAN, Debora: Framing art and sacred realism. Van Gogh's ways of seeing Arles, in: Van Gogh Museum Journal 2001, hg. v. Van Gogh Museum Amsterdam, Zwolle 2001, S. 44-61.

STEELE, Marcia u. H. Travers NEWTON: The Postman, in: Van Gogh. Repetitions, (Ausst. Kat. Washington D.C., The Phillips Collection, 12. Oktober 2013-26. Januar 2014; The Cleveland Museum of Art, 2. März-26. Mai 2014), New Haven, London 2013, S. 62-81. 
STEELE, Marcia u. Elizabeth STEELE: Methods for making Repetitions, in: Van Gogh. Repetitions, hg. v. Eliza E. Rathbone, William H. Robinson, Elizabeth Steele u. Marcia Steele (Ausst. Kat. Washington D.C., The Phillips Collection, 12. Oktober 2013-26. Januar 2014; The Cleveland Museum of Art, 2. März-26. Mai 2014), New Haven, London 2013, S. 170-177.

STEELE, Elizabeth: La Berceuse, in: Van Gogh. Repetitions, hg. v. Eliza E. Rathbone, William H. Robinson, Elizabeth Steele u. Marcia Steele (Ausst. Kat. Washington D.C., The Phillips Collection, 12. Oktober 2013-26. Januar 2014; The Cleveland Museum of Art, 2. März-26. Mai 2014), New Haven, London 2013, S. 118-139.

STOLWIJK, Chris: How Nature Speaks. Holland, 1881-85, in: Van Gogh and Nature, hg. v. Richard Kendall, Sjraar van Heugten u. Chris Stolwijk (Ausst. Kat. Williamstown, Clark Art Institute, 14. Juni-13. September 2015), New Haven, London 2015, S. 27-65.

STOLWIJK, Chris: Such Expression and Atmosphere and Sentiment. Van Gogh's Early Ideas about the Expressive Power of Painting, in: Van Gogh and Expressionism, hg. v. Jill Lloyd (Ausst. Kat. Amsterdam, Van Gogh Museum, 24. November 2006-4. März 4 2007, New York, Neue Galerie, 23. März-2. Juli 2007). Ostfildern 2007, S. 29-36.

STOLWIJK, Chris: Van Gogh's Nature, in: Van Goghs Musée imaginaire, hg. v. Chris Stolwijk, Sjraar van Heugten, Leo Jansen und Andreas Blühm (Ausst. Kat. Amsterdam, Van Gogh Museum 14. Februar-13. Juni 2003), London 2003, S. 25-36.

THOMSON, Richard: Die kulturelle Geografie des Petit Boulevard, in: Vincent van Gogh und die Maler des Petit Boulevard, hg. v. Cornelia Homburg (Ausst. Kat. Saint Louis, Art Museum, 17. Februar-13. Mai 2001; Frankfurt, Städelsches Kunstinstitut und Städelsche Galerie, 8. Juni-2. September 2001), Ostfildern-Ruit 2001, S. 67-114.

TILBORGH, Louis van: Les Quatre Saisons, in: Millet. Van Gogh, hg. v. Louis van Tilborgh (Ausst. Kat. Paris, Musée d'Orsay, 14. September 1998-3. Januar 1999), Paris 1998, S. 68-79.

TILBORGH, Louis van: The Potato Eaters by / De aardappeleters van Vincent van Gogh, Zwolle 1993.

TILBORGH, Louis van: The same, but different. Van Gogh and his Mentor Millet, in: Van Gogh \& Millet, hg. v. Louis van Tilborgh u. Sraar van Heugten: (Ausst. Kat. Amsterdam, Van Gogh Museum, 9. Dezember 1988-26. Februar 1989) Zwolle 1989, S. 9-24.

TRALBAUT, Mark Edo: Van Goghiana, Bd. 7, Antwerpen 1970.

UITERT, Evert van: Van Gogh's Taste for Reality, on Earth as it is in Heaven, in: Van Goghs Musée imaginaire, hg. v. Chris Stolwijk, Sjraar van Heugten, Leo Jansen und Andreas Blühm (Ausst. Kat. Amsterdam, Van Gogh Museum 14. Februar-13. Juni 2003), London 2003, S. 73-86. 
VEEN, Wouter van der: An avid reader - Van Gogh and Literature, in: Van Goghs Musée imaginaire, hg. v. Chris Stolwijk, Sjraar van Heugten, Leo Jansen und Andreas Blühm (Ausst. Kat. Amsterdam, Van Gogh Museum 14. Februar-13. Juni 2003), London 2003, S. 49-60.

VELDHORST, Natascha: Van Gogh \& Muziek. Symfonie in Blauw en Geel, Amsterdam 2015.

VELLEKOOP, Marije: Van Gogh in the Borinage. From Evangelist to Artist, in: Van Gogh. The Birth of an Artist, hg. v. Sjraar van Heugten (Ausst. Kat. Mons, Musée des Beaux-Arts, 25. Januar-17 Mai 2015), New Haven, London 2015, S. 50-77.

VELLEKOOP, Marije, Muriel GELDORF, Ella HENDRICKS, Leo JANSEN u. Alberto de Tagle (Hgg.): Van Gogh's Studio Practice, Amsterdam 2013.

WERTHEMANN, Seraina u. Nina ZIMMER: Saint-Rémy. Katalog der ausgestellten Werke, in: Vincent van Gogh. Zwischen Erde und Himmel. Die Landschaften, hg. v. Kunstmuseum Basel (Ausst. Kat. Basel, Kunstmuseum, 26. April-27. September 2009), Ostfildern 2009, S. 236-265.

ZIMMER, Nina: Van Goghs in Serie Zyklen, Gruppen, Triptychen, in: Vincent van Gogh. Zwischen Erde und Himmel. Die Landschaften, hg. v. Kunstmuseum Basel (Ausst. Kat. Basel, Kunstmuseum, 26. April-27. September 2009), Ostfildern 2009, S. 96-118.

\section{b. Sonstige Sekundärliteratur}

Jean Fouquet. Peintre et enlumineur du XVe siècle, hg. v. François AVRIL (Ausst.

Kat. Paris, Bibliothèque nationale de France, site Richelieu, Galerie Mazarine, 25. März - 22 Juni 2003), Paris 2003.

Cézanne. Aufbruch in die Moderne, hg. v. Felix A. BAUMANN, Walter FEILCHENFELDT u. Hubertus GASSNER (Ausst. Kat. Essen, Museum Folkwang, 18. September 2004-16. Januar 2005), Ostfildern-Ruit 2004.

BAUMANN, Felix A.: Malen „sur le motif“ und im Atelier. Von Valenciennes zu Corot, von Corot zu Cézanne, in: Sehnsucht Italien, hg. v. Felix A. Baumann (Ausst. Kat. Baden, Museum Langmatt, 1. April-18. Juli 2004), Heidelberg 2004, S. 14-35.

BECKS-MALORNY, Ulrike: Paul Cézanne 1839-1906. Wegbereiter der Moderne, Köln 2007.

BENJAMIN, Walter: The Work of Art in the Age of Mechanical Reproduction, übersetzt in das Englische von J. A. Underwood, London 2008.

BOCKEMÜHL, Michael: Der Traum der Sinne und die innere Einheit, in: Paul Gauguin. Das verlorene Paradies, hg. v. Georg-W. Költzsch (Ausst. Kat. Essen, Museum Folkwang, 17. Juni 1998-18. Oktober 1998; Berlin, Neue Nationalgalerie, 31. Oktober-10. Januar 1999), Köln 1998, S. 102-117. 
BOEHM, Gottfried: Paul Cézanne. Montagne Sainte-Victoire, Frankfurt 1988.

BOEHM, Gottfried: Werk und Serie. Probleme des modernen Bildbegriffs seit Monet, in: Die Sichtbarkeit der Zeit, hg. v. Ralph Ubl, Paderborn 2017, S. 137-146 (zuerst erschienen in: Hess, Daniel u. Gundolf Winter (Hg.), Kreativität und Werkerfahrung. Festschrift für Ilse Krahl zum 65. Geburtstag (Duisburger Studien), Duisburg 1988, S. 17-24).

BÖSEN, Willibald: Der letzte Tag des Jesus von Nazaret. Was wirklich geschah, Freiburg u.a. 1994.

BOIME, Albert: The Academy and French Painting in the Nineteenth Century, London 1971.

BRETTELL, Richard R., Paul Hayes TUCKER u. Natalie H. LEE (Hgg.): The Robert Lehman Collection at the Metropolitan Museum of Art, Bd. 3, Nineteenth- and Twentieth-Century Paintings. New York 2009.

CAHN, Isabelle u. Antoine TERRASSE (Hgg.): Gauguin und die Schule von Pont-Aven, München 1998.

CLARK, Kenneth: Landscape into Art, 2. überarb. Aufl., London 1979.

CONISBEE, Philip: Pre-Romantic Plein-Air Painting, in: Art History, Bd. 2, Oxford 1979, S. 413-428.

Serial Imagery, hg. v. The New York Graphic Society in association with The Pasadena Art Museum, Text von John COPLANS (Ausst. Kat. Pasadena Art Museum, 17. September-27 Oktober 1968; Seattle, University of Washington, 17. November - 22. Dezember 1968; Santa Barbara Museum of Art, 25. Januar-23. Februar 1969), New York 1968.

DELISLE, Léopold: Les Livres d'heures du Duc de Berry, Extrait de la Gazette des Beaux-Arts, février, avril et mai 1884, Paris 1884.

DEMUS, Klaus: „Die Zeiten des Jahres“, in: Katalog der Gemäldegalerie. Flämische Malerei von Jan van Eyck bis Pieter Bruegel d. Ä., Teil 1, zusammengestellt von Klaus Demus, Friderike Klauner u. Karl Schütz, Wien 1981, S. 86-103.

DEMUS, Klaus: Die Zeiten des Jahres, in: Pieter Bruegel d. Ä. im Kunsthistorischen Museum Wien, hg. v. Wilfried Seipel (Ausst. Kat. Wien, Kunsthistorisches Museum, 7. Dezember 1997-14. April 1998), Mailand 1997, S. 84-89.

DERENTHAL, Ludger: „Die Erziehung des Auges“. Die serielle Photographie, das wissenschaftliche Experiment und Monets „Getreideschober“, in: Monets Vermächtnis. Serie, Ordnung und Obsession, hg. v. Uwe M. Schneede (Ausst. Kat. Hamburg, Kunsthalle, 28. September 2001-6. Januar 2002), OstfildernRuit 2001, S. 23-28.

DITTMANN, Lorenz: Die Kunst Cézannes. Farbe, Rhythmus, Symbolik, Köln 2005.

DIVJAK, Johannes u. Wolfgang WISCHMEYER: Das Kalenderhandbuch von 354. Der Chronograph des Filocalus, Bd. 1 u. 2, Wien 2014. 
FEIST, Peter H. u. Ingo F. WALTHER: Impressionist Art. Impressionism in France, Bd. 1, Köln 1993.

FRÜCHTEL, Ursula: Mit der Bibel Symbole entdecken, Göttingen 21994.

FUCHS, Martina: Trauer, Rauch und Bäckereidinge... Zu einem nie ausgeführten Konzept von Edgar Degas, in: Monets Vermächtnis. Serie, Ordnung und Obsession, hg. v. Uwe M. Schneede (Ausst. Kat. Hamburg, Kunsthalle, 28. September 2001-6. Januar 2002), Ostfildern-Ruit 2001, S. 29-32.

GÖRGEN, Annabelle: Die Unschuld des Auges. Serielle Wiederholung und die Suche nach den Ursprüngen, in: Monets Vermächtnis. Serie, Ordnung und Obsession, hg. v. Uwe M. Schneede (Ausst. Kat. Hamburg, Kunsthalle, 28. September 2001-6. Januar 2002), Ostfildern-Ruit 2001, S. 45-52.

Inventing Impressionism. Paul Durand-Ruel and the Modern Art Market, hg. v. Jan GREEN (Ausst. Kat. London, National Gallery, 4. März-31 Mai 2015 u.a.), London 2015.

HAMILTON, George Heard: The Dying of the Light, in: Aspects of Monet, hg. v. John Rewald u. Frances Weitzenhoffer, New York 1984, S. 218-241.

HANSEN, Wilhelm: Kalenderminiaturen der Stundenbücher. Mittelalterliches Leben im Jahreslauf, München 1984.

HAYES TUCKER, Paul: Monet in the '90s. The Series Paintings (zugleich Ausst. Kat. Boston, Museum of Fine Arts; Chicago, The Art Institute u. London, Royal Academy of Arts 1989), New Haven u.a. 1989.

HEFLING, Stephen E.: The Genesis of "Ich bin der Welt abhanden gekommen“, in: Gustav Mahler. Ich bin der Welt abhanden gekommen, Facsimile Edition of the Autograph Manuscripts, hg. v. Gilbert Kaplan, New York 2015, S. 17-33.

HEINRICH, Christoph: Serie - Ordnung und Obsession, in: Monets Vermächtnis. Serie, Ordnung und Obsession, hg. v. Uwe M. Schneede (Ausst. Kat. Hamburg, Kunsthalle, 28. September 2001-6. Januar 2002), Ostfildern-Ruit 2001, S. 7-12.

HEINRICH, Christoph: Une série d'effets différents. Monets „Getreideschober“ als Hülle für das Licht, die Zeit, das Universum - und „die märchenhafte Pracht der Malerei“, in: Monets Vermächtnis. Serie, Ordnung und Obsession, hg. v. Uwe M. Schneede (Ausst. Kat. Hamburg, Kunsthalle, 28. September 2001-6. Januar 2002), Ostfildern-Ruit 2001, S. 13-22.

HENISCH, Bridget Ann: The Medieval Calendar Year, Pennsylvania 1999.

HERBERT, Robert L.: The decorative and the natural in Monet's Cathedrals, in: Aspects of Monet, hg. v. John Rewald u. Frances Weitzenhoffer, New York 1984, S. 160-179.

HEROLD, Inge: Pieter Bruegel. Die Jahreszeiten, München 2002.

KLEIN, John: The Dispersal of the Modernist Series, in: The Oxford Art Journal, Bd. 21, Heft 1, Oxford 1998, S. 121-135. 
KREN, Thomas: New Directions in Manuscript Painting. Circa 1510-1561, in: Illuminating the Renaissance, hg. v. Thomas Kren u. Scott McKendrick (Ausst. Kat. Los Angeles, The J. Paul Getty Museum, 17. Juni-7. September 2003; London, The Royal Academy of Arts, London, 29. November 200322. Februar 2004), London 2003, S. 411-515.

KURZ, Martina: Bild-Verdichtungen. Cézannes Realisation als poetisches Prinzip bei Rilke und Handke (Palaestra. Untersuchungen aus der deutschen und skandinavischen Philologie, Bd. 315; zugl. Diss. phil. Trier 1999) Göttingen 2003.

LANGMUIR, Erika: The National Gallery Companion Guide, London 2006.

MAINARDI, Patricia: The 19th-Century Art Trade: Copies, Variations, Replicas, in: Van Gogh Museum Journal 2000, hg. v. Van Gogh Museum Amsterdam, Zwolle 2000, S. 63-74.

MOFFETT, Charles S.: Monet's Haystacks, in: Aspects of Monet, hg. v. John Rewald u. Frances Weitzenhoffer, New York 1984, S. 140-159.

MÜLLER HOFSTEDE, Justus: Zur Interpretation von Pieter Bruegels Landschaft. Ästhetischer Landschaftsbegriff und Stoische Weltbetrachtung, in: Pieter Bruegel und seine Welt, hg. v. Otto von Simson und Matthias Winner, Berlin 1979, S. 73-142.

Delacroix and the Rise of Modern Art, hg. v. Patrick NOONE u. Christopher RIOPELLE (Ausst. Kat. Minneapolis Institute of Art, 18. Oktober 2015-10. Januar 2016; London, National Gallery, 17. Februar-22. Mai 2016), London 2015.

NOVOTNY, Fritz: Die Monatsbilder Pieter Bruegels d. Ä., Wien 1948.

PHILIPP, Wolfgang: Das Werden der Aufklärung in theologiegeschichtlicher Sicht (Forschungen zur systematischen Theologie und Religionsphilosophie, Bd. 3), Göttingen 1957.

REWALD, John: The History of Impressionism, New York 1961.

RIOPELLE, Christopher: Afterlife. Delacroix's Posthumous Fame, in: Delacroix and the Rise of Modern Art, hg. v. Patrick Noone u. Christopher Riopelle (Ausst. Kat. Minneapolis Institute of Art, 18. Oktober 2015-10. Januar 2016; London, National Gallery, 17. Februar-22. Mai 2016), London 2015, S. 37-63.

RUBIN, James H.: Impressionism, London, New York 1999, Nachdruck: 2001.

RUBIN, James H.: Impressionism and the Modern Landscape, Technology and Urbanization from Manet to van Gogh, Berkeley 2008.

SAUERLÄNDER, Willibald: Das Königsportal in Chartres: Heilsgeschichte und Lebenswirklichkeit, Frankfurt 1996. 
SAUERLÄNDER, Willibald: Die Jahreszeiten. Ein Beitrag zur allegorischen Landschaft beim späten Poussin, in: Münchner Jahrbuch der bildenden Kunst, hg. v. d. Staatlichen Kunstsammlungen u. d. Zentralinstitut für Kunstgeschichte in München, Heft 7, München 1956, S. 169-184.

SCHAEFER, Claude: Jean Fouquet. An der Schwelle zur Renaissance, Dresden u. Basel, 1994.

SCHMIDT, Bertram: Cézannes Lehre, Kiel 2004.

SHIFF, Richard: Cézanne and the End of Impressionism. A Study of the Theory, Technique, and Critical Evaluation of Modern Art, Chicago u. London 1986.

SONNTAG, Dina: Gauguins Weg nach Tahiti, in: Paul Gauguin. Tahiti, hg. v. Christoph Becker (Ausst. Kat. Stuttgart, Staatsgalerie, 7. Februar-1. Juni 1998), Ostfildern-Ruit 1998, S. 85-105.

SOUBIRAN, Jean-Roger: La Montagne Sainte-Victoire. Un Atelier du Paysage Provençal de Constantin à Cézanne, Avignon 2006.

STECHOW, Wolfgang: Pieter Bruegel the Elder, New York 1969.

SYKORA, Katharina: Das Phänomen des Seriellen in der Kunst. Aspekte einer künstlerischen Methode von Monet bis zur amerikanischen Pop Art, (Diss. phil. Heidelberg 1982) Würzburg 1983.

TOMPKINS LEWIS, Mary: Cézanne, London 2000.

\section{c. Auktions- und Antiquariatskataloge}

Arnim, Manfred von: Position 64, Calendar. In disem teütschen calendar vindet man gar hübsch nach einander die zwelff zeychen [...] Augsburg: Johann Schönsberger, 12. November 1492, in: A Choice of Early Printed Books (1454-1577), Dr. Jörn Günther Antiquariat, Hamburg 2002, S. 278-283, S. 281

Internetseite des Auktionshauses Christie's, abgerufen für die Katalogisierungen von Kornfeld, Blick auf die Kirche von Saint-Paul-de-Mausole, hier Los 12, Auktion 8049, 7.2.2012, London, unter:

http:/www.christies.com/lotfinder/paintings/vincent-van-gogh-vue-de-lasileet-5532359-details.aspx.

sowie Gepflügte Äcker, hier Los 28A, Auktion 15004, 13.11.2017, New York, am 28.10.2017, unter: http://www.christies.com/lotfinder/paintings/vincentvan-gogh-laboureur-dans-un-champ-6108742-details.aspx?from=salesummary\&intObjectID=6108742\&lid $=1$.

Internetseite des Auktionshauses Sotheby's, abgerufen für die Katalogisierung von Camille Pissarros Les Quatre Saisons (L'hiver, Le printemps, L'eté, L'automne), hier Los 19, L17002, 1.3.2017, London, abgerufen unter: http://www.sothebys.com/en/auctions/ecatalogue/lot.pdf.L17002.html/f/19/ L17002-19.pdf 
d. Lexika und Nachschlagewerke

Hall's Dictionary of Subjects \& Symbols in Art, mit einer Einführung von Kenneth Clark, überarbeitete Neuauflage, London 1996.

Lexikon für Theologie und Kirche, hg. v. Walter Kasper u.a., Bd. 4, Franca bis Hermenegild, Freiburg 1995.

Meyers großes Taschenlexikon, Bd. 20 u. Bd. 25, red. Leitung Annette Zwahr, Mannheim 1999 (7. Auflage).

Prestel Lexikon. Kunst und Künstler im 20. Jahrhundert, Sagner-Düchting, Karin und Hajo Düchting (Red.), München 1999.

Realencyclopädie der classischen Altertumswissenschaft, hg. v. Georg Wissowa, Bd. 3, 2, Campanus ager-Claudius, Stuttgart 1899.

The Grove Encyclopedia of Medieval Art and Architecture, hg. v. Colum P. Hourihane, Bd. 1, Aachen-Cecco di Pietro, New York 2012.

\section{Onlineressourcen}

[Vollständiges und editiertes Verzeichnis der Briefe von und an Vincent van Gogh]

Vincent van Gogh. The Letters, hg. v. Leo JANSEN, Hans LUIJTEN u. Nienke BAKKER, Amsterdam u. Den Haag 2009 (Version: Dezember 2010), abrufbar unter: http://vangoghletters.org

SPRINSON DE JESÚS, Mary: Pieter Bruegel the Elder, The Harvesters [Kornernte], Beitrag aus dem Bestandskatalog der Sammlung des Metropolitan Museums of Art in New York, abgerufen unter: https://www.metmuseum. org/art/collection/search/435809.

Dictionnaire de l'Académie des Beaux-Arts, hg. v. Institut de France, Bd. 4, chorégraphie bis cour, Paris 1884, abgerufen als Online-Faksimile, unter http:// bibliotheque-numerique.inha.fr/viewer/8934/?offset=\#page=300\&viewer=picture.

Alle Bibelzitate sind der Lutherbibel 2017 entnommen, abrufbar unter https:// www.bibleserver.com, Stand 17.2.2018.

Sämtliche Adressen der Online-Quellen entsprechen dem Stand am 17.2.2018. 


\section{Abbildungen}

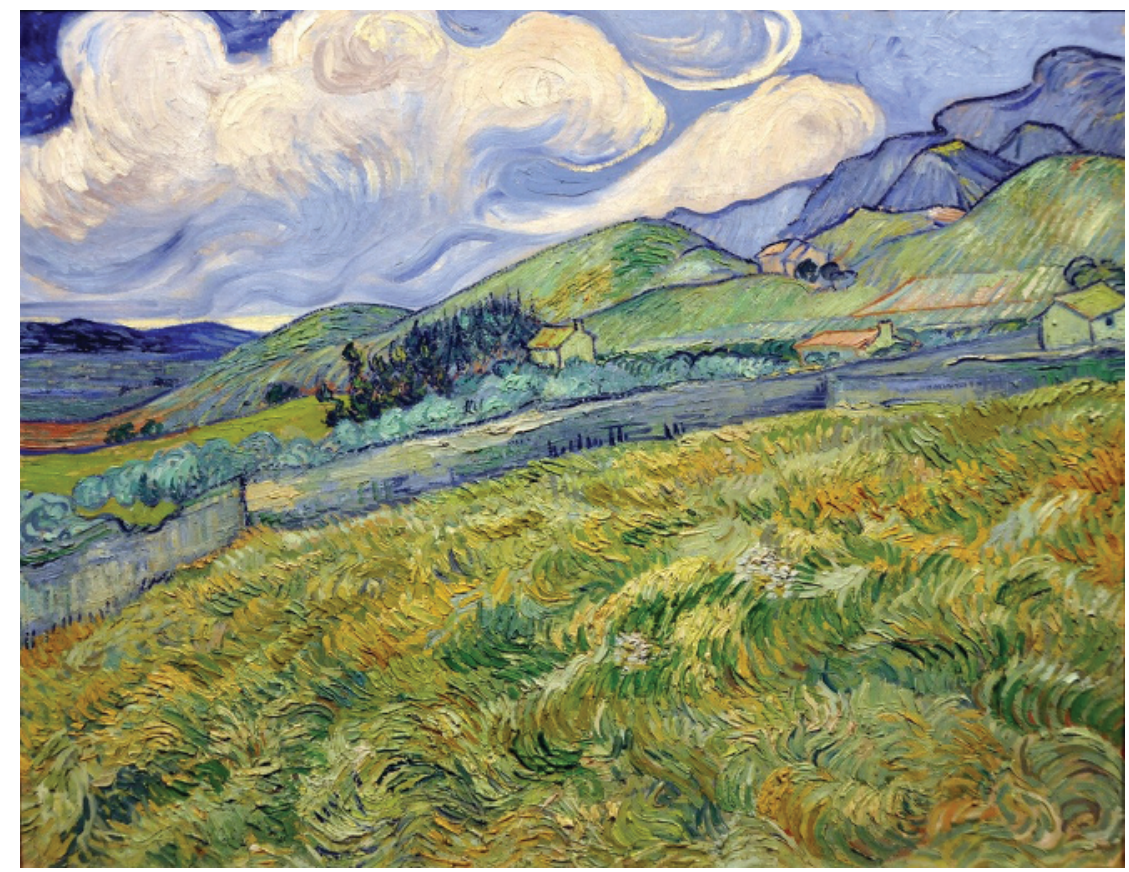

Abb. 1 Kornfeld, nach dem Unwetter, Juni 1889, Öl auf Leinwand, 70,5 x 88,5 cm, Ny Carlsberg Glyptothek, Kopenhagen, F 611, JH 1723.

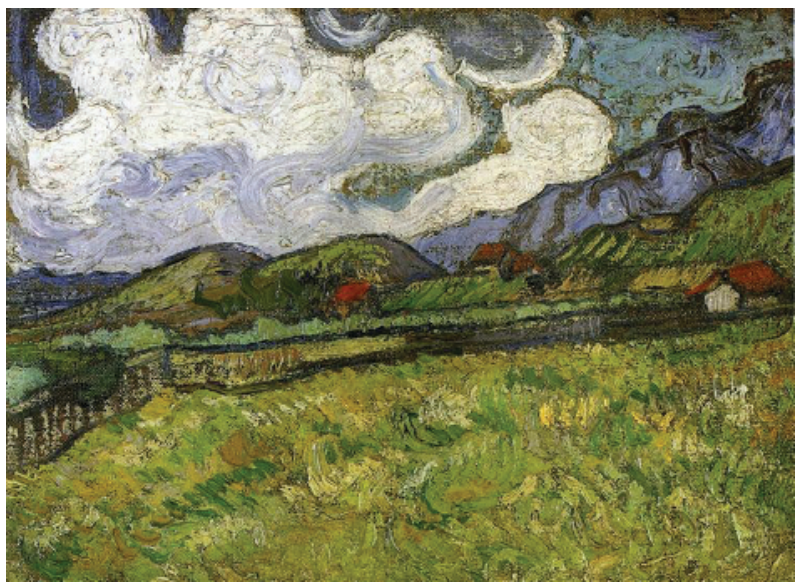

Abb. 2

Kornfeld, nach dem Unwetter, „réduction“, November-Dezember 1889, Öl auf Leinwand, $24,1 \times 33,7 \mathrm{~cm}$,

Richmond, Virginia Museum of Fine Arts, F 722, JH 1872. 


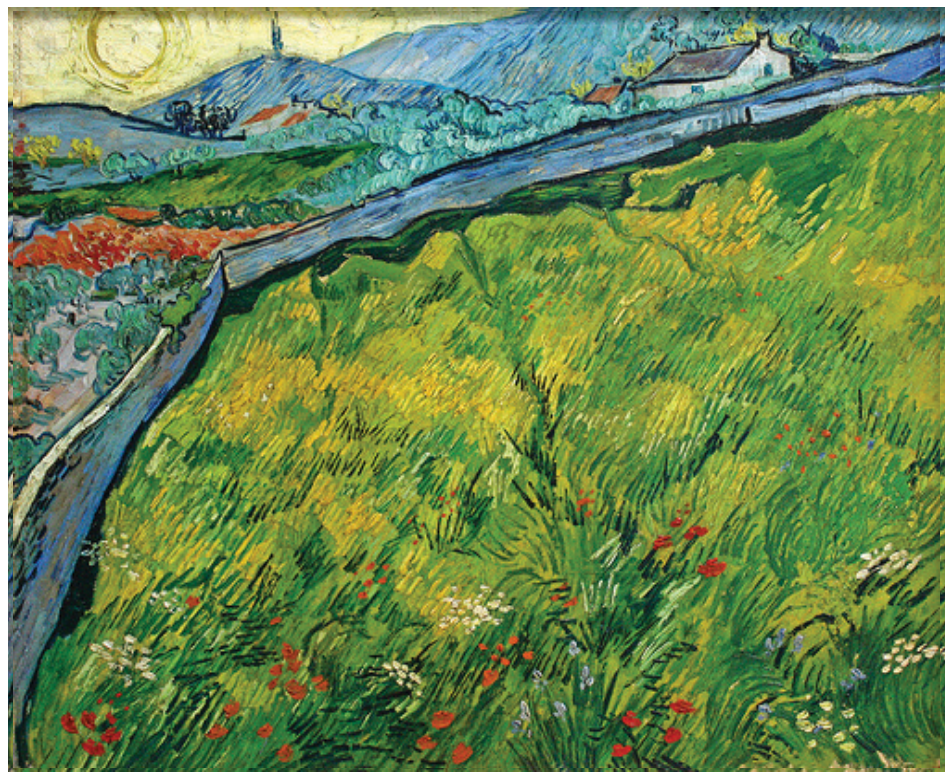

Abb. 3 Kornfeld, Ende Mai oder Anfang Juni 1889,

Öl auf Leinwand, 72 x 92 cm, Kröller-Müller Museum, Otterlo, F 720, JH 1728.

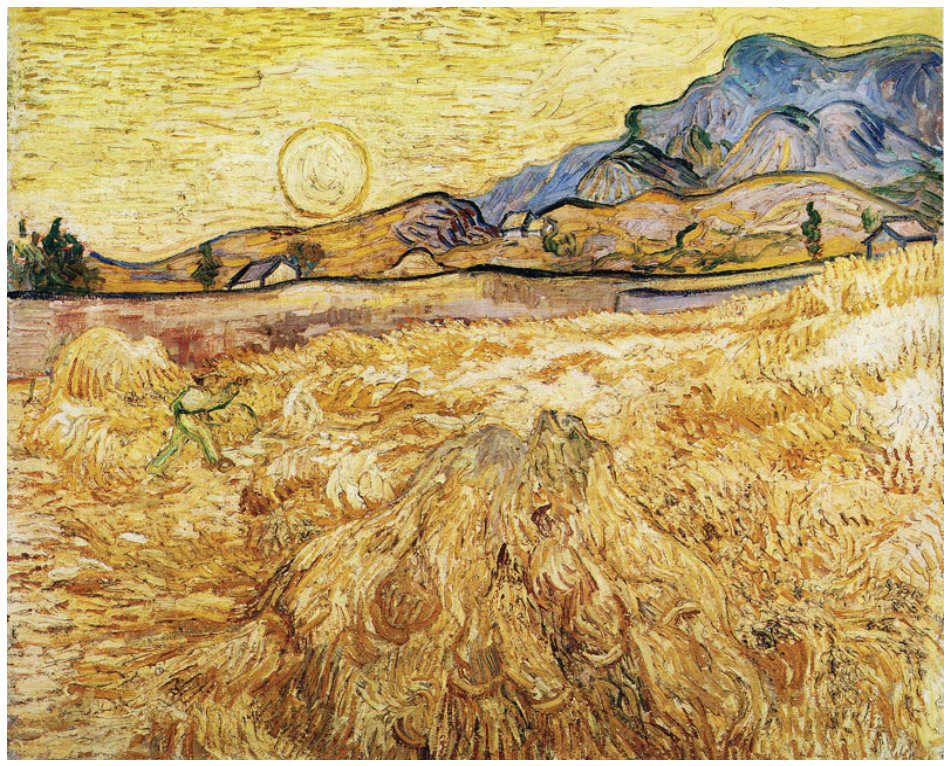

Abb. 4 Kornfeld, der Schnitter, „étude“, Juni-Juli 1889,

Öl auf Leinwand, 72 x 92 cm, Kröller-Müller Museum, Otterlo, F 617, JH 1753. 


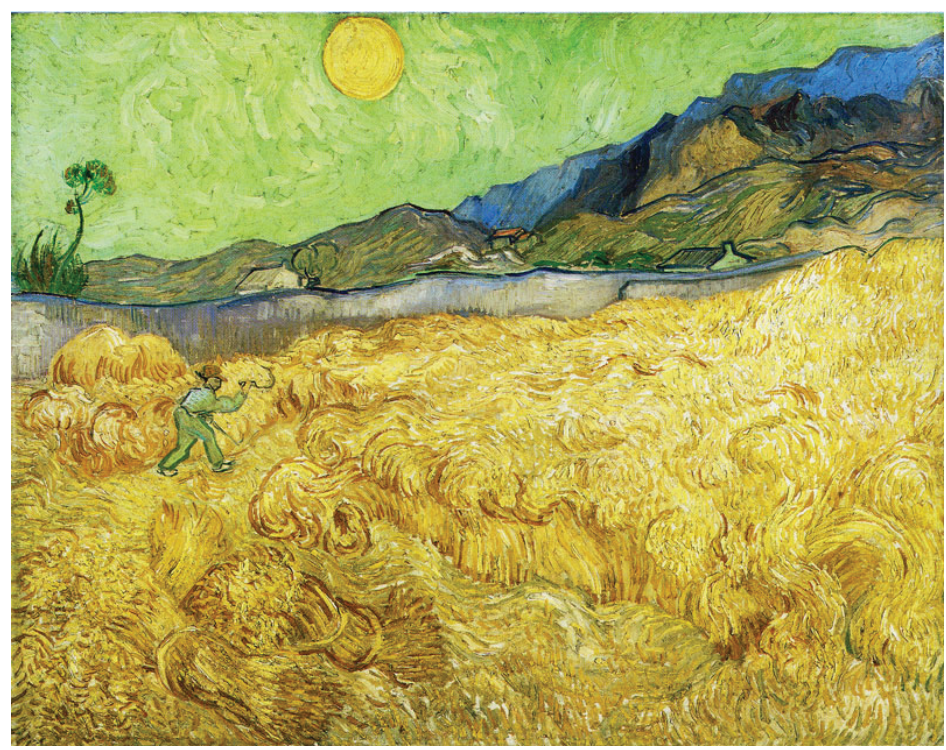

Abb. 5 Kornfeld, der Schnitter, „tableau“, September 1889, Öl auf Leinwand, 73 x $92 \mathrm{~cm}$, Van Gogh Museum, Amsterdam F 618, JH 1773.

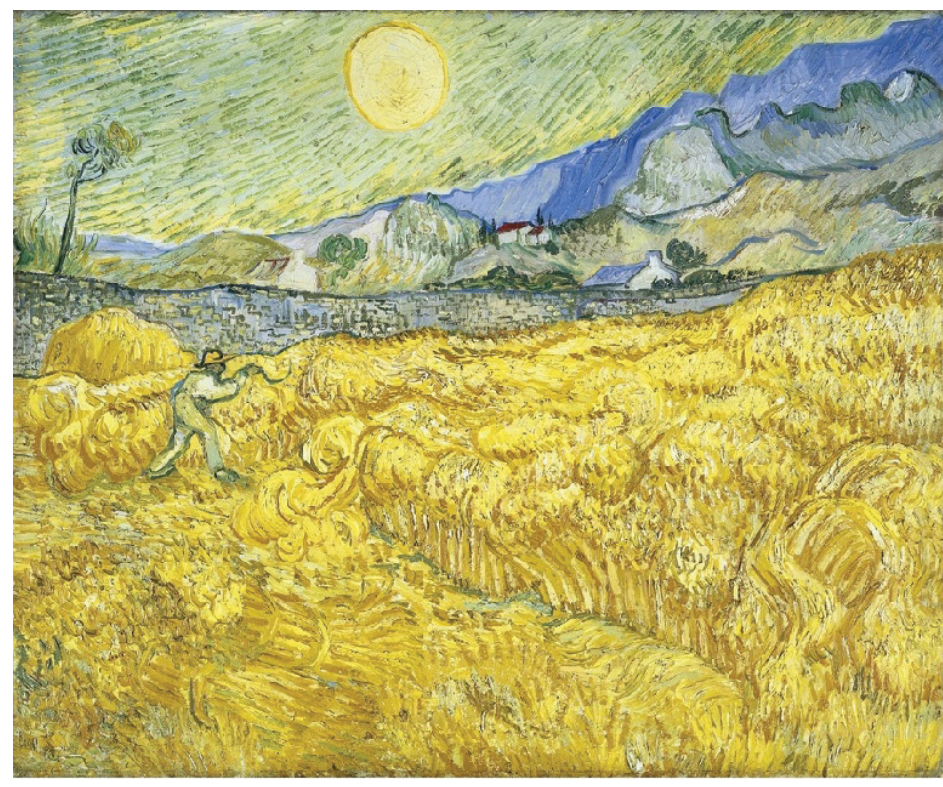

Abb. 6 Kornfeld, der Schnitter, „réduction“, Oktober 1889, Öl auf Leinwand, 59,5 x 73 cm, Museum Folkwang, Essen, F 619, JH 1792. 


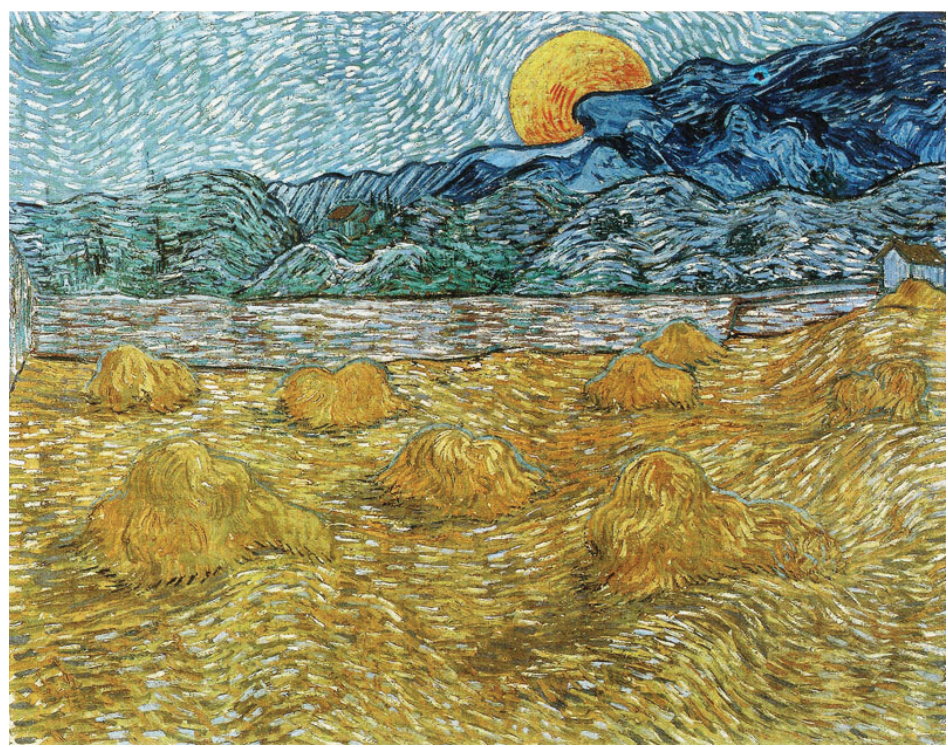

Abb. 7 Kornfeld, Mondaufgang, Juli 1889, Öl auf Leinwand, 72 x 92 cm, Kröller-Müller Museum, Otterlo, F 735, JH 1761.

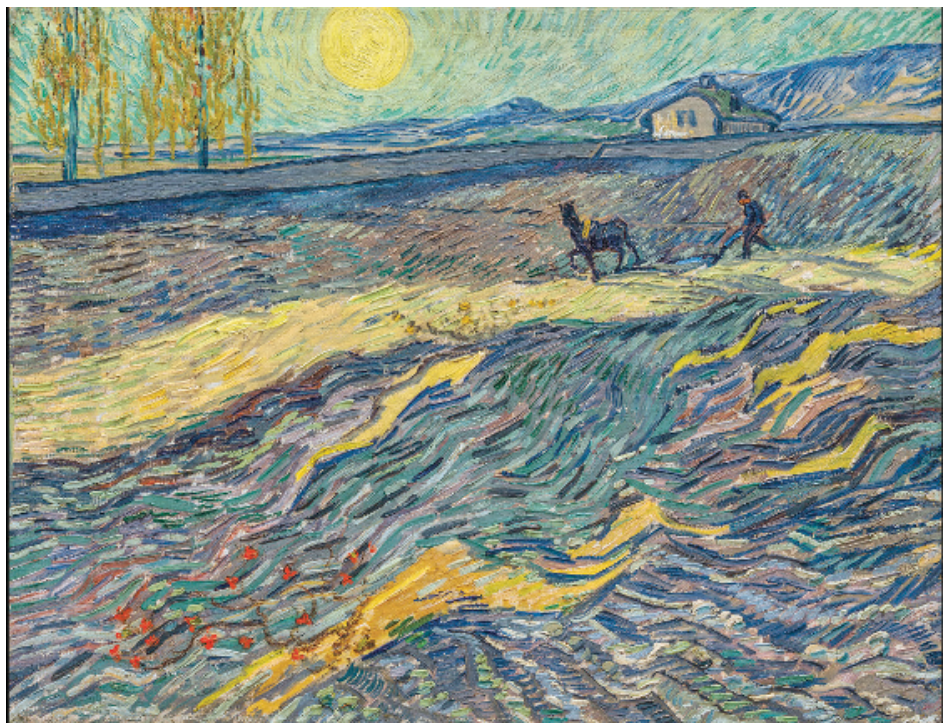

Abb. 8 Gepflügte Äcker, Ende August, vor 2.9.1889, Öl auf Leinwand, 49 x 62 cm, Privatbesitz, F 625, JH 1768. 


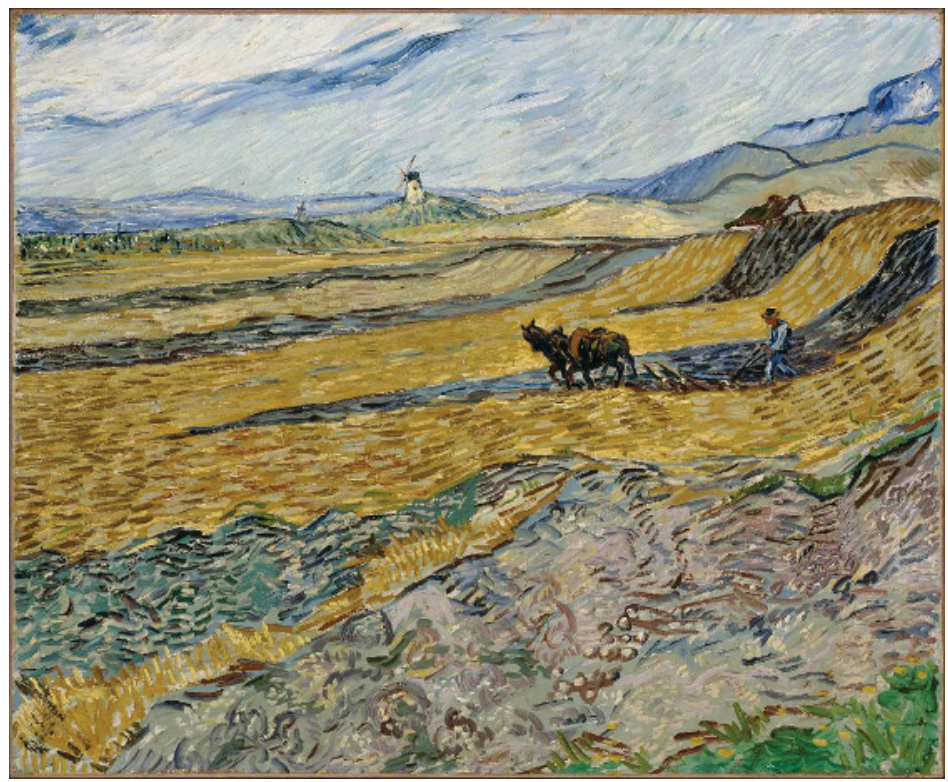

Abb. 9 Gepflügte Äcker, Morgenlicht, September 1889, Öl auf Leinwand, 54 × $67 \mathrm{~cm}$, Museum of Fine Arts, Boston, F 706, JH 1794.

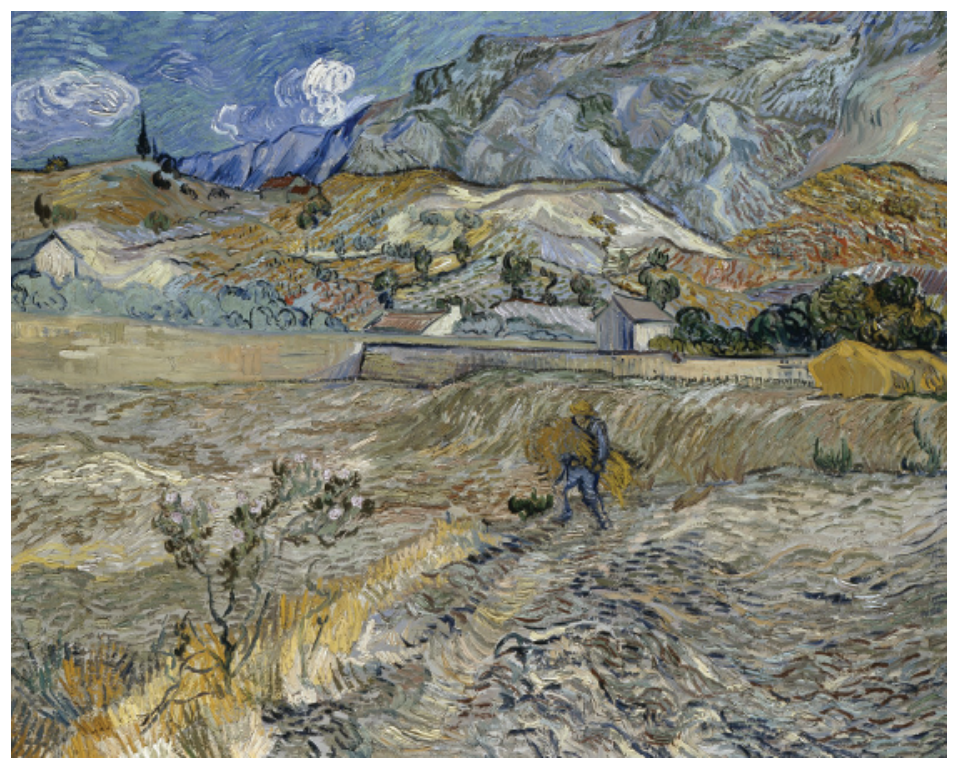

Abb. 10 Ummauertes Feld mit Bauern, Oktober 1889,

Öl auf Leinwand, 73 x $92 \mathrm{~cm}$, Indianapolis Museum of Art, F 641, JH 1795. 


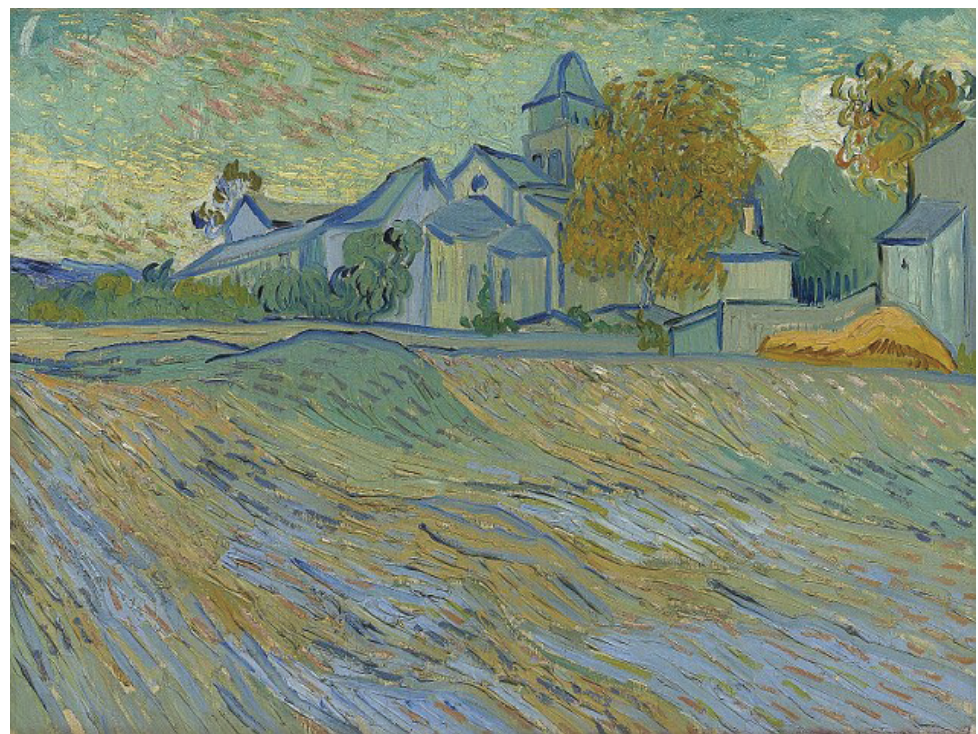

Abb. 11 Kornfeld, Blick auf die Kirche von Saint-Paul-de-Mausole, Herbst 1889, 45,1 x 60,4 cm, Öl auf Leinwand, Privatsammlung, F 803, JH 2124.

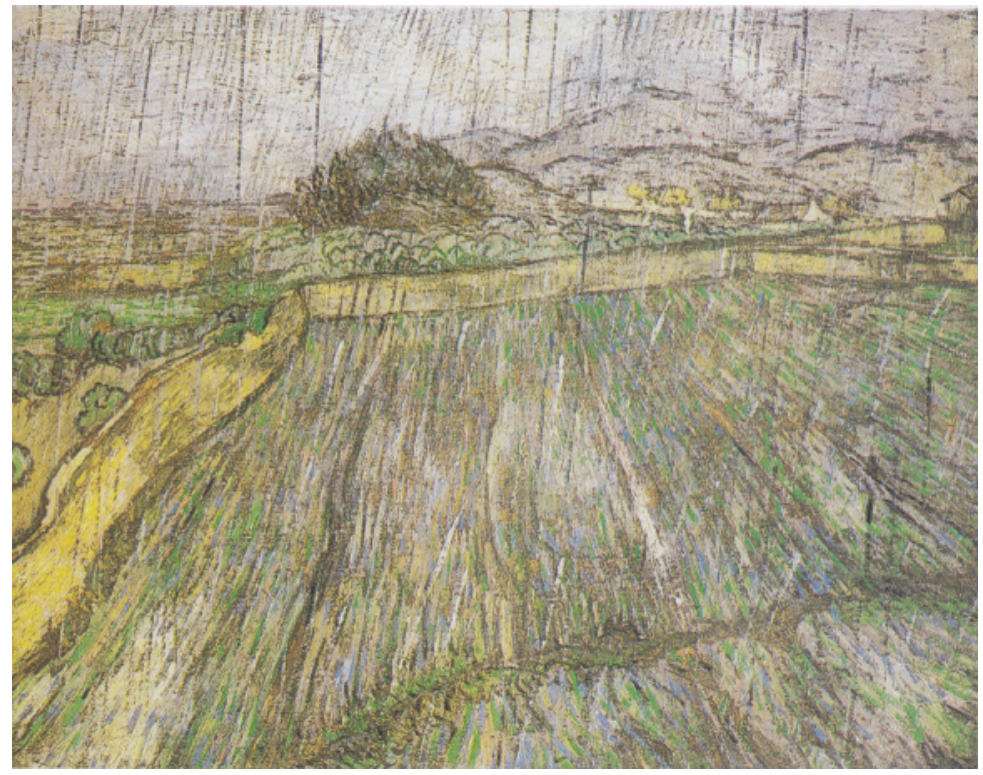

Abb. 12 Ummauertes Feld, Regen, November 1889, 73,5 x 92,5 cm, Öl auf Leinwand, Philadelphia Museum of Art, F 650, JH 1839. 


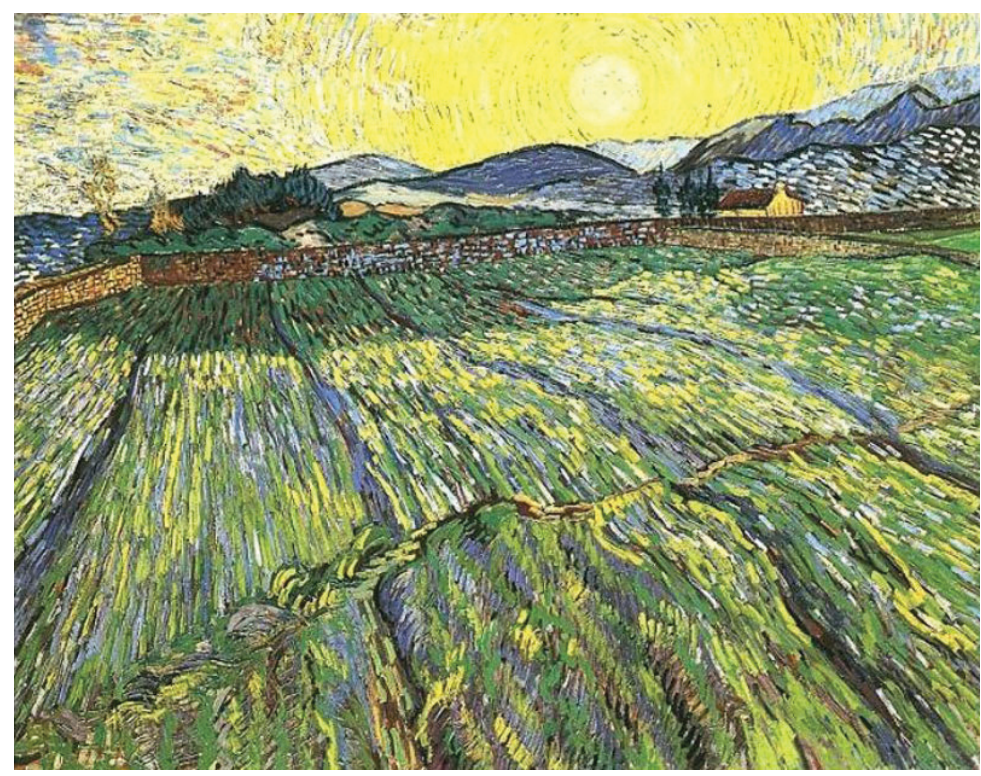

Abb. 13 Kornfeld, Sonnenaufgang, November 1889, Öl auf Leinwand, 71 x 90,5 cm, Privatsammlung, F 737, JH 1862.

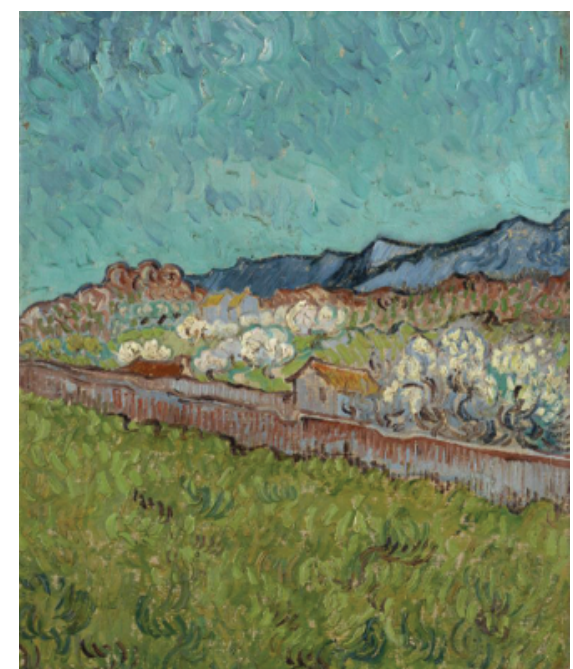

Abb. 14 Ummauertes Feld mit den Alpillen im Hintergrund, Januar-Februar 1890, Öl auf Leinwand, $33 \times 28.5 \mathrm{~cm}$, Van Gogh Museum, Amsterdam, F 723, JH 1722. 


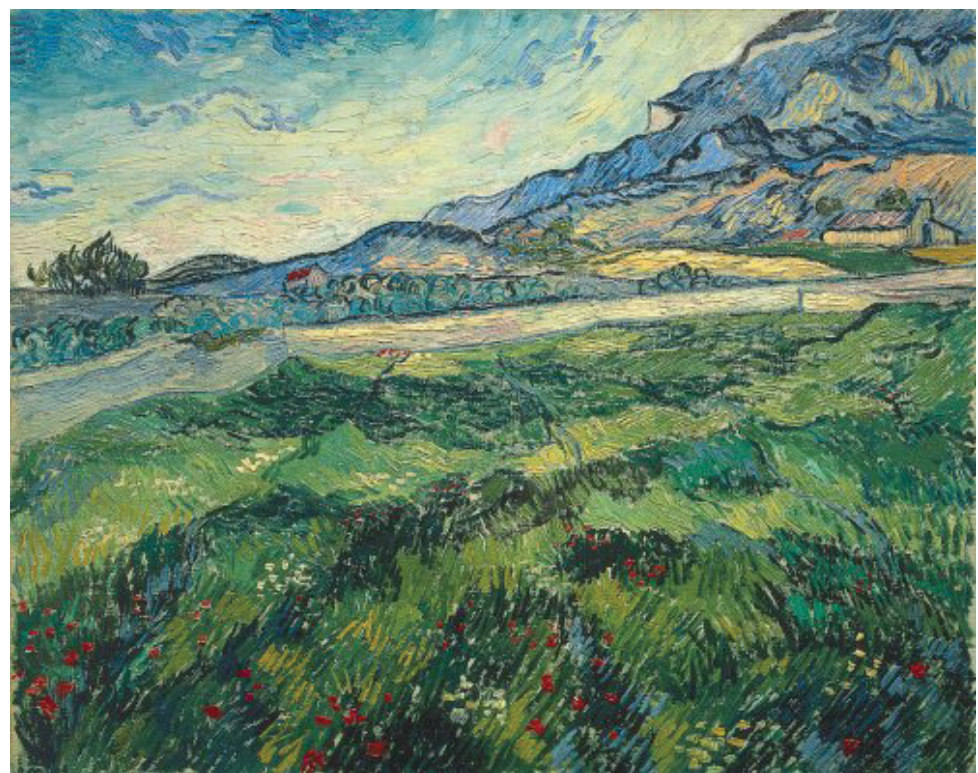

Abb. 15 Kornfeld, Mai 1890, Öl auf Leinwand, 73 x 92 cm, Verbleib unbekannt, F 718, JH 1727.

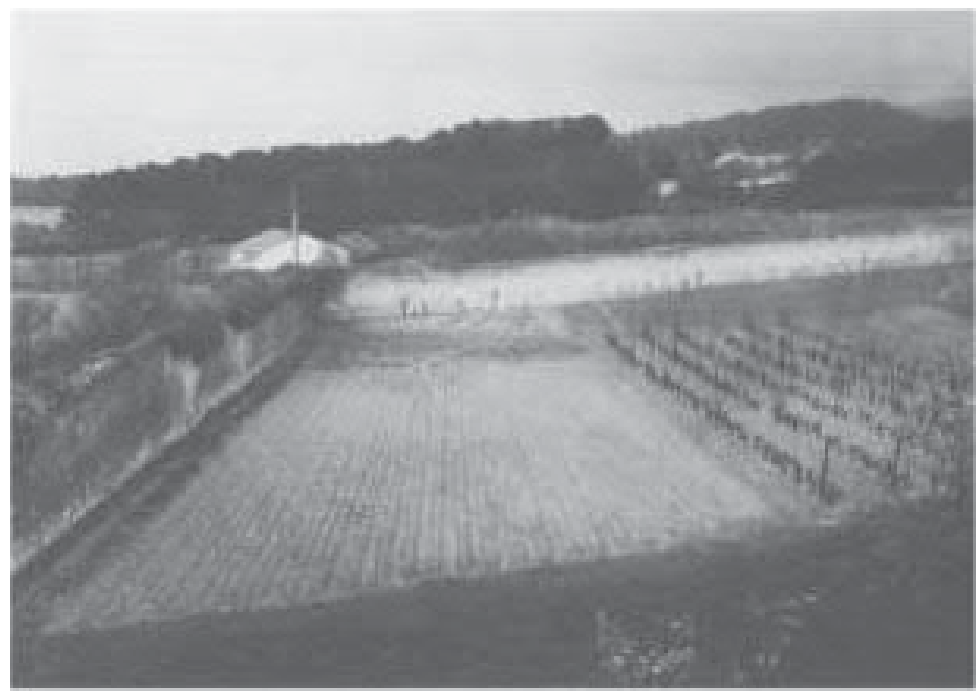

Abb. 16 Blick aus dem Zimmer Van Goghs in der Nervenheilanstalt in Saint-Rémy auf das ummauerte Kornfeld, ca. 1950, Van Gogh Museum, Amsterdam. 


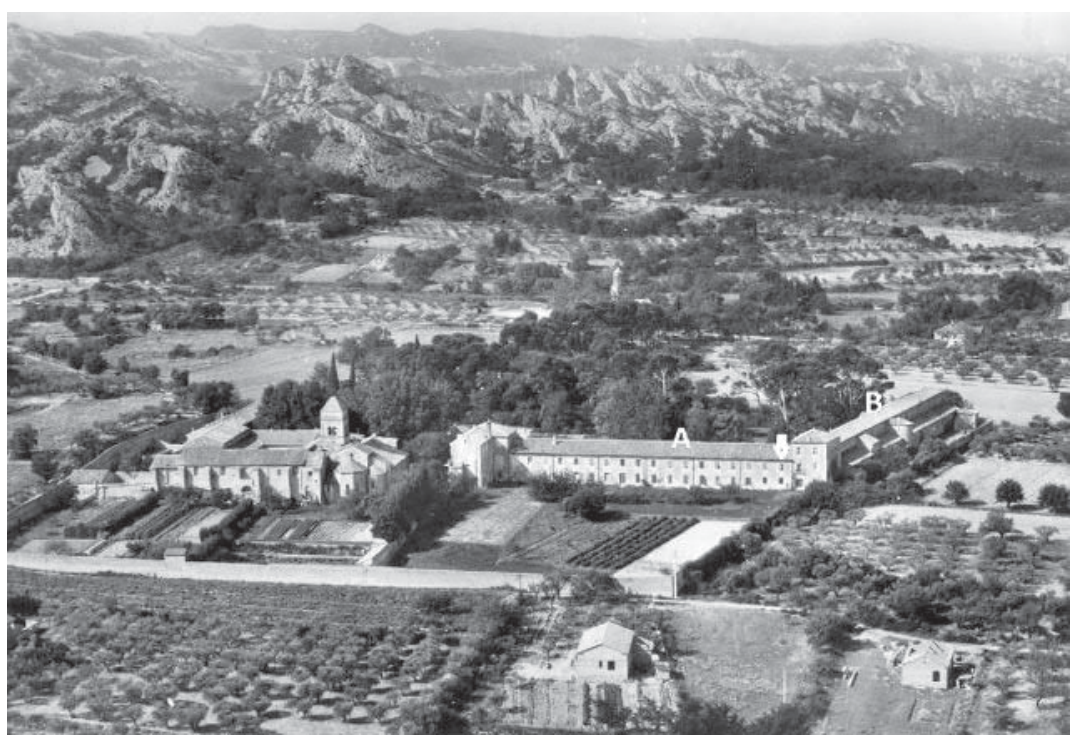

Abb. 17 Luftaufnahme der Nervenheilanstalt Saint-Paul-de-Mausole in SaintRémy. Das Zimmer Van Goghs ist mit einem Pfeil markiert. A und B kennzeichnen die einzelnen Flügel des Anstaltsgebäudes, Datierung unbekannt.

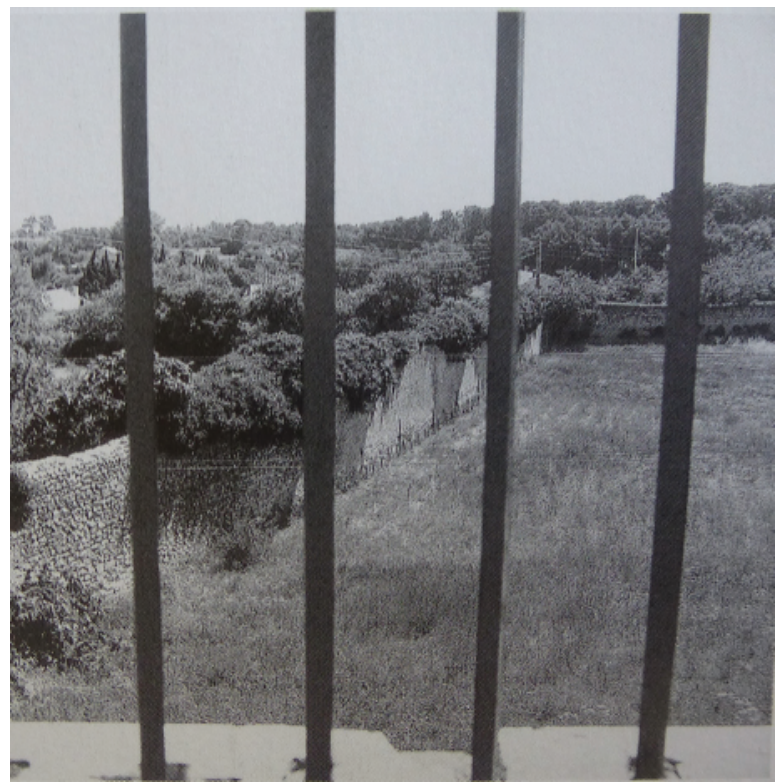

Abb. 18 Blick aus dem Zimmer Van Goghs in der Nervenheilanstalt Saint-Paul-de-Mausole auf das ummauerte Feld. 

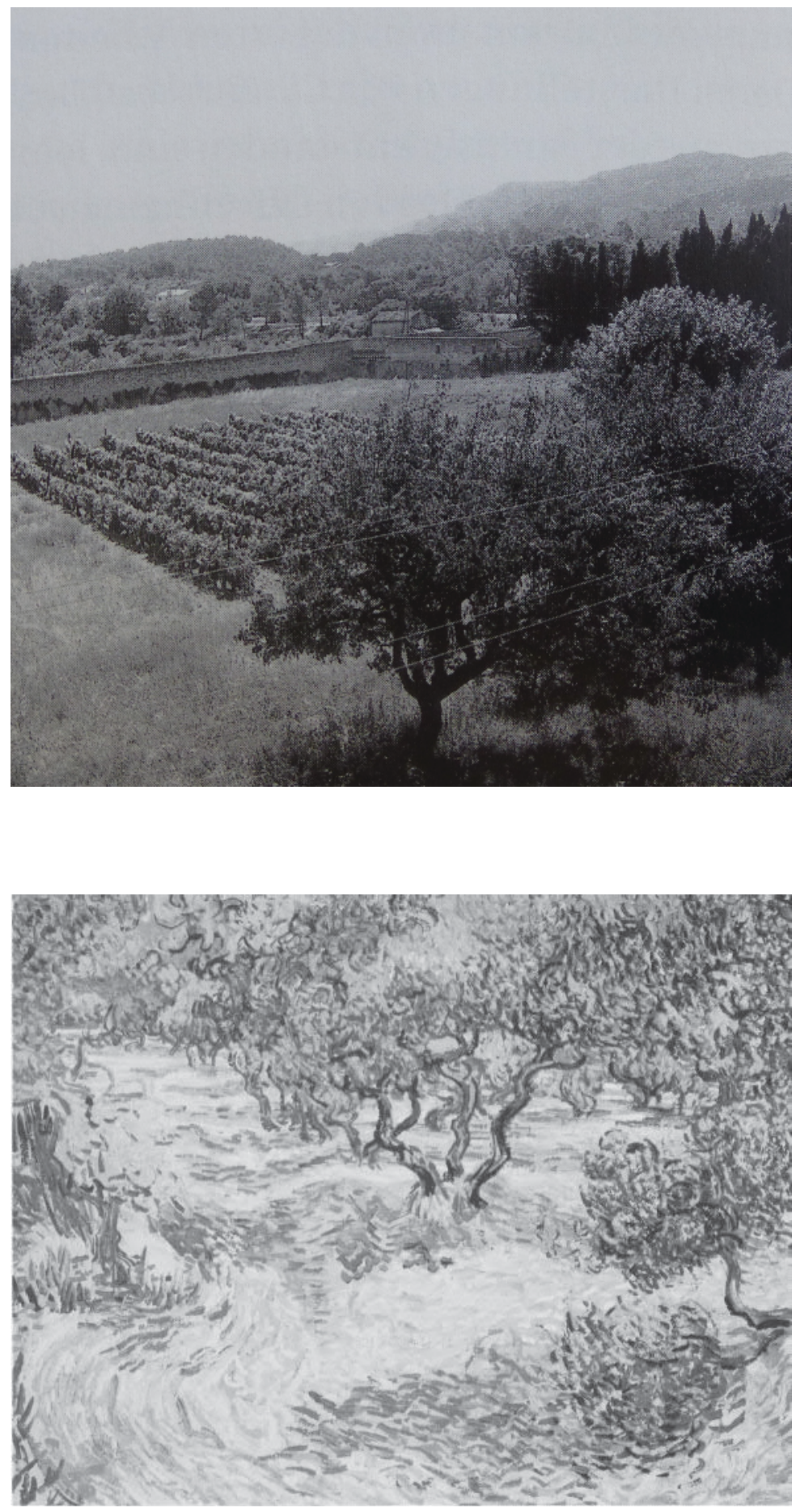

Abb. 19

Blick aus dem Zimmer Van Goghs in der Nervenheilanstalt Saint-Paulde-Mausole auf das ummauerte Feld und den ansteigenden Alpillen im Hintergrund.

Abb. 20

Olivenhain, Saint-Rémy, Juni-Juli, Öl auf Leinwand, 73,1 $x 93,1 \mathrm{~cm}$, Kansas City, The Nelson Atkins Museum of Art, F 715, JH 1759. 


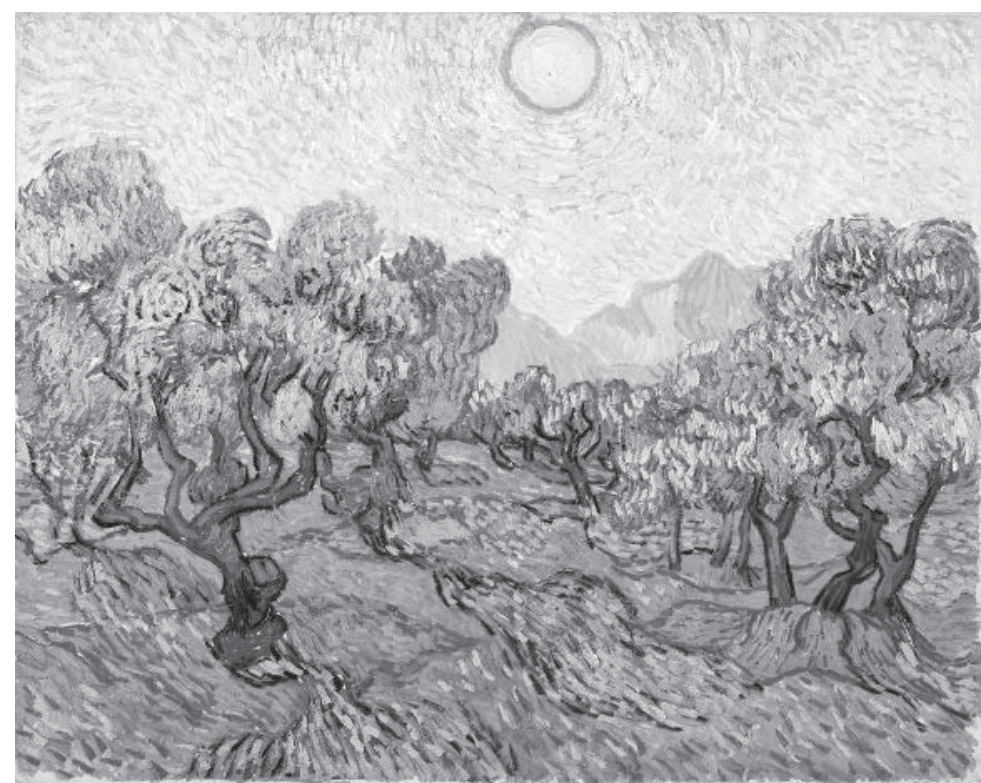

Abb. 21 Olivenbäume mit gelbem Himmel und Sonne, Saint-Rémy, November 1889, Öl auf Leinwand, 73,7 cm x 92,7 cm, The Minneapolis Institute of Arts, F 710, JH 1856.

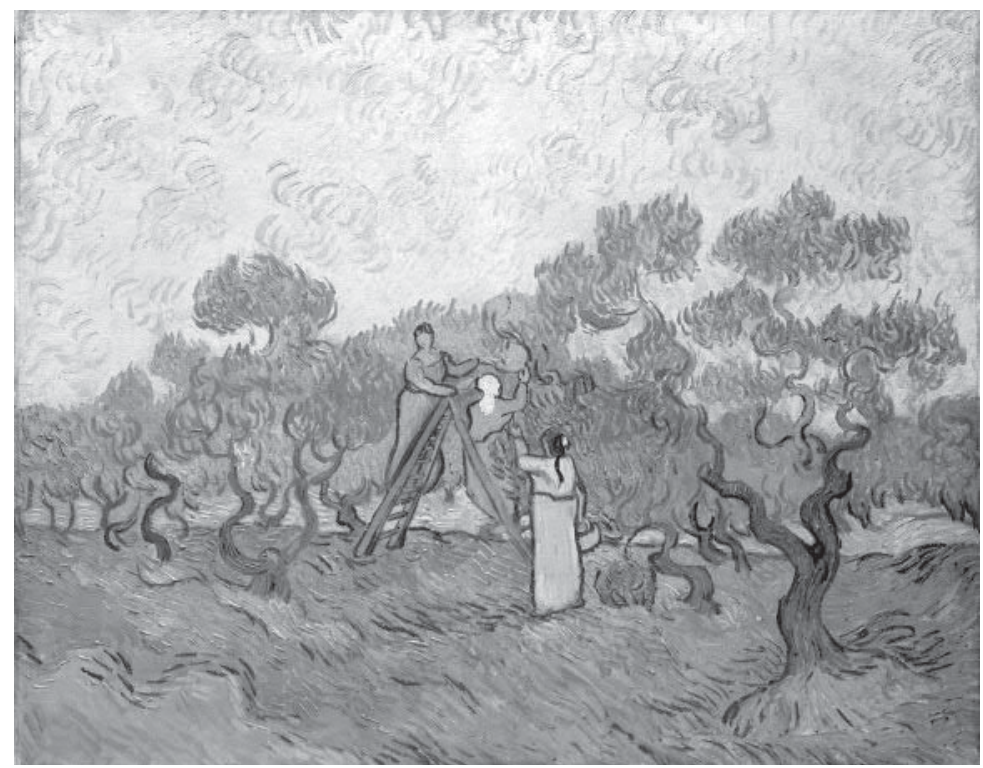

Abb. 22 Olivenpflücker, Saint-Rémy, Dezember 1889, Öl auf Leinwand, 72,4 x 89,9 cm, New York, The Metropolitan Museum of Art, F 655, JH 1869. 


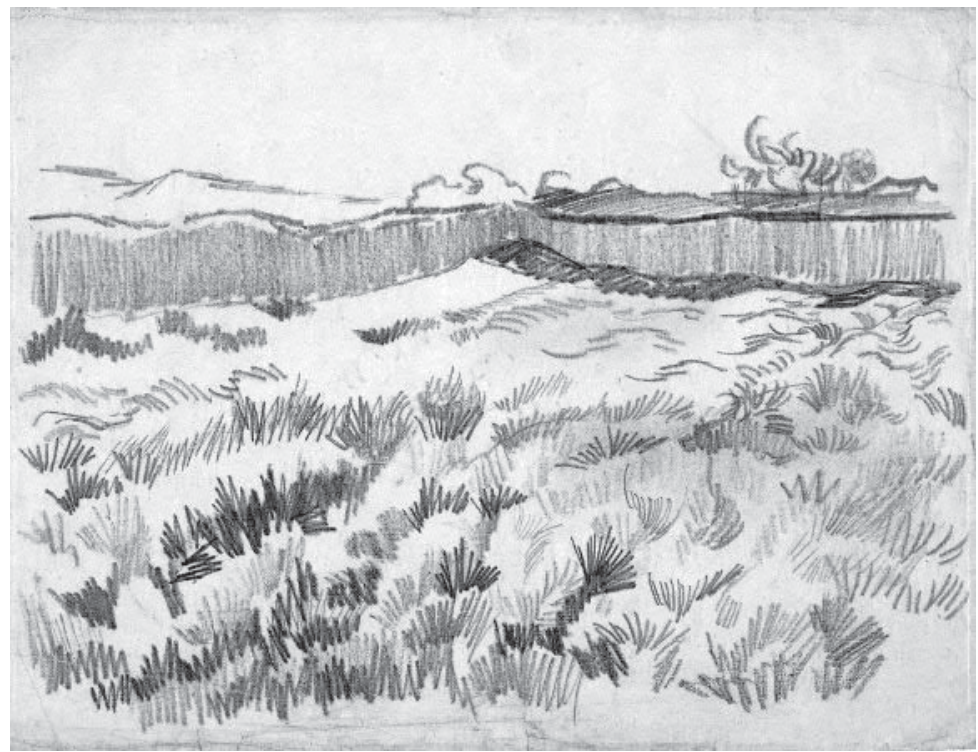

Abb. 23 Ummauertes Feld, April-Mai 1890, Bleistift, 25,3 x 32,5 cm, Amsterdam, Van Gogh Museum, F 1556, JH 1714.

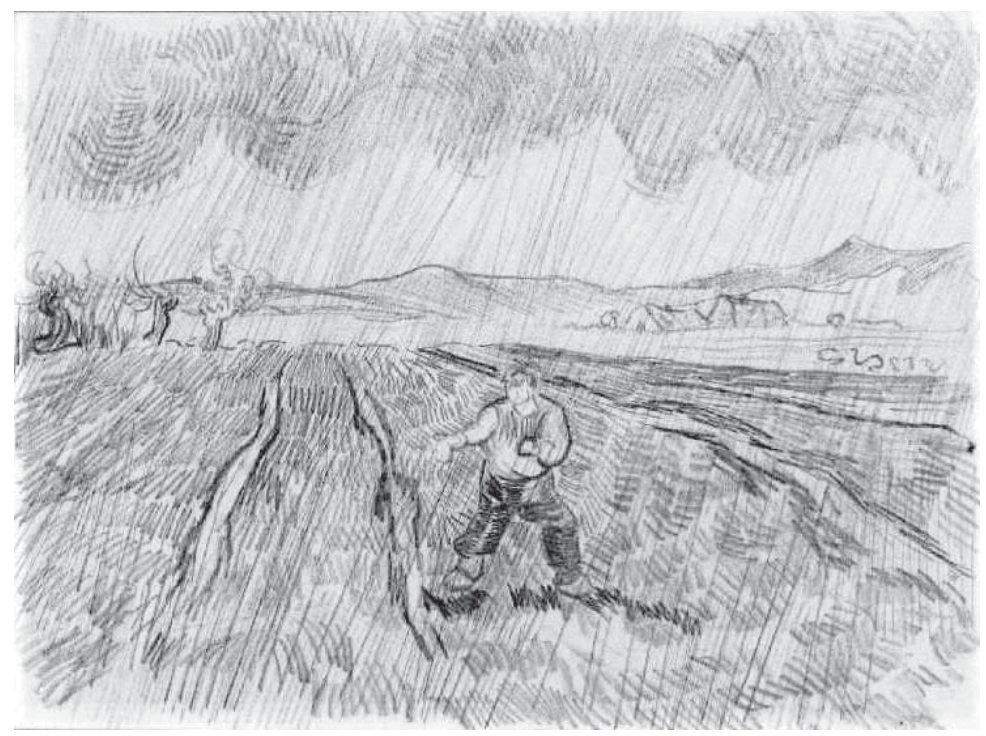

Abb. 24 Ummauertes Feld mit Sämann im Regen, März-April 1890, Bleistift und schwarze Kreide auf Papier, 23,5 x 31,5 cm, Essen, Museum Folkwang, F1550, JH1897. 


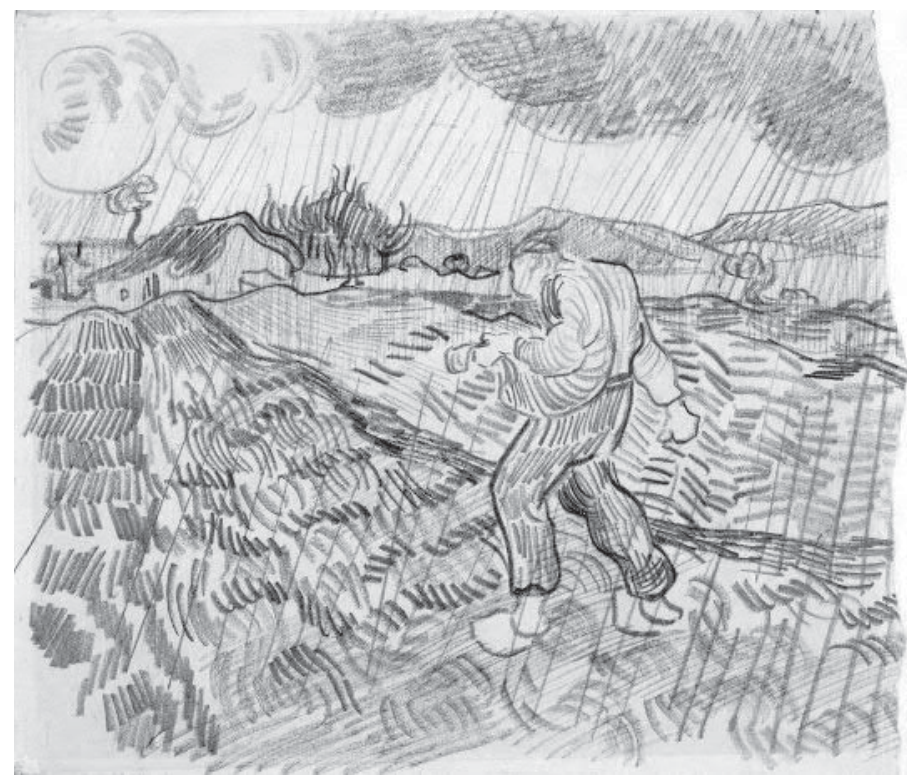

Abb. 25 Ummauertes Feld mit Sämann im Regen, März-April 1890, Bleistift auf Papier, 23,9 x 27,3cm, Amsterdam, Van Gogh Museum, F 1551r, JH1898.

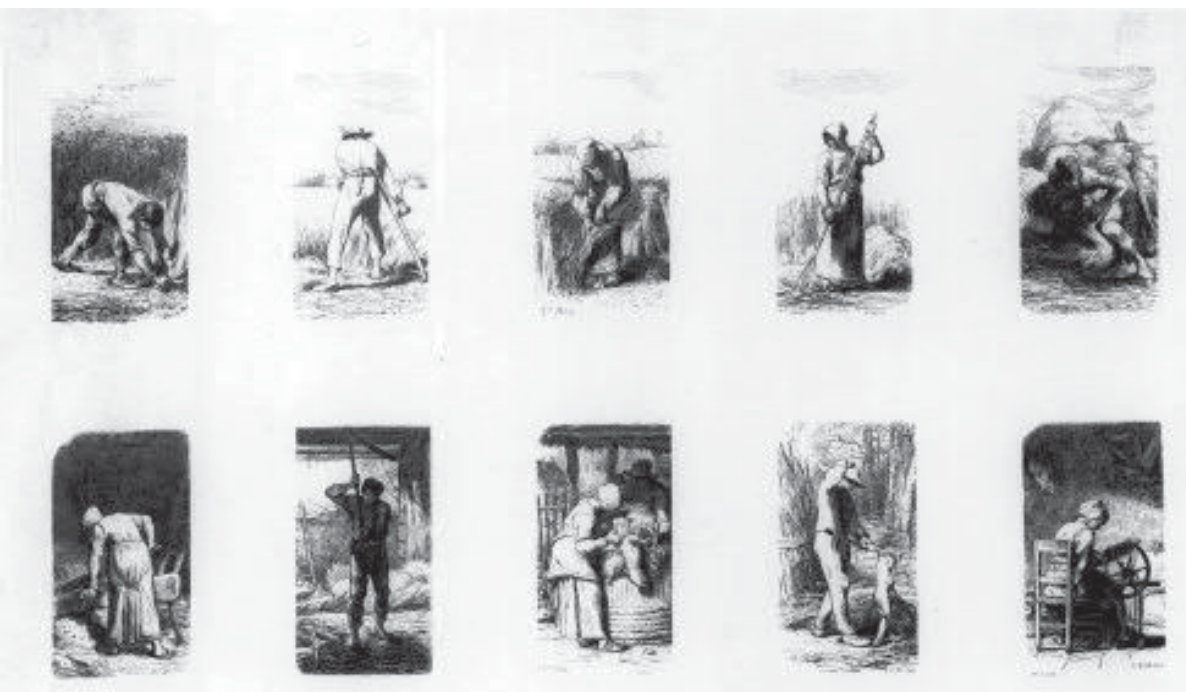

Abb. 26 Adrien Lavieille (1848-1920) nach Jean-François Millet (1814-1875), Les travaux des champs, Serie von 10 Holzschnitten, 1853, Amsterdam, Van Gogh Museum. 


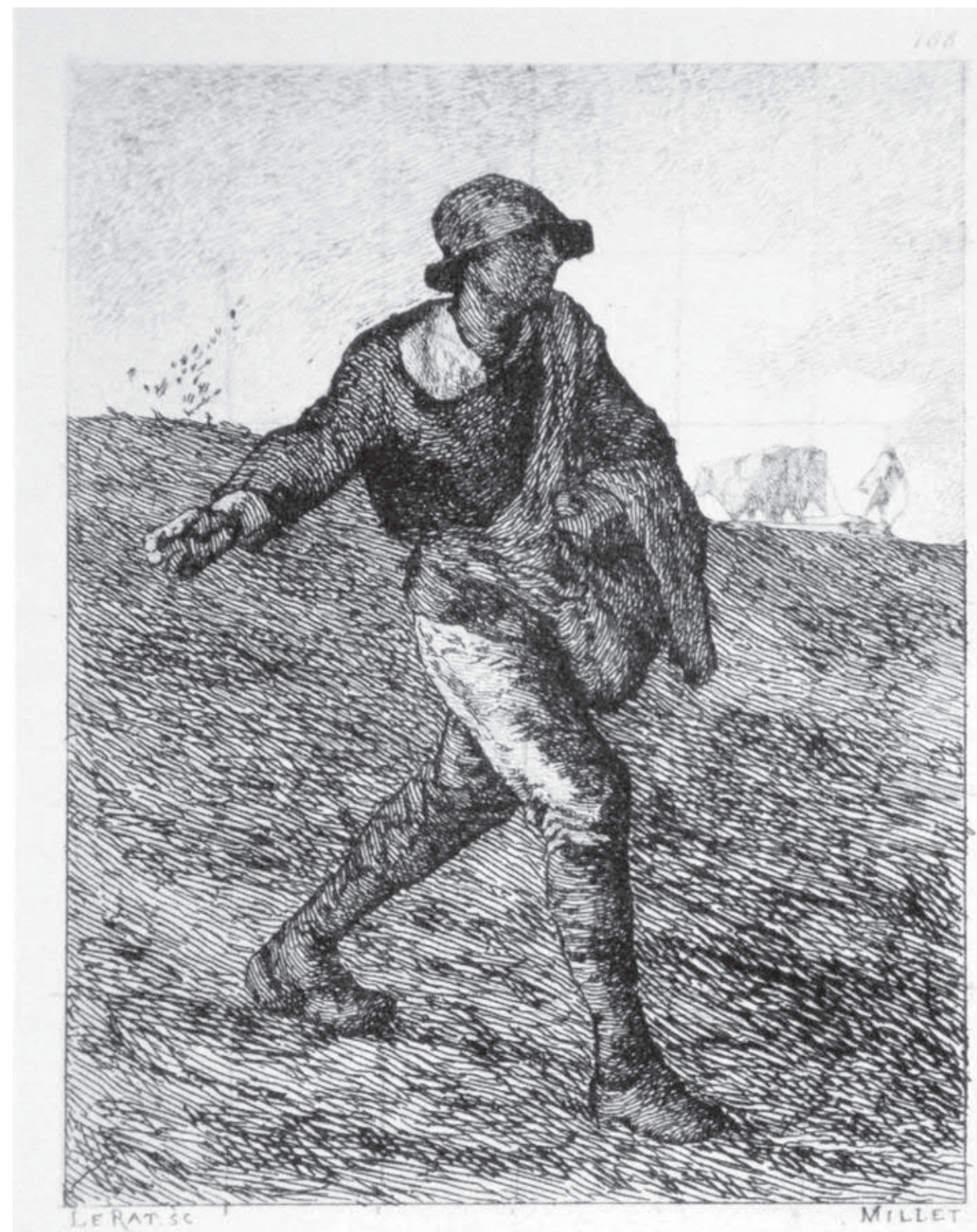

Abb. 27 Paul-Edmé le Rat (1849-1892), Der Sämann (nach Millet), 1873, Radierung, 12 × 9,5 cm, Amsterdam, Van Gogh Museum. 


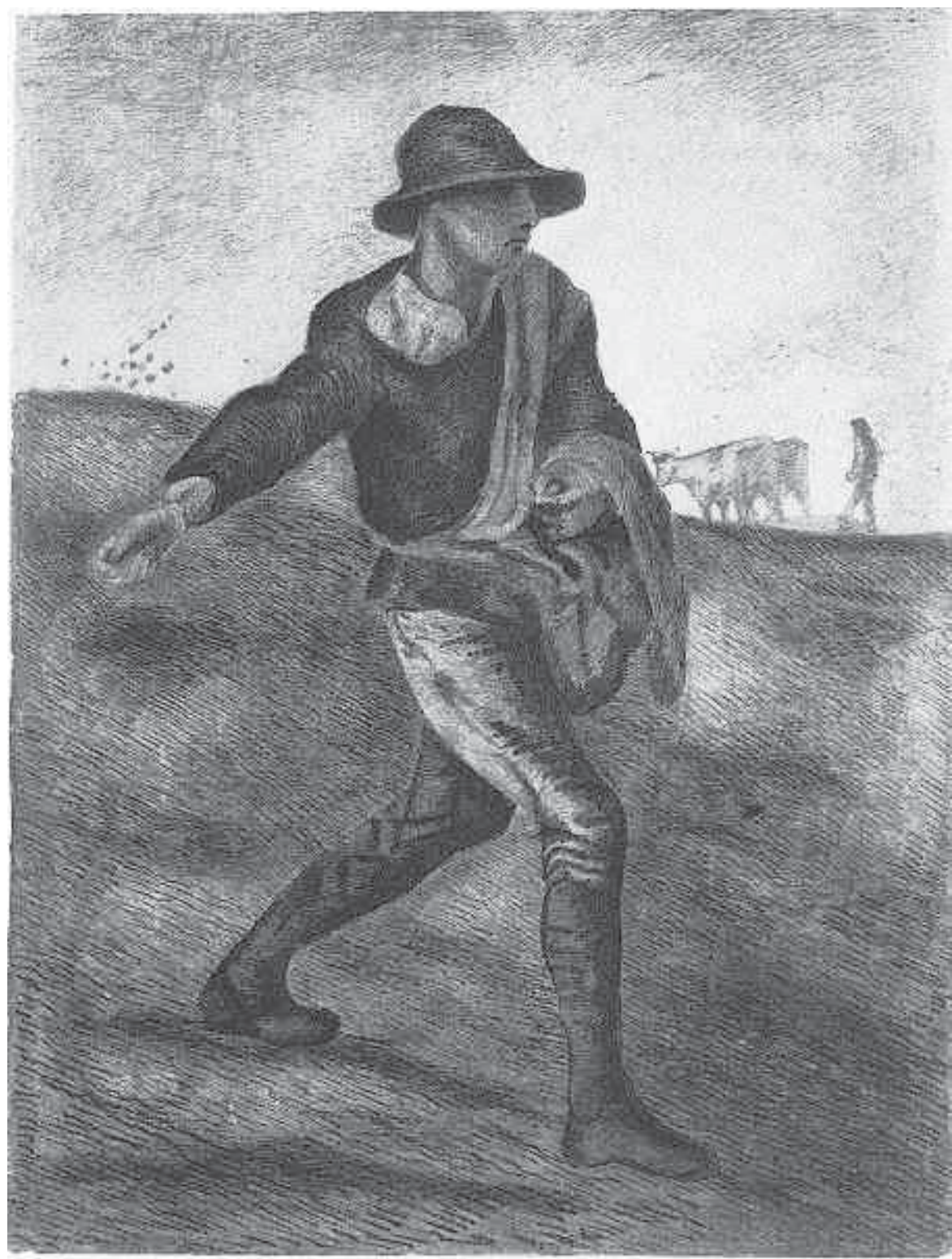

Abb. 28 Der Sämann, April 1881, Zeichnung, 48,1 x 36,7 cm, Amsterdam, Van Gogh Museum, F 830, JH 1. 


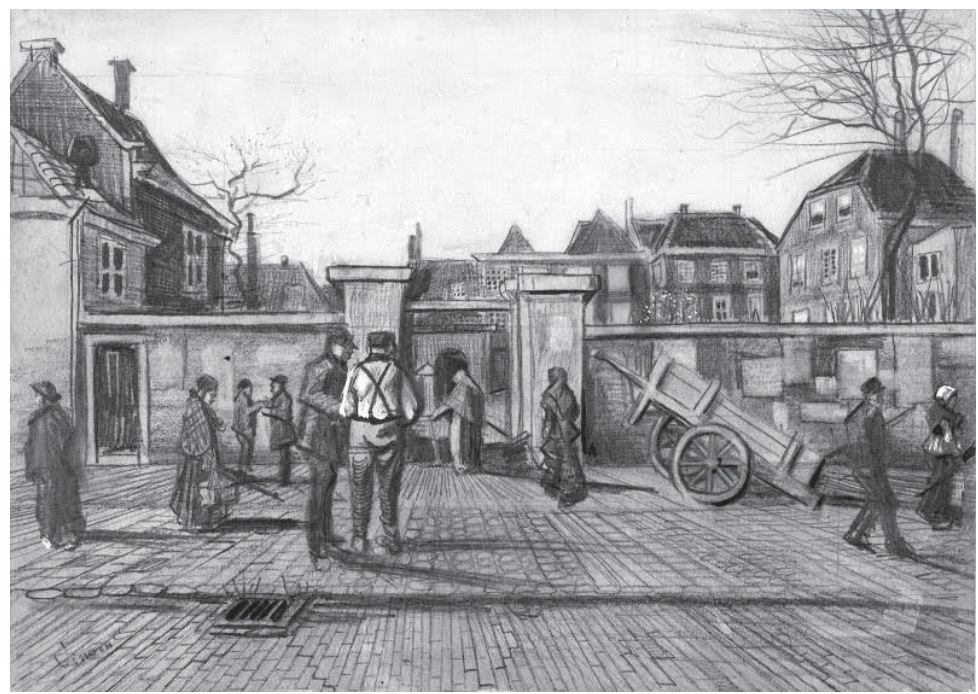

Abb. 29 Das Pfandleihhaus in Den Haag, März 1882, Bleistift, Feder, braune Tinte (urspr. schwarz), Aquarell, weiß gehöht und Spuren eines Rasters auf Papier, 24 x 34 cm, Amsterdam, Van Gogh Museum, F -, JH 126.

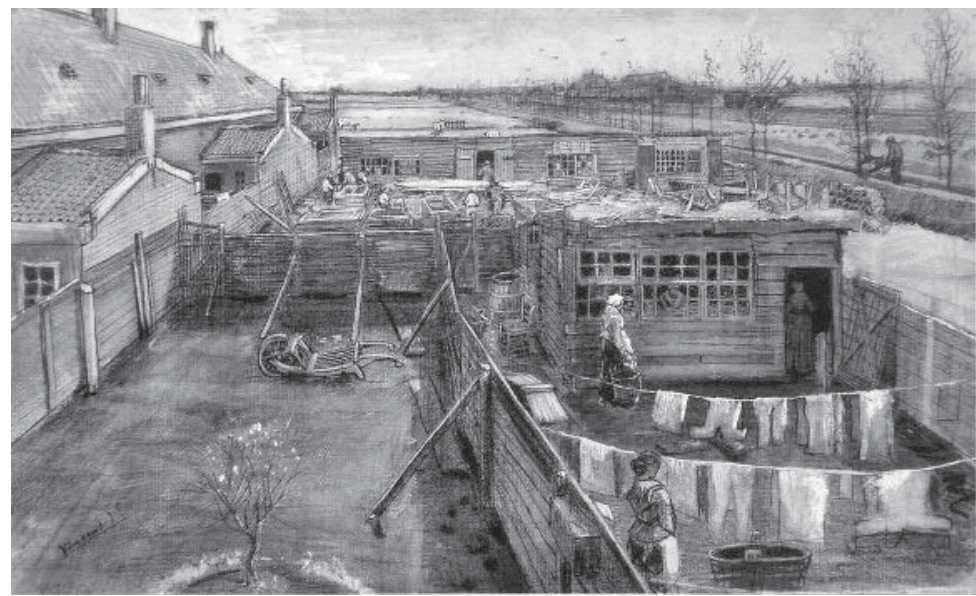

Abb. 30 Zimmermannsschuppen und Wäscherei, Frühling 1882, Bleistift, schwarze Kreide, Feder, Pinsel, schwarze Tinte, Aquarell, weiß gehöht und Spuren eines Rasters auf Papier, 28,5 x 47 cm, Otterlo, Kröller-Müller Museum, F 939, JH 150. 


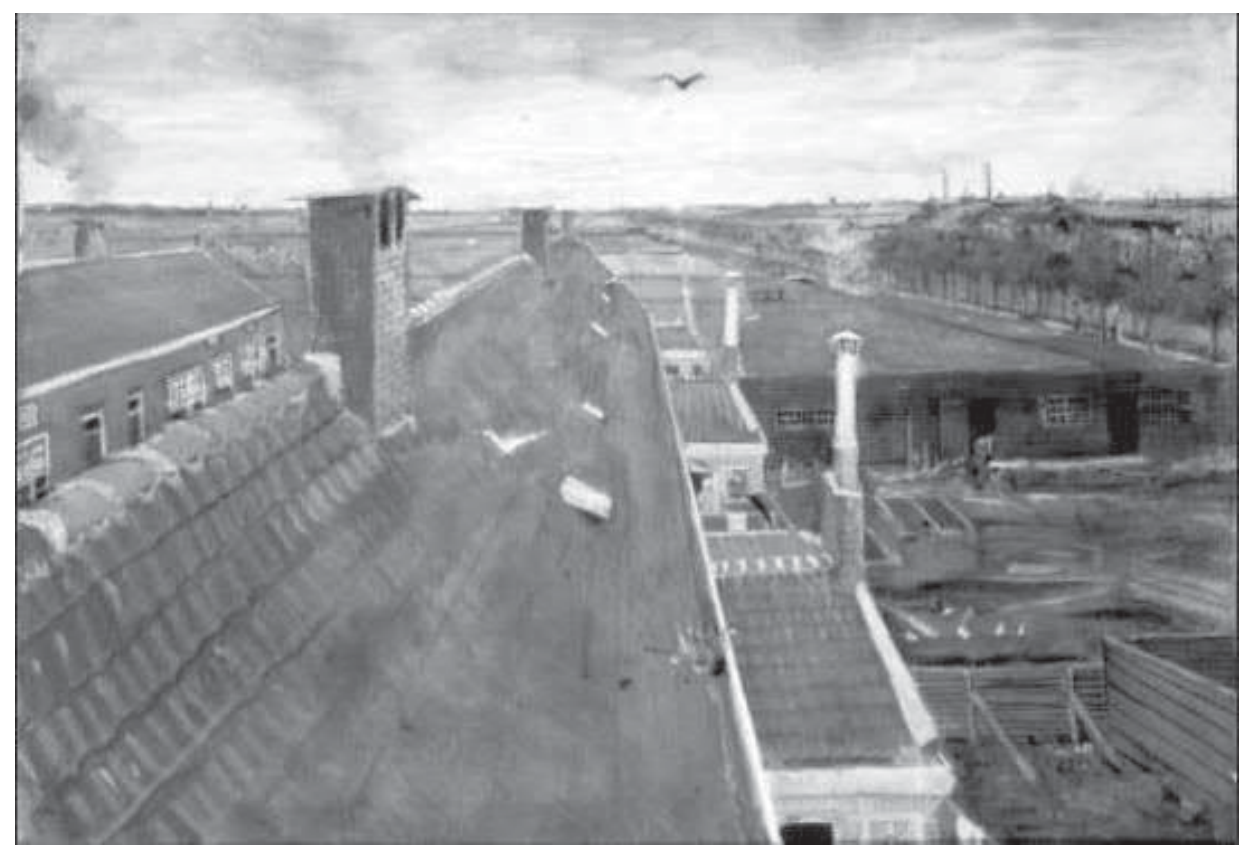

Abb. 31 Dächer, Juli 1882, Aquarellfarben, weißgehöht auf Papier, 39 x 55 cm, Privatbesitz, zuletzt Sotheby's New York, Auktion 3.5.2006, F 943, JH 156.

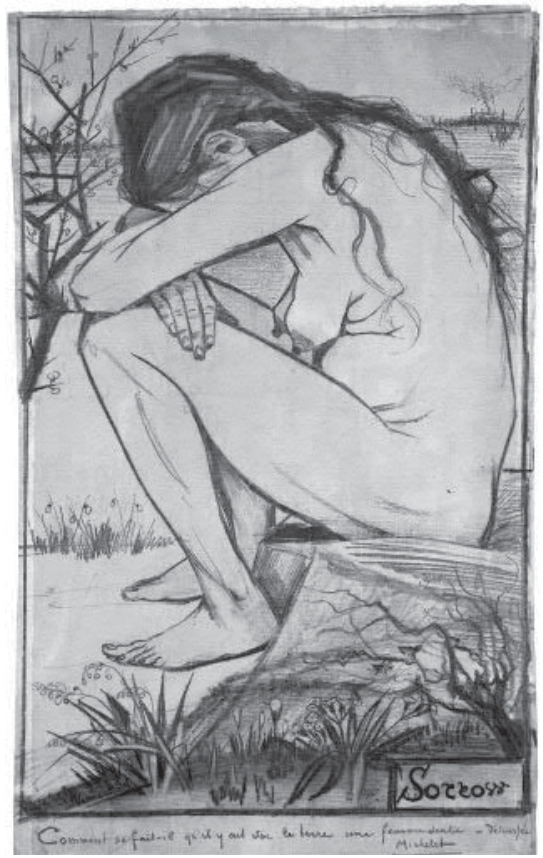

Abb. 32

Sorrow, April 1882, schwarze Kreide auf Papier, $44,5 \times 27 \mathrm{~cm}$, Walsall Museum and Art Gallery, F 929a, JH 130. 


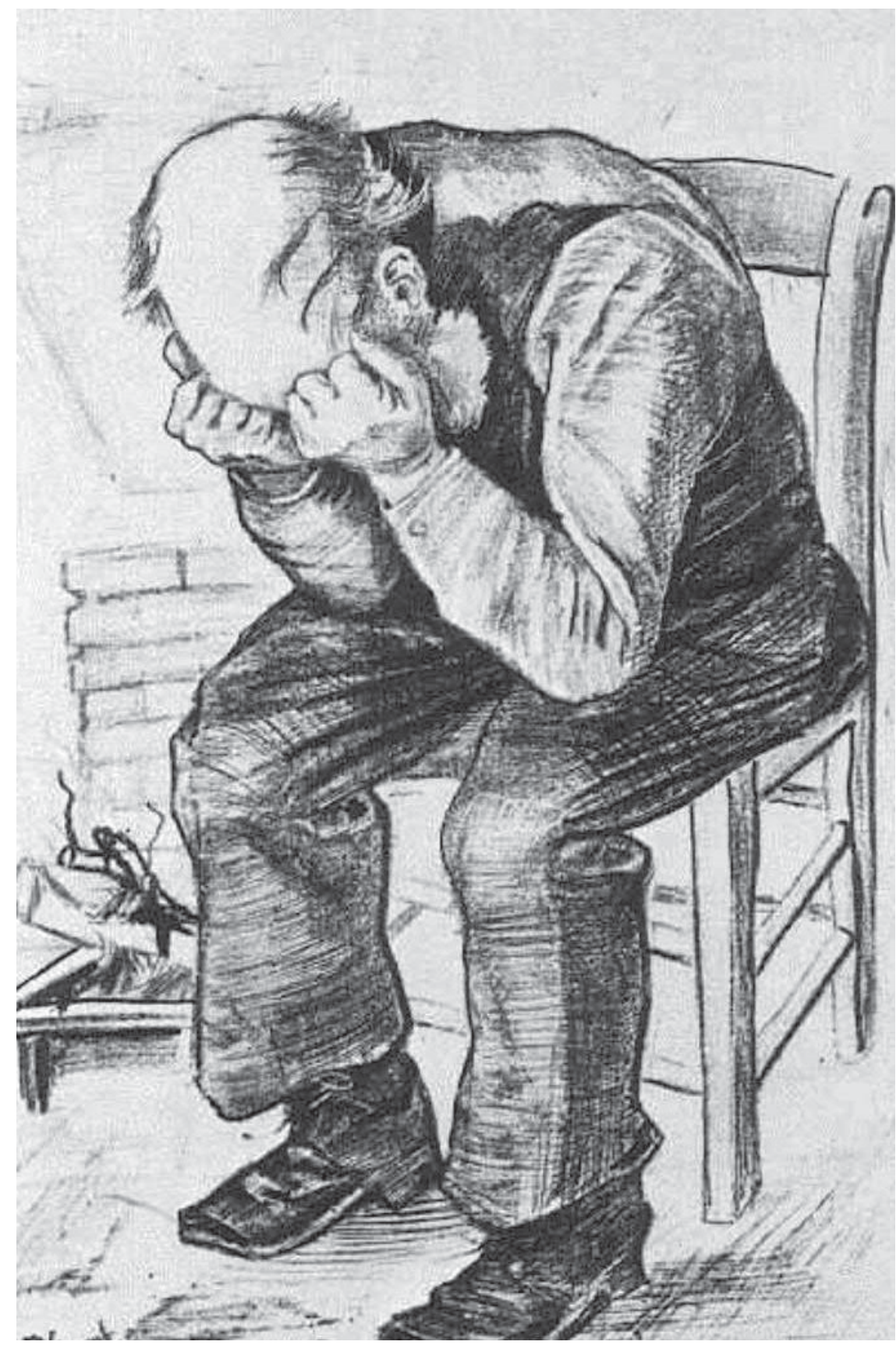

Abb. 33 Trauernder Alter Mann („At Eternity’s Gate“), November 1882, Lithographie, 55,5 x 36,5 cm, diverse Sammlungen, u.a. Amsterdam, Van Gogh Museum, F 1662, JH 268. 


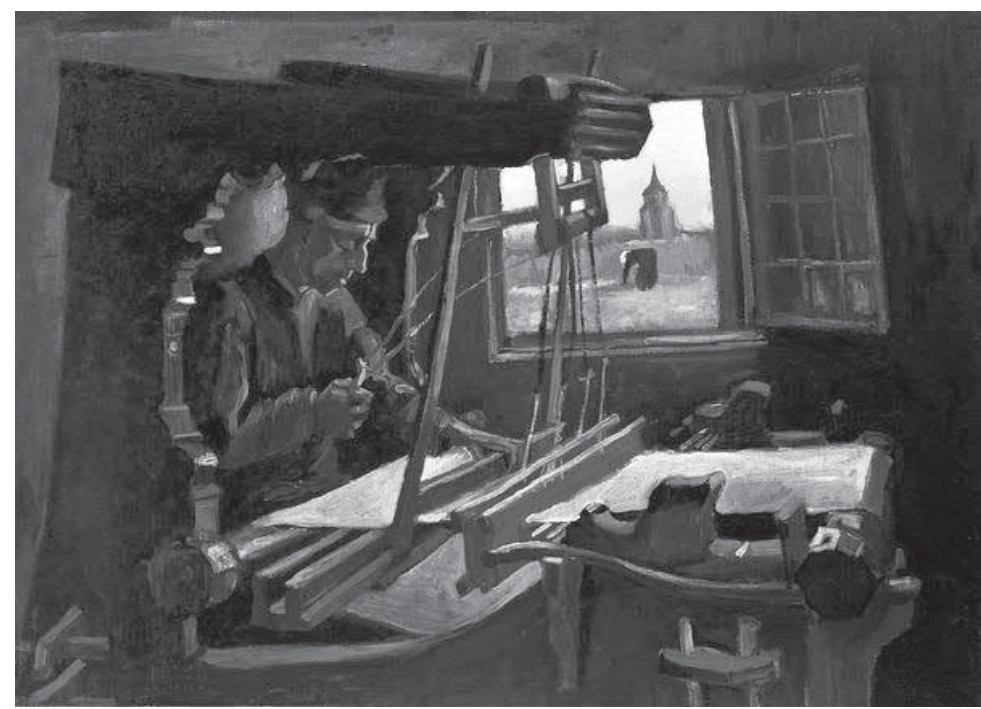

Abb. 34 Weber, 1884, Öl auf Leinwand auf Karton, 68,5 x 93 cm, München, Neue Pinakothek, F 24, JH 500.

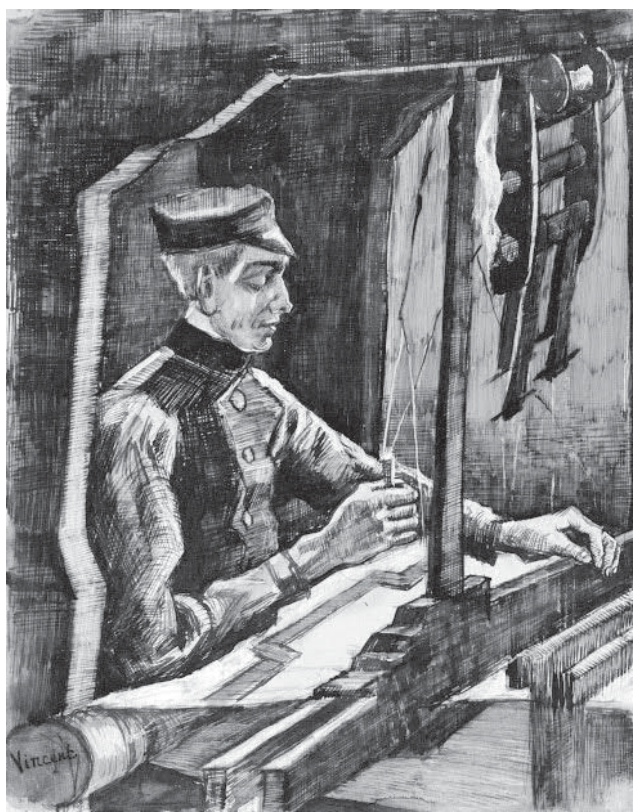

Abb. 35 Weber, Februar-März 1884, Federzeichnung, Bister und Weißhöhung, 26 x $21 \mathrm{~cm}$, Amsterdam, Van Gogh Museum, F 1122, JH 454. 


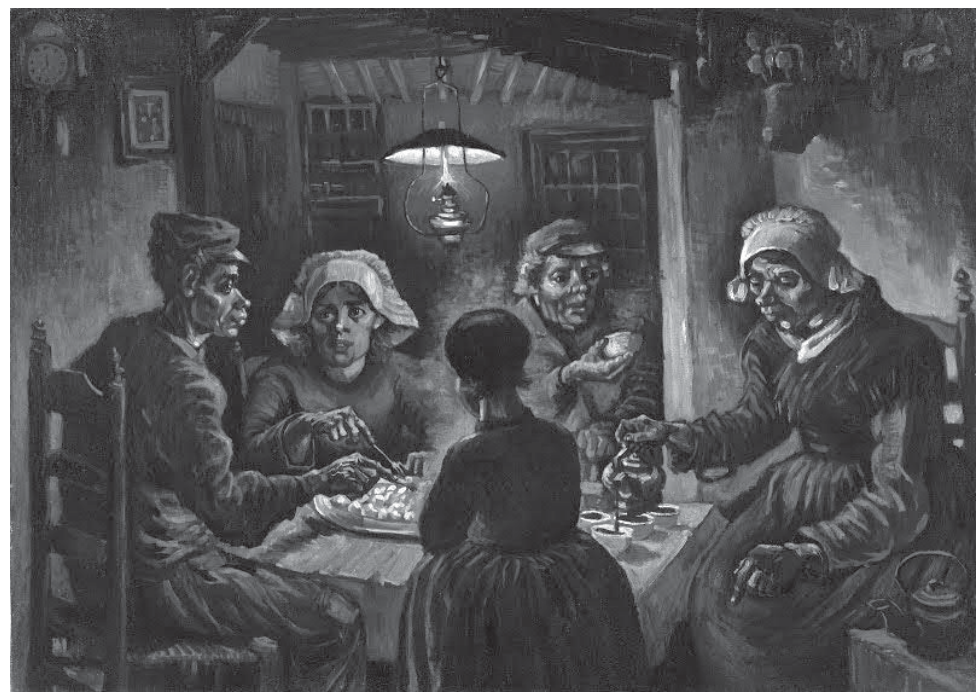

Abb. 36 Die Kartoffelesser, April-Mai 1885, Öl auf Leinwand, 82 x 114 cm, Amsterdam, Van Gogh Museum, F 82, JH 764.

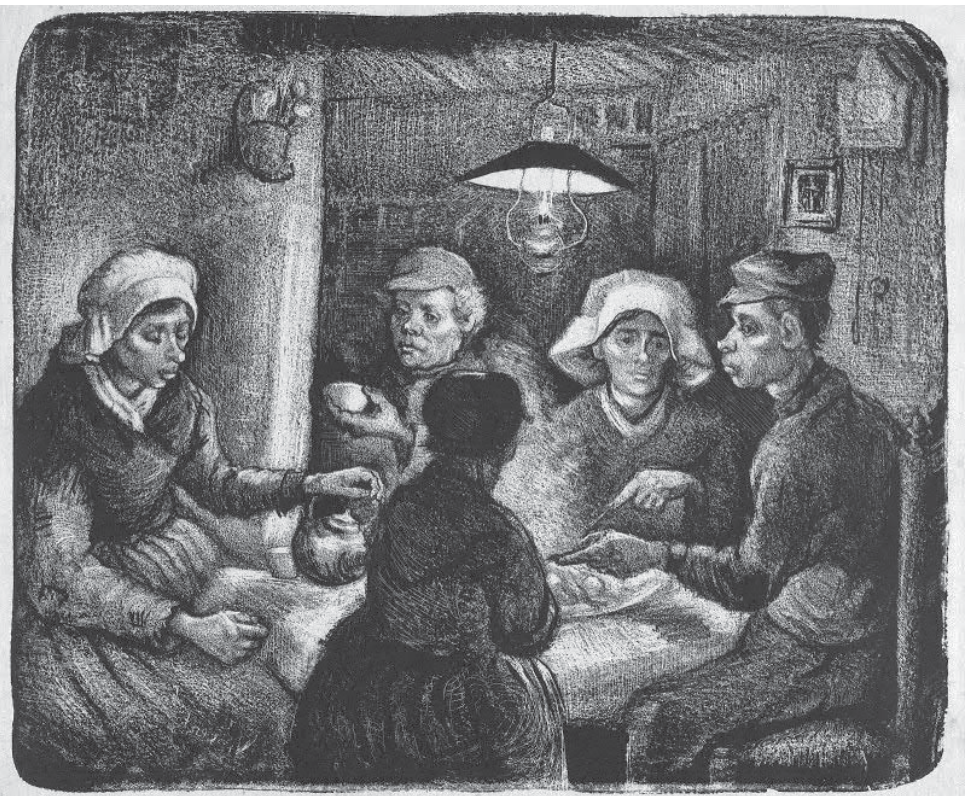

Abb. 37 Die Kartoffelesser, nach der Studie, April 1885, Lithographie auf Velinpapier, 26,9 x 31,8 cm, Amsterdam, Van Gogh Museum, F 1661, JH 737. 


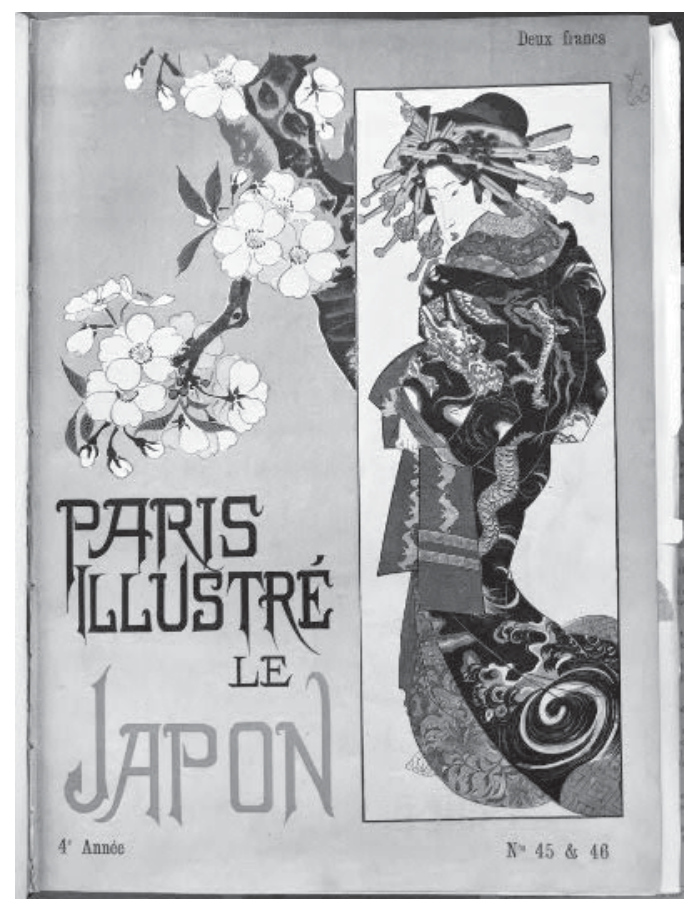

Abb. 38 Titelseite von Paris Illustrè. Le Japon, Bd. IV, Nr. 45 u. 46, Mai 1886.

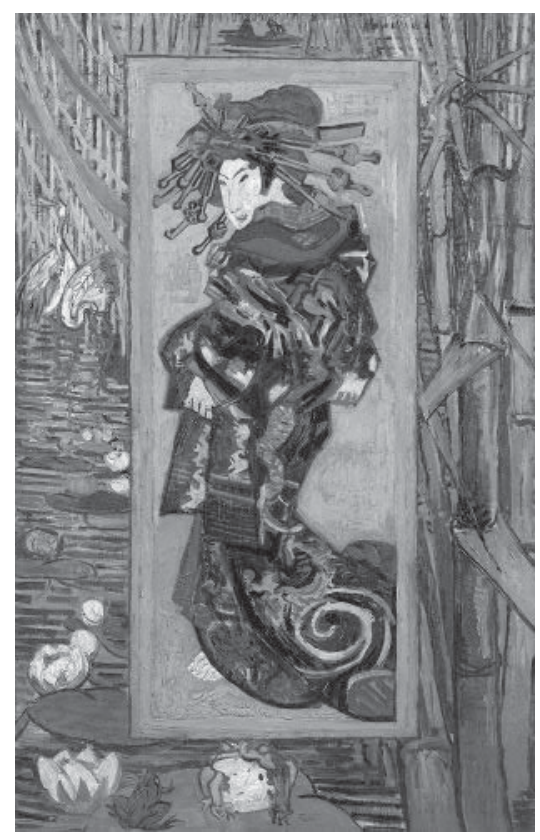

Abb. 40

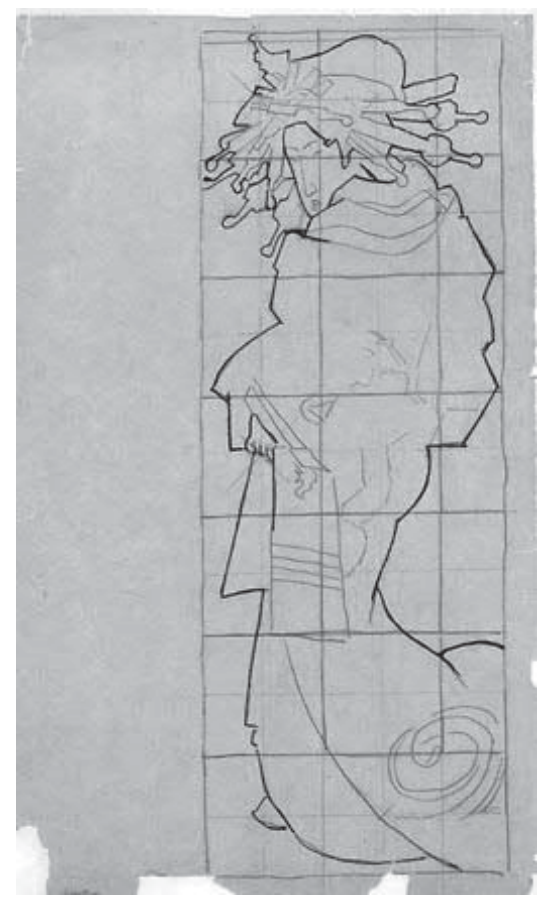

Abb. 39 Abpausskizze der Titelseite von Paris Illustrè. Le Japon, Bleistift und Tinte auf Papier, $39,4 \mathrm{~cm} \times 26,3 \mathrm{~cm}$, Amsterdam, Van Gogh Museum, nicht im Werkverzeichnis.

Die Kurtisane (nach Eisen), 1887,

Öl auf Leinwand, 105,5 x 60,5 cm, Amsterdam, Van Gogh Museum, F 373, JH 1298. 


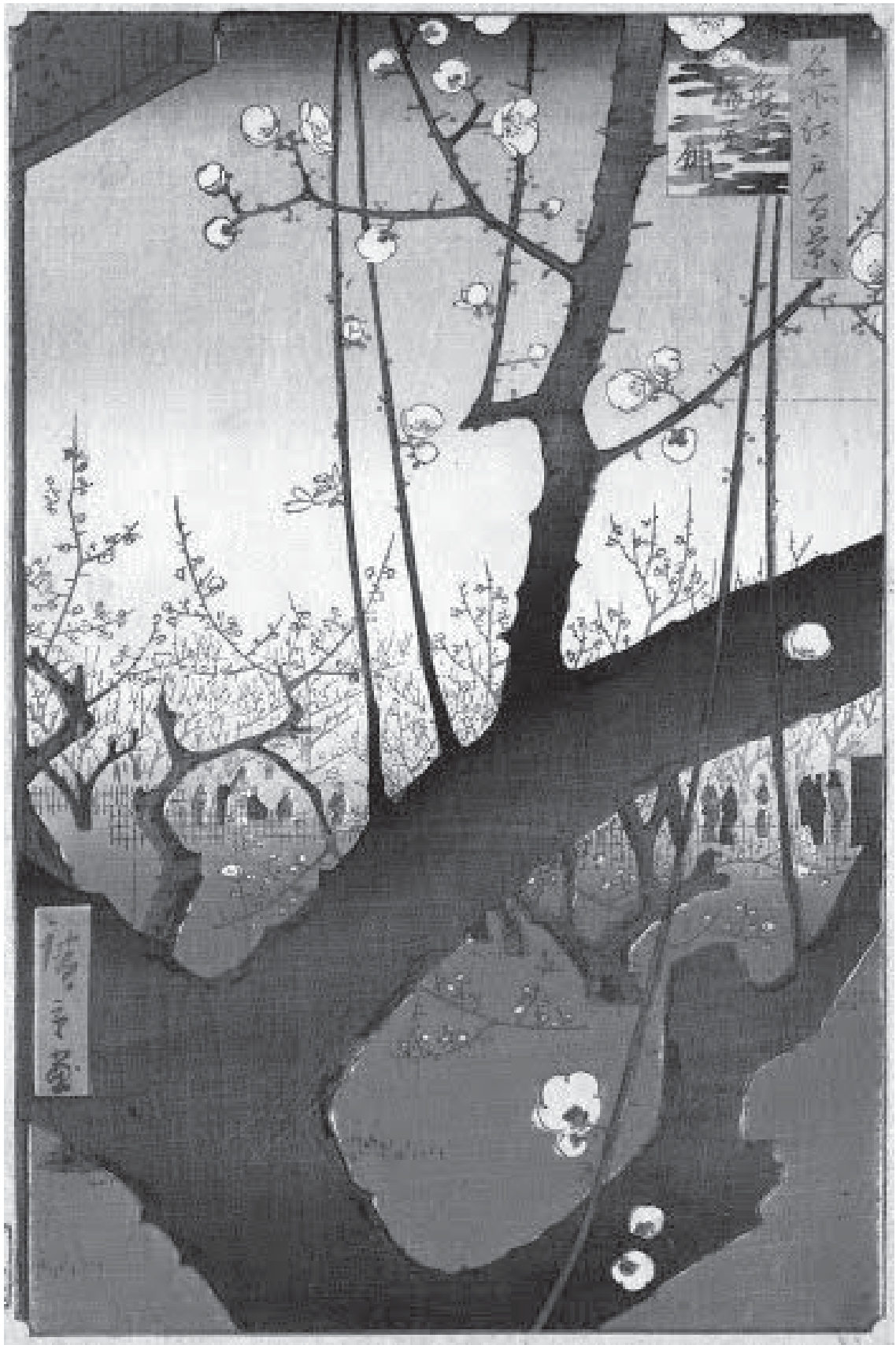

Abb. 41 Utagawa Hiroshige (1797-1858), Garten der Pflaumenbäume in Kameido, 11. Monat, aus Hundert berühmte Ansichten von Edo, 1857, Holzschnitt, 36 x 24,1 cm, Amsterdam, Van Gogh Museum. 


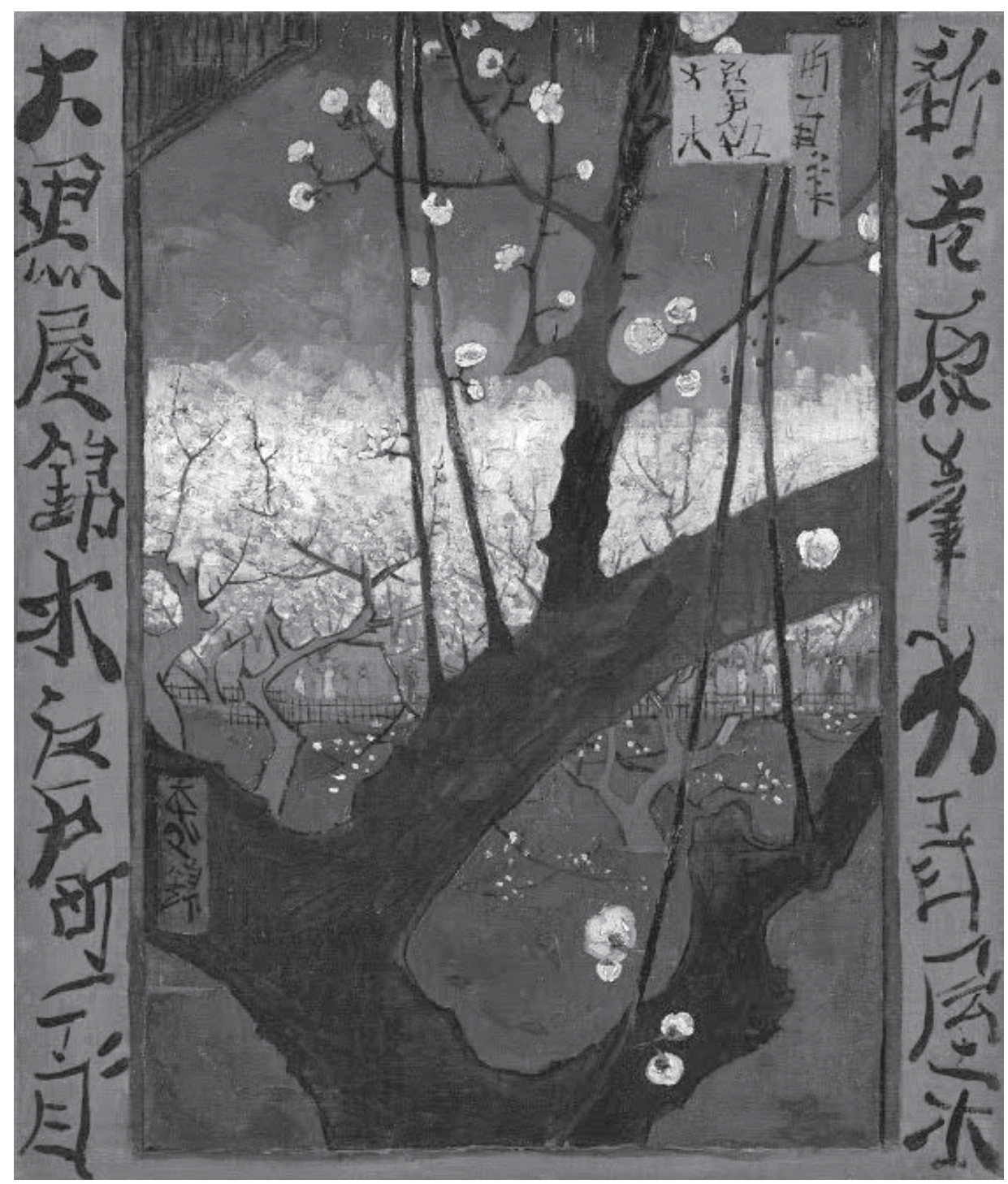

Abb. 42 Blühender Pflaumenbaum (nach Hiroshige), September-Oktober 1887, Öl auf Leinwand, 55 x 46 cm, Amsterdam, Van Gogh Museum, F 371, JH 1296. 


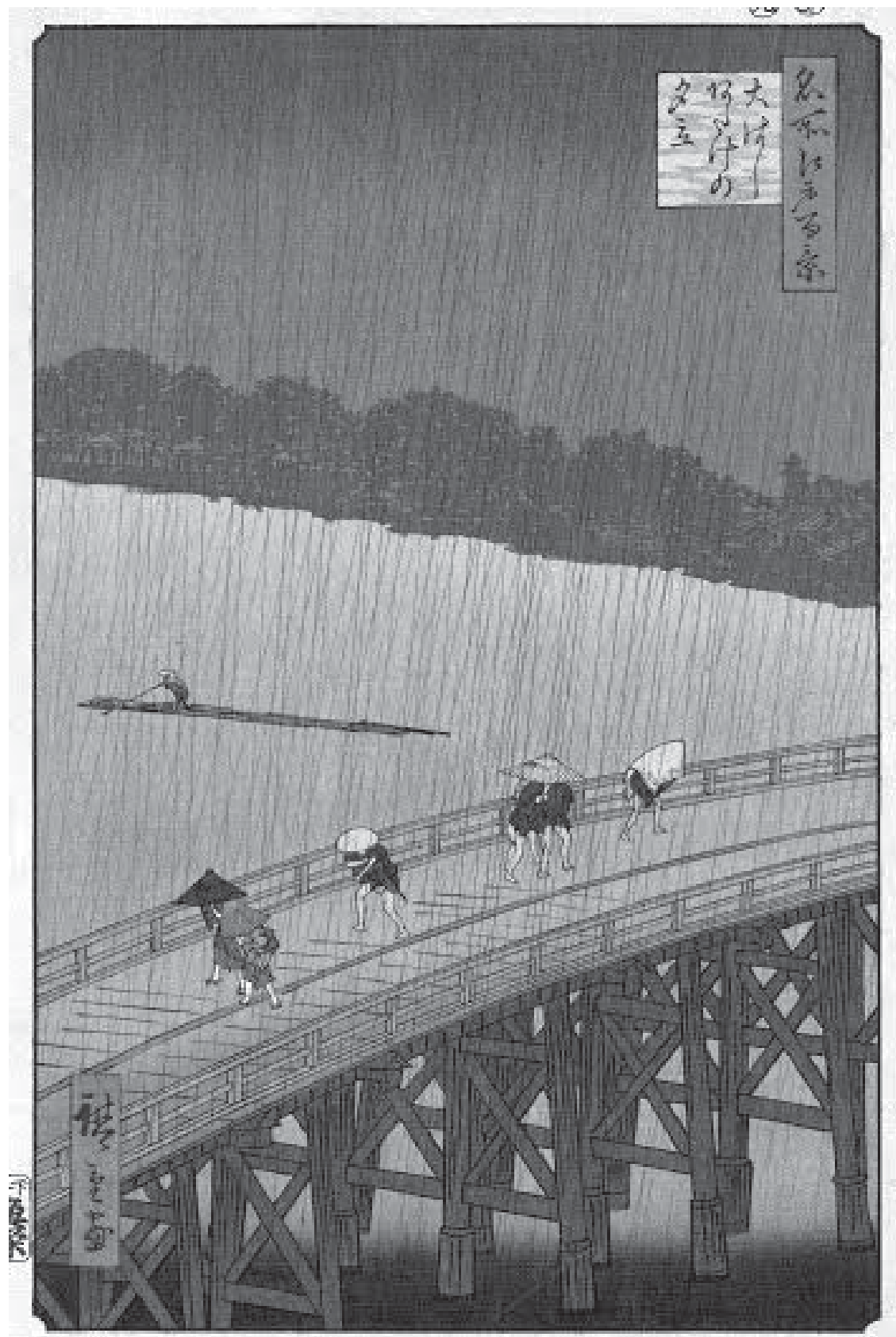

Abb. 43 Utagawa Hiroshige (1797-1858), Regen über der Ohashi-Brücke, 9. Monat, aus Hundert berühmte Ansichten von Edo, 1857, Holzschnitt, $22.6 \mathrm{~cm} \mathrm{x}$ $33.8 \mathrm{~cm}$, Amsterdam, Van Gogh Museum. 


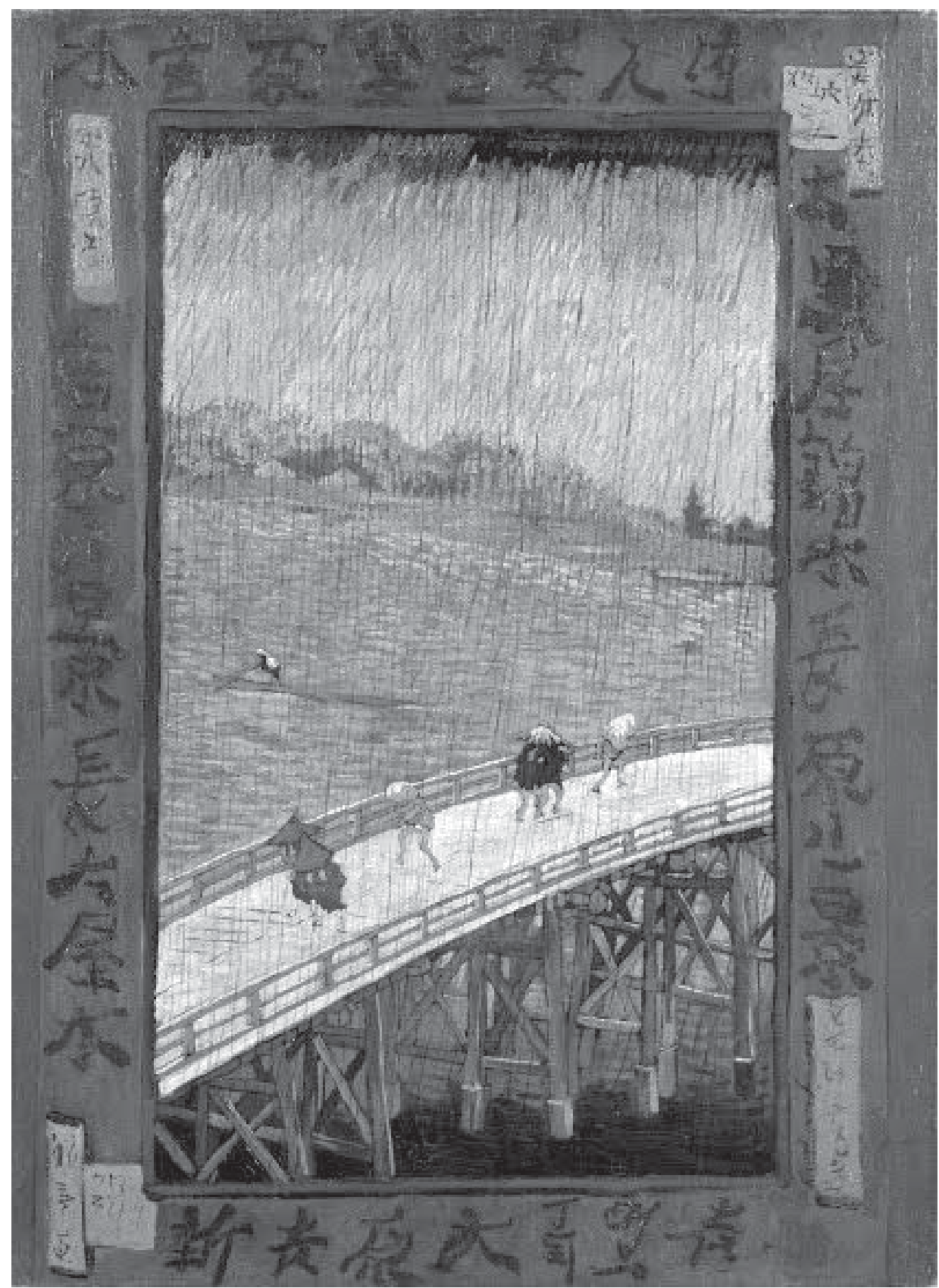

Abb. 44 Die Brücke im Regen (nach Hiroshige), September/Oktober 1887, Öl auf Leinwand, 73 x 54 cm, Amsterdam, Van Gogh Museum, F372, JH1297. 


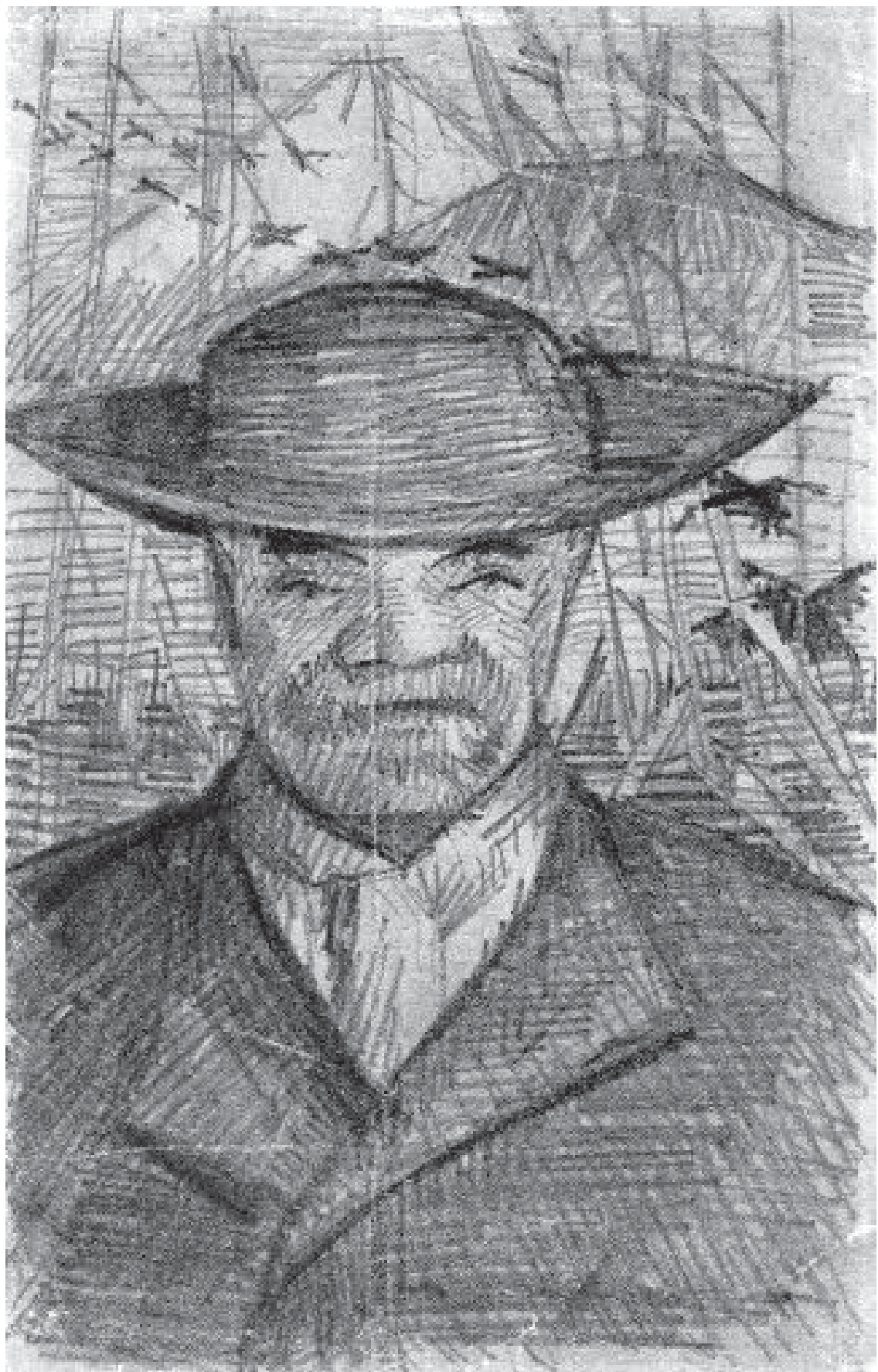

Abb. 45 Père Tanguy, Winter 1887, Bleistiftzeichnung,

21,5 x 13,5 cm, Amsterdam, Van Gogh Museum, F 1412, JH 1350. 


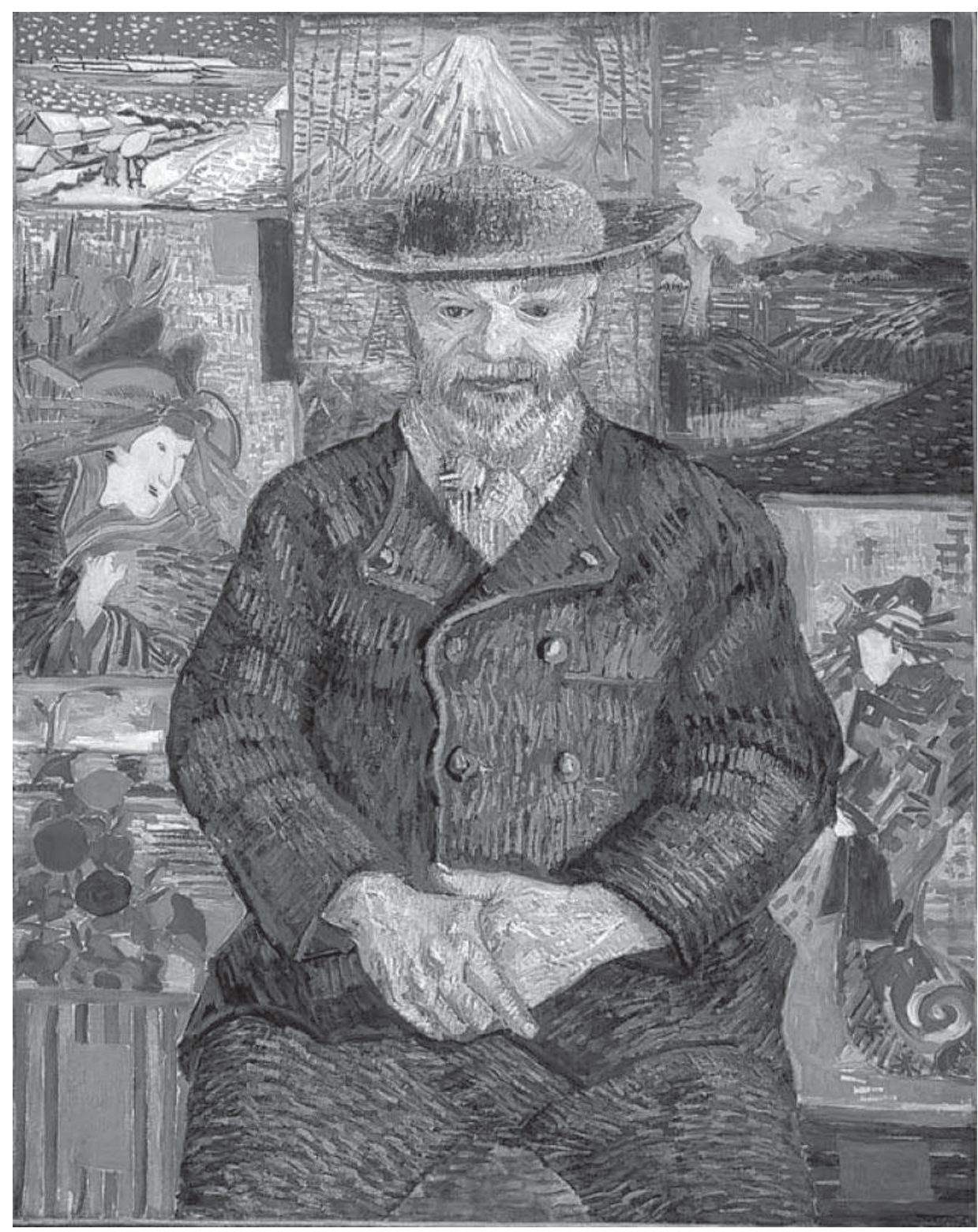

Abb. 46 Père Tanguy, Winter 1887-88, Öl auf Leinwand, 92 x 75 cm, Paris, Musée Rodin, F 363, JH 1351. 


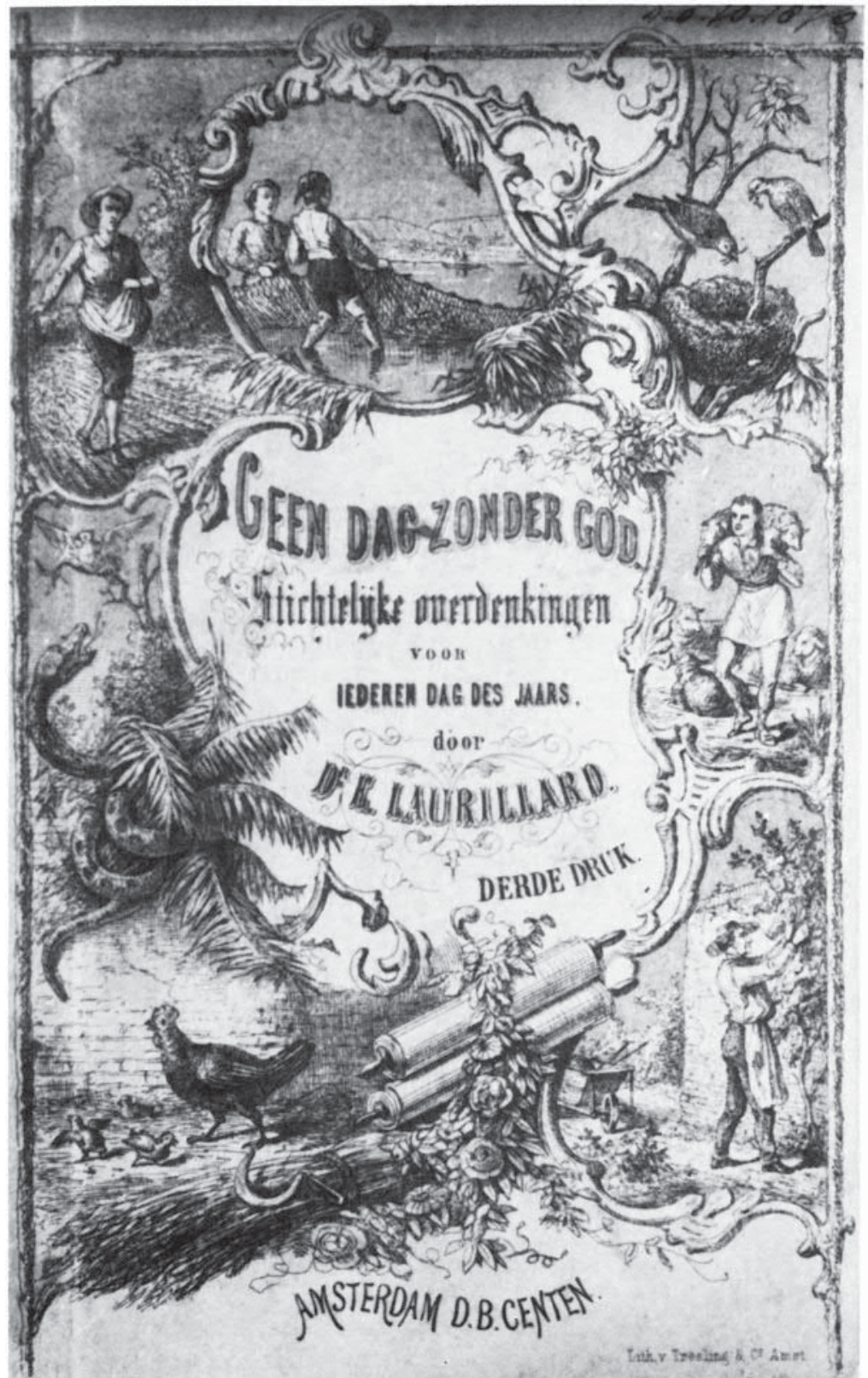

Abb. 47 Eliza Laurillard, Geen dag zonder God, Amsterdam 1876 (dritte Ausgabe). 


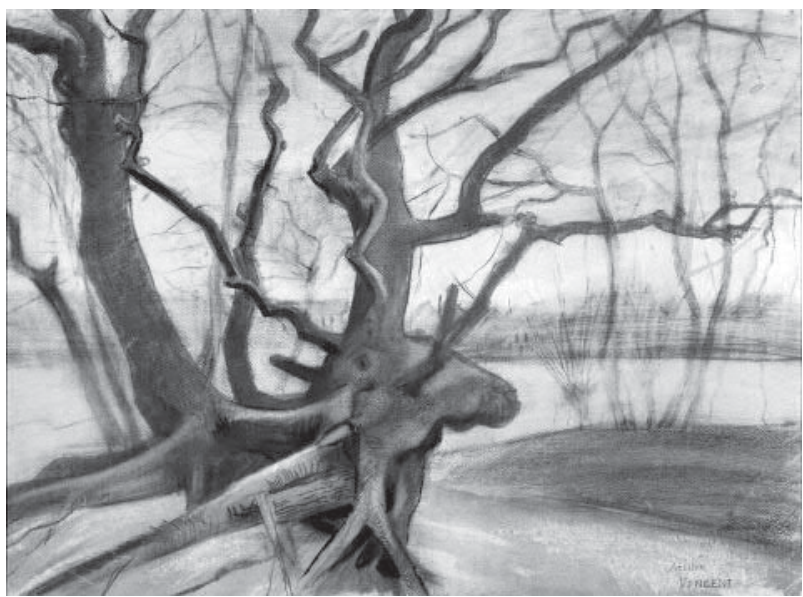

Abb. 48

Les Racines, April-Mai 1882, Bleistift, schwarze Kreide, Tinte, braune und graue Lavierung sowie deckende Aquarellfarben auf Papier, $51,5 \times 70,7 \mathrm{~cm}$, Otterlo, Kröller-Müller Museum, F 933r, JH 142.

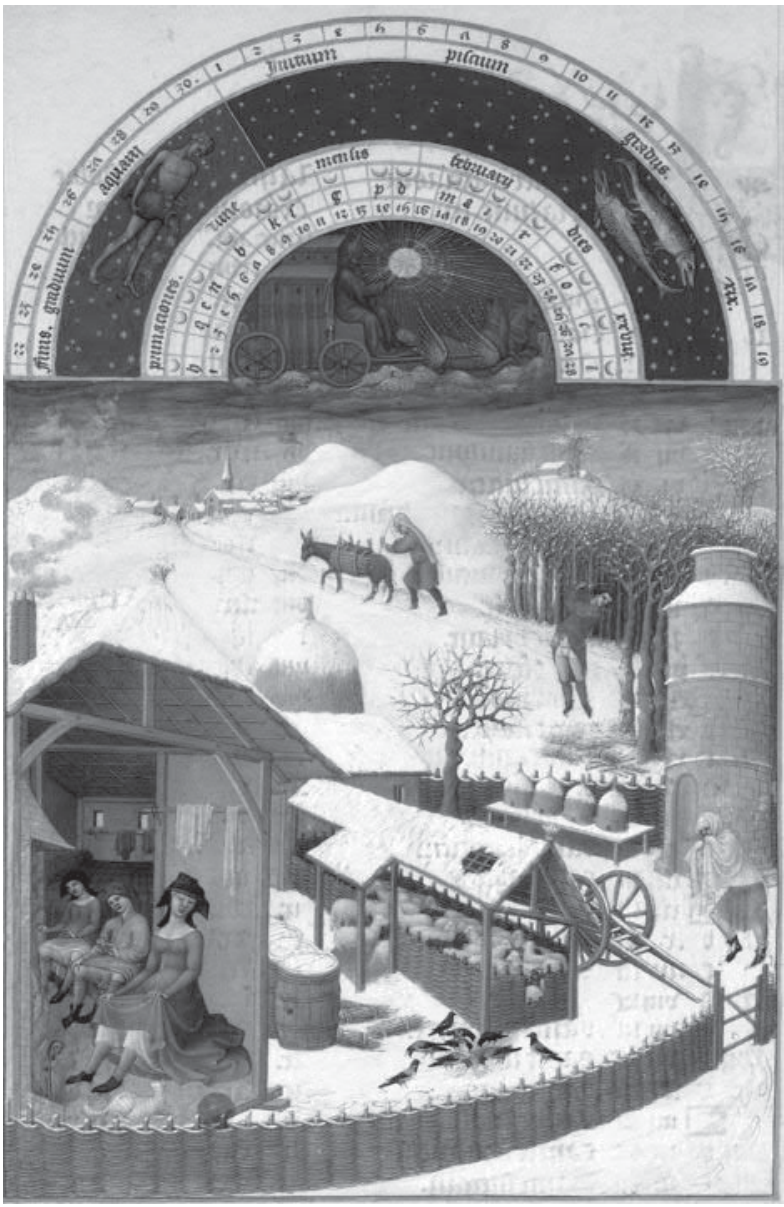

Abb. 49

Februar, Paul, Hermann u. Jean von Limburg (zw. 1385 u. 1390-1416), Très Riches Heures, 1413-1416 (1485 vollendet durch Jean Colombe (1430/35-1493)), Chantilly, Musèe Condè, MS 65, folio 2v. 


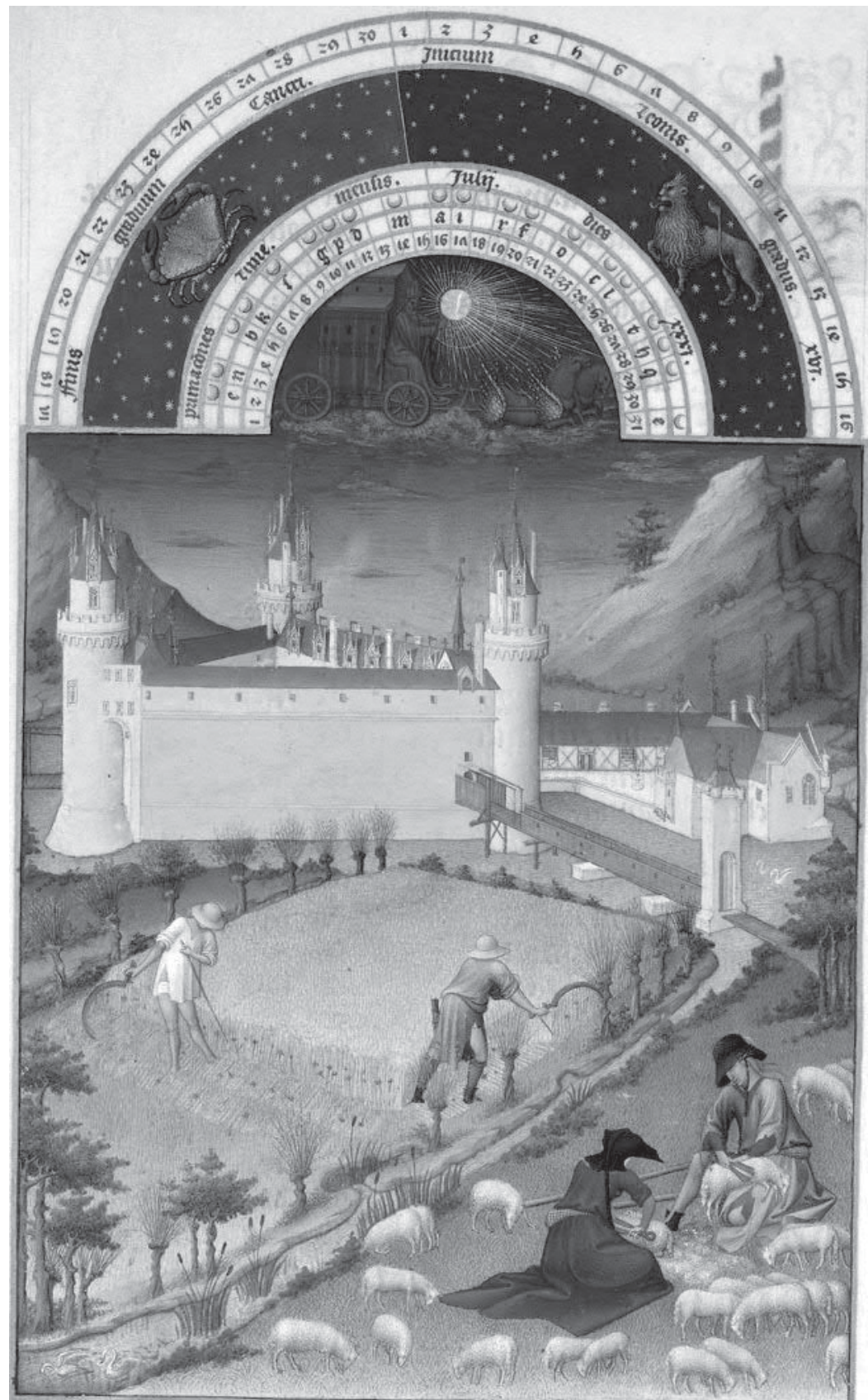

Abb. 50 Juli, Paul, Hermann u. Jean von Limburg (zw. 1385 u. 1390-1416), Très Riches Heures, 1413-1416 (1485 vollendet durch Jean Colombe (1430/35-1493)), Chantilly, Musèe Condè, MS 65, folio 7v. 


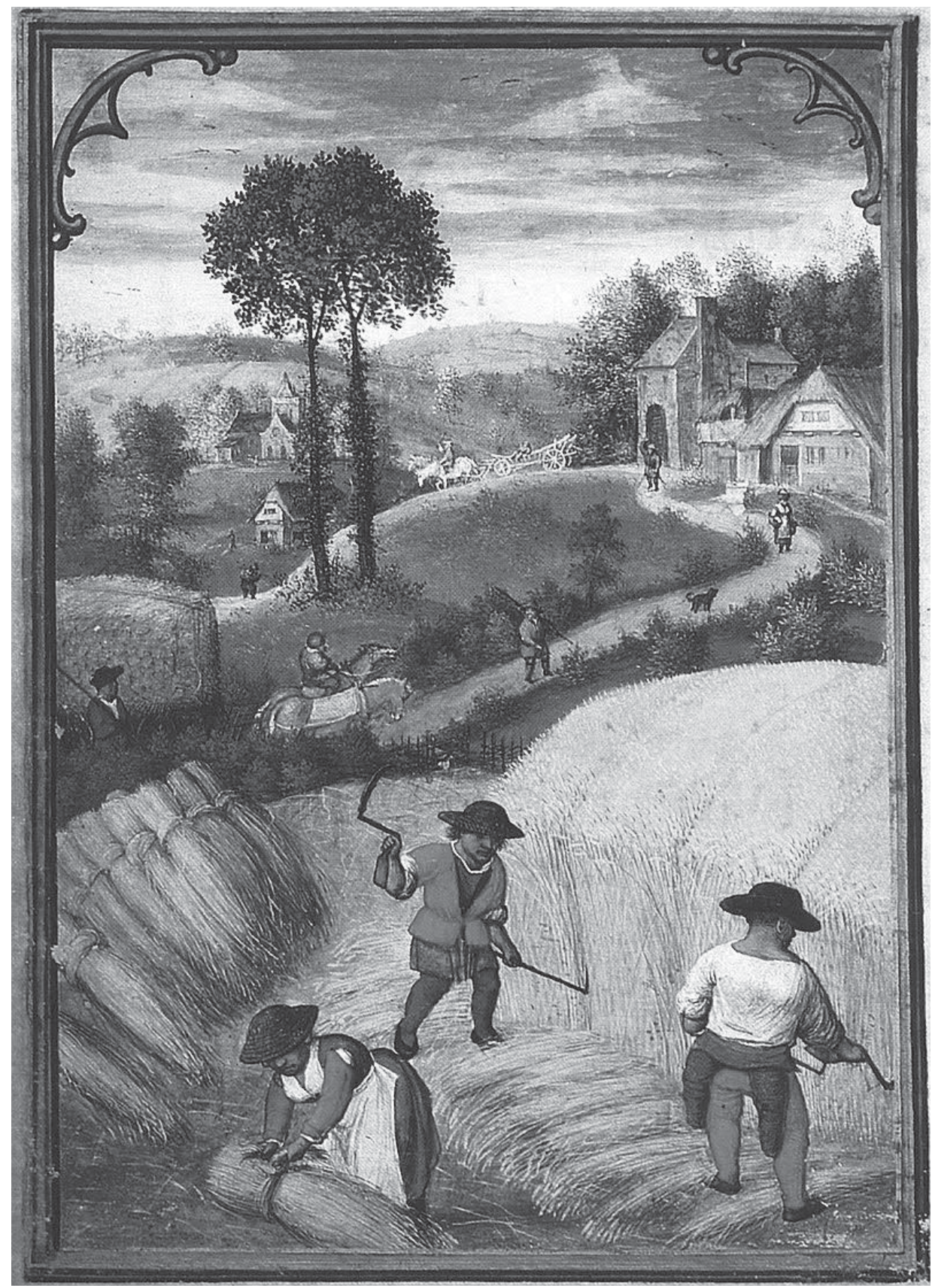

Abb. 51 August, Simon Bening (1483 od. 1484-1561), München-Montserrat Stundenbuch (oder Flämischer Kalender), Brügge, um 1540, München, Bayerische Staatsbibliothek, cod. lat. 23638, folio 9v. 


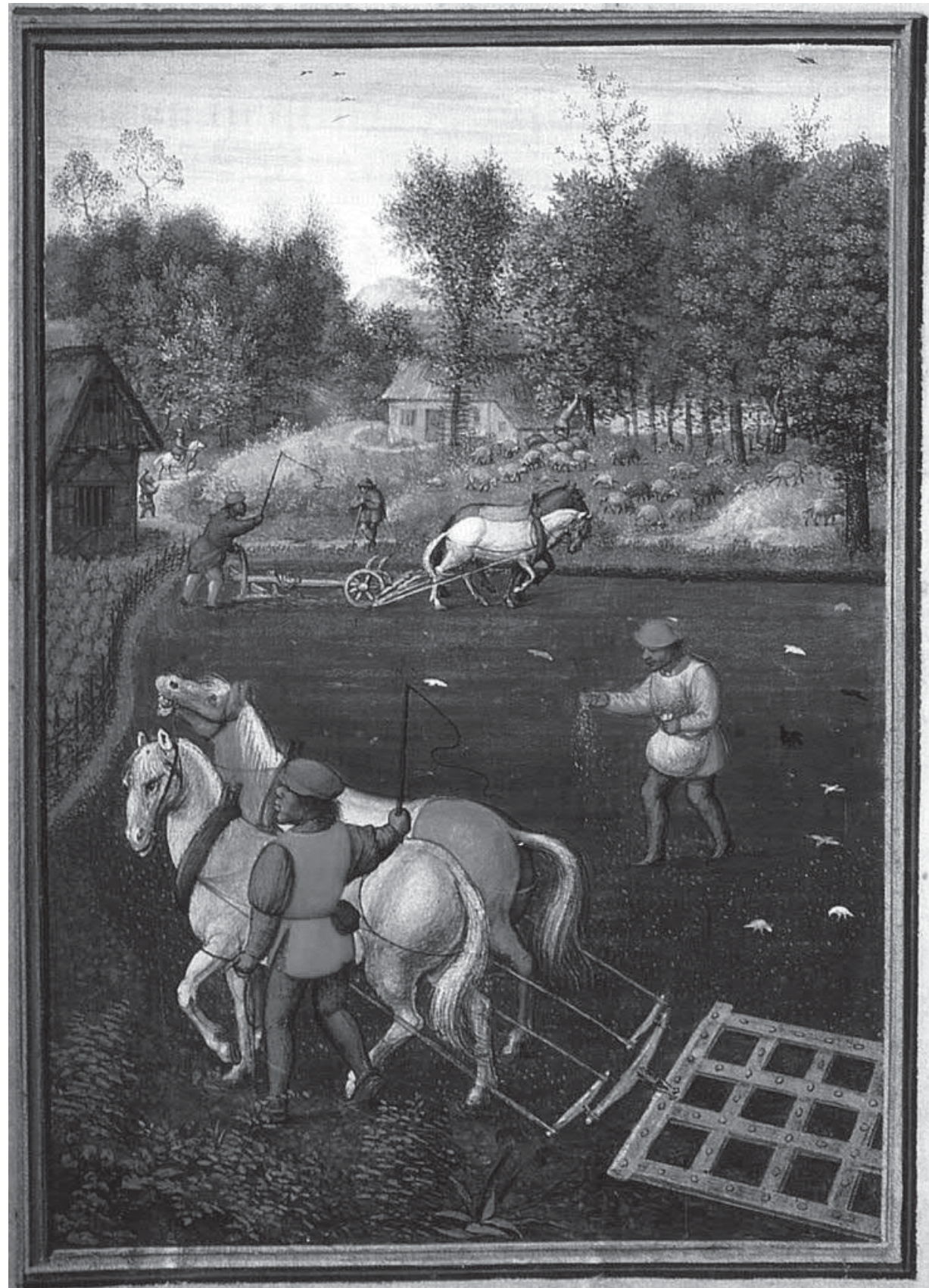

Abb. 52 September, Simon Bening (1483 od. 1484-1561), München-Montserrat Stundenbuch (oder Flämischer Kalender), Brügge, um 1540, München, Bayerische Staatsbibliothek, cod. lat. 23638, fol. 10v. 


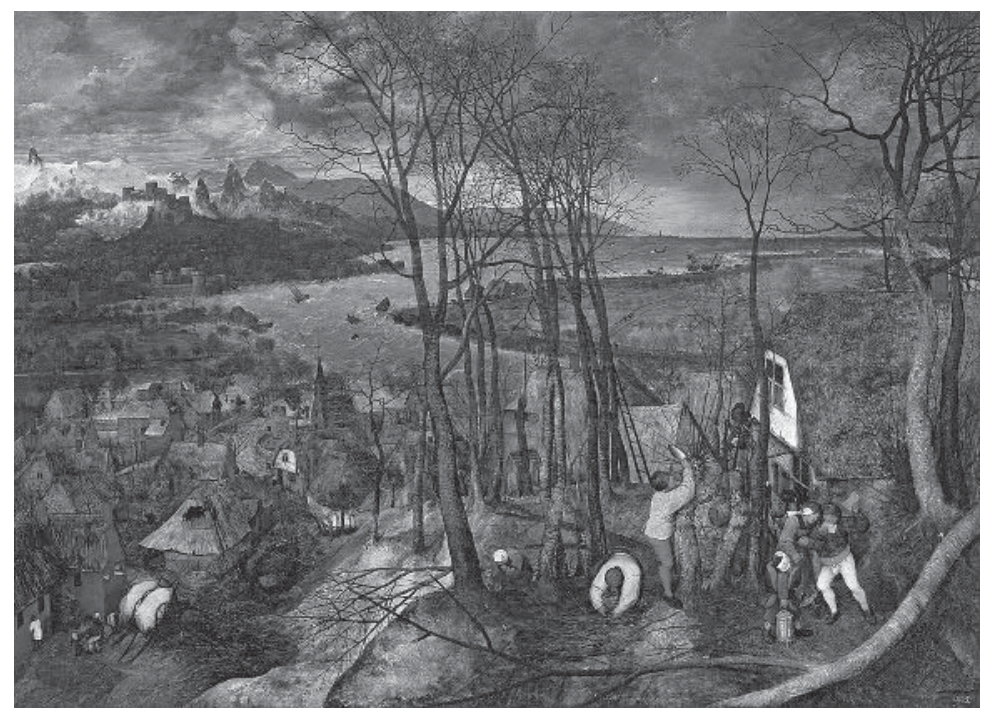

Abb. 53 Pieter Bruegel d. Ä. (um 1530-1569), Der düstere Tag, 1565, Öl auf Holz, 118 x 163 cm, Wien, Kunsthistorisches Museum.

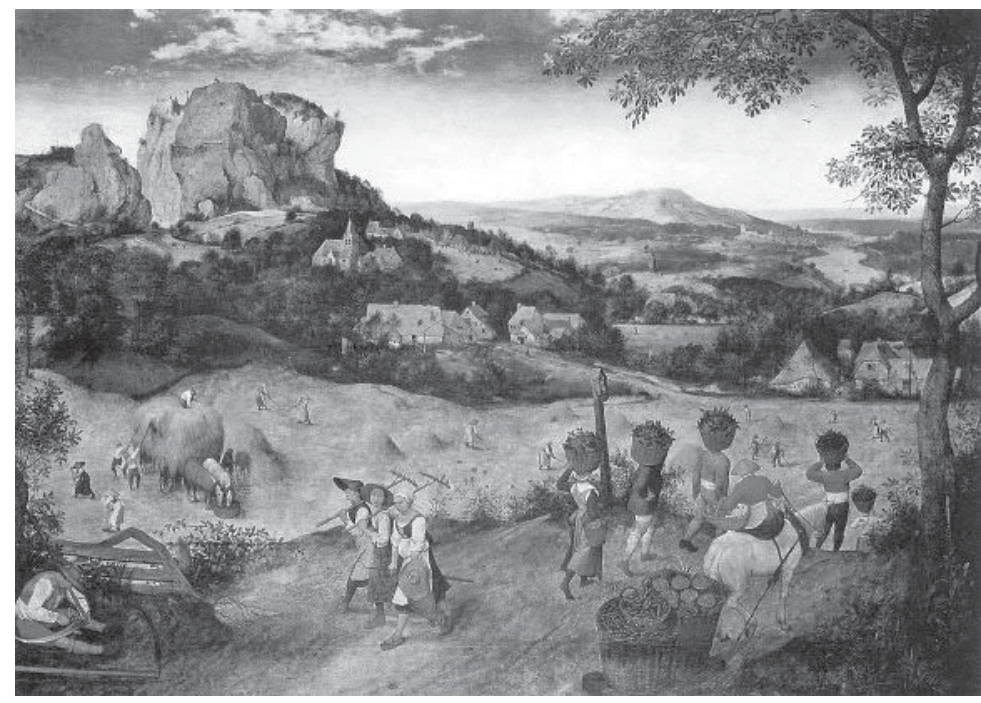

Abb. 54 Pieter Bruegel d. Ä. (um 1530-1569), Die Heuernte, 1565, Öl auf Holz, 114 x 158 cm, Prag, Palais Lobkowitz. 


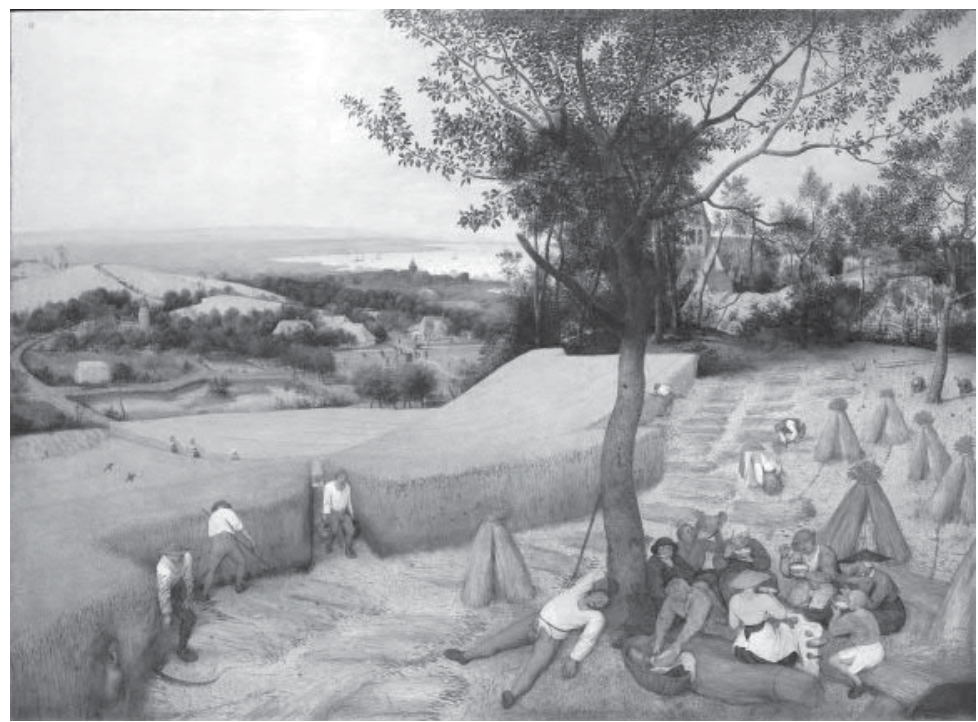

Abb. 55 Pieter Bruegel d. Ä. (um 1530-1569), Die Kornernte, 1565, Öl auf Holz, 119 x 162 cm, New York, Metropolitan Museum of Art.

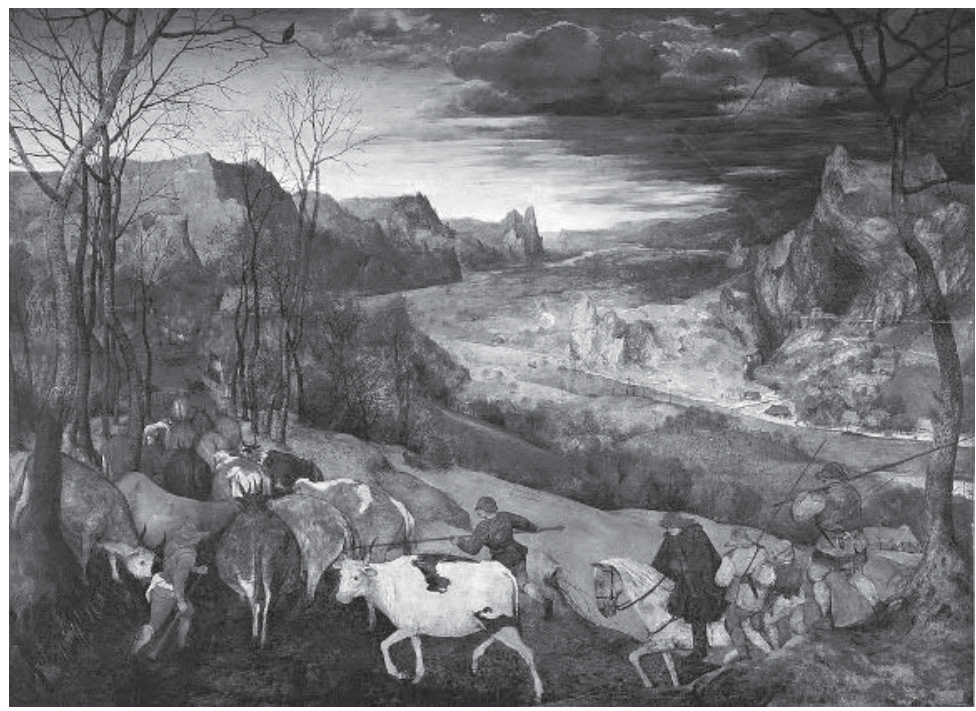

Abb. 56 Pieter Bruegel d. Ä. (um 1530-1569), Die Heimkehr der Herde, 1565, Öl auf Holz, 117 x 159 cm, Wien, Kunsthistorisches Museum. 


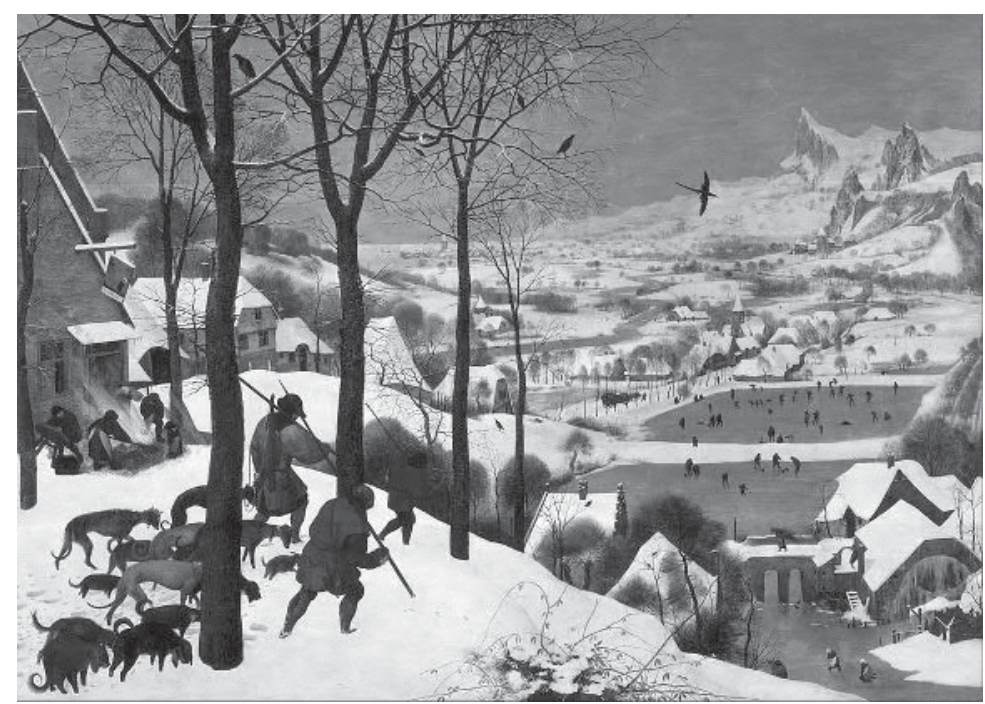

Abb. 57 Pieter Bruegel d. Ä. (um 1530-1569), Die Jäger im Schnee, 1565, Öl auf Holz, 117 x 162 cm, Wien, Kunsthistorisches Museum.

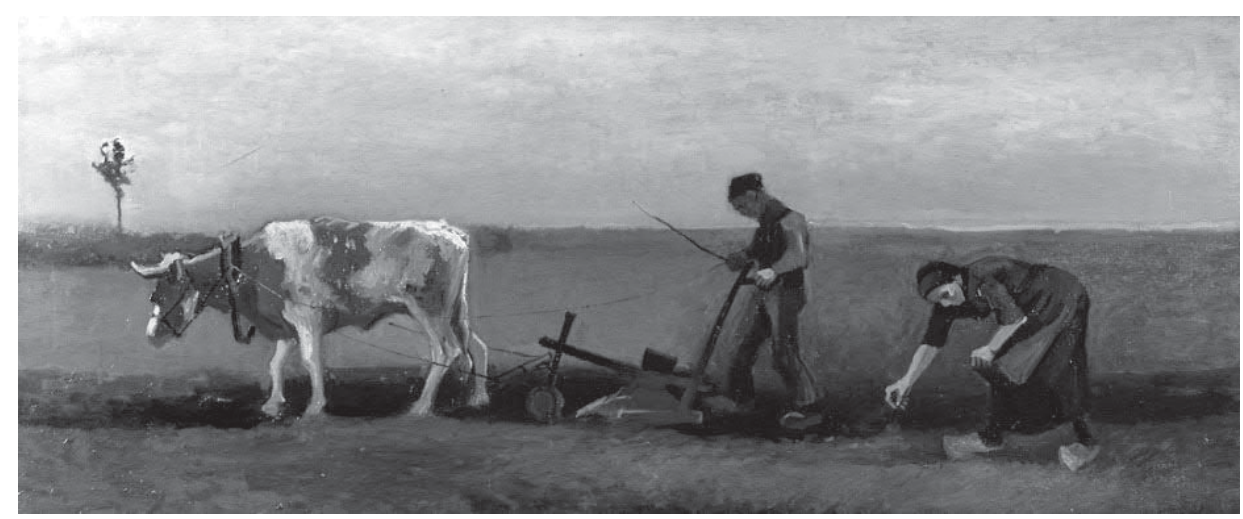

Abb. 58 Ochsenpflug, 1884, Öl auf Leinwand, 70,5 cm x $170 \mathrm{~cm}$, Wuppertal, Von der Heydt-Museum, F 172, JH 514. 


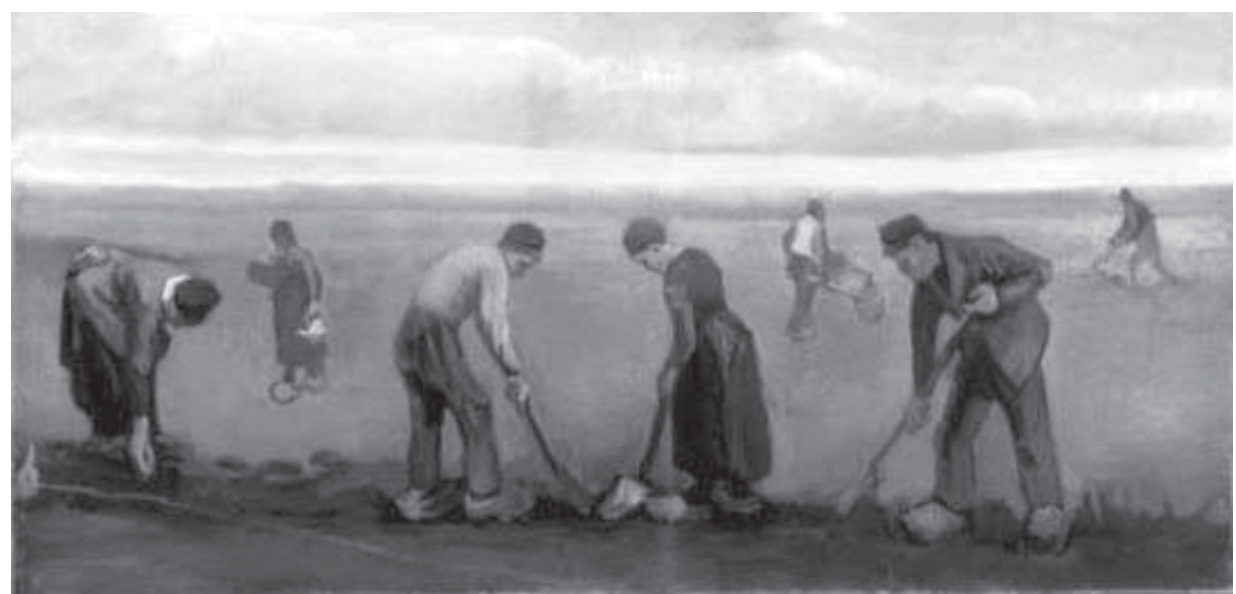

Abb. 59 Kartoffellegen, 1884, Öl auf Leinwand, 66 x 149 cm, Otterlo, Kröller-Müller Museum, F 41, JH 513.

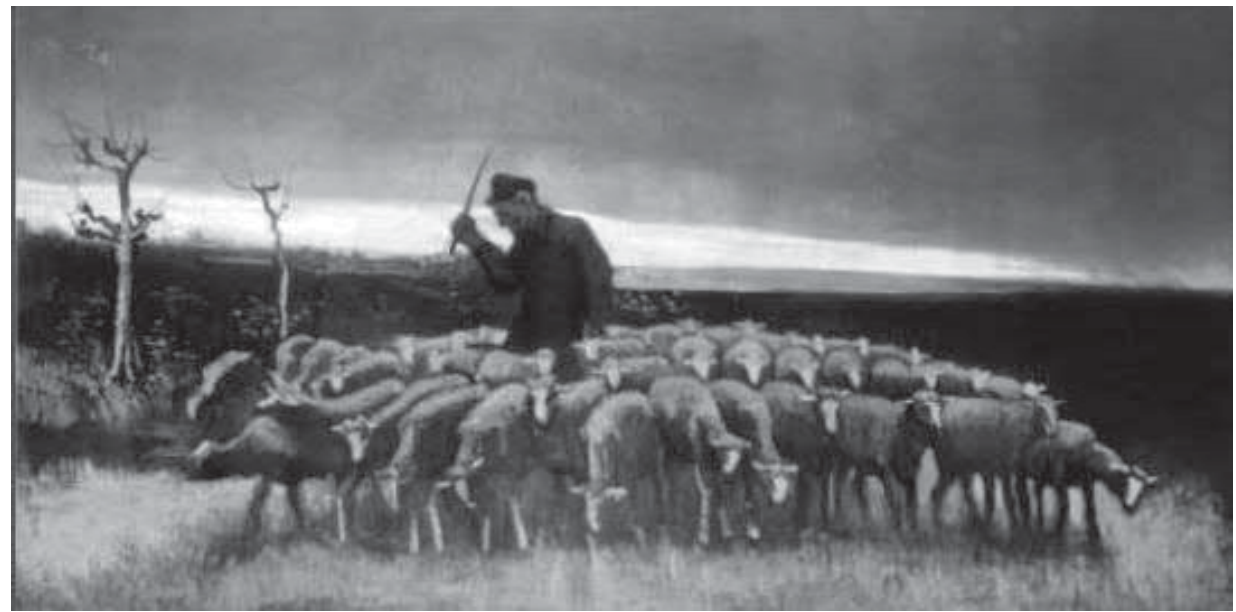

Abb. 60 Hirte, 1884, Öl auf Karton, 67 x 126 cm, Privatsammlung, F 42, JH 517.

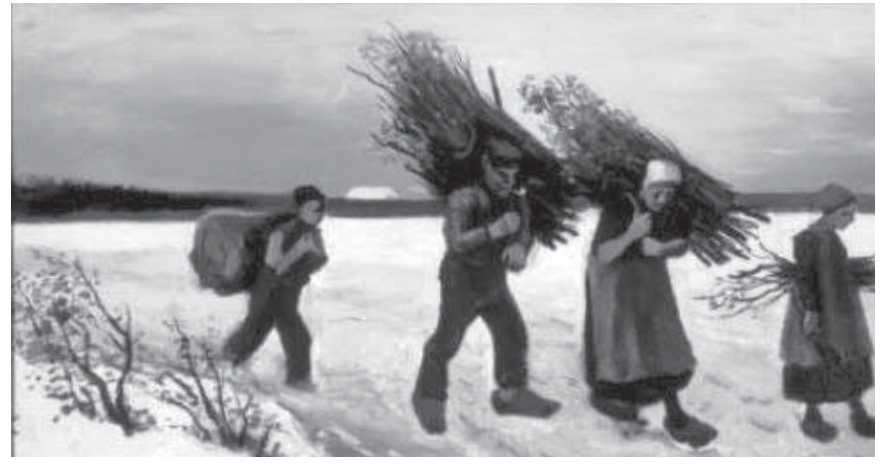

Abb. 61 Reisigsammler (Schneestimmung), 1884 ,

Öl auf Holz, $67 \times 126$,

Privatsammlung, F 43, JH 516. 


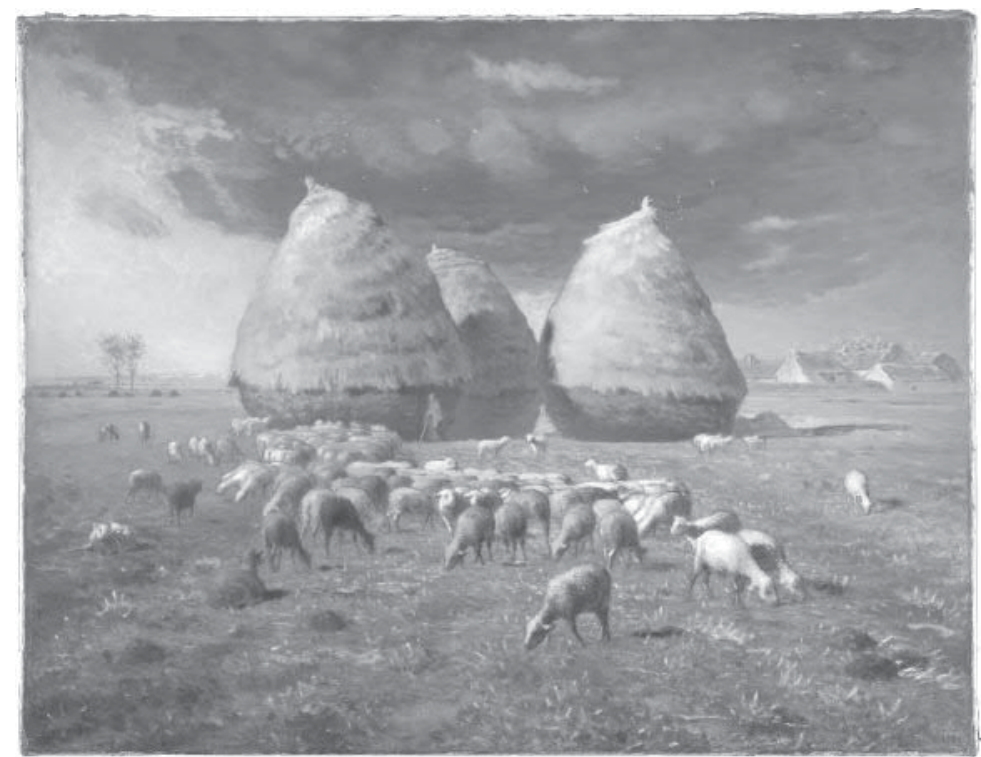

Abb. 62 Jean-François Millet (1814-1875), Herbst, Getreideschober, 1868-1874, Öl auf Leinwand, 85,1 x 110,2 cm, New York, The Metropolitan Museum of Art.

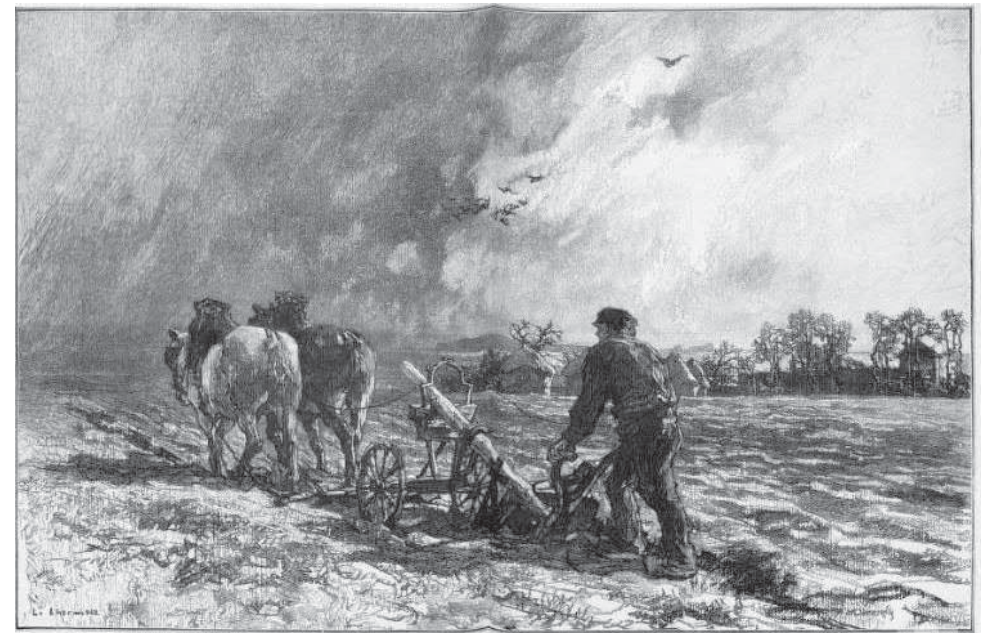

Abb. 63 Léon-Augustin Lhermitte (1844-1925), Le Labourage, Darstellung des Monats März aus der Serie Les Mois Rustiques, druckgraphische Reproduktion publiziert in Le Monde illustré, 25.04.1885, Paris 1885. 


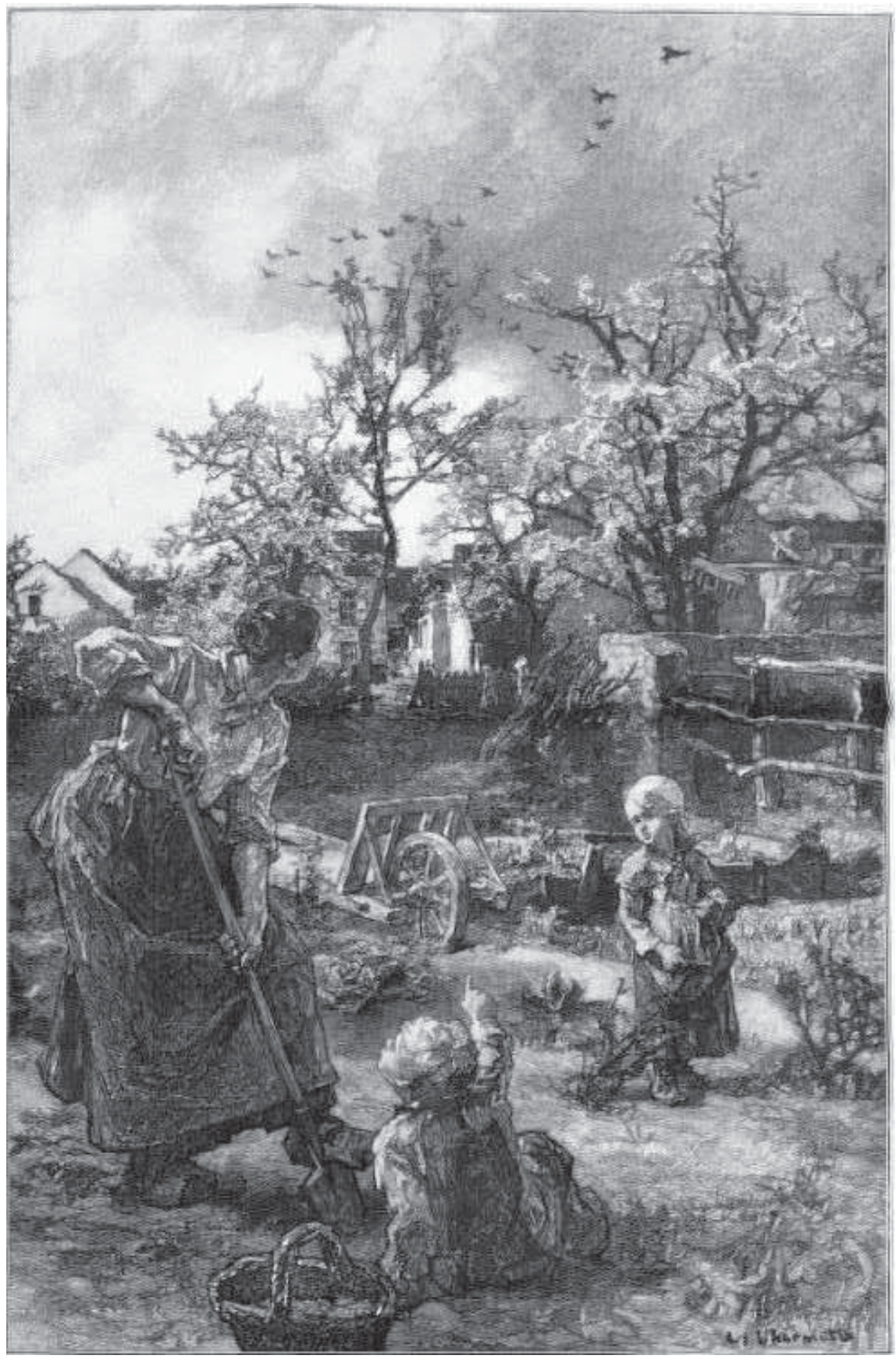

Abb. 64 Léon-Augustin Lhermitte (1844-1925), Le Jardinage, Darstellung des Monats April aus der Serie Les Mois Rustiques, druckgraphische Reproduktion publiziert in Le Monde illustré, 25.04.1885. 


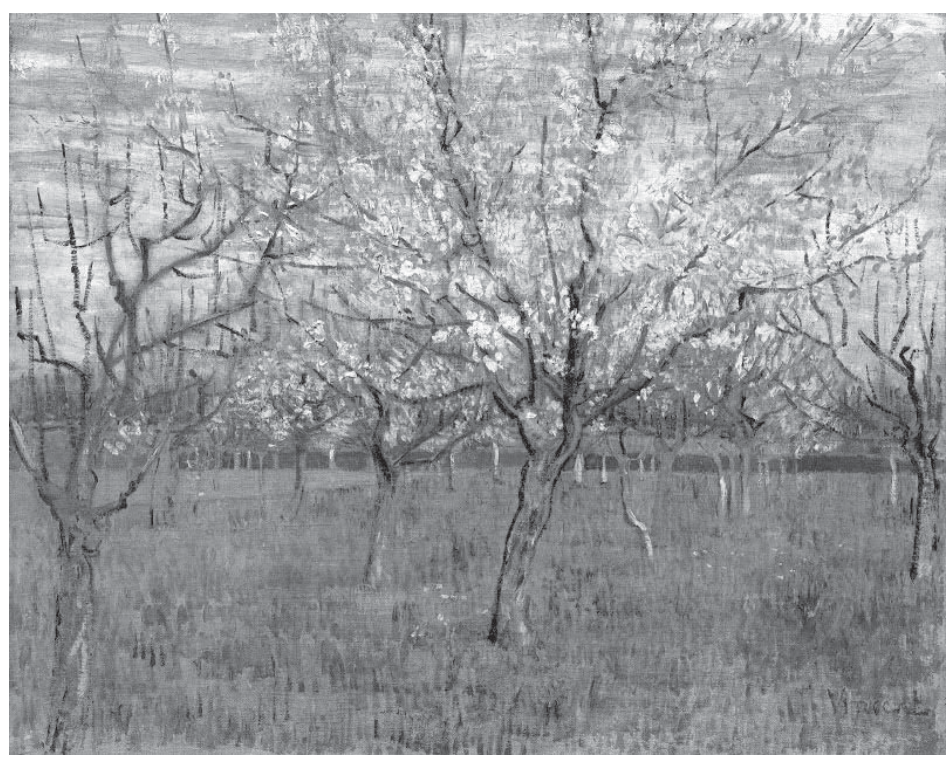

Abb. 65 Obstgarten mit blühenden Aprikosenbäumen, März 1888, Öl auf Leinwand, 65,5 x $80 \mathrm{~cm}$, Amsterdam, Van Gogh Museum, F 555, JH 1380.

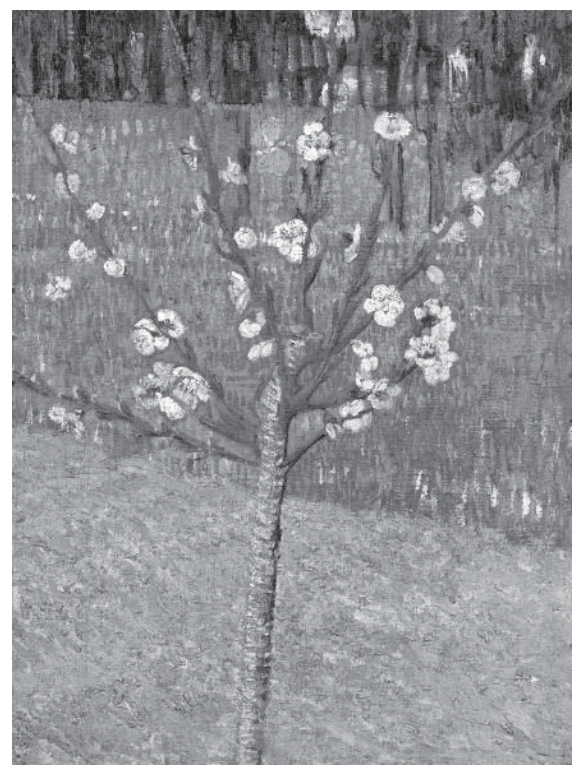

Abb. 66 Blühender Pfirsichbaum, April 1888, Öl auf Leinwand, $50 \mathrm{~cm} \times 37.5 \mathrm{~cm}$, Amsterdam, Van Gogh Museum, F 557, JH 1397. 


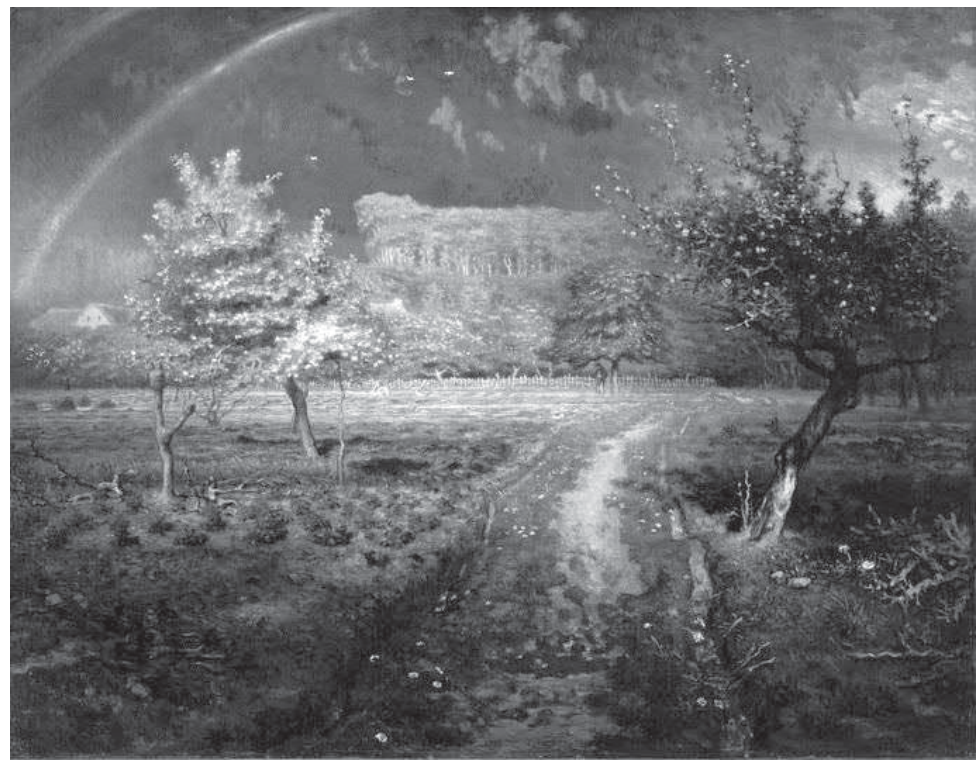

Abb. 67 Jean-François Millet (1814-1875), Frühling, 1868-1873, Öl auf Leinwand, 86 x $111 \mathrm{~cm}$, Paris, Musée d'Orsay.

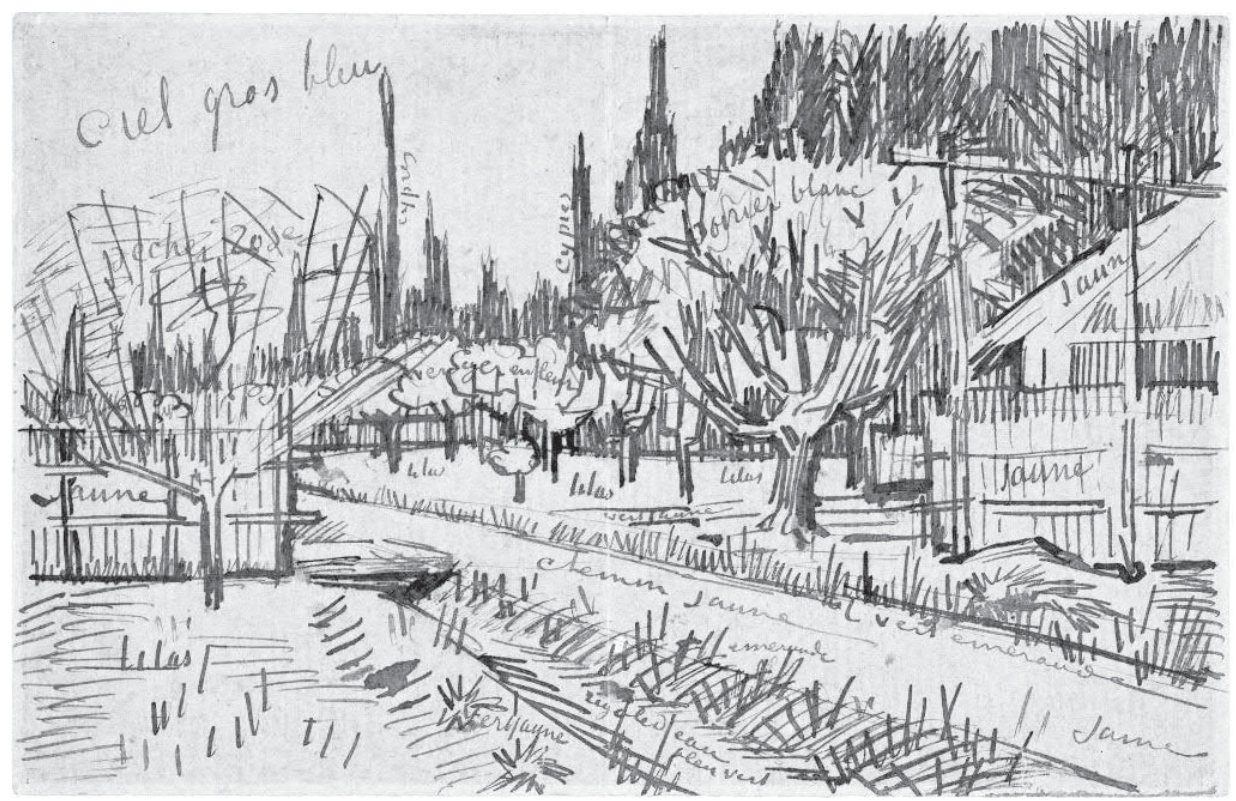

Abb. 68 Skizze aus Brief 596/B 3, Obstgarten, von Zypressen gesäumt, 12.4.1888, Bleistift und Tinte, 13,3 x 20,7 cm, New York, The Morgan Library, F-, JH 1390. 


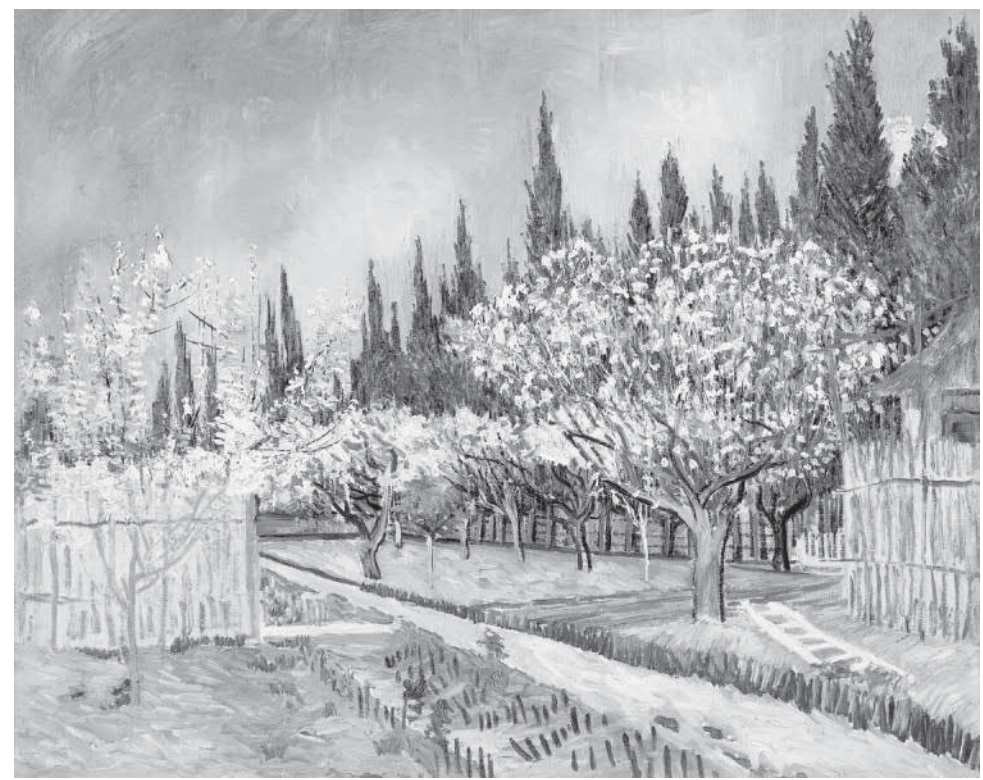

Abb. 69 Obstgarten, von Zypressen gesäumt, April 1888,

Öl auf Leinwand, 65 x 81 cm, Otterlo, Kröller-Müller Museum, F 513, JH 1389.

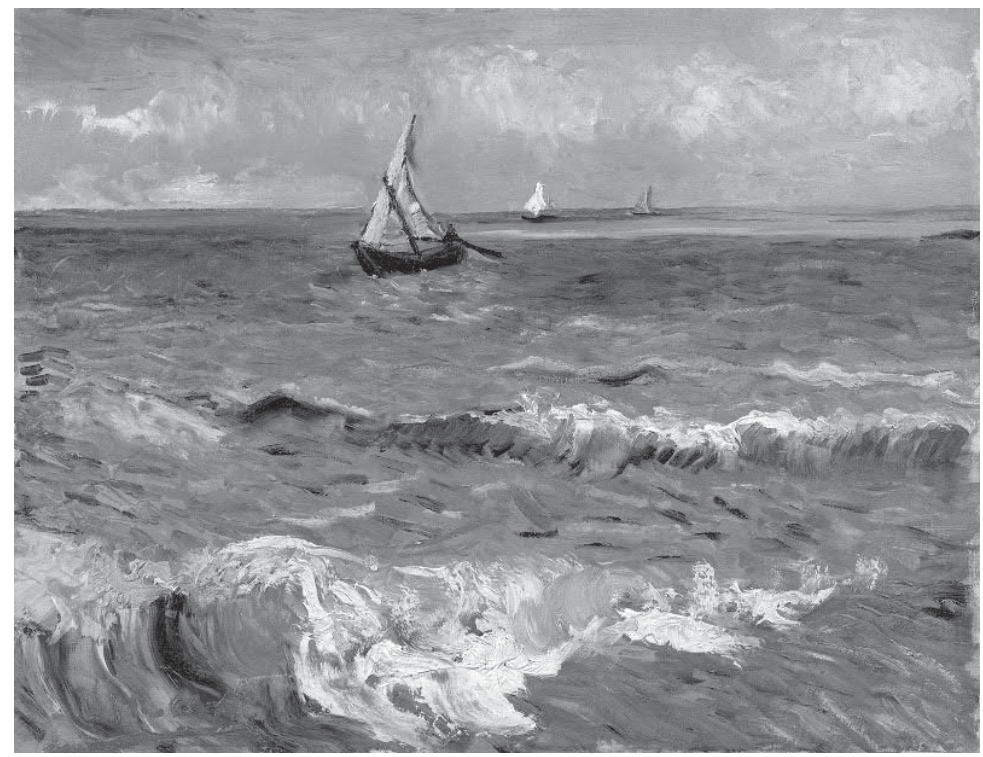

Abb. 70 Seestück in Saintes-Maries-de-la-Mer, zw. 30.5.-3.6.1888, Öl auf Leinwand, 51 x 64 cm, Amsterdam, Van Gogh Museum, F 415, JH 1452. 


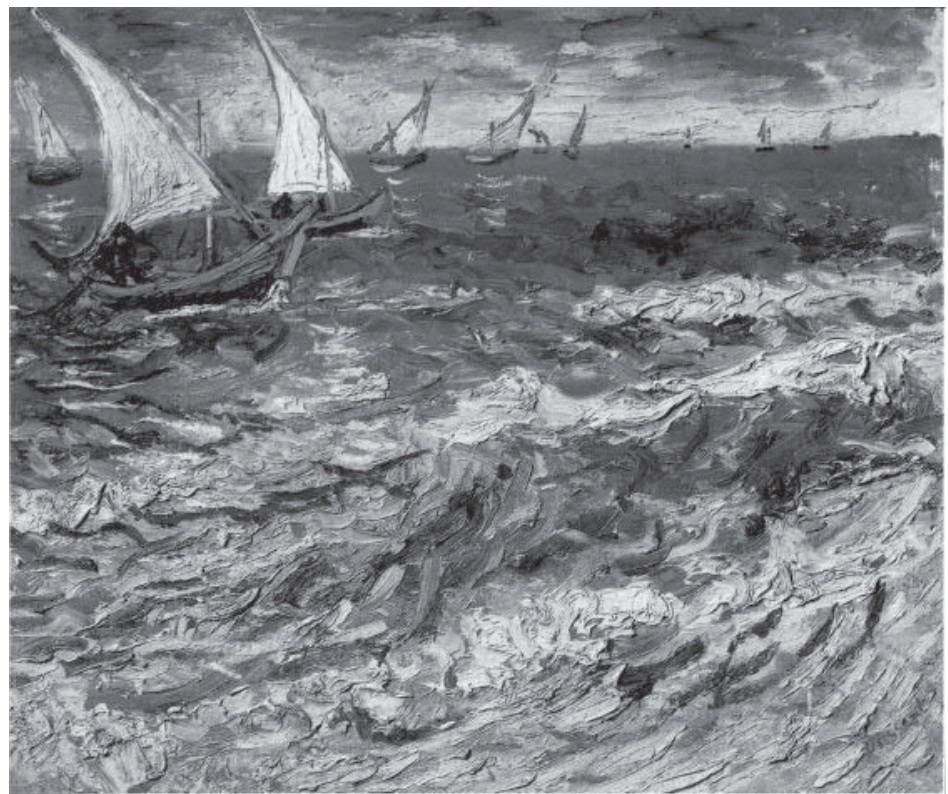

Abb. 71 Kleines Seestück in Saintes-Maries-de-la-Mer, zw. 30.5.-3.6.1888, Öl auf Leinwand, 44 x $53 \mathrm{~cm}$, Moskau, Puschkin-Museum, F 417, JH 1453.

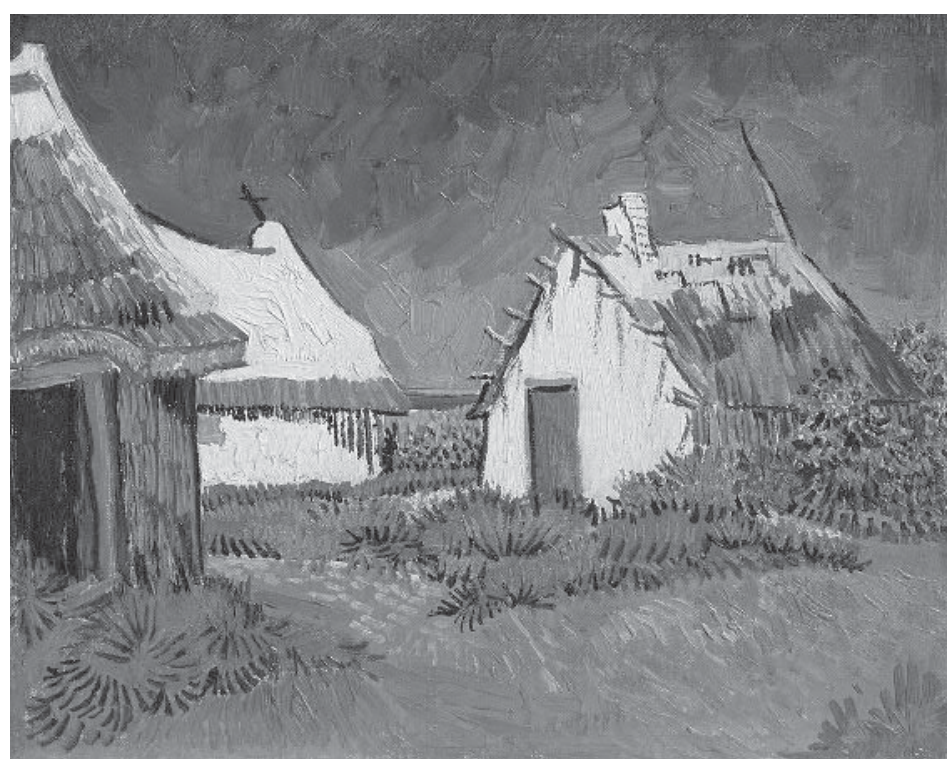

Abb. 72 Drei Hütten in Saintes-Maries-de-la-Mer, ca. 5. Juni 1888, Öl auf Leinwand, 33,5 x 41,5 cm, Kunsthaus Zürich, F 419, JH 1465. 


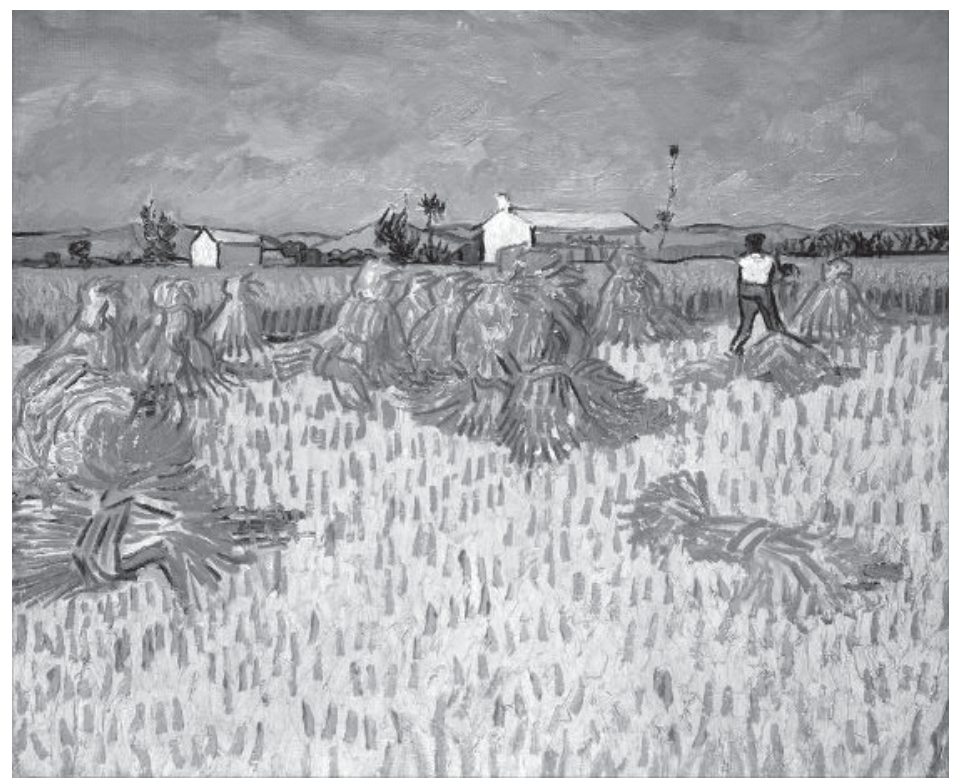

Abb. 73 Kornernte in der Provence, Juni 1888, Öl auf Leinwand, 50 x 60 cm, Jerusalem, The Israel Museum, F 558, JH 1481.

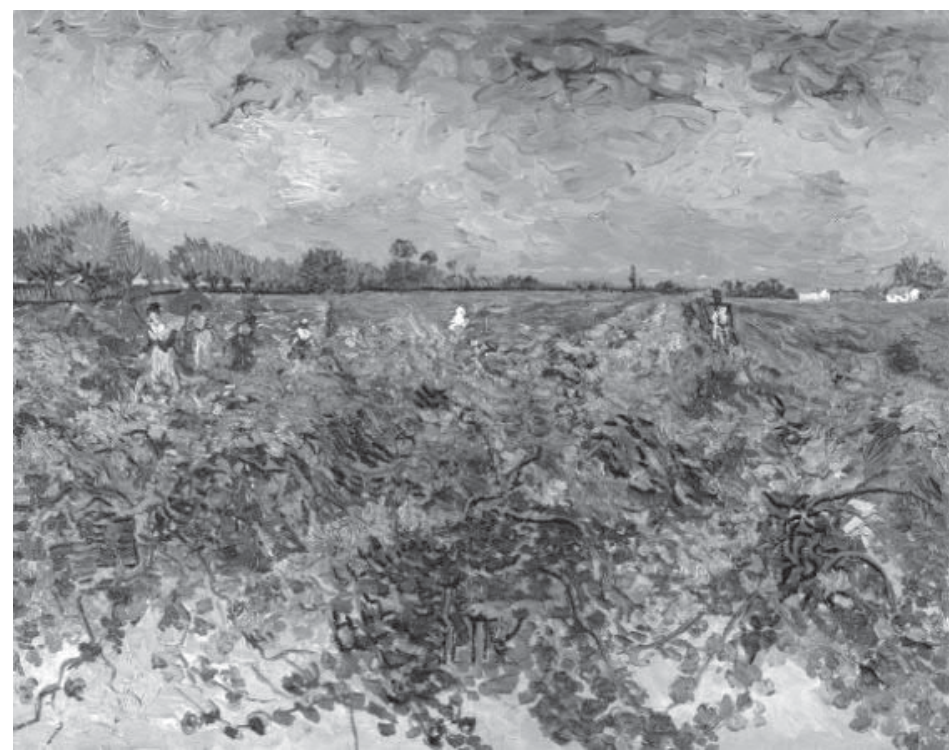

Abb. 74 Der grüne Weinberg, Oktober 1888, Öl auf Leinwand, 73,5 cm x 92,5 cm, Kröller-Müller Museum, Otterlo, F 475, JH 1595. 


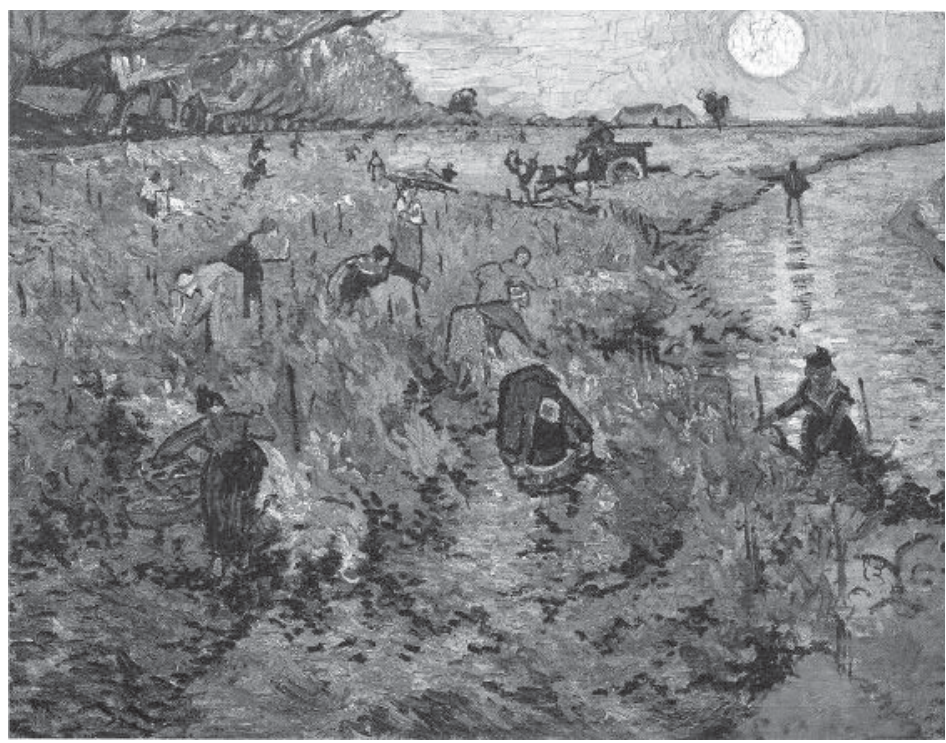

Abb. 75 Der rote Weinberg, November 1888, Öl auf Leinwand, 75 x 93 cm, Moskau, Puschkin-Museum, F 495, JH 1626.

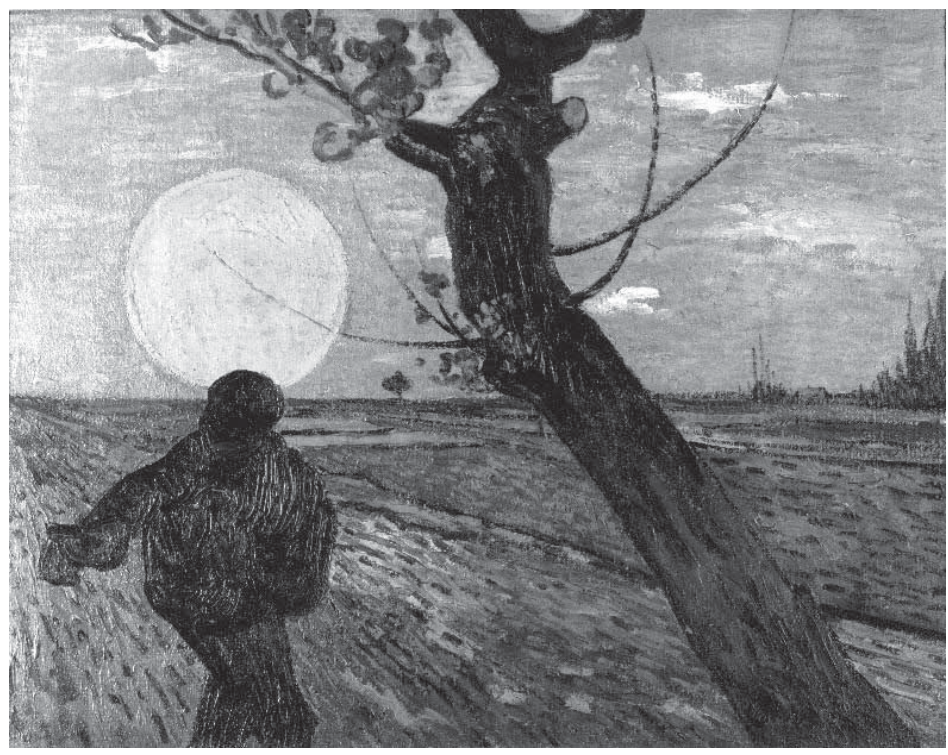

Abb. 76 Der Sämann bei untergehender Sonne, 1888, Öl auf Leinwand, 73,5 x $93 \mathrm{~cm}$, Zürich, Stiftung Sammlung E. G. Bührle, F 450, JH1627. 


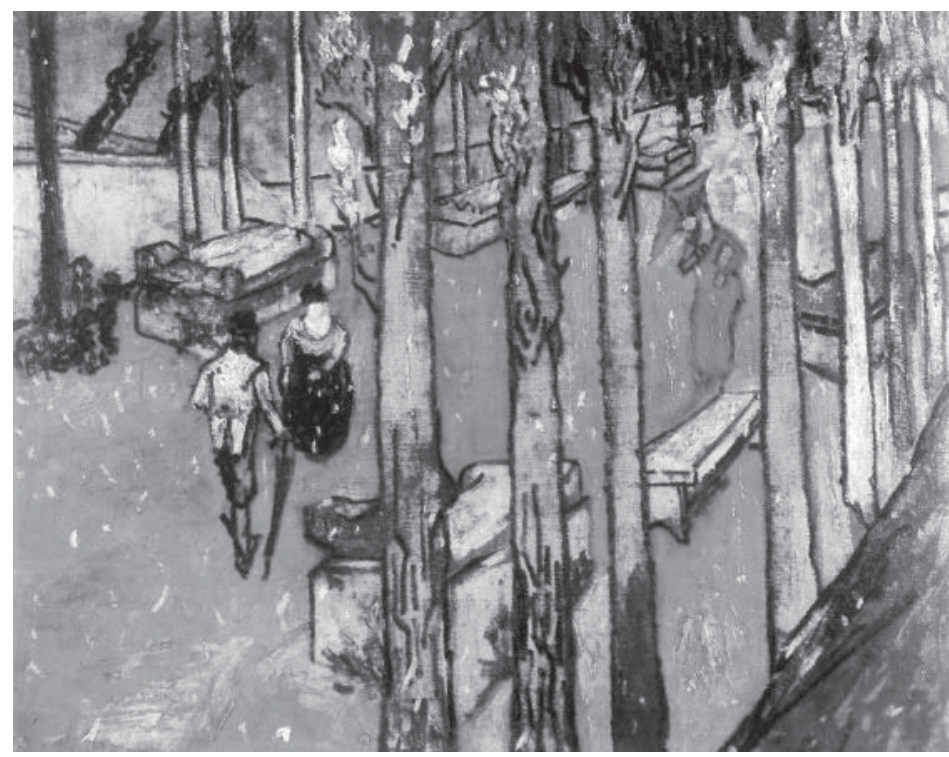

Abb. 77 Fallende Blätter (Les Alyscamps), ca. 1. November 1888, 73 x 92 cm, Öl auf Sackleinen, Otterlo, Kröller-Müller Museum, F 486, JH 1620.

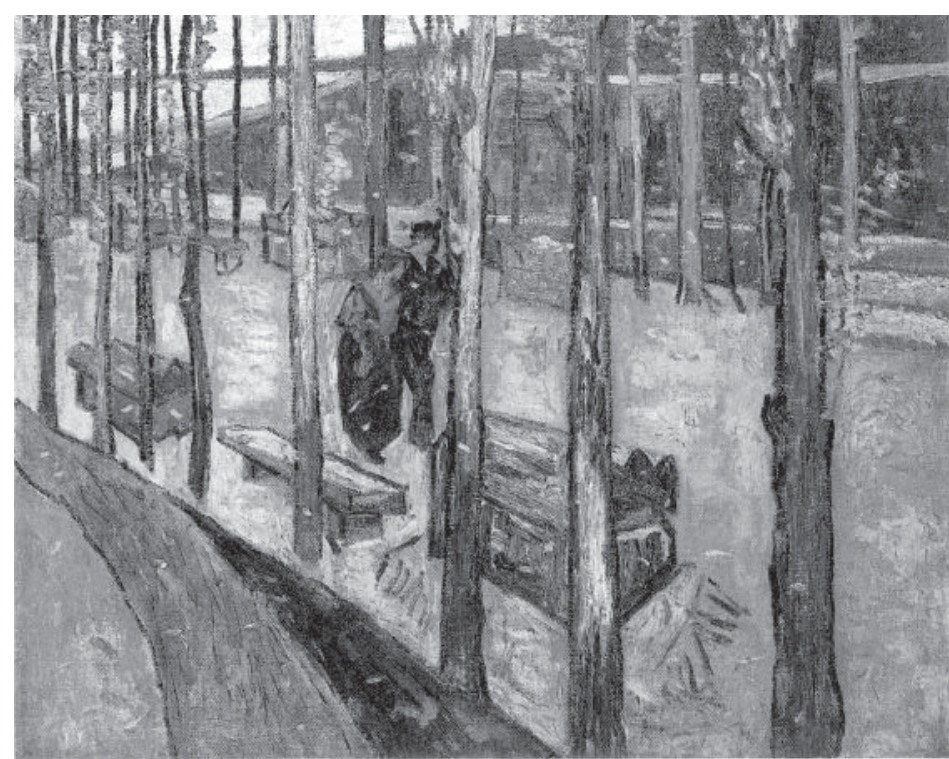

Abb. 78 Fallende Blätter (Les Alyscamps), ca. 1. November 1888, $72 \times 91 \mathrm{~cm}$, Öl auf Sackleinen, Privatbesitz, F 487, JH 1621. 


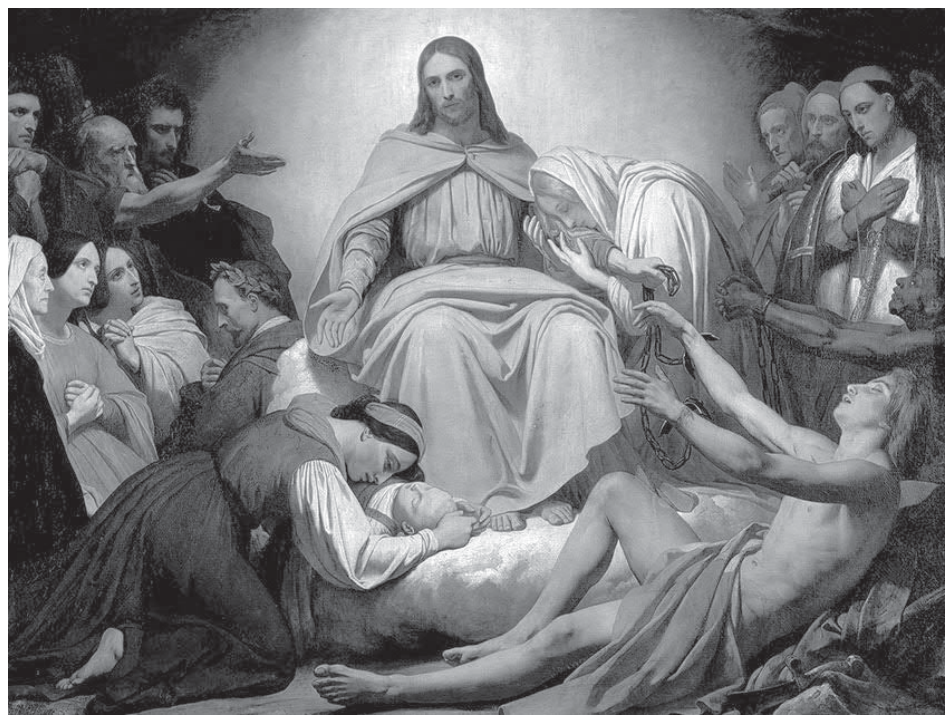

Abb. 79 Ary Scheffer (1795-1858), Christus Consolator, 1837, Öl auf Leinwand, Maße unbekannt, Amsterdam, Van Gogh Museum (Leihgabe des Amsterdams Historisch Museum).

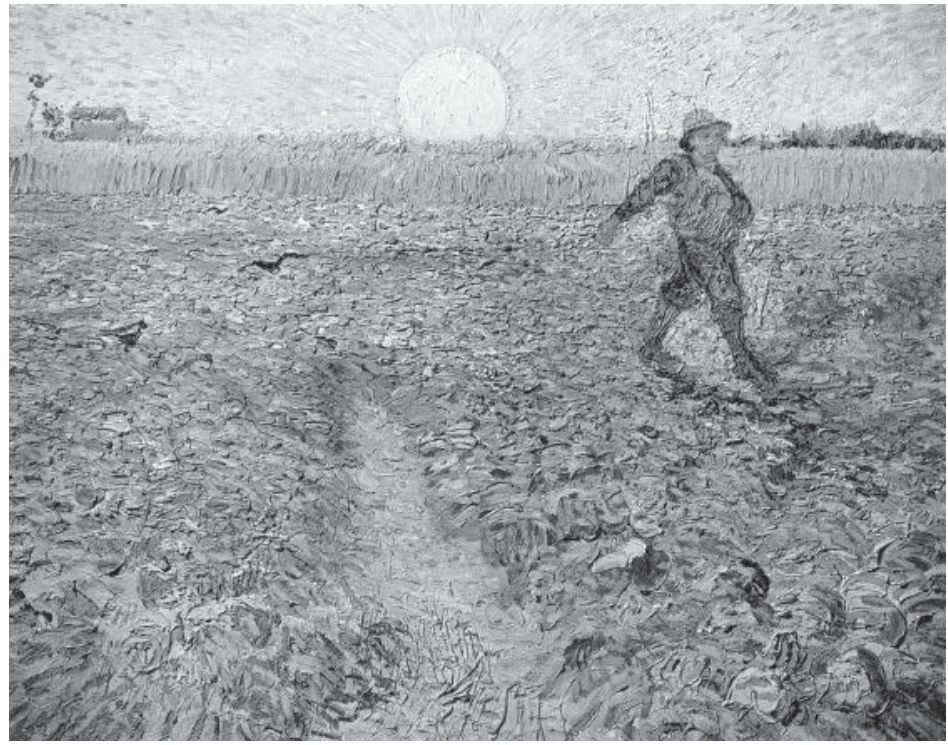

Abb. 80 Sämann bei Sonnenuntergang, Juni 1888, Öl auf Leinwand, 64 x 80,5 cm, Otterlo, Kröller-Müller Museum, F 422, JH 1470. 


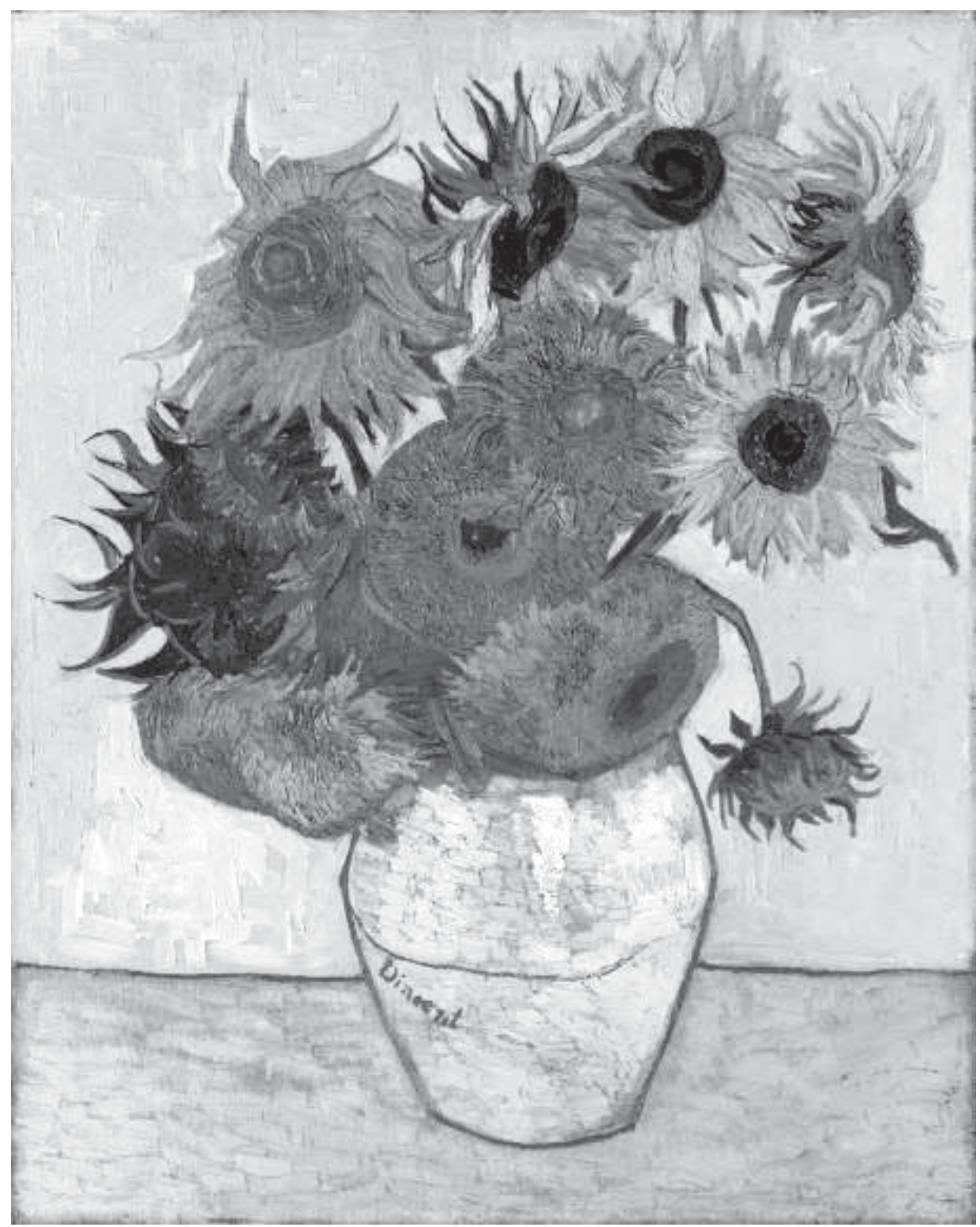

Abb. 81 Sonnenblumen, Ende August 1888, Öl auf Leinwand, 91 x 71 cm, München, Neue Pinakothek, F 456, JH 1561. 


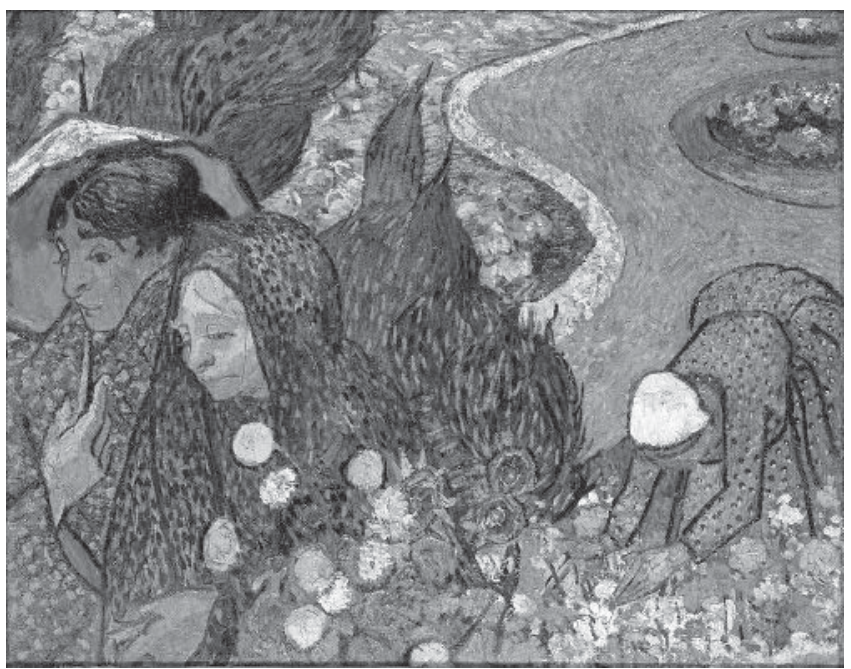

Abb. 82 Erinnerung an den Garten in Etten, November $1888,73,5 \times 92,5 \mathrm{~cm}$, Öl auf Leinwand,

St. Petersburg, Eremitage Museum, F 496, JH 1630.

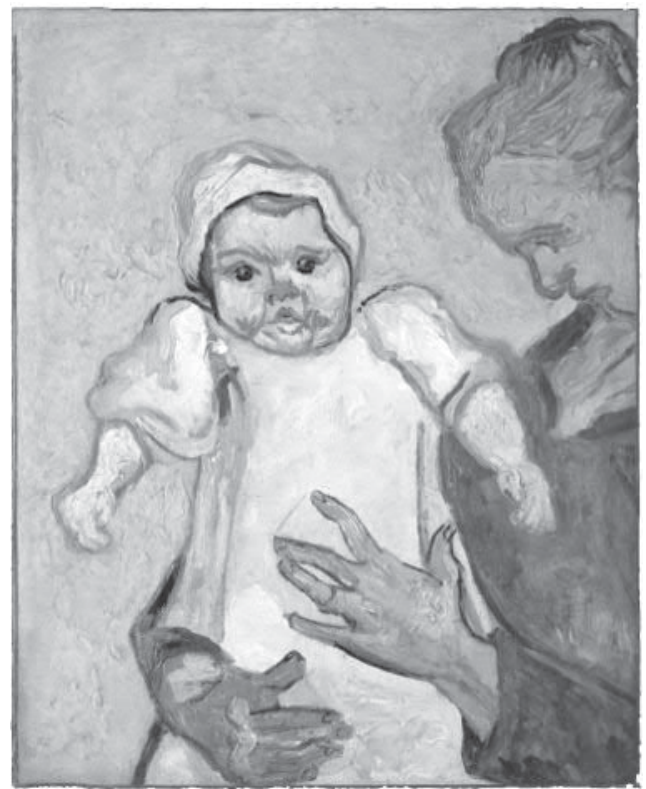

Abb. 83 Porträt von Madame Augustine Roulin und Baby Marcelle, November-Dezember 1888, Öl auf Leinwand, 92,4 x $73,5 \mathrm{~cm}$, New York, The Metropolitan Museum of Art, F 491, JH 1638. 


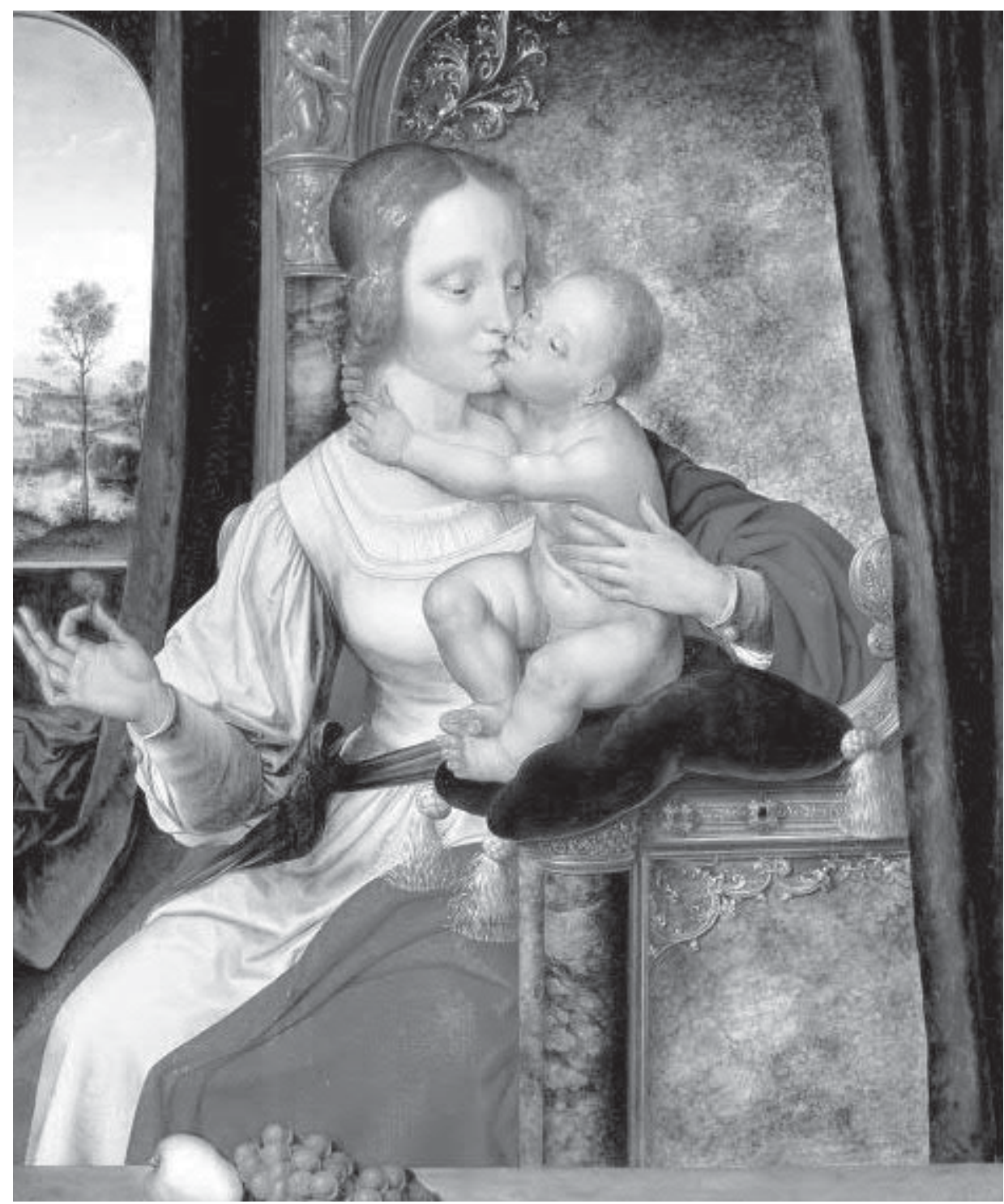

Abb. 84 Quentin Metsys (1466-1530), Madonna mit den Kirschen, 1520er Jahre, Öl auf Holz, 75,4 x 62,9 cm, Sarasota,

The John and Mable Ringling Museum of Art. 


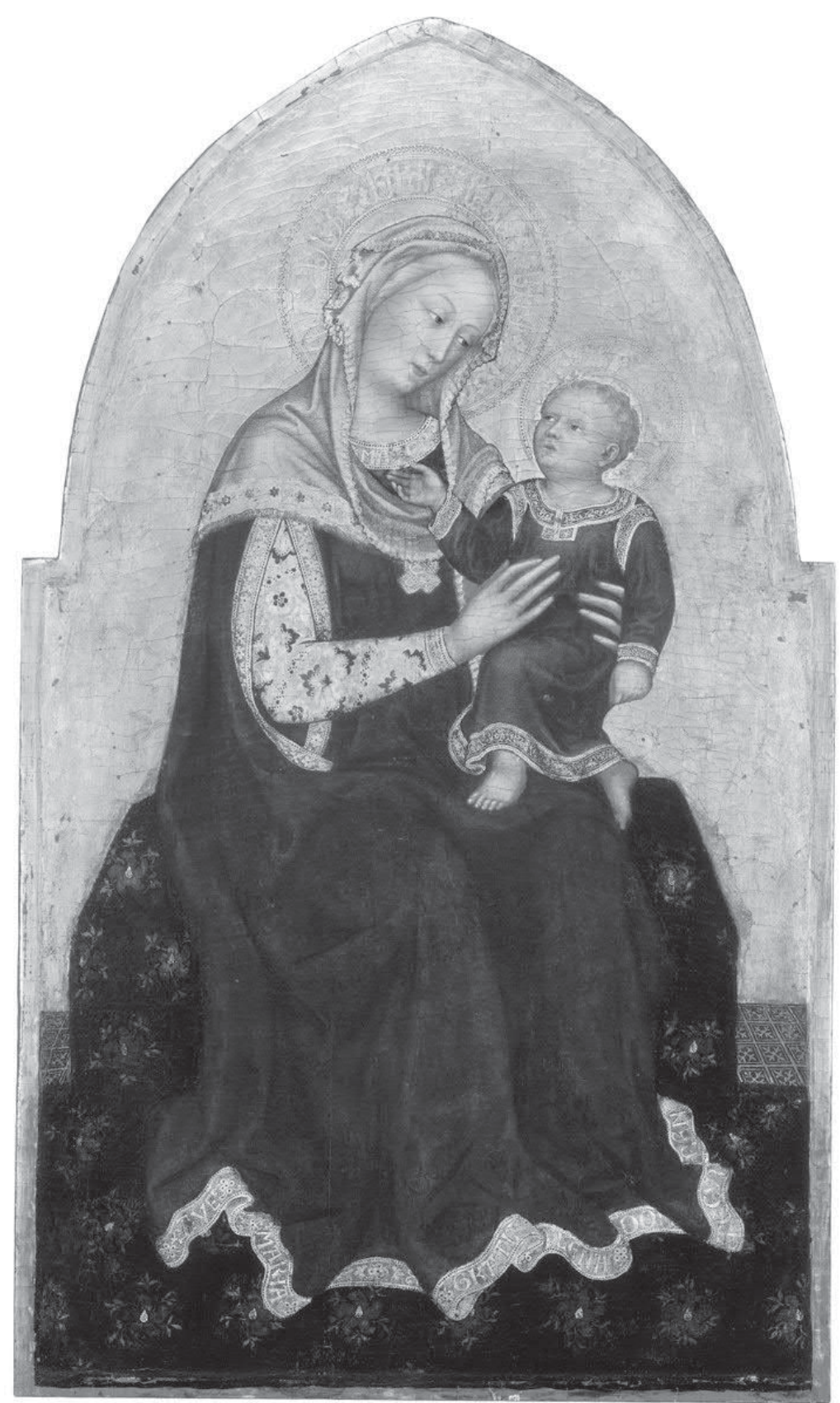

Abb. 85 Gentile da Fabriano (ca. 1370-1427) Madonna mit Kind, Tempera auf Holz, 95,9 x 56,6 cm, Washington D.C., National Gallery of Art. 


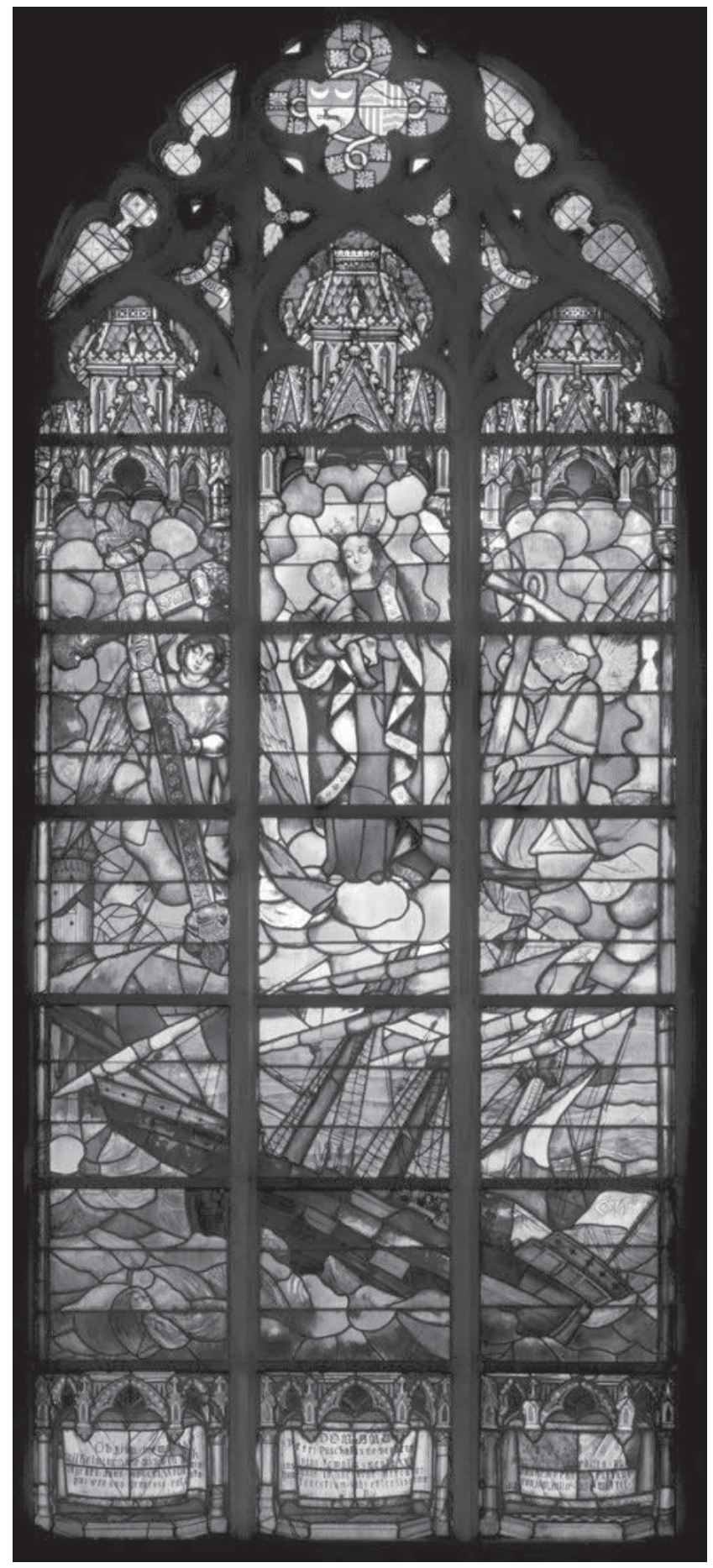

Abb. 86

Henri Dobbelaere (gestorben 1885), Stella Maris, 1866 , Glasfenster, Antwerpen, Sint-Andries Kirche, (1889 zerstört, hier eine moderne Replik). 


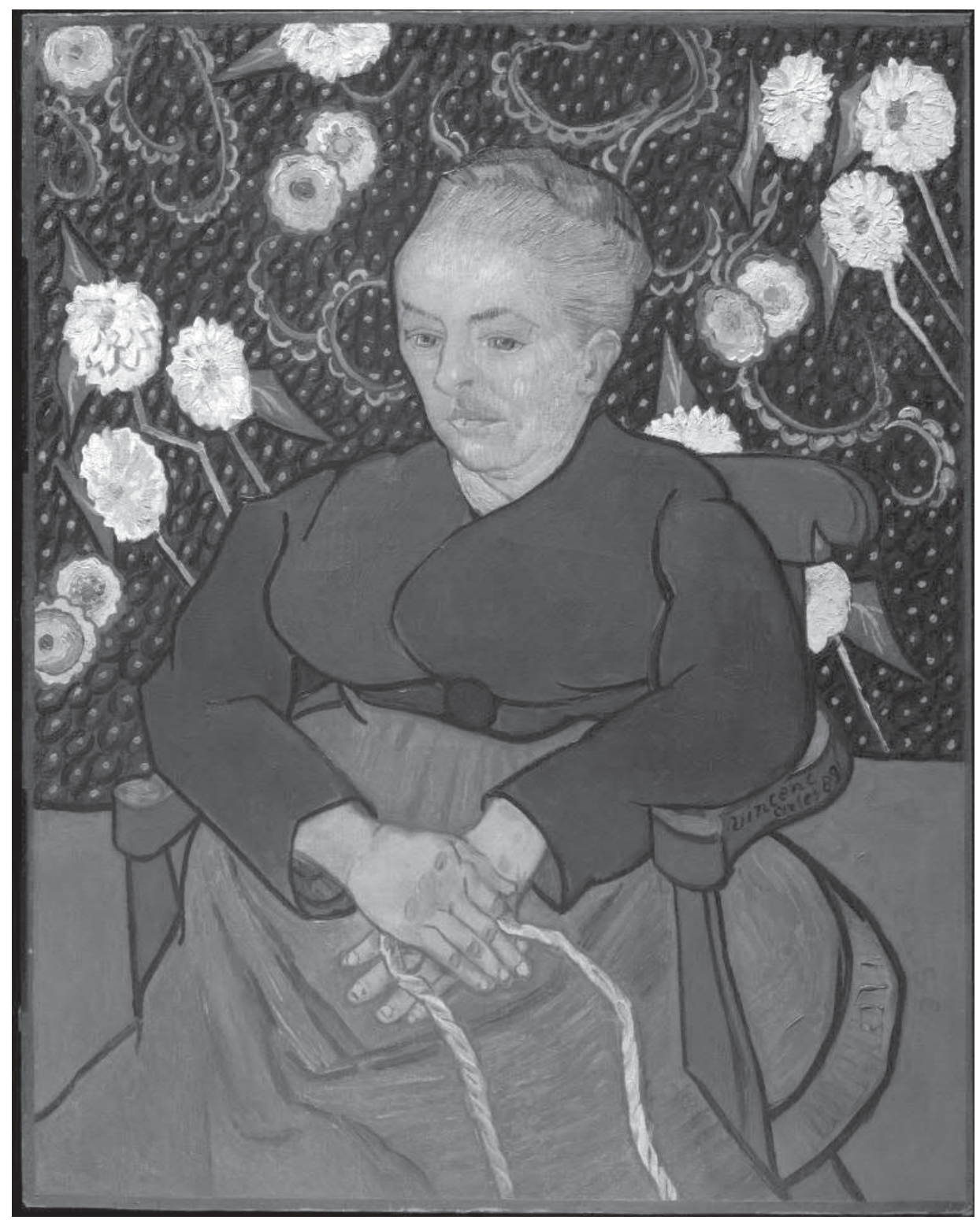

Abb. 87 La Berceuse (Porträt Madame Roulins), Januar 1889, Öl auf Leinwand, 92,7 x 73,7 cm, New York, The Metropolitan Museum of Art, F 505, JH 669. 


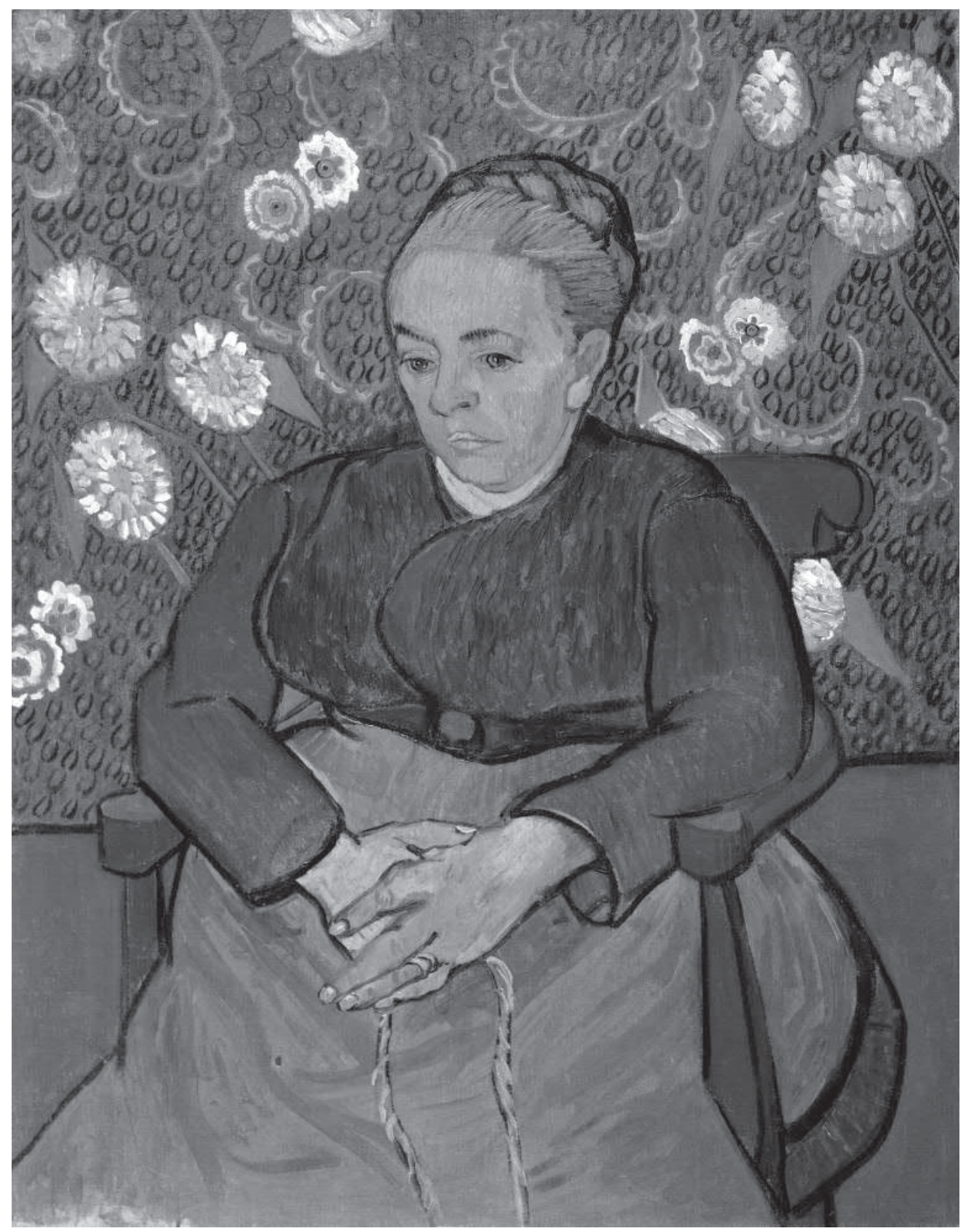

Abb. 88 La Berceuse (Porträt Madame Roulins), März 1889, Öl auf Leinwand, $91 \times 71,5$ cm, Amsterdam, Stedelijk Museum, F 507, JH 1672. 


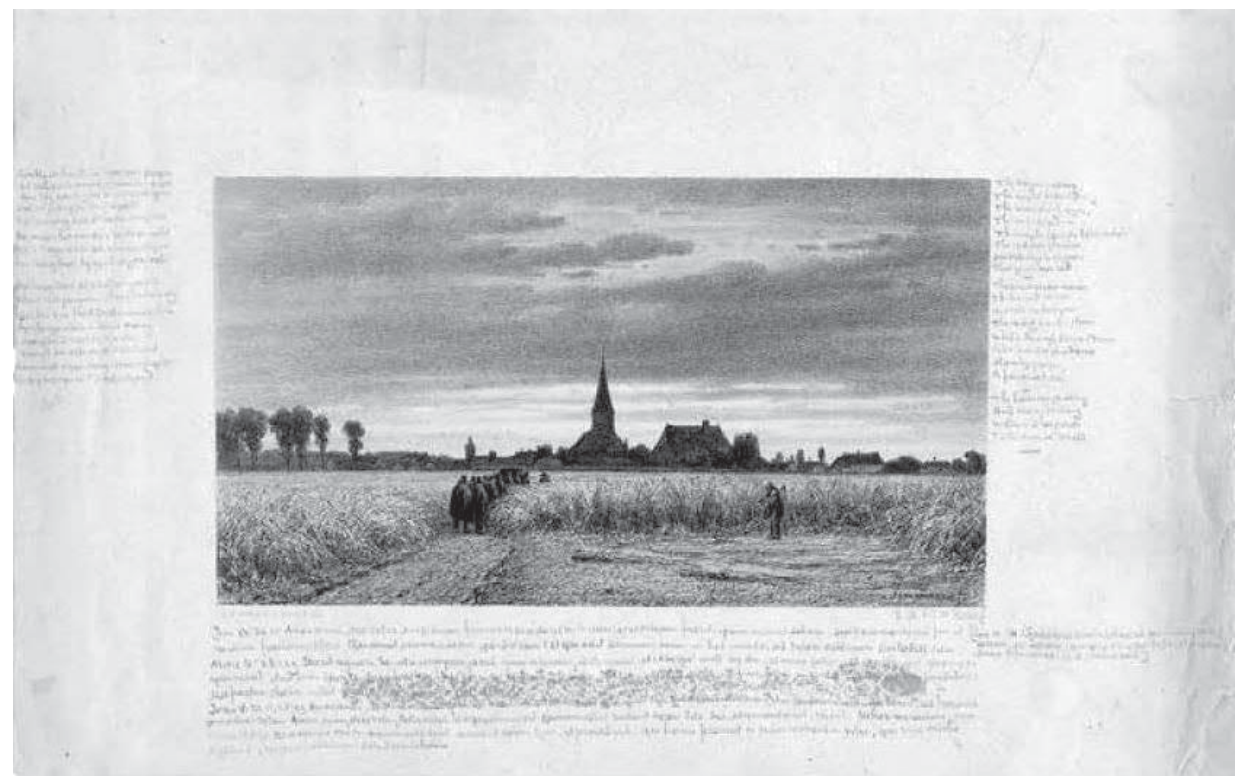

Abb. 89 Jacobus Jan van der Maaten (1820-1879), Trauerzug durchs Kornfeld,

Lithographie, erschienen in Kunstkronijk, Bd. III, 1862, no. 20, S. 78-79, Van Goghs Exemplar mit seinen Anmerkungen heute in Amsterdam, Universiteitsbibliotheek, Ms. XIII C 13a.

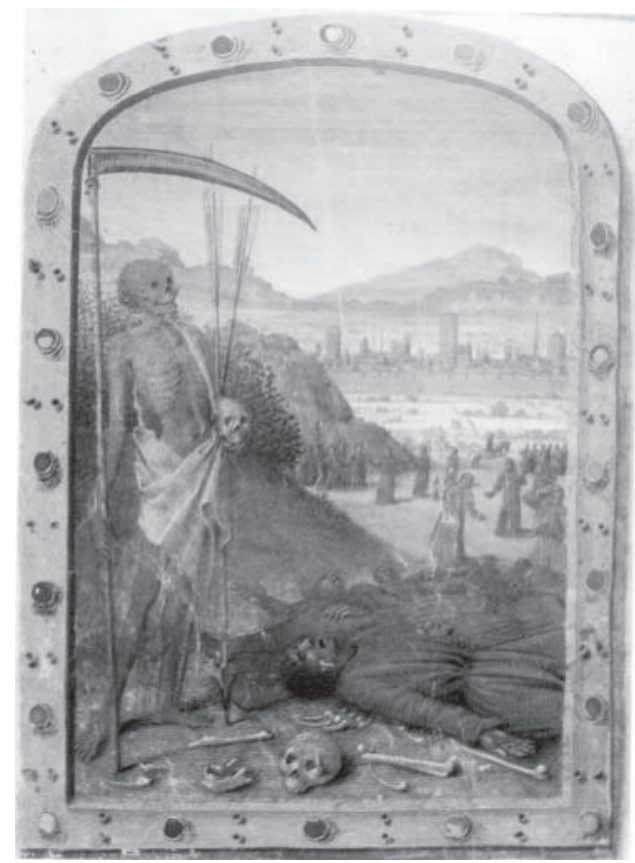

Abb. 90

Jean Fouquet (ca. 1420-1478?) zugeschrieben, Der Tod, sog. de VeauceStundenbuch, Amsterdam, Bibliotheca Philosophica Hermetica, BPH 74, folio 120 . 


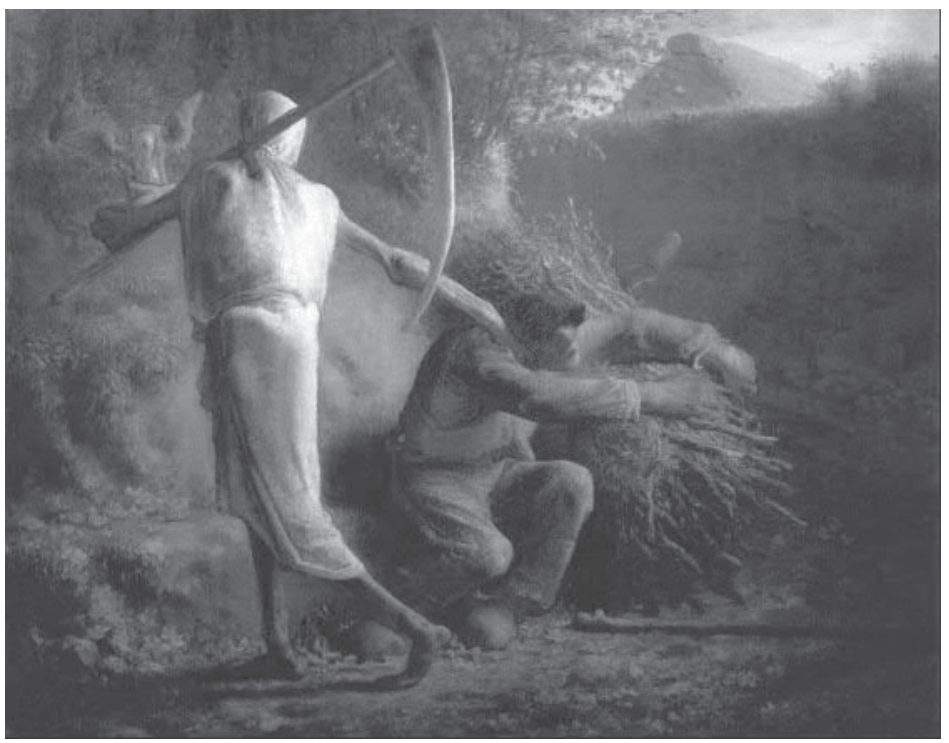

Abb. 91

Jean-François

Millet (1814-

1875), La Mort

et le bûcheron,

1859, Öl auf

Leinwand, Maße

unbekannt,

Ny Carlsberg

Glyptothek,

Kopenhagen.

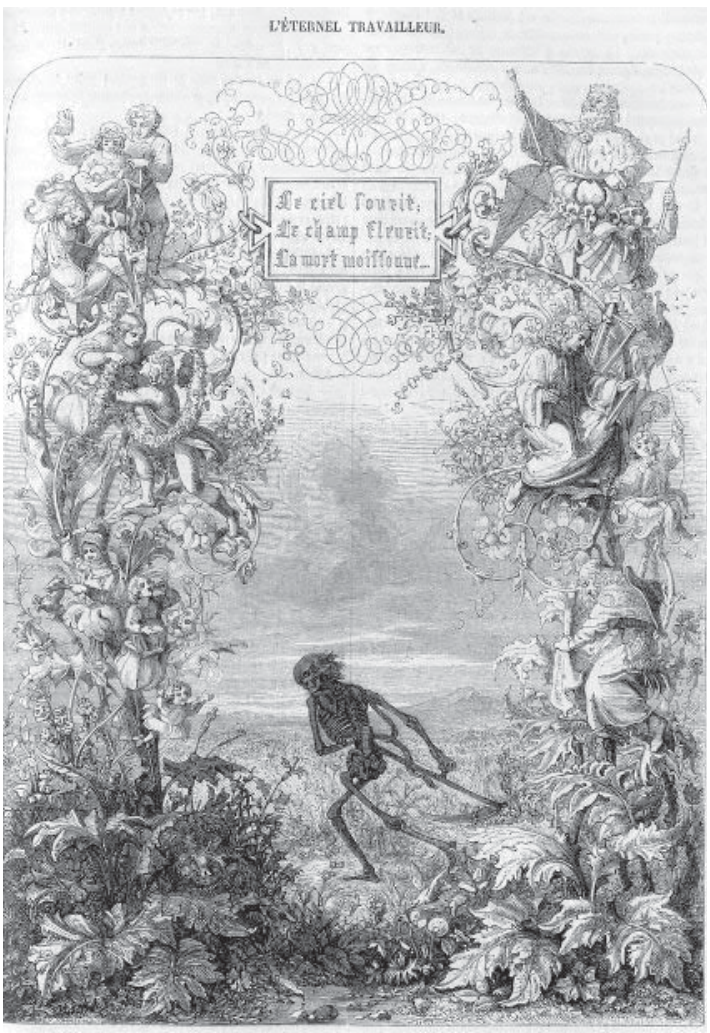

Abb. 92

Holzstich nach Neurather, in Magasin Pittoresque, 


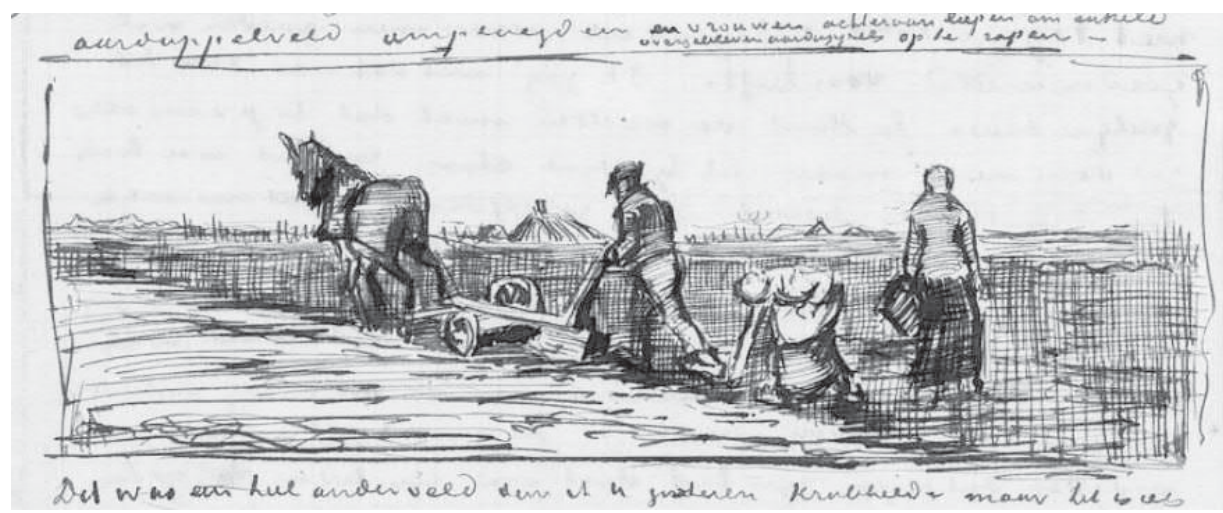

Abb. 93 Pflügender Bauer mit Bäuerinnen, ca. 16.10.1883, Skizze aus Brief 397/333, Amsterdam, Van Gogh Museum, F-, JH 412.

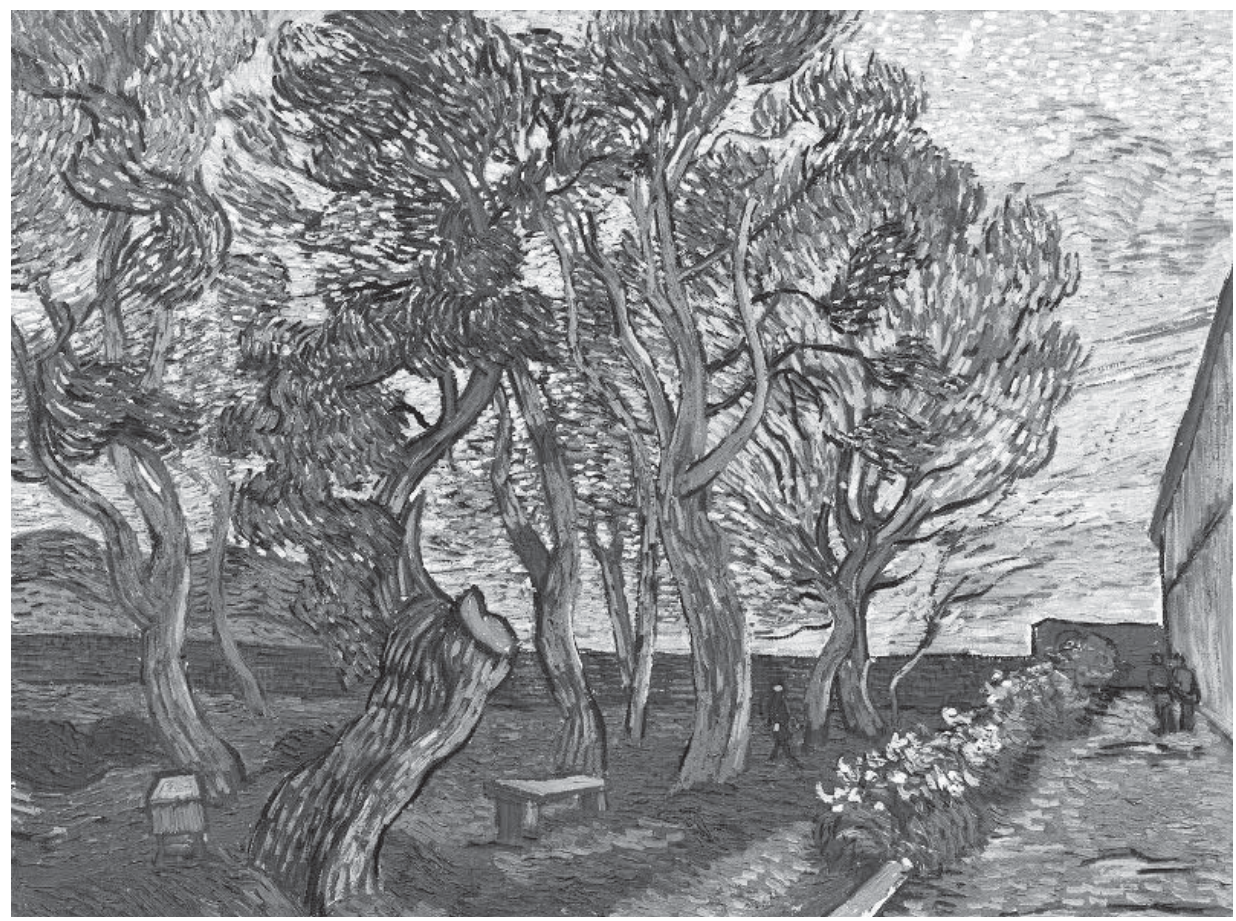

Abb. 94 Der Garten von St. Paul, November 1889, Öl auf Leinwand, 71,5 x 90,5 cm, Van Gogh Museum, Amsterdam, F 659, JH 1850. 


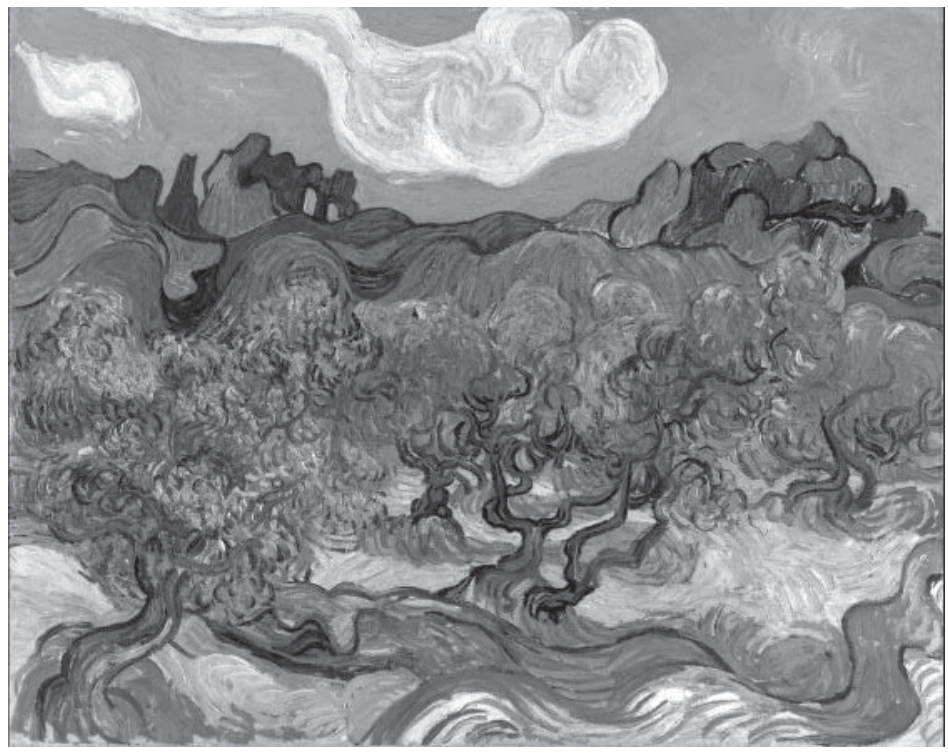

Abb. 95 Olivenbäume mit Alpillen im Hintergrund, Saint-Rémy, Juni 1889, Öl auf Leinwand, 72,5 x 92 cm, New York, Museum of Modern Art, F 712, JH 1740.

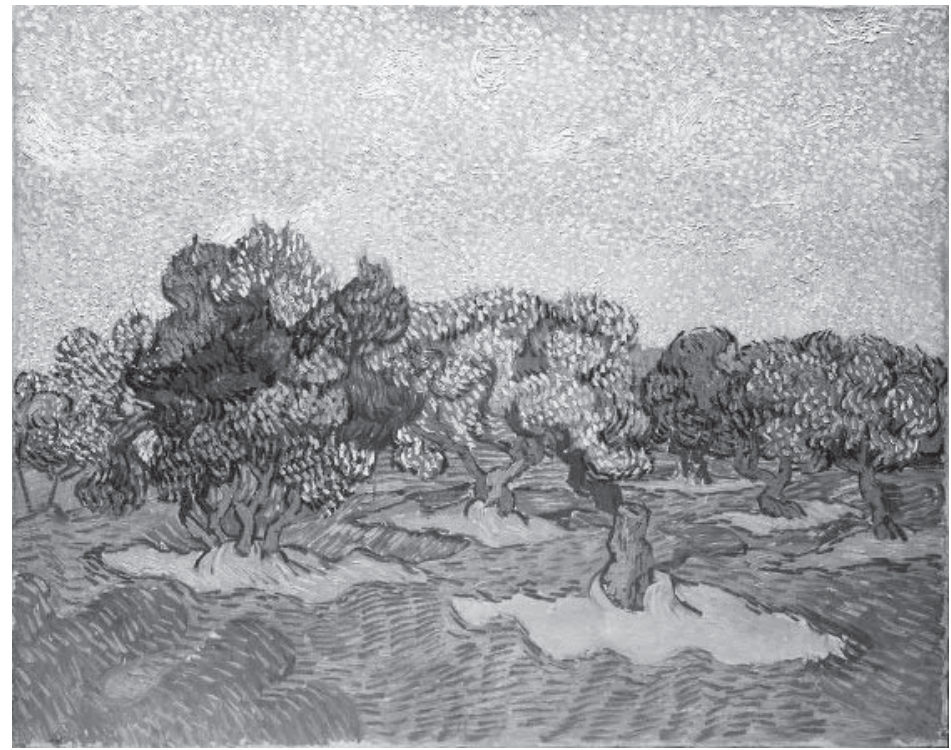

Abb. 96 Olivenhain, Saint-Rémy, November 1889, Öl auf Leinwand, 72,7 x 92,1 cm, New York, The Metropolitan Museum of Art, F 708, JH 1855. 


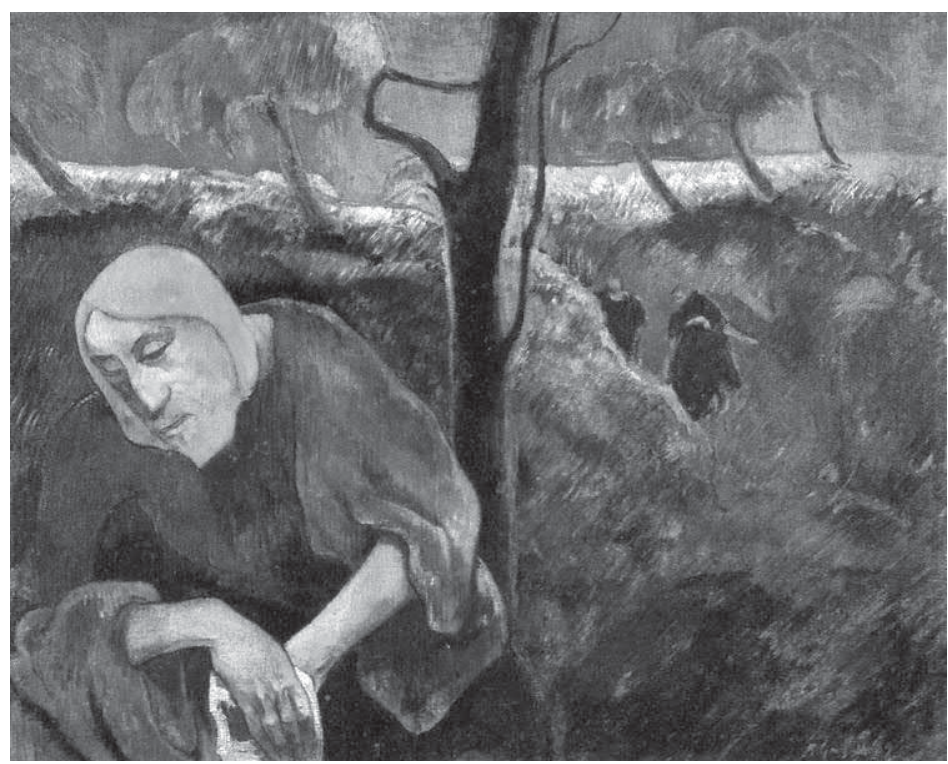

Abb. 97 Paul Gauguin (1848-1903), Christus im Garten Gethsemane, 1889, Öl auf Leinwand, 72 x $90 \mathrm{~cm}$, Norton Museum of Art, West Palm Beach.

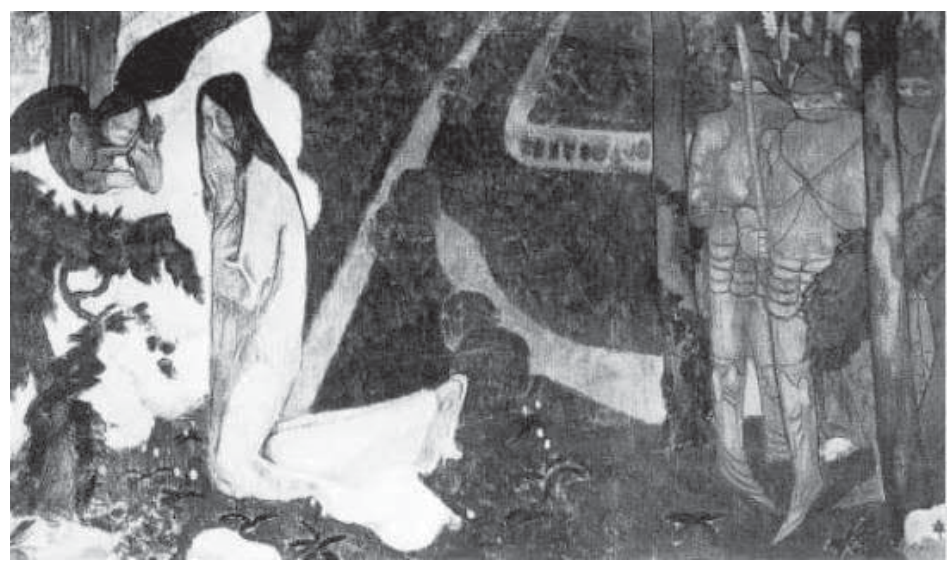

Abb. 98 Émile Bernard (1868-1941), Christus am Ölberg,1889, Öl auf Leinwand, Maße und derzeitiger Aufenthaltsort unbekannt. 


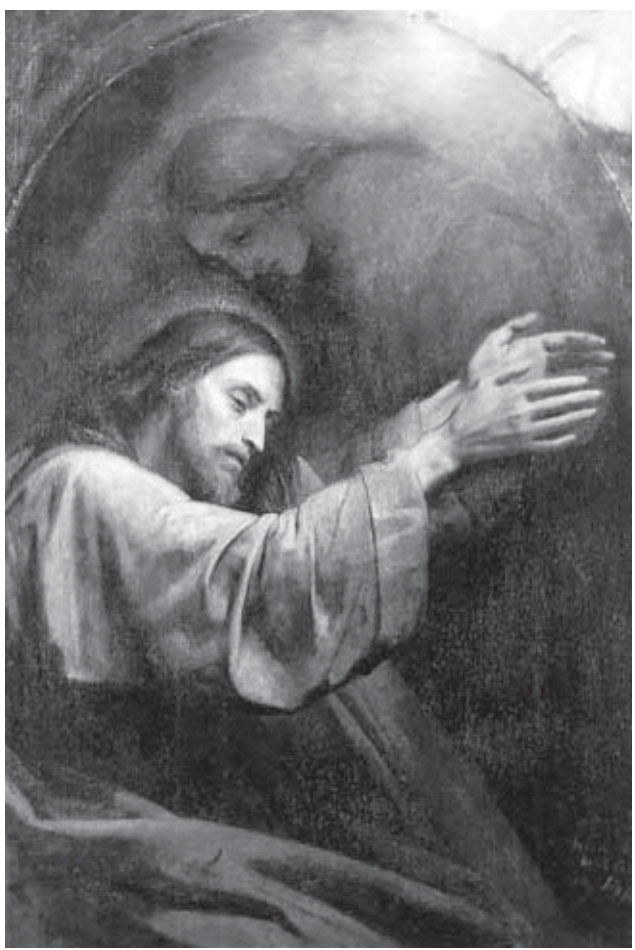

Abb. 99

Ary Scheffer (1795-1858), Christus in Gethsemane, 1839, Öl auf Leinwand, Dordrechts Museum.

Abb. 100

Der Schnitter (nach Millet), September 1889, Öl auf Leinwand, $43,5 \times 25 \mathrm{~cm}$, Privatbesitz, zuletzt Christie's London, Auktion 14239, 27.06.2017, Los 6, F 688, JH 1783.

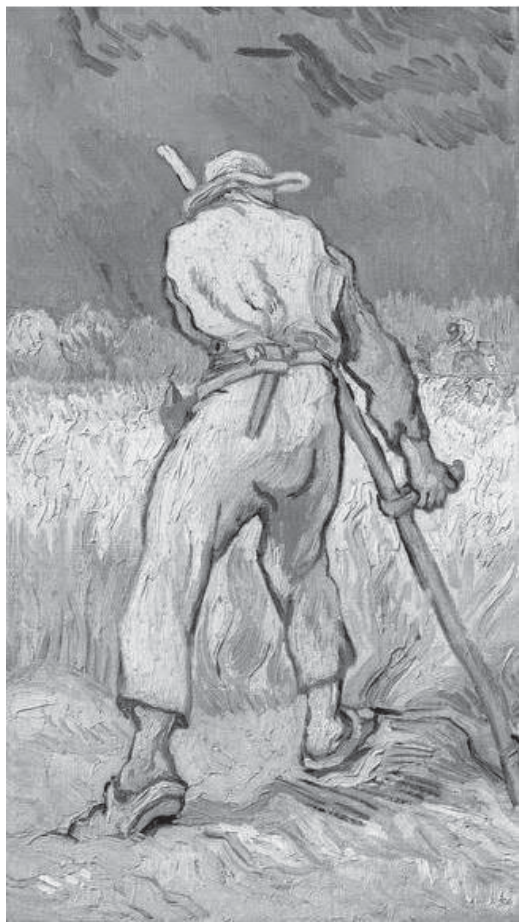




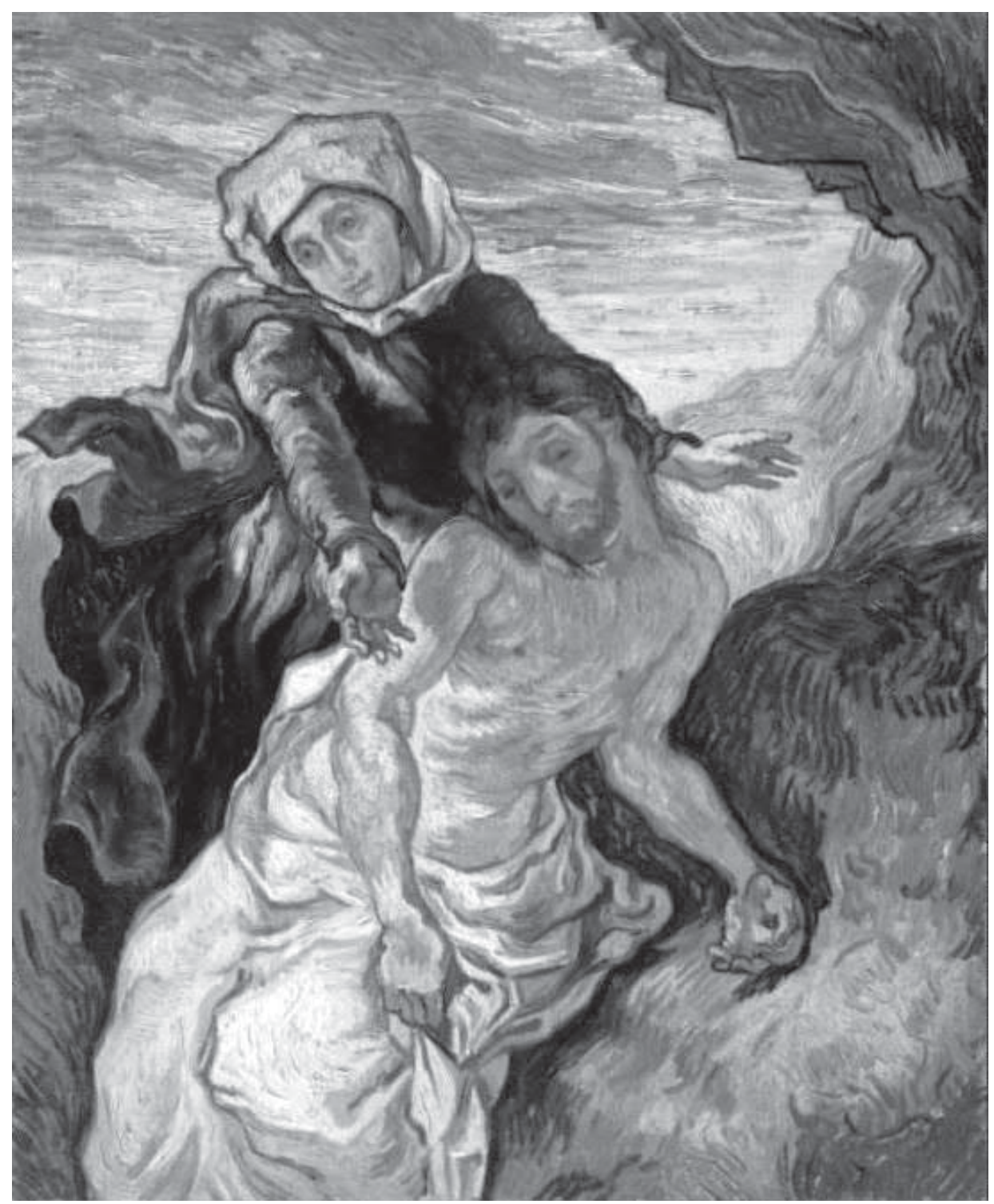

Abb. 101 Pietà (nach Delacroix), 1889, Öl auf Leinwand, 73 x 60,5 cm, Amsterdam, van Gogh Museum, F 630, JH 1775. 


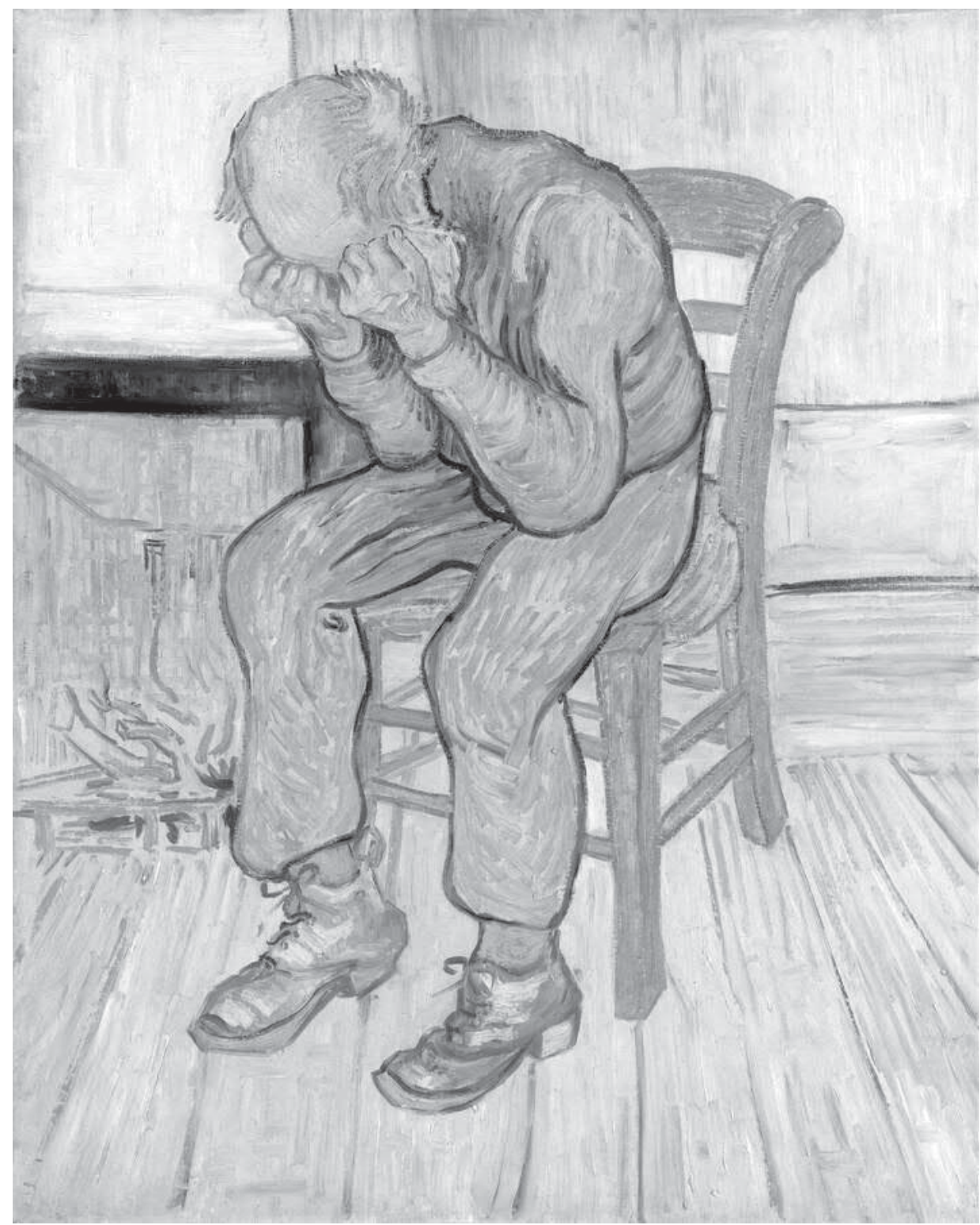

Abb. 102 Trauernder alter Mann („At Eternity’s Gate“), Mai 1890, Öl auf Leinwand, 80 cm x 64 cm, Otterlo, Kröller-Müller Museum, F 702, JH 1967. 


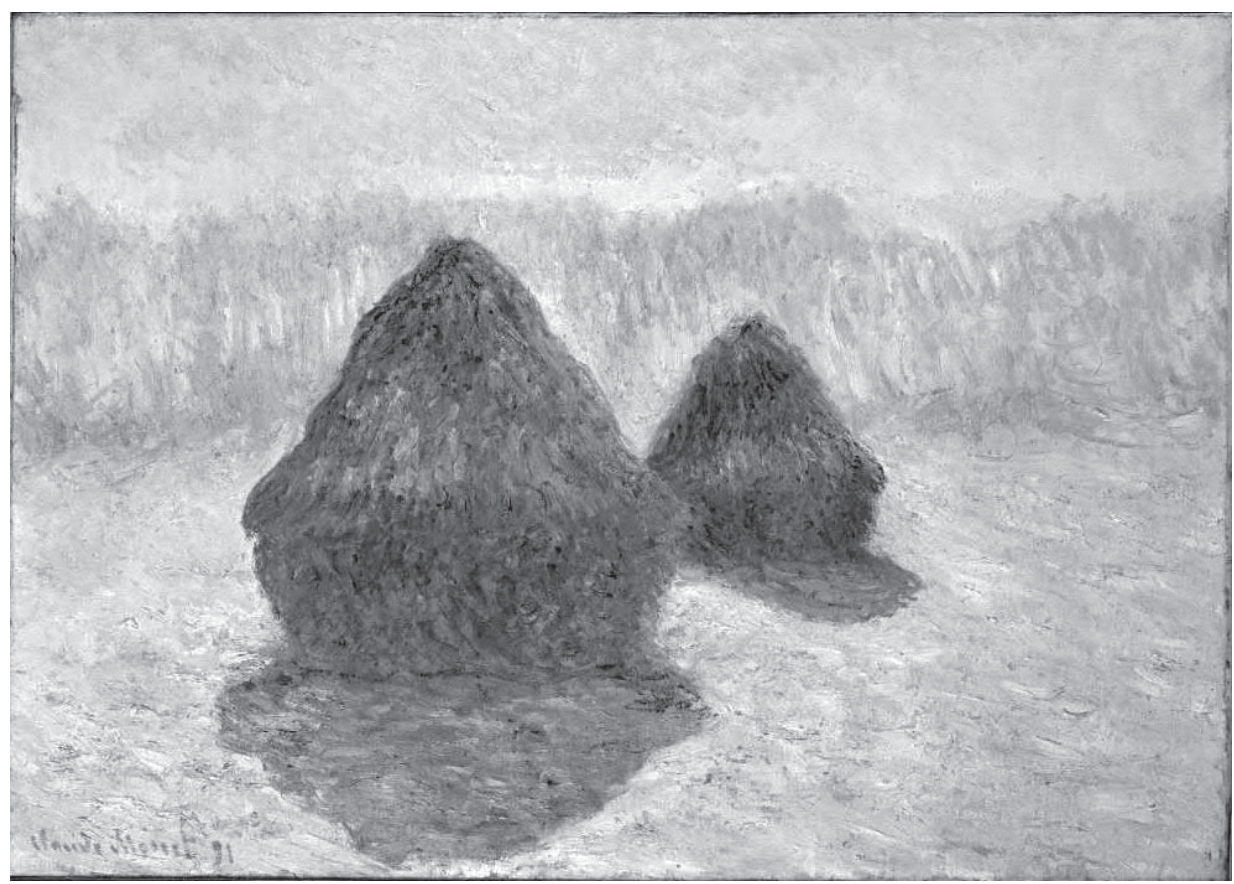

Abb. 103 Claude Monet (1840-1926), Meules, effet de neige, 1891, Öl auf Leinwand, 65,4 x 92,1 cm, New York, Metropolitan Museum of Art, W 1279.

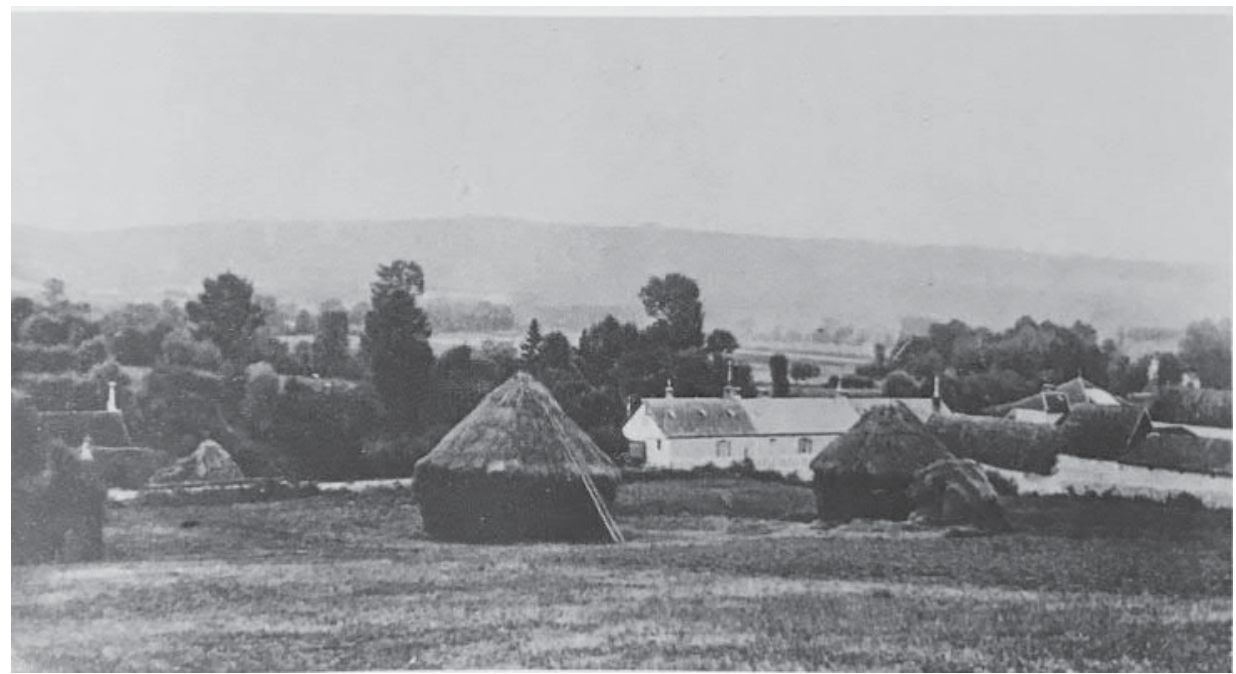

Abb. 104 Photographie der Getreideschober hinter Claude Monets Hause in Giverny, 1905. 


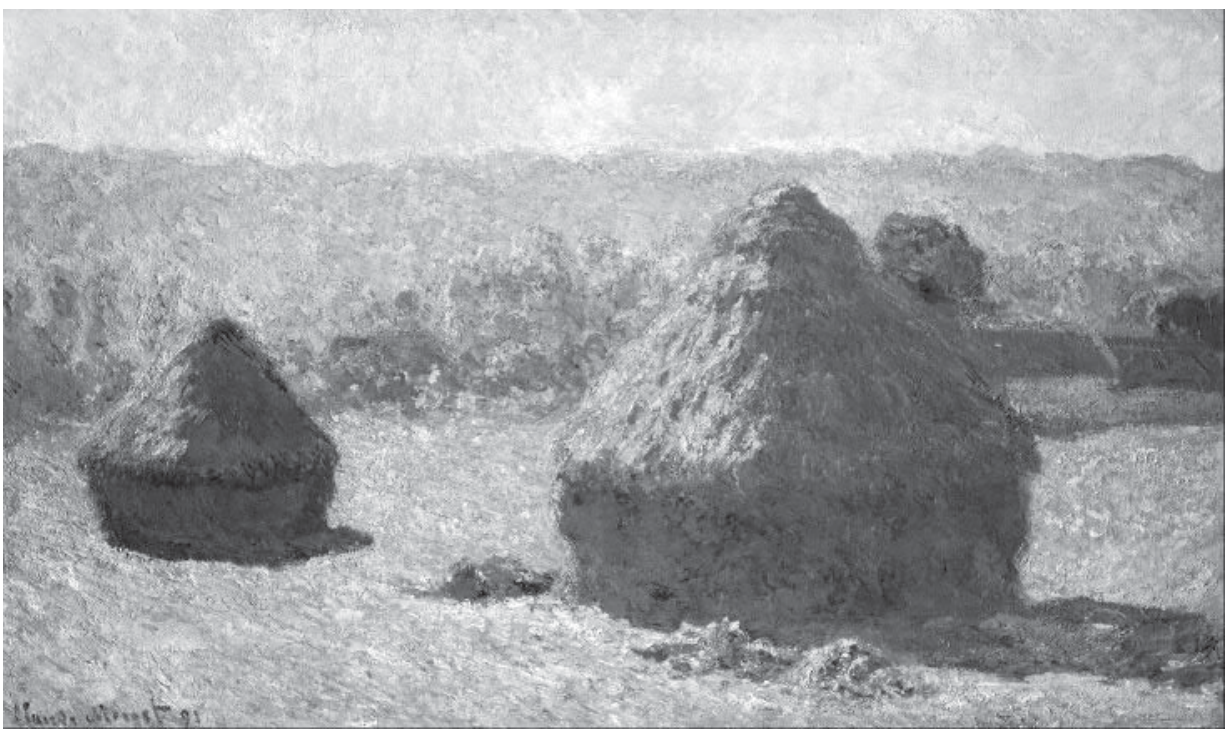

Abb. 105 Claude Monet (1840-1926), Meules, fin de l'été, effet du matin, 1891, Öl auf Leinwand, 60,5 x 100,5 cm, Paris, Musée d'Orsay, W 1266.

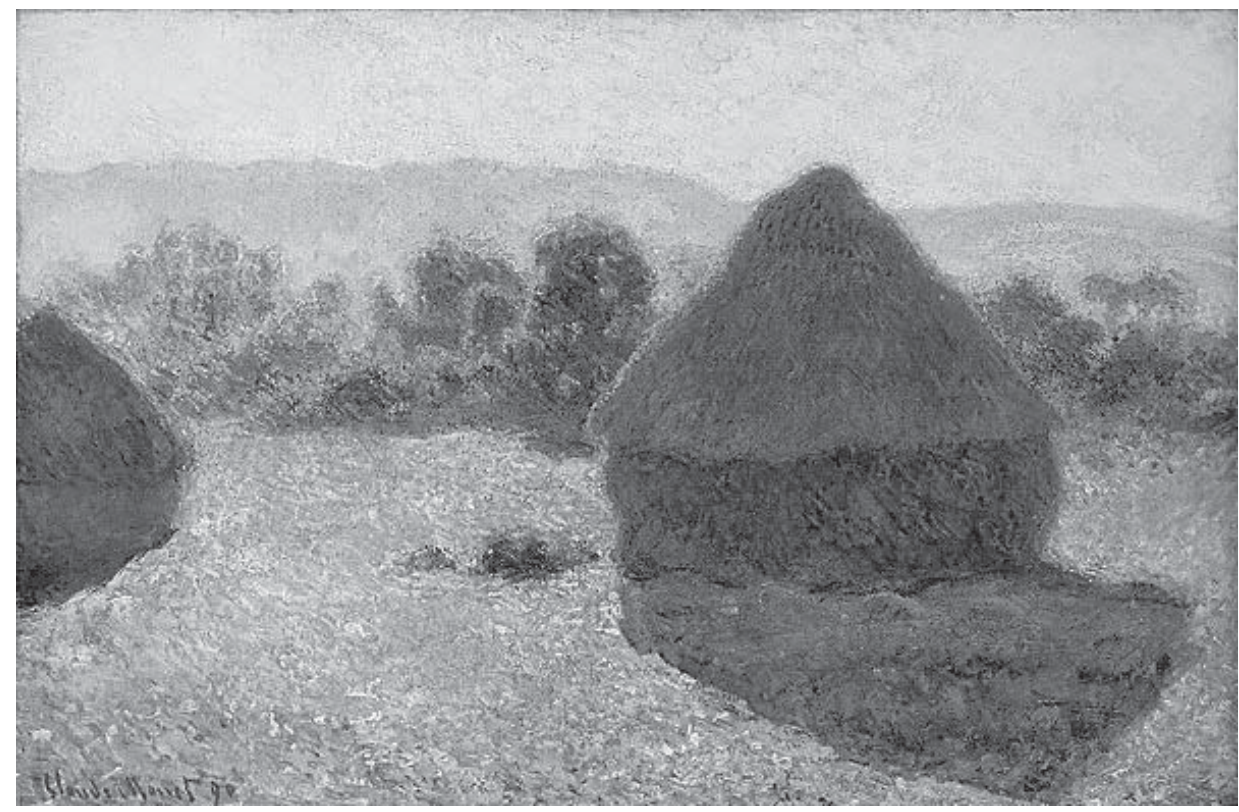

Abb. 106 Claude Monet (1840-1926), Meules au soleil, midi, 1890, Öl auf Leinwand, 65,6 x 100,6 cm, Canberra, National Gallery of Australia, W 1271. 


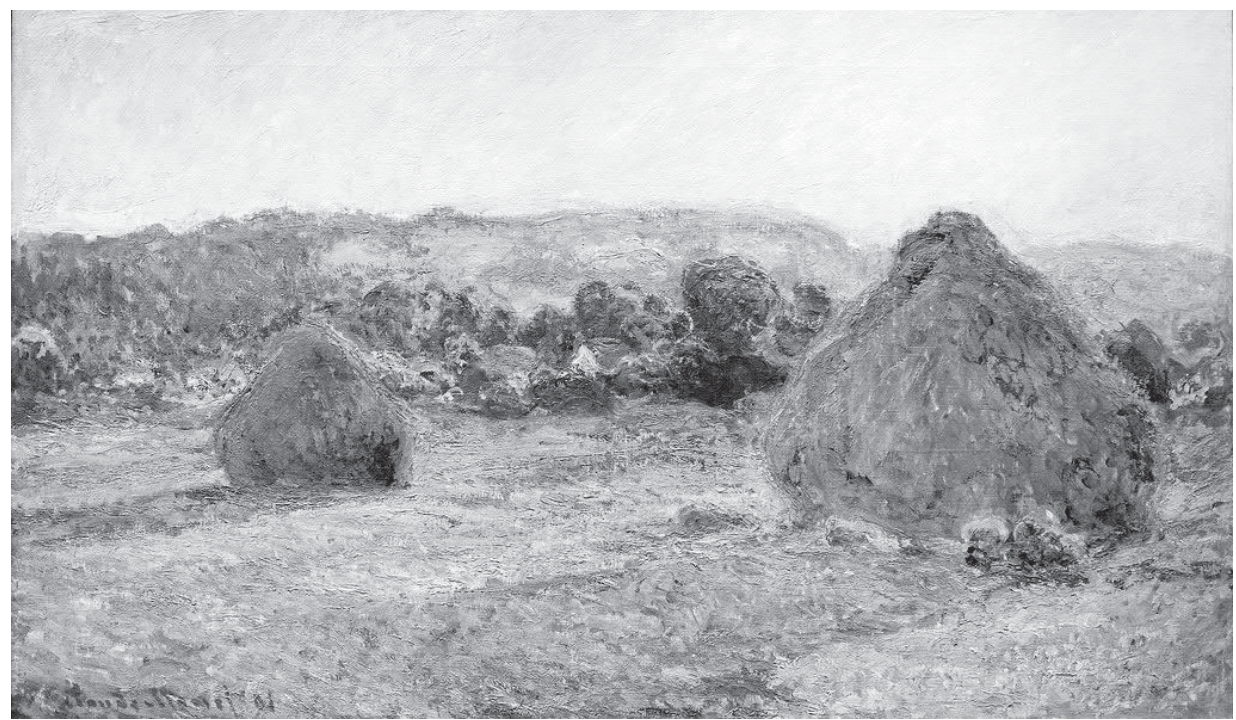

Abb. 107 Claude Monet (1840-1926), Meules, fin de l'été, effet du soir, 1890-1891, Öl auf Leinwand, 60 x 100 cm, Art Institute of Chicago, W 1269.

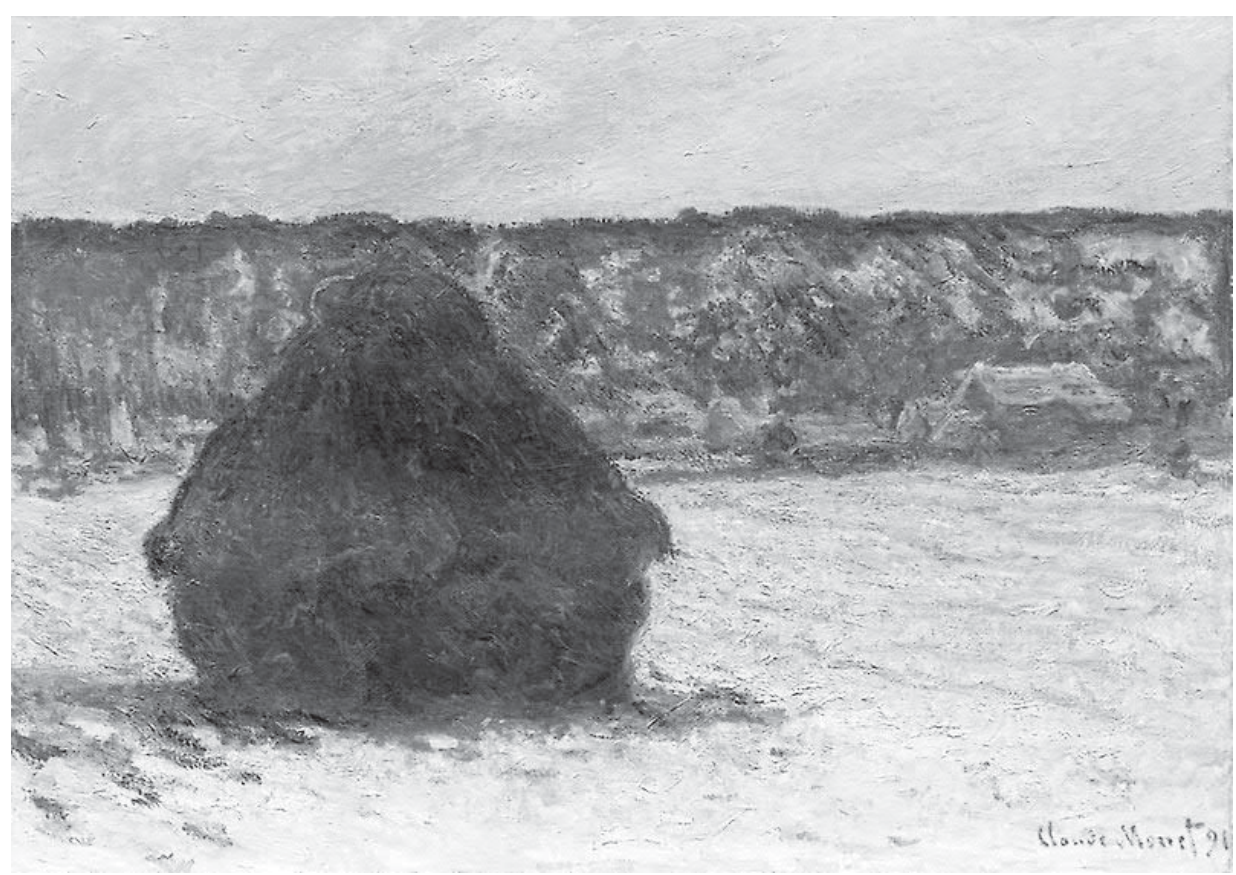

Abb. 108 Claude Monet (1840-1926), Meule, effet de neige, temps couvert, 1890-1891, Öl auf Leinwand, 66 x 93, Art Institute of Chicago, W 1281. 


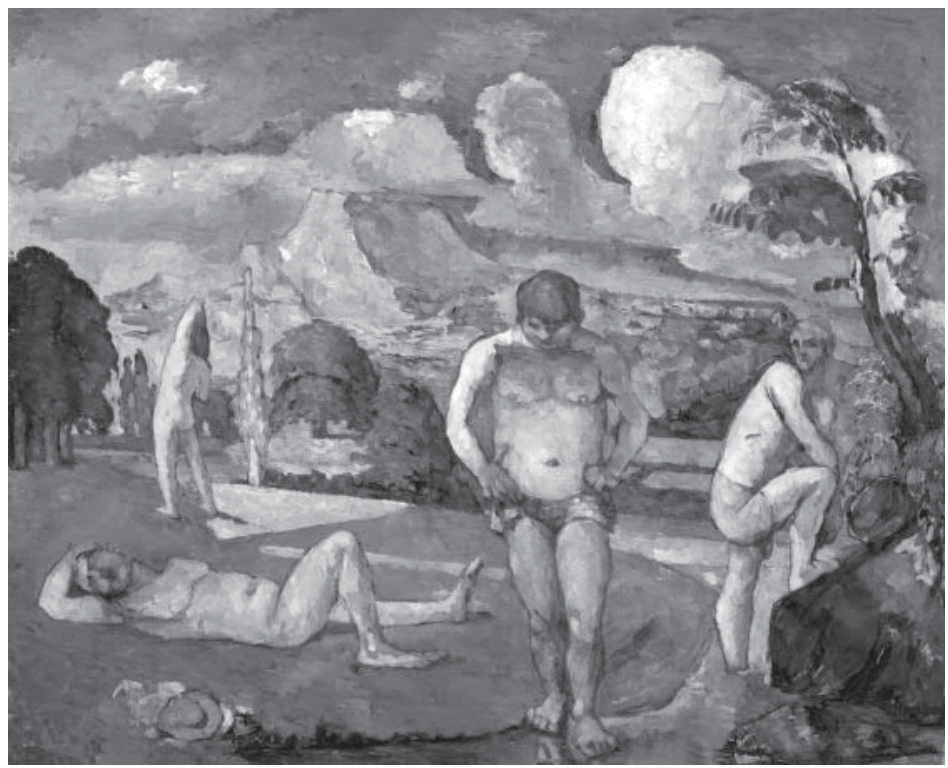

Abb. 109 Paul Cézanne (1839-1906), Baigneurs au Repos III, 1876-1877, Öl auf Leinwand, 79 x $97 \mathrm{~cm}$,

Barnes Foundation, Merion (Pennsylvania), R 261.

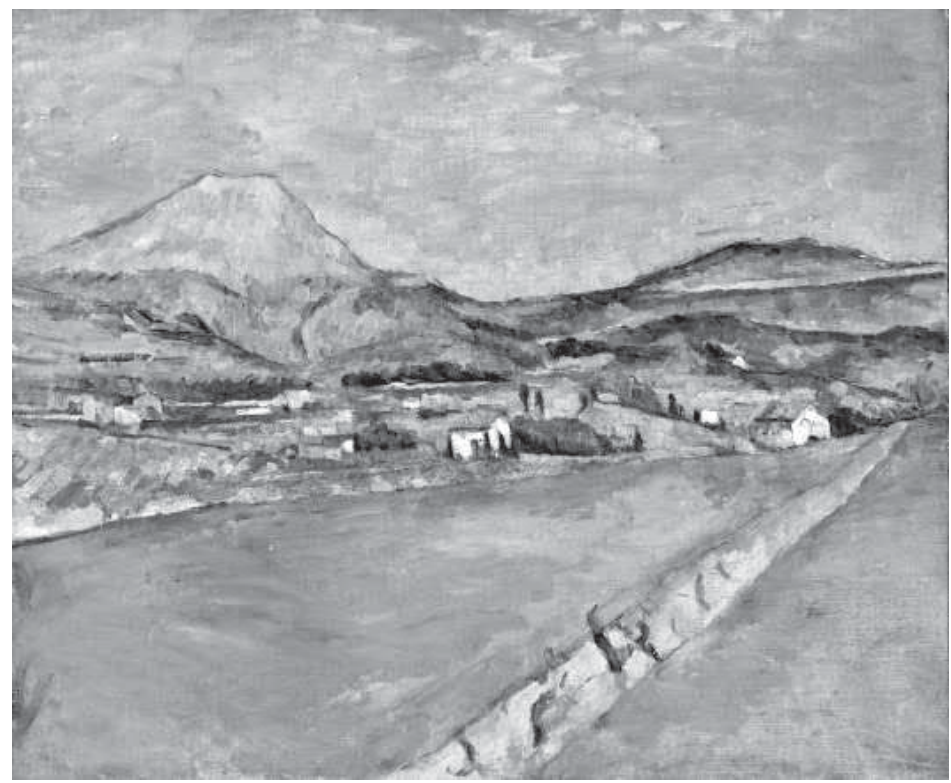

Abb. 110 Paul Cézanne (1839-1906), Vers la Montagne SainteVictoire, 1878-79, Öl auf Leinwand, $45 \times 53,3 \mathrm{~cm}$, Barnes Foundation, Merion (Pennsylvania), R 397. 


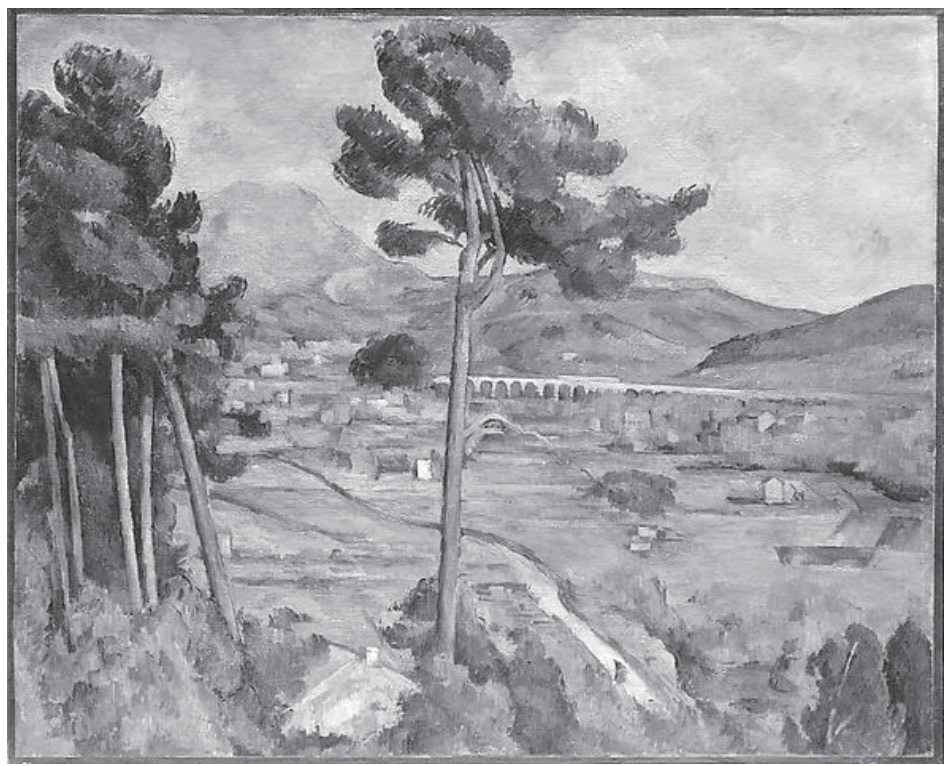

Abb. 111 Paul Cézanne (1839-1906), La Montagne Sainte-Victoire Vue de Bellevue, 1882-85, Öl auf Leinwand, 65 x 81,7 cm, Metropolitan Museum of Art, New York, R 511.

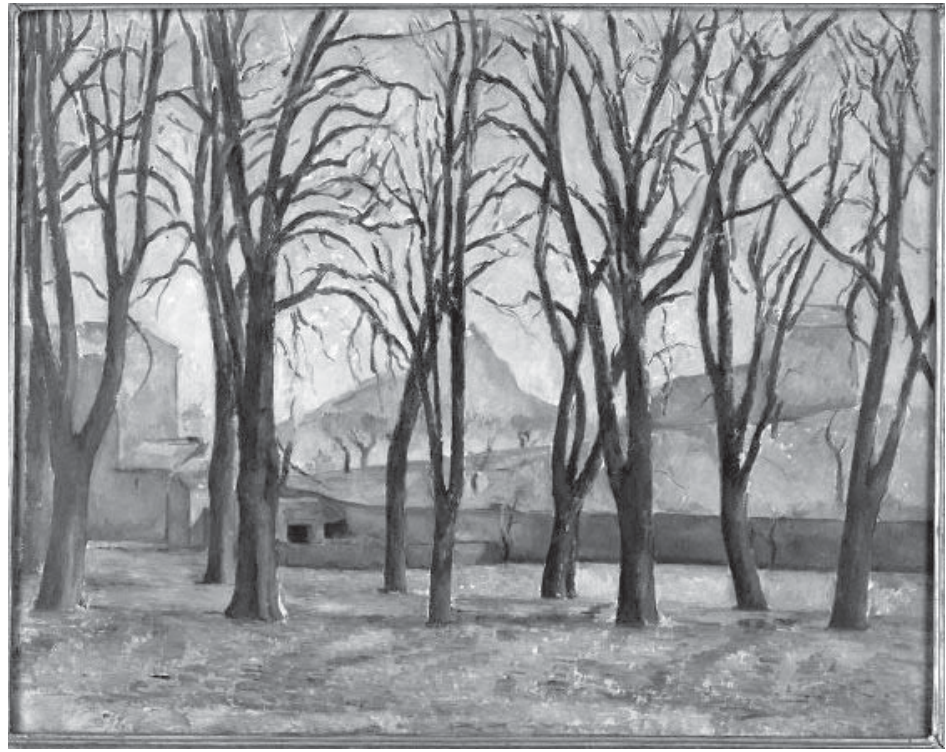

Abb. 112 Paul Cézanne (1839-1906), Les Marronniers du Jas de Bouffan en Hiver, 1885-86, Öl auf Leinwand, 73 x $92 \mathrm{~cm}$, Minneapolis, The Minneapolis Institute of Arts, R 551. 


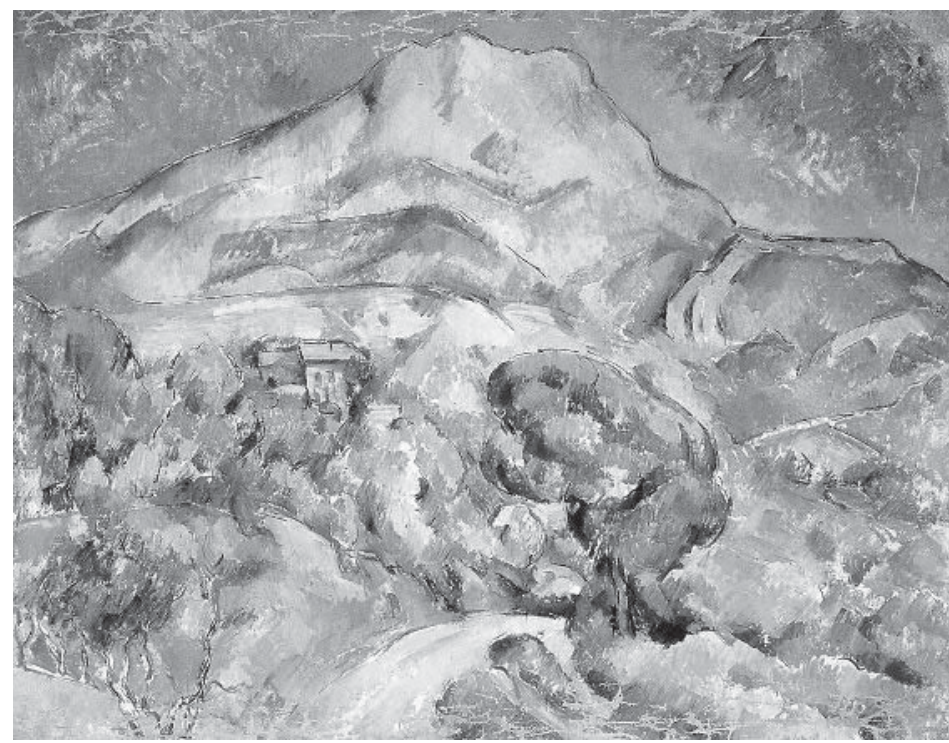

Abb. 113 Paul Cézanne (1839-1906), La Montagne Sainte-Victoire au dessus de la Route du Tholonet, 1896-98, Öl auf Leinwand, 78 x 98 cm, St. Petersburg, Eremitage, R 899.

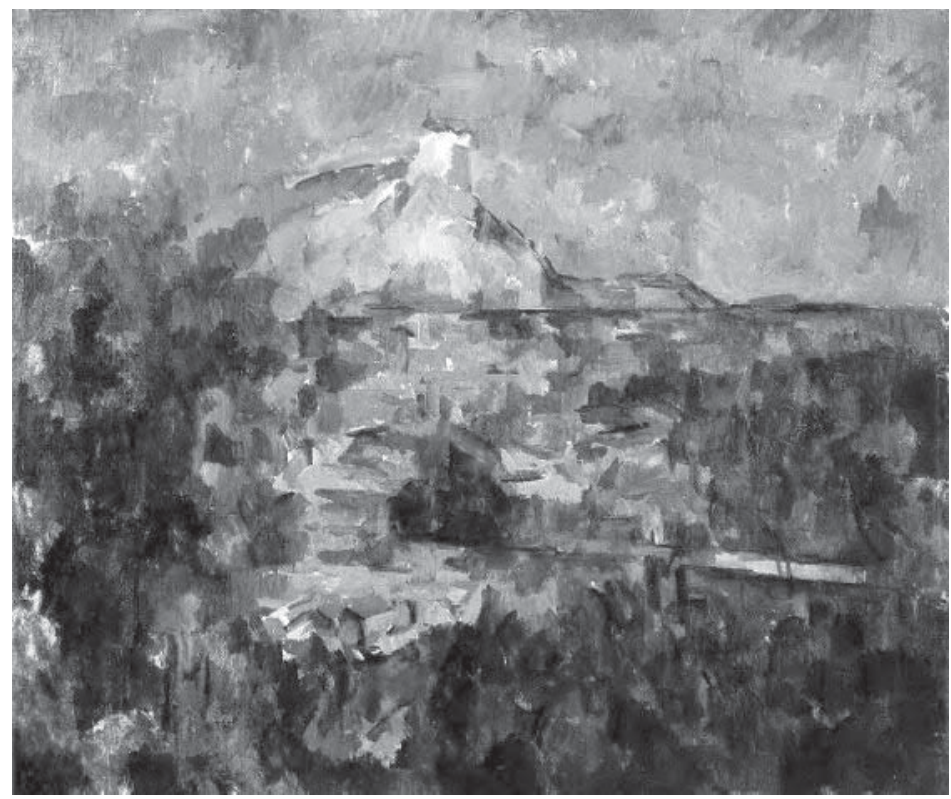

Abb. 114 Paul Cézanne (1839-1906), Le Mont Saint-Victoire vu des Lauves, 1904-6, Öl auf Leinwand, 60 x 72 cm, Kunstmuseum Basel, R 931. 


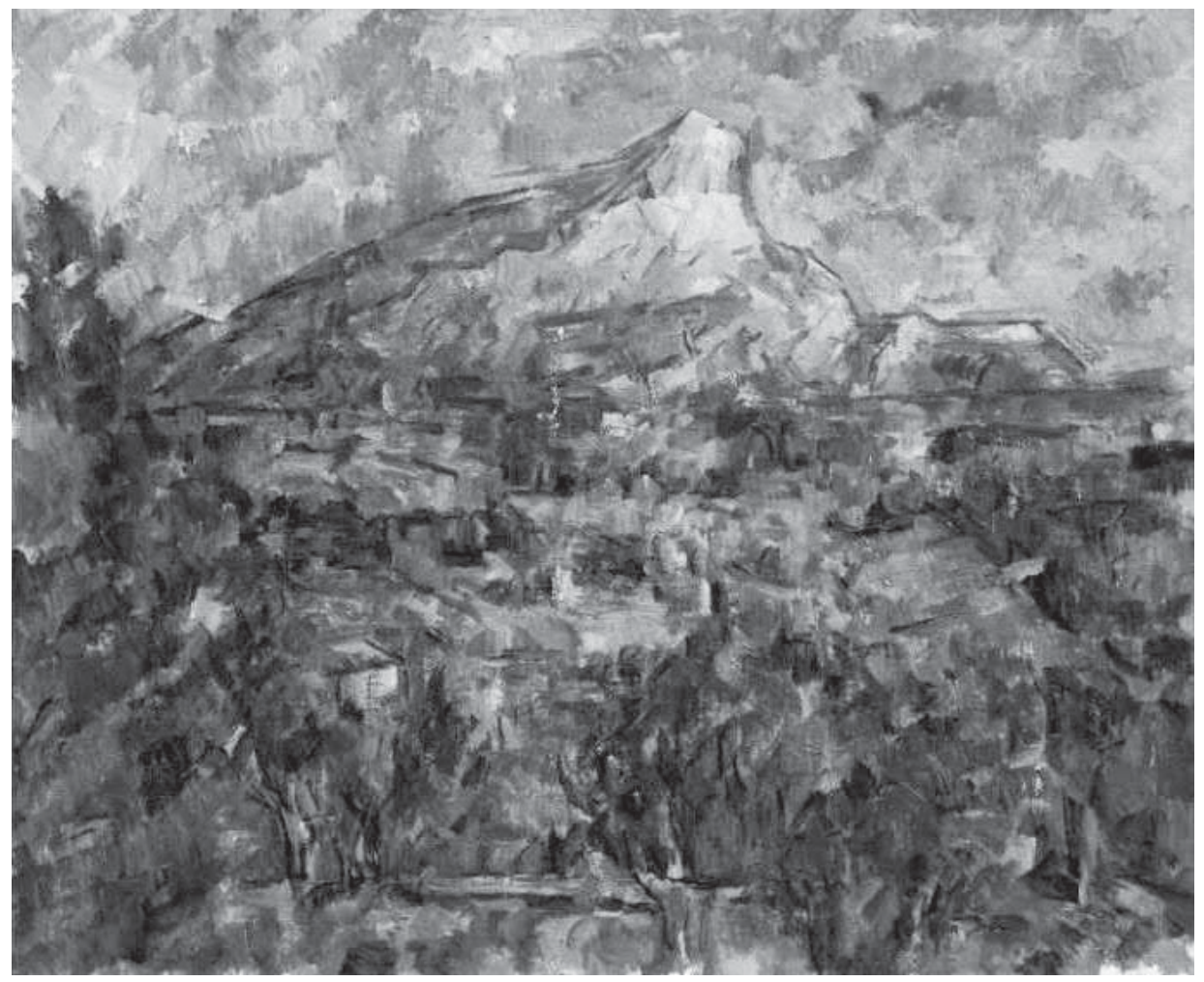

Abb. 115 Paul Cézanne (1839-1906), Le Mont Saint-Victoire vu des Lauves, 1904-6, Öl auf Leinwand, 60 x 73 cm, Moskau, Puschkin Museum, R 932. 


\section{Abbildungsnachweis}

1. Van Gogh, Felder. Das Mohnfeld und der Künstlerstreit, hg. v. Wulf Herzogenrath u. Dorothee Hansen (Ausst. Kat. Bremen, Kunsthalle, 19. Oktober 2002-26. Januar 2003), Ostfildern-Ruit 2002, S. 81.

2. Van Gogh. Repetitions, hg. v. Eliza E. Rathbone, William H. Robinson, Elizabeth Steele u. Marcia Steele (Ausst. Kat. Washington D.C., The Phillips Collection, 12. Oktober 2013-26. Januar 2014; The Cleveland Museum of Art, 2. März-26. Mai 2014), New Haven u. London 2013, S. 33 .

3. Van Gogh, Felder. Das Mohnfeld und der Künstlerstreit, hg. v. Wulf Herzogenrath u. Dorothee Hansen (Ausst. Kat. Bremen, Kunsthalle, 19. Oktober 2002-26. Januar 2003), Ostfildern-Ruit 2002, S. 103.

4. Van Gogh and Nature, hg. v. Richard Kendall, Sjraar van Heugten u. Chris Stolwijk (Ausst. Kat. Williamstown, Clark Art Institute, 14. Juni13. September 2015), New Haven u. London 2015, S. 178.

5. Van Gogh, Felder. Das Mohnfeld und der Künstlerstreit, hg. v. Wulf Herzogenrath u. Dorothee Hansen (Ausst. Kat. Bremen, Kunsthalle, 19. Oktober 2002-26. Januar 2003), Ostfildern-Ruit 2002, S. 103.

6. Vincent van Gogh. Zwischen Erde und Himmel. Die Landschaften, hg. v. Kunstmuseum Basel (Ausst. Kat. Basel, Kunstmuseum, 26. April-27. September 2009), Ostfildern 2009, S. 251.

7. Van Gogh, Felder. Das Mohnfeld und der Künstlerstreit, hg. v. Wulf Herzogenrath u. Dorothee Hansen (Ausst. Kat. Bremen, Kunsthalle, 19. Oktober 2002-26. Januar 2003), Ostfildern-Ruit 2002, S. 92.

8. Internetseite des Auktionshauses Christie's, abgerufen unter: http://www. christies.com/lotfinder/paintings/vincent-van-gogh-laboureur-dansun-champ-6108742-details.aspx?from=salesummary\&intObjectID=$6108742 \&$ lid $=1$.

9. Vincent van Gogh. Zwischen Erde und Himmel. Die Landschaften, hg. v. Kunstmuseum Basel (Ausst. Kat. Basel, Kunstmuseum, 26. April-27. September 2009), Ostfildern 2009, S. 253.

10. Internetseite des Indianapolis Museum of Art, abgerufen unter http://collection.imamuseum.org/artwork/56838/.

11. Internetseite des Auktionshauses Christie's, abgerufen unter: http://www.christies.com/lotfinder/paintings/vincent-van-gogh-vue-delasile-et-5532359-details.aspx. 
12. Internetseite des Philadelphia Museum of Art, abgerufen unter: http://www.philamuseum.org/collections/permanent/82820.html.

13. Vincent van Gogh. Zwischen Erde und Himmel. Die Landschaften, hg. v. Kunstmuseum Basel (Ausst. Kat. Basel, Kunstmuseum, 26. April-27. September 2009), Ostfildern 2009, S. 238.

14. Internetseite des Van Gogh Museums, abgerufen unter: https://www. vangoghmuseum.nl/en/collection/s0417M1990.

15. Walther, Ingo F. u. Metzger, Rainer: Vincent van Gogh. Sämtliche Werke, Köln 2015, S. 504.

16. Internetseite des Auktionshauses Sotheby's, fig. 1, abgerufen unter: http://www.sothebys.com/de/auctions/ecatalogue/2011/impressionistmodern-art-day-sale-n08851/lot.144.lotnum.html.

17. Internetseite Van Gogh's Studio Practice: an introduction, abgerufen unter: http://www.vangoghsatelierpraktijk.nl/2011/07/atelier-achter-tralies/\# more-5620.

18. Van Gogh, Felder. Das Mohnfeld und der Künstlerstreit, hg. v. Wulf Herzogenrath u. Dorothee Hansen (Ausst. Kat. Bremen, Kunsthalle, 19. Oktober 2002-26. Januar 2003), Ostfildern-Ruit 2002, S. 30.

19. Van Gogh, Felder. Das Mohnfeld und der Künstlerstreit, hg. v. Wulf Herzogenrath u. Dorothee Hansen (Ausst. Kat. Bremen, Kunsthalle, 19. Oktober 2002-26. Januar 2003), Ostfildern-Ruit 2002, S. 30.

20. Walther, Ingo F. u. Metzger, Rainer: Vincent van Gogh. Sämtliche Werke, Köln 2015, S. 516.

21. Internetseite des Minneapolis Institute of Art, abgerufen unter: https://collections.artsmia.org/art/1218/olive-trees-vincent-van-gogh.

22. Internetseite des Metropolitan Museum of Art, abgerufen unter: https://www.metmuseum.org/art/collection/search/436536.

23. Internetseite des Van Gogh Museums, abgerufen unter: https://www.vangoghmuseum.nl/en/collection/d0251V1969.

24. Vellekoop, Marie u. Roelie Zwikker: Vincent van Gogh. Drawings. Arles, Saint-Rémy \& Auvers-sur-Oise. 1888-1890, Van Gogh Museum, Bd. IV, Amsterdam 2007, S. 303.

25. Internetseite des Van Gogh Museums, abgerufen unter: https:/www.vangoghmuseum.nl/en/collection/d0338V1962r.

26. Online-Verzeichnis der Briefe, abgerufen unter: http://vangoghletters.org/vg/letters/let156/letter.html. 
27. Van Gogh. Repetitions, hg. v. Eliza E. Rathbone, William H. Robinson, Elizabeth Steele u. Marcia Steele (Ausst. Kat. Washington D.C., The Phillips Collection, 12. Oktober 2013-26. Januar 2014; The Cleveland Museum of Art, 2. März-26. Mai 2014), New Haven u. London 2013, S. 18.

28. Van Gogh. Repetitions, hg. v. Eliza E. Rathbone, William H. Robinson, Elizabeth Steele u. Marcia Steele (Ausst. Kat. Washington D.C., The Phillips Collection, 12. Oktober 2013-26. Januar 2014; The Cleveland Museum of Art, 2. März-26. Mai 2014), New Haven u. London 2013, S. 18 .

29. Internetseite des Van Gogh Museums, abgerufen unter: https://www.vangoghmuseum.nl/en/collection/d0374V1975.

30. Vincent Van Gogh. The Drawings, hg. v. John P. O’Neill u.a. (Ausst. Kat. Amsterdam, Van Gogh Museum, 1. Juli-18. September 2005; New York, The Metropolitan Museum of Art, 12. Oktober-31. Dezember 2005), New Haven u. London, S. 77.

31. Online-Verzeichnis der Briefe, abgerufen unter: http://vangoghletters.org/vg/letters/let250/letter.html\#.

32. Internetseite des Walsall Museums and Art Gallery, abgerufen unter: http://thenewartgallerywalsall.org.uk/item/sorrow/.

33. Internetseite des Van Gogh Museum, abgerufen unter: https://www.vangoghmuseum.nl/en/collection/p0007V1962.

34. Internetseite der Neuen Pinakothek, abgerufen unter: https://www.pinakothek.de/kunst/vincent-van-gogh/der-weber.

35. Internetseite des Van Gogh Museum, abgerufen unter: https://www.vangoghmuseum.nl/en/collection/d0079V1962.

36. Internetseite des Van Gogh Museum, abgerufen unter: https://www.vangoghmuseum.nl/en/collection/s0005V1962

37. Internetseite des Van Gogh Museum, abgerufen unter: https://www.vangoghmuseum.nl/en/collection/p0016V1962.

38. Eigene Aufnahme der Ausgabe in der British Library, London.

39. Internetseite des Van Gogh Museums, abgerufen unter: https://www.vangoghmuseum.nl/en/collection/d0773V1962.

40. Internetseite des Van Gogh Museums, abgerufen unter: https://www.vangoghmuseum.nl/en/collection/s0116V1962. 
41. Internetseite des Van Gogh Museums, abgerufen unter: https:/www.vangoghmuseum.nl/en/collection/s0115V1962.

42. Internetseite des Van Gogh Museums, abgerufen unter: https://www.vangoghmuseum.nl/en/collection/n0077V1962.

43. Internetseite des Van Gogh Museums, abgerufen unter: https://www.vangoghmuseum.nl/en/collection/n0566M1985.

44. Internetseite des Van Gogh Museums, abgerufen unter: https://www.vangoghmuseum.nl/en/collection/s0114V1962.

45. Internetseite des Van Gogh Museums, abgerufen unter: https://www.vangoghmuseum.nl/en/collection/d0147V1962.

46. Internetseite des Musée Rodin, abgerufen unter: http://www.musee-rodin.fr/en/collections/paintings/pere-tanguy.

47. Kōdera, Tsukasa: Vincent van Gogh. Christianity versus nature, Oculi. Studies in the Arts of the Low Countries, hg. v. Bert W. Meijer u. Rob Ruurs, Bd. III, Amsterdam u. Philadelphia 1990 (zugl. Universität Amsterdam, Diss., 1988), Abbildung 16.

48. Internetseite des Kröller-Müller Museums, abgerufen unter: https://krollermuller.nl/vincent-van-gogh-boomwortels-in-een-zandgrondles-racines.

49. Malo, Henri: Les Très Riches Heures du Duc de Berry, Paris 1945, Bildtafel 2.

50. Malo, Henri: Les Très Riches Heures du Duc de Berry, Paris 1945, Bildtafel 7.

51. Hansen, Wilhelm: Kalenderminiaturen der Stundenbücher. Mittelalterliches Leben im Jahreslauf, München 1984, S. 24.

52. Hansen, Wilhelm: Kalenderminiaturen der Stundenbücher. Mittelalterliches Leben im Jahreslauf, München 1984, S. 25.

53. Internetseite des Kunsthistorischen Museums Wien, abgerufen unter: https://www.khm.at/objectdb/detail/325/.

54. Internetseite der Lobkowicz-Sammlung, abgerufen unter: http://www.lobkowicz.com/en/collections/\#modal.

55. Internetseite des Metropolitan Museum of Art, abgerufen unter: https://www.metmuseum.org/art/collection/search/435809.

56. Internetseite des Kunsthistorischen Museums Wien, abgerufen unter: http://www.khm.at/objektdb/detail/326/?offset=14\&lv=list. 
57. Internetseite des Kunsthistorischen Museums Wien, abgerufen unter: http://www.khm.at/objektdb/detail/327/?offset=16\&lv=list.

58. Online-Verzeichnis der Briefe, abgerufen unter: http://vangoghletters.org/vg/letters/let459/letter.html.

59. Online-Verzeichnis der Briefe, abgerufen unter: http://vangoghletters.org/vg/letters/let459/letter.html.

60. Online-Verzeichnis der Briefe, abgerufen unter: http://vangoghletters.org/vg/letters/let459/letter.html.

61. Online-Verzeichnis der Briefe, abgerufen unter: http://vangoghletters.org/vg/letters/let459/letter.html.

62. Internetseite des Metropolitan Museum of Art, abgerufen unter: https://metmuseum.org/art/collection/search/437097.

63. Van Gogh and the Seasons, hg. v. Sjraar van Heugten (Ausst. Kat., Melbourne, National Gallery of Victoria, 28. April-9. Juli 2017), Princeton 2018, S. 75.

64. Van Gogh and the Seasons, hg. v. Sjraar van Heugten (Ausst. Kat., Melbourne, National Gallery of Victoria, 28. April-9. Juli 2017), Princeton 2018, S. 75.

65. Internetseite des Van Gogh Museums, abgerufen unter: https://www.vangoghmuseum.nl/en/collection/s0026V1962.

66. Internetseite des Van Gogh Museums, abgerufen unter: https://www.vangoghmuseum.nl/en/collection/s0035V1962.

67. Internetseite des Musée d'Orsay, abgerufen unter: http://www.museeorsay. fr/index.php?id=851\&L=1\&tx_commentaire_pi1 [showUid] =7093\&no_cache $=1$

68. Internetseite der Morgan Library, abgerufen unter: http:/www.themorgan.org/drawings/item/267923.

69. Internetseite des Kröller-Müller Museums, abgerufen unter: https://krollermuller.nl/en/vincent-van-gogh-orchard-bordered-by-cypresses.

70. Internetseite des Van Gogh Museums, abgerufen unter: https://www.vangoghmuseum.nl/en/collection/s0117V1962.

71. Van Gogh in Arles, hg. v. Ronald Pickvance (Ausst. Kat. New York, The Metropolitan Museum of Art, 18. Oktober-30 Dezember 1984), New York 1984, S. 90. 
72. Van Gogh in Arles, hg. v. Ronald Pickvance (Ausst. Kat. New York, The Metropolitan Museum of Art, 18. Oktober-30 Dezember 1984), New York 1984, S. 92.

73. Vincent van Gogh. Zwischen Erde und Himmel. Die Landschaften, hg. v. Kunstmuseum Basel (Ausst. Kat. Basel, Kunstmuseum, 26. April27. September 2009), Ostfildern 2009, S. 211.

74. Internetseite des Kröller-Müller Museums, abgerufen unter: https://krollermuller.nl/en/vincent-van-gogh-the-green-vineyard.

75. Van Gogh in Arles, hg. v. Ronald Pickvance (Ausst. Kat. New York, The Metropolitan Museum of Art, 18. Oktober-30 Dezember 1984), New York 1984, S. 207.

76. Van Gogh in Arles, hg. v. Ronald Pickvance (Ausst. Kat. New York, The Metropolitan Museum of Art, 18. Oktober-30 Dezember 1984), New York 1984, S. 219.

77. Van Gogh in Arles, hg. v. Ronald Pickvance (Ausst. Kat. New York, The Metropolitan Museum of Art, 18. Oktober-30 Dezember 1984), New York 1984, S. 198.

78. Van Gogh in Arles, hg. v. Ronald Pickvance (Ausst. Kat. New York, The Metropolitan Museum of Art, 18. Oktober-30 Dezember 1984), New York 1984, S. 199.

79. Van Goghs Musée imaginaire, hg. v. Chris Stolwijk, Sjraar van Heugten, Leo Jansen und Andreas Blühm (Ausst. Kat. Amsterdam, Van Gogh Museum 14. Februar-13. Juni 2003), London 2003, Bildtafel 9.

80. Van Gogh in Arles, hg. v. Ronald Pickvance (Ausst. Kat. New York, The Metropolitan Museum of Art, 18. Oktober-30 Dezember 1984), New York 1984, S.103.

81. Internetseite der Neuen Pinakothek, abgerufen unter:

https:/www.pinakothek.de/kunst/meisterwerk/vincent-van-gogh/sonnenblumen.

82. Van Gogh in Arles, hg. v. Ronald Pickvance (Ausst. Kat. New York, The Metropolitan Museum of Art, 18. Oktober-30 Dezember 1984), New York 1984, S.215.

83. Van Gogh. Repetitions, hg. v. Eliza E. Rathbone, William H. Robinson, Elizabeth Steele u. Marcia Steele (Ausst. Kat. Washington D.C., The Phillips Collection, 12. Oktober 2013-26. Januar 2014; The Cleveland Museum of Art, 2. März-26. Mai 2014), New Haven u. London 2013, S. 103. 
84. Van Gogh. Repetitions, hg. v. Eliza E. Rathbone, William H. Robinson, Elizabeth Steele u. Marcia Steele (Ausst. Kat. Washington D.C., The Phillips Collection, 12. Oktober 2013-26. Januar 2014; The Cleveland Museum of Art, 2. März-26. Mai 2014), New Haven u. London 2013, S. 104.

85. Van Gogh and Gauguin. Studio of the South, hg. v. Douglas W. Druick u. Peter Kort Zegers (Ausst. Kat. Chicago, The Art Institute, 22. September 2001-13. Januar 2002; Amsterdam, Van Gogh Museum, 9. Februar-2. Juni 2002), New York u. London 2001, S. 227.

86. Online-Verzeichnis der Briefe, abgerufen unter: http://vangoghletters.org/vg/letters/let551/letter.html\#.

87. Van Gogh. Repetitions, hg. v. Eliza E. Rathbone, William H. Robinson, Elizabeth Steele u. Marcia Steele (Ausst. Kat. Washington D.C., The Phillips Collection, 12. Oktober 2013-26. Januar 2014; The Cleveland Museum of Art, 2. März-26. Mai 2014), New Haven u. London 2013, S. 121 .

88. Van Gogh. Repetitions, hg. v. Eliza E. Rathbone, William H. Robinson, Elizabeth Steele u. Marcia Steele (Ausst. Kat. Washington D.C., The Phillips Collection, 12. Oktober 2013-26. Januar 2014; The Cleveland Museum of Art, 2. März-26. Mai 2014), New Haven u. London 2013, S. 123 .

89. Van Gogh and the Seasons, hg. v. Sjraar van Heugten (Ausst. Kat., Melbourne, National Gallery of Victoria, 28. April-9. Juli 2017), Princeton 2018, S. 68.

90. Schaefer, Claude: Jean Fouquet. An der Schwelle zur Renaissance, Dresden u. Basel, 1994, S. 260.

91. Wikiart, abgerufen unter: https://www.wikiart.org/fr/jean-francois-millet/la-mort-et-le-bucheron1859.

92. Van Gogh \& Millet, hg. v. Louis van Tilborgh u. Sraar van Heugten: (Ausst. Kat. Amsterdam, Van Gogh Museum, 9. Dezember 1988-26. Februar 1989) Zwolle 1989, S. 78.

93. Online-Verzeichnis der Briefe, abgerufen unter: http://vangoghletters.org/vg/letters/let397/letter.html.

94. Internetseite des Van Gogh Museums, abgerufen unter: https://www.vangoghmuseum.nl/en/collection/s0196V1962.

95. Internetseite des Museums of Modern Art, abgerufen unter: https://www.moma.org/collection/works/80013. 
96. Internetseite des Metropolitan Museum of Art, abgerufen unter: https://images.metmuseum.org/CRDImages/ep/original/DT1946.jpg.

97. Vincent van Gogh. Zwischen Erde und Himmel. Die Landschaften, hg. v. Kunstmuseum Basel (Ausst. Kat. Basel, Kunstmuseum, 26. April-27. September 2009), Ostfildern 2009, S. 242.

98. Online-Verzeichnis der Briefe, abgerufen unter: http://vangoghletters.org/vg/letters/let819/letter.html.

99. Van Goghs Musée imaginaire, hg. v. Chris Stolwijk, Sjraar van Heugten, Leo Jansen und Andreas Blühm (Ausst. Kat. Amsterdam, Van Gogh Museum 14. Februar-13. Juni 2003), London 2003, Bildtafel 8.

100. Internetseite des Auktionshauses Christie's, abgerufen unter: https:/www.christies.com/lotfinder/vincent-van-gogh-le-moissonneur6089477-details.aspx?from=salesummary\&intObjectID=6089477\&lid=1 .

101. Online-Verzeichnis der Briefe, abgerufen unter: http://vangoghletters.org/vg/letters/let804/letter.html.

102. Internetseite des Kröller-Müller Museums, abgerufen unter: https://krollermuller.nl/en/vincent-van-gogh-sorrowing-old-man-at-eternity-s-gate.

103. Internetseite des Metropolitan Museum of Art, abgerufen unter: https:// images.metmuseum.org/CRDImages/ep/original/DT1035.jpg

104. Hayes Tucker, Paul: Monet in the '90s. The Series Paintings (zugleich Ausst. Kat. Boston, Museum of Fine Arts; Chicago, The Art Institute u. London, Royal Academy of Arts 1989), New Haven u.a. 1989, S. 95.

105. Internetseite des Musée d'Orsay, abgerufen unter: http://www.museeorsay.fr/fr/info/gdzoom.html?tx_damzoom_pi1\%5Bzoom $\% 5 \mathrm{D}=1 \& \mathrm{tx}$ damzoom_pi1\%5BxmlId\%5D=001178\&tx_damzoom_ pi $1 \% 5 \mathrm{Bback} \% 5 \mathrm{D}=\mathrm{fr} \% 2 \mathrm{Fcollections} \% 2 \mathrm{Fcatalogue}$-des-oeuvres $\% 2$ Fresultat-collection.html\%3Fno_cache\%3D1\%26zsz\%3D9\&cHash=f584b3b144.

106. Internetseite der National Gallery of Australia, abgerufen unter: https:// nga.gov.au/MonetJapan/Detail.cfm? WorkID=W1271\&ZoomID=3.

107. Internetseite des Art Institute of Chicago, abgerufen unter: http://www.artic.edu/aic/collections/artwork/64818.

108. Internetseite des Art Institute of Chicago, abgerufen unter: http://www.artic.edu/aic/collections/artwork/16560. 
109. Internetseite der Barnes Foundation, abgerufen unter: https://collection.barnesfoundation.org/objects/5003/Bathers-at-Rest(Baigneurs-au-repos)/.

110. Internetseite der Barnes Foundation, abgerufen unter: https://collection.barnesfoundation.org/objects/6048/Toward-Mont-Sainte-Victoire-(Vers-la-Montagne-Sainte-Victoire)/details.

111. Internetseite des Metropolitan Museum of Art, abgerufen unter: https://www.metmuseum.org/art/collection/search/435877.

112. Feilchenfeldt, Walter, Jayne Warman, u. David Nash. Les Marronniers du Jas de Bouffan en hiver, 1885-86 (cat. no. 216). The Paintings of Paul Cézanne: An Online Catalogue Raisonné, abgerufen unter http://www. cezannecatalogue.com/catalogue/entry.php?id=538.

113. Wikimedia, abgerufen unter:

https://upload.wikimedia.org/wikipedia/commons/9/94/

Paul_C\%C3\%A9zanne_208.jpg.

114. Becks-Malorny, Ulrike: Paul Cézanne 1839-1906. Wegbereiter der Moderne, Köln 2007, S. 75.

115. Lewis, Mary Tompkin: Cézanne, London 2000, S. 307. 



\section{Danksagung}

Der Umfang der Literatur über Vincent van Gogh ist bereits kaum mehr zu überblicken und nimmt weiter kontinuierlich zu. In den meisten Einführungen zu Arbeiten über van Gogh ist es daher mittlerweile Usus, eine Entschuldigung dafür voranzustellen, dass ein weiteres Werk die bereits vorhandenen Regalmeter an Literatur noch weiter vermehrt. Doch unbestritten bleibt, dass van Gogh auch nach Jahrzehnten eine ungebrochen starke Faszination auf Laien und Forscher ausübt, die zu immer neuen Fragestellungen führt und damit neue Untersuchungen rechtfertigt. Seit der ersten kurzen Erwähnung durch den Kunstkritiker Albert Aurier, noch zu Lebzeiten van Goghs, haben sich nun bereits mehrere Generationen von Kunstkritikern, Kunsthistorikern, Philosophen, Psychoanalytikern und Vertretern anderer Disziplinen mit dem Künstler befasst und so die unvergleichliche, dabei fast ausschließlich posthume Erfolgsgeschichte begleitet und in gewissen Teilen erst begründet. Ein Ermüdungseffekt scheint kaum einzutreten.

Den Ausgangspunkt für die Entstehung dieser Dissertation bildete eine intensive Beschäftigung mit van Gogh in Seminaren und im Rahmen einer Exkursion nach Otterlo und Amsterdam im Sommer 2012, die schließlich in einer Masterarbeit über van Gogh mündete. Damals noch an der Universität Bonn eingeschrieben, folgte ich für die Doktorarbeit meinem Betreuer, Herrn Professor Thomas Noll, an die Universität Göttingen. Mein großer Dank gilt daher ihm, nicht nur für das Erwecken meines Interesses an van Gogh, sondern auch für das Aufzeigen des methodischen Zugangs zum Verständnis der Symbolik des Werkes van Goghs, bei dem die Briefe des Künstlers eine wichtige Rolle einnehmen.

Wie mit jedem Unterfangen, das über mehrere Jahre eine herausragende Rolle im Leben einnimmt, ist auch in diese Arbeit viel Zeit, Mühe und Herzensblut geflossen. Doch ohne die Hilfe anderer wäre die Umsetzung kaum möglich gewesen. Daher sei besonders Alex und meinen beiden Familien in Deutschland und England von Herzen für ihre nicht endende Geduld und Unterstützung gedankt. Ich widme diese Arbeit meinen Eltern, zum Abschluss von 25 bewegten Ausbildungsjahren, während der sie mich mit Güte und Verständnis durch Höhen und Tiefen begleitet haben. Zu großem Dank verpflichtet bin ich außerdem Steffi und Peter Prussog, Laura Langelüddecke, Constanze von Hoensbroech, Mara Hofmann und Pfarrer Rudolf Göttle, die mir großzügig, in unterschiedlichen Funktionen, mit Rat und Tat bei thematischen Fragen und der Fertigstellung der Arbeit zur Seite standen.

Richmond (London) im November 2018 
- in paar Wochen, bevor van Gogh sich im Frühjahr 1889 in eine Nervenklinik in Saint-Rémy einwies, hatte er an Gauguin geschrieben, dass er eine „Kunst des Trostes für zerrissene Herzen“ schaffen wollte. Vom Fenster seines Schlafzimmers in der Klinik blickte er auf ein ummauertes Kornfeld herab. Im Laufe eines Jahres inspirierten die jahreszeitlichen Veränderungen auf dem Feld Van Gogh dazu, einen Zyklus dieses Kornfeldes zu malen und es als allegorische Darstellung des Schicksals des menschlichen Lebens aufzufassen, das ihm dadurch Trost zu spenden vermochte.

Ziel dieser Untersuchung war es, den Zyklus mit seiner komplexen Entstehungsgeschichte zu analysieren und schließlich in den Kontext fast zeitgleich entstandener Serien von Claude Monet und Paul Cézanne zu stellen und dadurch zu einem besseren Verständnis dieser drei Künstler beizutragen. Dabei handelt es sich um eine Kontextualisierung, die trotz unterschiedlicher Ausstellungsprojekte zu diesem Thema bisher nur am Rande erfolgt ist.

ISBN: $978-3-86395-395-9$

Universitätsverlag Göttingen 